\title{
Fenomenología y Hermenéutica
}

ACTAS DEL I CONGRESO INTERNACIONAL

DE FENOMENOLOGÍA Y HERMENÉUTICA

Editora

Sylvia Eyzaguirre Tafra

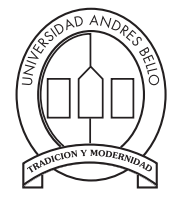

UNNIVIERSIDAAD

ANDRRES BELLO)

Facultad de Humanidades y Educación

Departamento de Artes y Humanidades 
Fenomenología y Hermenéutica

Actas del I Congreso Internacional de Fenomenología y Hermenéutica

Primera edición: septiembre de 2008

(c) Sylvia Eyzaguirre Tafra

Edita y distribuye:

Departamento de Artes y Humanidades

Facultad de Humanidades y Educación

Universidad Andrés Bello

Av. Fernández Concha 700, Las Condes

Impresión y encuadernación: RIL Editores

Corrección y formato: Daniela Orostegui Iribarren

Diseño y diagramación: M. Teresa Delgeon S.

Dirección de Marketing

Vicerrectoría de Comunicaciones

Universidad Andrés Bello

Editora: Sylvia Eyzaguirre Tafra

Impreso en Chile

ISBN: 978-956-319-481-4

Queda prohibida toda reproducción de este libro sin permiso de la editora. 




\section{INDICE}

Presentación

\section{CONFERENCIAS}

INTERSECTION BETWEEN FOUR PHENOMENOLOGICAL APPROACHES OF THE WORK OF ART

Jacques Taminiaux

EL TEMA DEL MUNDO Y LA PREGUNTA POR EL MÉTODO

FENOMENOLÓGICO

Roberto Walton

GOODBYE, HEIDEGGER! MI INTRODUCCIÓN CENSURADA A LOS BEITRÄGE ZUR PHILOSOPHIE

Franco Volpi

LA HERMENÉUTICA FENOMENOLÓGICA

Y LA CONTEMPORANEIDAD DEL PASADO

Ramón Rodríguez

\section{FENOMENOLOGÍA Y LENGUAJE}

PRIORIDAD DE LAS ORACIONES APOFÁNTICAS SOBRE LAS OTRAS ORACIONES. INTERPRETACIÓN DE UN PLANTEAMIENTO EN INVESTIGACIONES LÓGICAS DE HUSSERL Mirko Skarica

LAS PALABRAS SON TRANSPARENTES

Patricia Moya

EL LENGUAJE EN EL PENSAMIENTO DE MERLEAU-PONTY

Jaime Aspiunza

\section{FENOMENOLOGÍA DEL CUERPO}

PROLEGÓMENOS A UNA FENOMENOLOGÍA DE LAS EMOCIONES. EL ANÁLISIS DE LAS DISPOSICIONES DE ÁNIMO SEGÚN ALEXANDER PFÄNDER

Mariano Crespo

EL ENIGMA DE LO SENSIBLE: CUERPOS QUE SIENTEN Y DESEAN

Graciela Ralón

SEXUALIDAD Y PODER EN EL MARCO DE LA FENOMENOLOGÍA DEL CUERPO (J. -P. SARTRE, M. MERLEAU-PONTY Y S. DE BEAUVOIR)

Esteban García

FUNCIÓN DEL TEMPLE Y DISFUNCIÓN DE LA CORPOREIDAD EN LA EXPERIENCIA FUNDAMENTAL DEL PENSAR EN HEIDEGGER TARDÍO

Valentina Bulo

"HÒ ÁNTHROPOS ARITMETÍZEI”. FINITUD INTUITIVA E INFINITUD SIMBÓLICA EN LA FILOSOFÍA DE LA ARITMÉTICA DE HUSSERL

Rosemary Rizo-Patrón

PETER SLOTERDIJK: ESFERAS, FENOMENOLOGÍA Y ONTOGÉNESIS DE LOS ESPACIOS HUMANOS

Adolfo Vásquez 


\section{ALTERIDAD E INTERSUBJETIVIDAD}

CUATRO SENTIDOS DE LA EPOCHÉ Y EL PROBLEMA DE LA INTERSUBJETIVIDAD EN HUSSERL

Emilio Morales

EL PROBLEMA DE LA INTERSUBJETIVIDAD EN LA DIALÉCTICA Y EN LA FENOMENOLOGÍA: HEGEL Y SARTRE

Eduardo Álvarez

HACIA EL DIÁLOGO ENTRE FILOSOFÍA Y CIENCIAS SOCIALES:

DOS POSIBILIDADES DE CONSTITUCIÓN DE LA SUBJETIVIDAD

HERMENÉUTICA

Diego Barragán

FATIGA Y ACOGIDA DE SÍ. INTRODUCCIÓN AL PROBLEMA DE LA RESPONSABILIDAD EN E. LÉVINAS

Enoc Muñoz

PERDÓN Y ÁGAPE: DOS MANIFESTACIONES DEL RECONOCIMIENTO MUTUO

Manuel Prada

DYNAMIQUE D'UNE RÉBELLION: LA NOTION SARTRIENNE DE «GROUPE» ET LA RÉBELLION DE LOPE DE AGUIRRE EN 1559

Hernán Neira

OLVIDO, MEMORIA Y ESPERANZA EN JEAN LOUIS CHRÉTIEN

Rodrigo Figueroa

\section{EL PROBLEMA DEL MÉTODO}

ATISBOS EN TORNO A UN PROBLEMA FUNDAMENTAL DE LA FENOMENOLOGÍA: EL CONCEPTO DE INTENCIONALIDAD EN HUSSERL Y HEIDEGGER CON RESPECTO A LOS PRESUPUESTOS DEL IDEALISMO CARTESIANO

Sandra Baquedano

FENOMENOLOGÍA NEGATIVA. EL SENTIDO METÓDICO DE LA NEGATIVIDAD EN HEIDEGGER

Francisco de Lara

AMPLIACIÓN DE LA RAZÓN Y LA CIENCIA

Jorge Peña

\section{FENOMENOLOGÍA DE HEIDEGGER}

EL SECRETO MEJOR GUARDADO: LA HISTORIA BAJO RESERVAS

Cristóbal Durán

EL PROBLEMA ANTROPOLÓGICO EN LA FILOSOFÍA HEIDEGGERIANA

JUICIO RETÓRICAMENTE MOTIVADO Y APERTURIDAD: HEIDEGGER LECTOR DE LA RETÓRICA ARISTOTÉLICA 
LA ONTO-TEO-LOGÍA Y SU SUPERACIÓN

Cristóbal Holzapfel

SENTIDO PRÁCTICO DE LA EXISTENCIA. LAS PROPUESTAS DE

HUSSERL Y HEIDEGGER

Hugo Herrera

VII. FENOMENOLOGÍA E HISTORIA

FUTURO E HISTORICIDAD EN LA HERMENÉUTICA DEL DASEIN

Carlos di Silvestre

LA CONSTITUCIÓN DEL TIEMPO Y LA TEMPORALIDAD DE UNA HISTORIA COLECTIVA AUTÉNTICA

Víctor Farías

VIII. HERMENÉUTICA

LA EXPERIENCIA DE APROPIACIÓN DEL SENTIDO DE LA COMPRENSIÓN. HACIA UNA HERMENÉUTICA HISTÓRICO-FIGURATIVA DE MODERNIDAD 397 Fernando Vergara

LENGUAJE, DIVERSIDAD Y ESCUCHA EN LA HERMENÉUTICA

FILOSÓFICA DE H. G. GADAMER

Cecilia Monteagudo

EL DOBLE SENTIDO DE LA EXPERIENCIA HERMENÉUTICA

Marcelino Arias

HERMENÉUTICA SIN VERDAD HERMENÉUTICA. COMENTARIOS CRÍTICOS ACERCA DEL CONCEPTO DE VERDAD HERMENÉUTICA DE GADAMER

Matthias Günther

IX. ESTÉTICA

EL CONCEPTO DE CONTINUO SUBJETIVO. HACIA UNA ESTÉTICA FENOMENOLÓGICA Y UNA HERMENÉUTICA DE LA IMAGINACIÓN

Francisco de Undurraga

PARA UNA POÉTICA DE LA INVENCIÓN. ENTRE PAUL RICOEUR

Y CLAUDE ROMANO

Patricio Mena

EL SECRETO DE UN SECRETO QUE PUEDE (NO) SER QUE LO SEA. DEL ANUNCIO PÚBLICO DEL SECRETO O DE LA LITERATURA Iván Trujillo

EL ACCESO A LA NOCIÓN DE ALEGORÍA EN LA POESÍA DE DANTE

Joaquín Barceló

LA METÁFORA DEL AGUA COMO EXPRESIÓN MÁGICA Y MISTERIOSA DE LA UNIÓN ENTRE EL CIELO Y LA TIERRA EN ÁNGELES DE COMPOSTELA, DE GERARDO DIEGO

Ángel Rodríguez

O QUE É ISTO?

Gabriela Castro 


\section{Presentación}

El volumen que aquí presentamos recoge los diversos aportes que académicos de distintas universidades de Latinoamérica y Europa realizaron en el $I$ Congreso Internacional de Fenomenología y Hermenéutica, organizado por el Departamento de Artes y Humanidades de la Universidad Andrés Bello. La profundidad y variedad de los temas y cuestiones tratadas, así como las fructificas discusiones que se generaron, - muy por encima de las simples y a veces inútiles "disputas de escuela" - no son nada más que el fruto natural de la altura de quienes nos honraron con su asistencia y participación. Particular gratitud merecen nuestros conferencistas invitados: Jacques Taminiaux, Franco Volpi, Ramón Rodríguez y Roberto Walton. Ellos no solamente nos ilustraron con notables conferencias, sino además participaron activamente en cada una de las discusiones. Gracias también a la Dirección de Extensión Académica, que financió el congreso, y al Decano de la Facultad de Humanidades y Educación, Sr. Vicente Cordero, que en todo momento apoyó este proyecto y otorgó los recursos para la publicación de estas actas. Por último, un muy especial agradecimiento a Sylvia Eyzaguirre, auténtica gestora del congreso y de estas actas.

No obstante la extraordinaria diversidad de temáticas abordadas en este congreso, no resulta difícil reconocer un horizonte común. La conjunción de "fenomenología y hermenéutica" - a pesar de su obvia diversidad como "escuelas filosóficas" - no resulta en modo alguno casual. Decir "fenomenología y hermenéutica" no es solamente señalar dos de las más importantes corrientes del pensamiento contemporáneo, sino también recapitular y manifestar gran parte de los motivos y tensiones del siglo que recién pasó y que todavía marcan decisivamente las tendencias más fecundas del pensamiento contemporáneo. Es seguro que esta particular capacidad de reflejar una historicidad concreta, de hacerse cargo de ella, de replicarla de alguna manera en un nivel superior, es uno de los rasgos más característicos de la fenomenología y de la hermenéutica. Sin embargo, este ser reflejo de una época, este no poder sino constituirse bajo el horizonte de una temporalidad inapelablemente única, en nada se opone a su aspiración de universalidad. Antes al contrario, solamente desde una asunción consciente de la propia historicidad parece ser legítimo apelar a la universalidad. Digo esto porque bajo los nombres "técnicos" y casi ininteligibles de "fenomenología" y "hermenéutica", bajo la indudable abstracción y complejidad de muchos de sus problemas, se esconde también el insoslayable suelo nutricio del cual surgen. Este suelo nutricio se puede llamar de muchas maneras - mundo de la vida (Lebenswelt), existencia, temporalidad, historicidad, mundo de la cultura (Kulturwelt) - , pero siempre lo que allí se expresa y reivindica es una singular rehabilitación de la razón en su vocación más plena. Frente a una razón unilateral y desarraigada del suelo nutricio de la vida, 
frente a la manquedad del "modelo racionalista", puramente objetivamente y naturalista, Husserl insiste constantemente -especialmente en Crisis- que la filosofía ha de tratar de las preguntas por el sentido y el sinsentido del todo de la existencia humana. La crisis de Europa, la crisis de la ciencia europea, consiste en una perdida de significación para la vida. Denunciar la crisis de la razón no consiste, pues, en renunciar a la razón, sino en restituir su legítima vocación. Y ello de tal manera que lo que está en juego, como afirma Husserl, no es solamente el destino de la razón y de la ciencia, sino el de una humanidad auténtica. Recuerdo estos "tópicos" simplemente para manifestar que bajo la apariencia intangible y a veces abstrusa de muchos de los temas que se trataron en este congreso, se esconden problemas y cuestiones enormemente vitales, muchas de ellas incluso existencialmente acuciantes y que conforman a menudo la trama misma de nuestra vida cotidiana.

Y si hemos de ser fieles a esta trama de la vida, como quería Husserl, sin duda un congreso es una oportunidad única para que la filosofía exprese su impulso más vital. Pero no un congreso simplemente como instancia formal y profesional de ejercicio "políticamente correcto" de la filosofía, por así decirlo, sino como lugar de cruce, como expresión de un mundo común y de alguna manera compartido. Ese mundo compartido ciertamente sólo podrá comparecer bajo el abrigo no de un logos ensimismado y que se solace en su propia contemplación, sino de un logos que se abra dilectamente al otro. Este logos común - en expresión de Heráclito y como lo quiere parte importante de la hermenéutica contemporánea - es sin duda el diálogo filosófico. Es muy probable que el diálogo constituya la vida misma de la filosofía. Estamos seguros que el diálogo y la amistad han sido el signo distintivo de este congreso, signo de vida que aspiramos también se refleje de alguna manera en estas actas.

Gustavo Cataldo Sanguinetti Departamento de Artes y Humanidades Universidad Andrés Bello 
I. CONFERENCIAS 


\title{
Intersection between four Phenomenological Approaches of the Work of Art
}

\author{
Jacques Taminiaux \\ Universidad de Lovaina
}

I have announced that my lecture would check the intersection between four phenomenological approaches of the work of art.

\section{Husserl}

At the beginning of my presentation, let me recall briefly the teaching of Husserl on the work of art. As a matter of fact, the problematic of the founder of the phenomenological movement on the topic is narrowly circumscribed. There is no place within his approach for the questions which in the history of German philosophy had worried thinkers like Schiller, Schelling, Hölderlin, Hegel, and later on Schopenhauer and Nietzsche, i.e., issues such as: why do human beings produce works of art? How does their relation to artworks operate among their activities? Did that relation undergo metamorphoses throughout history?, etc. Those questions have no place whatsoever in Husserl's investigation, which is focused exclusively on the only basic phenomenon taken by him to deserve examination, i.e., intentionality.

Intentionality, according to Husserl, is a fundamental relationship between two poles whose essence can appear to the phenomenologist: an intentio and an intentum, or a noesis and a noema. The Husserlian examination of that relationship claims to avoid explanation and genealogy. Its aim is strictly descriptive, but the description at stake is eidetic for it bears upon essences and not upon facts offered to an empirical observation. In its initial purpose, it takes as a primordial axis the Erkenntnislehre, the theory of knowledge considered not a psychological investigation but as a transcendental one because, like Kant's criticism, it searches for universal and necessary conditions of possibility.

Precisely because it is concerned with essences instead of facts, the phenomenological investigation requires a suspending, the famous epochè, of the natural attitude as a whole, which means abstaining from the manifold positing of existence carried out by common experience on the basis of everyday perception, or by scientific research whatever its objects and methods. Only such generalized suspending allows what Husserl calls reduction, i.e., a return to the phenomenon of intentionality and thus an eidetic survey of all the intentional modalities and of their relations. 
That twofold discipline of epochè and eidetic reduction is a must in order for transcendental phenomenology to become pure.

It is in the framework of that theoretical project, but so to speak in its margins, that Husserl wrote a few pages on the artwork and our relation to it: a letter sent in 1907 to the poet von Hofmannstahl and a well-known paragraph of Ideas I, a book published in 1913 .

Let me consider those two texts.

At the time he wrote his letter to the poet, Husserl, then professor at the University of Göttingen, was preparing his famous lessons on The Idea of Phenomenology which were an attempt to characterize the specific features of the phenomenological method which had already been used by him, though not yet thematized in the Logical Investigations.

We find an allusion to those lessons when Husserl writes to von Hofmannstahl: «Intuiting a pure aesthetic artwork implies that the intellect abstains from any existential position; it also excludes any stance by feeling and by will since that stance involves such an existential position. Better: the artwork brings us (almost compells us) to a state of pure aesthetic intuition which excludes those existential stances.»

As a result of that exclusion of the existential positions belonging to the natural attitude, the production as well as the reception of the works of art are comparable with phenomenology. In both cases there is access to a pure seeing, which supposes abstention from all positing of existence and which focuses exclusively on a phenomenon considered qua appearing and not qua being. The only difference between those two seeings is that the aesthetic one gives rise to a specific enjoyment, whereas the phenomenological one gives rise to the discovery of the "meaning» of the phenomena at stake, thereby opening the way to "grasping it in concepts».

In the second text, the famous paragraph 111 of Ideas I, Husserl describes the contemplation of a particular work of art: Dürer's engraving The knight, death and the devil. The title of the chapter in which the paragraph takes place is significant: «Problematic of the noetico-noematic structures». The title of the chapter indicates that Husserl deals with the contemplation of artworks in the strict limits of the intentional relationship. Moreover the very title of the paragraph - "The neutrality modification and fantasy» - confirms a continuity with the theme insisted upon in the letter to von Hofmannstahl, i.e., the exclusion of all position of existence. According to Husserl, the intentional Erlebnis, of which the aesthetic contemplation of Dürer's engraving is a mere instance, is an act of consciousness called Phantasieren. From an eidetic point 
of view, the act of fantasy is characterized by a neutralisation of all existential position, thereby differing from the perceiving act, which posits in a present moment the existence of the perceived and differing as well from the act of remembering, which presentifies again but qua past what was previously perceived.

To be sure, the act called Phantasieren is based (fundiert) upon perceiving acts such as being aware of the thing "engraving» hanging on the wall, and the perceptual recognition of the shapes of a horse, a horseman, the devil, and so on, but it becomes specifically aesthetic by overcoming the positions involved in those basing acts in such a way, that its essence is to focus exclusively upon a fictional scene grouping entities offered «neither as being nor as not-being nor under any other positing modality». Of course, it is allowed to claim that the aesthetic act is referred to a world but only with the proviso that it is a "purely fictional world», differing essentially from the world intended by natural attitude in perceiving acts, emotional acts, cognitive acts, shaping acts and so on. Indeed, in all those acts, the existence of the world is posited, whereas the world to which the aesthetic act is related is intended as purely fictional "without granting to it the seal of being or not-being».

In its purism, the Husserlian description of the aesthetic act is comparable to Kant's analytic of the judgment of taste in the third Critique. Indeed, Husserl somehow retrieves phenomenologically the emphasis put by Kant on the play of imagination along with the disinterestedness of the pure judgment of taste. But it should be noticed that Husserl does not seem to retrieve in any way Kant's teaching, in his «deduction of the pure aesthetic judgments» about the sensus communis, taken as the ability to take into consideration the views of the others. Moreover, Husserl doesn't seem to retrieve either the teaching of Kant's «dialectics» about the relation between the Beautiful and the Good.

On the other hand, since Husserl argues in the rigorous framewok of an eidetic investigation carried out, so to speak, sub specie aeternitatis, there is no trace in the analysis I have recalled of any attention paid to the research of the historians about the links between Dürer and his predecessors, or his contemporaries, or about the impact of the famous engraving upon the development of his art.

\section{Heidegger}

Upon the backdrop of those preliminary remarks, I am now in a position to consider advisedly the approach of the work of art by the second founder of the phenomenological movement, Martin Heidegger. His explicit interrogation on the topic emerged only during the thirties, after the publication of his 
masterpiece, Being and Time. In that interrogation, the notion of world plays a decisive role that I would like to elucidate in order to clarify the intersection I am dealing with.

But, since Heidegger's insistance on that notion in his reflection on art depends on what he had expounded in Being and Time, a writing in which being-in-theworld is a central theme, I must recall briefly its problematic which claims to be phenomenological, hence to implement in some way the method discovered by Husserl, to whom the book was dedicated.

Heidegger himself in a lecture course on The Basic Problems of Phenomenology, given in Marburg a few months after the publication of the opus magnum, explains his own concept of the phenomenological method in the following way: "For Husserl, the phenomenological reduction which he worked out for the first time expressly in the Ideas Toward a Pure Phenomenology and Phenomenological Philosophy (1913), is the method of leading phenomenological vision from the natural attitude of the human being whose life is involved in the world of things and persons back to the transcendental life of consciousness and its noetic-noematic experiences, in which objects are constituted as correlates of consciousness. For us phenomenological reduction means leading phenomenological vision back from the apprehension of a being, whatever may be the character of that apprehension, to the understanding of the Being of this being (projecting upon the way it is unconcealed)».

Heidegger's comparison between him and Husserl is fair as far as methodology is concerned, but there is a striking difference between the master and the pupil. The Husserlian reduction excludes all position of Being and its primary aim is not ontological but gnoseological, whereas the Heideggerian reduction is focused on the Seinsfrage and its aim is a fundamental ontology. As a result, the field to be described is no longer Bewusstsein but Dasein, i.e., the being for whom to be is a question. The metamorphosis entails that the phenomenological problematic does no longer operate sub specie aeternitatis in a realm of pure quiddities. It is deliberately historical for several reasons.

Indeed, Heidegger insists that the word Dasein does not designate an omnitemporal generality but somebody who hic et nunc replies to the question Who?

Moreover, the analytic of the individualized way of Being of the Dasein discloses constitutive factors called existentialia, such as understanding, discourse, disposition, which operate on two opposite levels: on the one hand, an everyday concern wherein the Dasein pays attention to beings other than itself and publicly available to everybody and nobody in particular, to das Man, the

\footnotetext{
${ }^{1}$ Martin Heidegger. GA Bd. 24, translator Hofstadter, p. 21.
} 
They; on the other hand, the level of care in which the Dasein discovers itself thrown in Being among other beings, things and persons, and confronted to the task of taking up its own existence as a project which is its ownmost potentiality-for-Being. Care is essentially finite, because the end of Dasein, its own death, determine its projective character. It is also essentially temporal, but the temporality involved is not an infinite stream but rather the ek-static openness of a Self to a finite future towards which it projects itself by retrieving its own past. Compared to the radical Selfhood of care, everyday concern is in a position of fall. Care is authentic, concern is inauthentic.

Finally, the historical character of fundamental ontology stands out in the introductin by Heidegger of a new component of the phenomenological method: deconstruction. The point in deconstruction is to reappropriate in the texts of the entire history of philosophy from Plato to Nietzsche what corresponds to the understanding of Being by Dasein and to reject by the same token what blocks or covers up that understanding.

Such deconstruction, which repeatedly favours Greek philosophy, was already carried out by Heideger in his Marburg teaching before the publication of Being and Time. As I have tried to demonstrate in several writings since my book on Heidegger's Project of Fundamental Ontology, that early teaching which dealt primordially with Greek philosophical texts shows that the antithesis between inauthentic concern for an everyday surrounding world and authentic care for a Self-world is rooted first of all in Heidegger's reappropriation with respect to Dasein of Plato's parable of the cave, in which a sharp distinction is made between the common views of the polloi, the Many, focused on copies or semblances, and the solitary contemplation of truth by the wise man. It is also rooted in an existential reappropriation upon that Platonist backdrop of the distinction made by Aristotle in the Nicomachean Ethics between several levels of excellence and, more precisely, the distinction between the productive comportment called poiesis, enlightened by a peculiar know-how called technè, and the comportment called praxis, which is the conduct of one's own life in the light of a discernment called phronèsis. Heidegger reappropriated as well with respect to the human Dasein the Aristotelian analysis of the superiority of the solitary sophia pursued by the philosopher upon all type of epistèmè.

What is the link between all that and the interrogation on the artwork?

There is almost nothing on the issue in Being and Time and in the Marburg lecture courses. Theodore Kisiel does not even mention the word «art» in the Index of subject matter of his careful analysis of The Genesis of Heidegger's Being and Time. Nevertheless, it turns out that it is in the wake of fundamental ontology that Heidegger's reflection on the work of art emerged. On close ins- 
pection, indeed, it is possible to realize that the key notions of that reflection appear for the first time expressly in a lecture course given by Heidegger in Freiburg in 1931-32 and dealing with The Essence of Truth on the basis of a reappropriation of Plato's parable of the cave, hence in continuity with a major topic of the Marburg teaching.

The first key notion to be found in that lecture course is the notion of origin, which is going to take center stage in the essays on the work of art. According to the lecture course, freedom means «understanding Being as such». That freedom obtains Ursprünglichkeit, thanks to «the decisiveness (Entschiedenheit) of the tie to beings as they are and to the sight of the Being of those beings as it is, what understands itself only as Dasein, moved back in the isolation and thrownness of its historical provenance and future» ${ }^{2}$.

The second key notion is the explicit reformulation in existential terms of the Platonic philosopher-king, a reformulation which two years later will be at the core of the sadly famous Rectoral Address of 1933 on The Self-affirmation of German University ${ }^{3}$.

The third notion concerns theontological status of great art. Heidegger claims that when art is great, as it was the case in Greece, for example, in the "great poetry» of Sophocles, it has the capacity to manifest «the internal power of the human understanding of Being, the sight of light». He warns that in order to grasp this, one has to stop «considering the problem of art as a problem of aesthetics» because neither aesthetic enjoyment nor the scholarship of art historians are adjusted to that ontological power. ${ }^{4}$

Those three notions establish the parameters of Heidegger's interrogation on the origin of the work of art which was articulated and developed in the murky context of the triumph of National-socialism and which took advantage of that situation to transfer to the Dasein of the German people the question Who? previously focused on individuals, thereby granting to that broad Dasein the decisiveness and resoluteness previously limited to the individual potentiality-for-Being.

This is what shines forth right away in the first elaboration of that interrogation where Heidegger writes, at the very beginning, that for him there is "only one thing which matters»: "Namely, in spite of what has been thought and stated for a long time, to define the essence of art, to contribute to the preparation of a transformed fundamental position of our Dasein toward art». ${ }^{5}$

\footnotetext{
${ }^{2}$ Martin Heidegger, GA Bd. 34, p. 60.

${ }^{3}$ Cf. ibid, p. 100.

${ }^{4}$ Ibid, pp. 63-64.

${ }^{5}$ Martin Heidegger, "Vom Ursprung des Kunstwerks: Erste Ausarbeitung” in: Heidegger Studies, vol. 5, 1989, p. 5.
} 
The possessive adjective used by Heidegger - «our Dasein» - is significant of the broadening of his problematic to the ontological potentiality of a people. But, because the decisiveness pervading the text the broadening preserves the antithesis inauthenticity-authenticity which was structuring the existential analytic. That antithesis motivates, for reasons of ontological blindness and fallenness in public and superficial concerns, Heidegger's disdain for aesthetics and for the work of the art historians. The same antithesis explains why he elevates Greek art to the rank of a paradigm by contrast to the arts created afterwards. He insists, accordingly, on the ontological power of the basic features of the Greek work of art while detecting an ontological deficiency in what he takes to be the main feature of the western artworks after the collapse of Ancient Greece.

According to Heidegger, who argues in ontological terms, the Greek artwork managed to combine the setting-up (Aufstellung) of a world and the setting forth (Herstellung) of an earth. By contrast the posthellenic works of art until nowadays are limited to a mere representation (Darstellung).

Let me consider the contrast without going into details as I did in my last book (Art et Evénement).

Heidegger claims that the Greek temple around a divine statue was setting up a world as an unfamiliar realm which not only was «more being than any of the tangible present at hand things among which we believe ourselves to be at home in everyday life», but which also had a function of «rejection of the usual presence at hand $»^{6}$. That setting up is described by the philosopher, obviously inspired by the chapter on "The Religion of Art» in Hegel's Phenomenology of Spirit, as a "consecration» which "opens up the holy as holy»". Thanks to that theophanic power, the world gets a verbal status: it is a "guiding escor " which overcomes from above the familiar character of our everyday surroundings.

The second feature of the Greek artwork, the setting forth of an earth, is no less ontological. The word "earth" used by Heidegger does not designate a stock of raw materials waiting for an elaboration in which their crudeness would vanish; instead of designating a matter waiting for a form, it designates «the inexhaustible fullness» of «a ground which, because essentially and always self-sealing off, is an abyss» ${ }^{8}$.

Since the world opened up by the artwork is an active disclosure whereas the earth simultaneously set forth preserves its secret, great art is the advent of a «contest» (Streit) between an opening and a closing.

One could be tempted to consider such a contest as an enigma calling for a persistant meditation, but Heidegger makes clear that for him the resolute

\footnotetext{
${ }^{6}$ Ibid, p. 9 .

${ }^{7}$ Ibid.

${ }^{8}$ Ibid, p. 11.
} 
selfhood of a Dasein prevails upon attention to an enigma. Indeed he writes: "Towering up in a world an going back into the earth, the temple opens the There $(D a)$, in which a people comes to its own- i.e. comes to the ordaining power of its God». And the language he uses evokes a conquest: «In the work the There gets won» ${ }^{9}$. The swaggering tonality is confirmed by the introduction in the same context of a call to a "decision» (Entscheidung): "With this essential determination of the work-being of the work a position is won, which makes a decision possible about the widespread and common view of the artwork as representation of something)» ${ }^{10}$.

The rule of the view of art as representation includes the entire history of art in the western world after Greece. In all the stages of that long history, the work of art was meant to be the allegorical exhibition, in visible appearances, of a reality which is not to be found in them, either a supersensible reality in the Christian era, or a natural reality visible elsewhere in the modern age. Heidegger claims that during that long rule of representation, the fine arts lost the authentic ontological function they had in Greece. In Greece, he says, «the artwork does not represent anything - and this for the sole and simple reason that it has nothing that it should represent» ${ }^{11}$. On the contrary, «it wins for the first time the open, the clearing in whole light the being as such encounters us as on the first day or - if become everyday-like - metamorphosed». When Heidegger claims that the traditional priviledge of representation depends on a traditional interpretation of Plato's distinction between the model and the copy, it is easy to realize that his criticism of Darstellung presupposes his own criticism of the traditional notion of truth as adaequatio, on behalf of truth as alètheia. Indeed, what is at stake for him in the contest between world and earth is precisely his own notion of truth as alètheia, that is, as a tension between concealment and unconcealment. That tension is meant when he writes that «the essence of art is the setting to work of truth» ${ }^{12}$. And in that tension the Dasein is involved.

Three quotes suffice to show that the text I am dealing with is in continuity with the previous analytic of Dasein and its emphasis on the disclosing project by which authenticity is conquered against the fallenness of everydayness.

First quote. Heidegger writes: "If truth first comes to work with the artwork and in it and is not present at hand anywhere beforehand, then it must become. (...) Truth is never read off from what is already present at hand. On the contrary, the openness of what is occurs by being projected...» ${ }^{13}$. In other words, there is no truth without project. And of course, there is no project without Dasein.

\footnotetext{
${ }^{9}$ Ibid, p. 12.

${ }^{10}$ Ibid.

${ }^{11}$ Ibid, p. 13.

12 Ibid, p. 16.

${ }^{13}$ Ibid, p. 17.
} 
The second quote is focused on the strictly singular historicality of the one who decides to take upon himself to be the "There» of the ontological openness. Heidegger writes the following on the subject: «Who takes upon himself to be this 'There'? Answer: Man (...) if he stands towards Being (Seyn) as such. This way of being the There we call history. When man is the There, i.e. is historical, he becomes a people». And Heidegger insists that «this There itself is never something universal - rather it is at each time this one and something singular» ${ }^{14}$.

The third quote is the very conclusion of the essay: «In the questioning about art what is at stake is this decision: Is art essential to us? Is it an origin (Ursprung) and therefore a jump forward (Vor-sprung) in our history? A start or only still a supplement that gets brought along as the 'expression' of something present at hand and pursued further for ornamentation and amusement, for relaxation and excitement? Are we in the nearness of the essence of art as origin or are we not?(...) For clarity over who we are and who we are not is already the decisive jump (Sprung) into the nearness of the origin. Such nearness alone guarantees a truly grounded historical Dasein as authentic on this earth ${ }^{15}$.

It is obvious that those three signs of ontological decisionism not only prolong with reference to the singular Dasein of the German people the existential analytic of Being and Time but also rejects the teaching of Husserl, who claimed that the work of art demands a purely aesthetic attitude, excluding all ontological position and consequently has nothing to do with the project of making history in the monumental sense of an ontological move. Moreover, there is no doubt that the engraving of Dürer relished by Husserl is implicitly included among the targets of Heidegger's polemic against representation.

\section{Arendt}

I am now able to consider the approach to the artwork by two thinkers who repeatedly claimed to have their philosophical roots in the legacy of the masters of the phenomenological movement, namely Arendt and Levinas.

I have tried to show in several essays, since my book The Thracian Maid and the Professional Thinker, that Arendt's analysis of active life and of the life of the mind is to a large extent a reply to the biases and mistakes entailed in the work of Heidegger, who had been her first teacher, by a Platonist celebration of the bios theorètikos.

Hannah Arendt did not hesitate to introduce herself as a phenomenologist insofar as the main issue of her analyses was an unprejudiced descrition of phe-

\footnotetext{
${ }^{14}$ Ibid, pp. 19-20.

${ }^{15}$ Ibid, p. 22.
} 
nomena. She also claimed to practice a sort of deconstruction, but a peculiar one, which instead of deriving from the perspectives of contemplativee life was targeting all its prejudices.

I intend to underscore the divergence between her and Heidegger by paying attention to the reflections on the work of art contained in The Human Condition, a book on active life about which she wrote to Heidegger in May 1954 that it owed much to his teaching. But of course this acknowlegment of an intellectual debt does not all mean that she considered herself to be a disciple of the German thinker.

Indeed, already in the first chapter of her book, Arendt claims that Plato, when he decided, after the trial of Socrates, to grant to the solitary pursuit of contemplative life an «enormous superiority (...) over action of any kind $»^{16}$, he founded a tradition which «has blurred the distinctions and articulations within the vita aciva itself $x^{17}$ and has obliterated the previous excellence of the sharing of words and deeds which pervaded the bios politikos of the democratic city.

I have reminded you that in Heidegger's fundamental ontology the reappropriation of Plato's celebration of the bios theorètikos entailed an antithesis between everydayness and authenticity, with the result that the philosopher alone was truly competent in political matters. As I said, that antithesis was maintained in the interrogation on the work of art.

There is of course no avail to search for traces of such an antithesis in Arendt's description of active life, and in her reflections on art in the framework of that description.

At the very beginning of the text I have commented, Heidegger writes: «To the public the only relation of the artwork is to destroy it. And the greatness of an artwork is measured by this destructive power» ${ }^{18}$. By contrast, Arendt in her first allusion to the artwork, in the second chapter of her book, underlines its public character. In her terminology, the word "public» refers to an "appearing» which is not a semblance but a reality constituted by «being seen and heard by others as well as by ourselves». The work of art is public in sofar as the artist has the ability to transfigure in a reality perceived by many people a «private» and solitary experience which without that transfiguration would lead a shadowy existence ${ }^{19}$.

But the word "public» in her terminology also designates a second phenomenon, namely «the world itself, insofar as it is common to all of us and

\footnotetext{
${ }^{16}$ Hannah Arendt. The Human Condition, p. 14.

17 Ibid, p. 17.

18 Martin Heidegger. Vom Ursprung des Kunstwerks: Erste Ausarbeitung, op. cit, p. 8.

19 Cf. Hannah Arendt. The Human Condition, p. 50.
} 
distinguished from our privately owned place in it ${ }^{20}$. The phenomenon of the world so understood obviously escapes the Heideggerian antithesis between inauthentic concern with utensils and authentic care. Indeed, Arendt insists that in her view the world «is related to the human artifact, the fabrication of human hands, as well as to affairs which go on among those who inhabit it», and consequently that «to live together in the world means essentially that a world of things is between those who have it in common as a table is located between those who have it in common». The comparison is highly significant, it means that «the world, like every in-between relates and separates men at the same time» and thus "prevents our falling over each other so to speak» ${ }^{21}$.

By claiming that the world is a set of artifacts which relates and separates those who live in it, Arendt manifests a clear divergence from the teaching of Being and Time, which considers the surrounding set of artifacts as the realm of the They, which lets human beings fall over each other, and which opposes to the sense of security offered by that dwelling place the Unheimlichkeit, the uncanny essence of the authentic being-in-the-world, i.e., of care understood as strictly singular and separated.

It is to be noticed that Arendt argues the way she does because, unlike Heidegger, her descrption is not focused on the pursuit of a solitary contemplation but on the articulations of active life. Indeed, by relating and separating at the same time those who live in it, the world as a public and common habitat turns out to be favourable to an activity which is higher than the work necessary for the fabrication of artifacts. That higher activity called "action" by Arendt is what Aristotle called praxis, distinguished by him from poiesis, fabrication. In Arendt's description of active life, there are three levels of activity: the activity of labour which is conditioned by life, the activity of work conditioned by a world, and the activity of action conditioned by plurality, i.e., in her language, by the fact that human beings are all alike but all different. According to her description, action is an ever renewed sharing of words and deeds, interlocution and interaction, between individuals who, because they are all alike, are able to understand one another, but who, because they are all different, must show who they are by taking initiatives in words and deeds.

In the context of plurality, any single human being is considered able to reply on his own to the question Who?, which is a central question for Arendt as it was for Heidegger, with the basic difference that for her the question is raised by the others whereas for him question and answer occur in the circle of Selfhood since the Dasein confronts authentically who he is in his unique ontological project by replying alone to a call emanating from himself.

The divergence becomes blatant if we compare the two thinkers in their analysis of the relation between artwork and world.

\footnotetext{
20 Ibid, p. 52.

${ }^{21}$ Ibid.
} 
In Heidegger's analysis, the relation is ruled by the antithesis inauthentic everydayness and authentic project. The authentic work of art has the ontological character of an origin, a leap forward missing in ordinary artifacts, and thanks to that leap the singular Dasein of a unique people projects itself resolutely towards its future in a contest between Being and Nothingness.

By contrast Arendt underlines a continuity between artifacts and artworks. In her description, the products of the activity of labour are doomed to disappear in human consumption whereas the artifacts produced by the activity of work do not vanish in the devouring cycle of biological life; on the contrary, they introduce a tangibility and permanence which are essential to the constitution of the world as a habitat. The works of art increase and protect that lasting tangibility. She writes: «The man-made world of things, the human artifice erected by homo faber, becomes a home for mortal men, whose stability will endure and outlast the ever-changing movement of their lives and actions, only insomuch as it transcends both the sheer functionalism of things produced for consumption and the sheer utility of objects produced for use (...) If the animal laborans needs the help of homo faber to ease his labor and remove his pain, and if mortals need his help to erect a home on earth, acting and speaking men need the help of homo faber in his highest capacity, that is, the help of the artist, of poets and historiographers, of monument-builders or writers, because without them the only product of their activity, the story they enact and tell, would not survive at all $»^{22}$.

Needless to insist on the divergence between Arendt and her former teacher. It is significant that Arendt associates the artworks and the narratives written by historiographers whereas Heidegger relegates those narratives in a superficial Kunstbetrieb, art-management blind by definition to the ontological process of monumental history. No less significant is the fact that when Arendt deals with poetry in the same context she recalls that the Greeks held remembrance, Mnèmosynè, for the mother of the muses ${ }^{23}$ whereas Heidegger, the other way round, claimed that the real power of poetry is to open ontologically the future of a people.

Moreover, when Arendt criticizes contemporary culture she does not argue like Heidegger in ontological terms, and she does not depreciate the contemporary artits. Her only point is to warn that the stabilizing function of art is endangered if the triumph of animal laborans in mass-society reduces art to sheer entertainment.

\footnotetext{
22 Ibid, p. 173.

${ }^{23}$ Cf. ibid, pp. 169-170.
} 


\section{Levinas}

What about the artwork in Levinas' thought?

In 1987 he wrote the following in his preface to the German translation of Totality and Infinity: "This book which wants and feels itself of phenomenological inspiration proceeds from a long familiarity with Husserl's texts and from a ceaseless attentiveness to Sein und Zeit».

Indeed, the debate with both Husserl and Heidegger is a constant feature in Levinas's writings.

I would like to show how the debate goes on in the few pages where Levinas deals with the work of art. They are to be found in the first book he published after World war II, From existence to the existant (1947), and in an article which came out one year later in Les Temps Modernes: «Reality and its shadow».

In the foreword to the book of 1947, Levinas warns that his essay anticipates further and broader investigations «devoted to the problem of the Good, to Time and to the Relation with the Other as a movement toward the Good». About those further investigations, he writes: «The Platonist formula which sets the Good beyond Being is the most general and emptiest indication orienting them ${ }^{24}$.

Right away the debate with Heidegger looms up in those words. Indeed, Heidegger in the wake of Being and Time had also reappropriated Plato's formula (to agathon epekeina tès ousias) but without any ethical connotation, for he focused its meaning upon the ontological Selfhood of the Dasein, writing in Vom Wesen des Grundes: "The essence of the agathon lies in the power of oneself as hou eneka» ${ }^{25}$. In other words, Plato's formula in Heidegger's retrieval of it simply means that the Dasein exists for its own sake. There is a deliberate objection to Heidegger when Levinas writes: «the movement which leads an existent toward the Good is not a transcendence by which the existent raises itself up to a higher existence, but a departure from Being and from the categories which describe it: an 'ex-cendence'»" ${ }^{26}$. In other words, Levinas claims that ontology cannot be fundamental since it reduces the Good to Being, thereby obliterating the primacy of ethics. He also rejects implicitly, by the same token, the Heideggerian antithesis between the inauthenticity of everyday concern and the authenticity of care focused upon Dasein's ownmost existence. At any rate, it is significant in this regard that when Levinas describes further on in his book our everyday comportment, he underscores what he calls its «sincerity». He writes forcefully: «Our existence in the world, with

\footnotetext{
${ }^{24}$ Emmanuel Levinas. From existence to the existant. Translator Linguis, p. 15.

${ }^{25}$ Martin Heidegger. Vom Wesen des Grundes, 6st. ed., p. 41.

${ }^{26}$ Emmanuel Levinas. From existence to the existant. Translator Linguis, p. 15
} 
its desires and everyday agitation, is then not an immense fraud, a fall into inauthenticity, an evasion from our deepest destiny» ${ }^{27}$.

However, it would be wrong to infer from the words I just quoted that Levinas discards as null and void all interest in ontology. On the one hand, he expresses what he calls a "profound need to leave the climate» of Heidegger's thought, but on the other hand, he insists that does not want to return to a "pre-heideggerian» philosophy and he acknowledges his debt when he writes: "At the beginning our reflections are in large measure inspired by the philosophy of Martin Heidegger where we find the concept of ontology and of the relationship which man sustains with Being» ${ }^{28}$. By acknowledging that his debt concerns ontology, Levinas suggests that the distinction Being-beings deserves serious consideration. But by expressing his reservation, he suggests, by the same token, that he does not endorse the meaning given to the distinction by Heidegger.

The divergence shines out when Levinas indicates that the purpose of his book is "to approach the idea of Being in general in its impersonality so as to then be able to analyse the notion of the present and of position, in which a being, a subject, an existent, arises in impersonal Being through a hypostasis ${ }^{29}$. All the words of that quote denote a sharp difference.

Whereas Heidegger defines the relationship with Being in terms of ownmost selfhood, Levinas affirms the neutral and impersonal character of Being; whereas the former insists on project, the latter argues in terms of a position; on one side, the future prevails, on the other side, the emphasis is put on the present; on the one hand, the key word is ek-stasis, on the other hand, it is hypostasis.

The divergence is confirmed at the outset of the first chapter of the book when Levinas writes, in a clear opposition to Heidegger: "Existence is not synonymous with the relationship with a world; it is antecedent to the world. In the situation of an end of the world the primary relationship which binds us to being becomes palpable» ${ }^{30}$. Given that Being is primarily anonymous and impersonal, given that Being is first of all the sheer fact that «there is», the primary relationship with Being occurs beneath intentionality and escapes all decision or "struggle for a future» ${ }^{31}$. It is an event we can approach by paying attention to phenomena such as weariness and indolence, which obviously are neither lived experiences ruled by an intention of consciousness nor modalities of a projective comportment.

\footnotetext{
${ }^{27}$ Ibid, p. 44.

${ }^{28}$ Ibid, p. 19.

${ }^{29}$ Ibid.

${ }^{30} \mathrm{Ibid}, \mathrm{p} .21$.

${ }^{31}$ Ibid, p. 23.
} 
When he deals with those phenomena, Levinas shows the limits of both the Husserlian and the Heideggerian descriptions. For instance, he obviously points out the flaws of Heidegger's existential analytic when he claims that weariness is a "refusal to exist ${ }^{32}$ and that indolence is felt as "an impossibility of beginning ${ }^{33}$, a "holding back from the future ${ }^{34}$, a condemnation to the present which indicates that "the future, a virginal instant, is impossible in a solitary subject ${ }^{35}$.

The substitution for the Heideggerian ek-stasis of the notion of hypostasis means that for Levinas our primary relation with Being consists in staying under the burden of an anonymous «there is».

Such is the background of Levinas's reflections on the work of art.

Those reflections are developed in a chapter whose title is significant of the divergence I am underlining: «Existence without world». The title of the section in which those reflections take place - «exoticism» - is no less significant for exoticism here means that the work of art does not belong to the world. About that artistic exoticism Levinas writes: "We can in our relation with the world tear ourselves away from it. Things refer to an inside, as parts of the given world, objects of knowledge or objects of use, caught up in the system of practice wherein their alterity hardly emerges. Art makes them stand out from the world, extracts them from this belongingness to a subject» ${ }^{36}$.

Given the comparative character of my presentation, I could say that the guideline of Levinas's remarks on the exoticism of the work of art is an ontological radicalisation of aesthetics. What does that mean? How does that radicalisation concern Levinas's relation to his two masters in phenomenology, Husserl and Heidegger?

The answer is provided by a precise analysis of the exoticism he attributes to the work of art. The point is this: the work of art subjugates the spectator or listener under a set of impressions whose impact is such that what is seen or heard is an alterity so strong that it escapes the subject-object relationship which pervades our theoretical or practical dealings with the world.

In other words, the disinterestedness underscored by Kant in his analysis of taste is, so to speak, maximized by Levinas in such a way that our relation to the artwork becomes a state in which all power of a subject upon a specific object disappears. In our dealings with the world, the sense impressions we receive are immediately inserted in an objectifying process which is perception:

\footnotetext{
32 Ibid, p. 25.

${ }^{33}$ Ibid, p. 26.

${ }^{34}$ Ibid, p. 29.

${ }^{35} \mathrm{Ibid}$.

${ }^{36}$ Ibid, p. 52.
} 
we perceive things which have specific characteristics and persons responding to a name. By contrast, according to Levinas, «the movement of art consists in leaving perception to rehabilitate sensation»; that movement «instead of arriving at the object gets lost in the sensation itself», a sensation "detaching the quality from this object references ${ }^{37}$. As a result, sensation returns to "the impersonality of an elements ${ }^{38}$.

The Levinassian desciption of that return to sensation is in no way psychological, it is ontological: indeed the standing out of the impersonal element of sensation is an event, the sheerly factual emergence of the "There is» in its «essential anonymity» ${ }^{39}$.

In that context Levinas comes to terms, either expressly or implicitly, with his two masters in phenomenology.

He explicitly regrets that Eugen Fink, in agreement with Husserl about this, considers what is depicted by a painting to be a «neutralised and suspended world» instead of ackowleging that it is something which has lost its worldquality, «a reality without world».

As far as Heidegger is concerned, it is obvious that the Levinassian notion of exoticism is the opposite of the Heideggerian notion of a setting up of a world by the work of art. The same opposition is obvious in the rehabilitation of aisthèsis, which was treated as a superficial factor in Heidegger's polemic against aesthetics.

The contrast shines forth when, considering the last version of Heidegger's interrogation on The Origin of the Work of Art, a version published after World war II , we compare what he was writing about a modern painting - Van Gogh's peasant shoes - with Levinas's remarks on the paintings of his time (abstraction, matierism, surealism, etc.). When Heidegger describes Van Gogh's painting, he does not pay any attention whatsoever to colours, lines, rhythm and shapes, his only point is to find in the painting an illustration of what he takes to be a setting of truth into work, namely the disclosure of the essence of a tool, reliability defined a reciprocity between world and earth for a peasant woman.

By contrast, what Levinas salutes in modern painting is the effort to introduce by the mere interplay of lines ad colours an elementary spectacle in which the coherence of a world disappears and is replaced by the exhibition of the alterity of the "There is».

\footnotetext{
${ }^{37}$ Ibid, p. 53.

${ }^{38}$ Ibid.

${ }^{39}$ Ibid, p. 58.
} 
I conclude by pointing out in the article of 1948 on «Reality and its shadow» a confirmation of the contrast I wanted to underscore.

In an allusion to Greek scupture, Levinas observes that the statue of the pagan God displays the stupidity of an idol and manifests an existence which is a mere shadow of reality for it accomplishes the paradox of a petrified «instant lasting without a future», whereas Heidegger conversely was claiming that the statue was more real than anything else and had the power to open a future.

Moreover, instead of opposing like Heidegger one art, the Greek, to the arts of other cultures in which allegory supposedly prevails, Levinas detects in the statues of the Greek gods, the clearest proof of the allegorical nature of all art. Which means that all work of art, whatever its cultural origin, manifests that all reality is accompanied by its shadow, the shadow of the "There is», in which it gets petrified unless an ethical opening to the others allows a liberation from that petrification.

Further on, in the same article Levinas writes forcefully: «The fact that mankind could give to itself an art reveals in time the uncertainty of its continuation». Since he mentions in that context the teaching of Descartes about the discontinuity of duration, there is no doubt that the quote I just made has to be connected with the conclusion of the article where Levinas claims that without a relation to the others there would be no future, no opening of time. This is of course an anticipation of the ethical developments carried out later in Totality and Infinity. But the insistance on the link between time and the other implies a strong objection to Heidegger for whom the opening of time depends exclusively from the Self.

Finally, the article of 1948 already suggests that it is the ethical relation to the others, a relation underrated by Heidegger, which introduces above and beyond the mere repetition of petrified instants a diachrony of dialogues, of initiatives, and of responsible choices which justifies the work of the historians of art, disdained by Heidegger, but which forbids to grant to any work a theophanic power. 


\title{
El Tema del Mundo y la Pregunta por el Método Fenomenológico
}

\author{
Roberto J. Walton \\ Universidad de Buenos Aires
}

\begin{abstract}
Resumen
En este trabajo considero (1) el análisis del predarse del mundo en la fenomenología de Husserl, (2) la crítica de Eugen Fink a la noción husserliana de mundo en los escritos relacionados con sus ańos de asistente junto a Husserl ${ }^{1}$, y (3) la relación de esta crítica con el tema de la presencia inalienable del mundo en Merleau-Ponty.
\end{abstract}

Es conveniente la mención previa de algunas circunstancias. En marzo de 1939, en una carta a Herman Van Breda, quien, luego de la muerte de Husserl en abril del ańo anterior, había puesto a salvo los manuscritos y organizaba el Archivo-Husserl en Lovaina, Merleau-Ponty señala que se ocupa de elaborar una fenomenología de la percepción e indaga acerca de la posibilidad de consultar escritos de Husserl. Además, ańade esta pregunta: "Me permito preguntarle al mismo tiempo si la obra de Fink, de la que un fragmento acaba de aparecer en la Revue Internationale de Philosophie, ha de ser impresa pronto en Bélgica. [...]"2. Ante la respuesta positiva de Van Breda sobre la posibilidad de efectuar las lecturas, Merleau-Ponty se establece en Lovaina entre el 1o y el 7 de abril como primer visitante externo al Archivo. Allí conoce a Fink, quien había llegado a mediados del mes anterior para transcribir manuscritos. Fink fue asistente de Husserl desde 1928, redactó bajo su dirección su escrito de habilitación, la VIa. Meditación cartesiana, que se ocupa de la teoría trascendental del método, y fue considerado por Husserl no en esa condición sino como un "colaborador" (Mitarbeiter): “[...] pensamos en común: somos como dos vasos comunicantes" (HuaDok III/4, 94; III/7, 89) ${ }^{3}$. Van Breda nos informa, sin decir nada acerca del contenido de las conversaciones entre Fink y Merleau-Ponty, que "ellos tuvieron un largo intercambio de puntos de vista, apasionante por lo demás, [...]”“4. Respecto del contenido que no es posible reconstruir se debe tener en cuenta una pregunta sobre la posible publicación ulterior de la obra de Fink efectuada por Merleau-Ponty en la mencionada

${ }^{1}$ Cf. Fink, Eugen. Phänomenologische Werkstatt. Teilband 1: Die Doktorarbeit und erste Assistenzjahre bei Husserl, ed. por Ronald Bruzina. Freiburg/München: Karl Alber, 2006.

${ }^{2}$ Cf. Van Breda, Herman Leo. "Maurice Merleau-Ponty et les Archives-Husserel à Louvain". Revue de Métaphysique et de Morale. No 67 (1962), p. 412.

${ }^{3}$ La sigla corresponde con indicación de tomo y página a Husserl, Edmund. Husserliana-Gesammelte Werke (Hua), vols. I-XXXIX, -Dokumente (HuaDok), vols. I-IV, y -Materialien (HuaMat), vols. I-VIII. Dordrecht: Springer (con anterioridad, Haag: Martinus Nijhoff; Dordrecht/Boston/London: Kluwer Academic Publishers), 1950-2007.

${ }^{4}$ Van Breda, H. L. "Maurice Merleau-Ponty et les Archives-Husserl à Louvain”, p. 413 s. 
carta a Van Breda. Ella se formuló porque el artículo de Fink, con el título "El problema de la fenomenología de Edmund Husserl”, había sido presentado como el fragmento inicial de un escrito mayor. Es significativo que el trabajo finalice con una alusión al problema de si aquello por medio de lo cual tenemos acceso objetos puede ser determinado con los conceptos por medio de los cuales nos referimos a objetos 5 . Sobre la relación ulterior entre ambos pensadores se ha de tener en cuenta que, en una carta a Fink de 1959, Merleau-Ponty afirma que "hoy como en el pasado, estoy muy cerca de sus preocupaciones y de su meditación, aun si el enfoque y el modo de expresión son diferentes”, y manifiesta la esperanza de poder responder positivamente a su invitación para ir a Friburgo y nuevamente "mantener una larga conversación".

\section{El darse previo del mundo según Husserl}

El tema husserliano del mundo de la vida se asocia con la idea de un nuevo camino hacia la fenomenología trascendental ante las insuficiencias de la vía cartesiana. Ante todo, la reducción tiene en ella el carácter de una pérdida, y la conciencia se presenta como un residuo, es decir, como algo que queda luego de la puesta entre paréntesis del mundo. El $\$ 49$ de Ideas I lleva como título "La conciencia absoluta como residuo de la aniquilación del mundo" y contiene la afirmación de que el ser inmanente es absoluto en el sentido de que no necesita nada para existir (cf. Hua III/1, 104). Husserl mismo se dio cuenta de que hablar de "exclusión del mundo" o de "aniquilación del mundo" o de la "conciencia como residuo" puede conducir a equívocos. En un texto caracterizado por él como "un manuscrito de 1924 con autocrítica" (Hua VIII, 573), escribe: "Este lenguaje conduce fácilmente a creer que el mundo en adelante deja de ser tema fenomenológico y que en su lugar solo serían tema los actos 'subjetivos', las maneras de aparición, etc., que se refieren al mundo" (Hua VIII, 432). En el $\$ 43$ de la Crisis, Husserl afirma que la vía 'cartesiana "tiene la gran desventaja de que conduce como de un salto al ego trascendental y lo trae, porque debe faltar toda explicitación previa, a la visión de un aparente vacío de contenido, ante el cual uno se encuentra ante todo perplejo sobre lo que se ha ganado en ella y sobre cómo se ha de obtener a partir de allí una nueva ciencia fundamental, decisiva y de índole totalmente nueva para la filosofía" (Hua VI, 157 s.). Por eso el primer paso en la nueva vía hacia la fenomenología trascendental que parte del mundo de la vida es elaborar una ontología de este mundo que ponga de manifiesto sus estructuras esenciales. Para establecer esta ontología es necesaria una primera reducción de todas construcciones ideales que encubren al mundo de la vida. Luego de haber desarrollado la ontología del mundo de la vida, Husserl se ocupa del tema ego-cogitatio-cogitatum "según el modo de hablar cartesiano", pero aclara: "Si bien estos nombres son

\footnotetext{
${ }^{5}$ Cf. Fink, Eugen. Studien zur Phänomenologie 1930-1939. Den Haag: Martinus Nijhoff, 1966, pp. 179, 222 s. Cf. Bruzina, Ronald. "Eugen Fink y Maurice Merleau-Ponty: The Philosophical Lineage in Phenomenology". Toadvine; Ted y Embree, Lester (eds.). Merleau-Ponty's Reading of Husserl. Dordrecht/ Boston/London: Kluwer Academia Publishers, 2002, p. 190.

${ }^{6}$ La carta se cita según Bruzina, R. "Eugen Fink y Maurice Merleau-Ponty", p. 199 n.
} 
inseparables uno de otro, uno debe ocuparse de ellos uno a la vez y manteniendo un orden en el sentido inverso al seguido por el enfoque cartesiano" (Hua VI, 175). El punto de partida no ha de estar en el cogito sino del lado del correlato, y esto significa que se encuentra en la ontología del mundo de la vida. El mundo de las cosas, y sus estructuras fundamentales, son tomadas como índices o hilos conductores para el esclarecimiento de su constitución, de modo que el análisis trascendental tiene desde el comienzo una plenitud en los que concierne a su contenido. El segundo paso de la vía que parte del mundo de la vida consiste en una segunda reducción por medio de la cual sus estructuras ontológicas son puestas en correlación con la vida intencional de la subjetividad trascendental. La vía hacia la fenomenología trascendental que parte de la ontología del mundo de la vida no tiene los defectos de la vía cartesiana porque deja de aparecer como una pérdida del mundo y una limitación a la conciencia.

Husserl señala que en virtud de la epojé se accede a un nuevo modo de vida en que el filósofo es por primera vez libre, "y ante todo libre de la atadura interior más fuerte y universal, y a la vez más oculta: la atadura al darse-previo del mundo" (Hua VI, 154). En la actitud natural, nos encontramos ante un darse previo del mundo: "El hombre en situación de mundaneidad (Weltlichkeit) vive en el darse previo de sí y del mundo, [...]. La subjetividad trascendental no está predada en la mundaneidad humana, y, sin embargo, está 'velada' en ella en la medida en que el hombre, el que 'sabe' de sí mismo y del mundo, y es para sí hombre en este saber, puede efectuar la reducción trascendental y quebrantar su mundaneidad" (Hua XV, 389). Después de la epojé, dejamos de ser "hijos del mundo" porque el darse-previo del mundo es válido como fenómeno para la subjetividad trascendental, es decir, como correlato de las operaciones pasadas: "Conozco el darse-previo, y lo comprendo como operación trascendental, operación de los intereses trascendentales" (Hua XXXIV, 317). Aun si la comprensión trascendental implica una nueva manera de considerar el darse-previo inherente a la actitud natural a partir de una dimensión que no estaba previamente dada, estos horizontes de familiaridad son el hilo conductor para la exploración trascendental de las maneras de darse. Como lo explica Husserl en la Crisis, la actitud trascendental está "por encima” (über) del darse-previo del mundo en la actitud natural, y, por tanto, puede indagar "el cómo del darse-previo del mundo", esto es, "el cómo de sus maneras de darse" (Hua VI, 150, 154, 160). Al inhibir los sentidos y las vigencias predados y colocarse sobre ellos, la liberación de la atadura del darse-previo del mundo permite el descubrimiento de la correlación entre el mundo y la conciencia del mundo, y nos enfrenta con una "dación previa de otra índole como fenómeno de mundo" (HuaDok II/1, 204). El tema es decisivo y Husserl plantea como tarea de la fenomenología "una ciencia del cómo universal del predarse del mundo, esto es, de lo que configura su ser-suelo (Bodensein) universal para cada objetividad" (Hua VI, 149). 


\section{El mundo como continente según Fink}

En un intento de ordenar y articular los problemas de la fenomenología, Fink redactó en agosto de 1930 el "Plan para el 'Sistema de filosofía fenomenológica’ de Edmund Husserl”. Esta exposición sistemática se inicia con el tema "Del comienzo y principio de la fenomenología" y se ocupa del darse previo del mundo y la reducción fenomenológica. Fink escribe: "Darse previo no solo del mundo en cada caso propio actualmente experienciado, sino del pleno sentido 'mundo'. Mundo como integridad de lo predado por medio de la experiencia inmediata y sobre todo mediata: mundo, ¡una tradición intersubjetiva!” (HuaDok II/2, 5). Fink propone reconsiderar el signficado del mundo luego de hacer investigación fenomenológica en el marco de la epojé porque advierte que el predarse del mundo implica un ineludible y omnienglobante condicionamiento. Sostiene que "el mundo mismo es la verdadera situación a la que la meditación radical sobre sí se remite" (HuaDok II/2, 24). Y añade: "El mundo no es el contrapeso de una vida mundana colectiva o de la vida mundana del yo de la experiencia última sino que es la unidad de esta correlación misma que nos engloba en tanto momento de ella misma" (HuaDok II/2, 62) ${ }^{7}$.

En sus propios manuscritos o notas al margen de la redacción de trabajos encargados por Husserl, Fink señala que el mundo no se constituye a través de modificaciones intencionales, es decir, horizontes a los que es posible acceder por medio del "yo puedo siempre de nuevo" de la explicitación, porque su horizonticidad no es una potencialidad actualizable en una conciencia objetivante. No estamos en camino al mundo a través de la explicitación de objetos sino que el mundo es anterior a la constitución de objetos. Si bien extiende nuestro acceso al mundo, el esquema de plenificación dentro del horizonte por medio de la conciencia del " $y$ así sucesivamente" presupone el horizonte de accesibilidad. Nunca nos permite alcanzar el mundo porque la conciencia del mundo tiene el carácter de un "salto-sobre" (Übersprung): "El enfoque de Husserl sobre el problema constitutivo es el intento de poder captar los 'continentes' ('Enthalte') por medio de los 'contenidos' ('Inhalte'), los horizontes por medio de lo intrahorizóntico"8. En lugar de avanzar por la vía de los contenidos explicitables en el horizonte, es necesario concebir el horizonte como una totalidad precedente: "A la totalidad precedente, no compuesta de contenidos, que ofrece en franquía un en-lo-cual (Worin) para posibles 'contenidos', la llamamos continente (Enthalt). Así, el mundo nunca es determinable como suma de lo que es, de 'contenidos', sino de un modo único y solamente como continente. El mundo es el continente de todo ente" ${ }^{\text {". }}$ El mundo no se encuentra en el margen de los objetos, ni es algo constitutivamente inacabado, ni es un hori-

\footnotetext{
${ }^{7}$ Fink señala que "la reducción tiene ella misma su situación mundana en la que ella comienza y en la que ella en cierto modo permanece", porque esta situación mundana es, en la reducción fenomenológica, "un momento estructural que no puede ser eliminado por el pensamiento (ein unwegdenkbares Strukturmoment)" (Fink, E. Studien zur Phänomenologie 1930-1939, p. 14).

${ }^{8}$ Manuscrito del Eugen-Fink-Archiv Z-VII XVII/15a. Citado por Bruzina, Ronald. "Redoing the Phenomenology of the World in the Freiburg Workshop, 1930-1934. Alter. No 6 (1998), p. 65.

${ }^{9}$ Fink, E. Phänomenologische Werkstatt, p. 300 (Ms. E-F-A Z-V VI/9a).
} 
zonte de posibilidad, ni es una lejanía en el sentido de una distancia: "En el 'yo puedo' se constituye la extensión de la accesibilidad, pero nunca el mundo, esto es, lo inaccesible, lo insaldable (das Unzugängliche, Uneinlösbare)"10.

El mundo es predado como un continente o contenedor (Enthalt) que no se organiza a partir de sus contenidos sino que proporciona un ámbito para ellos. Nos es predado como un ámbito que se resiste al intento de captarlo en términos de las cosas que aparecen dentro de él. Incluye todo y se nos sustrae, como lo indica la connotación inherente al prefijo Ent-, en el sentido de que escapa a todo intento de captarlo en términos de aquello que contiene, es decir, sus contenidos. Esto quiere decir que el horizonte es algo que atraviesa tanto los contenidos como lo que está más allá de ellos. El horizonte no es solo el índice de un posible "más", sino que tenemos una percatación original de él, no como un objeto que ha de ser ulteriormente determinado, sino como un contenedor para estas determinaciones o contenidos. El horizonte podría estar dado sin contenidos como el horizonte auditivo se da en el modo del silencio como un contenedor para posibles sonidos como contenidos ${ }^{11}$. Además, el mundo no se despliega delante de los actos sino que los envuelve y los estructura de modo que se encuentra alrededor y no delante de nosotros. Así, el sujeto está incluido en el mundo que no es ni la suma total de los objetos ni un horizonte universal que puede ser explicitado en términos de objetos. La estructura intencional de la conciencia solo es posible porque el mundo como continente incluye también la subjetividad. Es la unidad de la correlación entre el mundo y la conciencia del mundo, e incluye al sujeto como momento de esta unidad: "[...] el mundo es el todo correlacional de la inmanencia y la trascendencia"12.

Se plantea así el problema de cómo es posible que el ser humano se percate del mundo como un horizonte que, por condicionar todas sus experiencias y acciones, no es accesible a través de ellas. Aquí está en juego una intencionalidad que no es ni la intencionalidad de acto ni la intencionalidad de horizonte concebida como una modificación intencional de la intencionalidad de acto: "La equiparación de intención y conciencia de acto es un estrechamiento del significado originario de 'intención'; la intención es básicamente más amplia que la conciencia de acto, es el modo de la vida subjetiva en cuanto tal"13. Nos damos cuenta del mundo a través de un aspecto omnicomprensivo de la vida de la conciencia, esto es, una forma básica de la conciencia que tiene que ser considerada no en la forma de los actos de un yo que está en plena posesión de sí mismo. Se trata de una dimensión operante y no temática de la subjetividad trascendental, esto es, una dimensión de la conciencia más fundamental que la egológica con una intencionalidad que funciona por debajo de la intencionalidad de acto como una percatación no temática del mundo. Fink se refiere a

\footnotetext{
${ }^{10}$ Eugen-Fink-Archiv Z-VII X/1 a-b. Citado en Bruzina, R. "Redoing ...”, p. 66 s.

${ }^{11}$ Cf. Cairns, Dorion. Conversations with Husserl and Fink. The Hague: Martinus Nijhoff, 1976, p. 98 s.

${ }^{12}$ Ms. E-F-A Z-XII 11c. Citado en Bruzina, R. "Redoing ...”, p. 68

${ }^{13}$ Ms. E-F-A Z-VII IX/6a. Citado en Bruzina, R. "Redoing ...”, p. 71.
} 
una vigilia o apertura primaria al mundo como "situación del predarse"14, y la caracteriza también como "una relación con lo indeterminado, una intencionalidad divergente, un 'sentir oceánico”"15.

Fink no se atiene a la crítica de Heidegger a Husserl porque lo que es válido para la intencionalidad en tanto relación sujeto-objeto se aplica también a la trascendencia: "No es que haya el mundo porque el Dasein como trascendencia sea 'extáticamente' más allá de todo ente, sino que la estructura extática del Dasein solo es posible, porque el mundo como continente cósmico incluye también al Dasein" "16. El error de la crítica reside, en primer lugar, en considerar que la investigación trascendental necesariamente tiene que ajustarse al esquema sujeto-objeto para la intencionalidad cuando hay otras formas de intencionalidad, y, en segundo lugar, en desconocer que el ser-en-el-mundo resulta también de operaciones constituyentes: "Husserl es ciego para la trascendencia, Heidegger es ciego para la constitución" ${ }^{17}$. No ver la trascendencia implica no tener en cuenta una intencionalidad ajena a la relación sujeto-objeto, y desconocer la constitución significa no advertir las operaciones trascendentales que subyacen a la trascendencia. El mundo no debe ser considerado como existencial del Dasein porque entonces un ente del mundo sería a la vez óntico y trascendental. Estaría presupuesto por el ente e incluido en el ente. Sería condición de apertura del horizonte del mundo dentro del cual se encuentra como ente. Por tanto, es necesario retroceder a los procesos constituyentes a partir de los cuales emerge la relación sujeto-objeto y a la vez separarse de todo ente: "Husserl no se plantea con razón la pregunta por el modo de ser de la subjetividad absoluta" ${ }^{18}$. Su posición es más radical que la de Heidegger porque, como lo expresa la VIa. Meditación, la subjetividad trascendental "es de un modo que trasciende la idea de ser" (HuaDok, II/1, 84). Husserl asiente a la afirmación, aunque inserta la palabra "natural" en la expresión "idea de ser". En sus propias notas, Fink presenta la relación entre lo que es y aquello que está en el origen de lo que es como la relación entre lo que es y lo que no es, es decir, la relación entre to on y to me on, y proyecta una meóntica cuyo tema es esta dimensión que trasciende al ser: "Solo la captación meóntica de la subjetividad absoluta muestra la constitución como una relación meóntica, como no-óntica, como relación no entre lo que es sino 'entre' mundo (ser) y 'nada'; como relación de origen y estado-de-originado (Ursprung und Entsprungenheit)"19.

En la VIa. Meditación, Fink observa que la subjetividad trascendental no está separada del ser del mundo porque el mundo es el plano de las terminaciones

\footnotetext{
${ }^{14}$ Ms. E-F-A Z-VI 57a. Citado en Bruzina, R. "Redoing ...”, p. 74. Cf. Bruzina, Ronald. Edmund Husserl \& Eugen Fink. Beginnings and Ends in Phenomenology 1928-1938. New Haven \& London: Yale University Press, 2004, pp. 189-196.

${ }^{15}$ Fink, E. Phänomenologische Werkstatt, p. 417 (Ms. E-F-A M-II).

${ }^{16}$ Ms. E-F-A Z-XIV II/2b. Citado en Bruzina, R. "Redoing ...”, p. 69 s.

${ }^{17}$ Ms. E-F-A Z-X 15a. Citado en Bruzina, R. Edmund Husserl \& Eugen Fink, p.128.

${ }^{18}$ Fink, E. Phänomenologische Werkstatt, p. 321 (Ms. E-F-A Z-V VII 12ab).

${ }^{19}$ Citado en Bruzina, Ronald. "Einleitung des Herausgebers". Fink, E. Phänomenologische Werkstatt, p. lxxxvi (Ms. E-F-A Z-XV 112b).
} 
de sus procesos constitutivos, y que la actitud natural consiste en la restricción a lo que existe en el mundo y el olvido de los estratos profundos de la constitución que no son en sentido mundano. En sus notas, subraya que ni la actitud natural ni el predarse del mundo como un componente intrínseco de ella constituyen una condición contingente para el ser humano: "La actitud natural no es una actitud, sino la condición de posibilidad de adoptar tácticamente tal o cual actitud"20. Se trata de algo más profundo que un punto de vista que puede ser modificado a voluntad por la persona que la ha adoptado. Por eso se hace necesario un cambio de terminología y Fink recurre al término "cautiverio en el mundo" en lugar de "actitud natural" para designar la condición del ser humano mismo en lugar de un punto de vista adoptado de modo ingenuo por el ser humano individual: "El cautiverio en el mundo no es un cautiverio del hombre, sino que es el ser-hombre mismo" ${ }^{21}$. Al estar cautivo en el mundo solo puedo estar abierto a lo que se presenta dentro del mundo, pero no abierto al mundo mismo, es decir, no a la estructura del cautiverio sino a las cosas que se presentan dentro de ella. Fink traza un paralelo con lo que sucede cuando me encuentro en una determinada postura axiológica: solo se me revela lo que es bueno o malo de acuerdo con ella, pero no ella misma en tanto postura. Análogamente, Husserl ha examinado el mundo según caracteres atribuibles a lo que se presenta dentro de él: "La relación constitutiva entre la conciencia pura y el mundo es llevada adelante en las 'Ideas', especialmente y en una necesaria abstracción, como intencionalidad-del-objeto, con lo cual el de-donde (Woher) de la intención y el en-qué (Worin) de los objetos permaneció en un no-desvelamiento" ${ }^{22}$. En la formulación husserliana de la epojé, el concepto de actitud natural está pensado de acuerdo con la actitud directa orientada hacia los objetos y según el carácter dóxico de esta experiencia de los objetos. Por eso Husserl pone entre paréntesis el carácter dóxico del mundo en el modo en que se pone entre paréntesis el carácter dóxico de los objetos. Pero de este modo el mundo no ha sido adecuadamente puesto de manifiesto, y, por tanto, no puede ser sometido a la epojé. En lugar de un análisis de lo que es propio del mundo se ha producido una "fijación a lo que es", y Fink se pregunta: “¿Cómo ha de ser excluido el 'mundo' cuando aún ni siquiera ha sido llevado a la visión?”23. Por eso la formulación de la reducción en Ideas I tiene que ser provisoria y es necesario ahondar la investigación. Fink caracteriza el predarse del mundo como cautiverio en el mundo y sostiene que la epojé permite pasar del simple cautiverio no reconocido, es decir, de la llamada actitud natural, al reconocimiento de la prisión. Este reconocimiento no puede anular ónticamente la prisión, sino que ella tiene que ser interpretada meónticamente mediante la puesta de relieve del origen del mundo en procesos constituyentes últimos que carecen de ser: "El conocimiento del cautiverio en el mundo configura la conciencia que nosotros queremos llamar prisión en el mundo. La prisión no puede ser ónticamente superada por ninguna filosofía, ella es

\footnotetext{
${ }^{20}$ Ms. E-F-A Z-VII XVIII. Citado en Bruzina, R. “Redoing ...”, p. 56.

${ }^{21}$ Ms. E-F-A Z-XI XCIII/2a. Citado en Bruzina, R. "Redoing ...”, p. 58.

${ }^{22}$ Fink, E. Phänomenologische Werkstatt, p. 261 (Ms. E-F-A Z-IV 98a).

${ }^{23}$ Ms. E-F-A Z-XIII XVIII/2a. Citado en Bruzina, R. "Redoing ...”, p. 58.
} 
ónticamente insuperable. La reducción fenomenológica no es una superación óntica sino meóntica de la prisión en el mundo, la anulación de la 'esclavitud' por el 'señorío' del espíritu”24.

\section{La presencia inalienable del mundo según Merleau-Ponty}

Merleau-Ponty tuvo la oportunidad de leer la VIa. Meditación cartesiana en el otońo de 1942. En una carta a Van Breda del 1o de octubre de ese año, escribe: "He podido en Marsella consultar junto a G. Berger, la VIa. Meditación; la he leído en la tranquilidad de la pequeña ciudad universitaria de Aix-en-Provence, y esta lectura aumenta aún más mi curiosidad <por los inéditos>”25. El agradecimiento se expresa en una nota en la primera página del "Prefacio" a la Fenomenología de la percepción, cuya tesis central es que redescubro el mundo en mí como una dimensión a la cual no puedo escapar: "El mundo está allí antes de todo análisis que yo puedo hacer de él [...]. El mundo no es un objeto del que poseo ante mí la ley de constitución, sino el medio natural y el campo de todos mis pensamientos y de todas mis percepciones explícitas" (PP iv s.) ${ }^{26}$. Merleau-Ponty explica que, sin renunciar a la certeza de la actitud natural, debemos abstenernos de ella para hacerla aparecer como tal. Porque somos un ser-en-el-mundo, y de un cabo a otro relación con el mundo, la única manera de aprehenderlo, es rehusarnos a esta complicidad con el mundo poniéndola fuera de juego: "[...] para ver el mundo y aprehenderlo como paradoja, es necesario romper nuestra familiaridad con él, y esta ruptura no puede enseñarnos otra cosa que el surgimiento inmotivado del mundo. La más grande enseñanza de la reducción es la imposibilidad de una reducción completa" (PP, viii). Merleau-Ponty no es ni ciego para la trascendencia ni ciego para la constitución. Sabe que "por debajo de la 'intencionalidad de acto' [...] es necesario reconocer una intencionalidad 'operante' (fungierende Intentionalität) que hace posible la primera y que Heidegger llama trascendencia” (PP, 478), pero, además, no deja de reconocer que "todo Ser y Tiempo ha salido de una indicación de Husserl” (PP, i), y que "el 'In-der-Welt-sein' de Heidegger no aparece sino sobre el fondo de la reducción fenomenológica” (PP, ix) a la vez que pone de relieve "los sedimentos de una constitución previa" (PP, 249), esto es, "un trabajo ya hecho, una síntesis general constituida de una vez por todas" (PP, 275).

En el primer párrafo del "Prefacio" aparecen mencionadas, junto con las Meditaciones Cartesianas y la "fenomenología genética", la VIa. Meditación Cartesiana de Fink y la "fenomenología constructiva". Mientras que la fenomenología regresiva retrocede de lo dado objetivamente a sus condiciones subjetivas de posibilidad, la fenomenología progresiva o constructiva se ocupa de aquello que no es dado en la intuición, es decir, de problemas marginales que no son

\footnotetext{
${ }^{24}$ Ms. E-F-A Z-XIII XIII/5a. Citado en Bruzina, R. “Redoing ...”, p. 60.

${ }^{25}$ Van Breda, H. L. "Maurice Merleau-Ponty et les Archives-Husserl à Louvain”, p. 421 s.

${ }^{26}$ La sigla corresponde a Merleau-Ponty, Maurice. Phénoménologie de la perception. Paris: Gallimard, 1945.
} 
solucionables en la fenomenología regresiva como el origen y el fin de la vida constituyente o nuestra infancia previa al alcance de nuestra rememoración. Mientras que en la fenomenología regresiva tanto el espectador fenomenológico como la vida trascendental constituyente tienen la misma dignidad de ser porque poseen efectividad actual, el espectador en la fenomenología constructiva tiene preeminencia sobre esa vida trascendental a la que procura acceder por medio de sus construcciones porque él tiene y ella carece de una existencia trascendental actual. La vida trascendental no dada que se ha de poner al descubierto constructivamente no tiene un espectador establecido por ella misma y solo puede acceder a sí misma en el espectador de la vida trascendental dada: "Y en la medida en que el espectador fenomenologizante en la fenomenología constructiva participa en su propio modo en la actualidad efectiva, en la medida en que, por el contrario, su objetividad temática no participa, el ser del espectador fenomenologizante precede en un cierto respecto al ser de su tema construido" (Hua II/1, 73). Del contraste entre ambas fenomenologías en razón de la preeminencia del espectador trascendental sobre la vida trascendental observada en la fenomenología constructiva, MerleauPonty obtiene una base para diferenciar la explicitación de un ser previo y la fundación del ser. En la siguiente afirmación del "Prefacio", en ocasión de los términos "espectador imparcial" y "se establecen", dos notas remiten a la VIa. Meditación cartesiana: "Pero el ego meditante, el espectador imparcial (uninteressierter Zuschauer) no se juntan con una racionalidad ya dada, ellos 'se establecen' y la establecen por una iniciativa que no tiene garantía en el ser y cuyo derecho reposa enteramente sobre el poder efectivo que ella nos proporciona de asumir nuestra historia. El mundo fenomenológico no es la explicitación de un ser previo, sino la fundación del ser, la filosofía no es el reflejo de una verdad previa, sino como el arte la realización de una verdad" (PP, xv). Lo que para Fink, y para Husserl, era la construcción de algo no dado ni dable en la intuición en virtud de una excedencia de posibilidades del espectador trascendental respecto de la vida trascendental, se convierte en Merleau-Ponty en la instauración de una verdad y una racionalidad por parte del pensador en virtud de una excedencia respecto del mundo dado. El papel del espectador trascendental lo asume quien no se limita a la esfera dada de sentido e instituye originariamente sentido, en tanto que el papel de la vida trascendenal dada lo asume la herencia de sentidos que ha de ser trascendida por la nueva institución. Así como la insuficiencia de lo dado en la intuición posibilita la primacía del espectador trascendental, la insuficiencia del mundo de sentido dado posibilita la primacía de la nueva institución de sentido que sobrepasa los sentidos precedentes. En el escrito "El problema de la fenomenología de Edmund Husserl", Fink se había referido a la "precaptación" del "ordenamiento interno de sentido de la conciencia" como "momento constructivo" del análisis intencional para subrayar que no se limita a la comprobación de datos de la conciencia que nos salen al encuentro ${ }^{27}$.

${ }^{27}$ Cf. Fink, E. Studien zur Phänomenologie 1930-1939, p. 205. 
En el párrafo que cierra la segunda parte de la Fenomenología de la percepción, Merleau-Ponty ofrece también un significativo análisis de su relación con la fenomenología de Husserl. A la noción de "un mundo transparente, sin sombras y sin opacidad" que se extendería delante de un sujeto imparcial, antepone "la vida ambigua en la que tiene lugar el Ursprung de las trascendencias" (PP, 418). Esta es la dimensión en que debe instalarse la filosofía si quiere "convertirse en radical, es decir, en trascendental" (PP, 76). Y ańade: "A la fenomenología como descripción directa debe añadirse una fenomenología de la fenomenología" (PP, 419). Husserl se había ocupado reiteradamente de autocríticas a sus descripciones en un nivel superior de reflexión, y en un escrito de 1930 habla de una "fenomenología de nivel superior, que considera el yo fenomenologizante y su vida: fenomenología de la fenomenología" (Hua XXXIV, 176). Fink desarrolla el tema en la VIa. Meditación como una investigación que se ocupa de analizar en una reflexión de segundo orden la índole de la reflexión que en un primer nivel investiga la constitución del mundo. Para Merleau-Ponty se trata de buscar en el cogito "un Logos más fundamental que el del conocimiento objetivo" (PP, 419). Esto converge con las tesis de Fink de que el nivel fundamental no puede ser alcanzado como fenómeno en una evidencia intuitiva, es decir, un acto intencional sometido al esquema sujetoobjeto porque es precisamente la condición para que emerja esta fenomenalidad. Tal vez un eco de la meóntica esté presente inmediatamente después de la ya mencionada referencia a la "fenomenología de la fenomenología" al término de la segunda sección de la Fenomenología de la percepción: "En el plano del ser, jamás se comprenderá que el sujeto sea a la vez naturante y naturado, infinito y finito. Pero si reencontramos el tiempo bajo el sujeto [...], comprendemos que más allá no hay nada para comprender" (PP, 419). Precisamente la prototemporalización configura para Fink la dimensión que está más allá del ser.

En los escritos tardíos, Merleau-Ponty manifiesta, con respecto a Husserl, que procura "recomenzar su esfuerzo, retomar, más que sus tesis, el movimiento de su reflexión" $(\mathrm{S}, 105)^{28}$. En las Notas de trabajo, subraya que "la reducción finalmente, no es, para Husserl, inmanencia trascendental, sino desvelamiento de la Weltthesis, [...]" (VI, 233) ${ }^{29}$. Se refiere a "la incompleción de la reducción" y la interpreta como "el redescubrimiento del ser vertical" (VI, 232), es decir, de un "ser bruto o salvaje" no aplastado por el conocimiento objetivo: "[...] se trata de operar la reducción, es decir, para mí, de desvelar poco a poco, y de más en más, el mundo 'salvaje' o 'vertical”" (VI, 230 s.; cf. 281). En términos que también reiteran los del Prólogo de la Fenomenología de la percepción, se refiere al "surgimiento inmotivado del Ser bruto (Etre brut)" (VI, 264) y propone la siguiente tarea: "Desvelamiento del Ser salvaje o bruto por el camino de Husserl y del Lebenswelt sobre el cual uno se abre" (VI, 237). Merleau-Ponty considera que, con la noción de uno-en-otro o entramado (Ineinander), Husserl ha vislumbrado la pertenencia recíproca de lo sentiente y lo sensible, esto es, la relación por la cual el cuerpo se enlaza con las cosas

\footnotetext{
${ }^{28}$ La sigla remite a Merleau-Ponty, Maurice. Signes. Paris: Gallimard, 1960.

${ }^{29}$ La sigla remite a Merleau-Ponty, Maurice. Le visible et l'invisible. Paris: Gallimard, 1964.
} 
por su ontogénesis y el resto del mundo sensible se siente en mí en un proceso simultáneo en virtud del cual el mundo se adueña de nosotros en la medida en que lo aprehendemos, e, inversamente, lo conocemos en la medida en que nos atraviesa. Nos recuerda que Husserl mismo se ha referido, en Ideas II, a las relaciones entre naturaleza, cuerpo y alma, y seńala que ellas implican una relación envuelto-envolvente para cada uno de los términos. Una "reversibilidad" o "ser englobante-englobado", en el sentido de una "remisión intencional recíproca” (VI, 297) o "intencionalidad interior al ser" (VI, 298), marca el límite de la analítica intencional atada a un lugar de contemplación absoluta, porque es el punto en que ella da lugar a una filosofía de la trascendencia que se ocupa de un Ser de trascendencia, es decir, un ser que no se deja reducir a las perspectivas de la conciencia. Al tratar esta dimensión metaintencional, Merleau-Ponty se refiere a un escrito de Fink, "La filosofía tardía de Husserl en la época de Friburgo", en el que se destacan tres motivos fundamentales en el legado husserliano que procuran expresar "lo que se sustrae a la posibilidad del decir" ${ }^{30}$ : un presente viviente que está fuera del tiempo, pero en el que se funda todo tiempo; una profundidad de la vida de la conciencia que escapa a la distinción entre hecho y esencia, efectividad y posibilidad o ejemplar y especie; y un proto-yo que antecede a la distinción entre el yo y el otro. Además, al señalar que los hilos intencionales distintos son esquematizaciones del torbellino de la carne, Merleau-Ponty remite al artículo "El análisis intencional y el problema del pensamiento especulativo" ${ }^{31}$, en que Fink sostiene que la fenomenología no puede contraponerse al pensamiento especulativo, que hay un elemento especulativo oculto en el pensamiento de Husserl cuando interpreta el horizonte como modificación del acto, y que el mundo es más originario que todos los objetos y todos los sujetos (cf. VI, 297 s.).

En este contexto es decisivo para Merleau-Ponty el concepto husserliano de horizonte como índice de "un nuevo tipo de ser" dentro del cual opera la reversibilidad: "[...] aquel delante del cual se abre el horizonte se encuentra aprehendido y englobado en él” (VI, 195). Es lo que afirmaba Fink con la idea de continente. Merleau-Ponty rechaza también, al igual que Fink, la idea de que la horizonticidad sea solo potencialidad actualizable: "La apertura al mundo supone que el mundo sea y permanezca como horizonte, no porque mi visión la empuje más allá de ella misma, sino porque, de alguna manera, aquel que ve es de ella y está en ella" (VI, 136). Y en otro texto añade: "Nos basta por el momento constatar que aquel que ve solo puede poseer lo visible si él es poseído por ello, si él es de ello (sỉl en est), si, por principio, según lo que es prescrito por la articulación de la mirada y las cosas, él es uno de los visibles, capaz, por una singular inversión, de verlas, él que es uno de ellas" (VI, 177 s.). Por consiguiente, la noción de Ineinander significa que "toda relación con el ser es simultáneamente captar y ser captado, la captación es captada, ella está

\footnotetext{
${ }^{30}$ Fink, Eugen. "Die Spätphilosophie Husserls in der Freiburger Zeit”.Van Breda, H. L. y Taminiaux J. (eds.), Edmund Husserl 1859-1959. La Haye: Martinus Nijhoff, 1959, p. 113.

${ }^{31}$ Fink, Eugen. "L'analyse intentionelle et le problème de la pensée speculative". Van Breda, H. L. (ed.), Problèmes actuels de la phénoménologie. Bruxelles: Desclée de Brouwer, 1952, pp. 53-87.
} 
inscrita e inscrita en el mismo ser que ella capta” (VI, 319). Por tanto, la filosofía no es captación total y posesión intelectual sino la "experiencia simultánea de lo captante y lo captado en todos los órdenes" (VI, 319).

La idea de Fink según la cual el mundo es el todo correlacional de la inmanencia y la trascendencia aparece muy claramente formulada en la siguiente afirmación de Merleau-Ponty: "Se trata de comprender que [...] la 'subjetividad' y el 'objeto' son un solo todo, que las 'vivencias' subjetivas cuentan en el mundo, forman parte de la Weltlichkeit del 'espíritu', son asentadas en el 'registro' que es el Ser, que el objeto no es otra cosa que el mechón de sus Abschattungen ..." (VI, 239). Pero hay una significativa diferencia. Si Fink pone de relieve el mundo como un continente en el que estamos incluidos, Merleau-Ponty establece un equilibrio entre dos movimientos. Una cosa es decir, según la imagen de un contenedor, que el mundo es el todo correlacional de la inmanencia y la trascendencia y otra cosa es afirmar, bajo el signo de la reversibilidad, que "las cosas son la prolongación de mi cuerpo y mi cuerpo es la prolongación del mundo por la cual el mundo me rodea" (VI, 308; cf. 83). Merleau-Ponty compone un movimiento del mundo que nos envuelve junto con un movimiento que va de nosotros al mundo. Fink solo ve un movimiento y pasa por alto el entrelazo. 


\title{
Goodbye, Heidegger! Mi Introducción Censurada a los Beiträge zur Philosophie
}

\author{
Franco Volpi \\ Universidad de Padua \\ Traducido por Joaquín Barceló Larraín \\ Universidad Andrés Bello
}

\begin{abstract}
En torno a esta obra se respira desde hace tiempo un hálito esotérico. A las expectativas abrigadas por los estudiosos, quienes la anunciaban, ya antes de su publicación, como el más importante de una serie de tratados inéditos posteriores a la "vuelta", incluso como la "segunda obra capital" 1 o derechamente el "verdadero magnum opus" de Heidegger, se añadieron las primeras sugerencias debidas a la circulación clandestina del manuscrito entre los adeptos y a la convicción de que en aquellas páginas se hallaba la clave para descifrar el pensamiento del "segundo" Heidegger. Construida con una atrevida arquitectura, en seis "fugas" que dibujan otros tantos escorzos sobre el acontecer del Ser, y escrita en un lenguaje insólito y sorprendente por sustraerse al dominio de los conceptos metafísicos y abrir una nueva aproximación al problema del Ser, esta obra ha permanecido envuelta en esa atmósfera críptica y todavía, después de varios años desde su aparición, está por interpretarse en su integridad. Y más allá de lo que se ha dicho y escrito hasta ahora, se abre paso una duda: ¿serán acaso las Contribuciones a la filosofía el diario de navegación de un naufragio? ¿Un nuevo hundimiento en el mar del Ser después de aquél por causa del cual Ser y Tiempo quedó incompleto?
\end{abstract}

\section{1. "Ser y tiempo", obra maestra incompleta}

Redactadas entre 1936 y 1938 durante una radical reorganización del propio pensamiento que coincidió con una profunda crisis personal ${ }^{3}$, las Contribuciones a la filosofía fueron dejadas voluntariamente inéditas y publicadas sólo en 1989 para el centenario del nacimiento de su autor como volumen 65 de la Gesamtausgabe 4 . Ellas representan -después de la "vuelta", o más precisamente a continuación de la interrupción del proyecto de Ser y Tiempo y después del intermedio político del rectorado de 1933/34- el intento sistemático más orgánico y coherente de retomar la problemática que debería haber sido tratada

\footnotetext{
${ }^{1}$ F.-W. von Hermann. Wege ins Ereignis. Zu Heideggers "Beiträgen zur Philosophie”. Klostermann, Frankfurt a. M., 1994, p. 6.

${ }^{2}$ O. Pöggeler. Heidegger und die hermeneutische Theologie. En Verifikationen. Festschrift für Gerhard Ebeling, a cargo de E. Jüngel, Mohr, Tübingen, 1982, p. 481.
} 
en la parte dejada inédita del opus magnum. Marcan el abandono, ahora ya consumado, de la "analítica existencial" (existenziale Analytik) como acceso privilegiado al problema del ser basado en ese ente especial capaz de planteárselo, el ser ahí, y la primera elaboración de un pensamiento conforme con la historia del Ser (seynsgeschichtliches Denken).

Cuando Heidegger inició en 1936 la redacción de este tratado, ya había trascurrido casi un decenio desde la publicación de Ser y Tiempo, que apareció en 1927 con las palabras "Primera parte" en el Jahrbuch für Philosophie und phänomenologische Forschung de Husserl. En las ediciones ulteriores aparecidas hasta ese momento -la segunda se publicó en 1929, la tercera en 1931, la cuarta en 1935- se conservaban las palabras "Primera parte" (Erste Hälfte), evidentemente porque Heidegger tenía la intención de terminar la obra. Todavía algunos ańos más tarde, al solicitar el 17 de Julio de 1943 la concesión de un semestre sabático en el invierno 1943/44, Heidegger indicaba como motivo la exigencia de completar un trabajo iniciado tiempo atrás y concerniente a "la pregunta fundamental del pensamiento metafísico, cuya exposición está prevista para el segundo volumen de Ser y Tiempo"'s. El hecho de que Heidegger no hubiese abandonado aún entonces la esperanza de concluir la obra se confirma, porque la especificación "Primera parte", omitida por una inadvertencia tipográfica en la quinta edición de 1941, fue restablecida después de la guerra en la sexta edición de 1949. Ella fue definitivamente suprimida sólo a partir de la séptima edición de 1953, y en lugar de la "Segunda parte" se publicó ese mismo ańo, con algunos arreglos, el curso del semestre de verano de 1935, Introducción a la metafísica ${ }^{6}$.

La pregunta es inevitable: en el momento en que Heidegger inició la redacción de las Contribuciones a la filosofía ¿qué ocurría con el proyecto incompleto de Ser y Tiempo? ¿Cuál es la relación de ambas obras entre sí?

\section{La "vuelta"}

En la Carta sobre el humanismo, publicada inmediatamente después de la segunda guerra mundial, a comienzos de 1947, Heidegger había sugerido la idea de una "vuelta" (Kehre) en su pensamiento para dar razón del paso de la ontología fundamental de Ser y Tiempo, centrada en el ser ahí, al pensar del

\footnotetext{
${ }^{3}$ En una carta del 2 de julio de 1937 a su mujer Elfride Petri, Heidegger alude a una "nueva crisis espiritual cuya vehemencia logra atormentarme hasta en el cuerpo" ("Mein liebes Seelchen!" Briefe Martin Heideggers an seine Frau Elfride. 1915-1970, a cargo de G. Heidegger, Deutsche Verlags-Anstalt, München, 2005, pp. 195-96). Según Pöggeler la crisis llevó a Heidegger a pensar en el suicidio (cfr. O. Pöggeler, Schicksal und Geschichte. Antigone im Spiegel der Deutungen und Gestaltungen seit Hegel und Hölderlin, Fink, München, 2004, p. 144).

${ }^{4}$ Klostermann, Frankfurt a. M., 1975 (en adelante GA).

${ }^{5}$ Este documento de archivo está publicado en la edición alemana del libro de Víctor Farías, Heidegger und der Nationalsozialismus. Fischer, Frankfurt a. M., 1989, p. 357.

${ }^{6}$ M. Heidegger. Einführung in die Metaphysik. Niemeyer, Tübingen, 1953. La versión original de 1935 está editada ahora en GA, vol. 40, 1983.
} 
Ser mismo entendido como Ereignis. Puesto que de aquella indicación autobiográfica ha surgido una tradición crítica, que ha insistido particularmente sobre tal "vuelta". Vale la pena recordar sus palabras exactas: "Experimentar suficientemente y participar en este pensar distinto que abandona la subjetividad", escribía Heidegger, "se ha hecho empero más difícil por cuanto con la publicación de Ser y Tiempo no se publicó la tercera sección de la primera parte, 'Tiempo y Ser'. Aquí el todo se invierte (Hier kehrt sich das Ganze um). La sección en cuestión no fue publicada, porque el pensar no lograba expresar adecuadamente esta vuelta (Kehre) ni decirla con ayuda del lenguaje de la metafísica" De la esencia de la verdad, pensada y leída en 1930 pero publicada sólo en 1943, permite hacerse una cierta idea del pensamiento de la vuelta desde Ser y Tiempo hasta 'Tiempo y Ser"'.

Leyéndolo bien, las razones del giro se encuentran en verdad ya en Ser y Tiempo. No en el sentido de la autointerpretación que Heidegger ha hecho de su propio itinerario especulativo cuando, después de la "vuelta", ha procurado insistentemente antedatar su pensar del Ser como si "siempre hubiese querido y hecho la misma cosa”, pensaban maliciosamente al respecto Jaspers y Hanna Arendt ya en $1949^{\circ}$. Pero sí en el sentido de que el problema de la finitud y de la facticidad del ser ahí, recogido en Ser y Tiempo, conduce por su propia dinámica más allá de la analítica de la existencia. El punto crítico se alcanza hacia el final de la parte publicada de la obra, en el parágrafo 72, cuando Heidegger, invirtiendo la perspectiva seguida hasta ese momento, que analiza el ser ahí en su proyección futura hacia lo posible y hasta aquella posibilidad-límite que es la muerte, se pregunta si la investigación, para ser completa, no debería incluir también el análisis de la proveniencia del ser ahí. He aquí su argumentación: "Puede ocurrir que la problemática relativa a la totalidad del ser ahí haya alcanzado su claridad ontológica genuina, como puede ocurrir también que haya encontrado en el ser-para-el-fin una respuesta adecuada. Ello no impide que la muerte sea solamente el 'fin' del ser ahí y, formalmente considerada, tan sólo uno de los términos que delimitan la totalidad del ser ahí. El otro 'fin' es el 'inicio', el 'nacimiento'. El todo de que estamos en búsqueda es, pues,

\footnotetext{
${ }^{7}$ M. Heidegger. Brief über den "Humanismus”. En Wegmarken, en GA, vol. 9, 1976, p. 326. En las lecciones del primer trimestre de 1941 hay detalles adicionales: "La tercera sección de la primera parte, 'Tiempo y Ser', se reveló insuficiente durante su impresión. La decisión de interrumpir el trabajo fue adoptada en los últimos días de diciembre de 1926 durante una permanencia donde Jaspers en Heidelberg, en la que gracias a confrontaciones vivaces y amistosas, con las pruebas de imprenta de Ser y Tiempo a mano, se me hizo claro que la elaboración hasta entonces lograda de esta importantísima parte (I,3) habría quedado necesariamente incomprensible. La decisión de interrumpir la publicación fue adoptada el día en que se recibió la noticia de la muerte de R. M. Rilke [29 de diciembre de 1926]. No obstante, en aquella época yo estaba convencido de que en un año iba a lograr decirlo todo de un modo más claro. Era una ilusión. En el curso de los años siguientes logré publicar algo que por caminos oblicuos habría debido conducir a la auténtica pregunta" (M. Heidegger, Die Metaphysik des deutschen Idealismus. Zur erneuten Auslegung von Schelling: Philosophische Untersuchungen über das Wesen der menschlichen Freiheit und die damit zusammenhängenden Gegenstände (1809), en GA, vol. 49, 1991, pp. 39-40).

${ }^{8}$ Loc. cit. Al margen de su copia personal de la conferencia Vom Wesen der Wahrheit anota Heidegger: "Entre los parágrafos 5 y 6 el salto en la vuelta (que es esencialmente en el evento)" (Wegmarken, cit., p. 193).

${ }^{9}$ H. Arendt - K. Jaspers. Briefwechsel 1926-1969, a cargo de L. Kohler y H. Saner, Piper, München-Zürich, 985, pp. 177-78.
} 
el ente que se extiende 'entre' el nacimiento y la muerte. En consecuencia, la orientación seguida por la analítica hasta ahora queda 'unilateral', a pesar de su tendencia hacia el ser-un-todo existente y de la genuina explicación del serpara-la-muerte auténtico e inauténtico. El ser ahí ha sido asumido como tema sólo en su existir, por así decirlo, 'hacia adelante', desentendiéndose de todo lo que había sido 'anteriormente"'10. Heidegger se plantea, pues, la pregunta por la proveniencia del ser ahí: ¿de qué inalcanzable origen derivan la existencia finita y la facticidad en que el ser ahí se encuentra arrojado? ¿Puede este último iluminar la dimensión que lo condiciona si por principio ella se sustrae a su vista y a su disponibilidad? ¿Y no se pondría, cada vez que intentase hacerlo, en la misma situación contradictoria del barón de Münchhausen, que pretendía salir del pantano en que se hundía tirándose de sus propios cabellos? ¿Cómo se puede tematizar el Ser sin hacer del ente, ni siquiera de ese ente privilegiado que es el ser ahí, el punto de Arquímedes que se absolutiza a sí mismo? Se abre aquí el problema de la historia y de la historicidad del ser ahí.

Los cursos universitarios de que hoy disponemos nos permiten articular con mayor precisión la indicación de Heidegger sobre la "vuelta" y seguir paso a paso el camino que lo condujo a renunciar al proyecto de Ser y Tiempo y a radicalizar la puesta en su lugar de la pregunta por el ser. Las importantes lecciones del semestre de verano de 1927 son ya, según una nota al pie de la primera página, una "nueva elaboración de la tercera sección de la primera parte de Ser y Tiempo", a saber, aquella titulada "Tiempo y Ser" que habría debido completar el tratamiento sistemático ${ }^{11}$. Varias insinuaciones en los semestres siguientes aluden también a tal continuación, por ejemplo, el concepto interesante pero problemático de "metaontología" que aparece en el curso del verano de $1928^{12}$, o bien el uso del concepto de "metafísica del ser ahî" en el libro Kant y el problema de la metafísica (1929) y sobre todo en el cambio de rumbo que se observa en las lecciones de los primeros ańos treinta. Heidegger trabaja todavía entonces en parte con los conceptos de Ser y Tiempo, y en parte, especialmente después del intermedio del rectorado, abre la nueva visión de la historia del Ser entendido como evento-apropiación. El paso de la perspectiva ontológico-trascendental a aquella histórico-eventual aparece completado en el curso denso y fundamental del verano de 1935, Introducción a la metafísica, en que se sobreponen varios motivos: el tratamiento de la pregunta "¿Por qué es en general el ente y no más bien la Nada?” en respuesta a las críticas de Carnap y a su "superación de la metafísica mediante el análisis lógico del lenguaje"; la idea de la historia de la metafísica como olvido del ser; la valorización del pensamiento poetizante (Parménides, Heráclito) y del poetizar pensante (Sófocles) como alternativa; la resbalosa mención de la "íntima verdad y gran-

\footnotetext{
${ }^{10}$ M. Heidegger. Sein und Zeit, 12a ed. (la última aprobada por Heidegger), Niemeyer, Tübingen, 1972, pp. 372-73.

${ }^{11}$ M. Heidegger. Die Grundprobleme der Phänomenologie. En GA, vol. 24, 1975, p 1.

${ }^{12}$ Cfr. M. Heidegger. Metaphysische Anfangsgründe der Logik im Ausgang von Leibniz. En GA, vol. 26, 1978, pp. 198 ss.
} 
deza" ${ }^{13}$ del nacionalsocialismo y la tesis geopolítica según la cual Europa estaría aprisionada por la "gran mordaza de Rusia por un lado y Norteamérica por el otro" ${ }^{14}$. Cuando publicó este curso en 1953, junto con la séptima edición de Ser y Tiempo, en que están suprimidas las palabras "Primera parte", Heidegger anunció que aquél contenía una "dilucidación ulterior" del problema dejado en suspenso en el opus magnum. ${ }^{15}$

\section{3. "No estoy escribiendo 'Ser y Tiempo II"}

En buenas cuentas, las Contribuciones se sitúan en una fase crucial de transición. A los programas de Heidegger en este período ha de parangonarse sobre todo su epistolario privado. Desde la soledad de la cabaña de Todtnauberg escribió a su amiga Elisabeth Blochmann, el 18 de septiembre de 1932, que tenía "la sensación de volver a crecer" y de haber reencontrado el hilo de su propio trabajo: "Por el momento estoy estudiando mis manuscritos, esto es, me leo a mí mismo, y debo decir que esto, en lo positivo y en lo negativo, es mucho más fructífero que otras lecturas" ${ }^{16}$. ¿Un perro que se muerde la cola? No. Heidegger está reencontrándose a sí mismo, protegido por la fama adquirida con Ser y Tiempo. Luego añade una información de gran interés para nosotros: "Ya hay especulaciones y se hacen discursos sobre el hecho de que estaría escribiendo Ser y Tiempo II. Está bien. Sin embargo, puesto que Ser y Tiempo I ha sido para mí un camino que me ha llevado a alguna parte pero que ahora no está siendo recorrido y ya está cubierto de vegetación, no puedo en absoluto escribir Ser y Tiempo II. Tampoco estoy escribiendo otro libro"17.

Un primer estrato de las Contribuciones a la filosofía-de acuerdo con una nota autobiográfica de 1937/38 titulada Über die Bewahrung des Versuchten

\footnotetext{
${ }^{13}$ M. Heidegger. Einführung in die Metaphysik (1935). En GA, vol. 40, p. 208. Cuando Heidegger publicó este curso en 1953, evitó la palabra nacionalsocialismo y habló de "movimiento", añadiendo entre paréntesis una precisión despolitizante y la frase se transformó: "íntima verdad y grandeza de este movimiento (es decir, del encuentro de la técnica planetaria y el hombre moderno)." (Einführung in die Metaphysik [1953], cit., p. 152). En la GA no se ha restablecido en este caso el texto de 1935, pero el problema está señalado en el epílogo del editor (Einfïhrung in die Metaphysik [1935], cit., p. 233).

${ }^{14}$ Ibid, p. 40.

${ }^{15}$ M. Heidegger. Sein und Zeit, cit., p. V. Y lo refuerza en una carta del 15 de septiembre de 1953 al semanario "Die Zeit", VIII, 39, 1953, p. 18, reproducida en GA, vol. 40, cit., pp. 232-33: "La Introducción a la metafísica del semestre del verano de 1935 ha sido escogida entre los cursos que desde hace tiempo ya he programado publicar, porque la considero particularmente apta, por su temática, para hacer visible un trecho del camino desde Ser y Tiempo (1927) hasta las últimas publicaciones. Es por eso que la séptima edición de Ser y Tiempo, aparecida contemporáneamente en la misma Editorial, remite a esta Introducción".

${ }^{16}$ M. Heidegger - E. Blochmann. Briefwechsel 1918-1969, a cargo de J. Storck, Deutsche Schillergesellschaft, Marbach a. N., 1989, p. 53.

${ }^{17}$ Ibid, p. 54
} 
e incluida en el testamento Wunsch und Wille ${ }^{18}$ - remonta a los comienzos de 1932. Pero las obligaciones del rectorado lo apartaron del trabajo filosófico. Él mismo admitió no haber estado en condiciones de desarrollar ni siquiera el curso universitario del semestre de verano de 1933 por estar absorbido como lo estaba en la administración ${ }^{19}$. Tan sólo después de haber dejado atrás el lastre fatal del rectorado encontró nuevamente Heidegger la concentración necesaria para la investigación filosófica. El $1^{\circ}$ de julio de 1935 , cuando concluía ya el curso de Introducción a la metafísica, confesó a su amigo Jaspers que "avanzaba fatigosamente a tientas" y le escribió: "Desde hace sólo pocos meses he vuelto a encontrar el hilo del trabajo interrumpido en el invierno de 1932/33 (semestre sabático), pero no es sino un débil balbuceo"20.

Algunos meses más tarde la renovada concentración dio sus primeros frutos. El 20 de diciembre de 1935 comunicó a Elisabeth Blochmann, quien había emigrado entretanto a Oxford, que deseaba regalarle algunas páginas suyas originadas "en el afortunado período de trabajo de los años 1931 y 1932, con el cual he reencontrado ahora un vínculo pleno y bastante maduro". Y le recomienda: "Aquí me solicitan de muchas partes que publique, pero aún no lo he decidido, y por este motivo le rogaría que por el momento no entregue estas hojas a otras manos" ${ }^{21}$. Luego le confía: "Se multiplican las páginas en un cartapacio con el encabezamiento: 'Crítica a Ser y Tiempo'. Poco a poco comprendo este libro, cuyo problema concibo ahora con mayor claridad; veo la gran imprudencia que en él se esconde, pero acaso es necesario hacer 'saltos' semejantes para llegar al gran salto. Se trata ahora tan sólo de plantear una vez más la misma pregunta en términos mucho más originarios y mucho más liberados de todo lo que es contemporáneo, académico y erudito”22.

\footnotetext{
${ }^{18}$ Publicado con el título Beilage zu Wunsch und Wille (Über die Bewahrung des Versuchten), como apéndice a M. Heidegger. Besinnung, en GA, vol. 47, 1997, pp. 419-28, aquí p. 424. El hecho de que Heidegger hiciera entonces un testamento es para Pöggeler una señal indirecta de su intención de suicidarse. "En mi libro sobre Antígona" me escribía Pöggeler en una carta del 27 de diciembre de 2004 "me he referido a la tentación de Heidegger, en 1937/38, de suicidarse. Ahora se me piden las pruebas. Sería decisivo hacer público el testamento que Heidegger redactó en esa época, respecto del cual las observaciones sobre el legado son tan sólo un anexo (Beilage)". Con anterioridad (9 de noviembre de 2004) me había dado mayores precisiones: "A raíz de una protesta de Hermann Heidegger le he escrito lo que sigue, que ciertamente le interesará a usted: 'En la pág. 144 de mi libro sobre Antígona afirmo que en 1937/38 su padre veía la propia obra como un 'legado' del que otros deberían tener que ocuparse. Nadie habla de su propio 'legado' si no piensa en la muerte. A mediados de los años 50 [...] se me dijo que en 1937 se temía que su padre se hubiera suicidado. [...] Cuando, en 1959, lo visité por primera vez, estaba preparando la edición de los textos inéditos sobre Nietzsche. La madre de usted no estaba en absoluto de acuerdo: aparecería de nuevo la depresión anterior. Pero su padre se impuso, porque con sus trabajos sobre Nietzsche quería hacer visible un trecho de su camino especulativo [...].

Me di cuenta entonces de que la determinación del nihilismo según la historia del ser tiene una entonación completamente diversa ('mística') respecto por ejemplo de las primeras lecciones. El curso sobre el nihilismo señala el momento de la crisis. Le dije a su padre que debía explicar esta crisis. Prometió hacerlo en un prefacio o un epílogo. Más tarde supe (tal vez por Marion Heinz) que efectivamente existirían apuntes en tal sentido. Luego se discutió sobre su dicho: 'Nietzsche me ha destruido' [...]. Es usted quien tiene la posibilidad de leer en su 'testamento' de entonces'”.

${ }^{19}$ Ibid, p. 422.

${ }^{20}$ M. Heidegger - K. Jaspers. Briefwechsel 1920-1963, a cargo de W. Biemel y H. Saner, Klostermann-Piper, Frankfurt a. M.-München-Zürich, 1990, p. 157.

${ }^{21}$ M. Heidegger - E. Blochmann. Briefwechsel, cit., p. 87.

${ }^{22}$ Ibid, pp. 87-88.
} 
En buenas cuentas, Heidegger confiesa aquí sus intenciones y su línea de investigación: abandonado el planteamiento de Ser y Tiempo, intenta retomar en términos más radicales el problema dejado en suspenso en dicha obra. Durante un par de años se ocupará de la redacción de las Contribuciones, que pueden ser consideradas por tanto como un nuevo intento orgánico y sistemático de llevar a cumplimiento la reformulación del problema del Ser emprendido con Ser y Tiempo. Ésta es una hipótesis avalada también por la nota autobiográfica mencionada en que Heidegger afirma: "Estas 'anotaciones' no pretenden 'terminar' Ser y Tiempo, sino fijar la problemática entera de modo más originario e inscribirla en el horizonte correspondiente" ${ }^{23}$.

Años más tarde, al reanudar después de la guerra el contacto con Hannah Arendt y relatarle el camino recorrido entretanto, le escribió al respecto haciendo una precisión que aquí resulta preciosa: "Vi que la analítica del ser ahí es todavía un recorrido que se realiza constantemente en las cumbres y expuesto a la doble amenaza de un precipicio, sea por la vertiente de un subjetivismo sólo modificado, sea por el de la ả $\lambda \hat{\theta} \theta \epsilon \alpha$ aún no pensada -y que permanece del todo inaccesible desde la perspectiva del pensamiento metafísico. Eso llegué a verlo sólo en 1935, después de haberme liberado interiormente el ańo anterior del rectorado y de haber restablecido poco a poco mis fuerzas. Después recibí otro impulso en 1937/38, cuando se me aclaró la catástrofe de Alemania, y de este peso irradió una presión que me volvió más tenaz y más libre en el pensar partiendo de la cosa en cuestión" ${ }^{24}$.

\section{La redacción de las "Contribuciones a la filosofía"}

Estamos, pues, en el momento crucial. "En este semestre tengo asueto" le escribe a Elisabeth Blochmann el 12 de abril de 1938 "y quisiera, si lo consigo hacer, dar una forma más completa a algunos trabajos preliminares [...]. Durante el verano quisiera permanecer más tiempo en la cabaña, donde todo está aún como antes" ${ }^{25}$. Heidegger hace referencia a la redacción de las Contribuciones, a las que se había dedicado en el período 1936/37 y que retoma y arregla en 1938 en un trabajo escrito casi clandestino, paralelo al trabajo "público" que desarrolla en las lecciones universitarias, en las que se lamenta ante Jaspers: "me estoy moviendo sólo en interpretaciones"26, en una aplicación cotidiana hecha "siempre y únicamente de exégesis" ${ }^{27}$. Las lecciones son, sin embargo, "una nueva ocasión de experimentar cuán grande es la distancia de las posibilidades de un pensamiento efectivo" ${ }^{28}$, es decir, de la especulación

\footnotetext{
${ }^{23}$ Cfr. M. Heidegger. Besinnung, cit., p. 424.

${ }^{24}$ H. Arendt - M. Heidegger. Briefe 1925 bis 1975. Und andere Zeugnisse. Frankfurt a. M.: Klostermann, 1998, p. 104.

${ }^{25}$ M. Heidegger -E. Blochmann. Briefwechsel, cit., p. 91.

${ }^{26}$ M. Heidegger - K. Jaspers. Briefwechsel 1920-1963, cit., p. 157.

${ }^{27}$ Ibid, p. 161.

${ }^{28}$ Ibid, p. 157.
} 
original e innovadora, independiente de la exégesis histórico-filosófica, y que Heidegger confía a la obra que está escribiendo en secreto y sobre la cual mantendrá una estricta reserva.

La ya recordada nota autobiográfica de 1937/38, Über die Bewahrung des Versuchten, ilumina las razones de tal secretismo. Tal vez recordando todo lo que la tradición hace con el corpus Aristotelicum, Heidegger parece querer aplicar a su propia obra la partición entre escritos exotéricos destinados al público y escritos esotéricos reservados a quien está dispuesto a prepararse debidamente para ellos. Y al agruparlos parece prever un camino iniciático para llegar progresivamente al corazón de su propio pensamiento:

1) las lecciones universitarias,

2) las conferencias,

3) los apuntes para los ejercicios de los seminarios,

4) trabajos preliminares a la obra,

5) reflexiones e indicaciones,

6) el curso sobre Hölderlin (semestre de invierno 1934/35) y los apuntes sobre el Empédocles,

\section{Del evento (Contribuciones a la filosofía)}

Como puede verse, el recorrido comienza con textos de carácter protréptico e introductivo, sucesivamente pasa a los materiales más difíciles de profundización y de estudio, para llegar por fin a la que Heidegger considera aquí secretamente (estamos en 1938/39) su obra propia y verdadera: Del evento (Contribuciones a la filosofía). Si bien él estima "no haber alcanzado aún la forma que justamente en este caso considero necesaria para su publicación como 'obra'”29, las Contribuciones están en la mayor cercanía al tratamiento ideal imaginado por él para concebir y exponer en términos adecuados el evento-apropiación del Ser.

Ahora aparece claro el motivo del doble título de la obra: subrayar el carácter esotérico y la necesidad de un camino preparatorio que introduzca a sus escondites. Contribuciones a la filosofía es un título insignificante por su generalidad, cuya única función es la de mantener la superficie, la fachada pública, no confundida con aquello que se esconde detrás, de modo que se destaque más aún el carácter esotérico del contenido. El título propio y verdadero es por consiguiente Vom Ereignis, que además ha de ser leído no como se entendería espontáneamente, como un complemento de argumento, sino como lo recomienda Heidegger con una lectio difficilior, como complemento de proveniencia. Entonces no Del evento sino Desde el evento, como para acentuar el carácter inspirado del texto. Coherentemente, en dos notas al margen en su

${ }^{29}$ M. Heidegger. Besinnung, cit., p. 427. 
copia personal de la Carta sobre el "bumanismo", Heidegger señala que desde 1936, es decir desde el inicio de la redacción de las Contribuciones, Ereignis es la palabra guía de su pensamiento ${ }^{30}$.

En las Contribuciones adquiere forma, pues, un universo especulativo nuevo y sorprendente si se le compara con el de Ser y Tiempo. Abandonada la comprensión casi trascendental del ser ahí, concentrada en su autodeterminarse y proyectarse en posibilidades, la atención se vuelve hacia la inmemorial proveniencia de la existencia. No obstante, para remontarse al origen de la finitud y de la facticidad es preciso mirar hacia la historia del Ser, es decir, hacia aquel horizonte que al ser ahí se le aparece infinito pero que Heidegger quiere coger como tal en su desmenuzarse histórico-eventual sin reducirlo a una "mala finitud”. El camino intentado por Heidegger es pensar el Ser como Ereignis, evento-apropiación, esto es, como copertenencia de Ser y ser ahí en su recíproco cubrirse en una alternancia de donaciones y sustracciones, concesiones y rechazos, manifestaciones y ocultamientos que adoptan el ritmo de las "épocas" de la historia entre un primer inicio griego, el advenimiento de la metafísica, y "otro inicio" anunciado por la muerte del "último Dios" y preparado por los "venideros". En este cuadro, sobre la base de su potente interpretación de lo griego, Heidegger esboza un diagnóstico de la modernidad como una época señalada por el "desierto que avanza", por la negatividad y el nihilismo, esto es, por el olvido del Ser y la hipertrofia del ente. Se refiere, pues, a la importancia histórico-epocal de dos figuras que examina a fondo en los cursos universitarios de aquellos años: Nietzsche, que da remate a la metafísica, y Hölderlin, que vaticina la edad por venir. La obra orquesta, por consiguiente, el conjunto de los motivos que forman el pensar del Ser como Ereignis, desentrañando la compleja trama especulativa que subyace a las reflexiones aparentemente inconexas del último Heidegger, que aquí cristalizan en una límpida y atrevida visión de conjunto.

\section{Estilo y estructura}

Desde el punto de vista formal, Heidegger ensaya un estilo y una arquitectónica que quieren corresponder a la novedad y a la dificultad de la empresa: pensar el Ser como evento-apropiación en el paso de la edad metafísica a un nuevo comienzo de la historia. Puesto que el tratamiento no está construido como argumentación sistemática ni en prosa continua, sino que reúne trozos y reflexiones relativamente breves, se ha hablado de sentencias y hasta de aforismos. Y se ha hecho referencia al estilo de los presocráticos que en los inicios de los años treinta Heidegger había comenzado a valorizar como paradigma de pensamiento poetizante, pero también a los fragmentos de la Voluntad de poder de Nietzsche, que en sus lecciones Heidegger procuraba obstinada-

\footnotetext{
${ }^{30}$ Cfr. M. Heidegger. Brief über den "Humanismus", cit., pp. 313 - 316.
} 
mente anudar en una interpretación coherente y de los que justo entonces, por encargo del Archivo de Weimar, preparaba una nueva edición. En realidad, el estilo de las Contribuciones no es sentencial ni aforístico, sino algo diferente. Aprovechando el registro de la brevedad, de la insistencia, de la repetitividad, tradicionalmente propias de los mantras, de la oración y de las letanías más que de la argumentación filosófica, Heidegger quiere fijar para sí e inculcar en quien lo está leyendo los rasgos esenciales de su visión del Ser entendido como Ereignis.

En cuanto a la estructura, después de una amplia "Mirada preliminar" (Vorblick) que presenta el conjunto de la obra e ilustra su carácter y motivos, el texto se articula en seis "fugas" (Fugen) o "combinaciones" (Fügungen), es decir, "junturas" o "articulaciones" que estructuran el acontecer del Ereignis y ofrecen la perspectiva para penetrarlo y comprenderlo: "La resonancia" (Der Anklang), "El juego del pase" (Das Zuspiel), "El salto" (Der Sprung), "La fundación" (Die Gründung), "Los venideros" (Die Zukünftigen) y "El último Dios" (Der letzte Gott).

"La resonancia" intenta mostrar que aún en el más completo abandono del hombre por parte del Ser y en el correspondiente olvido del Ser por parte del hombre, esto es, en el nihilismo perfecto, resuena todavía un eco del Ser. Tal resonancia puede ser escuchada por aquellos "pocos y raros" que advierten la condición de "necesidad" (Not) junto con la "necesariedad" de una vuelta (Not-wendigkeit), hallándose ellos dispuestos en el "estado de ánimo" (Stimmung) de la "contención" (Verhaltenheit) que incluye "turbación" (Erschrecken) y "pudor" (Scheu), y los hace capaces de "presagiar" (erahnen) de modo análogo a como los primeros pensadores griegos eran capaces de "sorprenderse" (erstaunen). Para quien sabe captar sus "señales" (Winke), el Ser también se manifiesta en la forma del "negarse" (Versagen), e incluso en esa intensificación de la "denegación" (Versagung, Versagnis) que es el "rechazo" (Verweigerung). Es en el cuadro de la "resonancia" que Heidegger esboza la teoría crítica de la modernidad a la que nos hemos referido, caracterizada por algunos fenómenos esenciales como la técnica planetaria, el levantarse de lo "gigantesco", la tiranía del cálculo y de lo útil, la reducción del hombre a sujeto, analizados aquí por primera vez de modo temático.

La segunda fuga se denomina "el juego del pase", con un término que alude a cuanto ocurre en el juego del fútbol cuando la pelota es pasada por un jugador a otro, efectuando aquello que con una metáfora se llama "sugestión". Bajo esta forma concibe Heidegger la relación del pensar el Ser con la historia de la filosofía. Esta última aparece en la resonancia del Ser como un primer inicio del pensar que "sugiere" otro inicio, haciendo un "pase" como herencia y como tarea de toda una serie de problemas que se procura repensar, siendo el primero de todos el del ente en cuanto tal en su unidad y en su polisemia. 
Pero para este re-pensamiento, que recibiendo el pase abre la alternativa a la metafísica, y al cual contribuyen las interpretaciones desarrolladas en sus contemporáneas lecciones histórico-filosóficas, no hay puentes ni mediaciones hermenéuticas practicables.

La única manera de llevarlo a cabo es realizar "El salto", la tercera fuga, con la que el pensar deja a sus espaldas la historia de la filosofía y "salta" desde el ente directamente al Ser, cuya riqueza ya no es la riqueza metafísica de la polisemia categorial, sino que se presenta ahora como el resultado de una dinámica interna del evento-apropiación mismo: el Ser, en su "permanencia esencial" (Wesung), empezando a "vibrar" (erzittern) y a "oscilar" (erschwingen) dilatándose o contrayéndose según el "espacio-tiempo" (Zeit-Raum), "se hiende" (Zerklüftung) en modalidades y, por consiguiente, en múltiples aspectos y determinaciones.

Con "La fundación", que es la fuga más compleja y articulada, se penetra en el corazón del evento-apropiación, de su Wesung. Ella está determinada por la tensión polar de Ser y ser ahí que funda y deja ser a aquel "entre", el ser-ahí, en el que el hombre -que no es simplemente idéntico al ser ahí- es arrojado y al que debe "hacer frente" (Beständnis). En el "ahî" se abre, como un "claro" (Lichtung), la verdad entendida como evento de la manifestación y del ocultamiento de la correlatividad de Ser y ser ahí.

Las dos últimas fugas, breves pero particularmente densas, tituladas "Los venideros" y "El último Dios", representan, por así decirlo, la coda escatológica de la obra. Heidegger, de hecho, no concibe el pensar el Ser como una teoría neutral e indiferente respecto del actuar, sino que lo carga de un significado salvífico y del correspondiente tono profético. Corresponder al Ser implica consecuencias esenciales para el actuar, la "ontología" se transforma en una ética originaria: operari sequitur esse. Que luego en el manuscrito la obra termine justamente con estas dos fugas, les confiere un relieve particular. En la edición publicada, que la traducción ha seguido, la obra termina en cambio con la sección "El Ser" (Das Seyn), una suerte de compendio del todo, que en el manuscrito está colocado al comienzo, después de la "Mirada preliminar", pero que el editor alemán ha decidido colocar al final.

\section{Terminología}

Diré algunas palabras para introducir ciertos conceptos cardinales que se encuentran en el texto, además de los ya mencionados, y para ilustrar la traducción adoptada. 
En lo que concierne a Sein o Seyn, en italiano hemos señalado la distinción mediante la minúscula o la mayúscula: "ser" o "Ser". Heidegger usa la primera grafía para indicar el concepto tradicional, pero la segunda para su propio concepto de Ser, si bien no siempre de manera coherente. Es un hábito que se ha prestado a críticas y que incluso ha molestado a ciertos alumnos bien dispuestos hacia él en sus confrontaciones. Así, por ejemplo, Hannah Arendt, que en una carta a Jaspers del 29 de septiembre de 1949 comenta al respecto: "He leído la carta contra el humanismo, también bastante problemática y en muchos aspectos ambigua, y no obstante la primera cosa nueva al nivel de otro tiempo. (Ayer he leído los ensayos sobre Hölderlin y algunas lecciones sobre Nietzsche absolutamente horrendas y ripiosas). Esta vida de él en Todtnauberg, renegando de la civilización y escribiendo Sein con $y$, es en verdad sólo la guarida en que se ha refugiado" ${ }^{31}$. Pero Heidegger advierte: el expediente ortográfico no es sino el aspecto exterior de un esfuerzo radical y profundo por desvincularse del lenguaje de la metafísica y en primer lugar del concepto tradicional de ser. Ello aparece ya claramente en las consideraciones "sobre la gramática y sobre la etimología" de la palabra "ser" que él desarrolló en la Introducción a la metafísica de 1935. Por consiguiente, la diferenciación ortográfica no puede ser pensada separadamente de los contenidos a los que reenvía.

La grafía Seyn es adoptada aquí y en otros tratados inéditos de los años 40, así como en algunas glosas anotadas al margen de Ser y Tiempo; sin embargo, el primer texto publicado en que Heidegger hace uso de ella es el ensayo sobre Hölderlin de 1943, "Andenken"32. El mismo expediente gráfico vuelve a ser empleado en el primer párrafo, ańadido en la segunda edición (1949), de la nota con que concluye la conferencia De la esencia de la verdad (redactada en 1930, pero editada en 1943) ${ }^{33}$. No es, sin embargo, una solución satisfactoria, y mucho menos definitiva. Las mismas meditaciones correspondientes sobre el Ser, incluso la tan discutida doctrina de la diferencia ontológica entre Ser y ente, son inevitablemente demasiado metafísicas todavía en la medida en que reflejan el paso de un inicio al otro. Por esto, Heidegger renuncia también por fin a la grafía con la $y$, y en el escrito Sobre el problema del ser de 1955 ensaya otra solución y escribe el término con una barra en cruz (Sépin), como para cancelar el sentido tradicional de la palabra, y tal vez para aludir al propio concepto del Geviert, el "conjunto de los Cuatro", Cielo y Tierra, mortales e inmortales ${ }^{34}$.

En el trabajo conceptual dedicado a desasirse de la metafísica y superarla, Heidegger hace uso también de los recursos de la etimología. Se apoya en instrumentos clásicos como el "Kittel" para el griego ${ }^{35}$, el diccionario de los

\footnotetext{
${ }^{31}$ H. Arendt - K. Jaspers. Briefwechsel, cit., p. 178.

${ }^{32}$ M. Heidegger. Erläuterungen zu Hölderlins Dichtung. En GA, vol. 4, 1981, p. 134.

${ }^{33}$ Cfr. M. Heidegger. Wegmarken, cit., p. 201.

${ }^{34}$ Ibid, p. 411 ss.

${ }^{35}$ G. Kittel. Theologisches Wörterbuch zum Neuen Testament, continuado por G. Friedrich, Kohlhammer, Stuttgart, 1933-1979, que ofrece en la primera parte de cada voz, para cada término griego, la historia de su significado y de su empleo desde Homero hasta la época cristiana. Entre otros, contribuyó con algunas voces Rudolf Bultmann.
} 
hermanos Grimm y el "Kluge" para el alemán ${ }^{36}$ y el "Pokorny” para las lenguas indogermánicas en general ${ }^{37}$. En la imposibilidad de abrir aquí un paréntesis sobre el uso filosófico de la etimología y su legitimidad, una vexata quaestio que ha sido discutida desde los tiempos antiguos ${ }^{38}$, nos limitamos a preguntar con Heidegger: ¿puede ayudar la etimología a esclarecer el problema filosófico del ser? En la Introducción a la metafísica, que precede inmediatamente a la redacción de las Contribuciones, la respuesta es negativa: la etimología ayuda a descubrir y fijar tres significados fundamentales de sein, pero ellos ya se perdieron, anulados en el concepto abstracto de ser que hoy domina. Ellos están ligados a las tres raíces de que derivan, que Heidegger había podido conocer por vez primera a través del tratado de Carl Braig Vom Sein: Abriss der Ontologie, que él había leído y usado en su juventud ${ }^{39}$ : es "vivir", *bhul *bheu "abrirse", "brotar", wes "permanecer".

Justamente de esta última raíz recupera Heidegger y explota en clave filosófica el verbo wesen, durativo de sein, muerto como tal en el alemán de hoy pero conservado en algunas formas gramaticales, por ejemplo en el participio pasado gewesen, y en los compuestos anwesen ("presentarse", "estar en presencia"), abwesen ("ausentarse", "no estar presente") y verwesen ("degenerar", "podrirse"). El verbo wesen significa, por tanto, "estar duraderamente presente", "durar", "permanecer". Heidegger prefiere usarlo para indicar el modo en que el Ser es. Constitutivamente forman parte del Wesen del Ser su oposición (Gegenwesen) y su negación (Unwesen). Cuando quiere subrayar la diferencia ontológica entre Ser y ente, Heidegger usa el verbo wesen para el primero y

\footnotetext{
${ }^{36}$ J. y W. Grimm. Deutsches Wörterbuch. Hirzel, Leipzig, 1854-1960; F. Kluge, Etymologisches Wörterbuch der deutschen Sprache, de Gruyter, Berlin, 1883, puesto al día por A. Götze (desde 1910) y W. Mitzka (desde 1957).

${ }^{37}$ A. Walde - J. Pokorny. Vergleichendes Wörterbuch der indogermanischen Sprachen, de Gruyter, Berlin, $1927-$ 1932 (Luego J. Pokorny, Indogermanisches etymologisches Wörterbuch, Francke, Tübingen-Basel, 1959, 3a edición, 1994).

${ }^{38}$ Entre las primeras formulaciones del problema, que valdría la pena recordar aunque Heidegger no la menciona, se encuentra aquélla fundamental contenida en el De lingua latina de Marco Terencio Varrón (116-27 a.C.). Al comienzo de la parte conservada del tratado (los libros V-X, de los 25 originales), precisamente en el libro V, 7-8, afirma Varrón que la etimología contempla cuatro grados de interpretación (quattuor explanandi gradus) a través de los cuales se alcanza el conocimiento de las palabras:

1) quo populus etiam venit: "donde también el pueblo llega", esto es, el grado de las etimologías más simples y evidentes, como argentifodinae, "minas de plata", de argentum y fodina;

2) quo grammatica ascendit antiqua: "donde alcanzan los gramáticos antiguos", o sea, los alejandrinos que comentaban a los clásicos procurando explicar las palabras difíciles a través de su origen;

3) quo philosophia ascendens pervenit: "donde, remontándose, llega la filosofía", vale decir, la filosofía de los estoicos que indagaban las razones por las cuales un cierto significado es expresado por un determinado significante;

4) ubi est adytum et initia Regis: "donde se encuentra el santuario y los comienzos de los tiempos del Rey", esto es, donde se entra en el misterio inexplicable del origen del lenguaje.

Varrón declara que este último grado es tan elevado que debe ser considerado como un límite al que es imposible acceder. En su indagación se detiene, por consiguiente, en los grados segundo y tercero, considerando que un cierto uso filosófico pero limitado de la etimología es posible.

Acerca de la etimología de los términos alemanes se podría comenzar con el tratado de Johannes Clauberg, Ars etymologica Teutonum e philosophiae fontibus derivata, Duisburg, 1663 (reproducido en G. W. Leibniz. Collectanea etymologica. Foerster, Hannover, 1717).

${ }^{39}$ Cfr. C. Braig. Vom Sein. Abriss der Ontologie. Herder, Freiburg i. Br., 1896, p. 20. Braig cita a su vez como fuente a G. Curtius. Grundzüge der griechischen Etymologie. Teubner, Leipzig, 1858-1862.
} 
sein para el segundo: "Das Seiende ist, Das Seyn west"40. Del verbo wesen deriva el sustantivo Wesung, término fundamental y frecuente en las Contribuciones. Mutatis mutandis, éste corresponde al concepto griego de $\mu$ oví permanencia”, "estación" -de $\mu \epsilon ́ v \omega$, "permanezco", "me quedo"- usado por los neoplatónicos para indicar el permanecer inicial del Uno junto a sí mismo, al que suceden la

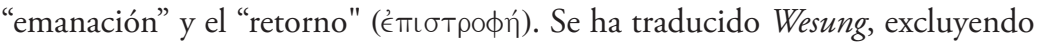
el empleo de "permanencia" que emplea la semántica neoplatónica, como "permanencia esencial", a veces también como "presentarse esencial”. En unas pocas ocasiones, para indicar el proceso de alcanzar la Wesung, en oposición a Verwesung, Heidegger emplea Erwesung ${ }^{41}$.

Pero el concepto principal en la concepción del Ser de las Contribuciones, y en torno al cual, como ya se ha dicho, gira todo el pensamiento heideggeriano sucesivo, es Ereignis. Un concepto intraducible, como lo es la palabra griega logos o la china Tao, declarará Heidegger en Identidad y diferencia (1957) ${ }^{42}$. Aquí, retrotrayendo el término a eigen y eignen -según una etimología no demostrada- ${ }^{43}$ y recurriendo también a la grafía Er-eignis o a la variante Ereignung, Heidegger lo entiende en el sentido de "apropiación" o "evento-apropiación”, donde tal es para él el modo en que el Ser se destina al hombre haciéndolo "enfuturecerse" y haciéndolo justamente en un vínculo de recíproca correlación. Su opuesto es Enteignis, "expropiación”, término con el que se indica la situación epocal en que el Ser se sustrae.

Hoy sabemos que la palabra Ereignis se encuentra ya en el joven Heidegger, pero todavía en la acepción común de "acaecimiento". Sólo en una oportunidad, en el Kriegsnotsemester de 1919, es empleada en un sentido filosófico específico, a saber, para indicar algo que acaece en cuanto es experimentado por mí, por ende en cuanto "acontecer vivido mío". En este sentido, Ereignis se contrapone a algo que acaece como simple "proceso físico" (Vorgang), neutro, sin relación con el yo que lo vive y lo experimenta ${ }^{44}$.

Totalmente diverso es el sentido de Ereignis en las Contribuciones, donde es asumido en la acepción indicada de "evento-apropiación" para pensar y expresar la copertenencia de Ser y ser ahí. Es decir: para no concebir más el ser ahí exclusivamente en su autoproyectarse puro como condición ontológico-trascendental del sentido del ser, sino precisamente en la insondable gratuidad de su darse junto con las cosas que son, junto con la maravilla de las maravillas: que el ente es, y por ende, en el fondo, junto con el Ser mismo en cuanto esencialmente unido a él.

\footnotetext{
${ }^{40}$ M. Heidegger. Beiträge zur Philosophie (Vom Ereignis). En GA, vol. 65, 1980, p. 30 y 74.

${ }^{41}$ El prefijo inseparable $e r$-, que añadido a un verbo indica en alemán el alcanzar u obtener algo mediante la acción indicada por el verbo, o bien el entrar a una determinada condición, figura entre los recursos lingüísticos más explotados por Heidegger, quien, además de erwesen, usa también erahnen, erfragen, erdenken, erschweigen, erschwingen, erwinken $\mathrm{y}$, naturalmente, ereignen.

${ }^{42}$ M. Heidegger. Identität und Differenz. Neske, Pfullingen, 1957, p. 25.

${ }^{43}$ Pero en Identität und Differenz indicará la etimología correcta a partir de er-äugnen, "avistar", "poner ante los ojos" (ibid, pp. 24-25).

${ }^{44}$ M. Heidegger. Zur Bestimmung der Philosophie. En GA, vol. 56/57, 1987, p.75.
} 
La elaboración del concepto llevada a cabo en las Contribuciones permanece decisiva también en lo sucesivo; tanto así que en las notas ya recordadas al margen de la Carta sobre el "humanismo", Heidegger declara que, desde 1936, Ereignis es la palabra guía de su pensamiento, y más tarde, en la recolección Zur Sache des Denkens, lo confirma ilustrando el concepto en todos sus aspectos y proveyendo de un mapa de los otros lugares importantes en que lo trata ${ }^{45}$. Esta recolección es fundamental, en particular el texto que la inicia, la conferencia Tiempo y Ser (1962), porque Heidegger dice aquí su última palabra pública sobre el camino recorrido después de la interrupción de Ser y Tiempo y después de las Contribuciones a la filosofía. Con todo, en Tiempo y Ser, lo que el Ereignis hace suceder no es tanto la copertenencia de Ser y ser ahí, como en las Contribuciones, sino más bien la copertenencia de los mortales en el mundo en cuanto "conjunto de los Cuatro", mortales e inmortales, Tierra y Cielo ${ }^{46}$. Aquí el Ereignis, del que provienen las diversas épocas históricas, es "él mismo no histórico, sino más bien carente de destino" ${ }^{37}$.

En este horizonte hay que interpretar cuanto dice Heidegger en las Contribuciones acerca de otros dos fenómenos relevantes para los cuales la fuente principal de inspiración es Hölderlin: la Götterung, término traducido como "acaecer divino", no menos que el "último Dios" y su "pasar de largo" (Vorbeigang). No se trata obviamente de una simple toma de posición en materia de religión o de teología. Como filósofo, Heidegger no se pronuncia acerca de la existencia del buen Dios o de su presunta muerte, sino que habla del "último Dios” -expresión ya utilizada, por lo demás, por Schelling- ${ }^{48}$ para preguntarse cómo volver a dar un sentido a la palabra Dios y dotar de un trompillón o clave de bóveda a la arquitectura de la finitud. ¿Es o no es posible? Ésta es para él una indicación formal análoga a la enigmática pregunta que Nietzsche se plantea en Más allá del bien y del mal (III, 56) cuando se interroga a sí mismo: “circulus vitiosus Deus?" ${ }^{49}$ En suma, la gratuidad del ser arrojados a la existencia ¿es todavía vinculable con un Dios como su última condición, o bien es ya "camino pasado de largo", de modo que no nos queda sino el Vorbeigang des letzten Gottes? Para Heidegger, que piensa después de Nietzsche y con Hölderlin, la verdadera cercanía de Dios está en su lejanía.

Otro concepto clave que Heidegger excogita con el fin de obtener determinaciones útiles para expresar la naturaleza del Ser es Grund junto con sus derivados y compuestos, como Gründung, título de la cuarta fuga, Ergründung, Abgrund, Ungrund. En el alemán corriente, Grund significa "fondo" -y en tal sentido es sinónimo de Boden, que indica la superficie del fondo, mientras que en Grund se percibe más bien la profundidad- y de fondo derivaría "funda-

\footnotetext{
${ }^{45}$ M. Heidegger. Zur Sache des Denkens. Niemeyer, Tübingen, 1969, pp. 38-39.

${ }^{46}$ Ibid, p. 45.

${ }^{47}$ Ibid, p. 44.

${ }^{48}$ F. W. J. Schelling. Philosophie der Kunst, en Sämtliche Werke, 14 vols. Cotta, Stuttgart, 1856-1861, sección I, vol. V, p. 432.

${ }^{49}$ F. Nietzsche. Al di là del bene e del male. Trad. ital. de F. Masini, en Opere complete dii Friedrich Nietzsche, a cargo de G. Colli y M. Montinari. Adelphi, Milano, vol. VI, tomo II, p. 62.
} 
mento": "Fundamentum est a fundo, qui Graecis basis" 50 . Por "fundamento" se usa también en alemán el extranjerismo Fundament, del que Heidegger se sirve a veces. Por ejemplo, Fundamentalontologie es en Ser y Tiempo la "ontología fundamental”, la que toma por fundamento al ser ahí y su análisis, y que, en el proyecto que quedó incompleto, debía fungir como base para las ontologías o "metafísicas" regionales. En el lenguaje filosófico, Grund tiene además el significado de "razón” y "causa": Satz vom zureichenden Grund es el "principio de razón suficiente". Es peculiar el uso heideggeriano del término que, hasta Ser y Tiempo, no es empleado aún para criticar el modo de pensar de la metafísica, la cual justamente busca un "fundamento" o una "razón" para todo en conformidad con lo que prescribe el principio de razón: nibil est sine ratione. Todavía en el escrito De la esencia del fundamento (1929), Heidegger abriga él mismo intenciones fundamentadoras, pero de aquí en lo sucesivo comienza a poner en cuestión la estructura del fundamento, mostrando que detrás de todo Grund se esconde un Ab-grund ("abismo", "fondo abismal") y que, por consiguiente, si se le piensa a fondo, Grund implica como correlato suyo la dimensión del Un-grund ("no-fundamento"). En este horizonte se insertan las reflexiones que Heidegger despliega en las Contribuciones a la filosofía a propósito de la "fundación" que tiene lugar en el ser ahí en cuanto correlato del Ser en el acontecimiento-apropiación. Más tarde, en una nota al margen en la Introducción añadida en 1949 con ocasión de la quinta edición de ¿Qué es metafísica? (1929), propondrá escribir el término, tal como lo había hecho con Sein, marcándolo con una cruz $(G r y<d)$ para indicar el carácter insondable del ser en cuanto no-fundamento ${ }^{51}$. Y en las lecciones tituladas El principio de razón (1957), contrapondrá a tal principio, que reclama un fundamento para todo, el célebre dístico de Ángel Silesio que dice: "La rosa es sin por qué..." 52 .

Otra palabra cuyo significado recibe una precisión importante en las Contribuciones a la filosofía es Kehre, "vuelta". Normalmente, la palabra indica esas curvas muy pronunciadas en los caminos de montaña llamadas "recodos", las cuales, aun determinando cambios de dirección, conducen a la misma meta, la cumbre de la montaña. Como ya se ha recordado, después de la guerra Heidegger se sirvió de esta metáfora para indicar el cambio de perspectiva que maduró después de Ser y Tiempo. De este modo, él mismo sugirió y avaló la idea de que la "vuelta" fuera ante todo una tal circunstancia de su propia biografía intelectual. De las Contribuciones a la filosofía resulta claramente, en cambio, que el término ha de ser entendido también en un sentido diverso, filosóficamente mucho más vinculante, implícito en el alemán Kehre y menos en el italiano svolta $^{53}$. Kehre es usado aquí para expresar la oposición polar (Widerwendigkeit, Gegenwendigkeit) que se desenvuelve en el acontecimiento-apropiación entre sus dos "lados" o sus dos "caras", el Ser y el ser ahíp4. Afirmando repetidamente que la Kehre se desenvuelve en el acontecimiento mismo del Ser, Heidegger

\footnotetext{
${ }^{50}$ R. Goclenius. Lexicon Philosophicum. Becker, Frankfurt, 1613, p. 605.

${ }^{51}$ Cfr. M. Heidegger. Vom Wesen des Grundes. En Wegmarken, cit., p. 367, nota b.

${ }^{52}$ M. Heidegger. Der Satz vom Grund. Neske, Pfullingen, 1957, p. 68 ss.

${ }^{53}$ Svolta, "vuelta", "giro", es el término que el autor emplea para traducir el alemán Kehre. (N.del T.)
} 
quiere decir que este último presenta un doble aspecto, esto es, se muestra por un lado y también por el "otro", por una y también por la "otra cara". Un poco como cuando se dice que una medalla tiene un anverso y un reverso: "la otra cara de la medalla” es en alemán die Kehrseite der Medaille. En otros términos, en el acontecimiento-apropiación la correlación de Ser y ser ahí no es fija sino que se "gira" o se "vuelve" de un término al otro, y el Ser mismo pasa entonces de la donación a la sustracción, de la manifestación al ocultamiento, y viceversa. En este sentido afirma Heidegger que el Ser mismo es kehrig, porque se vuelve "alternativamente" y "el ser ahí es el punto de inversión en la vuelta del acontecimiento, el centro que se abre desde la antítesis de llamada y pertenencia". Por eso la Kehre es llamada también Wider-kehre, "vuelta-alternativa".

Nos introducimos aquí, a través de la terminología, en el corazón de la experimentación lingüística y conceptual que Heidegger excogita para volver a dar significado al ser en modalidades libres de condicionamientos metafísicos. Él renuncia, por tanto, a categorías, predicables, postpredicamentos, trascendentales, doctrina de la "univocidad", de la "polisemia", de la "analogía", potencia y acto, modalidad, dialéctica, negatividad y todas las demás determinaciones elaboradas por la ontología tradicional. No obstante, cuando intenta decir cómo se despliega y se articula el Ser en su acaecer, Heidegger no hace otra cosa que transcribir y transfigurar en nuevas metáforas el antiguo problema. Y tal vez sea justamente esto de lo que él mismo está consciente cuando afirma que en el pasaje del primer al "otro inicio" el pensamiento permanece inevitablemente transitorio, por tanto provisorio, y que toda voluntad de superación debe inevitablemente presuponer lo que supera, quedando condicionada. Incluso la diferencia ontológica entre Ser y ente, que él ya había reivindicado como una intuición propia que permanecía no pensada en la metafísica occidental, se le aparece ahora hasta cierto punto demasiado metafísica.

Este continuo ponerse en guardia y defender la propia posición, pone en una situación de dificultad y de aporía a quien desea producir la superación. Heidegger sabe muy bien que quien cree ser original en filosofía es con frecuencia tan sólo ignorante. Se da cuenta, pues, de que la tradición metafísica amenaza a su esfuerzo por superarla con el peligro continuo de la recaída. Pero justamente esta presencia constante nos permite a nosotros, que advertimos qué cosas él procura dejar a sus espaldas, intuir también hacia dónde va avanzando y darle un sentido al áspero lenguaje de las Contribuciones a la filosofía. Sólo teniendo bien presentes las enseñanzas de la metafísica podemos imaginar qué quiere decir Heidegger cuando determina el Ser como acontecimientoapropiación y cuando ilustra una supuesta "esencia" o "dinámica", "inventada" deliberadamente para obligarnos a salir del cascarón de la metafísica tradicional. Él quiere liberar una visión del Ser, con su correspondiente aparato de imágenes, metáforas y determinaciones, que sea alternativa a las grandes concepciones de la filosofía occidental. Por ejemplo, a la visión parmenídea del

\footnotetext{
${ }^{54}$ Acaso al usar Widerwendigkeit y Gegenwendigkeit tenía Heidegger presente, como podría razonablemente suponerse, el comienzo de la Retórica en que Aristóteles afirma que la retórica es antístrophos, "correlativo", "opuesto polar" o "revés" de la dialéctica (Rhet. A, 1, 1354 a).
} 


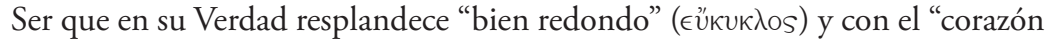

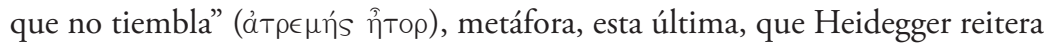
literalmente suponiendo que en el evento-apropiación ocurre una Erzitterung, una "vibración". O la imagen heraclítea de un todo atravesado por el conflicto

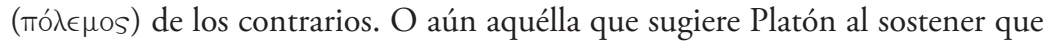
el ser es generado por dos principios, el Uno y la Díada, la unidad y la multiplicidad, y formulando en el Sofista la hipótesis de que se articula en "géneros

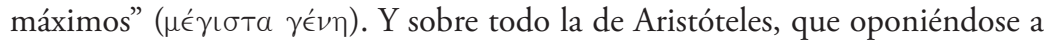
la imagen univocista del ser, lo define como un término polisémico que se dice

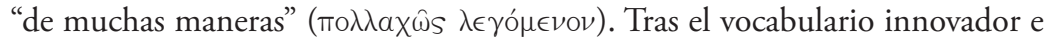
insólito de las Contribuciones se reconoce el extraordinario esfuerzo por describir la vida del Ser con imágenes y metáforas diferentes de las de la filosofía tradicional. Y se entrevé esa misma articulación de la unidad originaria en la multiplicidad que la tradición ha concebido en términos de identidad y diferencia, de dialéctica, negatividad, contradicción, oposición polar, pero con la preocupación constante de parte de Heidegger por evitar todas las determinaciones empleadas por las semánticas conceptuales metafísicas. Él cambia, por consiguiente, las imágenes, metáforas y conceptos, introduciendo alternativas para ellos, pero en el fondo el caso en cuestión es éste: el Ser en su simplicidad y en su riqueza, en el alternarse de su presentarse y desaparecer, donarse y sustraerse, darse y retirarse, en la alternancia de su manifestarse y negarse. Dando libre curso a la propia fantasía especulativa, Heidegger hace de la metáfora una filosofía y de la filosofía una metáfora: imagina que el evento-apropiación del Ser es atravesado por un temblor o una "vibración" (Erzitterung) que hiende su primigenia unidad y produce una "oscilación" (Erschwindung) que, alternando "impulso" (Schwung) y "contraimpulso" o "rebote" (Gegenschwung), la "hiende" y la recorta (Zerklüftung) en modalidades que generan una multiplicidad ulterior. Uno de los primeros "movimientos" que se verifican así en la vida del Ser es el llamado "espacio-tiempo" (Zeit-Raum): éste produce Entrückungen y Berückungen, dilataciones y contracciones, alejamientos y acercamientos, "éxtasis" y "atracciones", en los cuales el tiempo (con sus tres éxtasis) y el espacio (con sus dimensiones) se articulan abriendo el "claro" (Lichtung) en que el ser-ahí es hecho acontecer y lo es justamente por el Ser. En este nuevo cuadro también el término ser ahí recibe una connotación diversa: ya no indica tanto el modo particular de ser del hombre, sino más bien ese "entre" que se abre en el evento del Ser, en el que el hombre tiene la tarea de insertarse para hacerle frente.

\section{8. “Tengo la sensación de estar creciendo sólo en las raíces, ya no en las ramas"}

De este proyecto grandioso y comprometedor, Heidegger no hizo público casi nada, únicamente alguna indicación o alguna intuición. Comunica algunos 
pasajes, con la importante referencia a Nietzsche y Hölderlin y a su función de cumplimiento y transición, en el curso del semestre de invierno de 1937/38, pero editado sólo póstumamente ${ }^{55}$. En las contemporáneas conferencias sobre la obra de arte, de las que extrae el ensayo El origen de la obra de arte que en 1950 abrirá la recolección Senderos interrumpidos ${ }^{56}$, retoma y presenta la idea de una contienda entre tierra y mundo. Y poco más.

Se ha dicho que sólo las Contribuciones a la filosofía permiten entrever en su complejidad el amplio diseńo especulativo que subyace a las meditaciones aparentemente ocasionales y aisladas de los escritos después de la "vuelta”. Es verdad, pero es igualmente innegable que Heidegger jamás ha hecho público ese diseño como tal, y que en los años siguientes mantendrá solamente algunas tesis, mientras que otras, como por ejemplo la idea de una Erschwingung, Erzitterung y Zerklüftung del Ser, caerán. Y aun aquellas que serán retomadas sufrirán modificaciones o transformaciones. Por ejemplo, el fenómeno de la técnica planetaria, que aquí es diagnosticado principalmente en términos de "maquinación" (Machenschaft), será analizado más tarde bajo la guía del nuevo concepto de Gestell, "instalación", "montaje", "engranaje" o como se prefiera traducirlo. Hay luego conceptos ulteriores que caracterizan al pensamiento del último Heidegger, como Gelassenheit o Geviert, que aquí no aparecen todavía. En resumen, las Contribuciones a la filosofía son efectivamente fundamentales para entender el planteamiento y la estructuración del pensar el Ser como Ereignis, pero siguen siendo una obra de transición, sustancialmente circunscrita al intento emprendido en los años de su redacción, pero luego dejado caer. En el texto mismo, especialmente en las partes finales, se advierten la extrema cautela, la vigilancia crítica y en algún punto también la insatisfacción de Heidegger al revisar lo que va escribiendo por hallarlo aún demasiado metafísico y provisorio.

Tanto es así que, poco después de haber terminado la redacción, Heidegger vuelve a intentar decir lo mismo en un esfuerzo ulterior, aun más radical, por dejar la metafísica a sus espaldas. A las Contribuciones a la filosofía seguirán en rápida sucesión otros cuatro tratados análogos, aun cuando no de la misma amplitud y cuidado, que forman una suerte de pentalogía que permaneció inédita: Besinnung (1938/39), Über den Anfang (1941), Das Ereignis (1941/42), Die Stege des Anfangs $(1944)^{57}$. El genio filosófico de Heidegger, su fantasía y su creatividad, acompañadas y sostenidas por una disciplina de trabajo y por un rigor científico no comunes, parecen esterilizarse aquí y sufrir una involución. Ello se debe acaso a la naturaleza misma del preguntar filosófico, que forzándose hasta la máxima radicalidad no se detiene ante nada sino que ataca y corroe todo, y al final se quema a sí mismo en su propia llama. La inteligencia crítica, que por naturaleza no es bondadosa sino suspicaz y desconfiada, puede transformarse en una prisión, y termina, como una fiera en su jaula, por girar siempre en torno al mismo punto.

\footnotetext{
${ }^{55}$ M. Heidegger. Grundfragen der Philosophie. Ausgewälte "Probleme” der "Logik". En GA, vol. 45, 1984.

${ }^{56}$ Sentieri interrotti, traducción al italiano de Holzwege, que ha sido vertido a su vez al castellano bajo los títulos de Caminos de bosque o Sendas perdidas. (N. del T.).

${ }^{57}$ Los dos primeros están publicados en GA, vol. 46 (1997) y vol. 70 (2005).
} 
En la escuela de Nietzsche, maestro por excelencia de la sospecha, Heidegger aprende a exacerbar la práctica de la duda. En el extenuante cuerpo a cuerpo que traba con los fragmentos de la Voluntad de poder en las lecciones paralelas a las Contribuciones a la filosofía, termina por precipitarse él mismo en lo que a partir de un cierto momento llamará "el abismo de Nietzsche". En medio de la crisis filosófica y personal en que cae, confía al amigo de un tiempo, Jaspers, su desconsolada preocupación: "Tengo la sensación de crecer ahora tan sólo en las raíces, ya no en las ramas" ${ }^{\prime 2}$. En casa, y entre amigos, repite constantemente: “¿Ese Nietzsche me ha destruido!”.

\section{Náufrago en el mar del Ser}

Es ahora cuando el fuego encendido por Nietzsche quema ya toda la casa; ya no hay concepto, valor o propuesta filosófica que resista a un cuestionamiento suficientemente radical. La experiencia de Nietzsche vacía las metáforas de Heidegger, ahoga sus ímpetus, mina hasta sus fundamentos la construcción de las Contribuciones a la filosofía. ¿Es acaso por azar que Heidegger pone en el exergo de los dos volúmenes dedicados a Nietzsche (1961) un epígrafe tomado del Anticristo que corresponde exactamente a la conclusión de las Contribuciones? Éstas terminan con una "fuga" que trata del último Dios, y el primer capítulo del Nietzsche se abre con la cita: “¡Casi dos milenios trascurridos y ningún nuevo dios!".

Tal vez Heidegger ya no logró volver a levantarse filosóficamente desde el de profundis de Nietzsche. En la luz triste del agotamiento, el Ser -ese huésped habitualmente fugaz de nuestros pensamientos- permanece siendo para el gran Heidegger la última quimera que valga la pena soñar. Todos sus esfuerzos se orientan hacia esta única meta, el Ser, pero los senderos se han interrumpido. $\mathrm{Su}$ intermitente experimentación filosófica y su "proceder a tientas" en este sueño se ha prestado a críticas virulentas. Se ha dicho: Heidegger rechaza la racionalidad moderna con el mismo gesto sometido con el que reconoce su dominio, protesta contra la ciencia que "no piensa" en sus límites, demoniza a la técnica fingiendo aceptarla como destino, elabora una visión catastrofista del mundo, arriesga tesis geopolíticas al menos aventuradas -Europa amordazada entre americanismo y bolchevismo- avivando el mito greco-germánico de lo originario que hay que reconquistar. También sus geniales experimentaciones lingüísticas se encogen y adoptan cada vez más el aspecto de funambulismos, incluso de vaniloquios. Su uso de la etimología se revela abusivo (Varro docet). La convicción de que la verdadera filosofía puede hablar únicamente en griego antiguo y en alemán (¡y el latín?) se muestra hiperbólica. Su celebración del rol del poeta, una sobrevaloración. Las esperanzas puestas por él en el pensamiento poetizante, una ilusión piadosa. Su antropología de la Lichtung, en la

${ }^{58}$ M. Heidegger - K. Jaspers, Briefwechsel, cit. p. 174. 
que el hombre tiene la función de pastor del Ser, una propuesta inaceptable e impracticable. Enigmático no es tanto el pensamiento del último Heidegger, sino más bien la admiración servil y a menudo carente de espíritu crítico que se le ha tributado y que ha producido tanta escolástica.

Ciertamente, los mortales comunes se burlan con frecuencia de las soluciones de los filósofos sólo porque no entienden sus problemas. Por consiguiente, no está dicho en modo alguno que estas críticas den en el blanco. Pero si ése fuera el caso, entonces las Contribuciones a la filosofía serían verdaderamente el cuaderno de bitácora de un naufragio. Por adentrarse demasiado en el mar del Ser, el pensamiento de Heidegger se hunde. No obstante, como cuando es un gran navío el que se sumerge, el espectáculo que se ofrece a los ojos es sublime. 


\title{
La Hermenéutica Fenomenológica y la Contemporaneidad del Pasado
}

\author{
Ramón Rodríguez \\ Universidad Complutense
}

La Hermenéutica filosófica, tal como la ha expuesto Gadamer en Verdad y método, es, si se reduce a lo esencial, un intento de comprender cómo se produce el misterio de la actualidad del pasado, cómo puede ser actual; y esto significa, cómo puede afectarnos, interesarnos, movernos, más allá de toda curiosidad histórica. Parece como si el conjunto de la teoría gadameriana de la experiencia hermenéutica estuviera pensada para dejar su lugar legítimo a ese respeto a la pretensión de verdad de la tradición que es el núcleo de la comprensión del pasado. La polémica con la conciencia histórica que atraviesa toda la obra no es primordialmente de índole epistemológica, como si se tratara de una metodología inadecuada; no, se trata ante todo de que la posición objetivista que entrańa comporta la suspensión de la pretensión de verdad de la tradición, como cuando en un examen hablamos de un tema con un alumno no por el interés de la cosa, sino para apreciar lo que sabe. La contemporaneidad del pasado sin que éste deje de serlo, manteniendo su lejanía en medio de una cercanía esencial, es el problema de la comprensión histórica. Gadamer ha tenido la gran virtud de no hacer de esta cuestión un problema que la ciencia histórica tuviera que resolver ni por tanto hacer de la hermenéutica un saber metódico que estuviera en mejor condición que otros para afrontarlo. Lo que Verdad y método muestra es que no es un problema, sino un acontecer, el modo como realmente se produce la comprensión, que, como tal, forma parte de la dotación del ser histórico que somos. Lo que importa entonces es preguntarse cómo acontece, dejando que el proceso comparezca en todos sus momentos, y no preguntar por qué, como si ese proceso pudiera tener unas causas que no formaran parte de él mismo.

Pues bien, es en este punto donde yo quisiera sostener ante ustedes que la hermenéutica fenomenológica que Heidegger desarrolló durante los años 20 del pasado siglo ofrece un modelo de comprensión filosófica de ese acontecer del pasado, que explicita, de manera quizá más inteligible que la gadameriana teoría de la experiencia hermenéutica, ese misterio de la actualidad de los grandes pensamientos de la tradición. El mismo Gadamer ha dicho en alguna ocasión que la fascinación que le produjo la capacidad heideggeriana de convertir un pensamiento arrinconado en lo tradicional en un ser vivo que interpela y responde a nuestras más acuciantes preocupaciones fue lo que impulsó su propio pensamiento: "Las clases de Heidegger hacían que las cosas parecieran

\footnotetext{
${ }^{1}$ Este trabajo se enmarca en el ámbito del proyecto de investigación HUM2006-04630 del Plan Nacional de I+D del Ministerio de Educación y Ciencia de España.
} 
tan inmediatamente próximas que ya no había modo de distinguir si era él o el mismo Aristóteles quien estaba hablando. Era esta una de las más profundas verdades de la hermenéutica, que empezamos a experimentar entonces, y que más tarde intenté justificar y defender teóricamente”2.

Intentar ofrecer una posible clave, filosóficamente inteligible, de esa "profunda verdad de la hermenéutica” -que no se produce auténtica comprensión de un pensamiento si no se establece una suerte de contemporaneidad con él, de presencia viva junto a nosotros- significa penetrar en el sentido de la hermenéutica fenomenológica, que Heidegger diseñó y que practicó con insistencia en la época anterior a Ser y tiempo. Lo cual no comporta ahora tener que examinar necesariamente el completo proyecto de una hermenéutica fenomenológica de la facticidad; basta con tratar de hacerse cargo de lo que propiamente significa el adjetivo fenomenológica aplicado a esa práctica interpretativa, pues en él se encierra, no me cabe la menor duda, el poder actualizador que tanto seduce en esa peculiar comprensión del pasado.

Cuando en este contexto preguntamos por el significado de interpretación fenomenológica, el campo que se abre para su posible respuesta es ciertamente demasiado amplio. Sin duda que la pregunta apunta hacia lo que Heidegger denomina destrucción fenomenológica, que, como es bien sabido, es una parte constitutiva de la hermenéutica de la facticidad. La cuestión estriba en desde qué punto de vista y qué hay que mirar en esa tarea destructiva para determinar su carácter fenomenológico. Si nos fijamos ante todo en su inserción en el proyecto total de la hermenéutica de la facticidad, la cualificación de fenomenológica le vendría de esa "transformación hermenéutica de la fenomenología”, como la he llamado en otro lugar ${ }^{3}$, es decir, de la radicalización temática que Heidegger somete a la fenomenología de Husserl al preguntar por el ser de la intencionalidad, que le lleva a arribar a la facticidad del Dasein, y de la correspondiente transformación operada en el método en virtud de la interna historicidad de su tema. Sería entonces el hecho de provenir de una problemática fenomenológica radicalizada y de la necesidad, no menos fenomenológica, de una crítica que deshaga los encubrimientos del fenómeno, producto de la tradición, lo que justificaría apellidar de fenomenológica ese momento de crítica histórica.

Esta consideración, digamos topológica, aun siendo rigurosamente exacta, me parece, sin embargo, insuficiente, porque permanece, pese a todo, en una cierta exterioridad respecto del hecho de la interpretación del pasado. Cuando Heidegger piensa en una interpretación fenomenológica de Aristóteles o de la Crítica de la razón pura no quiere significar sólo que dichas interpretaciones son un momento esencial en la tarea fenomenológica de dejar ver las estructura del Dasein en su genuinidad, sino algo más radical: que el ejercicio interpretativo mismo, su modo de llevarlo a cabo es fenomenológico en sentido pleno. Y esto

\footnotetext{
${ }^{2}$ Gadamer, Hans-Georg. Mis años de aprendizaje. Barcelona: Herder, 1996, p. 253.

${ }^{3}$ Cfr. Ramón Rodríguez. La transformación hermenéutica de la fenomenología. Madrid: Tecnos, 1997.
} 
solo puede significar que la interpretación, en tanto que acercamiento a un pensamiento del pasado que abre un sentido no inmediatamente manifiesto, ejerce un modo de tratar los conceptos que es, en sí mismo, fenomenológico. ¿Es esto realmente así? ¿Cómo podemos entenderlo?

Para intentar responder hemos de proceder a través de tres pasos sucesivos, los dos primeros destinados a precisar el carácter fenomenológico de la interpretación ${ }^{4}$, el tercero a registrar qué peculiar forma de actualización del pasado implica.

Tomemos como base en esta primera etapa los textos capitales de los años 2223, cuando la hermenéutica fenomenológica de la facticidad toma su figura definitiva, sin que ello nos impida acudir a momentos ulteriores y anteriores, si con ello se esclarece el sentido del asunto. Me refiero al Informe Natorp, al curso Ontología. Hermenéutica de la facticidad y al primer curso de Marburgo, Introducción a la investigación fenomenológica. El conjunto de los textos, en lo que se refiere a lo que Heidegger entiende por fenómeno, es de una gran coherencia desde la primera aparición, en las lecciones sobre fenomenología de la religión (1920/21), de la triple dirección en que se estructura su sentido: objetivo, referencia y ejecución ${ }^{5}$. Pero es el Informe Natorp quien da de una manera explícita una definición de fenómeno que permite acuñar de manera precisa el cometido de la hermenéutica de la facticidad:

La hermenéutica es fenomenológica quiere decir que su campo temático (Gegenstandsfeld), la vida fáctica en el cómo de su ser y su decir, es vista temática y metódicamente como fenómeno. La estructura objetiva que caracteriza a algo como fenómeno, la intencionalidad plena (estar referido a algo, el hacia qué de la referencia, la ejecución del estar referido, la temporalización de esa ejecución, la conservación de esa ejecución) no es otra cosa que la del objeto de la forma de ser de la vida fáctica. La intencionalidad, tomada meramente como estar referido a, es el primer carácter fenoménico destacable en la movilidad básica de la vida, es decir, del cuidado (GA, 364-365).

Lo decisivo de este texto es que registra un doble movimiento de identificación entre vida fáctica y fenómeno: mientras la vida fáctica, el tema de la hermenéutica, es caracterizada metódicamente como fenómeno, lo que permite su análisis en términos de intencionalidad, el fenómeno es, por su parte, caracterizado temáticamente a partir de rasgos intencionales que no provienen del puro estar

\footnotetext{
${ }^{4}$ En estos dos pasos recojo lo esencial de mi trabajo La idea de una interpretación fenomenológica, en Devenires, VIII, no 16 (2007).

${ }^{5}$ Cfr. GA, 60, p. $63 ; 61$, p. 52-53.
} 
dirigido-a de la intencionalidad objetivante, sino de la propia facticidad, de la vida tal como es vivida en su fáctico acontecer. Es la forma de ser de la vida fáctica, precomprendida en el análisis intencional, la que obliga a ensanchar el concepto de fenómeno hacia una intencionalidad plena, la cual, a su vez, sólo puede ser convertida en tema explícito mediante su tratamiento fenomenológico siguiendo el hilo conductor de la intencionalidad. Culminan en este texto todos los esfuerzos de los años anteriores, que comenzaban en el análisis de la vivencia del mundo entorno (Umwelterlebnis) de 1919, por desligar la fenomenología de esa posición teorética en la que el comportamiento se refiere al mundo sumiéndose en él como en un complejo temático (Sachzusammenhang), como en una trama objetiva ${ }^{6}$. Las consecuencias negativas de esa implantación subrepticia en la actitud teórica para la concepción de la intencionalidad eran ya para Heidegger muy claras cuando daba sus lecciones sobre fenomenología de la religión: la ontología formal, a pesar de la indeterminación en que deja a su objeto, nos dice allí, resulta fatal a causa de la posición teórica desde la que se acerca a él, "ya que prescribe un sentido referencial teórico o al menos lo incluye en su prescripción; emboza lo relativo al ejercicio, lo cual es más fatal aún, y se dirige unilateralmente al contenido" (GA 60, 63). Es esta predeterminación teoretizante del modo de estar referidos los comportamientos, con la consiguiente difuminación del sentido específico con que en cada caso la referencia se ejerce, lo que la intencionalidad plena trata de denunciar, de un lado, y salvar, de otro, proponiendo que la mirada fenomenológica deje abierto de entrada el sentido para poder luego atender a su modalidad concreta; de ahí que el texto resalte en el sentido de ejecución dos modalidades más que lo precisan frente a su nivelación teórica: su temporalización y su forma de mantener o custodiar lo que realiza (Verwahrung). Con ello logra Heidegger dar cuerpo y forma a la reivindicación del carácter siempre significativo, situacional y multidireccional de la facticidad que había presidido su concepción de la fenomenología como ciencia originaria de la vida; las vivencias se transforman en situaciones vitales que no se muestran plenamente en su objetivación reflexiva, sino en la ejecución primaria del comportamiento inmerso en el contexto de sentido en que se produce. Por ello la "intuición plena" (volle Anschauung) a la que hay que llevar la experiencia fáctica de la vida (GA 58, 102) "tiene siempre la figura de una situación histórica concreta de la vida en y para sî”. La liberación de la intuición fenomenológica de su adscripción a la donación de objetos aislados forma parte del mismo movimiento de pensamiento por el que se amplía la noción de fenómeno a una intencionalidad plena de carácter multidireccional. Con ello no se renuncia, desde luego, a ese "paso decisivo que la fenomenología actual ha dado: el conocimiento de que la filosofía, en la medida en que es cognoscitiva, necesita una comprobación intuitiva de sus entramados expresivos, de sus conceptos" (GA, 58, 240). Es lo que tenemos que ver en la interpretación fenomenológica.

\footnotetext{
${ }^{6}$ Cfr. GA, 60, p. 48.
} 
Pero el texto contiene aún otro momento que conviene subrayar: la consagración del cuidado (Sorge) como el término que señala ya definitivamente la especificidad del estar en movimiento que es propio de la vida fáctica, lo que expresa, podríamos decir, la forma de su vitalidad frente a otros seres vivos. "El sentido fundamental de la movilidad fáctica de la vida es el cuidarse de (curare)" (GA, 62, 352). El Informe Natorp da carta de naturaleza como término técnico para designar la entera forma de acontecer de la facticidad a lo que el curso del semestre de invierno de 1921-22 consideraba tan sólo como el sentido referencial de la vida ${ }^{7}$. No hay en ello contradicción alguna, sino un ensanchamiento del concepto, resultado, probablemente, de la necesidad de caracterizar a la facticidad en su conjunto con un término que no se limite a reproducir la neutralidad vacía de la antropología tradicional y sea, a la vez, lo suficientemente expresivo para indicar hacia dónde debe ir la comprensión. Para ello el término que marcaba el sentido general de la referencia al mundo es el más adecuado, pues lo que prima en la facticidad entendida como fenómeno es su carácter intencional. Pero lo que me parece decisivo es que cuidado es un concepto que, si quiere expresar lo más distintivo de la vida fáctica, no puede dejar de cumplir la función fundamental que la hermenéutica de la facticidad atribuye a sus conceptos como indicaciones formales: ahuyentar la primacía de la posición teórica en la comprensión. Y, en efecto, "cuidado" realiza ese cometido en dos sentidos: en su significado inmediato, cuidarse u ocuparse de algo trae a la mente muchas faenas posibles, muchas formas de actividad con cosas y personas, pero nunca destaca entre ellas la consideración teórica de un asunto al modo de la reflexión del pensador o la simple percepción visual de algo, aunque no las excluya taxativamente. Además, y justo en virtud de esa amplitud, "la movilidad del cuidarse-de ofrece múltiples maneras de llevarlo a cabo y de estar referido a aquello con lo que trata" (GA, 62, 353). Cuidado busca dejar libre la posibilidad de destacar precisamente los dos sentidos constitutivos del fenómeno que la actitud teórica difuminaba u homogeneizaba: el sentido de ejecución y el de referencia; por ello Heidegger se esfuerza en añadir inmediatamente a la "definición" del cuidado una variedad de modalidades que no es meramente ilustrativa, sino constitutiva de su ser fáctico: El cuidado se da siempre en una modalidad ejecutiva y referencial determinada. Una multiplicidad, por tanto, que es tal a partir de la referencia y del modo en que esta es ejercida, no de su sentido objetivo (Gehaltssinn).

Un análisis riguroso de la estructura del cuidado proporcionará entonces la clave para acceder con garantías al fenómeno de que se trate, o dicho más exactamente, el cuidado, en su estructura completa, es el fenómeno, en el seno del cual aparecerá lo que, en sentido restringido, llamamos también fenómeno y que no son sino partes o momentos de él (el nóema -el sentido objetivo-, un sentimiento, un comportamiento, etc.). Un texto del primer curso de Marburgo, que, pese a su longitud merece la pena reproducir, expone, mejor que ninguno de esta época, la estructura precisa del cuidado y su función para el análisis fenomenológico:

${ }^{7}$ Cfr. GA, 61, p. 90 
La determinación de los caracteres ontológicos de un ente se hace posible a través de la interpretación del cuidado en el que tal ente, como este preciso ente, está. (...) La interpretación tiene como tema el modo y la manera de estar cuidándose de algo. Con la interpretación del modo y la manera del estar cuidándose de algo se hace visible este algo en cuanto específico 'de qué' del cuidado, aquello con lo que trata el cuidado. Se hace patente en la forma como en el cuidado está 'ahí'; a partir de este estar presente se hace visible qué posible ser tiene en cuanto sale al encuentro en y para este cuidado. El cuidado no es algo subjetivo ni deforma aquello de lo que se cuida, más bien lo deja venir a su auténtico ser. Cuando el ente es interrogado en relación al cuidado que lo abre, no debe investigarse su modo de ser captado, sino justamente el cómo del salir al encuentro desde sí mismo del ente. La cuestión es dar a conocer, para un determinado ente llamado conciencia, el cuidado en que por lo pronto está. Una tal interpretación encierra en sí la posibilidad de ver el cuidado específico en su ser mismo. Hay que decir, simplemente como hilo conductor para el carácter ontológico del cuidado, que en cuanto cuidarse-de abre aquello de lo que se cuida y que en su ser específico mantiene de un modo específico lo existente en cuanto tal por él abierto. Lo abierto y así mantenido por un cuidado es desarrollado, explicitado por él. Este explicitar no es un filosofar teorético sobre ello. Todo cuidado tiene su peculiar modo de desarrollar lo abierto. Lo desarrollado se torna para el cuidado aquello a lo que se entrega. Este entregarse radica en el sentido del estar cuidándose de algo. Finalmente aquello a lo que el cuidado se entrega llega a ser algo en lo que el cuidado se pierde. (GA, 17, 57-58).

Ante todo, hay que tener en cuenta que el texto se inserta en los momentos preparatorios de un análisis que, en sí mismo, es perfectamente relevante para nuestro problema -la interpretación fenomenológica de la tradición-, pues se trata de comprender el sentido genuino nada menos que del concepto "conciencia” de la tradición epistemológica moderna. Por eso hay que observar que la tesis a la que sirve la exposición de la estructura del cuidado es que la investigación ontológica que pretende establecer los caracteres de un ente cualquiera, sólo puede llevarse a cabo mediante un análisis del cuidado respectivo en que ese ente está. De ahí su relevancia. A estos efectos, lo primero contra lo que Heidegger previene es contra la inmediata tendencia a considerar subjetivista tal proceder interpretativo: el cuidado estando en el "sujeto", no subjetiviza lo que trata, sino que por el contrario, lo abre, hace posible acceder a él sin más: ¿Cómo podríamos saber de él sin una forma de tratarlo, de darse en sentido amplio? Pues bien, es obvio que si se trata de poner un ente en el marco del

\footnotetext{
${ }^{8}$ Que lo haga en su auténtico ser es ya una reflexión teorética sobre el hecho primario de la apertura del comportamiento; es obvio que el "auténtico ser", sea lo que sea, solo puede mostrarse en un determinado cuidado, que como tal lo abre.
} 
cuidado en que se da, tal ente ocupa en la estructura de éste el lugar del sentido objetivo y lo que resulta esclarecedor en la exposición heideggeriana es que toda ella está destinada a resaltar que aquello de lo que el cuidado se ocupa es lo que es solo en relación al cuidado en que se inserta: el modo de su venir al encuentro -una manera de expresar su Gegebenheitsweise-, que es lo que hay que investigar, es indisociable de la modalidad específica en que se ejerce la referencia al ente. Por eso el conjunto de los caracteres que articulan el sentido del cuidado (abrir, mantener, desarrollar, entregarse, perderse ${ }^{9}$ ) son expresiones que dicen la manera como se modaliza en concreto la referencia (formas del sentido ejecutivo), modalización conforme a la cual aparecen correlativamente los caracteres del ente.

\section{II}

¿Cómo se determina entonces el carácter fenomenológico de la comprensión de los conceptos y textos de la tradición? ¿En qué consiste, pues, una interpretación fenomenológica de Aristóteles, de la Crítica de la razón pura, de la conciencia o de las cuatro tesis fundamentales sobre el ser, para citar sólo algunos de los ámbitos específicos en que Heidegger mismo ha considerado que ejercía esa suerte de interpretación? Más que a textos programáticos o definitorios hay que acudir a la praxis interpretativa de Heidegger para ver cómo de hecho desarrolla su comprensión y en qué momentos clave la funda.

Pese a ello, abordemos la cuestión por el texto que más precisamente define la tarea de los conceptos heredados en el interior del programa de la hermenéutica de la facticidad.

La hermenéutica fenomenológica de la facticidad, en cuanto quiere contribuir por medio de la interpretación a la posibilidad de que la situación actual se apropie radicalmente de sí misma (...), se ve remitida a ablandar la interpretación habitual y dominante de acuerdo con sus motivos ocultos, tendencias y vías de interpretación implícitas y a avanzar, en un retroceso que desmonta (abbauende Rückgang), hasta las fuentes motivantes originarias de su explicación (GA, 62, 368).

La metáfora del ablandamiento de la tradición endurecida, que Ser y tiempo situaba en el eje de la destrucción de la historia de la ontología, está ya actuando significativamente para expresar el cometido central de la interpretación fenomenológica, que la obra mayor de Heidegger asume sin variación. Pero el texto citado y, en general, la hermenéutica fenomenológica de la facticidad aporta mayores pistas que Ser y tiempo para entender cómo hay que alcanzar e interpretar esas "experiencias originarias en las que se ganaron las primeras

\footnotetext{
${ }^{9}$ Erschliessen, behalten, ausbilden, sich verschreiben, sich verlieren son las expresiones que utiliza Heidegger en el texto citado.
} 
determinaciones del ser, decisivas para el futuro" (SZ, 22). Veámoslo. Heidegger seńala de manera precisa que el ablandamiento comporta un retroceso hacia algún lugar, aún indeterminado, retroceso que por su propia naturaleza desmonta, desconstruye lo construido y es en este desmontaje donde se produce el efecto doble de esponjar la compactación del sentido transmitido y sacar a la luz las capas de significado ocultas o implícitas. Como es obvio, lo decisivo del movimiento de pensamiento que es el retroceso es el hacia dónde, ese ámbito en el que radican las fuentes motivantes originarias, y que, avistándolo, abre la mirada hacia los motivos ocultos y las tendencias implícitas. Parece bastante obvio, tras lo que hemos visto en las páginas anteriores, que ese ámbito no puede ser otro que la estructura determinante de la facticidad, el cuidado (Sorge), el fenómeno por excelencia. Pero, naturalmente, no el concepto abstracto de cuidado, una especie de estructura universal que estuviera en la base de todo ocuparse concreto de algo ${ }^{10}$, sino una forma determinada, un comportamiento preciso. Esto es, veíamos, lo que subraya la primacía del sentido de ejecución: no se da, no hay una dirección general hacia el mundo, sino siempre modalizada, ejercida de una determinada manera. La concepción heideggeriana de la intencionalidad impide recurrir a una estructura abstracta que marque el sentido general de la facticidad y proporcione algo así como una directriz o pauta general de interpretación. Por eso la cuestión esencial que toda interpretación debe plantearse: “¿en qué sentido de ser previamente poseído (Seinsvorhabe) se encuentra esta objetividad” que se va a investigar? (GA, 62, 373) busca justamente romper con la tendencia a pensar que hay un sentido de ser genérico, abstracto, que fuera el presupuesto universal, no incardinado en ninguna experiencia determinada, y por tanto hermenéuticamente irrelevante.

Del mismo modo, el concepto de experiencia fundamental (Grunderfahrung), que el Informe Natorp utiliza profusamente para aludir al terreno del que brotan las determinaciones ontológicas, tiene el mismo carácter metódico-hermenéutico de remitir respectivamente a aquella experiencia -es decir, a aquella forma concreta de cuidado- en cuyo seno se acuñan originariamente las propiedades ontológicas del ente de que se trate (la vida fáctica misma, la conciencia, lo vorhanden, etc.); no designa por tanto una experiencia que fuera la fundamental de la facticidad ni mucho menos alude a alguna forma de experiencia privilegiada y extracotidiana. La experiencia es fundamental estrictamente respecto de lo en ella fundado, no de manera absoluta y descontextuada. Se trata, por ello, de un concepto hermenéutico y no ontológico, aunque sirva para localizar el suelo de la conceptuación ontológica. Que dicha experiencia fundamental es tratada siempre con la estructura intencional del cuidado resulta patente a partir de la forma como Heidegger la caracteriza, siempre ligada a expresiones

\footnotetext{
${ }^{10}$ Los Prolegómenos a la historia del concepto de tiempo, que dan ya a la Sorge el mismo status que Ser y tiempo de constituir la totalidad estructural del Dasein, rechazaban enérgicamente la idea de que con ella se hubiera conseguido un concepto universal: "Lo que se ha alcanzado con el fenómeno del cuidado como ser del Dasein no es un concepto abstracto, universal, que, en cuanto género, estuviera en la base de cada modo de ser; menos aún, que haya surgido como resultado del juego conjunto de diversas formas de ser, de forma que en cierto modo yo extraiga de ellas su la abstracta universalidad". (GA, 20, p. 422).
} 
que se ciñen inequívocamente a la correlación intencional, según los tres sentidos definidos. “¿Cómo surgen las estructuras ontológicas? Como desarrollos de una cierta manera de determinar nombrando y considerando las cosas, es decir, siguiendo el camino de una investigación que toma en determinadas perspectivas y articula según ellas el campo ontológico que una experiencia fundamental le ha dado por anticipado" (GA, 62, 374). La estructura intencional del cuidado sirve para analizar tanto esa experiencia fundamental que proporciona el campo ontológico previo, el "sentido arcóntico de ser", con arreglo al cual, correlativamente, el logos enuncia y determina las propiedades del ente, como para interpretar la forma misma de investigación filosófica con la que Aristóteles acuña las categorías del ente móvil ${ }^{11}$. Comportamiento productivo (poiesis) y ciencia (episteme), cada uno en su nivel-aquél como horizonte del que surge el sentido predado de ser, éste como forma explícita de tratar lo que aparece en dicho horizonte- son entendidos como formas determinadas del cuidado que, analizadas como tal, revelan el fenómeno completo que está en la base de las caracterizaciones fundamentales de la ontología antigua, "decisiva para el futuro" 12 .

De esta forma se entiende bien por qué el texto programático citado atribuía al retroceso llegar a "las fuentes originarias que motivan la explicación" de la interpretación heredada: porque la localización de la forma de cuidado en que consiste la experiencia ontológica previa y del modo de tratar lo que ella ofrece es lo que en sentido propio "motiva". El análisis del fenómeno completo del cuidado respectivo con su estructura anticipativa hace visible temáticamente aquello que mueve a tomar una región de ser de esta o de aquella manera y a conceptuarla así. Heidegger utiliza con frecuencia las ideas de motivación y tendencias latentes que viven en una teoría filosófica para referirse al cuidado de que nace, al terreno no tematizado por la teoría pero del que implícitamente vive $^{13}$. En la Introducción a la investigación fenomenológica, son numerosos los textos en que aparece el cuidado como lo que motiva un ámbito conceptual

\footnotetext{
${ }^{11}$ Sobre esta última, véase el siguiente texto del Informe Natorp: "Esta investigación (la aristotélica de la Física) hay que tomarla metódico-interpretativamente como fenómeno pleno e interpretarla por referencia al objeto en el modo (Wie) del trato investigador con él, por referencia a la experiencia fundamental en la que el objeto es previamente dado como arranque de la investigación, por referencia a la movilidad constitutiva del ejercicio investigador y a las formas concretas de mentar el objeto y articularlo conceptualmente". (GA, 62, p. 374).

${ }^{12} \mathrm{Al}$ comportamiento productivo dedican los Problemas fundamentales de la fenomenología de 1927 un largo análisis fenomenológico que, desarrollando pormenorizadamente las indicaciones del Informe Natorp, no deja dudas sobre la clave intencional del cuidado y su papel de horizonte general de la ontología griega. La misma clave conduce el análisis del comportamiento perceptivo, que aclara el sentido de la tesis kantiana sobre el ser ("ser no es un predicado real"), y permite sacar a la luz en la estructura de la percepción la presencia de la diferencia ontológica.

${ }^{13}$ Esto resulta especialmente patente en las indicaciones metodológicas que, para interpretar las Cartas de San Pablo, da la Introducción a la Fenomenología de la Religión. Si para esta tarea lo decisivo es tener en cuenta el "auténtico contexto motivacional", es obvio que la investigación de éste no puede hacerse atendiendo sólo al contenido objetivo (Gehalt) que las cartas transmiten, sino a "las referencias (Bezüge) y ejercicios (Vollzüge) que se pueden ver en el contenido (en cada configuración temporalmente condicionada)" (GA, 60, pp. 133, 136). Ahora bien, asignar a la investigación fenomenológica el cometido de mirar el contenido de una predicación (o teoría) inscribiéndola siempre en su sentido referencial y en su modo de ejecución es sencillamente retrotraerla a la intencionalidad plena del cuidado.
} 
o temático: "La cuestión es qué cuidado motiva la configuración de la conciencia como tema" (GA, 17, 59), "un concreto cuidado por el conocimiento conocido es el motivo general del peculiar papel que juega la conciencia” (GA, 17,62 ), qué cuidado motiva la crítica al naturalismo (GA, 17, 71), "qué tendencias viven (sind lebendig) en la crítica al naturalismo, por qué tipo de cuidado es conducida la elección del objeto y la crítica" (GA, 17, 72). Lo que importa destacar en nuestro contexto es que la motivación que aquí sale a la luz nada tiene que ver con la relación psicológica entre motivo y acción, ni con una relación causa-efecto, sino con una estructura de la intencionalidad: el cuidado de que se trate no causa ni produce ni impulsa a nada; tales ideas son formas impropias (en el mejor de los casos analógicas) de dar expresión a la relación hermenéutica de motivación, pues ella no se refiere a una vis a tergo que empuja ni a un conjunto de actividades que producen un resultado; instalados en un preciso y concreto comportamiento, en efecto, éste lleva a, tiende, motiva, mueve, a tomar las cosas de esta o de aquella manera; pero esto significa sencillamente que el fenómeno completo del cuidado abre la posibilidad fáctica de que el objeto se muestre de esta precisa manera, lo mantiene así visible y lo desarrolla con arreglo a esa faz mostrada. Se trata, pues, de un concepto estrictamente fenomenológico, que sólo trata de hacer comprensible el hecho del aparecer determinado de las cosas. La interpretación que da a comprender el sentido de una teoría se funda en un análisis intencional del cuidado que explica el aparecer asi del campo objetivo de que se ocupa. Por eso es una interpretación fenomenológica.

Pero lo que cualifica definitivamente como fenomenológico este remontarse al horizonte de sentido que constituye el suelo originario de una teoría o de un entramado conceptual es que no consiste en un retroceso temporal hacia un pasado evaporado, que fuera necesario reconstruir a partir de datos históricos, huellas de diverso orden o procedimientos filológicos de fijación de textos y reconstrucción del sentido. La des-construcción como apropiación positiva del pasado no es una reconstrucción más o menos verosímil de ese tipo. El retroceso en que se funda es hacia un comportamiento, hacia un trato con el mundo ejecutable en el presente, que forma parte de la situación real en que el investigador se encuentra, del horizonte fáctico de sus posibilidades. Es el análisis intencional de un comportamiento, que puede ser asumido, repetido o retomado por el filósofo, lo que proporciona la base de la interpretación. Los indicios diversos, propios de una reconstrucción histórica, son sin duda importantes, pero no constituyen la guía de la interpretación; ésta no es otra que la estructura intencional de un cuidado que, una vez localizado como la experiencia en la que arraiga el objeto de interpretación, puede ser analizada a partir de su ejecución en el presente vivo de la situación hermenéutica. A mi entender esta no es una tesis explícita de Heidegger, pero se deduce necesariamente del sentido general de su concepción de la facticidad y de su praxis hermenéutica real. En efecto, si se repara en cómo se lleva a cabo la interpre- 
tación de, por ejemplo, el ser de la conciencia en la citada Introducción a la investigación fenomenológica y de las dos primeras tesis sobre el ser, la de Kant y la clásica de esencia y existencia, en Los problemas fundamentales de la fenomenología de 1927, son tres las formas de cuidado o de comportamiento que entran en juego como claves de la interpretación: la percepción, la producción de objetos y el cuidado cognoscitivo, especialmente en su modalidad de "cuidado del conocimiento conocido". Ninguna de ellas es una configuración histórica, cuyo sentido necesite ser reconstruido mediante cualquiera de los recursos de la metodología histórica para obtener una primera comprensión de su estructura; por el contrario, basta de entrada con realizar un análisis intencional, de acuerdo con la triple forma de sentido que ya conocemos, puesto que esos comportamientos están, por así decir, disponibles para su repetición en la vida fáctica. Es lo que sin ninguna duda Heidegger realiza en los tres casos mencionados y, en general, en todas las múltiples interpretaciones de los textos aristotélicos. De la producción, utilizada como fondo de su interpretación de la ontología aristotélica y cristiano-medieval, dice Heidegger: "Lo que intentamos poner a la luz mediante el análisis fenomenológico de la estructura intencional del producir no tiene nada de inventado o de ficticio, sino que se encuentra ya en el comportamiento productivo prefilosófico, cotidiano, del Dasein" (GA, 24, 162).

Lo que distingue a la interpretación fenomenológica es este recurso a una forma determinada de trato con el mundo que, por darse como posibilidad ejecutable en la vida fáctica, en la situación actual, constituye un fenómeno analizable con el instrumental de la intencionalidad. Cuando Heidegger previene con frecuencia contra "la supuesta agudeza que argumenta sólo con conceptos que se dicen estrictos, pero que padece ceguera respecto de aquello a lo que propiamente apuntan los conceptos, esto es, que es ciega a los fenómenos" (GA, 24, 159), está pensando justamente, como muestra el contexto, en aquellas formas de interpretación que anteponen inadvertidamente el juego conceptual o los esquemas de la teoría del conocimiento a lo que revela el paciente análisis completo del fenómeno, en este caso, el sentido de la plena intencionalidad del producir. Es la ausencia de este análisis lo que vuelve ciegos o puramente hipotéticos a los conceptos hermenéuticos. Incluso el frecuente recurso heideggeriano a la etimología, que tanto juego le ha dado, tanto antes como después de la Kehre, resulta completamente insuficiente como clave de interpretación; puede ciertamente proporcionar una pista, o como el segundo Heidegger dirá, un guińo, pero es incapaz de comprender el sentido pleno del concepto; la oposición que Heidegger expone respecto de la actualitas entre el puro concepto verbal (Wortbegriff), que remite a un agere y su sentido como efectividad (Wirklichkeit) en la filosofía escolástica, que implica su inserción en el ámbito del producir, es sumamente esclarecedor de la insuficiencia fenomenológica de la etimología. 
¿En qué sentido debe, pues, entenderse el carácter fenomenológico de la interpretación del pasado filosófico? A partir de lo que acabamos de desarrollar, podemos concluir, a modo de resumen, diciendo que la interpretación aludida es fenomenológica:

1. Porque, en cuanto momento integrante del hecho de que la facticidad está siempre interpretada (Ausgelegtheit), forma parte del fenómeno pleno que ésta constituye. Un fenómeno que no es designado así, como "fenómeno", de manera casual, acogiéndose al sentido neutro de la palabra, sino en virtud de su tratamiento estrictamente fenomenológico, que lo caracteriza como intencional de principio a fin. Una comprensión de lo que en las representaciones vigentes es heredado implica hacerse cargo de la estructura intencional de la facticidad y de sus múltiples formas de "cuidado".

2. Porque el cuidado respectivo, intencionalmente leído, proporciona hermenéuticamente el horizonte global en el que ha de ser inserto, para su comprensión, cualquier conceptuación ontológica. Tanto la experiencia fundamental que anticipa el tipo ontológico, como el punto de vista específico (la investigación) que lo tematiza y conceptúa son leídas con el esquema intencional del cuidado, que es quien saca a la luz el sentido originario.

3. Porque la relación de motivación que se da entre el cuidado y el sentido que en él se origina tiene un significado puramente fenomenológico: no explica causalmente un acontecer histórico ni psicológicamente qué nos mueve a una acción, sino cómo aparece de una manera determinada, con tal sentido, un aspecto del mundo o una categoría.

4. Porque la estructura del cuidado que proporciona la clave hermenéutica es leída a partir de la experiencia prefilosófica real, de comportamientos repetibles y ejecutables en la existencia fáctica y no a través de una hipotética reconstrucción histórica. El análisis intencional que da las primeras indicaciones hermenéuticas recae sobre un presente vivo, no sobre un pasado reconstruido.

\section{III}

Si queremos plantear correctamente cuál es la forma propia con que el pasado de la filosofía se hace presente en esta forma de interpretación, lo primero que debemos hacer es no desgajarla del proyecto general que representa la hermenéutica de la facticidad. El recurso a la intencionalidad del cuidado, base de la destrucción fenomenológica, no es una metodología abstracta, un esquema fijo para analizar no importa qué configuración histórica; si olvidamos que 
surge como una necesidad interna de la tarea de exponer las estructuras de la existencia fáctica, la convertimos en un método de reconstrucción histórica objetiva, completamente ajeno a la intención que la funda. La interpretación fenomenológica no produce primordialmente el conocimiento de una determinada objetividad conceptual situada en un tiempo pasado (por ejemplo, las categorías de la metafísica aristotélica), que hubiéramos logrado reponer en su faz original, como cuando se reconstruye una iglesia románica semiderruida; lo que ella pretende es el esclarecimiento del sentido completo que tienen ciertas anticipaciones o expectativas que, ligadas a esas categorías, residen en nosotros, en el presente vivo de nuestra situación. Es precisamente la vinculación previa, ya dada y activamente vigente en nosotros de una configuración histórica, lo que la destrucción fenomenológica interpreta. "Lo que se nos presenta como pasado no es, desde luego el pasado, sino un mal presente" (GA, 17, 114). Por eso señala Heidegger en varias ocasiones que la crítica histórica de la destrucción no es una crítica del pasado, sino del presente (GA, $17,119,122)$. No son las posiciones de autores o sistemas lo que se critica, sino la manera como están presentes en nosotros. Es la situación misma del intérprete, el ejercicio de comprensión de la facticidad que se pone en marcha lo que busca ser esclarecido.

Esta vinculación de la destrucción al proyecto general de hermenéutica del Dasein determina por completo su comprensión de la tradición filosófica y exige en buena medida que la práctica concreta en que se despliega la interpretación tenga carácter fenomenológico. La unión de ambos momentos, motivación en la necesidad de desentrañar la situación actual y modo fenomenológico de interpretar, se completan mutuamente y marcan lo peculiar de la presencia del pasado.

Trataré de mostrarlo brevemente.

Es evidente que, al estar al servicio de una analítica del Dasein, la destrucción no puede arrinconar un pensamiento dado en un momento del pasado y convertirlo en objeto de pura curiosidad histórica, lo que no quiere decir que pase a ser, sin más, una mera ejemplificación ad hoc. Pensemos en los dos supuestos en el juego de la tradición que la hacen necesaria: a) la realidad y vigencia de lo transmitido en nosotros; b) la forma encubridora de esa presencia, su opacidad constitutiva (es este un rasgo típico de Heidegger, frente al papel esencialmente positivo de la tradición en Gadamer). Si la destrucción se limitara a aplicar las categorías existenciales a un pensamiento dado, no se comprende por qué sería necesaria para la obtención de esas mismas categorías; si por el contrario, la hermenéutica de la facticidad se limitara a asumir los conceptos legados, ignoraría su posible capacidad distorsionadora. La destrucción fenomenológica sólo tiene sentido si es capaz de devolver a los conceptos el sentido original difuminado entre las capas sedimentadas y si éste proporciona 
orientación al análisis de la facticidad, es decir, a la tarea de comprensión del presente. Las dos facetas son inseparables y se funden la una en la otra, por eso no puede asumir el papel de método historiográfico objetivo.

Precisemos un poco más. Cuando, comprendido el poder efectivo y ocultador a la vez de la tradición, la destrucción se pone en marcha, lo que acontece es un intento de suspensión de ese poder. Suspensión que no se produce mediante un acto o una modificación de actitud, sino a través de un ejercicio de interrogación, de la sucesión de preguntas que cuestionan el sentido dado y sugieren, con su solo planteamiento, posibilidades diferentes de delimitarlo. Es en ese proceso de imaginación de posibilidades, suscitado por la interrogación, donde el retroceso hacia el cuidado proporciona a la interpretación una guía coherente con la estructura básica de la movilidad de la vida, que el análisis intencional ha revelado. La interpretación fenomenológica propone entonces una visión del horizonte de experiencia, del terreno vital del que surge y crece el concepto, frente al sentido desgajado, abstracto, resultado de la obra de transmisión, en que directamente aparece. La interpretación fenomenológica entiende que esa visión del concepto en su horizonte de experiencia constituye su sentido originario, aquel que aspiraba a recuperar la destrucción. ¿En qué sentido hemos de tomar este carácter originario? ¿Hace referencia al concepto histórico de origen, es decir, al modo real y efectivo como nació el concepto? ¿o se trata más bien de un origen plausible, no históricamente comprobable, pero capaz de hacer inteligibles las vicisitudes históricas del concepto? ¿Tiene algo que ver ese origen con el sentido epistemológico de la validez del concepto desconstruido? Es evidente que la aclaración de estas cuestiones es determinante si pretendemos indagar el alcance y el valor de la interpretación fenomenológica. Pero me van a permitir que soslaye ahora este problema para ceńirme a nuestro tema, la contemporaneidad del pasado. $Y$ es que, a mi entender, la noción de origen tiene un sentido esencial precisamente en este contexto. Es Gadamer, que ha insistido en diversas ocasiones en que la destrucción fenomenológica nada tiene que ver con un "oscuro discurso sobre el origen y lo originario"14, quien ha dado la pista para pensar en esta dirección. Lo que la interpretación fenomenológica recupera no es el origen histórico o la experiencia primordial de un pensamiento filosófico, sino su capacidad de decirnos algo, de concernirnos o sentirnos afectados por él. Devolverle la vitalidad a un pensamiento del pasado consiste justamente en esto, en que anticipamos y recogemos en él un estímulo y una posibilidad de pensar nuestra situación y nuestra tarea. No quiero con ello decir que la noción de origen se reduzca a esto (lo que sería un fraude intelectual), sino destacar algo que me parece indudable: que en la interpretación fenomenológica la idea de lo originario está ligada sin separación posible a su carácter revulsivo, movilizador de posibilidades para el pensamiento de aqui y ahora. Lo originario no se queda en la constatación de un estado de cosas histórico como si fuera el término final en el que la interpretación se detiene y, por así decir, descansa, sino que retorna sobre el pensamiento del

\footnotetext{
${ }^{14}$ Deconstrucción y hermenéutica. En “El giro hermenéutico”. Madrid: Cátedra, 2001, p. 82.
} 
presente, provocándolo y orientándolo. La cuestión no es accesoria respecto del sentido primario de origen. Tan no lo es que Heidegger estima que en este retroceso, que plásticamente denomina Rückstoss, culatazo o golpe hacia atrás, radica el auténtico ser del pasado: "La objetividad de la destrucción es de tal forma que en ella el pasado es llevado a su auténtico ser, es decir, a su capacidad de retornar golpeando al presente. Sólo cuando el pasado es traído a esta posibilidad de retroceso (Rückstossmöglichkeit), surge su objetividad y la vinculación del presente con la historia” (GA, 17, 122). Estas palabras del primer curso de Marburgo no dejan lugar a dudas del papel esencial que la interpretación fenomenológica atribuye al retroceso sobre el presente: la comprensión de lo originario que ofrece significa simultáneamente que el pasado cobra una forma de presencia real y efectiva en nosotros de la que antes carecía. La oposición entre un ser auténtico y un ser inauténtico del pasado no expresa primordialmente una relación de verdad en nuestro conocimiento de él, sino la forma viva o muerta de su presencia en nosotros, el modo o la forma como de hecho lo vivimos; a lo que alude es a la diferencia entre el uso de representaciones habituales, cuyo origen ni se plantea, en las que no reparamos ni por tanto conocemos y la asunción consciente de significaciones que transmiten un mundo propio y por ello se contrastan inmediatamente con la situación, a la vez que manifiestan hasta qué punto somos deudores de ellas. Por esto debe ser llamada apropiación, porque al vivirlo conscientemente en la plenitud de sus implicaciones el pasado se hace propio en forma ejecutiva, integrando el sentido de ejecución de los actos en que pretendemos comprender nuestra facticidad y saliendo de la pasividad subterránea en la que vivía.

La acción que el pasado recuperado ejerce sobre el presente se percibe ahora con claridad: el acceso al horizonte de experiencia "originaria" de un pensamiento proporciona el campo propio de su significación, allí donde se encuentra "en casa" y a la vez los límites potenciales de su aplicación. Es aquí donde reside el momento decisivo en el que el pasado se hace contemporáneo: la conciencia del límite posible que inmediatamente surge sin reflexión abre el terreno de la verdad, en el sentido de que lo visto en el pensamiento deconstruido se piensa en su posible aplicación a la situación presente y a su tarea de investigación de la facticidad. La verdad que la apropiación pone en juego no es la adecuación del pensamiento del pasado con "su" mundo ni tampoco la objetividad de la destrucción, sino la adecuación de lo que la interpretación revela (el "auténtico" sentido de la ontología aristotélica, por ejemplo) a nuestro mundo, su capacidad de orientar el pensamiento del presente para comprender la forma actual de estar en el mundo. Esta primacía de la verdad como incorporación ejecutiva del pasado en la tarea filosófica del presente es lo que hace inteligibles las afirmaciones de Heidegger de que la destrucción no entra en refutaciones de las teorías históricas, buscando sus puntos débiles para asegurar la propia posición, ni discrimina en ellas lo verdadero de lo falso (GA, 17, 118-119). $\mathrm{El}$ aspecto positivo de la destrucción que Heidegger siempre destaca reside en 
esa apropiación orientadora que abre posibilidades al pensamiento y no en el legado de un contenido de verdad abstracto e intercambiable en cualquier situación. La destrucción no se dirige a juzgar la verdad o falsedad del pensamiento de Platón o Aristóteles, sino a comprender su sentido, lo que significa modificar el modo de su presencia en nosotros.

Esta manera de entender la contemporaneidad del pasado es perfectamente coherente con la estructura fenomenológica de la interpretación o, más exactamente, es consecuencia de la concepción que la hermenéutica fenomenológica de la facticidad tiene de lo que constituye el sentido pleno del fenómeno. En efecto, en dos puntos al menos se hace ello claramente visible: 1) recordemos que la clave de la interpretación de los conceptos históricamente dados la proporcionaba el análisis de una forma de cuidado tomada de la realidad fácticamente vivida en el presente y no indicios o hipótesis históricas (la percepción o la producción de objetos). En ese análisis late, como es lógico, el horizonte de significación del presente en que se hace, lo que implica, si no una identidad completa, sí una continuidad de sentido entre ese horizonte y el horizonte del concepto interpretado, de lo contrario la interpretación sería totalmente incongruente con su objeto y puramente arbitraria. Ahora bien, esa continuidad es sencillamente el factum de la pervivencia latente y real del pasado, del que la destrucción parte, y que la interpretación fenomenológica eleva a conciencia explícita, liberando su sentido originario para convertirlo en posibilidad. La interpretación encuentra la presencia viva del pasado porque ya la supone. 2) Ese mismo análisis del cuidado destacaba la primacía del sentido de ejecución, es decir, de la modalidad ejecutiva en que se realiza cualquier forma de cuidado, lo que también afecta al cuidado cognoscitivo propio de la labor investigadora. De esta forma, la investigación "histórica" de la destrucción se ve inevitablemente conducida a considerar que su rendimiento principal es la autenticidad en su relación con el pasado que el sujeto investigador adquiere, la modificación que produce en él, limitando sus prejuicios, rehaciendo sus expectativas, abriendo posibilidades, etc. Todo ello expresión del nuevo modo en que se instala en su situación y se dirige a su tema (Vollzugssinn).

Esta lectura unilateral del Rückstoss del pasado, centrada en el sentido de ejecución, deja en la sombra dilucidar cuál es el papel que el costado objetivo (Gehaltssinn), lo que la interpretación hace ver, juega en la fuerza que ese retroceso imprime sobre nosotros. ¿Puede entenderse esa fuerza sólo a partir de la modificación del sentido de ejecución? ¿No es precisamente la conveniencia o no con nuestra situación de lo que la interpretación transmite el núcleo de la aplicación y su capacidad orientadora? ¿No es el contenido de la interpretación lo que suscita de inmediato el contraste con lo que percibimos como nuestra situación y sugiere nuevas vías al pensamiento? ¿Y no supone eso una pretensión común de verdad a pensamiento interpretante y pensamiento interpretado? La referencia implícita del sentido objetivo de la destrucción al mundo 
presente abre un ámbito de verdad temática u objetiva a la investigación que va más allá de la incorporación auténtica del pasado en el acto interpretativo y sin el que esa incorporación sería difícilmente comprensible. Al comienzo decía que la teoría de la experiencia hermenéutica parecía pensada para dejar un lugar legítimo a la pretensión de verdad de la tradición. Ahora quisiera concluir diciendo que la hermenéutica fenomenológica, que tan profundamente ha hecho ver la vigencia del pasado, necesita ser completada por una reflexión que ahonde en esa dimensión de verdad, que haga justicia al papel que la pretensión de verdad, implícita tanto en las grandes obras del pensamiento como en nuestra aproximación a ellas, juega en la comprensión del pasado y en la orientación que proporciona. Es esta una tarea ineludible, al menos para quienes nos sentimos aludidos por esta forma de pensamiento. 
II. FENOMENOLOGÍA Y LENGUAJE 


\title{
Prioridad de las Oraciones Apofánticas sobre las otras Oraciones. Interpretación de un Planteamiento en Investigaciones Lógicas de Husserl ${ }^{1}$
}

\author{
Mirko Skarica \\ Universidad de Santiago de Chile
}

\begin{abstract}
Resumen
Contemporáneamente ha surgido un cuestionamiento a la idea de que las oraciones apofánticas constituyan un tipo de oraciones de tipo diferente que las otras oraciones, como imperativos, expresiones de deseo, etc.; así, por ejemplo en Austin o Wittgenstein. En el presente trabajo se propone, a partir de los planteamientos de Husserl, las razones de por qué las oraciones apofánticas, aún admitiendo su tratamiento bajo un mismo marco teórico que las restantes, tienen una prioridad respecto de las restantes oraciones.
\end{abstract}

En De Interpretatione, Aristóteles separa el tratamiento de la oración apofántica del tratamiento de los otros tipos de oración (ruego, por ejemplo), remitiéndolo a la Retórica o a la Poética ${ }^{2}$. ¿A qué se debe que se dé un tratamiento diferente a la oración apofántica respecto de las oraciones no-apofánticas? Podría decirse que la justificación de tal separación apunta a que sólo la oración apofántica puede expresar 'que es lo que es' y 'que no es lo que no es', y en tal sentido sólo ella puede ser verdadera o falsa ${ }^{3}$. De ser así resulta que sólo la oración apofántica tiene por característica el ser verdadera o falsa, no así las otras oraciones (no- apofánticas, como ruego, imperativo, etc. $)^{4}$.

Sea cual sea la razón de tal separación en el tratamiento de las oraciones (apofánticas y no-apofánticas), se da una constante ininterrumpida en la tradición filosófica desde Aristóteles a Frege en tal modo de tratar las oraciones. Este aislamiento en el tratamiento de la oración apofántica respecto de los otros tipos de oración es acogido incluso en nuestro tiempo, como puede detectarse en

\footnotetext{
${ }^{1}$ Este trabajo es parte del proyecto Dicyt 030653SZ financiado por la Universidad de Santiago de Chile.

${ }^{2} 4$ 17a 1-7. La oración apofántica es aquella que afirma o niega algo de algo, y por ende puede ser verdadera o falsa. Es la oración que algunos han denominado 'enunciativa' o 'asertiva'. Es, en suma, la oración predicativa, que consta de sujeto y predicado. Las restantes oraciones, como ruegos, imperativos, etc. se las ha considerado como oraciones que no afirman ni niegan algo de algo, y por ende, no pueden ser ni verdaderas ni falsas (las denominamos aquí 'no-apofánticas', por contraste con las apofánticas).

${ }^{3}$ Cf. Metafísica IV 1011b 25-29.

${ }^{4}$ De Int. 17a 1s.
} 
las Investigaciones Lógicas de Frege y en el Tractatus de Wittgentein. En Frege ${ }^{5}$ y Wittgenstein ${ }^{6}$, al igual que en Aristóteles, se sostiene que sólo la oración apofántica o asertiva admite un valor de verdad, no así otro tipo de oración, como imperativo, por ejemplo, lo que justificaría su separación de las otras oraciones, no-apofánticas.

Aparte de la justificación apuntada anteriormente, se suele añadir en la tradición, que sólo la oración apofántica es usada en las ciencias y en la filosofía, no así las otras, tal como puede verse en el comentario de Santo Tomás a De interpretatione $e^{7}$. Hoy en día también Frege y Wittgenstein asocian directamente las aserciones con las ciencias. En el caso de Frege, si bien incluye en su tratamiento a las oraciones interrogativas, sólo tiene en cuenta aquellas que pueden ser respondidas mediante una aserción, afirmación o negación, esto es, las interrogaciones sobre un contenido apofántico, y son las interrogaciones asociadas a las aserciones apofánticas las que permiten el desarrollo de las ciencias $^{8}$. Wittgenstein sostiene, por su parte, que la totalidad del lenguaje es la totalidad de las proposiciones de las ciencias; esto es, de las oraciones apofánticas, que pueden ser verdaderas o falsas?.

Ahora bien, esta separación en el tratamiento de las oraciones viene a ser cuestionada contemporáneamente en forma directa por Austin, quien reclama a la vez que se da una suerte de privilegio injustificado a las oraciones apofánticas respecto de los otros tipos de oración ${ }^{10}$. Y es justamente la oposición tradicio-

\footnotetext{
${ }^{5}$ Cf. "Der Gedanke" (“El pensamiento”) 62: "Para elaborar con más precisión lo que llamo pensamiento, distingo clase de oraciones. No se le puede negar un sentido a una oración imperativa, pero este sentido no es tal que se pueda preguntar por su verdad. Por eso no llamaré pensamiento al sentido de una oración imperativa. Igualmente se han de excluir las oraciones desiderativas y deprecativas. Pueden considerarse las oraciones en que comunicamos o afirmamos algo".

${ }^{6}$ Tractatus 4.05, 4.06-4062.

${ }^{7}$ Cf. Expositio libri PeryHermenias, Opera omnia iussi Leonis XIII P. M. Edita, T.I 1, Editio altera retractata (R-A. Gauthier). Roma-París: 1989 I 7 (17a 5). Explicando Santo Tomás el pasaje en que Aristóteles separa el tratamiento de la oración apofántica de las restantes, dice: "La razón de esto es que la consideración de este libro se ordena directamente a la ciencia demostrativa, en que la mente humana es inducida a asentir a lo verdadero de la cosa, y por ello quien demuestra no usa para su fin sino las oraciones apofánticas, las cuales significan las cosas en cuanto que su verdad se da en la mente".

${ }^{8}$ Cf. "Der Gedanke" ("El pensamiento") 62: "Un progreso en la ciencia ocurre usualmente de modo que primero es captado un pensamiento, tal como puede ser expresado en cierto modo en la pregunta por un contenido proposicional, sobre cuya base, después de ser emprendidas las investigaciones finalmente se le reconoce como verdadero".

${ }^{9}$ Cf. Tractatus logico-philosophicus 4.11: "La totalidad de las oraciones verdaderas es la ciencia natural en total (o la totalidad de las ciencias naturales". Wittgenstein excluye la Filosofía de entre las ciencias naturales.

${ }^{10}$ Cf. "Performative-constative". En Ch. Caton (ed.). Philosophy and ordinary language. Illinois: 1963, p. 31. Allí Austin refiriéndose a la separación en el tratamiento de las oraciones apofánticas ('constatativas' en su terminología) de las restantes oraciones, alegando una suerte de privilegio injustificado que se le da a aquellas, dice: "Aquí y ahora nos resta examinar, en forma más bien breve, esta manía de ser verdadero o falso, algo que la gente piensa que es peculiar sólo a las aserciones y deben ser puestas en un pedestal propio, antes de la batalla". Cf. también "Performative utterances", en Philosophical Papers. Aludiendo a cómo surge esta separación, dice: "Consideremos, en primer lugar, cómo surge este asunto. No necesitamos retroceder demasiado en la historia de la filosofía para descubrir que los filósofos dan por sentado como algo casi evidente que el único oficio, el único oficio interesante, de cualquier locución -o sea, de cualquiera cosa que digamos- consiste en ser verdadera o falsa".
} 
nal entre oraciones que tienen la peculiaridad de ser verdaderas o falsas y aquellas que no que Austin pasa a cuestionar en su principal obra, esto es, How to do things with words, y en algunos otros trabajos ${ }^{11}$. Austin presenta el contraste inicial, que él cuestiona, bajo la confrontación entre oraciones 'constatativas' y 'ejecutivas'. Las primeras tendrían la propiedad de ser verdaderas o falsas, y cumplirían el oficio de describir algo o informar acerca de ello, las segundas, en cambio, tendrían por oficio hacer algo, sin describir ni comunicar nada de ello, y por ende no podrían ser valoradas como verdaderas o falsas. Ejemplos de estas últimas serían, entre otros, las oraciones imperativas, las promesas, los ruegos, etc. En su obra How to do things with words, aparte de presentar el usual contraste entre oraciones constatativas y ejecutivas, Austin presenta su teoría de los 'actos de habla' (speech acts), como un marco para superar la distinción cuestionada, al considerar que no sólo las constatativas pueden ser valoradas como verdaderas o falsas, sino también las ejecutivas, dado que no sólo las constatativas tienen por oficio decir algo respecto de los hechos, sino también las ejecutivas ${ }^{12}$. Le sigue en este cuestionamiento su seguidor Searle, al menos en un primer momento, como se puede ver en su obra Speech Acts. Searle, al igual que Austin, no admite en dicha obra que sólo la oración apofántica pueda ser valorada en términos de verdad o falsedad. Si Austin sostiene que todas las oraciones, en tanto actos de habla, se relacionan con hechos, y por ende, pueden ser verdaderas o falsas de algún modo, Searle sostiene, por su parte, que toda oración, y no sólo las apofánticas tiene un carácter predicativo, y por ende, en todas ellas se suscita la cuestión acerca de su verdad o falsedad, si bien deja planteada la duda a este respecto ${ }^{13}$. En el caso de Searle se debe tener en cuenta que varía su posición posteriormente, al considerar que no en todas las oraciones se da un mismo tipo de adecuación, que él denomina 'dirección de ajuste' (direction of fit), entre oración y mundo ${ }^{14}$. Hay otros autores que si bien concuerdan en cierto modo con los planteamientos de Austin, siguen más bien la observación de Searle, y en consecuencia abordan el tratamiento de la oración apofántica dentro del esquema general de los actos de habla, sin perjuicio de aceptar que la relación de ella con los hechos difiere del modo en se relacionan con los hechos las oraciones de otro tipo. Tal es el caso de Tugendhat, por ejemplo. Éste distingue dos modos básicos de oraciones, las teoréticas y las prácticas. Las oraciones teoréticas (apofánticas, en nuestra terminología) concuerdan con los hechos de modo que pueden ser verificables; en cambio, las oraciones prácticas presentan la expectativa de su cumplimiento ${ }^{15}$. Debe

\footnotetext{
${ }^{11}$ Cf. "Performative-constative", citado en nota 10, y "Performative utterances", en Austin, Philosophical papers.

${ }^{12} \mathrm{Cf}$. How to do things with words, Lección VII, final, y siguientes.

${ }^{13}$ Cf. Speech acts. An essay in the philosophy of language. Cambridge: 1970, 5.7 "Rules of predication" . En la primera nota de este apartado, Searle explica por qué considera embarazoso su planteamiento, aunque lo considera ventajoso, a pesar de todo: "Es especialmente embarazoso para los imperativos, pues el objetivo de los imperativos es hacer que el mundo se adecue a las palabras, mientras que "verdadero, cuando se afirma de las ilocuciones, les atribuye éxito en conseguir que las palabras se adecuen al mundo".

${ }^{14}$ Cf. "A taxonomy of illocutionary acts". En Expression and Meaning. Cambridge University Press: 1979. Al considerar la diferente manera de dirección de ajuste entre palabra y mundo, Searle abre la posibilidad de separar en el tratamiento las oraciones apofánticas.

${ }^{15}$ Cf. Vorlesungen zur Einführung in die spachanalytsche Philosophie. Frankfurt am Main: Suhrkamp, 1979 lección 28.
} 
quedar entonces en claro que estos autores, Searle y Tugendhat, al admitir el diferente modo de relacionarse las oraciones apofánticas con los hechos con respecto a las oraciones no-apofánticas, no rechazan el planteamiento de que todas ellas deben ser tratadas bajo un mismo marco teórico, esto es, el de los actos de habla.

Wittgenstein, quien en su Tractatus, como vimos, acoge sólo las oraciones apofánticas, se critica a sí mismo con posterioridad, específicamente en su obra Investigaciones filosóficas, por haber hecho esta separación, pasando a tratar la oración apofántica dentro un planteamiento más comprensivo, el de los 'juegos del lenguaje' (Sprachspiele) ${ }^{16}$. El modelo común para explicar los diversos tipos de oraciones es la figura (Bild) de un hecho, por ejemplo, la de un boxeador en una determinada postura en una pelea. Una misma figura, en este caso la del boxeador, puede servir a la vez para comunicar cómo debe ponerse y cómo se ha puesto en la pelea. Mediante este símil, Wittgenstein trata de explicar en forma común tanto las oraciones apofánticas (enunciados) como las no-apofánticas (normas, p. ejemplo). Esta figura de un hecho vendría a ser un radical proposicional (Satzradikal). Lo que tiene en mente Wittgenstein aquí es que en las oraciones de diversos tipos el sentido puede ser el mismo, esto es, que diversos tipos de oración pueden tener en común un mismo contenido proposicional. La diversidad se daría en el uso de las oraciones. En esto no hay problema, la cuestión radica en si el uso de una figura para dar una norma coincide con el uso de una figura para describir algo, como parece pensar Wittgenstein, según la similitud que propone. En este punto la posición de Wittgenstein no es clara. Según mi parecer, tiende a asimilar las oraciones apofánticas a las oraciones de tipo práctico ${ }^{17}$.

A estas alturas cabe preguntarse cuál es propiamente el estado de la cuestión. Por lo dicho, pareciera que la cuestión planteada es si hay razones o no para que las oraciones apofánticas sean tratadas separadamente de las oraciones noapofánticas, si se atiende en especial al tenor de las críticas planteadas por Austin, y por el hecho de que ya es usual establecer un marco teórico común para todas las oraciones (por ejemplo, el de los actos de habla o el de los juegos de lenguaje en Austin y Wittgenstein, respectivamente). Pero en verdad no puede ser ese el cuestionamiento de fondo. De hecho, el planteamiento de un marco teórico común para el tratamiento de todas las oraciones ha estado siempre presente, aún cuando se haya aceptado una radical diferencia entre las oraciones apofánticas y las restantes; y, por lo tanto, este tipo de planteamiento no es nuevo. Ya Aristóteles en el inicio de De interpretatione, antes de tratar las oraciones apofánticas, presenta el marco teórico general bajo el cual considera las oraciones, incluidas las apofánticas. Todas ellas significan primariamente

\footnotetext{
${ }^{16}$ Cf. Philosophische Untersuchungen (Invetigaciones filosóficas), I 23.

${ }^{17}$ Cf. nota bajo el parágrafo 22 de Philosophische Untersuchungen. Sobre este aspecto del planteamiento de Wittgenstein me he referido en "Enunciación y verdad según Wittgenstein". En Philosophica 9-10 (1986/7), pp. 213-241; artículo reproducido también en Lenk-Skarica, Wittgenstein y el giro pragmático en la filosofía. Córdoba (Argentina): Ediciones del Copista, pp. 131-174.
} 
algo mental (afecciones del alma), y mediante ello, las cosas reales ${ }^{18}$. No es de extrañar por ello que su comentarista Tomás de Aquino, piense que el marco común de tratamiento de todas las oraciones, apofánticas y no-apofánticas, sea el de su adecuación con las cosas reales. La diferencia, según él, está en el diferente modo de adecuarse unas y otras con la realidad. En unas, las apofánticas, la adecuación está determinada por la realidad; en cambio, en otras, las prácticas, la adecuación está determinada por la oración. Es más, Tomás de Aquino considera que por ello en todas ellas se da la cuestión de la verdad; pero en unas se trata de la verdad teorética (en las apofánticas) y en otras, en cambio, de la verdad práctica (en las no-apofánticas) ${ }^{19}$.

Por lo visto, como puede apreciarse, no parece tener mucho sentido plantear específicamente el problema de si las oraciones apofánticas se diferencian de tal modo del restante tipo de oraciones (no-apofánticas), que sea menester un tratamiento aparte. Mi tesis es que el problema entre las oraciones apofánticas y no-apofánticas se presenta bajo otro respecto de más fondo. Nos puede ayudar a comprender el cuestionamiento más profundo si tomamos en cuenta la doctrina de Husserl acerca de la oración apofántica en sus Investigaciones lógicas. La cuestión que se plantea allí, según mi parecer, es si la oración apofántica goza de cierta prioridad ante las restantes oraciones y por qué. Sobre esto nos detendremos en adelante. Veamos, pues, cómo surge el asunto en Husserl, en especial en sus Investigaciones Lógicas, en donde se encamina a dilucidar el juicio predicativo y, en conexión con él, la oración apofántica. Como se puede apreciar en dicha obra, Husserl presenta un marco teórico común para el tratamiento del juicio predicativo y de la oración apofántica, a saber, el de los actos intencionales, como puede verse específicamente en su quinta Investigación Lógica. Desde esa perspectiva, el juicio predicativo, cuya expresión lingüística es la oración apofántica, es un acto intencional entre otros, de modo que todas las oraciones expresan a su modo un acto intencional. Ahora bien, un acto intencional, en general, se caracteriza por orientarse a un objeto, que se hace presente intencionalmente en la mente ${ }^{20}$. Es importante tener en cuenta que, según Husserl, la expresión del acto intencional y el acto intencional que le da sentido a la expresión constituyen una unidad, de tal modo que pasan a constituir un único acto $^{21}$. No debe sorprender, por tanto, que Husserl, en el análisis fenomenológico de los actos intencionales en general, y del juicio, en particular, se apoye a la vez en un análisis de las expre-

\footnotetext{
${ }^{18}$ De interpretatione, inicio.

${ }^{19}$ Cf. Expositio (op. cit. en nota 7) I 3 A 1 y I 7.

${ }^{20} \mathrm{~V} 20$.

${ }^{21}$ Cf. LU V 19: “Así, por ejemplo, un enunciado (Aussage), una afirmación (Behauptung), es una vivencia rigurosamente unitaria del género juicio (Urteil), como solemos decir. No encontramos en nosotros una mera suma de actos, sino un acto único, en el que distinguimos un lado corporal y otro espiritual". 'Enunciado’ y ‘afirmación' corresponde a lo que Husserl metafóricamente califica de corporal, la expresión oral, y 'juicio', a lo espiritual, la vivencia intencional.
} 
siones lingüísticas, esto es, las oraciones respectivas ${ }^{22}$. Volviendo al juicio predicativo, hay que tener en cuenta que éste tiene por objeto un 'estado de cosas'

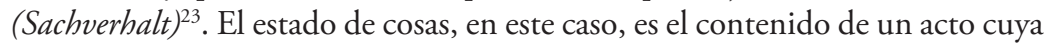
cualidad es la de un juicio. En la expresión lingüística de este acto de juzgar, la oración apofántica, con la cual el acto de juzgar forma una unidad, podríamos, con justa razón, distinguir un elemento lingüístico que expresa la cualidad del acto de juzgar y otro que expresa el contenido del juicio, en correspondencia con lo que en la filosofía analítica usualmente se denominan 'fuerza asertiva' y 'contenido proposicional' respectivamente. Otro tanto se podría hacer con las restantes oraciones. Se debe tener siempre en cuenta que actos intencionales con distinta cualidad pueden tener en común un mismo contenido, y por tanto, oraciones con diversas fuerzas, incluidas las apofánticas, pueden tener en común un mismo contenido proposicional ${ }^{24}$. Husserl, por tal razón, al englobar el acto de juzgar y su expresión, la oración apofántica, en el marco del tratamiento general de los actos intencionales, considera que el estado de cosas (Sachverhalt) juzgado o aseverado puede ser por igual contenido de otros actos con diferente cualidad, como por ejemplo, de una representación, de una pregunta, de un deseo, etc. Si bien la cualidad del acto es diferente en cada uno de ellos, el estado de cosas es el mismo en todos ellos, conforme a los ejemplos propuestos: "Tal vez hay en Marte seres inteligentes", como expresión de una representación; "Hay en Marte seres inteligentes, como expresión de un juicio; “¿Hay en Marte seres inteligentes?”, como expresión de una pregunta; “¡Ojalá haya en Marte seres inteligentes!”, como expresión de un deseo, etc. Todos ellos actos intencionales orientados al estado de cosas que hay en Marte seres inteligentes ${ }^{25}$. Y es aquí donde se presenta el problema. Desde la perspectiva señalada, no hay ninguna razón de prioridad de la oración apofántica respecto de las otras oraciones. Sólo puede señalarse la diferencia en lo que respecta a la cualidad de acto intencional que expresan, pero de ninguna manera una prioridad de la oración apofántica sobre las demás. Pero, según mi concepto, en Husserl hay algo más en su tratamiento del juicio y, por consiguiente, de la oración apofántica, que apuntaría a una solución en el sentido opuesto.

\footnotetext{
${ }^{22}$ Cf. LU V 20. Allí Husserl, al explicar y dar ejemplos de que actos intencionales de diferente 'cualidad' pueden tener un mismo 'contenido'; como, por ejemplo, la representación, el juicio, la pregunta, la duda, el deseo, etc.; respecto del estado de cosas de que haya seres inteligentes en Marte, dice: "De propósito formulamos en forma explícita las expresiones exactamente correspondientes. La igualdad del 'contenido' con diversa cualidad de acto encuentra su visible expresión gramatical, y la armonía de las fórmulas gramaticales puede indicar la dirección de nuestro análisis".

${ }^{23}$ La expresión Sachverhalt es traducida por García Morente de preferencia como 'situación objetiva', aunque en otros casos la traduce como 'situación de hecho'. Se la suele traducir por 'estado de cosas', en especial en las traducciones del Tractatus de Wittgenstein. La expresión 'estado de cosas' pretende dar cuenta de la etimología de la palabra Sachverhalt, más que al significado mismo. Si bien me parece que una traducción con más sentido podría ser simplemente 'hecho' adoptaré aquí la expresión 'estado de cosas' sólo por ser la más usual en las traducciones.

${ }^{24}$ Esta terminología, si bien es usual en la filosofía del análisis del lenguaje, puede venir en ayuda aquí, dado que Husserl no utiliza una terminología específica al referirse a los elementos de la expresión lingüística. En el caso de la oración apofántica como expresión del juicio predicativo Husserl distingue entre 'sujeto' y 'predicado', pero como elementos de la expresión del contenido.

${ }^{25}$ Cf. LU V 20. Nótese que en el caso de los ejemplos dados por Husserl en este pasaje se trata de expresiones lingüísticas, a las que acude Husserl en forma expresa, para apoyar su análisis fenomenológico.
} 
Antes que nada, hay que señalar que tiene presente en forma expresa el problema de la prioridad de la oración apofántica sobre las restantes oraciones, al menos como problema 'difícil e importante', según su propio parecer, frente, justamente, al planteamiento de los lógicos, desde Aristóteles. El problema se le presenta en los términos siguientes: si acaso las expresiones de deseos, preguntas, voliciones, etc., son de alguna manera enunciados sobre esos actos respectivamente. De ser así, todos los actos de esa índole serían reductibles a juicios ${ }^{26}$. Según Husserl, Bolzano, opuestamente a Aristóteles, respondería positivamente a esta cuestión. La posición de éste sería que una pregunta, o un deseo acerca de un estado de cosas, no enuncia nada acerca del estado de cosas mismo, sin embargo, enuncia la actitud mental respecto del estado de cosas acerca del cual se pregunta o se desea. De ese modo, una pregunta o un deseo podrían considerarse también verdaderos o falsos como los enunciados apofánticos. Husserl rechaza tal planteamiento, pues, según su parecer, se estaría confundiendo dos asuntos diferentes, a saber, el de la rectitud con el de la verdad o falsedad de una expresión lingüística ${ }^{27}$. Según lo visto, pareciera que la cuestión de la prioridad se reduce a poder determinar si las oraciones noapofánticas son reductibles de algún modo a las apofánticas. Sin embargo hay elementos en Husserl que nos llevan a plantear de otra manera el problema de la prioridad de las oraciones apofánticas sobre las restantes oraciones, como pasaremos a ver.

Se podría pensar que la prioridad se daría por vía de fundamentación de un acto sobre otro, como pareciera plantearse en Frege. En este autor el juicio aparece fundándose en un acto de interrogación. Según su planteamiento, el juicio consiste en el reconocimiento del valor de verdad de un contenido ('pensamiento') que se ha aprehendido previamente. Por su manera de ver las cosas / SEGÚN SU CONSIDERACIÓN, con anterioridad al juicio sobre un estado de cosas se daría la interrogación acerca del estado de cosas que se juzga, siendo el juicio posterior a ella, a la interrogación ${ }^{28}$. Pero por vía de la fundamentación de un acto en otro, está claro, entonces, que para Frege la aserción no tiene prioridad sobre la interrogación, al menos, sino ésta sobre aquella. ¿Qué ocurre con Husserl? Éste, por su parte, considera que un acto de una cualidad determinada puede ser fundamento de actos de cualidades diferentes. Así por ejemplo, el juicio acerca del estado de cosas de que la lluvia ha llegado puede fundar un acto de alegría por el mismo estado de cosas, como también una duda, un deseo, etc. Pero esto no significa que el juicio sea necesariamente fundamento de los otros tipos de acto, pues la fundamentación puede ser en sentido inverso, esto es, un deseo, o una pregunta, pueden ser a su vez

\footnotetext{
${ }^{26}$ LU VI 68: Refiriéndose a la cuestión "controvertida -de poca apariencia, pero bien mirada, tan difícil como importante", dice: "La capciosidad de la cuestión revélase en que los lógicos más significados, desde Aristóteles, no han podido ponerse de acuerdo sobre la solución”.

${ }^{27}$ Ibid.

${ }^{28}$ Según Frege, en su artículo "Der Gedanke" ("El pensamiento”) 62, el juzgar consiste en el reconocimiento de la verdad de un pensamiento, que es aprehendido previamente, lo que ocurre en el preguntar: "Al formar una pregunta hemos realizado el primer acto".
} 
fundamentos de un juicio ${ }^{29}$. En tal sentido, pues, por vía de fundamentación de un acto sobre otro, no se daría una prioridad del enunciado sobre las otras oraciones, según el planteamiento de Husserl. Pero hay algo más. Según Husserl, el contenido o estado de cosas de un juicio, no sólo puede ser objeto de actos intencionales de otro tipo, como deseo, duda, interrogación, etc., según vimos, sino que además puede ser puesto como nombre-sujeto de otra oración enunciativa. Por ejemplo, el estado de cosas del juicio: "La lluvia ha llegado" puede ser puesto como nombre-sujeto del juicio: "Que la lluvia ha llegado alegra a los campesinos". En este caso se muestra que un estado de cosas, aparte de poder ser juzgado, puede también ser nombrado. Pero no es lo mismo nombrar un estado de cosas que juzgarlo. ¿En qué radica la diferencia? De modo de establecer la diferencia entre nombrar y juzgar un estado de cosas, Husserl plantea que en el caso del nombrarlo, el estado de cosas se hace presente como un objeto constituido en la conciencia en su unidad compleja, pero que en el caso de juzgarlo, se le constituye como una unidad a partir de unidades objetivas más elementales, que corresponderían a los objetos correspondientes al nombre y al predicado. En el caso del juicio: "La lluvia ha llegado", los objetos constituyentes del estado de cosas serían la lluvia y el llegar. Husserl pasa, por eso, a explicar el acto de juzgar al modo de Aristóteles, esto es, como un acto bimembre de 'composición' o 'síntesis' ${ }^{30}$. El punto clave es que aquí Husserl habla de la constitución de la conciencia intencional del estado cosas, y sostiene que ésta se da 'originariamente' en el acto de juzgar del juicio predicativo simple ${ }^{31}$. Y es lo que nos induce a sostener que para Husserl hay una

\footnotetext{
${ }^{29}$ LU V 18: "Los juicios pueden fundar también presunciones, dudas, preguntas, deseos, actos de voluntad, etc.; y a la inversa, pueden aparecer como fundamentaciones actos de estas últimas clases".

${ }^{30}$ Sobre este punto me he referido en forma más detenida en mis artículos: "La doctrina aristotélica del juicio en la perspectiva de las Investigaciones lógicas de Husserl y Frege”. En Hypnos (Sao Paulo), No 7 (2001), pp. 107; reproducido también en Argumentaciones I, Akten der Tagung "Zur Geschichte der Urteilslehre" (Münster-Hamburg-London), 2003, pp. 239-249; y en "El juicio predicativo simple en Frege y Husserl: una confrontación", en Anuario Filosófico (Pamplona - España) XXXVII/1 (2004), pp.129-155; reproducido también en "Das einfache prädikative Urteil bei Frege und Husserl: eine Konfrontation”. En Existencia. An International Journal of Philosophy. Szeged - Budapest - Münster - Frankfurt a. Main, vol XIV 1-2, 2004, pp. 45 - 63. Cf. LU V 36: Aludiendo al ejemplo de la afirmación: "La lluvia ha llegado", dice: "En el simple enunciado juzgamos sobre la lluvia y su llegada; ambas cosas son para nosotros objetivas en el sentido estricto de la palabra, están representadas. Pero no llevamos a cabo una mera serie de representaciones, sino un juicio, una peculiar unidad de la conciencia, que enlaza las representaciones. $\mathrm{Y}$ en este enlace se constituye para nosotros la conciencia de la situación objetiva [del estado de cosas]. Es una misma cosa llevar a cabo el juicio y adquirir 'conciencia' de una situación objetiva [de un estado de cosas] en este modo 'sintético' que pone algo 'con respecto de algo'. Se lleva a cabo una tesis y con referencia a ella una segunda tesis dependiente; de tal suerte que en la fundamentación de una de estas tesis sobre la otra tiene lugar la constitución intencional de la unidad sintética de la situación de hecho [del estado de cosas]". (Nótese la resonancia del texto de De interpretatione en este pasaje). Es en este punto en el cual Husserl se separa de Frege, dado que para éste el estado de cosas que constituye el sentido del juicio (pensamiento) se da previamente en forma extramental, no pudiendo sostenerse por ende que el juicio predicativo consista en una suerte de composición, como puede verse en forma expresa en su Investigación lógica: "La negación".

${ }^{31}$ Cf. Logische Untersuchungen, V 36. Respecto de la razón de la posibilidad de nombrar un estado de cosas que ha sido objeto de un juicio, Husserl dice: "Por tanto, la conciencia de esta situación (Sachverhalt) se adquiere 'originariamente' en el juicio; la intención que se dirige a ella en un solo rayo [en el nombre] supone la plurirradial y alude en su propio sentido a ella. Ahora bien, a priori en todo modo plurirradial de conciencia fúndase la posibilidad (como posibilidad esencial 'ideal') de convertirse en la unirradial, en que la situación de hecho [estado de cosas] es 'representada' u 'objetiva' en sentido estricto".
} 
prioridad de la oración apofántica respecto de las otras oraciones. Es cierto que lo dicho hasta aquí sólo sostiene que la conciencia del estado de cosas en el juicio predicativo simple tiene prioridad sobre otros juicios que se fundan en un estado de cosas como objeto constituido, como es el caso de un juicio nuevo que tiene como nombre-sujeto el estado de cosas que ha sido contenido de un juicio predicativo simple enunciado con anterioridad. Lo mismo ocurre respecto de los juicios complejos, como el juicio condicional, que enlaza dos estados de cosas ya constituidos. Pero Husserl insiste también en otra obra sobre la preconstitución del estado de cosas como tal en el juicio predicativo simple. En el juicio predicativo, sostiene en su obra Experiencia y juicio, se preconstituye sin más el estado de cosas como objetividad categorial $^{32}$. De ser así, el juicio predicativo tendría aprioridad no sólo sobre los juicios que tienen como nombre un estado de cosas o los juicios complejos que enlazan diferentes estados de cosas, sino sobre todo otro acto intencional cuyo objeto sea un estado de cosas. Y de este modo la oración apofántica tendría prioridad sobre las oraciones no-apofánticas.

El asunto, empero, no es tan simple. La cuestión ahora es en qué sentido se da esta prioridad. No puede querer decir que, por ejemplo, antes que se establezca una pregunta, haya que formar un juicio sobre lo que se pregunta; pues en tal caso no tendría sentido la pregunta misma, pues ya se tiene la respuesta. Otro tanto vale para el caso de un deseo, por ejemplo, pues si se juzga que se posee lo que se desea, no tiene sentido desearlo. Mi interpretación, que da sentido a lo planteado por Husserl, es la siguiente: el estado de cosas que es objeto de un acto, como objetividad que se hace presente en la conciencia intencional, debe tener sentido, esto es, debe ser plausible; de lo contrario el acto no tendría sentido y sería absurdo. Pero la conciencia de la plausibilidad de los estados de cosas sólo se puede dar en la medida en que parece tener sentido establecer un juicio sobre ellos. En mi concepto, a esto apunta el planteamiento de Husserl. Sobre esto espero ahondar en un trabajo futuro.

${ }^{32}$ Cf. Erfahrung und Urteil (Experiencia y juicio), Segunda parte, II 58. 


\title{
Las Palabras son Transparentes
}

\author{
Patricia Moya C. \\ Universidad de los Andes
}

\begin{abstract}
Resumen
El artículo trata la concepción que Husserl tiene del lenguaje dentro del marco de la Primera Investigación Lógica, a través de la interpretación que en dos artículos hace R. Sokolowski. Busca mantener un equilibrio entre el carácter ideal del significado expresado en el lenguaje y la necesaria referencia a la realidad, entendida en un sentido amplio. El análisis de Sokolowski destaca la comprensión de Husserl del lenguaje ligada a la evidencia de la comunicación humana, como parte integrante del ser de la persona.
\end{abstract}

El psicologismo que Husserl critica de manera permanente en su obra a partir de las Investigaciones Lógicas, no ha desaparecido del horizonte filosófico, más bien muestra su plena vigencia en las formas del mentalismo y del representacionismo que laten en muchas de las teorías contemporáneas del conocimiento y del lenguaje. Como la hidra de Lerna que Heracles debía vencer, con sus siete cabezas que se reproducían al ser cortadas, el psicologismo parece resurgir con más fuerza cada vez que se le asestan golpes intentando eliminarlo. Si se le ataca quitando los contenidos mentales, reaparece en los hechos de conciencia; si se rechaza cualquier elemento ideal, se da paso al pragmatismo; y así resulta difícil eludir esta especie de sombra que se cierne sobre las explicaciones filosóficas de nuestra relación con el mundo y su expresión a través de las palabras.

También la filosofía del lenguaje de Husserl puede ser entendida desde una perspectiva mentalista especialmente por su explicación de la idealidad como un elemento indispensable en la comprensión del lenguaje. ¿Hay efectivamente una entificación de lo ideal en Husserl? ¿Cómo entender esta idealidad? ${ }^{1}$

Este trabajo sigue el análisis de Husserl en su primera Investigación Lógica junto con los comentarios de Robert Sokolowski en dos artículos: "Semiotics in Husserl's Logical Investigations", y "Exorcising Concepts"2. El conocido estudioso de Husserl refuta el mentalismo en una explicación del lenguaje que sortea hábilmente los obstáculos que provienen fundamentalmente del olvido del mundo de la vida. La tesis central de Sokolowski es que el lenguaje tiene su explicación en la capacidad humana de hacer presentes las cosas ausentes.

\footnotetext{
${ }^{1}$ Una interpretación de corte mentalista aparece en Simons, Peter, "Meaning and language" en Cambridge Companion to Husserl, Cambridge: Cambridge University Press, 1996, pp. 106-137.

2 Publicado, el primero, en Sabih, D. and Stjenfelt, F. eds. One Hundred Years of Phenomenology. Nether lands: Kluwer Academia Publishers, 2002, pp. 171-173. El segundo fue publicado por primera vez en The Review of Metaphysics, vol. 40 (1987), pp. 451-63. Más tarde apareció en Sokolowski, Robert. Pictures, Quotations, and Distinctions. Notre Dame and London: University of Notre Dame Press, 1992, pp. 173-185.
} 
1. Sokolowski propone dar una descripción filosófica de las palabras que no nos fuerce a suponer las ideas o conceptos como entidades mentales. Su descripción incluye cuatro elementos: 1) el hablante; 2) el sonido, que es la dimensión fonética de la palabra; 3) la cosa que es nombrada o a la que se refiere el hablante al usar la palabra; 4) alguien que escuche y entienda la palabra.

Es necesario admitir estos cuatro elementos, contra quienes sostienen que bastan los dos primeros para que sea posible la palabra. Para éstos serían suficientemente explicativos de la palabra el hablante y la dimensión fonética. La dificultad de esta afirmación es que estos dos elementos sólo pueden dar cuenta de la palabra si se supone la presencia del concepto entendido como entidad mental. Esta es la clásica explicación que, simplificándola, dice que cuando la palabra es pronunciada o imaginada, se activa el concepto en la mente del hablante. Por esta razón, tanto la cosa acerca de la que se habla como el interlocutor u oyente, pueden estar ausentes o, simplemente, no existir. En palabras de Saussure: 'L'entité linguistique n'existe que par l'association du signifiant et du signifié; dès qu'on ne retient qu'un de ces élements, elle s'évanouit" ("La entidad lingüística no existe sino por la asociación del significante y de lo significado; desde el momento que no se retiene más que uno de estos elementos, ella desaparece") ${ }^{3}$. La asociación a que se refiere Saussure exige la previa existencia mental del concepto que hace que al pronunciarse la palabra y producirse el sonido se dé el significado, todo esto al mismo tiempo. Esta explicación es la que Sokolowski quiere destruir, eliminando directamente el concepto entendido como entidad mental.

En expresión de Sokolowski, el concepto así entendido es una ilusión trascendental.

Normalmente una ilusión o engaño se debe a un enfoque inadecuado para comprender un asunto. En el caso de la explicación del significado de las palabras por una asociación mental, el punto de vista equivocado está en tratar de hablar y explicar las palabras y los pensamientos y no contentarnos con hablar de los objetos o cosas a las que se refieren las palabras y pensamientos. Si en el análisis del lenguaje enfocamos nuestra atención a la comunicación misma, es más probable que superemos esta ilusión trascendental.

2. Antes de continuar con la propuesta de Sokolowski se explica, muy esquemáticamente, los aspectos más relevantes de lo que podríamos llamar la filosofía del lenguaje de Husserl, tal como la presenta en la Primera Investigación Lógica.

Como es sabido, el análisis de Husserl acerca del lenguaje, comienza con la distinción entre las señales o indicaciones y los signos. Esta distinción esencial -como la llama- le permite precisar que la palabra, en cuanto expresión, es

\footnotetext{
${ }^{3}$ Saussure, Ferdinand de. Cours de Linguistique Générale. Paris: Payot, 1969, Chapitre II, §1.
} 
un signo. Como tal, tiene una función comunicativa que se realiza a través de la parte física o material del signo, el sonido y la parte formal, es decir, las vivencias psíquicas que la hacen ser expresión de algo. Para comprender la diferencia de esta explicación con las de corte psicologista, como la ya mencionada de Saussure, conviene tener en cuenta que el aspecto formal o las vivencias psíquicas, tienen en Husserl un sentido totalmente diferente a un episodio psicológico. Se refiere con el término "vivencias" a los actos constitutivos, por eso formales, del sujeto al otorgar intencionalidad a la palabra. Esto significa que la comunicación establece un comercio "espiritual" entre el hablante y el oyente $^{4}$. El término "espiritual" empleado por Husserl, quiere decir que hay algo más en este intercambio que la mera notificación entre los que se comunican de que uno habla y el otro percibe el sonido.

La palabra es una señal de que se comunican pensamientos. Hay una percepción interna, por parte del oyente, de las vivencias psíquicas del hablante, porque el oyente logra también vivirlas como propias ${ }^{5}$. Vivir la comprensión de la palabra es el fenómeno propio del lenguaje, que se da tanto en la comunicación, como en el caso del monólogo ${ }^{6}$.

Esta comprensión de la palabra supone que la expresión no es sólo una voz que nombra algo, sino que es una referencia cumplida de la expresión a su objetividad. Es decir, que la intención significativa del parlante se cumple en la referencia consciente del nombre a lo nombrado. Integrando los elementos de la descripción filosófica de las palabras de Sokolowski, se puede ver que aquí aparecen los elementos tres y cuatro. La palabra comunica, porque hay alguien que escucha y entiende la palabra, porque existe una cosa que es nombrada por la palabra. Esto es posible, porque "el sonido verbal es primeramente uno con la intención significativa; y ésta, a su vez, se une (...) al correspondiente cumplimiento significativo"”.

Se da lo que Husserl llama la expresión animada de sentido o expresión plena, porque se realiza una identificación entre la intención y el objeto que le ha dado cumplimiento ${ }^{8}$. La diferencia entre la voz que nombra algo y la palabra que expresa algo, es que en este último caso, no fijamos nuestra atención en la voz, sino en lo que la voz nombra, en el objeto, sea éste una cosa o un estado de cosas. La expresión es posible por la identificación ya señalada, entre intención y objeto, que permite que intencionemos las cosas que son mentadas al proferir las palabras y no las palabras mismas. "Dicho de un modo puramente fenomenológico, esto no significa sino que la representación intuitiva, en la cual se constituye el fenómeno verbal físico, experimenta una modificación fenoménica esencial, cuando su objeto asume la validez de una expresión".

\footnotetext{
${ }^{4}$ Cfr. Husserl, E. Investigaciones lógicas. Madrid: Revista de Occidente, 1929. Traducción de Morente, M.G. y Gaos, J. Primera Investigación Lógica, §7. Todas las citaciones, si no se indica otra cosa, de se refieren a esta investigación.

${ }^{5}$ Cfr. Husserl, E. Investigaciones lógicas, §7.

${ }^{6} \mathrm{Cfr}$. idem, $\S 8$.

${ }^{7}$ Idem. Investigaciones lógicas, $\$ 9$.

${ }^{8}$ Cfr. idem.

${ }^{9}$ Idem, $\$ 10$.
} 
¿Cómo se ha dado este cambio en el que la expresión 'usa' la palabra, pero se 'dirige' al objeto? El cambio no se da en el sujeto, sino en la perspectiva que éste asume cuando pasa de la mera notificación a la vivencia, es decir, cuando se da el acto constitutivo. Al considerar la expresión como portadora de sentido, la atención transita de la palabra a la cosa, la palabra deja ver la cosa. Dicho de otra manera, la expresión tiene sentido porque significa algo. Esto no quiere decir que se produzca una asociación con un concepto de la mente, sino que el sujeto cognoscente, que es parlante, se abre a una idealidad. Hay en la expresión, y por lo tanto en la palabra, el reconocimiento o la representación de una mismidad, de un quid idéntico y por eso siempre válido, aun en contextos particulares, que es lo que la hace ser significativa.

La significación idéntica -que es lo que Husserl llama idealidad- responde al juicio cierto de la validez objetiva de una situación que es, a su vez, objetiva, es decir, independiente de nuestro juicio, pero que se nos ha manifestado, se nos ha dado, y según esa manifestación la formulamos. Hemos dicho: "así es". Para que sea posible el juicio ha sido necesaria la manifestación de la situación que se juzga. Pero lo que ahora interesa no es el juzgar (que es un hecho psicológico correspondiente a la notificación de la situación), sino aquello sobre lo que se realiza el juicio, esto es el contenido. El juicio como hecho psicológico nace y muere, pero el enunciado del juicio es invariable en su contenido; éste no nace ni muere ${ }^{10}$.

En este punto del análisis se ha incorporado el conocimiento que, aunque todavía en esta Primera Investigación no ha sido totalmente explicitado, marca una diferencia crucial con la comprensión física de la palabra. El comercio "espiritual" es en realidad un comercio cognoscitivo y por eso no es satisfactoria la explicación del lenguaje por la capacidad de asociación que no repara en el hecho, evidente para el que comunica, que se comunica algo conocido ${ }^{11}$. Es justamente la omisión de la evidencia del conocimiento la que obliga al psicologista a poner como referente necesario de la palabra al concepto como entidad mental con que la palabra se asocia.

Hasta aquí este breve resumen de las ideas centrales que expone Husserl acerca del lenguaje en la Primera Investigación. Volvemos al análisis de Sokolowski.

3. La primera advertencia relevante que realiza Sokolowski es la de la exterioridad del signo expresivo en Husserl. Explica que se llega a la comprensión de la expresión a partir del hecho comunicativo en el que el parlante y el oyente se entienden y no por un análisis introspectivo de la conciencia o de la mente en el que se suponga ya una estructura psicológica que dé la clave de la comunicación. Hace notar que Husserl nunca trata el signo expresivo como resultado de la conexión con una entidad mental previa al fenómeno o al hecho de la

\footnotetext{
${ }^{10}$ Cfr. Husserl, E. Investigaciones lógicas, $\$ 11$.

${ }^{11}$ Cfr. Aristóteles. Peri hermeneias, 16a 5-8. Este famoso texto advierte la presencia del conocimiento en el origen del lenguaje.
} 
comunicación. La palabra se manifiesta en su exterioridad de signo, aunque se precisa para comprenderlo la presencia del pensamiento que satura la materialidad del signo, le permite adquirir su dimensión expresiva.

La terminología husserliana puede prestarse a equívocos si no se tienen en cuenta estas dos advertencias de Sokolowski por las cuales se comprende que en Husserl el término "pensamiento" no significa un proceso mental, sino la presencia de actos constitutivos de la objetualidad realizados por un sujeto cognoscente que son los que permiten entender la dimensión expresiva de la palabra que siempre se refieren a un objeto que se hace presente. Este es el sentido del término "saturar" que utiliza Husserl.

El ejemplo del arabesco -que aparece en la Quinta Investigación ${ }^{12}$ - sirve para explicar esta idea. Primeramente nos hallamos ante algo físico, unas formas grabadas y, en un segundo momento, cuando somos capaces de interpretarlo, esas formas se convierten en un texto que nos comunica. Esta nueva manera de intencionar las formas físicas es posible porque la materialidad de las marcas se ha saturado de pensamiento; ya no sólo percibimos el arabesco, sino que también lo leemos, interpretamos las marcas como diciéndonos algo.

Esta nueva intención, por la que somos capaces de entender y de leer unas marcas, traspasa las fronteras de lo actualmente presente, en cuanto meramente físico, llevándonos a una intencionalidad significativa, diferente de la intencionalidad perceptiva, haciendo presente de una manera nueva la cosa, en este caso, el arabesco.

El signo expresivo se manifiesta en su materialidad, aunque la comprensión requiera de la intencionalidad significativa. Este aspecto, relevante para Sokolowski, se une con otra dimensión también exterior del signo expresivo. Él quiere enfatizar este aspecto exterior - no mentalista- con el que Husserl aborda el tema del lenguaje. Así como el signo expresivo se manifiesta física o materialmente, también se reconoce la presencia del pensamiento y con ella el cambio de intencionalidad por la experiencia, que se podría llamar fáctica, de nuestro hacer en el mundo. Antes veíamos el arabesco e incluso podíamos alabar la belleza de sus formas; ahora entendemos lo que dice y nos conectamos con un cierto interlocutor que, a través del tiempo, nos habla. La experiencia de la comunicación a través del lenguaje responde a la estructura básica con la que Husserl entiende la relación del sujeto con el objeto, como se explica a continuación.

El significado que contiene en sí la proposición y por el que nos comprendemos en el lenguaje se reconoce por lo que estas intencionalidades nos permiten hacer, no por sí mismas. No podemos de antemano distinguir el arabesco

${ }^{12}$ Cfr. Investigaciones lógicas. Quinta Investigación, §14. 
como marca y como texto. Lo hacemos al reparar en el tipo de relación que se establece entre la intención significativa y el objeto y al contrastarlas entre sí.

El cambio de intencionalidad es el resultado de un acto significante o significativo por el que se tiene el significado y, con él, la referencia. El origen del significado está en la estrecha relación que se da entre la actividad significativa y el objeto, tal como se ha explicado antes siguiendo el análisis de Husserl. La palabra adquiere un sentido significativo en la medida que hace presente al objeto o al estado de cosas que expresa por el sonido o la grafía. Si la experiencia nos dice que al oír o leer una proposición, la entendemos y somos capaces de representar su contenido, esta experiencia se explica porque la expresión es significativa, no porque haya despertado en nosotros un fenómeno asociativo con respecto a imágenes o conceptos, sino porque el sonido o lectura de esas palabras es de suyo significativo; la proposición contiene en sí un significado, un contenido que somos capaces de comprender y, por eso, de representar. De alguna manera, la explicación husserliana se constata en la evidencia diaria de la comunicación: "La comprensión de la notificación no es un saber conceptual de la notificación; no es un juzgar de la misma especie que el enunciar; sino que consiste tan sólo en que el oyente aprehende (apercibe) o simplemente percibe al que habla y lo percibe intuitivamente como una persona que expresa esto o aquello" ${ }^{13}$.

Es sinónimo de "significado" lo que Husserl llama el contenido de los actos de dar sentido ${ }^{14}$, que no están dados previamente en la conciencia, como lo están los "significados" del psicologista, ni es estrictamente el objeto entendido fuera de esta relación significativa, como podría postular una concepción sensitiva "ingenua", sino que se entienden de una triple manera: (1) como significado; (2) como objeto y (3) como realización del sentido, es decir, como la vivencia de esa unidad de coincidencia entre el contenido impletivo (el objeto) y el intencional (el acto de significar). De esta manera, el objeto de intención está siendo a la vez 'dado' en su existencia física o material, y 'se tiene ante nosotros' como objeto, de una manera única, no como duplicado, en la vivencia de la unidad. La significación se entiende como una actividad del sujeto y, a la vez, como la posibilidad del objeto de ser expresado ${ }^{15}$.

Con palabras de Husserl: "Así como al comprender idealmente la esencia intencional del acto de dar significación obtenemos la significación intencional como idea, así también al aprehender idealmente la esencia correlativa del acto de cumplir la significación obtenemos también la significación impletiva, también como idea. Es ésta, en la percepción, el contenido idéntico perteneciente a la totalidad de los actos de percepción que mientan el mismo objeto (y lo mientan realmente como el mismo) en modo perceptivo.

\footnotetext{
${ }^{13}$ Husserl, E. Investigaciones lógicas, $\$ 7$.

${ }^{14}$ Cfr. idem, $\$ 12$.

${ }^{15}$ Cfr. Schérer, R. La fenomenología de las “Investigaciones Lógicas” de Husserl, Madrid: Gredos, 1969, pp. 160-1.
} 
Este contenido es, pues, el correlato ideal del propio uno, el cual por lo demás puede muy bien ser ficticio"16.

4. Recordemos que Sokolowski llama ilusión trascendental al fruto de un equivocado punto de vista en la comprensión de las palabras. Este se puede corregir si entendemos el significado de las palabras desde la posibilidad de presentar, por parte del parlante, y de ser presentado, por parte de la cosa. A este punto de vista es al que se refiere al decir que una idea es una cosa presentada o entendida ${ }^{17}$. Para evitar que el tema del significado se identifique con la existencia de cualidades mentales, es necesario acertar con el punto de vista adecuado y éste es el considerar la cosa como presentada por alguien a alguien. Desde esta perspectiva, la idea de la cosa no es algo mental, ni tampoco una entidad extramental. Es sencillamente la cosa.

El sonido es el vehículo por el cual la cosa es presentada; el sonido o la grafía es la cosa considerada como haciéndose presente por el que los emite: es la intencionalidad significativa. El significado del sonido o grafía es también la cosa, pero considerada como presentada por el hablante al oyente. Se da este comercio entre el parlante y el oyente en el que las palabras parecen poseer algo así como el "alma" de las cosas, porque dirigen la atención a la posibilidad que tienen las cosas de ser presentadas ellas mismas, o de ser ellas mismas en sus muchas maneras de ser experimentadas o entendidas. La idea antigua, señala Sokolowski, de que a través de las palabras se da a conocer "el alma" de las cosas, recoge la experiencia de la presencia de las cosas en el lenguaje.

Es útil en este punto volver a la diferencia entre una señal y una palabra. La seńal de la carretera hace pensar en una cosa, por ejemplo, en la ciudad de Viña del Mar que dista 80 kilómetros del punto en el que se encuentra una persona, pero no hace presente esa ciudad. Para la señal cabe de alguna manera el modelo asociativo, porque la señal en sí misma no tiene significado. Es indicativa de algo, pero no existe en ella una dimensión ideal a la que yo tenga que atender o que tenga que entender de manera explícita ${ }^{18}$. Las

\footnotetext{
${ }^{16}$ Husserl, Investigaciones lógicas, §14. Refiriéndose a la diferencia descriptiva entre el fenómeno físico del signo y su intención significativa, Husserl explica: “La palabra (como individuo externo) sigue siéndonos dada intuitivamente, sigue apareciéndosenos; pero ya no nos dirigimos hacia ella, ya que no es ella propiamente el objeto de nuestra "actuación psíquica". Nuestro interés, nuestra intención, nuestra mención -que en amplitud adecuada de expresiones de igual significado- se dirige exclusivamente a las cosas mentadas en el acto de dar sentido" $(\$ 10)$

${ }^{17}$ Cfr. Sokolowski, R., especialmente el artículo "Exorcising Concepts".

18 "En sentido propio sólo puede llamarse signo indicativo a algo, cuando este algo sirve efectivamente de señal de algo, para un ser pensante. $\mathrm{Si}$, pues, queremos aprehender lo común a todos, debemos retroceder a esos casos de la función viviente. Y encontramos que ese quid común es la circunstancia de que ciertos objetos o situaciones objetivas, de cuya existencia alguien tiene conocimiento actual, indican a ese alguien la existencia de ciertos otros objetos o situaciones objetivas -en el sentido de que la convicción de que los primeros existen, es vivida por dicho alguien como motivo (motivo no basado en la intelección) para la convicción o presunción de que también los segundos existen-. La motivación establece una unidad descriptiva entre los actos de juicio, en que se constituyen para el pensante las situaciones objetivas indicadoras e indicadas -unidad descriptiva que no debe concebirse como, verbigracia, una "cualidad de figura", fundada en los actos de juicio y, por tanto, en su totalidad, tiene un correlato aparente, una situación objetiva unitaria, que en ella parece existir y que en ella está mentada. Es claro que esta situación objetiva no dice otra cosa sino esto: que unas cosas pueden o deben existir, porque otras cosas son dadas" (§2).
} 
palabras, en cambio, sí tienen esta dimensión presentativa o presentacional, porque concitan tanto la iniciativa presentacional del hablante como el logro o cumplimiento de esta iniciativa. Sucede que para el que escucha la cosa se hace presente por la palabra del parlante: por su significado. La cosa no está presente por su ser físico, sino por la palabra ${ }^{19}$.

En la señal no hay tal presencia de la cosa, porque, repito, no hay significado. Hay una indicación de la cosa, pero no se nos dice qué es la cosa. Según Sokolowski, a la cosa se le incorpora el significado, al expresarla como palabra, es decir, como signo. Es ahí cuando sabemos qué debe ser dicho de la cosa porque la palabra no sólo nos da el nombre de la cosa y nos dirige a ella, sino que ese nombre expresa algo propio de la cosa. En cambio la señal, nos dirige hacia la cosa, nos hace pensar en ella, pero no nos dice qué debe ser dicho de la cosa, porque no nos da su significado ${ }^{20}$. La cosa y el nombre, tomado en cuanto palabra o significado, pertenecen el uno al otro en un sentido en el cual la cosa y su señal no pertenecen el uno al otro. No se puede separar el nombre de Viña del Mar de esa ciudad, en cambio sí se puede sustituir su nombre por otra ciudad en el cartel y permanece en él su carácter indicativo ${ }^{21}$.

A los cuatro elementos iniciales que describen filosóficamente la palabra, Sokolowski les añade ciertas precisiones. Se mantienen la cosa y el sonido. Se agregan el hablante y sus ejecuciones, el oyente y sus ejecuciones, porque ahora destaca la capacidad que tenemos para considerar un objeto como presentado por alguien a alguien, es decir, la capacidad lingüística de la persona.

Esta dimensión del ser humano nos abre a una nueva perspectiva, a un nuevo punto de vista, para considerar las cosas. No tenemos sólo cosas, sino cosas consideradas como presentadas por alguien para alguien. Es en este dominio del significado en el que se desarrolla la vida de la persona. Incluso cuando hablamos con nosotros mismos, se introduce esta perspectiva de cómo las cosas son presentables a nosotros mismos. En todo monólogo hay una conver-

\footnotetext{
${ }^{19} \mathrm{Al}$ explicar las distinciones fenomenológicas e intencionales que pertenecen a las expresiones como tales, Husserl distingue la expresión en su parte física y "cierto conjunto de vivencias psíquicas, que, enlazado por asociación a la expresión, convierte a ésta en expresión de algo". Esta vivencia generalmente se llama sentido o significado (cfr. §6). Explicando más este punto en el parágrafo siguiente dice: "El signo gráfico escrito se torna palabra hablada, discurso comunicativo, merced a que el que habla lo produce con el propósito de "manifestarse acerca de algo", o - dicho con otras palabras - merced a que el que habla le presta en ciertos actos psíquicos un sentido, que quiere comunicar al que escucha. Ahora bien, esta comunicación se hace posible, porque el que escucha comprende la intención del que habla. Y la comprende en cuanto que concibe al que habla no como una persona que emite meros sonidos, sino como una persona que le habla, que ejecuta, pues con las voces ciertos actos de prestar sentido - actos que esa persona quiere notificarle o cuyo sentido quiere comunicarle-. Lo que hace posible ante todo el comercio espiritual y caracteriza como discurso el discurso que enlaza a dos personas, es esa correlación, establecida por la parte física del discurso, entre las vivencias físicas y psíquicas, mutuamente implicadas, que experimentan las personas en comercio respectivo. El hablar y el oír, el notificar vivencias psíquicas con la palabra y el tomar nota de las mismas en la audición, hállanse en coordinación mutua" (\$7).

${ }^{20}$ Husserl, E. Investigaciones lógicas. "En la señal queda por completo excluida la intelección y, objetivamente hablando, el conocimiento de un nexo ideal entre los contenidos de los juicios en cuestión" (\$3).

${ }^{21}$ Idem. "Esas nuestras manifestaciones "significan" algo para él, por cuanto que él las interpreta; pero ni para él mismo tienen significaciones en el sentido preciso de signos verbales y sí sólo en el sentido de señales indicativas" $(\$ 5)$.
} 
sación incipiente, dice Husserl, pero el monólogo no exige la presentación o notificación propia de la comunicación, porque en ese caso, los actos psíquicos son vividos por el propio sujeto que no requiere que alguien se los notifique ${ }^{22}$. En el monólogo, la presencia es inmediata a la vivencia psíquica, porque es la presencia de la propia vivencia.

Para comprender adecuadamente la palabra sin la necesidad de remitirla o asociarla a una entidad mental, es de una importancia capital la presentación del objeto en el lenguaje y en esta presentación distinguir dos aspectos: primero, que el objeto es presentado por alguien a alguien; segundo, que es presentado de una determinada manera.

$\mathrm{Si}$ atendemos ahora a este segundo aspecto, se puede afirmar que la manera determinada en la que se presenta el objeto no se debe a excentricidades del lenguaje, mecanismos mentales o posibilidades psico-lingüísticas. Se debe a la cosa misma. Es ella la que determina los caminos, las posibilidades en las cuales las cosas llegan a ser significativas. El ser de las cosas comprende el poder presentarse de unas determinadas maneras y no de otras. Y si esta posibilidad no es ajena a la cosa, el significado de las palabras no es algo que está en la mente como un concepto psicológico que se asocia al sonido o grafía, sino que está en la cosa. No es tampoco el sustituto de una cosa que no está delante del que escucha, porque en ese caso la palabra sería como una copia. El significado está en la cosa, insiste Sokolowski, y es una pequeña parte del mundo, una parte ausente, que es considerada como presente por el parlante para el oyente en el sonido que profiere.

Esto es posible porque el significado se da en el contexto de una conversación sobre algo existente o ficticio, que determina la manera en que lo hago presente en este contexto.

Justamente, porque se hace presente, la palabra es significativa en la conversación.

El modo de hacerse presente lo ficticio o aquellos significados que son exclusivamente ideales, es diferente al modo de presentarse en el lenguaje las cosas o los estados de cosas, pero también se las puede considerar como presentes o "traídas a la presencia" por parte del hablante y del oyente, porque también estos contenidos ideales tienen sentido ${ }^{23}$.

\footnotetext{
22 Husserl, E. Investigaciones lógicas, §8: "En cierto sentido hablamos, sin duda, también en el discurso solitario; y seguramente que es posible en este aprehenderse a sí mismo como uno que habla y aun eventualmente como uno que habla consigo mismo. Así sucede cuando alguien se dice a sí mismo: lo has hecho mal, no puedes seguir así, etc. Pero en estos casos no hablamos en sentido propio, en sentido comunicativo; no nos comunicamos nada, sino que nos limitamos a representarnos a nosotros mismos como personas que hablan y comunican. En el discurso fonológico las palabras no pueden servirnos para la función de señalar, notificar la existencia de actos psíquicos, pues semejante señal aquí sería inútil, ya que los tales actos son vividos por nosotros en el mismo momento".

${ }^{23}$ Agradezco al Profesor Roberto Walton la observación que me hizo respecto a este punto, que ciertamente merece una mayor profundización que no me es posible realizar en este trabajo.
} 
La experiencia del error muchas veces nos induce a considerar el concepto como algo mental, pensando el significado de nuestras afirmaciones como algo que está "dentro" de la mente y que no coincide con lo que hay "fuera" de la mente. La explicación psicologista del error se da en términos de una discordancia "dentro" - "fuera". Pero podemos encontrar una razón más plausible del error en nuestro conocimiento reparando en la presentabilidad que tienen las cosas. El error se da porque al presentar una parte del mundo puedo interpretar esa parte equivocadamente o sin su referencia a la totalidad, es decir, parcialmente. El error es una posibilidad que surge en esta apertura de la cosa a ser presentada, pero no se debe a una falta de correspondencia entre una afirmación, fruto de la mente, y la cosa tal como es. Lo que no está en el error es la presencia entendida en su aspecto fuerte, como significado. La cosa sigue ausente, porque no ha habido conocimiento, no se ha dado con el significado, y no se logra presentar el modo como esa cosa es ${ }^{24}$.

El ser parlantes es parte de nuestra naturaleza y no consiste en una emergencia de entidades mentales, sino en nuestra persistente habilidad de considerar lo que experimentamos como presentado por, o como presentable para alguien en la conversación.

Esta habilidad nos permite tratar con las cosas como poseedoras de significado o como posibles poseedoras de significado. Somos capaces de hablar y de entendernos entre nosotros, porque las cosas se nos muestran como presentables y no solamente porque somos capaces de aprender gramática. La gramática y las palabras se sitúan en este espacio abierto por esta nueva perspectiva con la que consideramos las cosas, su ser presentable, sin el cual la composición de las palabras sería sólo un juego.

Nosotros vivimos en esta realidad del lenguaje y en un mundo significativo. La ilusión trascendental de las palabras como entidades mentales es fruto de una descontextualización del significado que lo explica como un producto exclusivo de la mente.

\footnotetext{
${ }^{24}$ Lo mismo sucede con los contenidos exclusivamente ideales que tienen un significado y por eso pueden presentarse en ocasiones erróneamente.
} 


\title{
El Lenguaje en el Pensamiento de Merleau-Ponty
}

\author{
Jaime Aspiunza \\ Universidad del País Vasco
}

\begin{abstract}
"En cierto sentido, como dice Husserl, toda la filosofía consiste en restituir un poder de significar, un nacimiento del sentido o un sentido salvaje, una expresión de la experiencia por la experiencia que ilumina particularmente el campo especial del lenguaje. $Y$, en cierto sentido, como dice Valéry, el lenguaje lo es todo, puesto que no es la voz de nadie, es la voz misma de las cosas, de las aguas y los bosques. Y lo que hay que entender es que entre estas dos ideas no hay inversión dialéctica, no tenemos por qué reunirlas en una síntesis: son dos aspectos de la reversibilidad que es la verdad última».
\end{abstract}

Lo visible y lo invisible, 192/203-4

Hace mucho tiempo que se habla sobre la Tierra, y las tres cuartas partes de lo que se dice pasan inadvertidas». Así comienza el primer capítulo de La prosa del mundo. No se está refiriendo Merleau-Ponty a que no escuchemos, no; continúa: «Una rosa, llueve, hace un tiempo hermoso, el hombre es mortal. Para nosotros son éstos casos de expresión pura. Nos parece que ésta alcanza su cima cuando señala inequívocamente acontecimientos, estados de cosas, ideas o relaciones, [es decir,] cuando hace que nos deslicemos hacia el objeto que designa. [...] Expresar no es entonces sino reemplazar una percepción o una idea por una señal convenida que la anuncia, la evoca o la abrevia ${ }^{1}$.

Así es cómo se entiende normalmente, y se ha entendido durante mucho tiempo, el lenguaje: en cuanto «reflejo» del mundo, en cuanto doble del ser. Decimos «la pizarra es negra» y «vemos» cómo se corresponden las palabras y la realidad. $\mathrm{O}$, mejor dicho, ni siquiera miramos y vemos que se correspondan: si la expresión funciona, las palabras se borran a sí mismas, y nos dejan con las cosas. De ahí el ideal de transparencia del lenguaje: «puro signo para una pura significación $»^{2}$.

Tan es así que la verdad se define precisamente de ese modo, como correspondencia entre las palabras y las cosas — la realidad. Y, por eso mismo, en cuanto se nos complican un poco las frases y dejamos de decir obviedades parece que la verdad se esfuma y que el lenguaje no cumple su función.

\footnotetext{
${ }^{1}$ Merleau-Ponty, M. La prosa del mundo. Madrid: Taurus, 1971, p. 25.

${ }^{2}$ Ib., p. 30
} 
¿Qué hay detrás de tal concepción del lenguaje en cuanto reflejo de la realidad? Un dualismo -y no entro ahora a calificarlo- que separa, oponiéndolos, lenguaje y realidad, eso sí, al precio de dar por supuesta una homología entre ambos: realidad y lenguaje estarían en el fondo hechos de la misma materia, o, en cualquier caso, se entenderían de la misma forma: como entes. El problema, entonces, es que no hay modo de comprender cómo se pueda decir una verdad nueva, cómo se pueda escribir literatura o hacer filosofía que aspiren a ser verdad.

Lo visible y lo invisible, el texto póstumo, inacabado de Merleau-Ponty, pretende ser una superación del dualismo ontológico. Del tradicional pero también del propio, bien que éste no fuera pretendido. En Fenomenología de la percepción, por más que explícitamente se quisiera dar cuenta de nuestro ser de mundo, la percepción, no obstante, no dejaba de ser un acto de la conciencia, de manera que a la postre la polaridad conciencia mundo volvía a reproducirse. Aparece allí una concepción novedosa del lenguaje en cuanto gesto corporal que vendría a cantar el mundo, pero lo que quieren decir las palabras y las cosas es algo que vemos aparecer en la conciencia originaria ${ }^{3}$. Hay, pues, cierta ambigüedad. Y no es que queramos verla nosotros. El propio Merleau-Ponty, en un par de notas de trabajo de 1959, refiriéndose a la Fenomenología de la percepción, dice: "Los problemas que quedan después de esta primera descripción se explican porque he conservado en parte la filosofía de la "conciencia" ". . Y un poco más adelante remata: «[...] son insolubles porque mi punto de partida es la distinción "conciencia" — "objeto" "

Efectivamente, en la tercera parte de la Fenomenología de la percepción trata de captar el verdadero sentido del ser de mundo con ayuda del «cogito tácito». Frente a la reducción intelectualista del mundo a mero objeto, propone la figura irreductible de lo percibido: el fenómeno. Sin embargo, el mundo se entiende de una manera implícita como realidad en sí, necesitada de una conciencia que dé cuenta de lo fenoménico. Que el cogito sea tácito es la manera como pretende escapar del intelectualismo: ¿qué significa, sin embargo, un cogito que se hace cargo del mundo sin ser conocimiento? Esa vía negativa de superar el intelectualismo queda en última instancia prendida de él. Si la conciencia ha de resolver el problema de lo fenoménico no puede seguir siendo algo contrapuesto al mundo, sino parte de él.

En el período intermedio de su pensamiento, entre los años 1949 y 1952, para evitar el subjetivismo introduce Merleau-Ponty en su reflexión la condición social o intersubjetiva del lenguaje. Aun cuando esto suponga el reconocimiento de un fundamento transcendental, puede entenderse también, sin embargo, que lo que se produce es el paso de la conciencia individual a la

\footnotetext{
${ }^{3}$ Merleau-Ponty, M. Fenomenología de la percepción. Barcelona: Península, 2000, p. 15.

${ }^{4}$ Merleau-Ponty, M. Lo visible y lo invisible. Barcelona: Seix Barral, 1970, p. 225.

${ }^{5}$ Ib., p. 244.
} 
conciencia social, con lo que, respecto del mundo, seguiríamos encontrando cierta polaridad. De ahí el que todavía en su última época vea Merleau-Ponty necesario seguir corrigiendo dicho dualismo. De lo que se trata en Lo visible $y$ lo invisible es de concebir el lugar del sujeto en el mundo sin recurrir a la conciencia y sin retornar por ello al realismo ni arriesgar la posibilidad de dar cuenta de la objetividad ${ }^{6}$.

En ese período intermedio, en torno a La prosa del mundo, se centra MerleauPonty en el asunto de la expresión, y esto va a ser lo que permita el paso a la ontología esbozada en sus últimos textos. No se trata ya en esta fase de entender el lenguaje como un modo de expresión corporal, sino de entrar a fondo en lo que significa la operación de expresión llevada a cabo por el lenguaje.

Lo primero de todo es desmontar esa tendencia del lenguaje al idealismo. El hecho de que, cuando la palabra resulta lograda, pasemos directamente al sentido por encima de las palabras, nos lleva a entender el lenguaje de modo idealista. El lenguaje en su funcionamiento se borra a sí mismo, su operación consiste en hacerse invisible, transparente, como quien dice inexistente; de ahí el que parezca abrir una dimensión diferente, que sería la de las ideas puras, siempre existentes y significantes. Para evitar esto se ocupará Merleau-Ponty de la palabra naciente, del momento de producción de la expresión, o de lo que el lenguaje tiene de expresión primordial. Esto le permitirá entender el mundo como origen de dicha expresión, como aquello que la expresión al tiempo revela y transforma.

La concepción clásica del lenguaje se apoya en la correspondencia unívoca entre signo y sentido:

Se cree que el sentido transciende a los signos como el pensamiento transcendería a indicios sonoros o visuales, y se le cree inmanente en los signos debido a que cada uno de ellos, al tener de una vez por todas su sentido, sería incapaz de interponer entre él y nosotros opacidad alguna, e incluso de darnos que pensar ${ }^{7}$.

Mas no es así. Si el lenguaje fuera realmente transparente, la significación carecería de sentido. Si fuera mera traducción de pensamiento a palabras, no se diría nunca nada, no tendríamos la sensación de vivir en el lenguaje. «El sentido está completamente embebido en el lenguaje, la palabra juega siempre sobre el fondo de palabra, nunca es más que un pliegue en el inmenso tejido del habla» ${ }^{8}$. El pensamiento no es algo que esté previamente dado.

\footnotetext{
${ }^{6}$ Cf. Barbaras, R. De l'être du phénomène: l'ontologie de Merleau-Ponty. Grenoble: Ed. Jérôme Millon, 1991, pp. 31-32.

${ }^{7}$ Merleau-Ponty, M. Signos. Barcelona: Seix Barral, 1964, p. 52.

${ }^{8}$ Loc. cit.
} 
El sentido no es, pues, correspondencia entre dos entes dados, sino operación del signo, fruto del juego entre signos. Cuando se atiende a la expresión naciente, «el sentido de las expresiones en formación es lateral u oblicuo, resultado del comercio de las palabras mismas (o de las significaciones disponibles)»?.

Esta concepción proviene de un ahondamiento en los hallazgos de la lingüística de Saussure. Veamos esto con mayor detalle.

Lo que Merleau-Ponty reconocerá de la lingüística saussuriana es el valor diacrítico de los signos: el hecho de que sea el juego de las diferencias y de las oposiciones lo que produce el sistema de valores de la lengua, lo que lleva a darnos el sentido. No obstante, antes de entrar en ello, hay que precisar que donde Merleau-Ponty va a encontrar la verdadera esencia, digamos, del lenguaje es en lo que Saussure llamaba el habla, la parole. Por ello, lo primero que debemos considerar es una corrección.

Lo que Merleau-Ponty critica de la distinción característica entre lengua y habla es el hecho de que tal separación devenga en mera yuxtaposición de experiencias diferentes que parecen no comunicar entre sí. Saussure propone una lingüística sincrónica del habla y una lingüística diacrónica de la lengua; el caso es que si ambas lingüísticas meramente se yuxtaponen, el resultado es que el lenguaje vivido - tal es el habla- parece que nada tiene que aportar al conocimiento del lenguaje, es decir, parece que de la experiencia del lenguaje nada tenemos que aprender acerca de lo que el lenguaje sea. ¡Y eso -objetará de manera tajante Merleau-Ponty- es imposible! ${ }^{10}$ Ciencia del lenguaje y fenomenología del habla deben entrar inevitablemente en confrontación: será lo que haga él con Saussure.

Merleau-Ponty indagará el habla, la palabra, la experiencia del lenguaje vivo. Pues en ella el lenguaje nos ofrece otra cara que considerado en cuanto lengua: en el habla, en la palabra viva, cuando es expresiva - «el diálogo, el relato, el juego de palabras, la confidencia, la promesa, la plegaria, la elocuencia, la literatura ${ }^{11}$, y la filosofía -, no es el sujeto el que aprehende el objeto, sino que la relación teórica con el mundo queda invertida: el habla es uno de esos casos en que el mundo, invadiéndome, me invita a convertirme en espectador: «cuando yo hablo o cuando comprendo, experimento la presencia de los demás en mí o de mí en los demás [...] En la medida en que lo que yo digo tiene sentido, yo soy para mí mismo, cuando hablo, otro "otro", y, en la medida en que comprendo, ya no sé quién habla y quién escucha» ${ }^{12}$. En el habla sale a la luz el modo de presencia del objeto para el sujeto, del mundo para el pensamiento. Por esa vía se podrá entender la relación entre realidad y lenguaje.

\footnotetext{
${ }^{9}$ Merleau-Ponty, M. La prosa del mundo, p. 80. [Cursiva, mía.]

${ }^{10}$ Merleau-Ponty, M. Signos, p. 103.

${ }^{11}$ Merleau-Ponty, M. La prosa del mundo, p. 25.

${ }^{12}$ Merleau-Ponty, M. Signos, p. 115.
} 
Considerando el habla llegará Merleau-Ponty a «una nueva concepción del ser del lenguaje» ${ }^{13}$. Obviamente, dentro del habla estamos distinguiendo el uso empírico del lenguaje ya hecho, del uso creador: el lenguaje auténtico, la palabra verdadera, a la cual llamará Merleau-Ponty lenguaje o palabra hablante u operante. A este lenguaje es al que nos vamos a referir a partir de aquí.

El habla/La palabra, en cuanto distinta de la lengua, es ese momento en que la intención significativa, muda aún y completamente en acto, se muestra capaz de incorporarse a la cultura [...] transformando el sentido de los instrumentos culturales ${ }^{14}$.

El lenguaje hablante es «el lenguaje que se hace en el momento de la expresión, y que va justamente a hacer que me deslice de los signos al sentido» ${ }^{15}$. Es la palabra del escritor, pero también la de la buena lectura, la de la lectura que engancha, y la de la conversación.

$\mathrm{Al}$ respecto nos dice Merleau-Ponty: cuando la lectura engancha, las palabras comunes nos van arrastrando a un mundo nuevo: «soy Stendhal cuando leo, pero eso es posible porque previamente Stendhal ha sabido instalarme en él» ${ }^{16}$. Al empezar a leer partimos de una lengua común, de unas significaciones adquiridas y disponibles, el libro entra en mi mundo — mas, si «engancha» quiere decir que nos arrastra, que nos saca de nosotros para llevarnos a sí, a otro lugar, a otro mundo. De alguna manera nuestro lenguaje va viéndose deformado por el libro, la significación retorcida, sometida a torsión, y al cabo de la lectura, somos nosotros los que hemos entrado en otro lugar, en otro mundo. Por eso, «Soy Stendhal» — se sobreentiende que tras haberlo leído.

Pero sabemos, y quizá más claro que en la lectura de una novela lo vemos en la lectura filosófica, que ese entrar en un autor nuevo no es cosa de un momento: al principio vamos manejándonos con las palabras tal como las tenemos aprendidas, aun cuando veamos que no es ése justamente el significado que el autor les da; una vez lograda cierta totalización, una vez entrevista alguna clave, un sentido global u orientativo, comenzamos a precisar la significación que requieren los términos para ser comprendidos, y así, gracias a una serie de movimientos de ida y vuelta desde las partes -las frases, que vamos leyendo una por una- al todo, todo siempre parcial y, en alguna medida, virtual... y del todo hacia las partes, se van afinando los conceptos, los presupuestos, las cuestiones clave, y después se pueden aclarar las formulaciones complejas, los puntos conflictivos. «Poco a poco -dice Merleau-Ponty- su palabra [la del filósofo] domina su lenguaje, y el uso que él hace de ella es lo que termina por afectarla con un significado nuevo y propio de él. En ese momento, él se ha hecho entender y su significado se ha instalado en mí» ${ }^{17}$.

\footnotetext{
13 Merleau-Ponty, M. Signos, p. 105.

${ }^{14}$ Merleau-Ponty, M. Signos, p. 110.

15 Merleau-Ponty, M. La prosa del mundo, p. 35.

${ }^{16} \mathrm{Ib}$., p. 37.

${ }^{17}$ Merleau-Ponty, M. Signos, p. 109.
} 
Por lo que hace al escritor, dice: «El escritor sólo tiene que ver con el lenguaje, y así es como de repente se encuentra rodeado de sentido» ${ }^{18}$. Así como el pintor tantea inconscientemente la pincelada, hasta el punto que parece que sea la mano la que decide, así el escritor «tantea la intención de significar», que sabemos que no es algo que esté dado previamente, salvo en esbozo.

De ahí que para llegar a donde se da la expresión en propiedad haya «que considerar la palabra antes de que se la pronuncie, el fondo de silencio que no deja de rodearla, sin el cual no diría nada, poner al descubierto los hilos de silencio de que está entremezclada ${ }^{19}$. Y si se quiere percibir la palabra en su operación más propia, naciendo, habría que evocar todas las que podrían haber surgido en su lugar — «hemos de ser sensibles a esos hilos de silencio de los que el tejido de la palabra se halla entreverado $»^{20}$. En fin, «si queremos entender el lenguaje, tenemos que fingir no haber hablado nunca» ${ }^{21}$.

$\mathrm{Y}$ ¿qué es lo que se encuentra cuando atendemos al momento en que se crea la expresión? Ahí es donde Merleau-Ponty recoge la concepción diacrítica del lenguaje de Saussure.

Saussure nos hacía notar en su Curso de lingüistica general que una cosa es lo que él llamaba la significación de un término y otra cosa el valor de empleo de dicho término, que depende de la frase en que se inserte, mas no sólo, sino también de sus relaciones de asociación y de las de los demás términos de la frase. Que, en definitiva, el sentido se origina a partir del sistema de valores de la lengua. De este modo se negaba la noción corriente de que cada palabra tenga su significado y sólo tengamos que componer los significados correspondientes para, por acumulación, entender una frase.

Tal hallazgo le llevaría a Saussure a decir de manera un tanto extrema: «en la lengua no hay más que diferencias [...] sólo hay diferencias sin términos positivos ${ }^{22}$. Y digo de manera extrema, porque tal sentencia hace referencia sólo a los significantes o a los significados tomados aisladamente, más no a los signos en su totalidad. En cualquier caso, es el juego de las diferencias y de las oposiciones el que produce el sistema de valores de la lengua.

Este carácter diacrítico de producción del sentido lo descubrirá Merleau-Ponty en la "palabra hablante», en la palabra verdadera. La fórmula ya hecha da la impresión de que se corresponde con la realidad como el significante se corresponde con el significado, pero sólo es producto acabado que exige antes el nacimiento de la palabra, la realización de su carácter expresivo.

\footnotetext{
${ }^{18}$ Op. cit., p. 55.

${ }^{19}$ Op. cit., p. 57.

${ }^{20}$ Op. cit., p. 80.

${ }^{21}$ Op. cit., p. 57.

${ }^{22}$ Saussure, F. Curso de lingüística general. Madrid: Alianza, 1993, p. 193.
} 
A cada momento, bajo el sistema de la gramática oficial [...] se ve trasparecer otro sistema expresivo que sostiene el primero y procede de otro modo que él: la expresión, en este caso, no se halla ordenada, punto por punto, a lo expresado; cada uno de sus elementos sólo se precisa y recibe la existencia lingüística por lo que recibe de los otros y por la modulación que les imprime a su vez. El todo es lo que posee un sentido, no cada parte ${ }^{23}$.

Es el todo de la lengua lo que posee un sentido, lo que dota de sentido a la expresión concreta. Se preguntará cómo es eso posible, pues aprender la lengua parece que significa ir de las partes al todo. Y, sin embargo, no basta. Hay una inminencia del todo en las partes ${ }^{24}$. De hecho aprender a hablar no es ir aprendiendo palabras, fórmulas de expresión, no es ir acumulando, sumando... Con las diferencias fonemáticas el nińo parece haber atrapado el principio de la diferenciación mutua de los signos y adquirido el sentido del signo: «el enlace lateral del signo al signo como base de una relación final del signo al sentido» — Toda la lengua se ve anticipada con las primeras oposiciones fonemáticas ${ }^{25}$.

Por ello nos dirá Merleau-Ponty que el sentido es lateral u oblicuo, porque resulta del comercio de las palabras con las palabras, dentro del sistema total de la lengua. Así, el pensamiento no consiste en tener ideas que el lenguaje llevaría a expresión. Expresar algo no es cifrar en palabras un texto previo de ideas — no hay tal texto ideal que las palabras traten de traducir.

Lo que hay es una intención significativa, un querer decir que consiste en «un vacio determinado que llenar con palabras, [que es] el exceso de lo que quiero decir sobre lo que es o ha sido ya dicho» ${ }^{26}$. Prueba de que lo que se quiere decir, cuando hay efectivamente expresión, novedad, no es algo que esté ya puesto en palabras es que las propias palabras nos sorprenden, haciéndonos ver, descubrir nuestro pensamiento.

«Existe un significado "lenguajero" - dice Merleau-Ponty- del lenguaje que realiza la mediación entre mi intención aún muda y las palabras $»^{27}$.

La expresión no es una operación segunda-comunicar el pensamiento-, sino que es «la adquisición de significados que sólo secretamente nos son presentes. ${ }^{28}$ Por eso mismo, la expresión nunca puede ser total. En la expresión, que propiamente es un tomar conciencia, «la intención significativa se da un cuerpo y se conoce a sí misma buscándose un equivalente en el sistema de significados disponibles de la lengua [...] y les hago decir algo que no han dicho nunca» ${ }^{29}$.

\footnotetext{
23 Merleau-Ponty, M. La prosa del mundo, p. 57.

${ }^{24}$ Merleau-Ponty, M. Signos, p. 51.

${ }^{25}$ Op. cit., p. 50.

26 Op. cit., p. 107.

27 Op. cit., p. 106.

${ }^{28}$ Op. cit., p. 108.

${ }^{29}$ Op. cit., p. 108.
} 
El poder expresivo del signo le viene de su integración en el sistema de la lengua, mas no es algo que se perciba intelectualmente, sino algo que se practica. Concebido desde la expresión, el lenguaje es un hacer, un operar. Con nuestro lenguaje nos instalamos en cierta situación a la que él es sensible, y lo que decimos es el balance final de esos intercambios ${ }^{30}$.

El lenguaje es, por lo tanto, elemento, medio y materia de nuestra vida. Estamos inmersos en el lenguaje y el lenguaje nos atraviesa, forma parte de nosotros. Tan es así, que en nuestra vida toda empresa espera un relato, tiene el deseo de manifestarse; dice Merleau-Ponty: «Excepto tal vez en algunos desdichados que sólo piensan en ganar, o en tener razón, todo acto, todo amor está transido de la espera de un relato que los cambiaría en su verdad, desde el momento en que por fin se sabría lo que realmente fueron ${ }^{31}$. Somos, por lo tanto, de tal manera que se da en nosotros espontáneamente el querer decir, la intención significativa: «es nosotros mismos con nuestras raíces, nuestro crecimiento y los frutos de nuestro trabajo» ${ }^{32}$. De ese modo han adquirido las palabras su potencia de significación: "por la vida sorda que han llevado y siguen llevando en nosotros» ${ }^{33}$.

$Y$ es que la expresión no es privativa del lenguaje, sino propia del cuerpo: movernos, mirar encierran ya el secreto de la "acción expresiva» ${ }^{34}$. La percepción es ya expresión primordial: "operación primera que constituye los signos, implanta un sentido donde no lo había, inaugura un orden, funda una institución o una tradición...» ${ }^{35}$ Por eso el mundo está también entreverado de lenguaje. No se trata de que el mundo sea en el fondo lenguaje, sea racional en esencia, sino de que el lenguaje es algo que arraiga en el mundo; hay, diríamos, una racionalidad emergente.

De este modo escapa Merleau-Ponty a los dos posibles extremos a que conducía el dualismo lenguaje/mundo de que partíamos: el mundo no es ni mudo ni elocuente, lo que redundaría en que el lenguaje sea o puramente activo y creador o puramente pasivo y reproductor. Ya hemos visto cómo en este último caso no tendría siquiera sentido hablar. En el primero, la consecuencia es que con el lenguaje no podríamos llegar al mundo, nos hallaríamos -algunos así lo pretenden- encerrados en la cárcel del lenguaje. Pero lo cierto es hay comunicación, hay sentido. Eso es lo que la pertenencia del lenguaje al mundo aspira a explicar.

Saussure nada dijo de la referencia del lenguaje; se contentó con señalar su funcionamiento interno. Merleau-Ponty encuentra precisamente en dicha vida interior el poder de significación, es decir, su capacidad para aludir, para

\footnotetext{
${ }^{30}$ Cf. Merleau-Ponty, M. La prosa del mundo, p. 168.

${ }^{31}$ Merleau-Ponty, M. Signos, p. 88.

33 Op. cit., p. 89.

${ }^{34}$ Op. cit., p. 89.

${ }^{35}$ Op. cit., p. 78.
} 
evocar, para decir el mundo. El sentido, ya lo hemos visto, siempre está «engastado en las palabras» ${ }^{36}$, pero como el lenguaje tiene su vida, es un ser que circula por todas partes, para decir algo, para expresar, «basta con que nos prestemos a su vida, a su movimiento de diferenciación y articulación, a su elocuente gesticulación ${ }^{37}$, pues es capaz de alojar en sí el universo entero. El lenguaje es un principio de distinción. No es que haya un diccionario interior, como no hay ideas ya dadas; hablar o entender no consiste en cifrar o en descifrar un texto de ideas; lo que se traduce es una situación que pugna por encarnar en palabras. Luego se verá si lo dicho satisface o no a quien lo dice. Así las cosas, carece de sentido pensar en que haya expresión completa: «todo lenguaje es indirecto o alusivo, es, si se quiere, silencio» ${ }^{38}$.

«El sentido es el movimiento total de la palabra y esta es la razón de que nuestro pensamiento circule por el lenguaje» ${ }^{39}$. Trabajando unas con otras, las palabras evocan su sentido. «El lenguaje significa cuando, en lugar de copiar el pensamiento, se deja deshacer y rehacer por él ${ }^{40}$. Por eso resulta el lenguaje más eficaz cuando renuncia a decir la cosa misma.

Hablará Merleau-Ponty de «expresión creadora», porque la «expresión re crea y metamorfosea ${ }^{41}$. Al pasar «del orden de los acontecimientos al de la expresión no se cambia de mundo: los mismos datos se convierten en sistema significante. Ahondados, trabajados, liberados por fin de ese peso sobre nosotros que los hacía dolorosos o hirientes, [...] por mucho que sufran una metamorfosis, no dejan de estar ahí» ${ }^{42}$. Y esto lo sabe bien el escritor, capaz de gozar con la materia de los dolores vividos. La obra es respuesta a esos datos ${ }^{43}$, no copia ni efecto. "La palabra recupera y sobrepasa la certidumbre sensible, aunque en otro sentido la conserve y la continúe» ${ }^{44}$. El lenguaje se mantiene unido a lo que viene a expresar, que sólo es aprehensible en la expresión. Recupera el mundo y lo rehace para conocerlo.

Si en los textos de esa fase media insiste Merleau-Ponty en señalar la vida interior del lenguaje, en Lo visible y lo invisible pondrá el acento en la reciprocidad de mundo y lenguaje: «El lenguaje es una vida: la nuestra y la de las cosas» ${ }^{45}$. Y en esa vida hay referencias hacia las cosas mudas, a las que interpela, y hacia el mundo de las cosas dichas, que va transformando.

De Lo visible y lo invisible sólo el cuarto capítulo nos ofrece un germen explícito de la ontología de Merleau-Ponty. El título, «el entrelazo — el quiasmo», hace

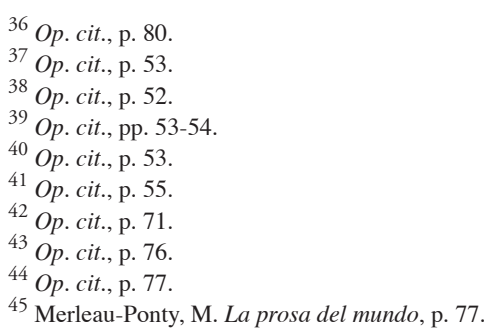


referencia a la reversibilidad, que, como dice cerrando el capítulo, es la «verdad última ${ }^{46}$. El mundo es primordialmente fenómeno, organización autóctona, tejido que se teje, carne. La reversibilidad es ese entrelazo, ese entretejerse primordial, irreductible de las cosas. Mas las cosas no son sólo lo visible, sino también el sentido, $\mathrm{y}$ «el sentido es invisible, pero lo invisible no es lo contrario de lo visible: lo visible tiene una contextura invisible, y lo in visible es la contrapartida secreta de lo visible, sólo aparece en lo visible», dice una densa nota de trabajo ${ }^{47}$. Y eso, en su reversibilidad, es la carne, "textura que se vuelve hacia sí misma y se conviene a sí misma» ${ }^{48}$. La carne es el "elemento, [el] emblema concreto de un modo de ser general ${ }^{49}$.

La reversibilidad viene a decir un modo de identidad en la diferencia, el mantenimiento de la ambigüedad de identidad y diferencia. La reversibilidad entra con la noción de que lo invisible ilumina lo visible, la idealidad invisible del lenguaje ilumina el mundo y pone de manifiesto su sentido. El lenguaje surge de la dehiscencia y repliegue sobre sí misma de la carne del mundo. El lenguaje es "otro cuerpo menos pesado, más transparente» ${ }^{50}$ que está al servicio de la expresión del mundo.

La reversibilidad de lo visible y lo invisible la entiende Merleau-Ponty como reflexión, en el doble sentido de reflejo y de pensamiento.

El lenguaje es el medio en que el mundo se refleja y se piensa. No duplica ni copia el mundo, es el modo como el sentido del mundo se despliega. Es el sentido del mundo que se separa de él para iluminarlo y al tiempo iluminarse. Esta relación de reciprocidad en que ninguno de los elementos es inteligible por sí mismo es la relación de reversibilidad. Lo que distingue al lenguaje de la percepción -cuya reversibilidad estaría en que no haya coincidencia plena con la cosa, con ser percepción de la $\cos ^{51}$ - es que el signo lingüístico pueda separarse en pensamiento.

El pensamiento es la relación de los signos consigo mismos, signos que llaman a otros signos para hacerse inteligibles. La reversibilidad se manifiesta en cuanto intercambiabilidad o traducibilidad. La marca del pensamiento que se ha encontrado a sí mismo es la libertad respecto de una formulación concreta; de ahí su apariencia espiritual. El pensamiento, aunque sea distinto del lenguaje permanece ligado a él, puesto que el sentido del pensamiento se halla en la reversibilidad de las formulaciones, fuera de ese intercambio no puede existir. El pensamiento «es lo invisible de este mundo, lo que lo habita, lo sostiene y lo hace visible, su posibilidad interior y propia, el Ser que este mundo es [l'Etre de cet étant $\aleph^{52}$. Así reúne el lenguaje pensamiento y mundo.

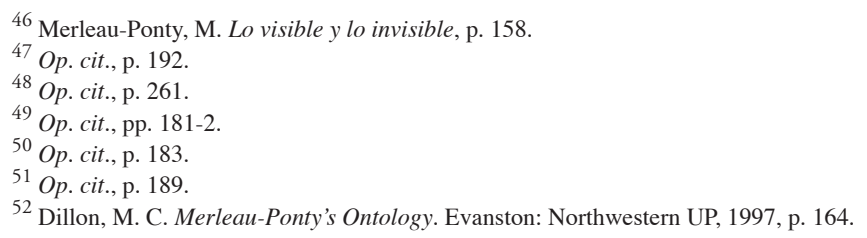


Lo visible y lo invisible acaba con estas palabras:

En cierto sentido, como dice Husserl, toda la filosofía consiste en restituir un poder de significar, un nacimiento del sentido o un sentido salvaje, una expresión de la experiencia por la experiencia que ilumina particularmente el campo especial del lenguaje. Y, en cierto sentido, como dice Valéry, el lenguaje lo es todo, puesto que no es la voz de nadie, es la voz misma de las cosas, de las aguas y los bosques. Y lo que hay que entender es que entre estas dos ideas no hay inversión dialéctica, no tenemos por qué reunirlas en una síntesis: son dos aspectos de la reversibilidad que es la verdad última ${ }^{53}$.

Se trata, pues, de la reversibilidad del lenguaje. Por un lado, surge el lenguaje de las cosas; por otro, no es meramente la voz de las cosas, que en sí son silenciosas, habría que decir, sino que ese lenguaje exige que se renueve siempre la capacidad de decir, que se recupere siempre el vínculo de la palabra con las cosas. Si nosotros no sabemos decir, las cosas callan.

\footnotetext{
${ }^{53}$ Merleau-Ponty, M. Lo visible y lo invisible, p. 187.

${ }^{54}$ Op. cit., p. 192.
} 
III. FENOMENOLOGÍA DEL CUERPO 


\title{
Prolegómenos a una Fenomenología de las Emociones. El Análisis de las Disposiciones de Ánimo según Alexander Pfänder ${ }^{1}$
}

\author{
Mariano Crespo \\ Pontificia Universidad Católica de Chile
}

\begin{abstract}
Resumen
El presente texto se ocupa de lo que podría denominarse un "primer capítulo" de una fenomenología de las emociones, a saber, del análisis de un tipo peculiar de vivencias, las denominadas "disposiciones de ánimo". Para ello se presentan las líneas fundamentales del examen de esas vivencias emprendido por Alexander Pfänder.
\end{abstract}

\section{Introducción}

A partir de la publicación en 1988 de las Vorlesungen über Ethik und Wertlehre, impartidas por Edmund Husserl en el periodo comprendido entre 1908 y 1914, se ha ido conociendo el interés que las cuestiones éticas tuvieron para el fundador del movimiento fenomenológico desde el inicio de su actividad filosófica. Otras dos publicaciones atestiguan este interés: por un lado, los artículos aparecidos en la revista Kaizo y, por otro, la aparición en la serie Husserliana del volumen Einleitung in die Ethik, el cual contiene una serie de lecciones pronunciadas durante los semestres de 1920 y repetidas en 1924 . A una prueba más del interés husserliano por las cuestiones éticas, en general, y por lo referente a la teoría del valor, en particular, se refiere Ulrich Melle en su introducción editorial a las mencionadas Vorlesungen über Ethik und Wertlehre. Ahí se señala que ya en otoño de 1909 Husserl se ocupaba intensamente en diversos manuscritos sobre la diferencia entre actos objetivantes y actos emotivos (Gemütsakte), así como de la relación de éstos a objetos. Dichos manuscritos se enmarcan dentro del ámbito más amplio de los extensos análisis fenomenológicos de los actos emotivos y de los actos de la voluntad, así como de las relaciones entre intelecto y afecto. Estos análisis pertenecen, a su vez, a las más amplias investigaciones de los años $1908-1914^{2}$ en las cuales Husserl intenta describir la conciencia toda en sus diferentes tipos de actos, de relaciones de fundación así como sus diferentes correlatos. Aunque estos análisis tienen lugar en los años en los que Husserl imparte varias de sus lecciones

\footnotetext{
${ }^{1}$ El texto de esta ponencia se enmarca dentro del Proyecto de Investigación. No: 1060670 "Las disposiciones de ánimo (Gesinnungen). Un análisis fenomenológico de su estructura intencional y de su relevancia moral" financiado por el Fondo Nacional de Desarrollo Científico y Tecnológico (FONDECYT).

${ }^{2}$ Algunos de estos manuscritos se remontan incluso a 1898, esto es, al tiempo anterior a la publicación de la primera edición de Investigaciones Lógicas.
} 
de carácter ético, éste, sin embargo, no desarrolló la conexión sistemática entre estas detalladas descripciones y sus lecciones éticas.

Lo que de todo esto me interesa señalar es que la preocupación por el análisis de la vida emocional y el interés por las estructuras a priori que en ellas se descubren, constituyó desde un primer momento un interés central de la fenomenología. Prueba de ello son los análisis de Max Scheler acerca de los sentimientos intencionales a través de los cuales los valores son captados.

Dentro de este interés por una exploración fenomenológica del mundo de las emociones, quisiera referirme hoy a los análisis de un tipo especial de vivencias pertenecientes a esta esfera, a saber, las denominadas disposiciones de ánimo tal y como se encuentran en la, lamentablemente, poco conocida obra de Alexander Pfänder, Zur Psychologie der Gesinnungen ${ }^{3}$. Los análisis contenidos en esta obra constituyen lo que en otro lugar he caracterizado como el "primer nivel de análisis fenomenológico" de las mismas 4 . Aquí no se trata de un análisis de la disposición de ánimo en el sentido en que este término es utilizado por Scheler, esto es, como una suerte de disposición de fondo enraizada en el yo central y consistente en una dirección fundamental de valor que caracteriza a la persona toda. En lo que sigue quisiera permanecer en el mencionado "primer nivel de análisis", renunciando por tanto a la consideración de la relevancia fundamental de esa disposición moral de fondo, tema al cual proyecto dedicar otro trabajo.

\section{La fenomenología de las disposiciones de ánimo: un capítulo de la teoría eidética de las vivencias}

El primer aspecto que, a mi juicio, ha de esclarecer cualquier estudio sistemático de estas vivencias - y de cualquier otra - tiene que ver con la disciplina científica que se ocupa de ellas. Ciertamente, el libro de Pfänder al que me he referido más arriba lleva por título Psicología de las disposiciones de ánimo. ¿¿Significa esto, por tanto, que no hay diferencia alguna entre el modo de proceder de la psicología y el de la fenomenología, de forma que la fenomenología de las disposiciones de ánimo no sería sino un capítulo del estudio psicológico de las mismas?

Responder a esta pregunta requiere una breve contextualización histórica. A ello ayuda un texto inédito de Pfänder, perteneciente a una lección dedicada a cuestiones de psicología impartida en la Universidad de Munich en 1920-

\footnotetext{
${ }^{3}$ Pfänder, Alexander. Zur Psychologie der Gesinnungen I. En Jahrbuch für Philosophie und phänomenologische Forschung. 1. Band. In Gemeinschaft mit Oskar Beckar (Freiburg), Moritz Geiger (München), Martin Heidegger (Freiburg), Alexander Pfänder (München), Adolf Reinach (Göttingen), Max Scheler (Berlin), herausgegeben von E. Husserl. Halle a. S.: Max Niemeyer Verlag, , 1913; Zur Psychologie der Gesinnungen II en Jahrbuch für Philosophie und phänomenologische Forschung. 3. Band, Halle, 1916.

${ }^{4}$ Crespo, Mariano. "Esbozo de una fenomenología de las disposiciones de ánimo" en Diálogo filosófico, 68 (2007), pp. 229-249.
} 
$1921^{5}$. En él se distingue entre dos tipos de psicología. Por un lado, se trata de esta disciplina en cuanto una serie de consideraciones científico-naturales, sobre todo de orden fisiológico. El representante de este modo de concebir la psicología es, según el Pfänder de esos años, Wilhelm Wundt. Este modo de interpretar la psicología conduce inevitablemente, siempre según Pfänder, a una concepción demasiado estrecha del objeto de la misma, la cual deja fuera de sí un ámbito sumamente importante, a saber, el relativo a los sentimientos y a la voluntad. El segundo tipo o forma de entender la psicología es más amplio que el anterior y parte de la teoría del conocimiento. Frente al primer modo de hacer psicología, el cual iba dirigido a lo "microscópico", la orientación de este segundo modo es más bien "macroscópica”. Está dirigida al conocimiento de la vida psíquica toda, en especial de la personalidad humana. Es, pues, en este segundo sentido más amplio, no fisicalista, de "psicología" en el que, según Pfänder, es justificado hablar de "psicología de las disposiciones de ánimo". Dentro de esta psicología en sentido amplio, desempeña un papel importante un modo de consideración de las vivencias de la conciencia radicalmente distinto a la forma en la que la psicología en el primero de los sentidos se ocupa de los fenómenos psíquicos. Mientras que en el primer sentido de "psicología" se considera a las vivencias como sucesos reales que transcurren en la conciencia, el "nuevo" modo de consideración de éstas opera desde una actitud diferente con respecto al primero. Formulado en términos husserlianos, de lo que se trata en definitiva es de la distinción entre la actitud natural - actitud en la cual se mueven las ciencias empíricas y entre ellas, paradigmáticamente, la psicología en el primero de los sentidos distinguidos por Pfänder $-\mathrm{y}$ la actitud fenomenológica. El análisis psicológico, en el segundo sentido del término "psicología" distinguido por Pfänder, o fenomenológico pretende, en última instancia, develar el "qué" de las mismas mediante una intuición esencial.

\section{Elementos esenciales del análisis de las disposiciones de ánimo}

En el trabajo citado en la nota 4 me he referido a las principales características de las disposiciones de ánimo que Pfänder encuentra. Permítaseme que las recuerde aquí brevemente.

En primer lugar, las disposiciones de ánimo son vivencias claramente intencionales. A diferencia de lo que sucede con los estados inmanentes de la conciencia -piénsese, por ejemplo, en el desasosiego o desazón que a veces experimentamos-, este tipo de vivencias siempre se refieren a algo distinto de ellas mismas.

En segundo lugar -y en estrecha conexión con su carácter intencional- las disposiciones de ánimo no aparecen como una característica de su objeto, ni

${ }^{5}$ El manuscrito de esta lección lleva por título "Grundzüge der Psychologie des Menschen” y se encuentra en la Bayerische Staatsbibliothek de Munich con la signatura Pfänderiana C IV 19. 
tampoco, en sentido estricto, como una propiedad o estado del sujeto que las experimenta, sino que, de alguna forma, se encuentran entre ambos salvando la "distancia anímica" entre éstos. Así, una disposición de ánimo positiva, como por ejemplo, el amor, aunque es vivida por su sujeto, -es vista por Pfänder como situada de algún modo entre éste y la persona amada. Lo mismo sucede con una disposición de ánimo negativa, como por ejemplo, el odio ${ }^{6}$.

En tercer lugar, toda disposición de ánimo tiene una dirección concreta, a saber, no "va" del objeto al sujeto, sino de éste a aquél. A esto es a lo que Pfänder se refiere cuando habla de la "dirección centrífuga" de estas vivencias. Continuamente nos dirigimos desde la centralidad de nuestro yo a las personas y objetos que nos rodean con disposiciones de ánimo positivas o negativas. Éstas presentan una amplia gama de matices que van desde el amor, la amistad y la benevolencia hasta la hostilidad, el menosprecio y el odio.

En cuarto lugar, podría pensarse que la dirección inmanente centrífuga del sujeto al objeto de la disposición de ánimo es sólo un mero "apuntar" (Zielung) de aquél a éste. Sin embargo, Pfänder piensa que no solamente esto sucede, sino que la disposición de ánimo "fluye" del sujeto como de su fuente y "desemboca" en el objeto. A diferencia de otras vivencias de la conciencia que "ocurren" o "suceden" en el sujeto, las disposiciones de ánimo son vivencias "en movimiento" que surgen del sujeto y desembocan en el objeto ${ }^{7}$. A esta nota se refiere Pfänder cuando habla de la "afluencia a partir de un sujeto activo" (zentrifugale Strömung) ${ }^{8}$.

En quinto lugar, como se desprende de lo que venimos diciendo, las disposiciones de ánimo se dividen en positivas (amor, benevolencia, amistad, etc.) y negativas (odio, mala voluntad con respecto a otra persona, enemistad, etc.). En las primeras se produce una afluencia emotiva (Gefühlsstrom) "vivificadora", "promotora" del objeto de la misma, mientras que en el caso de las disposiciones de ánimo negativas esa afluencia emotiva tiene un carácter "destructor" de su objeto. Ello se percibe claramente si comparamos el amor y el odio en sus respectivas relaciones con sus objetos. A esta "afluencia emotiva" -de uno u otro signo- se añade, en el caso de la disposición positiva, un acto de unificación interna con el objeto de la disposición. En el caso de la negativa se trata de un acto de desunión o negación.

Pfänder considera que la investigación fenomenológica de las disposiciones de ánimo - al igual que la fenomenología en general - no termina con la mera contemplación de las cosas mismas, sino que incluye también la comparación y la diferenciación. En este orden de cosas, podemos distinguir entre fenómenos que son claramente diferentes de las disposiciones de ánimo y fenómenos

\footnotetext{
${ }^{6}$ Pfänder señala que la disposición de ánimo está eingespannt entre su sujeto y su objeto. Cf. Zur Psychologie der Gesinnungen, p. 8.

${ }^{7}$ Pfänder, Alexander. Op.cit., p. 10.

${ }^{8}$ Por lo que respecta a esta característica podría discutirse si se trata de una nueva propiedad con respecto a la anterior o si, por el contrario, se trata tan sólo de una precisión de ella.
} 
que pueden identificarse fácilmente con las disposiciones de ánimo, pero que no lo son. Al primer grupo de fenómenos corresponden la atención, la apercepción y el mentar. Al segundo pertenecen las tendencias de la voluntad, el "carácter", "estados de ánimo", sentimientos de placer o displacer. En el trabajo anteriormente citado, me he referido explícitamente a las diferencias entre las disposiciones de ánimo y estos otros tipos de vivencias. En lo que sigue quisiera profundizar en otros aspectos de las mismas allí no abordados.

\section{Tipología de las disposiciones de ánimo}

Una de las contribuciones más originales de los análisis de Pfänder acerca de las disposiciones de ánimo tiene que ver con algunos aspectos referidos a su clasificación. La más general de estas clasificaciones es la que divide a este tipo de vivencias en actuales, virtuales y habituales. Las primeras son aquellas que existen en un momento dado en la vida anímica actual. Ejemplos de este tipo son un afecto positivo hacia otra persona en un momento determinado o un odio puntual contra alguien. Por su parte, las disposiciones de ánimos virtuales no se encuentran en el nivel de la actualidad de la conciencia, sino que están, si se me permite la expresión, "agazapadas" detrás de la misma. Es, por ejemplo, el caso de la persona llena de odio contra otra. Sigue estando llena de él aunque no piense conscientemente en esa persona y se ocupe de otras cosas. Lo mismo sucede con el amor. Dichas vivencias tienen, en la terminología de Dietrich von Hildebrand, un carácter sobreactual. De las disposiciones de ánimo actuales y de las virtuales Pfänder distingue un tercer nivel más profundo, que es al que nos referimos cuando usamos expresiones como "tal persona está permanentemente bien dispuesta para conmigo" o "esa otra persona está llena de un odio total contra mí". En este último caso, nos encontraríamos con las disposiciones de ánimo habituales, las cuales pueden aparecer o en disposiciones virtuales o en disposiciones actuales ${ }^{9}$. Desgraciadamente, los análisis de Pfänder, tanto en la primera como en la segunda parte de Zur Psychologie der Gesinnungen se reducen a las disposiciones de ánimo actuales, mientras que las virtuales y las habituales son dejadas sin consideración.

Junto a esta primerísima clasificación de las disposiciones de ánimo, Pfänder lleva a cabo, por un lado, una clasificación de las disposiciones anímicas según la dirección de la afluencia afectiva centrífuga y un detallado estudio de las modificaciones de estas disposiciones. Aquí me referiré únicamente a estas últimas.

Estas modificaciones pueden ser, según Pfänder, de tres tipos: las disposiciones inauténticas, las "exorbitantes" o "flotantes" y las refrenadas. Veamos, en primer lugar, qué sucede con las disposiciones inauténticas.

\footnotetext{
${ }^{9}$ No me resulta del todo convincente la distinción efectuada por Pfänder entre disposiciones de ánimo virtuales y disposiciones habituales. Me da, más bien, la impresión que se trata, en última instancia, del mismo tipo de disposición, pero observado desde dos puntos de vista diferentes: por un lado, el de su virtualidad o sobreactualidad y, por otro lado, el de su permanencia en la conciencia al modo de un hábito.
} 
Antes de entrar en su estudio es preciso, piensa Pfänder, aclarar que el término "inauténtico" no implica aquí valoración negativa alguna. Tan sólo apunta al carácter peculiar de cierto tipo de disposiciones actuales, tanto positivas como negativas. Con este tipo de disposiciones nos encontramos, por ejemplo, cuando bromeamos o jugamos. En esos casos, las personas que actúan amistosamente u odiosamente no están actualmente dispuestas positiva o negativamente. Pero, considera nuestro autor, contradiría lo que realmente sucede en el yo del sujeto si se pensara que no tiene lugar disposición anímica alguna. Lo característico de las disposiciones de ánimo inauténticas es el hecho que no surgen del "sí mismo" del sujeto como, por el contrario, sucede con las disposiciones auténticas. En este sentido, están en su interior "vacías o faltas de núcleo" ${ }^{10}$. Son, por así decir, subrogados pálidos de las disposiciones auténticas, pero no dejan por ello de ser hechos psíquicos reales. Eso sí, son artificiales, inauténticas.

Como decía más arriba, ejemplos de estas disposiciones encontramos en el juego, en las representaciones escénicas. Pero también, como atinadamente señala Urbano Ferrer, en las formas sociales que son sólo convencionales. Es lo que sucede cuando alguien "simula" interés acerca de una investigación nuestra sobre disposiciones de ánimo. En este último tipo de disposiciones inauténticas hay una cierta intención de ocultar su carácter inauténtico.

Es precisamente aquí donde nos encontramos con uno de los aspectos, a mi juicio, más interesantes de los análisis fenomenológicos de Pfänder acerca de las disposiciones de ánimo. Me refiero a las formas de enlace entre disposiciones inauténticas y auténticas. Nuestro autor señala cómo es posible que una disposición de ánimo auténtica sea recubierta por la opuesta inauténtica llegando incluso ésta a desplazar a la primera y a "arraigarse" en la conciencia del sujeto como auténtica. En este orden de cosas, las disposiciones inauténticas pueden sustituir a las genuinas en aquellos momentos en que no están disponibles las expresiones de estas. En ocasiones se unifican en una única disposición actual lo auténtico y lo inauténtico, como en las manifestaciones abultadas de amistad o de condolencia, en que se rebasa la materia anímica disposicional vivida. Lo interesante en estas disposiciones anímicas actuales exageradas es que la disposición actual en sí es auténtica y sólo un momento en ella, aquí en especial la dimensión de la fuerza vivificadora en las positivas y la virulencia corrosiva en las negativas es inauténtico.

Lo interesante de todo esto es que no parece que las disposiciones anímicas actuales auténticas puedan ser creadas directamente (no se puede directamente amar voluntariamente una persona o un objeto), mientras que las inauténticas (ya sean positivas o negativas) sí que se pueden "crear" voluntariamente. Parecería, por tanto, que de aquellas disposiciones de las que somos responsables en sentido estricto son las inauténticas. Sin embargo, parece que, de algún

\footnotetext{
${ }^{10}$ Cf. Ferrer, Urbano. Desarrollos de ética fenomenológica. Segunda edición. Albacete: Editorial Moralea,
} 2002, p. 60. 
modo, pueden "favorecerse" voluntariamente disposiciones de ánimo auténticas hasta el punto de poder plantear determinadas "exigencias" con respecto a ellas. Es lo que sucedería con mandamientos como "ama a tu prójimo como a ti mismo", "sé amable con todos", etc. Estos mandamientos no exigen disposiciones inauténticas, sino que constituyen más bien una invitación a "albergar" disposiciones auténticas de amor y amistad. Si exigen esto del hombre, suponen que a éste le es posible mediante el esfuerzo voluntario adoptar estas disposiciones anímicas positivas de amor y amistad con respecto a cualquier persona. A estos mandatos se les opone, sin embargo, la experiencia humana de que a determinadas personas no se les puede dar voluntariamente sin más amor auténtico y amistad auténtica. De esta forma, la justificación de los mandatos arriba mencionados y otros similares, que exigen una determinada disposición anímica auténtica con respecto a determinados objetos, parece ser puesta en cuestión. Parece injustificado exigir de alguien algo que no puede realizar mediante su esfuerzo.

La cuestión es aquí si las exigencias en las que se mandan a los hombres determinadas disposiciones auténticas con respecto a determinados objetos son injustificadas simplemente porque no pueden ser cumplidas directamente voluntariamente por los hombres. Estas exigencias estarán totalmente injustificadas - piensa Pfänder - si lo que realmente pidieran es "producir" voluntariamente auténtico amor con respecto a determinados objetos. Estas exigencias no son, sin embargo, injustificadas si aquello que exigen de su destinatario es el que honradamente se esfuerce, en la medida de sus posibilidades, por favorecer el surgimiento de auténtico amor. Luego, existen caminos al "favorecimiento" voluntario de disposiciones actuales auténticas.

La segunda modificación de las disposiciones de ánimo actuales tiene que ver con lo que Pfänder denomina disposiciones "exorbitantes" o "flotantes" (schwebende). Este tipo de disposiciones difieren de las inauténticas en que no se hacen pasar por reales, sino que quedan, por así decir, "en suspenso". Les falta la realidad plena que tienen, por ejemplo, las disposiciones de ánimo auténticas e inauténticas. Lo típico de ellas es movilizar recursos que exceden la base anímica vivida, sin pretender por ello crear o fingir una situación afectiva no presente. En este caso las manifestaciones de la Gesinnung original parecen emanciparse de ella, "flotan sobre la sólida realidad en vez de manifestarla" 11 (UF, 60). Dentro de esta forma de disposiciones de ánimo pueden distinguirse, a su vez, entre disposiciones trascendentes o suprarreales, disposiciones episódicas o co-reales y disposiciones provisionales o infrarreales. Las disposiciones suprarreales se caracterizan por una cierta "exhuberancia" de su materia anímica. Es el caso del orador que según va progresando en su discurso se va "acalorando" un poco o de una exagerada muestra de agradecimiento. A estas disposiciones les falta, por tanto, la realidad plena. 
Por su parte, las disposiciones episódicas o co-reales son aquellas que transcurren paralelamente a la vida anímica real en una suerte de segundo plano. Es lo que sucede cuando alguien advierte un movimiento de amistad con alguien con el que está despachando un negocio ${ }^{12}$.

Por último, las disposiciones provisionales o infrarreales son aquellas que no son aún plenamente reales, pero que están a la espera de su confirmación. Ferrer ofrece algunos ejemplos ilustrativos de las mismas: "una sospecha acerca del comportamiento de otro nos hace incoar una disposición latente hacia él, sin tenerla todavía por efectiva; o bien el no cumplimiento de ciertos anhelos provoca un estancamiento anímico o flujo vital contenido, que es también infrarreal. Vienen a ser un represamiento de la disposición anímica actual, a la que privan de dirección, quedando obstruida la entera manifestación de su realidad ${ }^{13}$.

El tercer tipo de modificaciones de las disposiciones de ánimo actuales es el constituido por las disposiciones "refrenadas". Aquí es importante ser consciente de que el sujeto psíquico no es siempre aquel que vive sus Gesinnungen de modo completamente pasivo (untätige Erleber), sino que toma postura con respecto a ellas. Este modo de comportarse o toma de postura con respecto a las propias disposiciones anímicas puede ser muy variado. Uno de estos modos es el "refrenar" las disposiciones que surgen en él. Es lo que sucede, por ejemplo, con un arrebato de hostilidad hacia alguien que nos está molestando, pero al que no se da curso ${ }^{14}$.

El análisis de las diversas variantes de Gesinnungen actuales nos ha mostrado que éstas se "acercan" y "alejan" del centro de la conciencia. Así veíamos que en el caso de las disposiciones anímicas actuales inauténticas el sujeto es capaz de provocarlas. En el caso de las auténticas es, más bien, capaz de favorecerlas o impedirlas, pero no de provocarlas en el sentido de una creación voluntaria directa. Ello muestra, a juicio de Pfänder, que el poder del sujeto sobre las vivencias anímicas no es absoluto. En ocasiones, surgirán disposiciones anímicas en la, por así decir, "periferia" de éste, sin su intervención directa ${ }^{15}$. En cualquier caso, lo que nos interesa destacar aquí es que con independencia de cómo sean de hecho, las disposiciones anímicas tienen su origen en el sujeto psíquico, el cual es no sólo el punto de partida de las Gesinnungen, sino también su fuente. Todo esto pone de manifiesto, según Pfänder, la necesidad de distinguir entre el "yo central" (Ich-Zentrum) y el "sí mismo" (Selbst). Sería un error considerar al sujeto psíquico como si se tratara de un "ser puntual” (ein punktförmiges Wesen) el cual no tuviera división alguna, cuando en realidad es

\footnotetext{
${ }^{12}$ Cf. Ferrer, Urbano, op.cit., p. 61.

${ }^{13}$ Ibid.

${ }^{14}$ El ejemplo es de U. Ferrer. Cf. ibid.

15 "El yo central activo emerge a veces de modo discontinuo, inmune a las disposiciones afectivas, pudiendo cerrarse por principio a ellas, como en los casos del juez o del investigador, o, en cambio, refrenarlas en algunas de sus dimensiones, como la intensidad, velocidad, peso..., o, por el contrario, darles cauce... El mismo yo central, que cuando está bajo el influjo de los movimientos disposicionales se sume en la pasividad, o que se recubre en parte con las disposiciones afectivas procedentes de la periferia, es el que también puede desprenderse de ellas, cuando se pronuncia voluntaria y responsablemente" (Ferrer, Urbano, op.cit., p. 62).
} 
"una entidad con divisiones" (ein in sich gegliedertes Gebilde) ${ }^{16}$. El sujeto psíquico posee una cierta extensión de diferentes lugares. Estos lugares no están todos en el mismo orden, sino que hay uno de ellos que es el centro psíquico de la totalidad de los otros lugares. Este centro psíquico es al que Pfänder llama yo-sujeto central (Ich-Zentrum) y a la totalidad de los otros lugares o "capas" del sujeto psíquico se le denomina sí mismo (Selbst).

Como señala Urbano Ferrer, los movimientos anímicos (no solamente las Gesinnungen) -se disponen "por referencia al yo central, que hace de punto medio para situar aquellos movimientos" ${ }^{\prime 1}$. Es precisamente - como señala también este autor - "desde la centralidad del yo, que toma una u otra posición en relación con las disposiciones afectivas, se hace posible su consideración ética" ${ }^{18}$. De este modo, llegamos a los umbrales de un nuevo nivel de análisis de las disposiciones de ánimo. Frente a una multiplicidad de este tipo de vivencias nos encontramos ahora con una suerte de disposición fundamental de ánimo - a la cual habría que denominar más acertadamente "disposición moral de fondo" - anclada en el yo central y responsable, en última instancia, de las diferentes tomas de posiciones con respecto a las múltiples disposiciones afectivas. Estamos pues ante una dirección voluntaria habitual que, en principio, puede entenderse como una orientación meramente formal de la voluntad (Kant) o como una dirección de valor aunque sin "contenido de imagen" (Scheler). En cualquier caso, como señala el Husserl de la Einleitung in die Ethik es a esta disposición moral de fondo a la que nos referimos cuando juzgamos el "carácter" de una persona.

Llamamos, 'ético' no solamente a las voliciones y acciones con sus fines, sino también a las permanentes disposiciones de ánimo en la personalidad en cuanto direcciones voluntarias habituales (habituelle Willensrichtungen). 'Éticos', más diferenciadamente, éticamente loables o rechazables, éticamente positivos o negativos, llamamos además a los deseos o a los fines de éstos en cuanto tales; también a algunos sentimientos y afectos. Así a algunas alegrías las denominamos 'bellas', nobles, malas, descaradas y vemos en ella predicados éticos. Lo mismo sucede con las disposiciones de ánimo correspondientes, con direcciones del sentimiento como amor y odio. De este modo, juzgamos la totalidad de las características anímicas habituales y, dicho con una sola palabra, el 'carácter' todo de una persona como ético o éticamente reprobable, tanto el carácter innato como el adquirido $\mathrm{y}$, en última instancia y muy especialmente, la persona misma ${ }^{19}$.

\footnotetext{
${ }^{16}$ Cf. Pfänder, A., Zur Psychologie der Gesinnungen, II, p. 66.

${ }^{17}$ Ferrer, U. op.cit., pp. 61-62.

${ }^{18} \mathrm{Ibid}$.

${ }^{19}$ E. Husserl. Einleitung in die Ethik. Vorlesungen Sommersemester 1920 und 1924. hrsg. v. Henning Peucker, Husserliana XXXVII, Dordrecht: Kluwer Academic Publishers, 2004, §2, p. 8. Trad. M.C.
} 


\title{
El Enigma de lo Sensible: Cuerpos que Sienten y Desean
}

\author{
Graciela Ralón de Walton
}

Universidad Nacional de San Martín

\begin{abstract}
Resumen
La rehabilitación ontológica de lo sensible encuentra su expresión en la noción de carne, que junto con la de reversibilidad constituyen la clave para la comprensión de la ontología merleaupontyana. La extraña adherencia entre lo sensible y el que siente, la generalización del sentir y la multiplicación de lo sensible como fenómeno de espejo configuran los núcleos para su explicitación.
\end{abstract}

En el curso titulado: "Naturaleza y logos: el cuerpo humano"1 Merleau-Ponty se propone, expresamente, considerar la relación de entrelazamiento entre el cuerpo humano y la Naturaleza. Se trata de describir la animación del cuerpo como la metamorfosis de la vida y el cuerpo como "cuerpo del espíritu". Esto exige, según el autor, una estesiología que debe dar cuenta de la capacidad de sentir y de desear tanto de mi cuerpo como de la de los otros.

Mi intención en este trabajo es bosquejar la teoría del sentir, que, al describir al cuerpo como sujeto de movimientos y de percepciones, hace visible la estructura sensorial de la carne. Comunión o extraña adherencia entre lo sensible y el que siente, generalización del sentir o propagación al cuerpo del otro y multiplicación de lo sensible como fenómeno de espejo constituyen los puntos centrales para la explicitación de la temática.

Es importante tener presente que al describir el sentir como la intencionalidad primordial en la que se sostiene la comunicación vital de nuestro cuerpo con el mundo ${ }^{2}$, Merleau-Ponty no pretende hacer una génesis empirista del pensamiento sino partir de la evidencia indiscutible de que "para pensar es necesario ver o sentir de algún modo y todo pensamiento conocido por nosotros le acontece a una carne" 3 . Si es evidente que la luz lastima los ojos y el placer o el dolor se siente a través de la piel es porque esas sensaciones afectan no a un yo pienso sino a un yo encarnado solicitado por el mundo. Se trata, con otras palabras, de despertar la relación carnal con el mundo, con las cosas y con los otros, que no es un puro accidente que sobreviene desde afuera, sino que constituye nuestra inserción primaria en el mundo. Esta inserción implica una relación de

\footnotetext{
${ }^{1}$ Merleau-Ponty, Maurice. Résumés de cours. Collège de France 1952-1960. Paris: Gallimard, 1968, pp. 171-180.

${ }^{2}$ Merleau-Ponty, Maurice. Phénoménologie de la perception. Paris: Gallimard, 1945, pp. 64-65.

${ }^{3}$ Merleau-Ponty, Maurice. L 'visible et le invisible: Paris: Gallimard, 1964, p. 191.
} 
mutua pertenencia, que Merleau-Ponty ha descrito como comunión o extraña adherencia entre lo sensible y el que siente.

Contra la interpretación intelectualista que subordina la sensación al pensar y obliga a dejar de ser para conocer, Merleau-Ponty afirma que sería absurdo decir que veo con mis ojos o escucho con mis oídos, porque mis ojos o mis oídos son incapaces, antes de ser en el mundo, de procurarse aquello que será visto u oído. La sensación sugiere y significa algo más allá de sí misma, pero aquello a lo que alude sólo es reconocido por la familiaridad del cuerpo con lo aludido, esto es, por un saber que sigue siendo latente y que le deja a lo percibido su opacidad y su ecceidad. Con otras palabras, la sensación es intencional porque el cuerpo encuentra en lo sensible la propuesta de un determinado ritmo de existencia, por el cual queda expuesto a lo exterior. "Si las cualidades irradian en torno suyo cierto modo de existencia, si tienen un poder de encantamiento y un valor sacramental, es porque el sujeto que siente simpatiza con ellas" ${ }^{4}$.

Más precisamente, las relaciones del hombre que siente y de lo sensible son comparadas con las de un hombre que quiere dormir y el sueño. Así, comenta Merleau-Ponty, en el momento en que alguien se acomoda para dormir dispone su respiración para invocar al sueño y, repentinamente, su boca comunica con algún pulmón exterior que solicita y rechaza la respiración, de manera tal que el sueño aludido como significación se convierte en situación ${ }^{5}$. Del mismo modo alguien oye o mira atentamente una situación y, de repente, lo sensible agarra su oído o su mirada, de manera que todo el cuerpo se entrega a esta manera de mirar y llenar el espacio que se llama el azul o el rojo. Lo que queremos poner de manifiesto es que de parte de lo sensible hay una solicitación a la que mi cuerpo responde con sus poderes perceptivos y esta sincronización está sostenida porque ambos emergemos de una sensibilidad que nos rodea y a la que debemos su espesor.

El sentir, tal como es descrito en el capítulo correspondiente de la Fenomenología de la percepción, es altamente significativo como preanuncio de la noción de carne. Si la mirada se acomoda al color y la mano se amolda a lo duro o a lo blando es porque de ambas partes proviene una iniciativa o una solicitud, que lleva a Merleau-Ponty a caracterizar el sentir como "comunión".

La elaboración de la noción de carne, como eje de la ontología merleaupontiana, se dirige a mostrar que el sujeto que ve o toca y el objeto visto o tocado deben ser pensados como emergentes de un tejido común que los engloba y del que emergen diferenciándose, sin por ello perder su identidad. La figura de la dehiscencia que Merleau-Ponty utiliza para ilustrar la doble apertura del cuerpo, sirve también para ilustrar cómo la carne del cuerpo y la carne del mundo, que constituyen las dimensiones de la carne, se enlazan o se articulan como sobre un mismo tronco.

\footnotetext{
${ }^{4}$ Merleau-Ponty, Maurice. Phénoménologie de la perception, p. 245.

${ }^{5}$ Cf. idem, p. 246.

${ }^{6}$ Idem, p. 247.
} 
Se trata de mostrar que entre el que ve y lo visible hay una extrańa adherencia por la que, al mismo tiempo que están entrelazados el uno en el otro, están, sin embargo, distantes uno del otro. Hay un espesor de la carne que forma la visibilidad de la cosa y la corporalidad del que ve, sin que signifique un obstáculo entre ambos, sino su medio de comunicación.

En virtud de ello, el ser que siente solo puede poseer lo sensible si lo sensible lo posee a él, si pertenece a lo sensible, "si con arreglo a lo prescrito por la articulación entre la mirada y las cosas, es alguien que siente, capaz, por una singular inflexión, de sentirlas, siendo él una de ellas"7. Ahora bien, el volverse hacia lo sensible tiene su reverso en un encontrarse rodeado por el mundo. Los dos órdenes a los que pertenece el sintiente sensible revierten uno en el otro y esto en virtud de la reflexividad corporal por la cual mi cuerpo se desdobla y, siendo cosa entre las cosas, las siente y se siente. Entre el cuerpo como cosa sensible y el cuerpo como sintiente hay "inserción recíproca y entrelazamiento de uno en otro" o mejor dicho, "hay dos círculos o dos torbellinos, o dos esferas, concéntricas cuando yo vivo ingenuamente, y desde que yo me interrogo, un poco descentradas una por relación a la otra" ${ }^{8}$.

Para describir esta mutua pertenencia quisiera citar un pasaje en el que Rilke describe de manera magnífica la experiencia de la carne puesta de manifiesto a través del color. En una carta del 22 de octubre de 1907 Rilke le escribe a su esposa: "La sala cierra hoy. Y como regreso por última vez, quisiera ir y volver a ver un violeta, un verde o aquellos tonos azules, los cuales me parece que hubiese tenido que verlos mejor para no olvidarlos jamás. Y, por más que me haya tan a menudo detenido con una perfecta atención, la gran arquitectura coloreada de La mujer en el sillón rojo se revela tan difícil a memorizar como un número de varios decimales. Sin embargo, yo me había impregnado de él cifra por cifra. La conciencia de su presencia exalta mi sensibilidad hasta en el sueño, mi sangre la describe en mí, pero el lenguaje permanece al exterior sin que uno lo invite a entrar. ¿Te he hablado de ello?”. Más adelante escribe en la misma carta: "Es como si cada punto del cuadro tuviera conocimiento de todos los otros. Tanto más participa cada uno, tanto más se combinan adaptación y rechazo; tanto más cada uno vela, a su manera, por el equilibrio y lo asegura... Todo no es más que un asunto de colores entre ellos. En este vaivén de mil influencias recíprocas, el interior del cuadro vibra, flota en sí mismo, sin un solo punto inmóvil... Te imaginas la dificultad de abordar de manera precisa estos hechos"

La experiencia de la pintura nos hace ver con claridad que el que ve y lo visible no están enfrentados, no hay cosas idénticas a sí mismas que posteriormente se ofrecen a un sujeto que las ve, ni tampoco el sujeto es un sujeto vacío que con posterioridad se abre a las cosas. Lo que hay son cosas que no podemos "ver

\footnotetext{
${ }^{7}$ Cf., Merleau-Ponty, M. Le visible et $l$ 'invisible, p. 178.

${ }^{8}$ Idem, p. 182.

${ }^{9}$ Rilke, Rainer María. Cartas sobre Cézanne. Madrid: Paidos, 1992, pp. 58-59.
} 
desnudas" porque la mirada las "envuelve", las "viste" con su carne. MerleauPonty se pregunta en qué consiste esa "[...] virtud singular de lo visible que hace que, estando en el extremo de mi mirada, sea sin embargo, más que el correlato de mi visión" ${ }^{10}$. Para comprender esto, el autor comienza por instalarse del lado de lo sentido examinando, como ejemplo, el modo de aparición del color. En primer lugar, advierte que la captación de un color no es la captación de un quale. Si bien su percepción exige una cierta manera de captarlo, el rojo percibido emerge de una tipicidad rojiza. El color rojo que solicita la mirada lo es en tanto que se encuentra ligado ya sea a otros tipos de rojo que están a su alrededor, y con los que forma una constelación, ya sea a otros colores. En otras palabras, el color no aparece como una cualidad que una vez recibida constituye en sí misma un mensaje indescifrable y evidente, sino que es "un nudo en la trama de lo simultáneo y de lo sucesivo"11.

Esta descripción revela que el color no solo se identifica en función de las asociaciones que provoca y se altera en función de su entorno, sino que, desde su lugar, señala hacia otros lugares y hacia otros acontecimientos próximos o lejanos. Por esta razón, lo visible no puede ser comprendido como un fragmento de ser absolutamente macizo que se ofrece a una visión vacía sino que, por el contrario, se trata de "[...] una cierta diferenciación, una modulación efímera en ese mundo, menos color o cosa, pues, que diferencia entre las cosas y los colores, cristalización momentánea del ser coloreado o de la visibilidad”12.

Si ahora consideramos la visión desde la perspectiva del que ve, es necesario insistir en que Merleau-Ponty descarta la posibilidad de una mirada que contemple el mundo desde afuera. Por el contrario, la mirada "envuelve, palpa y se ciñe a las cosas visibles". Como si el que ve estuviera con las cosas en una relación de "armonía preestablecida", como si, en su estilo brusco e imperioso, la mirada conociera las cosas antes de conocerlas y no se pudiera decir si es la mirada o son las cosas las que se imponen. La pregunta acerca de esta connivencia encuentra una respuesta en el carácter de la palpación táctil, ya que en ella el que interroga y lo interrogado se encuentran más próximos que en el caso de la visión. Así, al mismo tiempo que sentida desde adentro, una mano es accesible desde afuera como tangible para la otra mano y, en cuanto tangible para esa mano, ocupa un lugar entre las cosas que toca. A la vez tocante y tangible, la mano "abre sobre un tangible del que ella misma forma parte"13. Ahora bien, no solo hay una extensión de lo que toca y lo que ve sobre lo tocado y lo visto, sino también una superposición entre lo tangible y lo visible. Ambos pertenecen a un mismo mundo en tanto están "incrustados" entre sí por obra de un mismo cuerpo que ve y toca. Mirada y tacto no son extrańos al mundo que contemplan y entre ambos polos se establece un "espesor de la carne" que no es un obstáculo, sino, por el contrario, un medio de comunicación porque constituye la visibilidad y la tangibilidad a la vez que la corporeidad:

\footnotetext{
${ }^{10}$ Merleau-Ponty, M. Le visible et l'invisible, p. 173.

${ }^{11}$ Idem, p. 174.

${ }^{12}$ Idem, p. 175.

${ }^{13}$ Idem, p. 176.
} 
La visión y el tacto existen cuando un cierto visible, un cierto tangible, se vuelve sobre todo lo visible y todo lo tangible del que forma parte, o cuando repentinamente se encuentra rodeado de ellos, o cuando entre él y ellos y por su comercio se forma una Visibilidad, una Tangibilidad, que no pertenece con propiedad al cuerpo como hecho ni al mundo como hecho ${ }^{14}$.

La Visibilidad (lo mismo vale para la Tangibilidad) no remite ni a un sujeto ni a un objeto y concentra en ella la pasividad y la actividad, de tal manera que la Visibilidad no se limita a la simple reunión de los visibles que componen lo que Merleau-Ponty llama "la visibilidad primera", sino que abraza igualmente las líneas de fuerza y las dimensiones que los visibles sugieren dando vida a una "visibilidad segunda", entremezclándose y envolviendo a la primera como su horizonte interior y exterior ${ }^{15}$.

La explicitación de la noción de carne debe tener en cuenta que: 1) hay una remisión recíproca entre lo visible y el que ve y entre lo tocado y el que toca, 2) una inscripción del que toca en lo visible y de lo visible en el que toca, y, finalmente, 3) una adherencia entre la voz y el oído que hace posible la inserción de la palabra en el mundo del silencio. Asimismo, todos estos intercambios se propagan a otros cuerpos a los que veo, toco y escucho, lo que hace evidente el fenómeno de la intercorporalidad.

La presencia del otro me atestigua que la experiencia del sentir no se agota en el yo siento, porque "yo siento que se me siente y que se me siente estando sintiendo y estando sintiendo ese hecho mismo en que se me siente [...]"16. Los roles del sujeto y de lo que se ve o se siente se invierten e intercambian; el yo se descentra y la propiedad fundamental de sentirse, que, por otra parte, hace que cada yo sea único, tiende paradojalmente a difundirse. El papel que juega el cuerpo en relación con la percepción de los otros es un caso eminente. En un primer momento, el yo cree dar a lo que ve su sentido de cosa vista y, sin embargo, basta con que una de esas cosas se sustraiga a esta condición para que el espectáculo se dé a sí mismo su propio espectador que no es el yo; en otros términos: “[...] ¿`cómo puedo ver alguna cosa que se pone a ver?” ${ }^{17}$. La solución reside en comprender que el cuerpo "[...] quita a nuestra existencia la densidad de un acto absoluto y único, hace de la 'corporalidad' una significación transferible $[. .$.$] "18. En otros términos, desde el momento en que el$ sujeto comienza a usar su cuerpo para explorar el mundo, el yo descubre que la relación con éste puede generalizarse de tal manera que el otro se desliza en la percepción que lleva a cabo del mundo. De esta manera, la identificación del yo, la generalización del cuerpo y la percepción del otro descansan sobre la "universalidad del sentir".

\footnotetext{
${ }^{14}$ Idem, p. 183.

${ }^{15}$ Cf. idem, p. 195.

${ }^{16}$ Merleau-Ponty, Maurice. La prose du monde. Paris: Gallimard, 1969, p. 187.

${ }^{17}$ Merleau-Ponty. Le visible et l'invisible, p. 194.

${ }^{18}$ Ibidem.
} 
Para que el otro aparezca como realmente otro es necesario que el cuerpo del otro que veo, y su palabra que escucho, me presenten a su modo aquello en lo cual mi yo no estará nunca absolutamente presente: una ausencia. Esta ausencia debe ser comprendida como "[...] cierta diferencia con arreglo a dimensiones que desde el primer momento nos son comunes, que predestinen al otro a ser espejo de mí como yo lo soy de él [...]"19. La referencia al espejo aparece en diferentes pasajes de la obra del autor. El espejo indica las relaciones entre el yo y el otro, el yo y el mundo o la de los otros entre sí. Más precisamente, es usada para indicar la indivisión de esos términos en la carne. En una nota de trabajo Merleau-Ponty escribe: "la carne es fenómeno de espejo" ${ }^{20}$. Ver no es mirar en un único sentido. La visión supone siempre una visión de la visión: "Puesto que veo, es necesario [...] que la visión sea doblada por una visión complementaria o por otra visión: sí mismo visto desde afuera, tal como me vería otro, instalado en medio de lo visible $[\ldots]^{21}$.

Ahora bien, el cuerpo que siente es un cuerpo que desea; por lo tanto, la estesiología se prolonga en una teoría del cuerpo libidinal. En el capítulo dedicado al cuerpo y la sexualidad, en la Fenomenología de la percepción, Merleau-Ponty insiste en la necesidad de reconocer la afectividad como un modo de ser original de la conciencia. El carácter erótico de la percepción da cuenta de que a través del deseo un cuerpo aparece ligado a otro cuerpo. "La percepción erótica no es una cogitatio que apunta a un cogitatum, a través de un cuerpo apunta a otro cuerpo, se hace en el mundo y no en una conciencia" ${ }^{22}$. Hay una comprensión erótica que es del orden del deseo, que comprende ciegamente ligando un cuerpo a otro cuerpo. Por otra parte, hay que tener presente que la motricidad está siempre ligada a una experiencia emocional impuesta por una relación con otras personas. La relación con los demás es tan primaria como la de nuestro propio cuerpo. El cuerpo es un sistema de equivalencias que permite no solo la percepción de las cosas sino también la percepción de los otros. Si la relación con los demás es tan primaria como la relación con nuestro propio cuerpo, el análisis de la percepción en términos de la articulación de lo visible-invisible debe tener su paralelo en un análisis de la empatía (Einfühlung) que pone de manifiesto también el arraigo natural del ser-para-otro y la dimensión de lo oculto respecto de los otros.

En este punto es importante tener presente que el esquema corporal no solo está relacionado con su entorno sino que implica la relación con otros esquemas corporales. Así como la sinergia caracteriza a cada cuerpo, hay una sinergia que compone un mundo en común.

La dimensión libidinal del esquema, relación de proyección-introyección, pone de manifiesto que el esquema corporal es un medio para percibir los

\footnotetext{
${ }^{19}$ Idem, pp. 114-115.

${ }^{20}$ Idem, p. 309.

${ }^{21}$ Idem, p. 177.

${ }^{22}$ Merleau-Ponty. Phénoménologie de la perception, p. 183.
} 
comportamientos de otros cuerpos a la vez que los otros perciben los de mi cuerpo. La constitución del otro se presenta como una experiencia estesiológica prefigurada en la de mi mano tocada que llega a ser tocante. La apertura a lo sensible que se lleva a cabo por una cuasi-reflexión del cuerpo da testimonio de que lo sensible es una experiencia compartida por otros cuerpos. El ser de lo sensible aparece como ser de coexistencia, de co-implicación y de co-percepción que transforma la intersubjetividad en intercorporeidad.

El esquema corporal es el eje del para sí y el para otro. La visibilidad de mi cuerpo lo es para los demás. Por ejemplo, cuando una mujer siente con signos imperceptibles que su cuerpo es deseado y mirado, sin siquiera mirar a quienes la miran, es porque entre ambos cuerpos se da una telepatía. Con otras palabras, el sentir la presencia ajena es posible porque el cuerpo está rodeado de un "halo de visibilidad" y basta la más ínfima indicación realizada por otro para activar la presencia inminente del otro. Presencia al ausente o del ausente es presencia de lo inminente, de lo latente o de lo oculto. El psicoanálisis de la naturaleza o estesiología pondrá de manifiesto lo siguiente: "Lo inconsciente es el sentir, puesto que el sentir no es posesión intelectual de 'eso que' es sentido, sino desposeimiento de nosotros para su beneficio, apertura" ${ }^{23}$. A partir de estas reflexiones se puede concluir que el deseo inconsciente que trabaja en el interior del sentir es el origen natural de la expresión. El hecho de que cada uno tenga participación en el otro, de que sea "una cifra o símbolo del otro" obliga a plantear el problema del otro como "una iniciación a una simbólica y a una tipificación de los otros, cuyo ser para sí y cuyo ser para otro son variantes reflexivas y no sus formas esenciales" 24 .

Con otras palabras: "Antes de ser y para ser sometidos a mis condiciones de posibilidad [...] es necesario que ellos estén ahi como relieves, desviaciones, variantes de una única Visión en la cual yo también participo" ${ }^{25}$. Así, los otros no son ficciones, ni posibles para siempre inactuales, sino "carne de mi carne". Hay que aclarar que esto no quiere decir que cada sujeto pueda vivir la vida de los otros o los otros la de cada sujeto: “[...] están definitivamente ausentes de mí y yo de ellos. Pero esta distancia es una extraña proximidad en cuanto se da con el ser de lo sensible [...]"26. Esta "milagrosa multiplicación de lo sensible" es lo que permite que las cosas tengan fuerza para más de uno y que, en el caso de los animales y los cuerpos humanos, no solo tengan caras ocultas, sino que su otro lado "[...] es un otro sentir que se encuentra a partir de mi sensible" 27 . Así toma fuerza la ontología de lo sensible, que es la base del fenómeno de la encarnación y hace patente que ni las cosas pertenecen al espacio de la conciencia, ni las miradas son actos de conciencia, "[...] sino apertura de nuestra carne colmada al instante por la carne del universo" 28 .

\footnotetext{
${ }^{23}$ Merleau-Ponty, M. Résumés de cours. Collège de France 1952-1960, p. 179.

${ }_{24}^{24}$ Merleau-Ponty. Le visible et l'invisible, p. 114.

${ }^{25}$ Ibidem.

${ }^{26}$ Idem, p. 23.

${ }^{27}$ Ibidem.

${ }^{28}$ Ibidem.
} 


\title{
Sexualidad y Poder en el Marco de la Fenomenología del Cuerpo (J.-P. Sartre, M. Merleau-Ponty, S. de Beauvoir)
}

\author{
Esteban A. García \\ Universidad de Buenos Aires
}

\begin{abstract}
Resumen
Este trabajo se refiere a tres abordajes fenomenológicos de las relaciones entre la sexualidad y el poder, mostrando sus cercanías y contrastes. Sólo el reconocimiento de la prioridad de la socialidad (M. Merleau-Ponty) por sobre la dialéctica de la conciencia y su otro (J.-P. Sartre) permitirá elucidar el modo en que ambos órdenes se articulan. Ilustramos esta tesis refiriéndonos a la reflexión de S. de Beauvoir acerca de la diferencia sexual.
\end{abstract}

Para abordar las cuestiones específicas anticipadas en el título de este trabajo será necesario recordar primeramente algunos contrastes generales entre las filosofías de Sartre y Merleau-Ponty. Uno de los propósitos centrales de la Phénoménologie de la perception, de Merleau-Ponty, es afirmar la esencial encarnación de la conciencia o del yo, y mostrar las múltiples consecuencias de este "hecho esencial"1. En la anterior afirmación consideramos los términos "conciencia" y "yo" como equivalentes -aun si sus significados no son exactamente congruentes- ya que la afirmación merleaupontyana "yo soy un cuerpo" implica básicamente una crítica al modelo cartesiano según el cual la conciencia es yoica y el cuerpo es una parte de esa máquina universal que es la res extensa $a^{2}$. Frecuentemente Merleau-Ponty se refiere en su obra a la ontología fenomenológica de Sartre casi como a una mera variante de este dualismo propio de la tradición cartesiana (que dista de representar las complejidades del pensamiento de Descartes, tal como Merleau-Ponty advierte reiteradamente) ${ }^{3}$.

\footnotetext{
${ }^{1}$ Referirnos al "hecho esencial" de la "encarnación de la conciencia" puede acarrear ciertos malentendidos que es necesario disipar. El término "encarnación”, frecuentemente utilizado por Merleau-Ponty, no supone una previa existencia incorporal de la conciencia y, en este sentido, no conlleva connotaciones religiosas a pesar de sus resonancias. En cambio, el uso del término pretende indicar que la filosofía merleaupontyana se propone "encarnar" la conciencia cartesiana o, más en general, moderna, frecuentemente propuesta como incorporal. La conciencia sólo existe corporalmente, y de esto se sigue el entrelazamiento del ámbito de lo empírico y el de lo trascendental, hechos y esencias: "la esencia debe ser finalmente tan contingente como un hecho. Asimismo en la dirección opuesta, el hecho y el conocimiento de hechos debe contener un conocimiento de esencia, un conocimiento a priori". (Merleau-Ponty, Maurice. La fenomenología y las ciencias del hombre. Buenos Aires: Nova, 1977, pp. 65, 66). Dicho de un modo más simple, una vez reconocida la carnalidad de la conciencia, lo que la conciencia esencialmente es se torna inseparable de las contingencias históricas, geográficas y sociales en las que halla su realidad. Esto implica para MerleauPonty el abandono de una filosofía trascendental o a priori pura, y el entrelazamiento de la filosofía con las ciencias, en particular las ciencias humanas; recíprocamente, los resultados de estas últimas adquieren una significación trascendental.

${ }^{2}$ La afirmación "yo soy un cuerpo" puede leerse por ejemplo en Merleau-Ponty, Maurice. Fenomenología de la percepción. México: FCE, 1957, p. 82 (en adelante citada como FP).
} 
Paradójicamente, en la obra de Sartre L'être et le néant también puede leerse la afirmación de que la conciencia es su cuerpo, e incluso que el cuerpo es todo lo que la conciencia es, pero solamente con la salvedad inmediatamente ańadida de que lo más propio de la conciencia es su actividad negadora del ser. La conciencia "es lo que no es y no es lo que es", y ser conciente no consiste sino en este acto de "nadificar" (néantiser), lo que es, comenzado por lo más próximo, la corporalidad que se es: "yo soy mi cuerpo en la medida en que soy; no lo soy en la medida en que no soy lo que soy; le escapo por mi nihilización”“ ${ }^{\text {. Mi }}$ raza, mi clase, mi estructura fisiológica, mi pasado: todo ello -afirma Sartre- es mi cuerpo, y mi cuerpo es la forma particular que toma "la necesidad de mi contingencia" o, en términos propiamente sartreanos, la "facticidad". Pero esta facticidad, este ser dado, ser pasado o ser cuerpo de la conciencia es para Sartre continuamente trascendido: "aun esta invalidez que padezco [...] la trasciendo hacia mis propios proyectos, [...] no puedo ser inválido sin elegirme inválido,

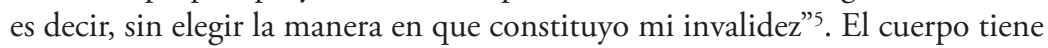
así en la ontología fenomenológica sartreana este extraño estatuto, que Merleau-Ponty define como el de una mala "ambivalencia" u oscilación: la encarnación es, en cierto sentido, esencial a la conciencia, pero sólo en la medida en que ella necesita apoyarse en el ser para ejercer la negación que la define. Como observa Merleau-Ponty, en definitiva para Sartre "lo que soy sólo lo soy a distancia, ahí, en ese cuerpo, ese personaje, esos pensamientos, que empujo

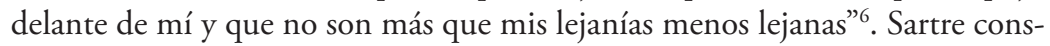
tató acertadamente, tal como Merleau-Ponty, que en el cuerpo se resumen todos los problemas de la trascendencia de la conciencia: tener un pasado, habitar un mundo, estar en relación -o, más precisamente, ser en relacióncon otras conciencias. Sin embargo, mientras que todo el análisis de Sartre preserva un núcleo de distanciamiento, libertad e instantaneidad como lo más propio de la conciencia, Merleau-Ponty acepta la condición carnal como un dato primario e insoslayable que hace necesario redefinir lo que buena parte de la filosofía moderna ha entendido por la conciencia.

El vaivén de la conciencia sartreana en relación con su carnalidad es paralelo - y en realidad idéntico- al de su relación con otras conciencias. Sartre afirma que

\footnotetext{
${ }^{3}$ Merleau-Ponty en diversas ocasiones alude a la "visión doble" de Descartes. Este último, observa Merleau-Ponty, "distingue el cuerpo tal como es concebido por el uso de la vida [dando lugar a la cuestión del compuesto alma-cuerpo], y el cuerpo tal como es concebido por el entendimiento [dando lugar a un dualismo ontológico estricto]" (FP, p. 219). La consideración merleaupontyana del sartrismo como deudor del cartesianismo se topa con importantes obstáculos, siendo uno de los más evidentes el que para Sartre, como es sabido, la conciencia no es esencialmente yoica, sino que el ego es en primera instancia un objeto para la conciencia (Cf. Sartre, Jean-Paul. La transcendance de l'égo: esquisse d'une description phénoménologique. Paris: Vrin, 1965). Merleau-Ponty hace caso omiso de esta cuestión, como le fuera reprochado por Beauvoir en su defensa de Sartre (Cf. De Beauvoir, Simone. Merleau-Ponty et le Pseudo-Sartrisme. Paris: Gallimard, 1955), aunque puede verse en aquella omisión merleaupontyana una crítica velada a las dificultades e incongruencias propias de la formulación sartreana misma. Es significativo en este sentido que Simone de Beauvoir haya cometido frecuentemente en El segundo sexo la misma omisión que le critica a Merleau-Ponty.

${ }^{4}$ Sartre, Jean-Paul. El ser y la nada. Ensayo de ontología fenomenológica. Barcelona: Altaya, 1993, p. 353 (en adelante citado como SN).

${ }^{5} \mathrm{SN}$, p. 355.

${ }^{6}$ Merleau-Ponty, Maurice. Lo visible y lo invisible. Barcelona: Seix Barral, 1970, p. 80 (en adelante citado como VI).
} 
la mirada del otro logra efectivamente que esa constante huida del ser que es la conciencia se coagule, quedando así enviscada en su cuerpo ${ }^{7}$. El otro se introduce en el movimiento de nihilización mismo que es la conciencia, mediante la experiencia de una pasividad como la que delata la vergüenza. Para Sartre el otro me da el ser, puesto que el cuerpo es lo único que la conciencia es y mi cuerpo es precisamente mi ser-para-otro: "si hay otro [...], tengo un afuera, tengo una naturaleza; mi caída original es la existencia del otro" ${ }^{8}$. Ahora bien, puesto que la mirada del otro me hace objeto o cuerpo, desde esta situación corporal puedo tomar distintas actitudes frente al otro para recuperar el no-ser, la ligereza del distanciamiento o de la nihilización que es lo más propio de la conciencia. Si pudiera remontar la alienación que sufro por la mirada del otro y encarnar absolutamente mi libertad llegaría a "ser mi propio fundamento": la conciencia sería "para-sí-en-si”". Para Sastre, siempre me dirijo al otro en esta empresa íntimamente contradictoria, destinada al fracaso e incluso "de mala fe". Mis relaciones con los otros se abren a dos opciones básicas: puedo intentar absorber la trascendencia o libertad ajena sin quitarle su carácter de tal mediante la relación amorosa, o bien la conciencia puede "elegir hacerse deseo" con el fin de objetivar al otro". El deseo sartreano es una forma de conciencia, y una vez definida la conciencia como libertad es necesario para Sartre pensar que el deseo surge de una elección. Es verdad que la conciencia queda "enviscada", "enturbiada" o "empastada" en el deseo, pero este carácter de pasividad propio de la conciencia, que es "arrastrada" por su deseo, deriva de quedar "atrapada en su propia trampa": la pasividad sartreana, tal como Merleau-Ponty advierte sagazmente en tono de crítica, es siempre secundaria o derivada de una actividad originaria, es "auto-pasivización" y por lo tanto es una falsa pasividad ${ }^{10}$. Según Sartre, el deseo consiste propiamente en la "caída en la complicidad con el cuerpo", o más exactamente, con la carne: "me hago carne en presencia del prójimo para apropiarme de su carne”. La chair (carne), en la acepción del filósofo, es el cuerpo desligado de sus referencias mundanas; es decir, el cuerpo que ha dejado de ser un centro de perspectiva en la percepción y de oficiar como hábil operador en tanto primer instrumento en el plexo utensiliario del mundo. En el deseo me hago ineficaz e inoperante para hacer inoperante al otro: "el deseo es una tentativa para desvestir el cuerpo de sus movimientos como de sus ropas y hacerlo existir como pura carne; es una tentativa de encarnación del cuerpo ajeno. “[...] Las caricias son apropiación

\footnotetext{
${ }^{7}$ La "viscosidad" es una propiedad a la que Sartre dedica largos análisis en El ser y la nada, y en tal propiedad, como notó Merleau-Ponty en Las aventuras de la dialéctica, se precipitan todos los problemas de la ontología sartreana. "Enviscada" se utiliza aquí en el sentido de "pegada" -lo que alude a una pérdida de la levedad y velocidad que caracteriza para Sartre a la conciencia-. La conciencia "enviscada" es también una conciencia "enturbiada", lo que connota la pérdida de su transparencia.

${ }^{8} S N$, pp. 290, 291. Ya que el cuerpo y el otro son cuestiones íntimamente asociadas en Sartre, los reparos de Merleau-Ponty son simétricos respecto de ambos análisis sartreanos: "la mirada ajena me saca de mí mismo pero su poder sobre mí viene exactamente medido por el consentimiento que le he dado a mi cuerpo, a mi situación; su fuerza alienadora procede de que me alieno yo mismo". Merleau-Ponty concluye que, en Sartre, "filosóficamente hablando, no hay experiencia del otro" (VI, p. 96).

${ }^{9} \mathrm{~S} N$, pp. 411, 415.

${ }^{10}$ Merleau-Ponty critica extensamente esta "falsa pasividad" sartreana en Le problème de la passivité: Le sommeil, l'inconscient, la mémoire. Notes de Cours au Collège de France (1954-1955). París: Belin, 2003, pp. 157 ss.
} 
del cuerpo del otro, [...] lo escinden de las posibilidades que lo rodean", lo desarman y desarticulan. Pero el proyecto de ser "en-sí-para-sî" que guía al deseo está condenado al fracaso: la conciencia nunca puede ser totalmente carne porque siempre continúa sabiéndose libre y transparente al dejarse hipnotizar o adormecer por la situación erótica. Siempre está un poco más allá del enredo y eso se le hace especialmente patente, según Sartre, cuando el deseo culmina en el placer del orgasmo que "motiva la aparición de una conciencia reflexiva que es atención al placer"11. Este nuevo despuntar de la conciencia pura da ocasión al análisis sartreano para considerar a continuación el sadismo, en el que sólo intento reducir al otro a su carne permaneciendo como sujeto no enviscado por el deseo, seco y frío. Sartre establece un círculo de posibles relaciones con el otro que no expondremos aquí: el amor, el masoquismo, el deseo sexual y el sadismo se suceden circularmente como tentativas frustradas de perseguir la imposible vocación humana de ser "en-sí-para-sí", llevando el fracaso de cada una a la otra. Así, "somos indefinidamente remitidos del otrosujeto al otro-objeto y recíprocamente, la carrera no se detiene nunca y esta carrera con sus bruscas inversiones de dirección constituye nuestra relación con el prójimo"12.

Mientras que en Sartre el cuerpo como ser-para-otro de la conciencia comporta un fuerte significado de alienación -idea ligada a que para el filósofo "el conflicto es el sentido originario del ser-para-otro" ${ }^{13}$-, para Merleau-Ponty el ser corporal de la conciencia seńala primeramente su participación en una intercorporalidad, en el seno de la cual el conflicto entre dos sólo es una figura parcial y derivada. Se hará necesario resumir algunas ideas centrales de la primera parte de la Phénoménologie de la Perception para hacer patente este contraste. La dimensión originaria de la experiencia que esta obra intenta elucidar es la propia del "cuerpo vivido". No vivo mi cuerpo como aquel que es descripto por la anátomo-fisiología, ni tampoco como una representación ni como una imagen. Me experimento corporalmente como un repertorio latente de posibilidades de comportamiento - un "esquema motriz"- que resulta de la sedimentación de hábitos, razón por la que Merleau-Ponty se refiere al cuerpo vivido como a un "cuerpo habitual". No solamente estos hábitos que conforman mi cuerpo vivido han sido aprendidos intercorporalmente en un determinado contexto cultural e histórico, sino que por sí mismos no son otra cosa más que modos particulares de arreglármelas con las cosas, de habitar entornos y -aquello que nos interesa particularmente aquí- de relacionarme con otros cuerpos. En ambos sentidos, entonces, me vivo corporalmente siempre como término de una relación, momento de una estructura, partícipe de una intercorporalidad: la ontología de la conciencia encarnada no es autónoma e independiente como la del cogito, sino que por ser cuerpo estoy siempre ya "en situación", ontológicamente "en circuito" e incluso "mezclado" con un mundo

\footnotetext{
${ }^{11}$ Resumimos aquí de modo muy simplificado los desarrollos de Sartre acerca del deseo erótico en $S N$, pp. 404 ss.

12 SN, p. 432.

${ }^{13}$ SN, p. 389.
} 
y otras conciencias corporales ${ }^{14}$. Así afirma Merleau-Ponty que "experimento mi cuerpo como facultad de determinadas conductas y de un determinado mundo. Ahora bien, es precisamente mi cuerpo el que percibe el cuerpo del otro y encuentra en él algo así como una prolongación milagrosa de sus propias intenciones. [...] De ahí en adelante, puesto que las partes de mi cuerpo forman conjuntamente un sistema, el cuerpo del otro y el mío forman un solo todo, el anverso y el reverso de un único fenómeno, y la existencia anónima, cuya huella es mi cuerpo en todo momento, habita [...] estos dos cuerpos a la vez" 15 . Desde esta perpectiva merleaupontyana en la que la "atmósfera social" o el "campo intersubjetivo" 16 de la existencia corporal es el dato primario, el problema del solipsismo se disuelve: "necesitamos, pues, redescubrir [...] el mundo social [...] como campo permanente o dimensión de la existencia: puedo muy bien apartarme de él, pero nunca dejar de estar situado en relación con él" ${ }^{\prime 1}$. El reproche que reitera Merleau-Ponty a Sartre a través de las páginas de Les aventures de la dialectique es precisamente su imposibilidad de pensar esta preexistencia de lo social respecto del drama individual de la conciencia y su otro: "lo social no puede entrar en su filosofía del cogito -dice MerleauPonty refiriéndose a la filosofía de Sartre- más que por el camino del alter ego. [...] La 'socialidad' dada es un escándalo para el yo pienso"18. La precedencia de lo social seńala también en el análisis merleaupontyano la precedencia de "ese intermundo que llamamos historia" respecto de toda voluntad autónoma y de toda conciencia dadora de sentido a los hechos: solamente "le doy un sentido a la historia porque ocupo en ella un cierto lugar de estacionamiento, porque otros lugares posibles me están ya designados por el paisaje histórico". También "el lugar del otro se encuentra ya preparado. [...] La conciencia verdaderamente comprometida en un mundo y en una historia sobre la cual tiene asidero, pero que la superan, no es una conciencia insular. Ya en el espesor del tejido sensible e histórico siente moverse otras presencias. [...] Entre su perspectiva y la de los demás existe una articulación y un pasaje regulado. [...] $\mathrm{Ni}$ en la historia privada ni en la historia pública la fórmula de sus relaciones es 'o él o yo' [...] porque esas relaciones ya no son más el 'tête-à-tête' de dos para-sí sino el engranaje de dos experiencias, una sobre la otra, que sin llegar nunca a coincidir dependen de un único mundo" ${ }^{19}$.

\footnotetext{
${ }^{14}$ Merleau-Ponty afirma reiteradamente que el cuerpo "es en circuito" con los otros cuerpos y con el mundo en sus cursos acerca de La Nature (Paris: Éditions du Seuil, 1995; en adelante citado como N). La afirmación de que estamos "mezclados con el mundo y con los demás en una confusión inextricable" se encuentra ya en $F P$, p. 497.

${ }^{15}$ FP, p. 389.

${ }^{16}$ FP, p. 494.

${ }^{17}$ FP, p. 397.

${ }^{18}$ Merleau-Ponty, Maurice. Las aventuras de la dialéctica. Buenos Aires: Leviatán, 1957, p. 174 (en adelante citado como $A D$ ). Desde el punto de vista de Merleau-Ponty, "en Sartre hay una pluralidad de sujetos, pero no hay intersubjetividad. [...] El mundo y la historia ya no es un sistema con varias entradas sino un haz de perspectivas inconciliables que nunca coexisten, que sólo el heroísmo sin esperanza del Yo mantiene juntos" (AD, p. 229).

${ }^{19}$ AD, pp. 222, 223.
} 
La sexualidad se integra al análisis de la Fenomenología de la percepción como una dimensión crucial de esta existencia encarnada que, en tanto corporal, es intercorporal, social e histórica. Más precisamente, según Merleau-Ponty, en la medida en que la sexualidad es la función de esas relaciones intercorporales que me constituyen haciéndome ser quien soy, ella no es tal o cual dimensión -ni siquiera la dimensión basal- de la existencia, sino la atmósfera misma en que se desarrolla nuestra existencia intercorporal. El cuerpo vivido en tanto esquema motriz, según la Phénoménologie de la perception, es a la vez un "esquema sexual" y toda intencionalidad perceptiva es inseparable de una "intencionalidad afectiva" y "libidinal" 20 . En sus últimos cursos el filósofo afirmará en sentido similar que "el deseo considerado desde el punto de vista trascendental es el tejido común de mi mundo como carnal y el mundo del otro [...]. El esquema corporal tiene una estructura libidinal [...] y sociológica. [...] La estructura estesiológica del cuerpo humano es pues una estructura libidinal, la percepción un modo del deseo" ${ }^{21}$. Estas reflexiones del último Merleau-Ponty no hacen más que enfatizar los términos de la Phénoménologie de la perception, donde ya se sostenía que la percepción de otro cuerpo humano como objeto "está habitada por una percepción más secreta: el cuerpo visible está subtendido por un esquema sexual [...] que acentúa las zonas erógenas, traza una fisonomía sexual y suscita los gestos del cuerpo masculino integrado en esta totalidad afectiva"22. Tras señalar la peculiaridad del ámbito ontológico correspondiente a esta intencionalidad libidinal, en la medida en que ésta no puede situarse ni en el organismo que describe la anátomo-fisiología ni en la inmaterialidad de un psiquismo, Merleau-Ponty afirma: "Un espectáculo tiene para mí una significación sexual, no cuando me represento, aunque sólo fuera confusamente, su relación posible con los órganos sexuales o con estados de placer, sino cuando existe para mi cuerpo, para esta facultad siempre lista a anudar los estímulos dados en una situación erótica y ajustar en ella una conducta sexual. Hay una 'comprehensión' erótica que no es del orden del entendimiento, puesto que el entendimiento comprende al apercibir una experiencia bajo una idea, mientras que el deseo comprende ciegamente ligando un cuerpo a otro cuerpo"23. Algunas teóricas feministas han señalado la omisión de la diferencia de género en este análisis merleaupontyano de la sexualidad. Sería posible deducir que, siendo el esquema sexual un repertorio de hábitos de comportamiento intercorporal aprendidos en el contexto de culturas particulares, las identidades de género serían patrones comportamentales idiosincráticos. Merleau-Ponty, sin embargo, no considera esta implicancia en su Fenomenología de la percepción. Allí puede leerse una universalización tácita de "los gestos del cuerpo masculino" -para citar sus términos- que no sólo parece diluir la diferencia genérica sino también invisibilizar sus aspectos asimétricos, dejando al margen la relación entre la sexualidad y el poder que el análisis

\footnotetext{
${ }^{20}$ Las ideas aquí resumidas se hallan expuestas en el capítulo titulado "El cuerpo como ser sexuado" de $F P$.

${ }^{21} N$, pp. $287,288,272$.

22 FP, p. 171.

${ }^{23} \mathrm{FP}, \mathrm{p} .172$.

${ }^{24}$ Cf. por ejemplo Grosz, Elizabeth. Volatile Bodies. Toward a Corporeal Feminism. Bloomington/Indianapolis: Indiana University Press, 1994, pp. 86-111.
} 
sartreano ponía en primer plano ${ }^{24}$. Sin embargo, Merleau-Ponty explicitará las implicancias que su concepción del cuerpo como atravesado por la intersubjetividad y la historia acarrea respecto de la diferencia genérica en los cursos de psicología dictados unos cuatro años después de publicada su Phénoménologie. Allí sostendrá que "la relación masculinidad-feminidad es un elemento dentro de un tejido total que comprende la relación madre-hijo, relación de la sociedad en cuestión con la naturaleza, relación con el extranjero y, en general, relación interhumana tal como existe en esta sociedad. No es posible hablar de lo femenino y de lo masculino puesto que cada civilización elabora un cierto tipo de masculinidad correlativo de un cierto tipo de feminidad, según su modo de existencia. Hay, en cambio, en el interior de una sociedad dada, un estereotipo sexual $^{25}$. La fecundidad de los conceptos merleaupontyanos para dar cuenta de la identidad de género desde el marco del cuerpo vivido como instancia de una cultura intercorporal -tal como el que esboza la Fenomenología de la Percepción- se comprobó, por otra parte, en análisis posteriores que de hecho se inspiraron en ellos. Nos referiremos brevemente en lo que sigue a los propios de $S$. de Beauvoir ${ }^{26}$.

Diversas teóricas, entre ellas Judith Butler y Sara Heinämaa, han discutido si Beauvoir piensa la diferencia sexual desde un marco sartreano o incluso clásicamente dualista -reformulando en términos del binario sexual la relación entre la conciencia y su otro, por un lado, y en términos del binario sexo/género la relación entre la naturaleza y la cultura- o bien escapa de estos dualismos desde la perspectiva merleaupontyana de la existencia encarnada ${ }^{27}$. Beauvoir efectivamente traduce la ontología fenomenológica sartreana a los términos de la díada sexual: la mujer es de hecho el Otro, el cuerpo y el sexo frente a una conciencia que se dice "humana" en el doble sentido del hombre y de la humanidad. Beauvoir se percata del hecho de que sólo al hombre le es posible ser propiamente conciencia en el sentido sartreano: guardar un núcleo de distanciamiento y trascendencia respecto de sus marcas corporales. Pero estas consideraciones distan de ser afirmaciones ontológicas acerca de una presunta esencia femenina, como parecen serlo en cambio las afirmaciones de la alteridad y el misterio femeninos en Le temps et l'Autre de Lévinas, a quien Beauvoir critica expresamente: "Supongo que el señor Lévinas no olvida que la mujer es también para sí, conciencia. Sin embargo, es chocante que adopte deliberadamente un punto de vista de hombre, sin seńalar la reciprocidad [...].

\footnotetext{
${ }^{25}$ Merleau-Ponty, Maurice. Merleau-Ponty à la Sorbonne. Resumé de cours 1949-1952. Dijon-Quetigny: Cynara, 1988, p. 495. El subrayado es de Merleau-Ponty.

${ }^{26}$ Recientemente Sara Ahmed se ha servido de los desarrollos merleaupontyanos para abordar el tema de la orientación sexual en Queer Phenomenology. Orientations, Objects, Others. Durham/London: Duke University Press, 2006. Ha sido particularmente Pierre Bourdieu quien abordó la relación entre diferencia genérica y dominación desde un marco que puede considerarse propiamente merleaupontyano, el de los hábitos comportamentales (Bourdieu, Pierre. La domination masculine. París: Seuil, 1998).

${ }^{27}$ Cf. Butler, Judith. Gender Trouble. Feminism and the Subversion of Identity. New York/London: Routledge, 1990; Heinämaa, Sara. “¿Qué es ser mujer? Butler y Beauvoir sobre los fundamentos de la diferencia sexual”. Mora, No 4 (1998), pp. 27-45. Si bien la reflexión de Beauvoir es anterior al desarrollo de la problemática explícita del binario sexo/género, Butler alega con buenas razones que una distinción semejante opera tácitamente en el modo de razonar de Beauvoir.
} 
Cuando escribe que la mujer es misterio, sobreentiende que es misterio para el hombre. De modo que esta descripción [...] es una afirmación del privilegio masculino" 28 . Ontológicamente, entonces, para Beauvoir hombres y mujeres son conciencias y, más enfáticamente que en Sartre y más cerca de MerleauPonty, conciencias encarnadas: "en verdad, el hombre, como la mujer, es carne, y por tanto, pasividad [...]. Cada uno de ellos vive a su manera el extrańo equívoco de la existencia hecha cuerpo. [...] En los dos sexos se desarrolla el mismo drama de la carne y el espíritu, de la finitud y la trascendencia; a ambos los roe el tiempo, los acecha la muerte" 29 . Sin embargo, continúa arguyendo Beauvoir, "lo que define de manera singular la situación de la mujer es que, siendo como todo ser humano una libertad autónoma, se descubre y se elige en un mundo donde los hombres le imponen que se asuma como lo Otro: se pretende fijarla en objeto y consagrarla a la inmanencia, ya que su trascendencia será perpetuamente trascendida por otra conciencia esencial y soberana" ${ }^{30}$. La mujer es entonces lo Otro porque históricamente "se ha constituido concretamente como lo Otro" ${ }^{31}$ y la perpetuación de los hechos tiende a transformarlos en esencias: "no se podrá impedir que la mujer no sea lo que ha sido hecha" ${ }^{2}$.

Así, lo que El segundo sexo pretende explicar es qué motivos particulares hicieron y hacen que las conciencias, en la medida en que nuestra cultura las distribuye en "dos categorías humanas" 33 , ocupen distintos lugares preasignados en la dialéctica existencial de la conciencia y su otro. En este sentido podría decirse que Beauvoir lee con ojos merleaupontyanos la ontología fenomenológica sartreana: hay una precedencia de la dimensión social e histórica -de ciertas "categorías humanas" - respecto de la dialéctica de las conciencias individuales, lo que las sitúa previamente en posiciones estructurales diferentes y asimétricas. Como observa Beauvoir, el problema no resulta "de una perversidad individual [...] sino de una situación contra la cual toda actitud singular es impotente" 34 , y esto hace que las posibilidades de cambio deban también plantearse en términos sociales. En este sentido Beauvoir recuerda la sabia sentencia de Stendhal que se refiere a la necesidad de plantar de una vez todo el bosque $^{35}$. En idéntico sentido Pierre Bourdieu, con espíritu merleaupontyano, ha señalado que si la experiencia femenina del cuerpo puede ser considerada el prototipo de la experiencia del "cuerpo-para-otro" -basta recordar la estrecha relación que en nuestra cultura tiene la mujer con su espejo-, esto es sólo una expresión particular de una entera estructura social. Esta última "está presente en el núcleo de la interacción, bajo la forma de los esquemas de percepción y

\footnotetext{
${ }^{28}$ De Beauvoir, Simone. El segundo sexo. Buenos Aires: Debolsillo, 2007, p. 19, nota (en adelante citado como $S S)$

${ }^{29}$ SS, pp. 721, 722 .

${ }^{30}$ SS, p. 31.

${ }^{31}$ SS, p. 139.

${ }^{32}$ SS, p. 719.

33 SS, p. 73.

${ }^{34}$ SS, p. 718.

${ }^{35}$ SS, p. 719.
} 
de apreciación inscritos en el cuerpo de los agentes interactivos. [...] Así pues, la mirada no es un mero poder universal y abstracto de objetivación como pretende Sartre; es un poder simbólico cuya eficacia depende de la posición relativa del que percibe y del que es percibido", posición que ha sido en cada caso predefinida social y culturalmente ${ }^{36}$.

También a la hora de intentar dar cuenta de los motivos que hicieron y hacen que los roles se distribuyan de esta manera, Beauvoir es deudora explícita de los desarrollos merleaupontyanos. Merleau-Ponty había escrito en su Fenomenología de la Percepción que aun aquellos sentimientos que, tales como el de "la paternidad, parecen inscritos en el cuerpo humano, son en realidad instituciones. Es imposible superponer en el hombre una primera capa de comportamientos que llamaríamos naturales y un mundo cultural o espiritual fabricado. En el hombre todo es natural y todo es fabricado" ${ }^{37}$. Este mismo entrelazamiento de la naturaleza y la cultura es el que Beauvoir indica al afirmar que la feminidad no resulta meramente de determinaciones biológicas, pero tampoco deriva de una construcción absolutamente inmotivada, sino del entrelazamiento histórico de dimensiones biológicas, económicas y culturales: "en la colectividad humana nada es natural [...]. La mujer es un producto elaborado por la civilización [...], no es definida ni por sus hormonas ni por misteriosos instintos, sino por el modo en que, a través de conciencias extrañas, recupera su cuerpo y sus relaciones con el mundo" 38 . La estructura misma de El segundo sexo, cuya primera sección presenta "Los datos de la biología", muestra que las determinaciones corporales tienen, en la visión de Beauvoir, un peso que los análisis de Sartre no podrían otorgarle: "estos datos biológicos son de suma importancia, representan en la historia de la mujer un papel de primer orden; son elemento esencial de su situación”. Sin embargo, agrega inmediatamente Beauvoir que los datos biológicos no representan un destino, "no bastan para definir una jerarquía de los sexos; no explican por qué la mujer es lo Otro; no la condenan a conservar eternamente ese papel subordinado" 39 . Si la biología no es destino para Beauvoir, no es porque -como pensaría Sartrela conciencia siempre trasciende su facticidad, sino más bien, como afirma Beauvoir glosando a Merleau-Ponty, porque "la Humanidad es algo distinto de una especie -es un devenir histórico- y se define por la manera en que asume la ficción natural" 40 . El segundo sexo es en buena medida una extensa y densa descripción de esta situación femenina en la que se entrelazan el peso de las determinaciones biológicas, económicas y culturales. Y tal como la Phénoménologie de la Perception reservaba una última sección a la cuestión de la libertad, Beauvoir culmina su obra con el capítulo titulado "Hacia la liberación" y una conclusión que intenta balancear el panorama sombrío que describió tan

\footnotetext{
${ }^{36}$ Bourdieu, Pierre. La dominación masculina. Barcelona: Anagrama, 2000, pp. 83-85.

${ }^{37}$ FP, p. 206.

${ }^{38} \mathrm{SS}, \mathrm{p} .718$.

${ }^{39}$ SS, p. 43.

${ }^{40}$ SS, p. 710. Merleau-Ponty había escrito casi idénticamente: "El hombre es una idea histórica y no una especie natural" (FP, p. 187).
} 
detalladamente en cientos de páginas. La libertad, para ambos pensadores, es evidentemente algo mucho más complejo que una elección de la conciencia: "reconocemos -dice Merleau-Ponty- alrededor de nuestras iniciativas y de este proyecto rigurosamente individual que nosotros somos, una zona de existencia generalizada, de proyectos ya hechos, significaciones que se arrastran entre nosotros y las cosas y que nos califican como hombre, como burgués o como obrero"; una conclusión a la que Beauvoir suscribiría agregando enfáticamente la calificación de mujer. El lugar exiguo que les reservan sus obras no significa que la libertad sea una palabra sin significado, sino, por el contrario, la cuestión más valiosa y también la más compleja, en tanto ambos reconocen que no se dirime en el drama subjetivo de una conciencia ${ }^{41}$.

Si los desarrollos de Merleau-Ponty y Beauvoir acerca de la sexualidad aventajan en cierto sentido a los análisis sartreanos, al incluir y priorizar la dimensión social e histórica que Sartre había pasado por alto, es posible sin embargo dejar indicadas algunas de sus limitaciones como invitación a continuar la reflexión. Si bien ambos pensadores, Merleau-Ponty y Beauvoir, pretendieron pensar el entrelazamiento indisociable de la naturaleza y la cultura, lo biológico y lo histórico-social, es claro que no pudieron sostener esta pretensión hasta sus últimas consecuencias. Hemos citado más arriba un párrafo en el que Merleau-Ponty hablaba de la construcción cultural estereotipada de "masculinidades" y "feminidades". Esta tesis implica que cada cultura elabora modos particulares de ser hombre y mujer sin llegar a cuestionar la universalidad de la díada sexual, la cual es supuesta como una suerte de "suelo natural" inconmovible. Asimismo, en El segundo sexo de Beauvoir se encuentra el postulado de la feminidad y la masculinidad -o más bien, feminidades y masculinidades- como géneros culturalmente construidos y por tanto abiertos a cierta variabilidad, pero no es cuestionado el binarismo mismo, es decir, la existencia biológica de los dos sexos. Volcando las ideas de la filósofa en términos que utilizarán los estudios de género posteriores, podría decirse que este básico binarismo sexual habría sido asumido en nuestra cultura bajo la forma de dos géneros asimétricos, y es este particular modo de generización jerárquica el que permitiría ser puesto en cuestión, pero no el binarismo biológico mismo. Así afirma Beauvoir que "siempre habrá entre el hombre y la mujer ciertas diferencias; al tener una figura singular, su erotismo, y por tanto su mundo sexual, no podrían dejar de engendrar en la mujer una sensualidad y una sensibilidad particulares; sus relaciones con su propio cuerpo, con el cuerpo masculino, con el hijo, no serán jamás idénticas a las que el hombre sostiene”. En este sentido afirma también que "liberar a la mujer es negarse a encerrarla en las relaciones que sostiene con el hombre, pero no negarlas. [...] La reciprocidad de sus relaciones no suprimirá los milagros que engendra la división de los seres humanos en dos categorías separadas" ${ }^{42}$. Se hace evidente en estas fórmulas que la asimetría pertenece para Beauvoir al orden de aquello que los estudios posteriores llamarán "género" (lo masculino y lo femenino) y al de la cultura, mientras que la dife-

\footnotetext{
41 "Tu libertad no puede quererse sin salir de su singularidad y sin querer la libertad" (FP, p. 499).

42 SS, p. 724.
} 
rencia binaria es del orden del sexo (el macho y la hembra) y es supuesta como natural, en el sentido fuerte de esencial y universal. Es necesario preguntarse, tal como lo hará Judith Butler, hasta qué punto es factible seguir sosteniendo la distinción entre ambos órdenes, y en qué medida la "materialidad" y la "naturaleza" del sexo no son efectos de una "materialización" y una "naturalización" de la normatividad genérica de nuestra cultura.

Es posible además introducir ciertos reparos y sospechas acerca del alcance de la presunta superación merleaupontyana de la filosofía abstracta de la conciencia sartreana, superación que hemos sugerido más arriba. Merleau-Ponty efectivamente acierta en afirmar, contra Sartre, la primariedad de la socialidad como estructura de relaciones intercorporales respecto de la experiencia solitaria de la conciencia y su otro. Sin embargo, no es evidente que esta socialidad intercorporal primaria constituya una armónica dimensión de "comunión", que prescinda absolutamente de asimetrías, conflictos y relaciones de poder. Como sugirió Sartre en el artículo que escribió como homenaje a su amigo filósofo en ocasión de su fallecimiento, probablemente Merleau-Ponty mantuvo en el horizonte de su pensamiento la confianza en una especie de paradisíaco "estado de naturaleza" originario. Si según la Fenomenología de la Percepción existimos originariamente "mezclados con los otros y con el mundo en una confusión inextricable", libres de todos los apremios que conocen nuestras relaciones interpersonales cotidianas, Sartre no dudó en calificar irónicamente este tipo de afirmaciones como ingenuas, atribuyéndolas -con vocabulario freudiano- a una especie de "regresión" merleaupontyana, a un "narcisismo primario" o a la persistencia de un "sentimiento oceánico" de indistinción como el que se presume es propio de los neonatos ${ }^{43}$. Desde esta perspectiva, ni Sartre ni Merleau-Ponty, a pesar de los esfuerzos de este último, habrían logrado despojarse absolutamente de la abstracción de una supuesta "naturaleza humana”, y su discusión remedaría las interminables querellas modernas entre los partidarios de la tesis del homo homini lupus y la del "buen salvaje". Ahora bien, si Merleau-Ponty dio algunas razones para esta sospecha, no es menos cierto que el entero movimiento de su pensamiento señala hacia una superación del individualismo propio de las filosofías modernas de la conciencia - por vía del reconocimiento de la prioridad de las estructuras de nuestras relaciones sociales-, como así también hacia una superación de la tesis de una "naturaleza humana" no atravesada por la cultura -por vía del reconocimiento de la constitución social de nuestra corporalidad-. Desde este punto de vista, el filósofo abrió la puerta al análisis de los diversos modos particulares en que la sexualidad y el poder se entrelazan en nuestras sociedades, invitación que retomaron -de muy diversos modos y con mayor o menor reconocimiento de su deuda, según el caso- pensadores tales como Simone de Beauvoir, Pierre Bourdieu, Michel Foucault o Judith Butler.

${ }^{43}$ Cf. Sartre, Jean-Paul. "Merleau-Ponty vivant”. Les Temps Modernes. Nos 184-185 (1961). 


\title{
Función del Temple y Disfunción de la Corporeidad en la Experiencia Fundamental del Pensar en Heidegger Tardío
}

\author{
Valentina Bulo Vargas \\ Universidad Austral de Chile
}

\begin{abstract}
Resumen
El escrito intenta aclarar, desde una perspectiva ontológica, la función del temple en la experiencia del pensar, como fondo que diseña y traza su estilo para luego demarcar la ausencia de corporeidad en la "experiencia ontológica” y esbozar desde allí el sentido de esta falta como disfunción.
\end{abstract}

El gran tema que cruza la totalidad del pensamiento heideggeriano es sin duda el Ser, y podríamos agregar, el modo de darse su unidad y diferenciación. El llamado pensamiento tardío de Heidegger no es, en primer término, un cambio respecto al "asunto" del pensamiento, pues la cuestión esencial, la más digna de ser preguntada, sigue siendo una. Explícitamente Heidegger declara un cierto fracaso en el sentido de no haber podido aproximarse a la cuestión esencial" ${ }^{2}$ su "giro" intenta pensar lo Mismo (y con esto ya estamos entrando de lleno en nuestro tema) desde otras palabras, otro camino y otra fundamentación: el Ser. Si tempranamente habla del sentido del ser e intenta describir lo que inmediata y regularmente (zunächst un zumeist) ${ }^{3}$, en su radicalidad fáctica acontece a este ente al que "le va" el ser mismo -al Da-sein-, y realiza con ello, en palabras de R. Rodríguez, una fundamentación óntica de la ontología ${ }^{4}$; el llamado segundo Heidegger intentará aproximarse a la misma cuestión "desde el Ser mismo", nombrado ahora como Seyn, Ereignis y nombres cada vez distintos para lo Mismo (en marcada vecindad con la poesía) pues su "interpretación” se da en el modo de la sugerencia (Zuspiel), palabra que en su juego "da un pase" a la posibilidad de un otro inicio histórico de lo Mismo.

De este mismo modo, el cambio desde Grundbefindlichkeit (disposición afectiva fundamental) a Grundstimmung (temple fundamental) ha de entenderse

\footnotetext{
${ }^{1}$ El presente texto forma parte de una versión preliminar del proyecto Postdoctoral Fondecyt asignado para 2007-8 "Miradas contemporáneas para una filosofía del cuerpo y la afectividad", no 3070001.

${ }^{2}$ Cf., por ejemplo, M. Heidegger. Prólogo a la tercera edición, ¿Qué es Metafísica? Buenos Aires: Ed. Siglo XX, 1979, p. 59

${ }^{3}$ Cf. para este tema, J. E. Rivera. "Zunächst und Zumeist" en: Heidegger y Zubiri. Santiago de Chile: Ed. Universitaria, 2001.

${ }^{4}$ Rodríguez, Ramón. La transformación hermenéutica de la filosofía. Madrid: Ed. Tecnos, 1997, p. 221.
} 
desde este juicio heideggeriano de fracaso de meditar el ser del ente: el giro de la disposición afectiva al temple no acontece por un fallo de la "experiencia", (de la angustia como tal), sino que se relaciona directamente con el "fracaso" de experimentar el ser "desde el ente", por lo que años más tarde procurará indicar el salto para una meditación "desde" el Ser mismo en copertenencia con el Dasein. Esto obviamente tendrá consecuencias en el modo de concebir a los temples mismos, pues ya no serán meramente una experiencia desde Dasein al ser del ente, sino que serán fundadores de un espacio de tiempo del Entre Dasein y Ser, es decir, intentarán ser concebidos “desde el Ser". Es lo que trataremos en la primera parte de este escrito.

La meditación heideggeriana, que pretende pensar el ser "desde el ser" es literalmente un movimiento del pensar, entendido como un ir "más allá del ser" en un doble sentido: por una parte se dirige a recuperar aquello que quedó olvidado en el pensar metafísico 5 , literalmente un "paso atrás" (Srittzurük) que piensa lo que se ha hecho presente en el modo de la ausencia, un diálogo con la historia del pensar en donde "el paso atrás se dirige hacia ese ámbito que se había pasado por alto hasta ahora y que es el primero desde el que merece ser pensada la esencia de la verdad" 6 . Por otra parte este movimiento es necesariamente un "salto" en donde acontece la experiencia del pensar como encuentro y co-apropiación de Hombre y ser, "el salto es la puerta que abre bruscamente la entrada al dominio en el que el hombre y el ser se han encontrado desde siempre en su esencia porque han pasado a ser propios uno del otro desde el momento en que se han alcanzado"7. Este es el pase (Zuspiel): un movimiento del pensar que sugiere desde lo sido hacia lo porvenir ${ }^{8}$, paso atrás y salto. El salto puede ser bosquejado desde el Dasein, que salta al ser, y en el mismo movimiento es también el ser al que se hace saltar, lo lanzado en el pro-yecto. Este proyecto es la verdad del Ser mismo, es el Ser quien salta y con ello se funda al Dasein, entendido, desde este respecto como "lugar" del salto.

De esta manera, el ser es ("lo" que está "tras" él) el acontecer del despliegue del ámbito relacional, del Entre, "el preguntar por el ser no piensa más desde el ente, sino que es forzado (ernötigt) por el Ser mismo como un pensar-en-

\footnotetext{
${ }^{5}$ Utilizo esta terminología con la expresa intención de dar un matiz algo distinto al que usualmente se alude en este punto con términos como "deconstrucción", desenmascaramiento, etc. Con ello quiero justamente recuperar una lectura más propositiva, en donde la radical diferencia con la tradición metafísica y su concepción del ser no sea un rompimiento tal que impida hablar de lo mismo. Por esta misma razón no creo contradecir las principales tesis que enuncia A. González en su brillante artículo "Ereignis y actualidad", allí efectivamente se intenta subrayar la diferencia entre ser, entendido como presencia, y Ereignis, las cuales comparto, aunque sí es necesario decir también, junto con Heidegger, que "ser y Ser son lo mismo y, sin embargo, radicalmente diferentes". (GA 65, p.171, tr. p. 126).

${ }^{6}$ Martin Heidegger. "La constitución onto-teo-lógica de la metafísica". Identidad y Diferencia. Barcelona: Edit. Antropos, 1988, p. 113.

${ }^{7}$ Heidegger, Martin. "El Principio de Identidad". En: Identidad y Diferencia. Op. cit., p. 79.

${ }^{8}$ Justamente por lo afirmado aquí, opto por las traducciones (interpretaciones) de Zuspiel como sugerencia o pase, de B. Onetto y D. Picotti respectivamente, y me distancio de la traducción de A. Escudero como "pasaje", porque en un pasaje no se escucha ninguna experiencia, ningún movimiento del pensar, sino, me parece, una representación estática, como si se tratara de un momento preparatorio de un tránsito aún no realizado.
} 
curso del Ser. El pensar-en-curso del Ser hace surgir a éste como el Entre"'; es justo el modo de resolver mismidad y diferencia, reunión y separación, pensar y ser se resuelven en copertenencia. Ereignis es el nombre que indica, siempre con seńas, a aquel momento relacional que acontece cada vez por entero (por decirlo de algún modo), es el movimiento del pensar mismo, como copertenencia de hombre y ser; es también el despliegue de la diferencia respecto al ente, como el esenciar diferenciadamente a partir de lo Mismo. "Ser y ente son lo Mismo; sólo en la diferenciación entre ser y ente está unido de propio lo Mismo en la unidad con él mismo. Ser no es algo distinto de lo ente; si fuera algo distinto sería, una vez más, ente. La diferencia (Unterschied) no emplaza a ambos uno al lado del otro, sino que abre al ente en su ser, lo une en la mismidad consigo mismo y diferencia-y-decide esta mismidad" ${ }^{10}$. Cuando Heidegger habla de la historia del Ser está hablando de la historia de la diferencia, los modos epocales son los modos concretos de acontecer el modo de darse la diferencia de ser y ente: como olvido en el abandono, como resonancia del olvido en el tránsito (que en rigor es un momento del abandono), propiamente como Ereignis en un posible otro inicio.

En primer término, si ha de ser posible transitar a otro inicio, éste ha de ser necesario en el movimiento del pensar, obviamente no puede tratarse de una necesidad lógica, pues ésta es el modo de la necesidad propia del pensar representativo y calculante. La necesidad ha de ser una especie "apretura" del Entre, en donde éste acontece como un no saber ni salir ni entrar en donde el Ser tensa de tal manera a los hombres y a los entes que a unos los fuerza y a otros los hace saltar para que surja la diferencia y con esto se posibilite la apertura del Entre como un modo del Ser ${ }^{11}$.

Esta necesidad es llamada por Heidegger apremio (die Not) y su modo de efectuarse, el modo de apremiar, es justamente templando: "el apremio apremia en el modo del temple"12, el temple aquí es el concreto "efectuarse" la necesidad de un inicio. "Cada apremio necesita (nötigt) del no saber ni la salida ni el acceso que como apremio templante apremia no sólo primero en una relación ya determinada al ente interpretado en su entidad y que se halla ya abierto, sino que éste fuerza primeramente a aquel Entre y En-medio, en cuyo espacio de juego de tiempo puede ser determinado el ente en total en su entidad. Aquel apremio del pensar inicial, al que hemos aludido aquí, puede apremiar templando solamente como un apremio esencial o, según decimos, en un temple fundamental ${ }^{\prime 13}$. Este texto se refiere concretamente al asombro

\footnotetext{
${ }^{9}$ Heidegger, Martin. Beiträge zur Philosophie (Vom Ereignis), Gesamtausgabe, Band 65. Frankfurt a.M.: Vittorio Klostermann, 1989. (Traducción de B. Onetto, edición limitada, Valparaíso: 2003), p. 452 (Tr. p. 296).

${ }^{10}$ Pöggeler, Otto. El camino del pensar de Martin Heidegger. Madrid: Ed. Alianza, 1986, p. 158 ss.

${ }^{11}$ Cf. Para esto y lo que sigue, M. Heidegger. Grundfragen der Philosophie, Gesamtausgabe, Band 45. Ausgewählte "Probleme" der "Logik", WS.1937/38. Frankfurt/aM. 1984, p. 152 ss.

${ }^{12}$ Heidegger, Martin. Grundfragen der Philosophie. GA, 45. Op.cit., p. 159

${ }^{13}$ Heidegger, Martin. Grundfragen der Philosophie. GA, 45, Op.cit., p. 154 s.
} 
(Erstaunen), temple del primer inicio, por esto Heidegger ocupa expresiones como el ente interpretado en su entidad, y es que quiere mostrar aquí no sólo que un inicio histórico acontece necesariamente desde un apremio templante, sino que en este mismo temple está "contenido" el modo epocal de desplegarse el ser, que en el caso del primer inicio es el abandono del Ser.

Pues bien, los temples fundamentales han de ser aquí la irrupción del trazo originario (der ursprüngliche Aufriß) que configurará y portará el modo concreto de acontecer el despliegue. Detengámonos aquí y vayamos tanteando poco a poco esta cuestión ${ }^{14}$.

1. Carácter modal del temple, trazado originario, modo concreto de acontecer: "El temple es el destello del temblor del Ser como acontecimiento de apropiación en el Da-sein. Destello: no como un mero desaparecer y extinguirse, sino al revés: como conservación de la chispa en el sentido del claro del Ahî"15.

El temple es, y no sólo en un inicio histórico sino en el acontecer mismo, el bosquejo, el trazo originario del modo de desplegarse el Ser entendido desde el Entre, es decir, el modo concreto de efectuarse la vinculación de hombre y mundo, de ser y ente, de dioses, tierra y cielo. El temblor del Ser es el puro durar del Ser, no hay un ser que luego tiembla, es despliegue que en su estremecimiento vibra en distintos tonos, ese es su destello. Si en otros textos Heidegger se refiere a la "voz del ser", el temple es su tono, su matiz propio de estremecimiento, es tono de voz del Ser. El temple de ánimo como destello del ser es la conservación de la chispa, la conservación del estar aconteciendo el Ereignis, el modo concreto de durar el Ser, el temple es quien contiene y preserva el despliegue, la concreta figura trazada por él. Si Ereignis es el acontecer del temblor del Ser en el Dasein, es justamente copertenencia de pensar y ser, el estar aconteciendo el Ereignis no es otra cosa que el pensar, y el temple preserva y conserva esa chispa.

Esto significa que el temple es lo que le da primeramente sentido a toda posible relación, es lo que las determina como relacionables. El temple es un verdadero principio ordenador, una "norma de reunión" como afirma respecto a la reserva. $Y$ es que el temple es "la experiencia de aquello que permite aparecer lo que se manifiesta en el horizonte, el mundo mismo. El mundo nos "dice" cosas distintas según el temple fundamental en el que nos surge como mundo" ${ }^{16}$. Desde la certeza, por ejemplo, el tipo de relaciones que se instaura, tanto entre las cosas, como entre el ente y el ser y el hombre mismo, es radi-

\footnotetext{
${ }^{14}$ Un análisis más detallado de este punto, así como de algunos temples concretos trabajados por Heidegger puede encontrarse en mi artículo "Die Grundstimmung en el pensamiento tardío de Heidegger". En: Revista Philosophica, vol. 28/2005, p. 23-46.

${ }^{15}$ Heidegger, Martin. Beiträge zur Philosophie. Op. cit., p. 21 (Tr. p. 32).

${ }^{16}$ Klaus Held. "Europa y el entendimiento intercultural". Investigaciones fenomenológicas, $\mathrm{n}^{\circ} 3$. Madrid: 2001, p. 310.
} 
calmente distinto a los modos de las relaciones que habría desde la reserva o el desasimiento. En este sentido es que "el temple fundamental abre el mundo, el que recibe el cuño del ser" ${ }^{\prime 17}$.

Así el asombro abre su singular asombrabilidad, esto es: el todo como lo total, lo total como el ente, el ente en total, que él es, lo que él es; el ente como el ente, el ens qua ens, Tò ồ ᄁ̣̂ öv. Esto, lo que aquí hemos designado con el "como", con el qua, con el, ḥ̂ es en el asombro el separador y arrojador "Entre", lo abierto de un espacio de tiempo aún difícilmente vislumbrado y pensado, en que el ente viene como tal al juego, o sea como el ente, lo que él es, en el juego de su ser ${ }^{18}$.

En el temple, como vemos, se traza el como del despliegue del Ser que en este caso es el ser del ente, es decir, donde el Ser se despliega retiradamente. Entre lo habitual y su inhabitualidad el asombro traza ya la figura del Ser como ente en total. Esta misma cita puede ser "aplicada" a todos los temples fundamentales en donde el Entre abre distintos espacios de tiempo: en el tránsito el ente viene deponedoramente, negativamente, como no-ente desde los distintos matices que abren cada temple en particular: como la huida del dios en el duelo sagrado, como lo indiferente en el aburrimiento, como la nada en la angustia, como el ab-ismo en el espanto; y luego, en el segundo inicio propiamente como Ereignis en la reserva.

El como es el modo de acontecer la diferencia y reunión Entre Ser, ente y hombre, por sólo demarcar algunos relatos. Respecto al ente, en el primer inicio esta diferencia es olvidada, desplegándose el Ser como ser del ente, como ente en total; el pensar, asimismo, se vacía de Ser quedando un puro representar, que luego se tornará en un pensar que "se experimenta" desvinculado del temple, donde la desvinculación es el modo como se está templado; el tránsito será la resonancia del Ser como retirado, como un "no estar siendo", un "nadear" (nichtet); en el segundo inicio, podríamos decir que el Ereignis acontece como Ereignis, en donde "el acontecimiento es el Entre respecto del paso del dios y la historia del hombre...la relación con el hombre es el permitir que surja y acontezca propiamente la fundación del Da-sein y, por tanto, la necesidad de recuperar la verdad del Ser en el ente como una restitución del ente"19. Aquí el Ser se despliega propiamente como Ereignis, como relación fundamental que permitirá la inserción del Ser en el ente y en el hombre (fundación del Da-sein).

2. "El temple nos traspone cada vez en esta y aquella relación fundamental con el ente como tal. Más exactamente: el temple es esto tras-ponedor (Ver-setzende),

\footnotetext{
${ }^{17}$ Martin Heidegger. Hölderlins Hymnen, Gesamtausgabe, Band 39. Frankfurt a.M.: Vittorio Klostermann, 1989. (Traducción inédita de Carolina Merino, Chile), p. 80.

${ }^{18}$ Heidegger, Martin. Grundfragen der Philosophie. Op. cit., p. 168 s.

${ }^{19}$ M. Heidegger. Beiträge zur Philosophie. GA 65. Op. cit., p. 27 (tr. p. 35).
} 
hasta tal punto traspone, que cofunde el espacio de tiempo de la trasposición misma" 20 .

Si antes nos referimos al temple desde el Entre, como el trazo mismo de la "figura" del ser, ha sido por establecer, de algún modo, un mapa de orientación mínima que permita transitar en este espacio del entremedio. Hemos establecido relatos e intentado demarcar la función del temple en su relacionabilidad, en donde acontece de un modo concreto (justo el como) la unión y separación de los relacionados en la articulación. Pero este análisis es completamente insuficiente si no nos acercamos a su fuerza irruptiva, que es la que remueve las capas topológicas y la que en definitiva tiene el poder de fundar un espaciotiempo.

Más que conceptos estáticos, Heidegger intenta señalar hacia el asunto con palabras-funciones, que articulan el ensamblaje del pensar. Es en este sentido que términos como el trasponer (versetzen), liberar (Ent-setzen), deponer (abgesetzen) o también el dislocamiento (Verrückung), el encanto o rapto (Entrückung), el insertarse (einrücken), el impulso (Ruck) apuntan al funcionamiento del engranaje, en donde "lo que se mueve", si pudiéramos seguir hablando así, es la articulación completa y eso es acontecer.

Desde este respecto, el temple, si ha de ser fundamental, si ha de ser el fondo del movimiento del pensar, ha de poseer la fuerza, el impulso, de dislocar una articulación, una vinculación y con ello fundar un concreto despliegue del acontecer histórico. El temple es lo tras-ponedor del modo de desplegarse el Ser, no en un sentido causal, el temple no es causa de un inicio histórico, el temple es la reconfiguración misma, el desplazamiento de la articulación. Los distintos términos con que Heidegger señala este desplazamiento corresponden también a distintos respectos desde donde es posible localizar este "movimiento de placas". En "Hölderlins Hymnen", por ejemplo, identifica cuatro caracteres del temple fundamental ${ }^{21}$ : encantador o extasiante, insertante, inaugurante y fundante (entrückende, einrückende, eröffnende, gründend), todos son el mismo momento, tomados -en el caso del duelo sagrado que es el temple que allí se trabaja- desde el temple como Entre: hacia los dioses extasiantes, que al mismo tiempo nos inserta en la tierra, inaugurando con ello una patencia determinada del ente en total y fundando así el fondo mismo del Dasein."El temple no representa nada,... sino que el temple en cuanto transportanteinsertante inaugura el recinto al interior del cual, recién, algo puede llegar a ser propiamente re-presentado...Esencialmente, un mundo nunca se deja inaugurar y pegotear como una recopilación ulterior de la diversidad de cosas percibidas, sino que es al interior de lo originario e inherentemente patente de

\footnotetext{
${ }^{20}$ M. Heidegger. Grundfragen der Philosophie. GA 45. Op.cit., p. 154. Opto aquí por la traducción de versetzen como trasponer. Aunque el término disponer (A. Xolocotzi) es mucho más claro, pierde, a mi modo de ver, lo específico de este carácter del temple, el dislocar, irrumpir, pudiéndose enlazar también con términos como verrücken que se dirigen justamente al desplazamiento, la dislocación de una articulación.

${ }^{21}$ Martin Heidegger. Hölderlins Hymnen. GA 39. Op.cit., p. 139.
} 
antemano, que recién nos puede salir al encuentro esto o aquello. La apertura inaugural del mundo acontece en el temple fundamental. El poder transportante, insertante y así inaugurante del temple fundamental es "a una" fundante, es decir, pone al Dasein en su fundamento y ante sus abismos" ${ }^{\text {"22 }}$.

Estos caracteres son propios de todo temple fundamental; nos detendremos en la inserción pues es aquel momento que nos llevará directamente a la cuestión última de este estudio que es la (des) vinculación de temple y cuerpo en la idea de experiencia de Heidegger.

Intentemos acercarnos ahora a esta trasposición o dislocación desde el ángulo del Dasein. Aunque es un ejemplo un poco espacializado, pensemos en una trasposición de placas tectónicas; tomadas éstas en su articulación conjunta, es la articulación misma la que se traspone; pero es posible también situarse en una de estas placas, desde el respecto del Dasein, la trasposición es desde aquí el Dasein mismo que se "inserta" de un nuevo modo en la articulación, y esta inserción, es justo experiencia. La experiencia es tratada ahora por Heidegger desde el Entre; como una inserción en la articulación, muy lejos está de ser considerada como el aspecto subjetivo y "particular" del Dasein hacia el Ser, es la apertura misma del espacio de un modo de despliegue.

El despliegue esencial (Wesung) es aquello en donde hemos de ingresar (einfahren). Eso es lo que quiere significar aquí "experiencia" (Erfahrung): ingresar en el despliegue, para que puestos en él lo soportemos, lo que acontece como Da-sein y su fundación ${ }^{23}$.

Este texto se refiere concretamente a la reserva, como experiencia fundamental del segundo inicio, es el momento en que el Dasein como Dasein se inserta en la historia del Ser, es "a una" el experimentar la pertenencia del hombre al ser, en donde acontece la fundación del Dasein, y el experimentar al Ser mismo. Esta misma experiencia, a mi modo de ver, es conceptuada luego desde el desasimiento, como la experiencia de pertenecer a algo anterior a nosotros mismos. Experiencia que se da no en el "captar" eso anterior a nosotros, sino en el confiarse, en el entregarse, dejarse imperar por eso.

Esta misma lectura puede "aplicarse" a los otros temples fundamentales, cada uno sería (visto desde el Dasein) un modo de experiencia que determinaría el modo de insertarse el hombre en la historia. Temples como la certeza son

\footnotetext{
22 Martin Heidegger. Hölderlins Hymnen. GA 39. Op.cit., p. 140 s. Dejo sin tratar algo esencial en este extracto y es que aquí encontramos las diferencias esenciales entre el representar y el temple. Aquí se piensa al temple como condición de posibilidad del representar: el modo de develar del temple no es representacional, el temple posibilita el representar como inauguración del recinto, como apertura de un espacio tiempo. El temple es condición de posibilidad del representar porque nos instala en esa unidad primaria y anterior desde donde toda representación adquiere sentido: el mundo. El mundo se abre como tal en el temple, y no meramente como si el temple fuera una ventana por la cual nos abrimos al mundo; es muchísimo más radical, el temple abre al mundo, lo instaura, lo inaugura como tal.

${ }^{23}$ M. Heidegger. Beiträge zur Philosophie. Op.cit., p. 289 (Tr. 201).
} 
"vivencia” de objetos (y del "yo"), y los temples del tránsito experimentarán desde distintos respectos una templante negación de esta modalidad.

El duelo se queja y duele 'con' la patria. ¿Qué quiere decir eso? ¿Acaso que el poeta explica sus sentimientos anímicos mediante los procesos naturales, el fluir de los ríos, el murmullo del bosque, y cosas semejantes, y simboliza así lo interno no sensible de la vivencia mediante lo exterior sensible e inteligible? Después de todo lo dicho hasta ahora, difícilmente aceptaremos despachar con tal ligereza la poesía, ni preguntaremos en esta dirección. El 'yo' que aquí habla, se queja con la patria porque este yo-mismo, en la medida en que está en sí, se experimenta precisamente como perteneciente a la patria... Esta patria no tiene ninguna necesidad de que le atribuyan tonalidades afectivas, porque es ella quien templa, y templa de un modo más inmediato y permanente cuando el hombre está radicalmente abierto al ente, en un temple fundamental. El estar-en-sí-mismo del duelo es un estar-abierto al imperar de aquello que templa, atraviesa y circunda al hombre. La tierra yace plena de esperanza bajo el cielo tormentoso, toda la naturaleza patria yace inmersa en este ensombrecimiento. Recién en tal patria, el hombre se experimenta como perteneciente a la tierra, a la que él no pone -por empatía- al servicio de sus tonalidades afectivas, sino a la inversa: desde ella deviene recién experimentable que con la yoidad aislada, que se confronta en primer lugar a todo para tomarlo solamente como un objeto de su complacencia y para empatizar sus vivencias, no pasa nada ${ }^{24}$.

Aquí lo experimentado en el duelo es el estar en sí mismo (in-sich-selbststehen) que pertenece a la tierra, y con ello "niega", no de un modo lógico sino templante, la vivencia de la yoidad y los objetos. La primera interpretación del dolerse con la patria descartada por Heidegger es la objetivante, en donde el temple es una vivencia interna, aislada, frente a los objetos, los procesos naturales. Desde la experiencia de la pertenencia a la tierra se hace experimentable el que no haya nada (nichts ist), en la vacuidad de la experiencia que se "autointerpreta" como vivencia, de un yo aislado frente al todo objetivado. Sólo a partir de un temple que devele a la tierra como el momento templante, y que se devele en la medida en que el que lo experimenta "está en sî", es que se puede experimentar la insuficiencia del yo frente al objeto. Asimismo, el propio temple se experimenta a sí mismo, por decirlo de algún modo, como un estar abierto, y ya no como vivencia interna que "empatiza", es decir, que proyecta su tonalidad al exterior y con ello pone la tierra a su servicio.

Aquí lo trasponedor no aparece explícitamente, pero se deja ver en su íntima articulación desde la experiencia. El hombre se experimenta como perteneciente a la tierra, y con ello se inserta de un nuevo modo respecto a todos los

\footnotetext{
${ }^{24}$ M. Heidegger. Hölderlins Hymnen. GA 39. Op. cit., p. 88 s.
} 
momentos que hemos detallado. Se trata de una dislocación desde la vacía experiencia del yo, con todos sus momentos: el temple mismo como vivencia, los objetos, la proyección de las vivencias a éstos. El dolerse con la patria será la experiencia que traspone lo anterior hacia un "estar en sí mismo" (no es el yo) con todos los momentos que implica: el temple mismo como un estar abierto (no es vivencia), la tierra templante (no es objeto), el dejarse imperar por aquello que templa (no es proyección). Es concretamente de este modo como surge, se traspone un espacio tiempo; en la experiencia de un temple.

Pues bien, es el momento justo de hacer notar la total falta de una "función del cuerpo" en la concepción de experiencia en el Heidegger tardío. Experiencia mienta en Heidegger el momento vinculativo, articulador, el fondo mismo del pensar, es una experiencia pensante-queriente-templante (parafraseo la expresión de gestimmt-wissenden-Willen de los años 50) pero no corpórea, pues justamente el cuerpo es para Heidegger conceptuado necesariamente desde un pensar objetivante y él quiere distinguir la experiencia fundamental del pensar del "experimento manipulador". Pero lo que es más grave es que para Heidegger la corporeidad no puede "cumplir funciones" ontológicas sino puramente ónticas; justamente los temples fundamentales se dirigen a cumplir esa función de concreción vinculativa y fundamental en el rango ontológico exigido en el Heidegger tardío, quien busca una experiencia fundamental del pensar que se diferencie (yo diría que se separe) constitutivamente de la llamada experiencia sensible, la experiencia del cuerpo.

Lo afirmado para el pensar tardío de Heidegger respecto al cuerpo es palpable ya en su pensar temprano: Categorías tradicionalmente corporales como la "experiencia perceptiva" son tempranamente "descartadas" por Heidegger como fundamentales y originarias; la apertura -lo que constituye originariamente al Dasein- acontece, con todo rigor, antes de cualquier percibir, y aún más, es condición de posibilidad de cualquier percibir. Lo dice explícitamente al tratar la estructura de la aperturidad en sus momentos de disposición afectiva y comprender:

1. "Y sólo por pertenecer ontológicamente a un ente cuyo modo de ser es el de estar-en-el-mundo como disposición afectiva, pueden los sentidos ser tocados y tener sentido para, de tal manera que lo que los toca se muestre en la afección. Eso que llamamos afección no podría tener lugar...si...no se encontrase ya consignado a la posibilidad, bosquejada por los estados de ánimo, de ser afectado por el ente intramundano"25.

2. "Al mostrar cómo toda visión se funda primariamente en el comprender... se le ha quitado a la pura intuición su primacía, la cual corresponde, en un plano noético, a la tradicional primacía ontológica de lo que está ahí. Tanto la intuición como el pensar son derivados ya lejanos del comprender" ${ }^{20}$.

\footnotetext{
${ }^{25}$ M. Heidegger. Sein und Zeit. Gesamtausbabe, Band 2. Tübingen: Max Niemeyer, 1977 (Traducción de J. Eduardo Rivera. Ser y Tiempo. Santiago: Ed. Universitaria, 1997), p. 137 s. (Tr. p. 162) las cursivas son mías.
} 
Estas afirmaciones son graves, y no sólo dicen que todo percibir es ya interpretativo-comprensor sino que no son "de suyo" aperientes, puesto que sólo "muestran" aquello que la disposición afectiva y el comprender les ha posibilitado ${ }^{27}$. El comprender afectivo bosqueja el marco de posibilidades dentro del cual puede aparecer lo percibido; Heidegger insiste continuamente en su anterioridad respecto al percibir y cada vez que se refiere al ver, oír tocar, etc. en un sentido más originario aclara, justamente, que se refiere a un ver, oír o tocar previo a su sentido "físico".

Heidegger, respecto a esta cuestión parte de un supuesto: el contenido del sentir es un dato "cerrado", y esto significa que se nos presenta necesariamente como algo que está ahí enfrente (Vorhandenheit ${ }^{28}$ ). Si reordenamos la oración del comprender citada, constatamos lo que aquí afirmo: la pura intuición es correspondencia noética de lo que está ahí. El intento de "destituir" la primacía ontológica de lo que está ahí supone para Heidegger una destitución de la primacía de la "pura intuición".

Es a partir de estos supuestos, a mi modo de ver, que Heidegger esquiva un análisis explícito de la corporeidad, pues ella, aunque se constituye como momento del "hecho fáctico", no entra ella misma en consideración. Y es que "la corporeidad no es, pues, ningún existencial, sino una estructura de la facticidad del Dasein, esto es, ella pertenece (dice Ser y Tiempo) solamente a los caracteres específicos de lo que está ahí del correspondiente existir del Dasein"29. La corporeidad no es para Heidegger un momento originario, "se da" exclusivamente como algo que está ahí y por tanto no puede constituir ningún momento existencial, ninguna función ontológica, sino meramente óntica. Quien ocupará el lugar de constituir una experiencia fundamental, una experiencia ontológica, en donde "la facticidad se revela como lo absolutamente originario...fundamento último de sentido...mostrando la pura facticidad como origen" ${ }^{30}$, es el temple de ánimo como experiencia fundamental.

Esto mismo acontece en los escritos tardíos de Heidegger. Aunque la experiencia es conceptuada desde el Entre, como ya seńalamos, ella no incluye corporeidad, ni siquiera en el modo de una "experiencia sensible". La vinculatividad

\footnotetext{
${ }^{26}$ Sein und Zeit. Op. cit. p. 147. Tr. p. 171.

${ }^{27}$ R. Rodriguez afirma que "Cuando Heidegger sostenía que el percibir es interpretativo comprensor estaba poniendo de relieve que también el simple percibir está ligado a la estrctura anticipativa del comprender, pero a la vez...lo que descubre, lo muestra como "la cosa misma"” (Rodríguez Ramón. Del sujeto y la verdad. Madrid: Ed. Síntesis, 2004, p.224). Me parece, respecto a la segunda parte de la afirmación, que lo dado en el percibir no remite (al menos por sí mismo) para Heidegger a "la cosa misma" pues no es originariamente dado "a los sentidos" sino al comprender afectivo.

${ }^{28}$ Cf. para este tema, Rivera. "Bewandtnis" en Heidegger y Zubiri. Op. cit., p. 63 ss.

${ }^{29}$ Cosmus Oliver. "Die Leiblichkeit im Denken Heideggers". En: Die erscheinende Welt. Berlin: Duncker \& Humbolt, 2002, p. 79. Hago notar que O. Cosmus llega a estas conclusiones a partir del análisis de los momentos de espacialidad y el estar-en, pero que en su argumentación y afirmaciones finales son completamente compatibles con lo que he intentado mostrar aquí.

${ }^{30}$ Cf. R. Rodríguez. La transformación hermenéutica de la fenomenología”. Op. cit. p. 210-221.
} 
del pensar está ya salvada por el temple, como he intentado mostrarlo, y las pocas veces que se refiere a la corporeidad de un modo explícito es situada siempre en los términos representativo-calculantes del dualismo cartesiano. Es claro que "Heidegger tampoco en su último pensamiento desarrolla ninguna fenomenología del cuerpo...no se encuentra planteamiento de esto en ningún texto publicado de Heidegger o algún discurso público obligado (gehaltenem), como por ej, una lección" 31 .

La única excepción a esta no tematización del cuerpo son los coloquios privados de Heidegger con el siquiatra suizo Medard Boss en los años 1961-1972, y los Protocolos del Seminario de Zollikoner entre 1959 y 1969. Respecto a estos escritos, como observa agudamente O. Cosmus, "no han sido impartidos ante estudiantes especializados sino ante un grupo de siquiatras y estudiantes de siquiatría... el seminario no le sirve para la profundización de cuestiones médicas o para la construcción de una investigación interdiciplinar, sino para la sola publicitación de su propio pensamiento"32. Allí se refiere principalmente a la recepción de su obra Ser y Tiempo adecuándose a la temática requerida por los siquiatras.

Hay ciertas afirmaciones en estos textos en donde Heidegger pareciera reasignarle a la corporeidad un lugar más originario, como cuando afirma que "todo entonces, lo que nosotros llamamos nuestra corporeidad, hasta aquella última fibra muscular y hasta la más recóndita (escondida) molécula hormonal, pertenece en el modo más esencial al interior del existir; no es fundamentalmente la materia inanimada, tampoco ha de ser un ámbito objetivado, óptico ni del visible poder ser percibido por la transcendencia del encuentro, el existir entero perdura desde el Da-sein" "33. Allí ciertamente está ya la afirmación que después hará explícita de que "todo cuerpo pertenece al existir y desde ese modo de ser es y permanece" ${ }^{\text {"34. }}$. Pero, por otra parte, no le asigna al cuerpo un ámbito propio, característico, sino más bien una pertenencia oscura y de algún modo no comprensiva al estar del Dasein. "El cuerpo pertenece como tal al estar-en-el-mundo. Pero el estar-en-el-mundo no se agota en el cuerpo. También pertenece al estar-en-el-mundo por ejemplo la comprensión del ser, cuyo comprender, que yo estoy en el claro del ser, y la correspondiente comprensión del ser, está determinado como ser en la comprensión. Esta delimitación es el horizonte de la comprensión del ser. Aquí no ha tenido lugar el cuerpo"35.

Pudiera parecer desde estos "textos de excepción" que en Heidegger hay una aceptación que otorga una mayor originariedad a la corporeidad, aunque luego no haya un desarrollo temático de ella. Sin negar esto, me parece que no se trata sólo de una "falta temática", sino de una carencia de cuerpo en la

\footnotetext{
${ }^{31}$ Cosmus, Oliver. "Die Leiblichkeit im Denken Heideggers". Op. cit. p. 81.

${ }^{32}$ Ibid.

${ }^{33}$ Heidegger, Martin. Zollikoner Seminare. Frankfurt am Main: Vittorio Klostermann, 1987, p. 292.

${ }^{34}$ Ibid, p. 296.

${ }^{35}$ Ibid, p. 244.
} 
remisión misma a las cosas y al hombre, esto es, una carencia respecto al tratamiento del Ser. Alguien podría decir que obviamente conceptos como la tierra, el espacio, el cielo y el Dasein mismo son también corpóreos, y es así; pero, y esto es lo esencial, ellos no están tratados corpóreamente: eso es en última instancia la exclusión Heideggeriana del cuerpo. En los mismos temples se ve reflejada esta cuestión, hay en ellos una "falta de cuerpo". Klaus Held critica en la concepción de los temples heideggerianos precisamente la necesidad de ser complementados con un análisis de su naturaleza somática ${ }^{36}$. Hay un carácter físico que no aparece en Heidegger. Heidegger intenta saltar al Ser y restituir al ente "desde" el Ser; el pensar tardío de Heidegger es un intento de pensar desde el Ser y en ese movimiento no hay una recuperación del cuerpo.

\footnotetext{
${ }^{36}$ Held, Klaus. "Europa y el entendimiento intercultural". En: Investigaciones Fenomenológicas, vol. 3. Madrid: 2001, p. 303-324, p. 307 nota 5.
} 


\title{
"Hò ánthropos aritmetítzei" Finitud Intuitiva e Infinitud Simbólica en la Filosofía de la Aritmética de Husserl
}

\author{
Rosemary Rizo-Patrón de Lerner \\ Pontificia Universidad Católica del Perú
}

\begin{abstract}
Resumen
La fenomenología de Husserl oscila entre una valoración positiva del cálculo técnico para compensar la limitada capacidad intuitiva de los seres humanos y una denuncia de la ceguera que su desarrollo ha ocasionado respecto de la verdadera naturaleza del pensamiento científico y filosófico. Asimismo, respecto de la intuición la fenomenología oscila entre una valoración positiva del carácter fundacional y auténtico de las representaciones intuitivas básicas y la observación de su finitud radical. El presente texto explora algunos rasgos de estas oscilaciones.
\end{abstract}

Si tuviésemos representaciones (Vorstellungen) auténticas de todos los números, como tenemos de aquellos del inicio de la serie numérica, no existiría la aritmética, pues sería completamente superflua ${ }^{1}$.

\section{$\$ 1$. Introducción}

El proyecto fundacional de Husserl desde la Filosofía de la aritmética hasta La crisis de las ciencias europeas y la fenomenologia trascendental se ha caracterizado por una ambigüedad en relación al valor, lugar y papel jugado en él por las representaciones intuitivas, de un lado, y los conceptos simbólicos, del otro. Además, ha trazado una clara diferencia entre el pensamiento filosófico (esto es, "lógico"), de un lado, y el arte o técnica del cálculo, del otro -entre episteme y techné. En efecto, el pensamiento filosófico o conceptual — tanto el primariamente auténtico o intuitivo como el secundariamente inauténtico o simbólico- , a pesar de ser fundacional en relación a toda forma de proceder calculante, es empero limitado y finito en su capacidad representativa. Los signos de las "técnicas calculatorias" reemplazan por ende ambos tipos de representaciones conceptuales (auténticas e inauténticas), permitiendo al entendimiento superar sus limitaciones operativas y extender sus posibilidades a construcciones abiertas e infinitas.

\footnotetext{
${ }^{1}$ Edmund Husserl. Philosophie der Arithmetik. Ed. Lothar Eley. Husserliana XII (The Hague: Nijhoff, 1970), p. 191. En adelante citado como 'Hua XII' con referencia a la página en alemán.
} 
Por ende, la fenomenología de Husserl oscila desde su inicio entre una valoración positiva del cálculo técnico para superar la limitada capacidad de los seres humanos y una denuncia de la ceguera que su extraordinario desarrollo ha causado en los últimos siglos respecto de la verdadera naturaleza del pensamiento científico y filosófico en tanto logos. Asimismo, en relación a la intuición, Husserl oscila entre una valoración positiva del carácter fundacional y auténtico de las representaciones intuitivas básicas y la observación de su radical finitud. Exploraremos a continuación algunos rasgos de estas oscilaciones.

\section{\$2. Del mundo finito al universo infinito}

La Crisis de la ciencias europeas y la fenomenología trascendental de 1936 toma una clara posición respecto de la "caracterización global del racionalismo fisicalista moderno" 2 que ha olvidado su fundamento de sentido en el mundo de la vida ${ }^{3}$. Allí sostiene Husserl que la concepción Galileana de la naturaleza como universo matemático está al origen de una nueva idea de la universalidad de la ciencia, una ciencia matemática natural sin precedentes, desconocida por los antiguos ${ }^{4}$. Más allá de la geometría euclidiana y su "idea de una teoría deductiva (...) sistemática y unitaria” — todavía dentro de las fronteras de una silogística aristotélica que descansa "en conceptos y principios fundamentales 'axiomáticos" o en verdades "incondicionada(s) mediata e inmediatamente evidentes" — una nueva infinitud ideal matemática surge en la Modernidad a partir de una abstracción formalizante, que empieza con la aritmetización de la geometría y la extensión de sus posibilidades con la introducción del álgebra ${ }^{6}$. El resultado de la introducción del álgebra, la geometría analítica y la matemática de los continuos es una nueva ciencia natural seguida y retomada por un racionalismo matemático. Un mundo en sí mismo, infinito e ideal, parece por fin asequible al conocimiento humano. Los datos empíricos intuitivos y la inducción proveen solo "el suelo para un método matemático idealizante, para encontrar leyes exactas del mundo" 7 , mientras que la nueva matemática formalizada provee la idea de una "omnisciencia" (Allwissenheit) "idealmente consumada"8. El naturalismo mediante el cual todo el universo debe pensarse en términos de la naturaleza física o su análogo es una consecuencia de ello. La humanidad asegura su dominio sobre el mundo circundante - físico, psicofísico, y aún cultural — viviendo en la "tranquilizadora certeza" de poseer "un

\footnotetext{
${ }^{2}$ Edmund Husserl. Die Krisis der europäischen Wissenschaften und die transzendentale Phänomenologie: Eine Einleitung in die phänomenologische Philosophie, Husserliana VI (The Hague: Nijhoff, 1962), 66; traducción castellana: La crisis de las ciencias europeas y la fenomenología trascendental, trad. Jacobo Muñoz y Salvador Más (Barcelona: Crítica, 1991), 68. En adelante citado como 'Hua VI' con referencia a la página en alemán, y como Crisis con referencia a la página en castellano.

${ }^{3}$ Cf. Hua VI, 48 (Crisis, 50) passim.

${ }^{4}$ Hua VI, 18 (Crisis, 20).

${ }^{5}$ Hua VI, 18-19 (Crisis, 21).

${ }^{6}$ Hua VI, 43-44 (Crisis, 45).

${ }^{7}$ Hua VI, 295 (Crisis, 303).

${ }^{8}$ Hua VI, 66 (Crisis, 68).
} 
método infalible para ampliar el conocimiento y en virtud del cual, a partir del Todo del ser, realmente todo debería resultar conocido en la plenitud de su ser-en-sí en un progreso infinito" .

La paradoja resultante es que el naturalismo - habiendo supuestamente destruido la teología y la metafísica como desvaríos de mentes enfebrecidasexpresa in extremis el punto de vista "teológico" de que el conocimiento de las matemáticas nos otorga una visión "absoluta" de las leyes del universo y sus determinaciones. Galileo, en Il Saggiatore (1623, \$48), y en sus Discorsi (1638) introdujo la concepción — luego retomada y fundada filosóficamente por Descartes - de que (a) el "libro del universo" ha sido escrito en lenguaje matemático, sub specie aeternitatis; mediante dicho lenguaje, si lo adquieren, los seres humanos pueden contemplar el universo como Dios mismo lo hace ${ }^{10}$; y, (b) que las matemáticas son el único paradigma científico que ha de ser imitado por la filosofía. Un par de siglos después el matemático y científico alemán Johann Carl Friedrich Gauss (1777-1855) — que no era un religioso conservador sino más bien un partidario del empirismo científico- perpetuó el punto de vista galileano con el dictum "hò theòs aritmetitzei"1. En su Was sind and was sollen die Zahlen?, Dedekind, uno de los antiguos alumnos de Gauss, parafrasea el dictum de su maestro con una expresión similar, aunque no idéntica, "aei hò anthropos aritmetitzei"12. Husserl rechaza esta versión en una nota al inicio de la segunda parte de su Filosofía de la aritmética ${ }^{13}$, pues aunque la idea de un Dios aritmético allí se ve reemplazada por la de un ser humano aritmético, esta nueva expresión preserva todavía la idea de un ordenamiento aritmético eterno del universo.

A Gauß se le menciona nuevamente en uno de los textos complementarios de la Crisis de $1936^{14}$, donde este paradigma —y el concepto moderno matematizante del universo explicable sobre la base de aritmética- es fuertemente criticado. La teoría aritmética aquí aludida no es aquella por la que los con-

\footnotetext{
${ }^{9}$ Hua VI, 67 (Crisis, 68-69). Modificamos ligeramente la traducción.

10 "La filosofía está escrita en ese grandioso libro que está continuamente abierto ante nuestros ojos (lo llamo universo). Pero no se puede descifrar si antes no se comprende el lenguaje y se conocen los caracteres en que está escrito. Está escrito en lenguaje matemático, siendo sus caracteres triángulos, círculos y figuras geométricas. Sin estos medios es humanamente imposible comprender una palabra; sin ellos, deambulamos vanamente por un oscuro laberinto". (Galileo Galilei, Il Saggiatore, §6; citamos de la "Introducción" de Carlos Solís en: Galileo Galilei, Consideraciones y demostraciones matemáticas sobre dos nuevas ciencias. Ed. C. Solis and J. Sadaba [Madrid: Editora Nacional, 1976], 29).

${ }^{11}$ Cf. R. N. Smid, "Introducción del Editor," en Edmund Husserl, Die Krisis der europäischen Wissens chaften und die transzendentale Phänomenologie, Ergänzungsband, Texte aus dem Nachlass 1934-1937, Husserliana XXIX, (Dordrecht: Kluwer, 1993), xxxiv-xxxv. En adelante citado como 'Hua XXIX' con referencia a la página en alemán.

${ }^{12}$ Con respecto a la influencia de Weierstraß, Cantor y Dedekind en la concepción y desarrollos tempranos de la aritmética y el análisis por parte de Husserl, cf. Ingeborg Strohmeyer, "Introducción de la Editora", en Edmund Husserl, Studien in Geometrie und Arithmetik. Texte aus dem Nachlass (1886-1901), Husserliana XXI (The Hague: Nijhoff, 1983), xiv. En adelante citado como 'Hua XXI' con referencia a la página en alemán.

${ }^{13}$ Hиа XII, 192

${ }^{14}$ Hua XXIX, 203-207. Dicho pasaje está destinado a reemplazar el comienzo del §60 de la Crisis.
} 
ceptos se refieren a números cardinales y conjuntos (Menge) construidos simbólicamente como series ilimitadas, sino aquella de números lógicos conceptuales concebidos en su generalidad incondicional y construidos sistemáticamente siguiendo un método conceptual para la construcción continua de más números ${ }^{15}$. Así, la aritmética deviene para Husserl el prototipo de toda ciencia moderna, incluyendo la geometría y la física: "El mos geometricus es (...) en verdad mos arithmeticus" ${ }^{16}$. Indirectamente, "bajo la hipótesis de poder construir una matematización gradual de la naturaleza"17, los físicos modernos y filósofos racionalistas sostienen que la totalidad de los cuerpos físicos es alcanzable sistemática y directamente (pasible de ser construida conceptualmente) desde sus ámbitos ya asegurados ("fertige"), hasta una infinitud pre-dada como horizonte de construcciones adicionales posibles.

La concepción de Gauß — inspirada por el racionalismo fisicalista modernoes errada, según Husserl. El universo no puede jamás tener un horizonte lógicamente determinable (logifizierbaren) "en una lógica que es logística"18. Esta concepción ha dominado al mundo occidental por trescientos años, sin embargo no se ha explicado cómo es teóricamente construible en una experiencia humana (trascendental).

Husserl ya manifiesta sus reparos respecto de esta incomprensión histórica de la naturaleza de la aritmética en su Filosofía de la aritmética de 1891. Con el objeto de explicarla en términos de experiencia humana, propone reemplazar las frases de Gauß y Dedekind: "Yo simplemente diría: 'El ser humano aritmetiza."” Pero es importante entender por qué dice esto.

\section{\$3. Comprensión filosófica versus dominio de técnicas}

A pesar de estar familiarizado con el análisis y haber trabajado con el "cálculo de variaciones" para su tesis doctoral, Husserl sorprendentemente se alía con la concepción de Weierstrass según la cual la aritmética, y su "concepto de número entero" básico ${ }^{19}$, parece ofrecer la posibilidad de una fundación unitaria de las matemáticas como un todo. Él seriamente piensa que el desarrollo de las técnicas operatorias matemáticas durante los siglos XVIII y XIX no ha traído un desarrollo concomitante de la filosofía de las matemáticas ${ }^{20}$, esto

\footnotetext{
${ }^{15}$ Cf. Ниа XXIX, 204.

${ }^{16}$ Husserl continúa: “La física alcanza su 'dominio' en la medida en que hipotéticamente presupone un analogon de la cerrada infinitud de la serie numérica - aunque pueda faltar aquí la evidencia constructiva por medio de la cual el dominio a priori es pre-dado como pasible de ser construido". (Hua XXIX, 204-205)

${ }^{17}$ Hua XXIX, 205.

${ }^{18}$ Así como cualquiera puede empezar con números alcanzados individualmente con lo que puede ser conducido a todos los demás números pensables_-evidentes para todos_cada uno puede idealiter extender la evidencia de su propia experiencia del universo in infinitum. Por ende cada uno se concibe a sí mismo como un Dios hecho finito, y concibe a Dios como un individuo hecho infinito, con lo que uno puede expandir su percepción finita limitada al infinito. (Hua XXIX, 205-206)

${ }^{19}$ Hиа XII, 289-338.

${ }^{20}$ Hua XII, 7.
} 
es, que aquellas técnicas "providenciales" ${ }^{21}$ no son el modo de alcanzar una comprensión filosófica de su naturaleza esencial ${ }^{22}$. En efecto, Husserl distingue claramente las técnicas calculatorias del logos propio del pensamiento científicofilosófico, y reafirma su preocupación por la falta de claridad filosófica sobre los fundamentos de las matemáticas ${ }^{23}$.

Por ello la comprensión de la naturaleza esencial de la matemática comenzando con la aritmética es una tarea filosófica; sostiene que fundarla filosóficamente significa explicar la naturaleza lógica de sus conceptos. Ahora bien —como Husserl mismo afirma en su "Sobre el concepto del número" de 1887- la lógica se comprende, según una de las principales tendencias de su tiempo, como (a) una tecnología o ars de juzgar correctamente; y, como (b) ella misma fundada en una "nueva psicología". Ésta estaría a cargo de plantear la cuestión del origen intuitivo (psicológico o "auténtico") y el carácter fenomenal de las representaciones primitivas lógicas y matemáticas — tales como las representaciones primitivas de tiempo, espacio, número, etc. Sólo sobre esta base psicológica previa —abandonando propiamente el terreno aritmético, y en cierto sentido desnaturalizándolo- puede ser luego planteada apropiadamente la cuestión de la naturaleza lógica de sus conceptos simbólicos o "inauténticos" 24 .

Así, Husserl empieza siguiendo los pasos de Brentano, rechazando los procedimientos fundacionales puramente analíticos como los de Helmholtz o Rie$\operatorname{mann}^{25}$. Sin embargo existen otras razones por las que las investigaciones sobre el origen psicológico e intuitivo de las representaciones deben preceder a aquéllas del origen lógico de los métodos simbólicos o inauténticos. Ellas tienen que ver, por un lado, con el hecho esencial de la constitución finita, temporal de las facultades cognitivas humanas, y, por el otro, con la extensión y carácter "portentoso" de las posibilidades abiertas por la formalización del pensamiento aritmético ${ }^{26}$. Husserl sostiene mutatis mutandis las mismas ideas hasta el final de su vida ${ }^{27}$.

\footnotetext{
${ }^{21}$ Hua VI, p. 46 (Crisis, 45).

${ }^{22}$ En su reseña ulterior del libro de Schröder, Vorlesungen über die Algebra der Logik (Exakte Logik), Husserl denuncia el intento de sustituir el dominio estrecho de la "deducción lógica pura" con "técnicas" inferenciales, a saber, aquellas del cálculo lógico. Cf. Edmund Husserl, Aufsätze und Rezensionen (18901910), Husserliana XXII (The Hague: Nijhoff, 1979), 3-43. En adelante citado como 'Hua XXII' con referencia a la página en alemán.

23 "La aritmética general, la más altamente desarrollada de las disciplinas calculantes (...), florece en adelante y hacia arriba aún cuando los más dotados de sus representantes están, y siempre han estado, muy distantes de una captación más profunda de sus principios fundamentales. (...) Esto también vale para el cálculo lógico. (Hua XXII, 22).

${ }^{24}$ Jean-Toussaint Desanti, "Postface". En: Frege-Husserl Correspondance (Mauvezin: T.E.R., 1987), 69.

${ }^{25}$ Hua XII, 290-293.

26 “Una extensión simbólica de la construcción substancialmente finita de grupos, es, según Husserl, necesaria puesto que somos seres finitos y temporales. Un ser eterno e infinito no calcula. La infinitud de las matemáticas sería pues concebida como una forma peculiar de finitud. Un infinito actual sería de entrada absurdo." Lothar Eley, "Introducción del Editor", en Hua XII, xiii-xiv.

27 "Hay que tener aquí en cuenta la poderosa difusión, (...) de las notaciones y de los modos de pensamiento algebraico, que tiene lugar en la época moderna desde Vieta (...). Esto significa, ante todo, un prodigioso acrecentamiento de las posibilidades del pensar aritmético heredado en las viejas fórmulas primitivas. (...) formas que vienen a ser ahora en su totalidad algebraicamente formalizadas con un propósito metódico. Toma cuerpo así la 'aritmetización de la geometría', (...) del dominio total de las formas puras (...) Son concebidas idealiter como mensurables de un modo exacto (...)". (Hua VI, 43-44 [Crisis, 44]).
} 
Sin embargo, la matematización de la ciencia natural en la Crisis de Husserl tiene una contraparte: también nos enfrenta a un "vaciamiento de su sentido" a través de la "tecnificación". Ya antes de Galileo — desde Vieta en adelanteeste vaciamiento de sentido comienza con la "aritmetización" de la geometría. Primero, ocurre una "liberación" del pensamiento aritmético "de toda realidad intuitiva", pasando "a ser un pensamiento apriórico sobre números en general, sobre relaciones y leyes numéricas" 28 , etc. Pero esta aritmetización a su vez se supera por una "formalización" completamente universal que "mejora" y "amplía" "la teoría algebraica de los números y de las magnitudes en un 'análisis' universal...puramente formal; camino de una 'teoría de la multiplicidad, de una 'logística"” 29 cuyo alcance primero apareció en la idea Leibniziana de una mathesis universalis. La aritmética desde los tiempos modernos gradualmente se convierte en una técnica calculatoria:

Se opera con letras, con signos de relación y de enlace $(+, \mathrm{x},=$, etc.) y obedeciendo las reglas de juego de su coordinación; de hecho, y en lo esencial, no de otro modo que en el juego de cartas o de dados. El pensamiento originario, que confiere auténtico sentido a este proceso técnico y verdad a los resultados obtenidos de acuerdo con las reglas, aunque se trate sólo de la "verdad formal" característica de la mathesis universalis formal, está aquí excluido... ${ }^{30}$

Como consecuencia de ello también se drena el sentido de todos los dominios de las matemáticas y de la ciencia natural. Los métodos experimentales de la ciencia son "mecanizados". La complicidad íntima y el "juego interactivo" entre la ciencia natural y la techné dan lugar a la "física experimental y (...) matemática"31. La estrategia de la Crisis — no muy distante en su meta de aquella de la Filosofía de la aritmética - es comprender (y así "recuperar") el olvidado fundamento de sentido de esta ciencia natural matematizada ${ }^{32}$. En ese sentido, Galileo es un "genio descubridor y encubridor" (entdeckender und verdeckender Genius) $)^{33}$, que revela al universo bajo la luz de la "ley de la legaliformidad exacta” verdadera (idealizada y matematizada) mientras que al mismo tiempo oculta el sentido de la matematización. Husserl aquí exige

Preguntar retrospectivamente por el sentido originario de todas $(. .)<$. las $>$ configuraciones de sentido <del científico $>$ y de todos sus métodos: por el sentido histórico de la fundación originaria y, sobre todo, por el sentido de todas las herencias de sentido asumidas inadvertidamente, así como por el de todas las posteriores en igual situación ${ }^{34}$.

\footnotetext{
${ }^{28}$ Hua VI, 43 (Crisis, 45).

${ }^{29}$ Hua VI, 45 (Crisis, 46).

${ }^{30}$ Hua VI, 46 (Crisis, 47-48).

${ }^{31}$ Hua VI, 48 (Crisis, 50).

${ }^{32}$ Hиа VI, 48 ss (Crisis, $\left.50 \mathrm{ss}\right)$.

${ }^{33}$ Hua VI, 53 (Crisis, 54).

${ }^{34}$ Hua VI, 57 (Crisis, 59)
} 
Bien, hasta ahora hemos visto dos exigencias antitéticas en Husserl: a) la de buscar una fundación filosófica en la experiencia intuitiva dadora de sentido, a pesar de su finitud radical; y, b) la de superar la experiencia finita para dar cuenta del dominio universal de la mathesis universalis, pasible de ser construido primero algebraicamente y luego a través de una formalización sofisticada de la aritmética en un proceso inacabado, a costas del vaciamiento de su fundamento de sentido. La primera exigencia se lleva a cabo a través de un movimiento reflexivo hacia el sujeto experimentante; la segunda se expresa en un movimiento orientado objetivamente, alejándose del sujeto. Ambas exigencias son necesarias, ninguna es completa sin la otra.

\section{\$4. Fundación intuitiva y fundación simbólica de la aritmética}

En la Filosofía de la aritmética la primera exigencia es dar cuenta de la realización, o del origen, de la aritmética en actos intuitivos, subjetivos, cognitivos y concretos. El concepto Husserliano de intencionalidad todavía no se ha desarrollado, y el de Brentano ni es mencionado, aunque su punto de partida sea una distinción del maestro entre representaciones "auténticas" (intuitivas o "plenas") e "inauténticas" (simbólicas o "vacías"). Inicialmente, el concepto de intuición (o representación auténtica) de Husserl parece muy limitado, y preso de un cierto "inmanentismo" o "fenomenalismo" heredado del propio Brentano. La evolución del concepto Husserliano de intuición durante la década que sucede a la publicación de la Filosofía de la aritmética es muy relevante, puesto que el alcance de este concepto se amplía considerablemente con la inclusión de la "idealidad", sin dejar nunca su terreno "finito". No obstante, pensamos que ya en la Filosofía de la aritmética el concepto Husserliano de intuición muestra rasgos de apartarse de la explicación psicológico-descriptiva de Brentano.

Siguiendo a Weierstraß, Husserl empieza con el concepto del número cardinal, positivo y natural (Grundzahlo Anzahl), que él interpreta como una "pluralidad" (Vielheit) —esto es, una cantidad, agregado o reunión ${ }^{35}$. Para transformar una "pluralidad" en un número, es preciso determinarla ${ }^{36}$. Husserl se pregunta cuál es el fenómeno concreto, intuitivo y originario, de donde puede abstraerse el concepto de "pluralidad". Responde que debe ser una totalidad o suma (Inbegriff) determinada de cualesquiera objetos ${ }^{37}$. A dichos objetos —-desprovistos de sus contenidos cualitativos respectivos y reducidos a meras unidades o "algo"- se añade "otra cosa": la relación de la combinación colectiva ${ }^{38}$. Esta última puede ser representada intuitivamente (auténticamente) a través de un

\footnotetext{
${ }^{35}$ Euclides había definido los números como una "pluralidad de unidades" a inicios del Libro VII de sus Elementos (Hua XII, 14).

${ }^{36}$ Hua XII, 15.

${ }^{37}$ En sus escritos tempranos Husserl se refirió a los "objetos" de las intuiciones como "contenidos", repitiendo con ello el equívoco en el que incurrió su maestro al caracterizar los "objetos intencionales" como "in-existencias", esto es, "contenidos". Husserl en cambio sí distingue claramente entre objetos y contenidos de los conceptos inauténticos.
} 
acto de "reflexión" guiado por un interés unitario ${ }^{39}$. Puesto que hay muchos tipos de totalidades con sus respectivos tipos de conexiones, debe señalarse la exacta naturaleza de la "combinación colectiva". Apoyándose en la distinción de Brentano entre fenómenos "psíquicos" y "físicos" Husserl distingue entre relaciones "físicas" (o internas) y "psíquicas" (o externas). Las primeras pueden ser relaciones "metafísicas" (como las que se dan entre la extensión espacial y el color; o entre el tallo, las espinas y las flores en una rosa), o inclusiones lógicas (como la del color y el rojo). Las relaciones "psíquicas", en cambio, están caracterizadas por la "in-existencia intencional" de sus contenidos o elementos ${ }^{40}$. La conexión colectiva que caracteriza el fenómeno de totalidad - a la base del concepto de pluralidad- es una "relación psíquica (externa)", sostiene Husserl, tiene una "naturaleza psicológica” ${ }^{41}$.

El concepto de pluralidad se abstrae pues de una totalidad cuyos elementos están conectados psíquicamente. Él se expresa bajo la forma del uno más uno más uno etc., cuya "relación" se representa por el "y" y los contenidos o fundamentos por las unidades añadidas ${ }^{42}$. Si suspendemos la indeterminación del concepto de pluralidad, o si nos detenemos en cualquier lugar de la serie $1+1+1+1$ etc., y denominamos (determinamos) las unidades alcanzadas, dicho concepto da lugar al concepto de número. Puesto que este proceso es limitado y torpe, el concepto general y abstracto de número se obtiene preferentemente mediante una abstracción de segundo nivel por el que se determina claramente la cantidad de unidades combinadas colectivamente — por decir, "desde abajo" ${ }^{33}$.

Ahora bien, tanto el concepto de pluralidad como aquel abstracto y general de número son ambos conceptos auténticos, pues están fundados directa

\footnotetext{
${ }^{38}$ Hиа XII, 79. En efecto, contra John St. Mill o incluso los filósofos escolásticos, y aliándose con Leibniz o Locke, Husserl sostiene que "todo objeto de representación, físico o psíquico, abstracto o concreto, dado a través de la sensación o la imaginación, puede ser relacionado con otro o con cualesquiera otros y, así, enumerado, como por ejemplo árboles determinados, el sol, la luna, la tierra y Marte; (...) La naturaleza de los contenidos individuales no interviene para nada." (Hua XII, 16) Dentro de la totalidad se observa una "conexión de elementos individuales en el todo" (Hua XII, 18-19). Él "usará, en adelante, el nombre de conexión colectiva para determinar la relación que caracteriza la totalidad" (Hua XII, 20).

${ }^{40}$ En una nota a pie de página Husserl se refiere a la famosa "Distinción entre fenómenos psíquicos y físicos" de Brentano, resaltando su relevancia y denunciando en ella el uso de terminología ambigua. Así, las "relaciones" primarias (horizontales) (en lugar de fenómenos físicos) se dan entre sus fundamentos y al mismo nivel que ellos (luego denominados - siguiendo a Stumpf - "contenidos dependientes"), y cualquier cambio en ellos afecta la relación misma (Hua XII, 19-20, 68-70). Por el contrario, si las relaciones psíquicas - siguiendo a Brentano- están caracterizadas por la "in-existencia intencional" de sus contenidos (o fundamentos) (Hua XII, 70), es porque se hallan en un distinto "nivel" que ellos. Cualquier cambio o variación en los contenidos no afecta la relación misma (Hua XII, 73). Además, las relaciones psíquicas son captadas inmediatamente a través de actos reflexivos, mientras que sus fundamentos solo de forma mediata (Hua XII, 69-70).

${ }^{41}$ Para Brentano, solo hay "percepción adecuada" de fenómenos "psíquicos", no de sus contenidos intencionales (fenómenos "físicos"), siendo captados estos últimos solo a través de una Falschnehmung. Cf. Hua XII, 64.

${ }^{42}$ Hua XII, 80.

${ }^{43}$ Hua XII, 81-83. Burt Hopkins argumenta sobre la necesidad de comprender adecuadamente el "concepto general de número cardinal". No tiene el sentido del concepto universal más tardío de Husserl, como correlato de una intuición ideal o categorial que determina a las unidades o pluralidades "desde arriba," sino más bien el sentido de "conceptos de la especie de los números" mismos, donde lo que da lugar al concepto de número ideal al que nos referimos aquí es una abstracción de objetos primero determinados por el acto de combinación colectiva (cf. su "Authentic and Symbolic Numbers in Husserl's Philosophy of Arithmetic". En: The New Yearbook of Phenomenology and Phenomenological Philosophy II (2002), 39-71, aquí, especialmente, 58-63).
} 
e intuitivamente en los Konkreta a su base. Sólo ofrecen el fundamento de la aritmética. Pero no bastan para explicar el edificio entero de la aritmética, y mucho menos del conjunto de las matemáticas. De allí que deba realizarse una abstracción simbólica, para reemplazar estos conceptos con conceptos "inauténticos" o "vacíos". El primer problema que emerge aquí concierne a las limitaciones humanas en el aprehender, construir y determinar multiplicidades infinitas mayores - del tipo de las series o procesos, en los que algunos grupos "entran" mientras otros "caen" ${ }^{44}$ :

Si tuviésemos auténticas representaciones (Vorstellungen) de todos los números, como los que poseemos del inicio de la serie numérica, entonces no existiría aritmética alguna, pues sería totalmente superflua. Las relaciones más complejas entre los números, que descubrimos ahora con dificultad a través de largos cálculos, serían intuidas simultáneamente con evidencia tales como las proposiciones del tipo $2+3=5$.... De facto, empero, estamos limitados en nuestras capacidades de representación. El hecho que hallamos algún tipo de límite en nosotros mismos, yace en la finitud de la naturaleza humana. Sólo pueden esperarse representaciones auténticas de todos los números en una mente infinita;... Así la aritmética entera, como veremos, no es otra cosa que la suma de medios técnicos para superar las imperfecciones (Unvollkommenheiten) esenciales de nuestro intelecto, que aquí mencionamos ${ }^{45}$.

Así, para Husserl la simbolización es el proceso de sustitución realizado por la mente para compensar aquella finitud de su constitución y de su capacidad auténtica o intuitiva de representación — por la que apenas puede superar los doce elementos ${ }^{46}$. La construcción de la aritmética —según Husserl—, más que la de cualquier otra ciencia, manifiesta el carácter finito e imperfecto de la constitución cognitiva humana. Éste es el contexto en el que Husserl introduce su frase "hò ànthropos aritmetítzei". Así, aunque el concepto simbólico no es una representación "fundamental" (o "fundacional") — pues reemplaza a la intuitiva, incluso cuando ésta sí es realizable - tiene un papel preponderante, pues ofrece una solución a las limitaciones inherentes a la aprehensión consciente humana de las series temporales:

Pensar que cualquier extensión de nuestra facultad cognitiva pueda capacitarnos para representar aquellos grupos <series numéricas >, de un modo efectivo, o por lo menos por medio de una sucesión exhaustiva, es imposible. He aquí una limitación incluso en nuestro poder de idealización ${ }^{47}$.

\footnotetext{
${ }^{44}$ Hиа XII, 198. Los números propiamente aritméticos no son las propiedades "figurativas" cuasi cualitativas que pertenecen a tipos grupales (que nos permiten reconocer rebaños, montones, filas, etc.). Éstos están construidos en la vida ordinaria (perceptiva), referidos con nombres generales, con un horizonte de posibilidades abiertas que permite que otros tipos puedan construirse $-\mathrm{o}$ denotarse - siguiendo ciertos intereses.

${ }^{45}$ Hua XII, 191-192.

${ }^{46}$ Hua XII, 191-196.
} 
Sin embargo, la simbolización y formación de las series numéricas conceptuales que propiamente da lugar al desarrollo de las matemáticas no puede ser construida por conceptos puramente simbólicos, inauténticos o "vacíos". El único modo de superar verdaderamente la finitud de nuestra capacidad representativa es yendo incluso más allá de las representaciones conceptuales inauténticas, determinándolas, nombrándolas y denotándolas con signos físicos para facilitar operaciones que de otro modo serían fácticamente imposibles de realizar. Los procedimientos deductivos son así reemplazados por "cálculos" que no deducen de conceptos sino que sólo operan con signos sensibles que facilitan dichas operaciones — como es el caso de las "figuras" y "reglas" de un juego ${ }^{48}$. La sustitución simbólica tiene así un doble carácter: por un lado, el concepto general auténtico de número se ve primero sustituido por el concepto simbólico, y éste se ve luego sustituido por un signo — ya que ni siquiera operamos con conceptos abstractos o generales, por ejemplo con el "concepto 5", sino con objetos o "signos" que los substituyen y representan en general; y, por el otro lado, las actividades psíquicas reales se ven sustituidas por "operaciones matemáticas de cálculo” por las cuales los signos se relacionan entre sí.

Pero pronto para Husserl este proceso originalmente "sustitutivo" adquiere no solo un papel preponderante en las matemáticas sino también uno "fundacional" cuando aparece absolutamente divorciado de la representación y el concepto intuitivo en su base, de toda actividad de idealización, y aún de toda función "sustitutiva", como en las operaciones más elevadas de la aritmética y las matemáticas, v. gr. al tratar de "conjuntos infinitos” y sus "contradicciones" lógicas.

Como consecuencia, la idea inicial de la Filosofía de la aritmética de determinar las fuentes "lógicas" de toda la arithmetica universalis ${ }^{49}$ pasando previamente por una "fundación psicológica" de la misma es claramente absurda, irrealizable idealiter ${ }^{50}$. Y sin embargo ¿cómo pueden justificarse los procesos formales calculantes si no hay un cierto paralelismo entre "conceptos" y "signos"? Yendo más lejos, ¿`cómo se puede legitimar la extensión del dominio numérico?

En un manuscrito de 1890 que trata de ese tema donde Husserl critica cuatro teorías de la extensión y luego discute aquéllas que son "verdaderas" ${ }_{1}$, su res-

\footnotetext{
${ }^{47}$ Hua XII, 219.

${ }^{48}$ Hua XII, 256-258. Como hemos dicho, hay diferentes tipos de representaciones simbólicas (cf. nota 44 supra): a) en la aprehensión perceptiva del carácter relacional de conjuntos o grupos más grandes -rebaños, manadas, filas, colas, etc. (Capítulo XI); b) aquellos construidos culturalmente que representan números o series numéricas más grandes, cuya aprehensión necesita de apoyos sensibles (Capítulo XII); y, finalmente, $c$ ) la representación simbólica que da lugar a la aritmética con el cálculo, siendo su tarea hallar números a partir de números dados. (Cf. Dallas Willard, "Introducción del traductor," en Edmund Husserl, Philosophy of Arithmetic, Psychological and Logical Investigations with Supplementary Texts from 1887-1901, [Dordrecht: Kluwer, 2003], liii-liv).

${ }^{49}$ Incluyendo el dominio numérico de números negativos, racionales, irracionales e imaginarios, siendo la introducción de números irracionales lo más difícil puesto que implica la inclusión de operaciones y conjuntos infinitos, y el infinito "actual" o "matemático" (I. Strohmeyer, "Introducción de la Editora". En Hua XXI, xvii).

${ }^{50}$ Cuando uno se refiere a "conjuntos infinitos" (como los puntos de una línea, o los límites en un continuum) y lo que podemos representar propiamente de ellos ("un proceso determinado ilimitado," o "lo que está incluido en su unidad conceptual"), Husserl admite que está tratando "con un concepto esencialmente nuevo, que no es el concepto de un conjunto en el sentido real de la palabra". Nosotros subrayamos. (Hua XII, 221).
} 
puesta — parecida a la cuarta teoría criticada - consiste en afirmar que la extensión del dominio numérico no depende de un fundamento conceptual sino de las reglas de los signos y de un cálculo propio de la técnica aritmética. De modo tal que no hay propiamente extensión del dominio conceptual numérico, sino solamente de la técnica aritmética. Esta extensión es pues sólo el producto de la matemática formal o de una filosofía del cálculo, a saber, del "formalismo puro"-libre de su base conceptual ${ }^{52}$. La investigación para el segundo volumen proyectado y finalmente nunca redactado de la Filosofia de la aritmética conduce a Husserl a desarrollar una filosofía del cálculo que, sobre la base del carácter formal de la aritmética y de modo unitario, pretende: (a) desarrollar el fundamento lógico de la aritmética general como una ciencia del cálculo; (b) resolver el problema de la extensión del dominio numérico como su extensión algorítmica entendida formalmente; y, (c) analizar la posibilidad de aplicar la aritmética a diferentes dominios conceptuales con idéntico algoritmo $^{53}$. En consecuencia, Husserl concluye que el dominio de los números naturales no es el fundamento de la aritmética, y en adelante no modifica su concepción inicial de esta última como una "teoría general de las operaciones" o una "ciencia del cálculo"

\section{\$5. Técnicos, lógicos y filósofos}

La reseña que Husserl escribe en 1891 sobre el Álgebra de la lógica de Schröder también trata de la distinción entre la técnica o arte del cálculo, por un lado, y el pensamiento lógico o filosófico, por el otro. Este último es originalmente auténtico, esto es, intuitivo, y secundariamente inauténtico, esto es, conceptual o simbólico, y en ambos sentidos limitado en su capacidad representativa.

\footnotetext{
${ }^{51}$ Las cuatro Erweiterungstheorien criticadas son: 1) la escéptica; 2) la dada a través de la definición de nuevos números; 3) la extensión a otros dominios conceptuales a través de "intuiciones ilustrativas" (Veranschaulichungen); y, 4) la legitimación de la extensión de un modo no conceptual. (Cf. Hua XXI, xviii-xxiii, y Apéndices II and III).

52 Strohmeyer observa que Husserl, en dicha época, mientras concebía la construcción de la arithmetica universalis mediante un algoritmo extendido y justificado por una técnica calculante, no necesitaba fundarla en axiomas (Hua XXI, xxxii-xxxvi; cf. también Text Nr. 5). Sólo cuando se muda a Göttingen en 1901 y cae bajo la influencia de Hilbert él reinterpreta su teoría previa de modo axiomático acercándose al programa hilbertiano de la fundación de la aritmética. Así su concepción inicial no estaba sujeta a la crítica ulterior de K. Gödel a los sistemas axiomáticos (cf. "Über formal unentscheidbare Sätze der Principia Mathematica und verwandter Systeme". En: Monatshefte für Mathematik und Physik 38 [1931], 173-198).

53 Cf. Hua XXI, xxxviii. "El concepto más general del dominio aritmetizable no es un concepto numérico ni cuantitativo, sino un conjunto (Menge) o una multiplicidad (Mannigfaltigkeit) (...) Estos conceptos son más generales (...), en la medida que están absolutamente abstraídos de la naturaleza particular, cuantitativa de sus objetos, y sólo representan un objeto o un algo" (Hua XXI, 66; cf. también Hua XII, 493). De allí el prólogo de las Investigaciones lógicas: "Cuando luego descubrí en la 'lógica matemática' una matemática que efectivamente no tiene nada que ver con la cantidad, (...) se me plantearon los importantes problemas sobre la esencia de lo matemático en general, (...) y especialmente sobre la relación entre lo formal de la aritmética y lo formal de la lógica”. (Edmund Husserl. Logische Untersuchungen. I: Prolegomena zur reinen Logik, ed. Lothar Eley, Husserliana XVIII [The Hague: Nijhoff, 1975], /A VI/. Traducción castellana: Investigaciones lógicas, Tomo I, trad. Manuel G. Morente y José Gaos [Madrid: Revista de Occidente, 1967]. En adelante citado como 'Hua XVIII' con referencia a las páginas en alemán, y como 'IL I', con referencia a las páginas en castellano).

54 “De hecho, ya en 1890 - comenta Strohmeyer - Husserl escribe a Stumpf que los análisis de otros conceptos numéricos (originales, negativos, etc.) llevan al conocimiento de que el concepto del número natural no constituye el fundamento de la aritmética general." (Hua XXI, xiv).
} 
Así, el arte del cálculo — los signos de la "técnica calculante" — substituye a ambas operaciones conceptuales — auténticas e inauténticas - y compensa las limitaciones de las capacidades humanas mentales.

Además de la ambigüedad ya mencionada entre una valoración positiva del desarrollo extraordinario del cálculo técnico y una denuncia de su ceguera respecto de la naturaleza del pensamiento científico y filosófico, otra ambigüedad — relacionada con la anterior — aparece claramente en esta reseńa crítica. Concierne los equívocos derivados de la relación entre la deducción lógica y el cálculo. En efecto, dice Husserl:

... todas las disciplinas deductivas desarrolladas utilizan técnicas simbólicas adicionales para la derivación de verdades: calculan con diversos algoritmos. Pero, ¿acaso el cálculo es deducción? De ninguna manera. El cálculo es un procedimiento ciego con símbolos, de acuerdo a reglas mecánicamente reiteradas para la transformación y transposición de signos en el respectivo algoritmo. ... Fue un error fundamental de la vieja lógica formal que, mientras se limitaba a este dominio estrecho de la pura deducción, seguía creyéndose capaz de alcanzar las metas de la lógica. La lógica algorítmica, que de hecho es el heredero directo de la vieja lógica, adoptó ese error. ... Ya la lógica escolástica degenera en una mera técnica deductiva. Estaba esencialmente dedicada al desarrollo de reglas técnicas. Siguiendo estas reglas dentro de las formas que, en general, tomó en consideración aquella lógica, se podían construir mecánicamente las conclusiones de cualquier conjunto dado de premisas, y así librarse de una deducción genuina. Esta técnica primitiva y limitada es la semilla de donde ha crecido el orgulloso edificio del cálculo lógico. Lejos de ser una teoría de la deducción pura es, más bien, un mecanismo para volver superflua a tal deducción ${ }^{55}$.

Los argumentos críticos de Husserl respecto de las implicaciones y consecuencias del Álgebra de la lógica son particularmente fuertes, puesto que intenta mostrar que a este supuesto cálculo no se le puede llamar "lógica", en el sentido propio de la palabra, sino solamente una "técnica para manipular signos" 56 . Husserl entonces deriva las consecuencias necesarias para distinguir entre las tareas - y cualidades - propias de los filósofos de la lógica, por un lado, y los técnicos lógicos, por el otro. No solamente no van de la mano, sino que frecuentemente se hallan enfrentados unos a otros ${ }^{57}$.

Esta distinción le permite a Husserl subrayar una vez más el carácter primordial —en su opinión— de la lógica de contenidos (Inhaltslogik) con respecto

\footnotetext{
${ }^{55}$ Hиа XXII, 7.

56 "No es otra cosa que una técnica para manipular signos (...). Pero el cálculo no es deducción. Es más bien un sustituto externo (äusserliches) de la deducción. (...) El cálculo lógico es, pues, un cálculo de la pura deducción; pero no es su lógica. Él no es una lógica, como tampoco la arithmetica universalis, extendida a todo el dominio de los números, es una lógica de dicho dominio." (Hua XXII, 8).
} 
a la lógica extensional denominada también lógica de clases (Umfangslogik): "Pues este cálculo trata con relaciones de clases. Pero las clases mismas no son sino colectividades, y el cálculo solamente las trata en tanto colectividades" 58 . Schröder, por cierto, argumenta a favor de la lógica de clases, supuestamente debido a la capacidad limitada de los seres humanos para determinar datos de contenido conceptual; puesto que las especificaciones extensionales compensan tal limitación, sólo ellas debieran estar a la base de la lógica ${ }^{59}$. Asimismo, los referidos "datos de contenidos" son — según Schröder - los supuestos constituyentes del "contenido ideal" de los conceptos, debiéndose su imperfección a que los contenidos no son nunca completamente "enumerados" con dichos conceptos. Sin embargo Husserl considera que Schröder se debate con un contrincante inexistente, pues en verdad ningún ser humano posee intuitivamente un contenido conceptual ideal (a saber, la totalidad de las propiedades comunes de todos los objetos que caen bajo el concepto), y considera que el modo de referirse a dicho contenido ideal conceptual es a través de las formas simbólicas que lo mientan "al vacío"

Íntimamente relacionada a la confusión de Schröder y de la tradición, entre el "cálculo" y el pensamiento deductivo, o entre techné y episteme, está — según Husserl - la confusión adicional según la cual el pretendido desarrollo de un "lenguaje exacto, técnico", libre de las ambigüedades y equívocos del lenguaje natural, explica por sí sólo la transformación de la vieja lógica en la nueva, comprendida ésta como un "cálculo." Asimismo, una nueva distinción tendría que introducirse entre lenguaje y algoritmo (en el sentido sui generis que Husserl da a este término): "Un lenguaje no es un método simbólico para la derivación de conclusiones, y un cálculo no es un método simbólico para la

\footnotetext{
57 "Se puede ser un extraordinario técnico de la lógica, siendo a la vez un filósofo de la lógica muy mediocre; y, uno puede ser un extraordinario matemático, siendo a la vez un filósofo de la lógica muy mediocre; (...) Es casi como si las actividades mentales requeridas en uno y en otro fueran en extremo heterogéneas, pues es sólo muy rara vez que se hallan unidas en una persona" (Hua XXII, 9). Apreciaciones similares con respecto a las diferencias en las actitudes de filósofos y científicos (matemáticos, lógicos), así como entre las actitudes crítico-fenomenológicas y dogmáticas, se ofrecen en otras obras (Cf. Ideen zu einer reinen Phänomenologie und phänomenologische Philosophie, I. Band, Allgemeine Einführung in die Phänomenologie, ed. Karl Schuhmann, Husserliana III/1 [The Hague: Nijhoff, 1977], §§ 25, 26, 62; traducción castellana: Ideas relativas a una fenomenología pura y una filosofía fenomenológica, Libro Primero, Introducción General a la Fenomenología Pura, trad. José Gaos [México/Argentina/Brasil/et al: Fondo de Cultura Económica, 1993]. En adelante citado como 'Hua III/1' con referencia a la página en alemán, e 'Ideas I' con referencia a la página en castellano. Cf. también Entwurf einer 'Vorrede' zu den 'Logischen Untersuchungen' [1913], en Tijdschrift voor Filosofie, 1 [Leuven: 1939], §5. En adelante citado como ' $E V$ ' con referencia a la página en alemán). Más tarde Husserl caracteriza a los matemáticos como siendo totalmente indiferentes a la fundación "positiva" de una "lógica de la verdad" formal, y al "posible ser de las objetividades que quizás correspondan a <sus > juicios", quedando su trabajo en el nivel de una mera lógica de la "no-contradicción", sosteniendo que las matemáticas no son un paradigma para el pensamiento filosófico y que hay una superioridad de la evidencia filosófica con respecto a la evidencia matemática (Formale und transzendentale Logik, Versuch einer Kritik der logischen Vernunft, ed. Paul Janssen, Husserliana XVII [The Hague: Nijhoff, 1974], §§52, 69, 59 passim. Traducción castellana: Lógica formal y lógica trascendental. Ensayo de una crítica de la razón lógica, trad. Luis Villoro [México D.F.: Universidad Nacional Autónoma de México, 1962]. En adelante citado como ' $F T L$ ' con referencia a la página en alemán, y como ' $L F T$ ' con referencia a la página en castellano).

${ }^{58}$ Hиа XXII, 14-15.

${ }^{59}$ Ниа XXII, 16.

${ }^{60}$ Hua XXII, 17-20.
} 
expresión sistemática de fenómenos mentales" ${ }^{61}$. De hecho, "con uno no está dado automáticamente el otro. Y es sobre todo seguro que el cálculo lógico es sólo un cálculo, y no es en absoluto un lenguaje"62.

En consecuencia, Husserl trata en esta reseña de dos parejas de oposiciones: por un lado, entre el "cálculo" y la "deducción lógica", en donde, a pesar de la finitud de la deducción lógica y la infinitud (potencial) del cálculo, la deducción es fundadora respecto del cálculo; y, por el otro lado; entre "lenguaje" y "cálculo", asimilando la "deducción lógica" a este último ${ }^{63}$.

\section{\$6. Conclusión: entre la finitud intuitiva ideal y la finita infinitud formal}

Lothar Eley comenta que Husserl en su Filosofía de la aritmética comprendió de que "una aritmética general sólo puede fundarse tomando en consideración el infinito actual. Y si no publicó su segundo volumen esto significa que el plan de Husserl para construir una aritmética finita estaba condenada al fracaso" ${ }^{\text {. }}$. Esto podía ser visto como su imposibilidad de dar cuenta de la tensión interna entre, por un lado, la naturaleza finita de la instanciación de la aritmética en actos subjetivos, cognitivos, concretos, y, por el otro, el carácter infinito del dominio objetivo, verdadero, ideal y "trascendente" de la mathesis universalis ${ }^{65}$.

La frase de Husserl "el hombre aritmetiza" se refiere a la capacidad virtual de los seres humanos de construir simbólica y técnicamente dominios infinitos sobre la base de herramientas intuitivas muy limitadas, y así superar su constitución imperfecta. En efecto, como hemos visto, los seres humanos que "aritmetizan" lo hacen presuponiendo que las herramientas a la base de su estrategia — a pesar de su finitud - no son puramente empíricas ni individuales (como afirma Brentano en su período tardío) sino que contienen una idealización sui generis de las representaciones originales en dos etapas: una que conduce de los elementos arbitrarios unificados por la combinación colectiva hasta el "concepto general abstracto de número"; y la otra que conduce de la simbolización de las series numéricas auténticas aunque inasequibles — por ser abiertas - hasta su formación conceptual puramente simbólica. La finitud inherente a estos dominios conceptuales explica la necesidad de reemplazarlos por una infinitud "técnica" de la extensión algorítmica del dominio numérico;

\footnotetext{
${ }^{61}$ Hua XXII, 21.

${ }^{62}$ Ниа XXII, 22.

${ }^{63}$ Husserl trata del mismo tema en "El cálculo deductivo y la lógica de los contenidos". (Cf. Hua XXII, 44-66, 67-72).

${ }^{64}$ Hua XII, p. xx.

${ }^{65}$ Bien conocido es el registro del diario de Husserl con fecha 25 de setiembre de 1906: "Desde inicios de este mes me he visto seriamente imbuido en mi trabajo (...) He leído bastante de la Filosofía de la aritmética. Cuán inmaduro, cuán ingenuo y casi infantil me ha parecido este trabajo. Bueno, no fue por nada que mi conciencia me atormentó cuando lo publiqué. En verdad, ya lo había superado cuando lo publiqué. Después de todo, había sido esencialmente escrito en los años 1886-87. Yo era un principiante, (...)". (Ed. Walter Biemel. "Edmund Husserl - Persönliche Aufzeichnungen”. En Philosophy and Phenomenological Research XVI: 3 [1956], 294).
} 
de ese modo Husserl resuelve la imposibilidad ideal de hallar en el dominio conceptual las "fuentes lógicas" de la arithmetica universalis. Pronto no queda paralelismo entre los "conceptos" y los "signos". La extensión (Erweiterung) del dominio numérico se legitima por otras vías, cuyos instrumentos Husserl todavía no ha desarrollado en 1891. El "formalismo puro" - libre de su base conceptual - tendrá que reemplazar a los anteriores procedimientos fundacionales. Posteriormente Husserl -como señala en sus Investigaciones lógicas de 1900 - tendrá que reformular "los importantes problemas sobre la esencia de lo matemático en general (...), sobre la relación entre lo formal de la aritmética y lo formal de la lógica" ${ }^{66}$, replantear la distinción kantiana entre juicios sintéticos y analíticos, y superar las huellas de un psicologismo sui generis que él detecta posteriormente en este trabajo inicial.

Y sin embargo, hasta la Crisis, Husserl nos recuerda continuamente que la superación de la finitud, y la infinitud alcanzada a través de la formalización técnica, se da y constituye desde la estructura temporal de la experiencia humana. La infinitud formal no es actual ni divina, sino más bien una infinitud temporal, humanamente finita.

${ }^{66}$ Hua XVIII, /A VI/, IL I, 20. 


\title{
Peter Sloterdijk: Esferas, Fenomenología y Ontogénesis de los Espacios Humanos
}

\author{
Adolfo Vásquez Rocca \\ Pontificia Universidad Católica de Valparaíso
}

\begin{abstract}
Resumen
Sloterdijk, a partir de análisis estético-epistemológicos, desarrolla un nuevo tipo de fenomenología y ontogénesis de los espacios humanos: relaciones intrauterinas, historias amorosas y comunidades políticas; modernos e hipercomplejos modos de estar en el mundo. Vivir es crear esferas, espacios de cobijo para las emociones escindidas. Por medio de construcciones científicas, ideológicas y religiosas se intenta recrear nuestra original caverna, confortable y protectora de nuestras microesferas íntimas y blindarse mediante politicas de climatización frente a los horrores de un espacio sin límite.
\end{abstract}

\section{Esferas, flujos y relaciones totales microclimáticas}

Los hombres, nos recuerda Sloterdijk ${ }^{1}$, vivimos en espacios, en esferas, en atmósferas. Vivir es crear esferas. Las historias amorosas y las comunidades solidarias no son sino la creación de espacios interiores para las emociones escindidas. Vivimos dentro de esferas como mínimo diádicas: placenta/feto; madre/niño; pareja de amantes; alma/dios o los buenos espíritus (daimones o ángeles) que han acompañado casi siempre a los hombres en las épocas premodernas.

El hombre emerge como una utopía bio-ontológica que intenta -por medio de construcciones científicas, ideológicas y religiosas- recrear su original caverna confortable y protectora, las microesferas íntimas, de las parejas no eróticas, sino ontológicas, los gemelos, la relación feto-placenta, individuo y colectividad, alma y Dios, y también las grandes esferas o "úteros fantásticos para masas infantilizadas" que son los imperios o los Estados-nación. Unas estructuras políticas que se comunican como los paranoicos, imponiendo la forma patológica del monólogo: el paranoico habla con el otro en su propia mente.

El drama esferológico del desarrollo -la apertura a la historia comienza- en el instante en el que individuos que eran polos de un campo de dúplice unicidad salen de él a los mundos multipolares de adultos ${ }^{2}$. Cuando estalla la primera

\footnotetext{
${ }^{1}$ Sloterdijk, Peter. Esferas I. Burbujas. Madrid: Ediciones Siruela, 2003, p. 22.

${ }^{2}$ Sloterdijk, Peter. Esferas I. Burbujas. Madrid: Ediciones Siruela, 2003, p. 59.
} 
burbuja sufren irremisiblemente una especie de shock de transcolonización, un desenraizamiento existencial.

Tal es la condición esencial de nuestro estar-en-el-mundo: habitamos siempre un espacio íntimo, una intimidad compartida. Para mostrar esto Sloterdijk realiza una atrevida arqueología y poética de lo intimo: de los espacios nutricios que albergan y entretejen las sutiles telas del alma humana que la unen a las demás y la hacen resonar consigo misma. Son las burbujas duales o polares en contraposición a la mónada autista, verdadero fetiche ensimismado de la moderna subjetividad.

Las burbujas diádicas, triádicas o multipolares son el exterior del interior y el interior del exterior. Son el entretejido extático de los sujetos en el espacio interior común donde se nutren mutuamente aquellos que viven en verdad juntos.

Sloterdijk, en búsqueda del espacio que habitamos y que habita en nosotros, redescribe los espacios íntimos, los frágiles y etéreos paneles de los glóbulos en los que anidamos; dando lugar al nuevo imaginario antropológico de un espacio-tiempo siempre compartido.

La filosofía de Sloterdijk intenta así dar cuenta del hombre como fracaso biológico a través del relato evolutivo del hombre como deriva biotecnológica, para ello presenta la historia natural de la especie y la historia social de la domesticación humana, alineadas en un mismo relato coherente, lo que supone que el último de los dualismos, la distinción entre naturaleza y cultura ha de ser eliminado. El hombre como animalitas fracasada es, fundamentalmente, lo indeterminado que transforma el medio en su mundo, y desde el cual adquiere una determinación relativa. En este sentido, lo que hay de natural en el hombre no pasa de ser una inadaptación y una vulnerabilidad, pero que paradojalmente si se quiere, le proporciona un momento de primigenia apertura por la que se desencadena la revolución antropogénica, esto es, su devenir un producto técnico, una unidad de naturaleza y cultura indistinta.

Desde la primera esfera en la que los hombres están inmersos, con "la clausura en la madre", todos los espacios de vida humanos no son sino reminiscencias de esa caverna original siempre añorada de la primera esfera humana. Sloterdijk comienza así su relato desde la primera esfera en que estamos inmersos, con la "clausura de la madre". Pertenece al drama de la vida el que siempre haya que abandonar espacios animados, en los que uno está inmerso y seguro, sin saber si se va a encontrar en los nuevos un recambio habitable. El primer traslado, exilio o extrańamiento, el primer acto del drama, pues, sucede con el nacimiento. ¿Dónde venimos cuando venimos "al mundo"?, pregunta Sloterdijk. El modo de afrontar el mundo fuera del seno materno viene determinado de manera difícilmente analizable por los restos de memoria prenatales. Todos 
hemos habitado en el seno materno un continente desaparecido, una "íntima Atlántida" que se sumergió con el nacimiento, no en el espacio, desde luego, sino en el tiempo, por eso se necesita una arqueología de los niveles emocionales profundos.

El drama esferológico - la apertura al mundo- supone estos tránsitos y desarraigos existenciales. Los seres humanos experimentan fascinados y tristes cómo entre cielo y tierra hay más cosas muertas y exteriores de las que puede soñar hacer suyas cualquier niño del mundo. Al despedirse los adolescentes del regazo materno les invaden magnitudes sin sujeto, externas, provocadoras e indómitas.

El descubrimiento de la metoikesis, el cambio de morada -el gran tránsito de un elemento de vida a otro- tiene un alcance amplio en la metafórica de Sloterdijk $\mathrm{k}^{3}$. La expresión traslado de morada - que es parte de canónicos y paliativos discursos-consoladores sobre el alma como entidad inmortal y trashumante, que atraviesa por diversos estados, en Sloterdijk, más allá incluso del empleo del término por la gran psicología, la expresión alude, con el rigor de una noción esencial a la cinética profunda del alma, que atraviesa diversos elementos, medios y esferas. De modo tal que el alma debe ser pensada como una vivacidad espiritual de irreductible dinámica de cambio. En la palabra metoikesis se oculta el motivo inicial de una teoría del cambio universal en la perspectiva antropológica. En el modo de ser del alma interpretada filosóficamente yace un proceso trifásico de entrada, travesía y salida del mundo físico. Preexistencia, existencia y pos-existencia son los grandes estadios del ser como alma, entre los que la metoikesis ha de servir de mediación. El primer contexto de la expresión podría facilitar la apariencia de que se trata, exclusivamente, de una metáfora de la muerte; con todo, en una segunda consideración, se hace patente que la palabra, por un lado, no sólo es metáfora, sino también concepto y, por otro, que no alude únicamente al fin del tránsito, sino que es válida, en general, para la evolución de la íntima movilidad humana. También la venida al mundo, la instalación en lo existente, representa un caso de metoikesis, y en consecuencia, los hombres deben ser entendidos como seres nacientes, vivientes y entrantes, en el sentido de reconocer en ellos a los animales que se trasladan y cambian de elemento.

A la luz de una antropología adventista, "traslado de morada" es la peculiaridad que aparta al hombre de la generalidad de las formas animales y lo sentencia a la aventura ontológica y, por lo mismo, a la existencia en el movimiento del venir al mundo.

Como seres que se trasladan, los hombres se hacen ubicuos; como seres que pasan, conforman sus lenguas metafóricas y metafísicas en las que son expresables puntos de vista sobre la totalidad; como animales que cambian de ele-

\footnotetext{
${ }^{3}$ Sloterdijk, Peter. Extrañamiento del mundo. Valencia: Pre-textos, 2001, p. 90.

${ }^{4}$ Sloterdijk, Peter. Extrañamiento del mundo. Valencia: Pre-textos, 2001, p. 91.
} 
mento, desarrollan su característica tensión hacia otra parte que, indefectiblemente, tienen presente como búsqueda y nostalgia; como sujetos de inseguridad elemental, los hombres evolucionan a metafísicos animales problemáticos que, incidentalmente, se enajenan en su inclusión en el mundo; como seres que se pueden extraviar en el entorno, se esfuerzan en poner remedio a la certeza de estar fuera de lugar y no en su elemento; como naturalezas problemáticas entre los productos de la evolución, los esforzados animales productores de historia acumulan experiencias desconcertantes con el peso del mundo y han de buscar su camino entre las verdades de la despreocupación y el desconsuelo. Si lográramos obtener referencias más exactas sobre estos movimientos de búsqueda, estas reflexiones alcanzarían su propósito; darían una idea de cómo debería formularse una guía de ruta antropológica de la posibilidad de huida del mundo.

Sloterdijk analiza así la conexión entre crisis vitales y los intentos fracasados de conformar espacios habitables; examina las catástrofes, cuando estalla una esfera. Cuando esto sucede los seres humanos deben aprender a arreglárselas para existir a la intemperie, expuestos al aliento frío del afuera. El ser humano descascarado busca así responder al enfriamiento exterior con el desarrollo de curiosas políticas de climatización ${ }^{5}$.

El hombre -en este proceso de descentramiento- ya no puede construir el todo a partir de su posición en el mundo, de su exigencia de intimidad, porque allá donde mire encuentra la extrańeza absoluta e inquietante de las heladas cósmicas. Aquí Sloterdijk refiere las consecuencias del giro copernicano que dio comienzo a la historia moderna del conocimiento y del desengaño. Se pierde el centro cosmológico, es el inicio de progresivas descentralizaciones. Se pierden las viejas protecciones, las cubiertas celestes que protegían nuestro mundo. "A fuerza de investigación y toma de conciencia, el ser humano se ha convertido en el idiota del cosmos; se ha condenado él mismo al exilio y se ha expatriado en lo sin-sentido, en lo que no le concierne, en lo que le ahuyenta de sí, perdiendo su inmemorial cobijo en las burbujas de ilusión entretejidas por él mismo. Con ayuda de su inteligencia incansablemente indagadora, el animal abierto derribó el tejado de su vieja casa desde dentro" ${ }^{6}$. La Modernidad se caracteriza porque produce técnicamente sus inmunidades y va eligiendo progresivamente sus estructuras de seguridad sacándolas de las tradicionales coberturas teológicas y cosmológicas. Los ciudadanos de la época moderna hubieron de acomodarse a una situación en la que, con la ilusión de la posición central de su patria en el universo, desapareció también la imagen consoladora de que la tierra estaba envuelta por bóvedas esféricas a modo de cálidos abrigos celestes. Desde entonces los seres humanos de la época tuvieron que aprender a arreglárselas para existir sin las viejas protecciones, sin los

\footnotetext{
${ }^{5}$ Vásquez Rocca, Adolfo. "Peter Sloterdijk; Esferas, helada cósmica y políticas de climatización”. Eikasia Revista de Filosofía, año I - número 5- julio 06, Oviedo, España, http://www.revistadefilosofia.com/SLOTERDIJK.pdf.

${ }^{6}$ Sloterdijk, Peter. Esferas I. Burbujas. Madrid: Ediciones Siruela, 2003, p. 30.
} 
sistemas de inmunidad desarrollados psicológica y evolutivamente, expuestos a la helada cósmica, helada y descentramiento de los cuales ya en el siglo XVI se acusan los primeros vértigos.

La humanidad de la era moderna contrarresta la helada cósmica que entra en la esfera humana por las ventanas violentamente abiertas de la ilustración con un pretendido efecto invernadero: tras la quiebra de los receptáculos celestes, acomete el esfuerzo de compensar su falta de envoltura en el espacio mediante un mundo artificial civilizador. Ése es el horizonte último del titanismo técnico euroamericano. "La civilización altamente tecnológica, el Estado del bienestar, el mercado mundial, la esfera de los media: todos esos grandes proyectos quieren imitar en una época descascarada la imaginaria seguridad de esferas que se ha vuelto imposible" 7 . Ante la perspectiva de un cielo abierto, frío y mudo, había que conseguir la edificación de la gran casa de la especie y una política global de calentamiento.

\section{La era de la falta de albergue metafísico y políticas de climatización}

Los hombres se blindan contra los horrores de un espacio sin límite, ampliado hasta el infinito, mediante la construcción, pragmática y utópica al mismo tiempo, de un invernadero universal que les garantice un habitáculo para la nueva forma moderna de vida al descubierto.

La civilización altamente tecnológica, el Estado del bienestar, el mercado mundial, la esfera de los media: todos esos grandes proyectos quieren imitar en una época descascarada la imaginaria seguridad de esferas que se ha vuelto imposible. Ahora, tiene que procurarse redes y pólizas de seguros han de ocupar el lugar de los caparazones celestes; la telecomunicación debe imitar a lo envolvente. El cuerpo de la humanidad quiere procurarse un nuevo estado de inmunidad dentro de una piel electrónico-mediática. La era de la falta de albergue metafísico generaliza el hábito de la huida.

El primer tomo de Esferas versa, como se ha señalado, sobre las situaciones tonales o las relaciones totales microclimáticas en las que los hombres "viven, se entretejen y son", en las que se disuelven y se sumergen de manera tan natural que, por lo general, no suelen ser objeto explícito de discusión. Las metáforas usadas provocativamente por Sloterdijk resucitan una y otra vez aquella dimensión cancelada por la modernidad, a saber: lo envolvente, la climatología anímica, lo atmosférico, los meteoros, en fin, que habitan, tejen, traman, y protegen la intimidad de los hombres.

La teoría de las esferas viene a ser de este modo un instrumento morfológico que permite reconstruir el éxodo del ser humano de la simbiosis primitiva al

\footnotetext{
${ }^{7}$ Sloterdijk, Peter, Esferas I. Burbujas. Madrid: Ediciones Siruela, 2003, p. 34.
} 
tráfico histórico-universal en imperios y sistemas globales como una historia coherente de extraversiones; ella reconstruye el fenómeno de la gran cultura como la novela de la transferencia de esferas desde el mínimo íntimo, el de la burbuja dual, hasta el máximo imperial, que había que representar como cosmos monádico redondo. Si la exclusividad de la burbuja es un motivo lírico, el de la inclusividad del globo es uno épico ${ }^{8}$.

\section{Autocobijo y sistemas metafísicos de inmunidad}

El destino de todos los sistemas metafísicos de inmunidad se decide frente a la cuestión de si los seres abiertos al gran mundo, los seres humanos de la época de imperios y ciudades, consiguen dar plenamente el salto del autocobijo colectivo en comunidades ciudadanas fortificadas al autoaseguramiento individual, más allá de patrias ocasionales. Es de interés existencial para ellos saber con claridad si serán capaces de llegar a vivir una vida plena también en el extranjero más remoto: una cuestión cifrada para estos en la consideración de si ellos, los mortales, que dependen de una familia y están apegados a un suelo, podrían familiarizarse también con el universo exterior. ¿Cuánto exilio es capaz de soportar el ser humano? ¿Cuánto desacostumbramiento de los primeros lugares necesita el alma capaz de pensar para recogerse en sí misma? ¿Cuánto desarraigo es necesario para hacerse sabio, es decir, resistente al destino?

Serán así viajantes de comercio, emigrantes, diplomáticos, misioneros -marcados por viajes, derrotas y destierros- ejercitados en la argumentación quienes lancen sus miradas escrutadoras por encima y más allá de la propia ciudad amurallada. Los primeros seres humanos burgueses saben mejor que nadie que también en otras partes viven gentes como ellos y que sólo se necesitarían unos pocos cambios triviales del destino para que fueran a parar al extranjero' ${ }^{9}$ Una tempestad marina, un viaje fracasado, una guerra perdida podrían cambiarlo todo. Así pues, lo que se llama el extranjero, ¿̨realmente sólo hay que suponerlo fuera? ¿No han hecho pie hace mucho tiempo ya la muerte y la exterioridad en lo propio, en lo nuestro? Esto es lo que comprenden los individuos que se desplazan de modo más fluido y frecuente, que tampoco la ciudad patria es capaz de satisfacer el profundo anhelo de arraigo. Si nos sentimos mal en ciudades extrańas, ello no habría de sorprendernos, pero si nos sentimos mal en la nuestra, es tiempo de meditar en la existencia en ciudades y en el mundo en general, es el momento de reparar en nuestra condición de fugitivos del cosmos, de la comuna exhalada.

Sloterdijk, movido por esta intranquilidad psicocosmológica, rastrea así la historia de las grandes esferas, desde los imaginarios globos celeste y terráqueo

\footnotetext{
${ }^{8}$ Sloterdijk, Peter. Esferas I. Burbujas. Madrid: Siruela, 2003, p. 71.

${ }^{9}$ Sloterdijk, Peter. Esferas II. Globos. Madrid: Siruela, 2004, p. 310.
} 
hasta las reales circunvalaciones terrestres y conquistas del mundo, hasta lo que hoy llamamos "globalización". La globalización electrónica informática, en la que -dice Sloterdijk - los hombres superan las distancias, y el mundo vuelve a hacerse más pequeño, porque si la segunda etapa generó el cosmopolitismo, la tercera globalización produce un provincianismo global ${ }^{10}$.

A las evasiones hacia lo más exterior se siguen invasiones de frío en la esfera interior humana provenientes de los helados mundos cósmicos y técnicos. Desde el inicio de la edad moderna el mundo humano tiene que aprender en cada siglo, en cada decenio, en cada ańo, cada día a aceptar e integrar verdades siempre nuevas sobre un exterior que no concierne al ser humano. Comenzando en las capas sociales ilustradas y siguiendo, progresivamente, en las masas informadas del Primer Mundo, desde el siglo XVII se expande la nueva y relevante sensación psico-cosmológica de la que los seres humanos no han sido el punto de mira de la evolución, esa diosa indiferente del devenir. Cualquier mirada a la fábrica terrestre y a los espacios extraterrestres basta para acrecentar la evidencia de que el ser humano es sobrepasado por todos los lados por exterioridades monstruosas que exhalan hacia él frío estelar y complejidad extrahumana ${ }^{11}$.

Pero quien ayuda a construir el invernadero global de la civilización cae en paradojas termopolíticas: para que su construcción se lleve a cabo -y esta fantasía espacial está en la base del proyecto de globalización-, ingentes cantidades de población, tanto en el centro como en la periferia, tienen que ser evacuadas de sus viejos cobijos de ilusión regional bien temperada y expuestas a las heladas de la libertad. El constructivismo total exige un precio inexorable. Para conseguir suelo libre para la esfera artificial de recambio, en todas las viejas naciones se dinamitan los restos de creencia en el mundo interior y las ficciones de seguridad, en nombre de una ilustración radical del mercado que promete mejor vida, pero que lo que consigue, para empezar, es reducir drásticamente los estándares de inmunidad de los proletarios y de los pueblos periféricos ${ }^{12}$. De pronto, masas desespiritualizadas se encuentran a la intemperie sin que jamás se les haya aclarado correctamente el sentido de su destierro. Decepcionadas, resfriadas y huérfanas se cobijan en sucedáneos de antiguas imágenes de mundo mientras éstas parezcan conservar todavía un hálito de la calidez de las viejas ilusiones humanas de circundación.

El concepto de esfera se ofrece para recapitular el tránsito desde el pliegue o clausura de la que el ser humano surge al estallido del espacio donde se ve psi-

\footnotetext{
${ }^{10}$ Vásquez Rocca, Adolfo, "Peter Sloterdijk: 'Extrañamiento del mundo'. Abstinencia, drogas y ritual”, En: Gazeta de Antropología, Universidad de Granada - España No. 22 / 2006 y Cuadernos de Materiales No 22, 2007 Universidad Complutense de Madrid, http://www.filosofia.net/materiales/num/num22/Sloterdijk.htm.

${ }^{11}$ Vásquez Rocca, Adolfo. "Peter Sloterdijk; Microesferas íntimas y úteros fantásticos para masas infantilizadas”. En: Nómadas. Revista Crítica de Ciencias Sociales y Jurídicas. Universidad Complutense de Madrid, No 15, Enero-Junio 2007, pp. 193-200.

${ }^{12}$ Sloterdijk, Peter, Esferas I. Burbujas. Madrid: Ediciones Siruela, 2003, p. 34.
} 
cológicamente expuesto y vulnerable. Así Sloterdijk transita del espacio más íntimo al más extenso y abarcante, donde se patentiza un extraño impulso a lo inmenso e inquietante.

'Burbujas', 'Globos' y 'Espumas' son los títulos de los tres volúmenes que integran Esferas. El discurso de Sloterdijk se abre en múltiples direcciones, explorando los caminos más excéntricos y sugerentes hasta nuestros días para ocuparse de cuestiones tan inmediatas como la globalización.

Sloterdijk hace estallar la herencia de la ilustración y la creencia en el progreso, proclama el fin del totalitarismo metafísico y la caducidad de la fatiga nihilista para encarar el mundo contemporáneo, abriendo una brecha entre los apocalípticos y los entusiastas de las nuevas tecnologías, incluida la genética; ha cambiado el eje del preguntar filosófico desde el tradicional ¿quiénes somos? al innovador ¿dónde estamos? Una filosofía espacial en la que el autor, un particular neo-nietzscheano, combina, renovándolas, numerosísimas fuentes, desde Platón hasta Hegel, desde Heidegger hasta Foucault, el psicoanálisis no-freudiano, el eurotaoísmo, la antropología, la biología moderna o el iluminismo tecnológico.

\section{Espumas, mundo poliesférico y complejidad extrahumana}

Finalmente y a modo de recapitulación tenemos que en Esferas I Sloterdijk desarrolla un sugestivo esfuerzo por mostrar que la esfera humana primaria - "burbuja"- era esencialmente relacional, bipolar, y en Esferas II lleva a cabo una narración completa de las tensiones inherentes a la constitución de las macroesferas -"globos"-, donde se narra de qué forma el pensamiento metafísico clásico, como contemplación del todo redondo, se propaga por el mundo, el globo, y pone en marcha formas diversas de globalización, fundando lugares absolutos que daban vida a la idea del Todo; Esferas III tiene, por su parte, asignado proponer una teoría que se haga cargo del nuevo espacio interrelacional del mundo contemporáneo, un mundo que, a pesar del generalizado discurso de la globalización, está marcado por el fin de la imagen centralizada del globo omnicomprensivo y unitario. A diferencia de la red, la metáfora inevitable desde la abrumadora expansión de Internet, la espuma subraya el aislamiento conectado, la diversidad de las conexiones, la constante movilidad de los puntos conectados y la irregularidad de la estructura total. Esferas III representa así el intento de comprender la situación actual como la conexión entre sí de "burbujas", pequeños ambientes que revisten múltiples formas (individuos, parejas, asociaciones de todo orden, consumidores, partidos, etc.), en ausencia de toda visión panóptica, de toda metáfora integradora. Allí donde todo es centro no puede existir un verdadero centro. Allí donde todo emite, el supuesto centro emisor se pierde entre los mensajes imbricados. 
Esta situación es lo que Sloterdijk quiere describir con la metafórica de la espuma, un agregado de múltiples celdillas, frágiles, desiguales, aisladas, permeables, pero sin efectiva comunicación. La esfera deja así de ser la imagen morfológica del mundo poliesférico que habitamos para dar paso a la espuma. Fragilidad, ausencia de centro y movilidad expansiva o decreciente son las características de esta nueva estructura que mantiene una "estabilidad por liquidez”, divisa posmoderna que refleja la íntima conformación de la espuma.

Ahora bien, la intersección telecomunicativa entre las burbujas individuales a través de sus particulares modos de interconexión, la conformación de audiencias y públicos, sustraídos a la "micro"-exterioridad-social de los gestos, requiere - de cualquier manera- un movimiento de ampliación de burbujas, allí tiene lugar la espuma, que -a su vez- se verá apremiada a conformar certeras separaciones y diferenciaciones, lo que el lenguaje telecomunicativo llamará segmentos.

Este espacio telecomunicativo no es -sin embargo- un a priori diferenciable de "la política" solidificada en nuestras sociedades "facilitadoras" y masificantes. Tampoco se puede diferenciar del espacio que nos creamos en la gestión del entretenimiento o nuestras demandas más o menos exigentes de cuidados en la sociedad del confort, demandas de atención a nuevos intereses asociados al prestigio y al lujo.

Ahora bien, estos individuos mimados no se ocupan de cultivar la "amistad", su principal interés es la autoconstrucción de infraestructuras espaciales ultraindividualistas airosas. Todo es en principio un contener y ser contenido en la compleja intersección de burbujas insospechadas. Los otros aparecen difusos en el horizonte proto-social -en el momento de entrada en el mundo hipercomplejo-, en el "espacio fetal" donde los otros -los menos próximos- son sólo objetos difusos que excitan la curiosidad y el interrogar intuitivo.

La problemática configuración de la esfera social obedece al hecho que las burbujas son ante todo un invernadero, un ámbito acondicionado y cerrado a un exterior tóxico, formado cada vez más por toda suerte de prótesis auditivas y visuales. Sloterdijk ve este fenómeno de explicitación creciente, mediante la técnica, de todos los elementos ocultos del cuerpo y del medio ambiente el rasgo más decisivo de la modernidad.

De aquí surge una extraordinaria preocupación por las condiciones de vida y la producción del bienestar, cuestión indisociable de nuestro modo de pensar y diseñar la vida en el momento post-histórico. Sloterdijk en esta última parte de su proyecto despliega su capacidad provocativa para denunciar la disparidad entre el Primer Mundo y las zonas menos desarrolladas, entre la sociedad del bienestar y la "psicosemántica de la necesidad". 
De acuerdo a las perspectivas propuestas, en el Primer Mundo se abre la posibilidad de una conducta no marcada por la necesidad, por la carga de la subsistencia y su ética de la sobrevivencia, sino por la abundancia y el derroche, una sociedad mimada por el confort, marcada por la levitación.

En un contexto global, el estilo de vida moderno, la arquitectura de la seguridad existencial, supone hombres que son, en todas las formaciones sociales, buscadores de certidumbres. Su existencia depende de la disponibilidad de estructuras de resguardo. Un recorrido por el panorama de las condiciones de seguridad en la modernidad sugiere una provocativa reflexión para pensar nuestro tiempo. 
IV. ALTERIDAD E INTERSUBJETIVIDAD 


\title{
Cuatro Sentidos de la Epoché y el Problema de la Intersubjetividad en Husserl
}

\author{
Emilio Morales de la Barrera \\ International Academy of Philosophy of Liechtenstein at \\ Pontificia Universidad Católica de Chile
}

\begin{abstract}
Resumen
El presente paper considera mostrar muy sucintamente el papel de la reducción en el conocimiento del otro tal como la expuso Husserl y esbozar un análisis crítico de las consideraciones husserlianas sobre la epoché y el problema de la intersubjetividad, investigando si efectivamente se da un conocimiento trascendente del otro en este autor.
\end{abstract}

\section{Introducción}

Cuando investigamos la posibilidad de conocer al otro, de tener la evidencia del otro en tanto que otro, los derroteros pueden ser bastante más azarosos y difíciles de lo que en una primera aproximación pudiera considerarse. En efecto, en ciertos análisis filosóficos se debe tratar de evitar sostenidamente diversas falacias no advertidas y trasposiciones indebidas, por ejemplo de un

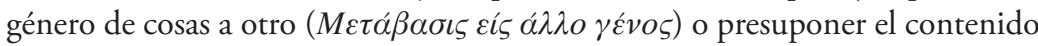
de una forma de conocimiento sin investigar el conocimiento concreto correspondiente.

En nuestro tema en particular, es importante saber mediante qué conocimiento concreto conocemos al otro en tanto que otro. Aquí, las investigaciones de Husserl respecto a la epoché (reducción) fenomenológica juegan un importante papel. Nuestra tarea en el presente paper considerará mostrar muy sucintamente el papel de la reducción en el conocimiento del otro tal como la expuso Husserl y esbozar un análisis crítico de las consideraciones husserlianas sobre la epoché y el problema de la intersubjetividad, investigando si efectivamente se da un conocimiento trascendente del otro en este autor.

\section{Cuatro sentidos de epoché en Husserl}

Para Husserl, Fenomenología, “designa un nuevo método descriptivo que hizo su aparición a principios de siglo $[\mathrm{XX}]$ y una ciencia apriorica que se desprende 
de él y que está destinada a suministrar el órgano fundamental para una filosofía rigurosamente científica y a posibilitar, en un desarrollo consecuente, una reforma metódica de todas las ciencias"1.

En este contexto, la epoché es el principio universal y necesario de la fenomenología. Este principio deriva del hecho de que los objetos de nuestro conocimiento proveen las pistas necesarias para la determinación de los métodos que son propios para su adecuada interpretación. Por ello, un método propio de las Realwissenschaften (ciencias "reales") no puede ser el mismo que el de las eidetische Wissenschaften (ciencias eidéticas). No puede, en efecto realizarse de una manera reduccionista una exploración de todos los objetos con el mismo tipo de método científico. De igual manera, no se puede conocer lo que las cosas son en sí mismas mediante el método científico utilizado por las ciencias positivas. En efecto, para conocer qué son dichas cosas, Husserl señaló que se debía "poner entre paréntesis" la existencia de los objetos, esto es, prescindir de la existencia de ellos y abstraer los momentos variantes empíricos de las esencias en objetos concretos para concentrarse en la esencia "pura". Este es el primer sentido de la epoché husserliana, y corresponde a la reducción eidética. Con ella, Husserl buscaba establecer aquellas verdades sintéticas a priori que son válidas en cualquier tiempo y lugar. Por ejemplo, cuando conozco la esencia reducida de la culpa "pura", sé que ésta es aplicable siempre, independiente del objeto empírico que la posea. De igual forma, cuando intuimos el color rojo, sabemos qué es, independientemente de cualquier objeto empírico rojo, tal como un auto rojo.

Un segundo sentido de la epoché corresponde a una ampliación del método que Husserl realiza a partir de 1905 y que nombra como reducción fenomenológica, esto es, se pone entre paréntesis o se prescinde de la creencia en la existencia trascendente del mundo. Aquí Husserl pone en suspenso la actitud natural hacia el mundo y transforma al mundo en "fenómeno puro", con vistas a obtener una experiencia interna genuina, y por lo tanto, a obtener una psicología pura que dé cuenta del fenómeno de nuestras vivencias con total prescindencia de las ciencias físicas o naturales, las cuales tienen por misión la exploración científica de los cuerpos animales. Una psicología pura, en cambio, dará cuenta de los conceptos fundamentales de lo psíquico conforme a sus determinaciones esencialmente propias ${ }^{2}$. Entonces, el mundo se nos aparecerá no como lo que simplemente existe, sino como un mundo "consciente como tal”, esto es, un mundo recordado, sentido, etc. Un mundo que aparece así o de cualquier otro modo para mi conciencia.

Sin embargo, Husserl señala que no podemos quedarnos sólo con esta reducción fenomenológica, puesto que:

\footnotetext{
${ }^{1}$ Husserl, Edmund. "Artículo Fenomenología de la Enciclopedia Británica”. Invitación a la Fenomenología. Barcelona: Paidos, ICE/UAB, 1992, p. 35.

${ }^{2}$ Husserl, Edmund. "Artículo Fenomenología de la Enciclopedia Británica”. Invitación a la Fenomenología. Barcelona: Paidos, ICE/UAB, 1992, p. 37.
} 
Si la reducción fenomenológica procuró el acceso a los fenómenos de la experiencia interna real y luego también de la posible, entonces el método de la reducción eidética fundado en ella, procura el acceso a las configuraciones esenciales invariantes de la esfera puramente anímica en su totalidad. ${ }^{3}$

Es decir, Husserl considera aquí un nuevo lugar para la reducción eidética, poniéndola después de la reducción fenomenológica y más bien fundada en ella. Gracias a la reducción eidética, dice Husserl, el yo aparece como un campo nuevo de investigación, pasando de la descripción estática del yo como sujeto de convicciones permanentes sobre el ser, sobre el valor, de la voluntad (yo, quiero), etc., al yo como un ser activo que "en el interior de formas estructurales invariantes, es consciente de sí mismo en continua validez habitual como algo que sigue formándose incesantemente” ${ }^{\text {. }}$.

Sin embargo, esta reducción fenomenológica y eidética, si bien arroja para Husserl una nueva luz al mundo del yo y de la conciencia, fundamentando una psicología pura frente a las ciencias naturales, no nos explica, en su vacía generalidad (la expresión es del mismo Husserl), cómo se producen las vivencias psicológicamente puras, esto es, cómo una vivencia psicológicamente pura puede hacer que en su inmanencia se presente algo como existente y no como presuntamente existente. Dicho de otro modo, cómo acreditamos la experiencia psicológicamente pura en su validez. Para ello es necesario, señala Husserl, recurrir a un tercer sentido de la epoché, esto es, la reducción trascendental.

Este tercer sentido de la epoché corresponde, para Huserl, a una ulterior "purificación" de la reducción psicológica, en la cual se somete a una epoché universal todo mundo ${ }^{5}$, mi ser hombre, y toda subjetividad psicológicamente pura. Ello, con el fin de concentrarse en "la vida intencional" en la cual se configura la apercepción total del mundo, de mi alma y mis vivencias. Esto corresponde al programa egológico del ego trascendental.

Después de 1907 este sentido de la epoché aparece con más fuerza, y conduce a un tipo especial de experiencia:

[...] la experiencia interna trascendental. Surgida de la epoché trascendental metódica, esta experiencia abre el campo ilimitado del ser trascendental. Este es el paralelo del campo psicológico ilimitado, así como su método de acceso es el paralelo del método puramente psicológico, el de la reducción psicológico-fenomenológica ${ }^{6}$.

\footnotetext{
${ }^{3}$ Idem, p. 46

${ }^{4}$ Husserl, Edmund. "Artículo Fenomenología de la Enciclopedia Británica". Invitación a la Fenomenología. Barcelona: Paidos, ICE/UAB, 1992, p. 49.

${ }^{5}$ Este tercer sentido de la epoché corresponde a la exclusión del mundo, el cual no sólo es puesto entre paréntesis sino excluido del análisis metodológico, atendiendo al puro noema, el cual no es autónomo sino dependiente de la conciencia. El noema es constituido en la conciencia pura, apareciendo, como conclusión de este tercer sentido, la reducción trascendental.

${ }^{6}$ Idem, p. 61.
} 
Este método para conocer la estructura esencial (eidética) de la conciencia y sus vivencias, pareciera tener un punto culminante en el Husserl de Krisis, para quien la totalidad de la objetividad real ha llegado a ser el enigma de todos los enigmas, de modo que toda la objetividad real mundana es constituida y realizada en ese sentido, incluida la de los hombres y la de los animales y también la de las almas ${ }^{7}$.

Finalmente, esta experiencia interna trascendental, permite, al decir de Husserl, transitar desde la egología a la comunidad de mónadas, apareciendo de esta forma y gracias a un cuarto sentido de la epoché, esto es, gracias a la epoché monadológica, un mundo intersubjetivo trascendental, tal como veremos en la próxima sección. ${ }^{8}$

\section{Epoché e intersubjetividad}

Inmerso dentro del método fenomenológico que introduce la epoché caracterizada, por los cuatro sentidos señalados más arriba, aparece el problema de la intersubjetividad, esto es, cómo se verifica desde la conciencia del Ego la trascendencia del Otro y cómo se percibe un mundo exterior objetivo. En efecto, ya desde temprano este último tema constituye uno de los problemas filosóficos más importantes para Husserl. Al respecto Edith Stein comentaba:

En su Curso sobre Naturaleza y Espíritu, Husserl había hablado de ello, esto es, un mundo exterior objetivo sólo puede llegar a ser experimentado intersubjetivamente, esto es, a través de una mayoría de individuos cognoscentes, los cuales están juntos en un entendimiento intercambiable. Por consiguiente, sería por eso presupuesta una experiencia de otros individuos. Husserl denominó a esta experiencia Empatía, en conexión con los trabajos de Theodor Lipps?.

Posteriormente, en la Quinta Meditación de Meditaciones Cartesianas, Husserl se haría cargo de las acusaciones de solipsismo que recaían sobre su método filosófico, acusaciones que tendían a considerar que dentro de la filosofía husserliana, especialmente dentro del momento de la reducción trascendental, era imposible un encuentro con el Otro. Al respecto, Husserl señalaba allí que: "Cuando yo, el yo mediado, me reduzco a mi mismo a mi ego trascendental absoluto por medio de la epoché fenomenológica, yo no llego a ser un solus ipse" ${ }^{10}$. De lo que se trata, entonces, es de que nosotros debemos, a través del método fenomenológico: "obtener por nosotros mismos intuiciones dentro

\footnotetext{
${ }^{7}$ Cf. Husserl, Edmund. Crisis, § 24 ff., especialmente pp. 90, 96-7, 204. Citado por Josef Seifert en Back to things in themselves, $2^{\circ}$ electronic edition. New York and London: Routledge and Kegan Paul, 1997, p. 144.

${ }^{8}$ En 1910-11, Husserl aplicó la reducción al problema de la intersubjetividad, en las lecciones sobre Gründprobleme der Phänomenologie.

${ }^{9}$ Referencia citada por Antonio Hidalgo. "Edith Stein, Theodor Lipps y el problema de la Empatía". Estudios sobre la filosofia de Edith Stein. Simposio Internacional Edith Stein, Eichstätt, 1991.

${ }^{10}$ Husserl, Edmund. "Fifth Meditation" en Cartesian Mediatations. The Hague: Martines Nijhoff, 1973, p. 89.
} 
de la implícita y explícita intencionalidad, donde los alter egos llegan a ser evidenciados y verificados en la realidad de nuestro ego trascendental" ${ }^{11}$. Y más adelante agrega: "En cualquier caso, entonces, dentro de mí mismo, dentro de los límites de mi vida consciente pura reducida trascendentalmente, yo experimento el mundo (incluidos los otros) - y, de acuerdo a esta sensación experiencial, no como (por así decir) mi formación sintética privada, sino como otro que es ajeno para mí, como un mundo intersubjetivo que está actualmente allí para cualquiera, accesible respecto de estos objetos para cualquiera" ${ }^{\prime 2}$.

Siguiendo con su argumentación, Husserl transita desde el programa egológico hacia la constitución del mundo por una comunidad de mónadas. Husserl habla allí de una ego-comunidad, la cual me incluye a mí, dentro de mi esfera de propiedad, pero también a los otros egos que, como comunidad de mónadas "existen con cada otro y para cada otro, lo cual constituye un mundo idéntico" $"$.

Pero Husserl mismo se pregunta: ¿Cómo puedo yo identificar el cuerpo experimentado del otro como efectivamente de otro? Esto ciertamente parece un enigma y pareciera que existe también un abismo que no puedo cruzar. Sin embargo, tal enigma se aprecia sólo si yo separo las dos experiencias originales de mi ego y del otro. Si no las separo y me atengo a lo experimentado manifiestamente, es decir, me atengo "sólo a una precisa explicación de la intencionalidad actualmente observable en nuestra experiencia de algún otro, y descubro las motivaciones esencialmente implícitas en esa intencionalidad, puedo superar el enigma" ${ }^{14}$. Husserl aplica aquí la reducción al problema de la intersubjetividad, transitando desde la egología a la monadología. Es el cuarto sentido de la epoché que señaláramos más arriba.

Cuando los polos-yo (que se refieren a la esfera privada del mundo) por medio de la empatía constituyen el mundo intersubjetivo y cuando yo experimento esta vivencia trascendental en la plenitud de su experiencia, ya no me quedo en mi polo-yo, sino que reconozco en mi experiencia la comunidad monádica. Dicho de otro modo, cuando transito desde mi presente original a la apresentificación del mundo en la comunidad de mónadas vivenciadas mediante la empatía, he alcanzado, para Husserl, la captación de los otros como otros. Más aún, he alcanzado la evidencia de los otros en cuanto otros.

\section{Análisis crítico, a modo de conclusión}

Ante las acusaciones de solipsismo como resultado de la aplicación de la epoché al comprender el problema del Otro, pareciera que la defensa husserliana tiene

\footnotetext{
${ }^{11}$ Idem, p. 90

${ }^{12}$ Idem, p. 91.

${ }^{13}$ Idem, p. 107.

${ }^{14}$ Idem, p. 121.
} 
una cierta consistencia dentro de su programa fenomenológico, si es que uno acepta sus premisas básicas. Sin embargo, pareciera que existe también -en su defensa final de las Meditaciones Cartesianas- una consideración no del todo clara de la existencia puesta entre paréntesis ya con la primera epoché, es decir, con la reducción eidética. Se podría argumentar aquí que está claro que el mundo en cuanto existente no desaparece del horizonte husserliano, puesto que sus reducciones fenomenológicas son sólo metodológicas, aplicadas para -separándose del mundo físico-químico y su modo natural de ser aprendidoestablecer la estructura del yo fenomenológico, eidético y trascendental universal con vistas a fundamentar finalmente la evidencia de la experiencia trascendental de la conciencia y la vivencia de la experiencia trascendental del otro en tanto otro.

Sin embargo, deseo plantear algunas objeciones a esta argumentación:

Efectivamente, el análisis del primer Husserl da un paso importante frente a la estructura trascendental kantiana que se mantiene presa en el interior del yo inmanente. Ello, frente a la experiencia que para Kant sólo es experiencia empírica. Al contrario, la experiencia husserliana busca la apertura desde un sujeto hacia fuera. Esto se nota claramente, por ejemplo, en la palabra apercepción. Etimológicamente dicha palabra contiene la preposición $a b$, hacia. Es una percepción hacia (una ab-percepción), desde un sujeto hacia fuera. Por algo Husserl no la denominó expercepción, porque ex, implica dirección desde una cosa hacia fuera, no desde un sujeto. Por ello este método resulta de utilidad para la comprensión de ciertas esencias necesarias. Sin embargo, en el último Husserl la constitución del mundo por la comunidad de mónadas es apresentada y apercibida por y para un ego trascendental, por lo cual ni el ego ni los alter ego poseen, no podrían poseer diría Husserl, un carácter metafísico. Al quedar la evidencia del noema radicada al interior de la conciencia humana, no se ve cómo se pueda entender la presencia de los otros como verificable, y, por cierto, menos como evidente ${ }^{15}$. Al respecto hay que recordar que Husserl, consciente de los problemas del subjetivismo señaló, finalmente, que éste sólo podía ser superado por el subjetivismo más universal y consecuente, el subjetivismo trascendental ${ }^{16}$.

Por ello y arriesgando alguna crítica, me parece que no es posible evidenciar adecuadamente la presencia del otro desde el programa de la fenomenología trascendental de Husserl, dado que el criterio allí expresado es, finalmente, inmanente a la conciencia.

\footnotetext{
${ }^{15}$ Como no sea al interior de la propia conciencia.

${ }^{16}$ Es importante considerar aquí el giro que se produjo en el propio Husserl después de las Investigaciones Lógicas, considerando a los fenomenólogos que no lo acompañaron en su etapa trascendental como "filósofos nä̈ve". En efecto, en su lucha contra el psicologismo y toda forma de reduccionismo, Husserl apuntaba efectivamente hacia una "vuelta a las cosas mismas", pero luego, el criterio de evidencia de las cosas mismas recayó en la conciencia trascendental, negando con ello la trascendencia en el conocer y la objetividad del conocimiento de las cosas en sí mismas. El conocimiento de lo real e independiente de nuestra conciencia resultaba un absurdo para el último Husserl.
} 
Esto es particularmente importante, puesto que el propio Husserl fue extremadamente riguroso para no caer en reduccionismos tales como el psicologista y el biologista ${ }^{17}$. En efecto, Husserl da la alerta para no caer en un $M \varepsilon \tau \alpha \dot{\beta} \beta \alpha \sigma \iota \varsigma$

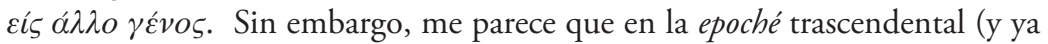
en la epoché fenomenológica que transforma el mundo en un puro cosmos de objetos intencionales se encuentra no solamente un paso metodológico, sino también una tesis ontológica de negación del sentido de un ser en sí mismo independiente del yo. Y aquí parece que existe una transposición inadecuada desde la inmanencia de la conciencia a la trascendencia del ente que es conocido por el conocimiento. No está en cuestión, ciertamente, que el mundo exista, sino cómo ese mundo y el yo de los otros es conocido. Y para Husserl el ser en sí sólo puede darse al interior de la propia conciencia, lo cual pareciera indicar que la trascendencia en el conocimiento no es posible, o al menos es y será por siempre un enigma ${ }^{18}$.

Pienso que, en este sentido, Edith Stein, Roman Ingarden, Karol Wojtyla y la tradición del realismo fenomenológico tal como la recoge Hildebrand y entre nosotros Josef Seifert, por ejemplo, logran una comprensión más profunda del problema de la intersubjetividad y de la evidencia del otro en tanto que otro, puesto que consideran, en general, en sus análisis la inclusión del sujeto humano como un ser substancial, esto es, cada sujeto, el yo y los otros yo, como poseedores de una subjetividad afincada en el ser. Ello les permite detenerse en lo verdaderamente irreductible de los sujetos ${ }^{19}$ y abrirse hacia el aspecto metafísico de los mismos, lo cual significa también que existe una trascendencia en el conocimiento ${ }^{20}$.

En este sentido, pienso también que faltaría en Husserl (o más bien en el último Husserl), el "órgano" adecuado para escuchar plenamente la voz del ser en el cual se verifica y se hace evidente el otro y se hace evidente también el locus filosófico de la intersubjetividad auténtica.

Sin embargo, estas objeciones, por su especificidad propia, darán para otras investigaciones que escapan al presente trabajo.

\footnotetext{
${ }^{17}$ Cf. Husserl, Edmund. "II Lección”. Idea de la Fenomenología. México: Fondo de Cultura Económica, 1982 y Kern, Iso, "The three Ways to the Transcendental Phenomenological Reduction in the Philosphy of Edmund Husserl". Ellison and McCornick (ed). Husserl. Expositions and Appraisals. University of Notre Dame Press, 1977, pp. 126-149.

${ }^{18}$ Contrario sensu, Roman Ingarden en la Carta 428 de 1918 citada por Mitscherling, Jeffrey in Lectures/ Class Notes, Phenomenological Realism as a response to Husserl, d.- Ingarden 's realist rejoinder to Husserl, señala: "according to the meaning of experience, as well as of truth, reality is a being which is different from conscious $\neg$ ness, from any kind of noematic meaning and which is an entity existing 'in itself'. This being different from conscious $\neg$ ness resp. of noematic meaning defines one signifiาcation of 'transcendence'. In this sense transcen $\neg$ dence of a real object does not exclude its 'being in itself', much more it demands it, insofar as the object should exist at all."

${ }^{19}$ No cayendo en reducciones indebidas a otros géneros, al analizar el conocimiento de la persona humana.

${ }^{20}$ Cf. los análisis de Edith Stein en Ser finito y eterno y de Karol Wojtyla en Persona y Acto y La subjetividad y lo irreductible en el hombre, muy especialmente. Cf también Josef Seifert. Back to Things in Themselves, ya citada, y Essere e Persona. Milano: Vita e Pensiero, 1989, Cap. Nono, p. 327 : "La persona possiede un essere sostanziale, sussiste in sé, in un modo assai più univoco e certo che qualunque altra sostanza. Solo la sostanza spirituale personale è infatti -in forza della sua essenza semplice ed indivisibile- un soggetto unico ed irrepetibile nel senso compiuto della parola."
} 


\title{
El Problema de la Intersubjetividad en la Dialéctica y en la Fenomenología: Hegel y Sartre
}

\author{
Eduardo Álvarez \\ Universidad Autónoma de Madrid
}

\begin{abstract}
Resumen
En el texto que sigue se contraponen dos formas de entender la intersubjetividad: la dialéctica que propone Hegel en la Fenomenología del espiritu y la interpretación fenomenológica desarrollada por Sartre en El ser y la nada sobre el trasfondo de la concepción de Husserl en la 5a de sus Meditaciones Cartesianas. Ello puede servir para arrojar luz sobre ambas posiciones y sobre el problema mismo de la intersubjetividad.
\end{abstract}

\section{El planteamiento de Hegel}

En Hegel la cuestión de la intersubjetividad se plantea en realidad como una expresión en el devenir del espíritu. En efecto, el lector de la Fenomenología del espiritu asiste a un complejo proceso en el que la conciencia individual se eleva hasta comprenderse como parte del espíritu universal, un proceso no obstante que se nos muestra, al mismo tiempo, como el de autoexposición del espíritu en la conciencia finita. Sin entrar ahora en la dificultad de entender el carácter complejo de ese proceso, hemos de concentrarnos en el momento en el que se presenta la relación intersubjetiva entre las autoconciencias. Pero antes conviene entender el modo en que hemos llegado a ese punto. Vayamos por partes.

En la Fenomenología del espiritu Hegel reconstruye las múltiples y diversas formas en que la conciencia experimenta su objeto, repensando así la historia de la filosofía y de la cultura en general, aunque reordenando sus momentos y presentando cada uno de ellos -al modo moderno- como una forma de la conciencia del mundo. En ese sentido, por cierto, la Fenomenología es la obra en la que Hegel más claramente rinde tributo a la modernidad. Y si en los tres primeros capítulos se ocupa de la experiencia cognitiva, en la que la conciencia busca enteramente la verdad en el objeto que le hace frente, en el capítulo IV vuelve sobre sí encontrando en la certeza de sí misma la verdad que antes buscaba en el objeto exterior. El tema ya no es ahora lo que sé del mundo experimentado, sino lo que sé de mí mismo como sujeto de aquel saber sobre el mundo. Por lo tanto, 
la actividad de la propia conciencia en la constitución del objeto conocido, que estaba implícita en los capítulos anteriores, se convierte ahora explícitamente en el objeto de consideración: la conciencia se experimenta a sí misma y lo hace como la actividad que constituye su objeto. Ése es el motivo por el cual desde sus primeras páginas el estudio de la autoconciencia se plantea como el de la acción, puesto que es ésta precisamente la que le permite al sujeto distinguirse y experimentarse como diverso de todo objeto. El hombre toma conciencia de sí a través de la acción.

Sin embargo, es curioso que nada más plantear el concepto de la autoconciencia, Hegel parece dar un salto en su discurso e inicia una discusión sobre el concepto de la vida en una transición que puede resultar sorprendente a primera vista, pero que se aclara atendiendo a su sentido de fondo. Adelantándose casi un siglo a discusiones que se desarrollarán a finales del siglo XIX, Hegel ve ya la autoconciencia como una forma de la vida. La vida es el medium de la autoconciencia, la cual por su parte convierte en objeto de su experiencia aquella escisión que en el plano de la vida puramente orgánica se produce de manera no consciente como naturaleza. En general, Hegel entiende la vida como el movimiento de una unidad universal que se fragmenta en los géneros, especies e individuos en los que se diferencia y despliega, y a través de los cuales se reproduce. Para el viviente singular esa infinitud de la vida se presenta del modo más inmediato como el impulso dirigido hacia otro viviente por cuya negación el primero se afirma como tal viviente. Pues bien, la autoconciencia renueva esa dialéctica en un nuevo plano en el que se alumbra la subjetividad humana, que es esa forma de vida cuya escisión característica se eleva al nivel consciente. Es decir, la autoconciencia ha interiorizado lo que el viviente ya es sin saberlo: ha interiorizado que es una identidad diferenciada cuya independencia se afirma mediante la negación o separación de la corriente de la vida. Lo que ocurre en el plano de la autoconciencia es que aquella negación inmediata que origina la identidad separada del viviente, cuya muerte por cierto es una nueva negación que le hace retornar a la corriente universal de la que procede, se convierte ahora en algo manifiesto, de modo que la autoconciencia expresa esa negación como parte de sí, en cuanto la experimenta, ya que el saberse como no siendo lo otro es precisamente lo que la constituye.

Dicho de otro modo: el hombre, en cuanto sujeto, no sólo vive, sino que está situado frente a su vivir; no sólo es vida, sino que se sustrae a la corriente universal de ésta en cuanto se sabe como sujeto diferenciado. O, en otros términos, no sólo vive en el sentido intransitivo del verbo, sino que es la vida que se vive frente a sí misma, que vuelve sobre sí haciéndose objeto de la reflexión consciente; y que en esa misma experiencia escapa, en cuanto sujeto, a su régimen puramente biológico: es, por lo tanto, vivencia. Y, por otro lado, este estar confrontado a sí mismo singulariza al hombre; de ahí que la autoconciencia signifique al mismo tiempo la eclosión de una forma nueva de individualidad, que ya no es sólo la del viviente, sino la del ser consciente de sí. 
De este modo nos dice Hegel que la vida humana no se agota en el plano puramente biológico, sino que es lo que más adelante en la Fenomenología denominará espíritu. En efecto, en la autoconciencia, la vida parece autotrascenderse a través de una torsión sobre sí misma que rompe la lógica del mundo orgánico para generar, más allá del viviente, un sujeto consciente de sí. Ahora bien, lo característico y profundamente original del enfoque hegeliano es que esa nueva comprensión se presenta como un momento que no puede separarse del proceso dialéctico de duplicación de la autoconciencia. Dicho de otro modo: el avance hacia la subjetividad humana no sólo implica la transgresión de la lógica imperante en el mundo orgánico, sino que entrańa también la comprensión del carácter intersubjetivo de esa autoconciencia, pues sólo puede entenderse a sí misma en conexión con otras.

Pero, según la explicación hegeliana, esta nueva figura de la experiencia se nos presenta con los rasgos complejos de una autoconciencia duplicada, ya que ésta se encuentra enfrentada a su propia subjetividad, comprendiéndose, por lo tanto, como el otro yo con respecto a sí, de modo que el objeto de su experiencia es también un sujeto que se alza frente a ella. Por lo tanto, Hegel lo plantea de manera especulativa tratando de deducir la duplicación de la autoconciencia a partir del concepto mismo de ésta. Y se trata de una deducción en el sentido impropio que encontramos una y otra vez en la Fenomenología, en la que la figura posterior se revela como la verdad resultante de la anterior y, sin embargo, como condición de ella. En este caso, nos hallamos ante uno de esos difíciles tránsitos del proceso fenomenológico en los que parece imponerse una lógica teleológica, pues en definitiva equivale a la afirmación de que la experiencia autoconsciente sólo es posible en el marco de la relación intersubjetiva y que la vida humana en general requiere de la comunidad interhumana: la subjetividad del hombre se revela como intersubjetividad.

Este desdoblamiento de la autoconciencia que origina su duplicación, concebida de este modo especulativo, tiene el significado profundo de que el sujeto no sólo está enfrentado al objeto, sino también a otros que con el mismo derecho que él pueden igualmente presentarse como un yo, como otro yo. Pero ese yo-otro en realidad está ya internamente formando parte de lo que soy, de tal forma que la alteridad está presente en el yo, que ya no puede entonces definirse de manera inmediata como la igualdad yo-yo. Por el contrario, el yo sólo podrá concebirse como resultado positivo de esa negación que es la alteridad, es decir: yo soy el otro del otro. O, si se prefiere, el otro es el yo que no soy. De ahí que la verdad de esta dialéctica se desarrolle como la relación entre las autoconciencias. Pero Hegel le confiere el significado de que el yo humano no puede satisfacer su deseo en la mera naturaleza, sino que necesita de otro ser humano ${ }^{1}$, de otro viviente que -al igual que él mismo- ha de ser capaz de negar la inmediatez de la vida. El deseo humano se sustrae de este modo a toda cosificación, mostrando así la inquietud característica de la subjetividad, que no

\footnotetext{
1 "La autoconciencia sólo alcanza su satisfacción en otra autoconciencia”. Phänomenologie des Geistes, Werke: in Bd. 20. Frankfurt am Main: Suhrkamp, 1986, Werke 3, p. 144.
} 
se deja fijar en una cosa: si la apetencia animal implica la fijación en su objeto, al que negará sin embargo su realidad separada, por su parte, la existencia del hombre es deseo de reconocimiento, porque en él la positividad de la vida es superada mediante la negación que le permite despegarse de ella.

Pero la relación entre los sujetos tiene necesariamente un carácter conflictivo, porque cada uno de ellos necesita al otro para afirmarse ante él de modo que lo reconozca como independiente de la vida, y para ello lo utiliza sirviéndose de él como de un mero viviente al servicio de su propio interés. Cada uno se sabe capaz de desear con independencia de la vida y trata de demostrárselo al otro para requerir su reconocimiento. Por ello debe mostrarse capaz de poner la vida en juego y de despreciarla si es preciso. El conflicto entre las autoconciencias no es algo accesorio, sino que es constituyente de su relación, aunque también pertenece a ésta el camino para su reconciliación, de modo que cada autoconciencia se vea reconocida a sí misma en la otra. Pero eso supondrá para el lector el descubrimiento del espíritu, el cual traspasa a los individuos y existe también como la relación objetiva entre ellos, aunque eso no se hace aún patente en este momento del camino fenomenológico. En cualquier caso, el conflicto es para Hegel la forma fundacional de la relación interhumana en tanto se trata de una relación entre autoconciencias contrapuestas en el elemento de la vida. En ello se manifiesta esa concepción moderna que atribuye al hombre natural una irreductible realidad individual, de modo que antes de cualesquiera otros conflictos explicables por la estructura de una formación social concreta, Hegel encuentra en la naturalidad del individuo, con sus impulsos e intereses, un motivo permanente de los conflictos que aquejan a los hombres.

Esta noción hegeliana de reconocimiento, aunque inspirada en Kant y en Fichte, se desarrolla de manera original a partir de una sugerencia hecha por Hölderlin que rompe desde el primer momento el subjetivismo fichteano: no se puede empezar por un sujeto individual aislado y la certeza que tiene de sí mismo, si se quiere explicar la experiencia objetiva de un mundo compartido en el que cada sujeto se encuentra ya inmerso en una experiencia común. Tiene que haber una unidad original de sujeto y objeto que envuelva a dichos individuos en la trama de una relación intersubjetiva. Pero, superando su intuición primera tomada de Hölderlin, la Fenomenología da forma discursiva a dicha unidad, mostrando su articulación a través del proceso fenomenológico que comprende el comienzo como resultado: esa unidad intersubjetiva ha de quedar demostrada en la propia dialéctica que opone a las autoconciencias, de modo que cada una de ellas no puede finalmente entenderse a sí misma si no es a través de la otra.

A partir de ahí, en el famoso pasaje acerca de la dialéctica del señor y el siervo, Hegel explica su idea de que la autoconciencia se realiza a través de esa lucha 
interior que se debate entre el apego a la vida -representado por el siervo- y el orgullo noble de saberse superior a ella -propio del señor-. En esa tensión interna consiste la subjetividad humana. Pero a partir de aquella duplicación del yo que dio paso a la relación intersubjetiva, Hegel puede plantear el conflicto interior a la autoconciencia como una lucha entre dos experiencias opuestas que son representadas simbólicamente en las figuras del señor y el siervo.

Pues bien, volviendo sobre lo anterior, lo que hemos visto es que la explicación hegeliana sobre la génesis de la subjetividad humana entrańa al mismo tiempo varios aspectos que se presentan, sin embargo, de forma inseparable: por un lado, esa génesis consiste en la constitución de un yo o autoconciencia que a través de la acción se distingue de los objetos alcanzando una distancia con respecto a ellos. En segundo lugar, esa distancia que le permite al sujeto sustraerse a la lógica que impera en el mundo objetivo es interiorizada por el propio sujeto, de tal modo que la autoconciencia se concibe no sólo enfrentada a los objetos, sino también frente a sí misma: la escisión es por lo tanto interior a la propia autoconciencia. Pero, en tercer lugar, esa escisión interior al yo es interpretada especulativamente como la duplicación de la autoconciencia, que por su propia esencia no puede dejar de objetivarse a sí misma como un yo-otro, lo cual permite a Hegel "deducir" la pluralidad de las autoconciencias como un momento esencial del concepto mismo de la subjetividad. Dicho en otros términos, la autoconciencia sólo es concebible en conexión intersubjetiva con otras autoconciencias. Es decir, el yo individual, lejos de ser un principio absoluto, se revela como determinado internamente por su relación con los otros, tan sólo a través de la cual llega a ser propiamente un yo: la autoconciencia es intersubjetiva.

Sin embargo, como veremos luego, la intersubjetividad no equivale sin más al concepto de la vida social, pues este último concepto incorpora además el momento de la objetividad, que parece desvanecerse en el de la relación intersubjetiva. Y es verdad que Hegel reconoce el papel mediador del objeto, en cuanto considera inicialmente a la otra autoconciencia como un yo objetivado y enfrentado a mi propia subjetividad. Pero su enfoque idealista finalmente reduce el yo del otro al propio movimiento de la autoconciencia que se objetiva a sí misma como yo-otro, aferrándose por lo tanto al primado del sujeto. Es verdad también que Hegel considera -en el pasaje que sigue a continuación- que la reconciliación del conflicto intersubjetivo entre el señor y el siervo sólo puede producirse por la transformación del mundo objetivo mediante el trabajo, reconociendo así que la relación intersubjetiva está mediada por los objetos. Pero con ello se indica que la intersubjetividad descansa en el espíritu como su verdad, y que eso se desvelará posteriormente al lector de la Fenomenología del espíritu, pero no lo sabrá la conciencia finita que se debate en la lucha por el reconocimiento. Un enfoque dialéctico no especulativo, 
en la línea de Marx o Adorno, puede reinterpretar la concepción hegeliana prescindiendo del espíritu, al menos en su sentido absoluto, y comprendiendo la intersubjetividad como un momento de la vida social objetiva, fuera de la cual carece de todo sentido. Y de ese modo puede aprovechar el significado adelantado por Hegel de una dialéctica de la vida intersubjetiva en relación con la objetividad. La riqueza y la consistencia de este enfoque se pierde, sin embargo, desde nuestro punto de vista, cuando la concepción de la intersubjetividad se inspira en un planteamiento como el cartesiano, aunque sea en los términos de una reinterpretación fenomenológica como la de Husserl o la de Sartre. Centraremos nuestra atención en este último.

\section{El enfoque de Sartre}

Recordemos brevemente que la posición de Sartre sobre la cuestión del sujeto sólo puede entenderse como un desarrollo de la fenomenología de Husserl reinterpretada en términos de una filosofía de la existencia que -a diferencia de la de Heidegger- se mantiene fiel al viejo paradigma moderno del sujeto. Sin embargo, Sartre introduce una revisión importante en esa concepción moderna del sujeto con su interpretación no egológica de la conciencia: el sujeto es conciencia, pero no es un $\mathrm{Yo}^{2}$. Aunque sigue a Husserl en cuanto al método fenomenológico, se aparta de él en este punto y considera que la fenomenología debe ser consecuente y desechar la tesis de un Yo unificador y originario: la epojé prescindirá de él, pues no hay evidencia apodíctica del ego, que de ese modo se revela como trascendente a la conciencia. Porque la conciencia, lejos de ser un poder unificador, se caracteriza esencialmente, por el contrario, como un principio que se revela al tiempo que introduce la dualidad o la escisión en todos sus actos. En efecto, cuando percibo un objeto, la conciencia de ese objeto es a la vez conciencia de mi conciencia de él; por otro lado, el placer o el dolor no es nada distinto de la conciencia del placer o del dolor; y la creencia es siempre conciencia de creencia: hay siempre ahí una inmanencia absoluta. El ser de la conciencia consiste en estar ante sí misma, o en ser para-sí. Y esta certeza de sí, que necesariamente acompaña a toda vivencia, que es previa a la reflexión y que en rigor constituye el ser de la conciencia en su forma más originaria, es lo que en El ser y la nada denomina Sartre el "cogito prerreflexivo"3, el cual constituye la base de la filosofía sartreana.

\footnotetext{
${ }^{2}$ Algunos autores sostienen que la filosofía de Sartre no es una filosofía del sujeto, porque identifican a éste con el Yo sin más. Ésta es la posición, por ejemplo, de Simone de Beauvoir en su polémica con Merleau-Ponty. Es verdad, por otra parte, que el término "sujeto" rara vez es empleado por Sartre y que la suya es ante todo una filosofía del cogito, una filosofía de la conciencia. Pero pensamos, siguiendo a Merleau-Ponty al menos en este punto, que puede ser calificada también como una filosofía del sujeto, con tal de dejar claro que se trata de un sujeto carente de unidad y atravesado por una escisión que le es interior y constituyente. Lo característico de Sartre no sería entonces tanto prescindir del sujeto cuanto someter más bien este concepto moderno a una revisión crítica. Adoptamos esta interpretación aun a sabiendas de la declaración en contra del propio Sartre, quien llega a decir en El ser y la nada que "somos sujeto en la medida en que somos ego", pues pensamos que él mismo usa allí el término "sujeto" en un sentido restrictivo y guiado por su sentido gramatical inmediato, como equivalente al Yo unitario.

${ }^{3}$ El ser y la nada. Trad. de Juan Valmar. Madrid: Alianza Ed., 1984, pp. 21 s.
} 
El análisis fenomenológico nos muestra que la conciencia no es una sustancia ni un Yo, sino que consiste más bien en una fisura del ser. En efecto,

el ser de la conciencia (...) consiste en existir a distancia de sí como presencia a sí, y esa distancia (...) es la nada ${ }^{4}$.

El ser de la conciencia es estar ante sí misma, frente a sí, o -según la definición de Sartre- ser-para-sí: tal es su denominación del cogito. Y esta fórmula que la comprende como el Para-sí tiene la ventaja de recoger al mismo tiempo tanto la noción de la escisión interior (la conciencia no llega a sí, no cierra la distancia que siempre está recorriendo hacia sí o huyendo de sí: está junto a sí, pues ella es esa distancia) como la del saber de sí. Pero también entraña la noción de que se trata de un defecto o carencia de ser: justamente lo que le falta al Para-sí es el En-sí. El Para-sí se determina perpetuamente a sí mismo a no ser el En-sí; es decir, se funda a partir del En-sí y contra él ${ }^{5}$, y al mismo tiempo consiste en su propio trascender hacia aquello de que carece en busca de una coincidencia consigo mismo que no se da jamás.

El Para-sí no es sino la pura nihilización del En-sí (...) Esa nihilización es suficiente para que un trastorno total le sobrevenga al En-sí. Ese trastorno es el mundo ${ }^{6}$.

Así pues, en contra de Hegel, Sartre sostiene que la negación no está en el ser, sino que procede siempre de la conciencia, tan sólo a través de la cual-como él dice- la nada adviene al mundo y llega a las cosas ${ }^{7}$. Desde el punto de vista antropológico, esta sombría tesis de El ser y la nada, por una parte, señala que el ser de la conciencia, contra lo que cree la tradición, no es la más alta dignidad de ser, sino al contrario una forma degradada del mismo. Y, por otro lado, promueve la idea de lo que podríamos caracterizar como absoluta soledad de la conciencia, que no sólo está separada-como veremos-de las otras conciencias, sino de todo ser en general e incluso de sí misma, porque ella es esa separación o "ahuecamiento del ser". No hay ningún ser donde la conciencia se reconcilie consigo misma, puesto que ella es el inconciliable poder negativo que se sustrae a toda identidad.

Pero esa distancia consigo mismo se ensancha en las estructuras del Para-sí examinadas sucesivamente en El ser y la nada, de tal forma que la nada va penetrando en él de manera cada vez más profunda: en efecto, la presencia ante sí (primera penetración del ser por la nada) se determina con un mayor grado de nihilización en la relación del Para-sí con su propia posibilidad, que Sartre denomina "ipseidad"; esa nihilización se hace aún más profunda con la reflexión, en la que la conciencia se separa de sí misma hasta el punto de

\footnotetext{
${ }^{4}$ Op. cit., p. 112.

${ }^{5}$ Op. cit., p. 119.

${ }^{6}$ Op. cit., pp. 638-9.

${ }^{7}$ Op. cit., pp. 58-60.

${ }^{8}$ Op. cit., pp. 135 s.
} 
tratar de captarse como objeto; pues bien, la nada penetra de modo aún más hondo en el Para-sí cuando éste se capta como "para-otro", es decir, como objeto de otra conciencia distinta de la mía. En realidad todas las formas de conciencia son distintas expresiones de una única conciencia, que consiste en el poder de nihilizar -puesto que es la nada de sí misma- y que lleva ese poder a distintos niveles, siendo cada una de esas nihilizaciones una forma de escisión que introduce la dualidad: primero es la escisión que entrańa el percatarse de sí, luego el saber reflexivo de sí, posteriormente el ser para otro, etc. De tal manera que aun siendo el Para-sí siempre una misma conciencia escindida, el alcance de esta escisión progresa en su interior ensanchándose la distancia consigo mismo.

Pues bien, un momento importante en esa nihilización que se produce en diversas fases se presenta cuando el Para-sí se aparece a sí mismo como el objeto de la mirada del otro o ser para-otro. El Para-sí es para-otro en tanto se sabe observado o considerado por alguien que le mira. Esa mirada le desplaza del centro en el que se hallaba, de modo que su experiencia de sí se ve penetrada de una manera nueva por la nada: el Para-sí se encuentra ahora separado de sí mismo por el otro que irrumpe en su experiencia y le desplaza del centro de su mundo. Pero nótese que el ser-para-otro es una estructura del Para-sí y no una manera de calificar al prójimo. En efecto, lo que dice Sartre es que la mera existencia del prójimo me revela como ser-para-otro, pero eso significa que ese nuevo modo de ser que descubro en mí no reside en el otro, sino que aparece en mí constituido por el otro.

El prójimo es el Para-sí que no soy yo. Y se me presenta como aquél que me objetiva, es decir, aquél que me permite tomar distancia conmigo hasta poder considerarme como objeto. Lo que no consigue la reflexión, a saber, captarme reduciéndome a objeto, lo consigue mi vivencia del prójimo, que desde afuera me hace sentir objeto que está ahí expuesto hacia afuera para él. En ese sentido, el prójimo es el mediador indispensable entre yo y yo mismo, ya que por su mera aparición estoy en condiciones de formular un juicio sobre mí mismo

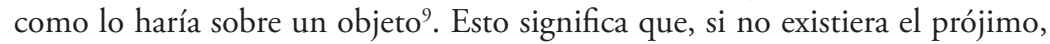
el Para-sí sólo sabría de sí mismo como sujeto esquivo y siempre presente en el cogito prerreflexivo; en cuanto a la reflexión, se trata de un intento fracasado de captarse como objeto, ya que cuando cree alcanzarse a sí mismo se descubre siempre diverso de toda identidad, como no siendo lo que era. Pero, ante los ojos del prójimo, me descubro como objeto para él, pues él me hace ser objeto, me cosifica y asigna una identidad. Ahora bien, es mi experiencia del prójimo lo que ha ensanchado la escisión constitutiva de mi conciencia hasta el punto de permitirme ganar esa distancia conmigo en la que puedo aparecerme como objeto. Pero -como dice Sartre siguiendo a Husserl- el prójimo es alguien que ha aparecido en $m i$ propia experiencia, sólo que mi experiencia de él me remite a algo que queda fuera de toda experiencia posible para mí: me remite a lo que

${ }^{9}$ Op. cit., p. 251. 
vislumbro como un mundo suyo de vivencias fuera de mi control, mundo cuyo centro no soy yo, puesto que en él soy más bien una realidad objetivada junto a otras:

El prójimo no es, en mi experiencia, un fenómeno que remite a mi experiencia, sino que se refiere por principio a fenómenos situados fuera de toda experiencia posible para mí ${ }^{10}$.

Encontramos aquí la idea de Husserl sobre la trascendencia en la inmanencia: dentro de mi propia experiencia y reducido a ella encuentro algo que me remite a lo que me trasciende, a saber: la experiencia del otro, la cual aun cuando incluye lo que me es ajeno, ha de poder ser reducida a su vez a mi propia experiencia como fuente de todo sentido. Pero Sartre reinterpreta la intencionalidad constituyente de la conciencia de que habla Husserl como el poder nihilizador que introduce la escisión en lo que pretendidamente era la unidad de la experiencia. Y así, mi conciencia se revela como otra que ella misma ante la presencia del otro: es decir, soy radicalmente ser-para-otro, pero eso que el otro me hace ser reside en mí, y no en él.

Por otro lado, la consideración de lo que soy como objeto, junto a mi condición como sujeto, no entrańa la concepción del Para-sí como sujeto-objeto. Pues, a diferencia de lo que hemos visto en Hegel, no hay aquí ninguna comprensión dialéctica: no soy sujeto en tanto que objeto y objeto en tanto que sujeto, como diría Hegel, sino que es una degradación de mi ser lo que me convierte en objeto. La mera existencia del otro me degrada, ante mí mismo, a la condición de objeto-para-él, y, sólo a partir de ahí, o sea, a través de él, puedo yo mismo verme como objeto. Pero, como veremos, nunca soy al mismo tiempo sujeto y objeto -aunque sea ambas cosas-, ya que jamás se reconcilian en mí esos dos momentos de mi ser. No hay superación de la escisión que me constituye.

Además, según veíamos antes, mi conciencia de ser una parte de la experiencia del otro incluye la posibilidad permanente de ser visto y de ser juzgado por una conciencia que me objetiva:

Pues, en efecto, el prójimo no es solamente aquél que veo, sino aquél que me ve ${ }^{11}$.

Que yo sea mirado por otro significa que soy de pronto alcanzado en mi ser por una determinación que me constituye en ser-para-otro, apareciendo así en mi modo de ser modificaciones esenciales que puedo captar y fijar por el cogito reflexivo: la mirada del prójimo provoca en mí una "hemorragia" interna en virtud de la cual mi mundo se "derrama" hacia él en un "deslizamiento coagulado" que me descentra ${ }^{12}$.

\footnotetext{
${ }^{10}$ Op. cit., p. 257.

${ }^{11}$ Ibídem.

12 Op. cit., p. 284.
} 
Mediante éstas y otras metáforas similares trata Sartre de expresar la idea de que la relación ontológica entre las conciencias no ha de formularse en términos de conocimiento. Y éste es un punto clave de su crítica de Hegel. En éste reconoce la idea genial de que el camino de la interioridad pasa por el otro, rechazando así la tesis tradicional que ve al yo y al prójimo como dos sustancias separadas, y proponiendo en su lugar la concepción de acuerdo con la cual la negación que constituye al otro en relación conmigo es una negación de interioridad: en efecto, esa negación constituyente de la conciencia se presenta ahora como un yo que es otro, como un no-yo. Sin embargo, para eludir el enfoque hegeliano, que -en la línea del idealismo alemán- plantea la cuestión en términos de conocimiento, Sartre recurre a todo tipo de metáforas, mediante las cuales explica que el significado ontológico de la aparición del prójimo se revela en ciertas experiencias que anteceden a todo conocimiento. De hecho, el conocimiento ni siquiera puede dar cuenta de la conciencia misma, ya que en el cogito prerreflexivo no hay conocimiento de sí. El conocimiento, en cuanto tentativa, sólo aparece con la reflexión. Pero la conciencia, según Sartre -que sigue aquí a Kierkegaard frente a Hegel- está ahí antes de ser conocida: el ser de la conciencia representa a un individuo y es anterior a todo conocimiento ${ }^{13}$. Del mismo modo, mi vinculación con el prójimo no es realizada por el conocimiento, ya que el prójimo me aparece inicialmente en ciertas experiencias con un valor afectivo, como, por ejemplo, el sentimiento de vergüenza:

La vergüenza o el orgullo me revelan la mirada del prójimo, y a mí mismo en el extremo de esa mirada; me hacen vivir, no conocer, la situación de mirado ${ }^{14}$.

Así pues, ciertas experiencias que nada tienen que ver con el conocimiento tienen el privilegio de provocar en mí una vivencia que se me impone de modo ineluctable: la vivencia de que hay otro yo que me hace ser objeto. Esa vivencia representa -como dice Sartre- mi "caída original” en la naturaleza. La vergüenza, en particular, es el sentimiento original de tener mi ser afuera, de ser un objeto o cuerpo en tanto que ser-para-otro ${ }^{15}$. Por eso, en la concepción sartreana es esencial la idea del otro como amenaza, pues el prójimo se presenta, en cierto sentido, como la negación radical de mi experiencia, en cuanto no sólo me roba el centro que soy de mi propio mundo de experiencias, sino que me aliena el mundo mismo, haciendo que éste se deslice hacia él conmigo dentro, convirtiéndome así en asunto de su propia experiencia:

Así, en la brusca sacudida que me agita cuando capto la mirada ajena, ocurre que, de pronto, vivo una sutil alienación de todas mis posibilidades, que se ordenan lejos de mí, en medio del mundo, con los objetos del mundo ${ }^{16}$.

\footnotetext{
${ }^{13}$ Por eso critica Sartre lo que él denomina "el optimismo epistemológico de Hegel". Vid. op. cit., p. 268.

${ }^{14}$ Op. cit., p. 289.

${ }^{15}$ Sartre distingue entre el cuerpo como ser-para-otro, u objeto, y el cuerpo como ser-para-sí, que está fundido con la conciencia. Vid. op. cit., pp. $333 \mathrm{~s}$.

16 Op. cit., p. 292.
} 
Eso quiere decir que, en tanto soy objeto para él, me descubro como imprevisible e indeterminado, ya que dependo en mi ser de una libertad que me es ajena $^{17}$.

Es decir, la relación con el prójimo, en primer lugar, rompe mi interior en cuanto me convierte en objeto para otro; y, en segundo lugar, rompe también la unidad aparente de mi universo, porque a partir de ahí percibo los objetos como no sólo percibidos por mí, sino también por él. Pero es que además, en tercer lugar, a través de esa mirada que me aliena el mundo, descubro en él que hay un afuera para mí. Y este afuera que trasciende al cogito se alcanza mediante la experiencia del prójimo. Es decir, según este enfoque de El ser y la nada, es la relación con el otro lo que me revela que hay una realidad objetiva o intermundo que me trasciende. Por eso, escribe Sartre:

Si hay un Otro, quienquiera que fuere, dondequiera que esté, cualesquiera que fueren sus relaciones conmigo, sin que actúe siquiera sobre mí, sino por el puro surgimiento de su ser, tengo un afuera, tengo una naturaleza; mi caída original es la existencia del Otro; y la vergüenza es, como el orgullo, la aprehensión de mí mismo como naturaleza ${ }^{18}$.

El intermundo es lo que hay entre las conciencias y fuera de ellas: el mundo común compartido que es de todos y de ninguno. Seguramente pensaba en esto mismo Antonio Machado cuando escribió: "lo que sabemos entre todos, eso, no lo sabe nadie". Y a ello mismo se refería Husserl con la tesis típicamente fenomenológica de que el fenómeno que apunta a un mundo común y compartido en el que nos encontramos ya siempre con los otros tiene que poder ser reducido a una conciencia intermonádica o intersubjetiva como su condición trascendental. En efecto, Husserl reconoce al otro como un centro de experiencia distinto del mío que contribuye al igual que yo mismo a conformar el mundo objetivo. Y lo reconoce además como una conciencia a cuya propia inmanencia reduce todo lo que experimenta como trascendente, y entre ello a mí mismo como objeto que soy de su propia experiencia. Y si hay un mundo de significados comunes, ello apunta a una conciencia intersubjetiva como condición del mismo. Pero, según Husserl, tanto la experiencia que realiza el otro como la propia conciencia intersubjetiva, han de poder ser reducidas al ego monádico y trascendental, como condición de todo sentido. Se trataría de una doble reducción, a través de la cual mi-ser-experimentado-por-el-otro se reduce a su vez a mi-experiencia-de-ser-experimentado-por-el-otro-al-queexperimento. Pues bien, también Sartre apunta en cierto modo al ego cogito como el último fundamento: la realidad de lo social, de significados comunes que se me aparecen como objetivos y trascendentes, se sustenta en que hay

\footnotetext{
${ }^{17}$ En este punto, Sartre se refiere a la maestría de Kafka para dar expresión literaria a la incertidumbre de mi experiencia en tanto que alienada por el extraño, en personajes como Joseph K., en El Proceso, o como el agrimensor, en El Castillo.

${ }^{18}$ Op. cit., pp. 290-1.
} 
otros con sus experiencias junto a la mía, lo cual a su vez se me revela como parte de mi propia experiencia, en la que ha irrumpido el prójimo. Por lo tanto, el orden de fundación del sentido va de mí a los otros y, a través de éstos, a la realidad objetiva: se inicia en mí y en lo que me aparece como mundo, el cual inicialmente es sólo mío y se hace presente en el "circuito de la ipseidad"19; luego alcanza a los otros que aparecen en mi experiencia, y finalmente llega hasta la realidad de los objetos que se me presentan como trascendentes. Sin embargo, a diferencia de Husserl, en Sartre no se cumple esa doble reducción que retrotrae todo sentido a mi conciencia como su fuente originaria, porque -según él- la irrupción del prójimo me arranca de mí mismo irreparablemente, de modo que a partir de ahí no es superable la alteridad. De este modo el lado existencial de la filosofía sartreana altera el enfoque fenomenológico. La pretensión de reducir a la unidad inmanente del ego cogito todo cuanto se le hace presente como trascendencia es un movimiento que en verdad se inicia en la conciencia, pero que se quiebra con la aparición del prójimo:

La mirada ajena me alcanza a través del mundo y no es solamente transformación de mí mismo, sino también metamorfosis total del mundo (...) Por la mirada ajena realizo la prueba concreta de que hay un más allá del mundo. El prójimo [en cambio] me es presente sin ningún intermediario, como una trascendencia que no es la mía ${ }^{20}$.

Así pues, si Descartes partiendo del cogito recurre a Dios para fundar la realidad objetiva del mundo exterior, en el caso de Sartre la garantía que representa Dios es reemplazada por la pluralidad de las conciencias. Pero esta pluralidad, si bien es cierto que me revela la existencia de un mundo común y compartido, nunca alcanza a fundarlo como un mundo que tenga una unidad objetiva: no hay valores ni interpretaciones que valgan objetivamente para todos más allá del conflicto entre las conciencias. Pero lo importante es que la dificultad de fundamentar la objetividad no se debe -en el plano teórico- a las limitaciones del conocimiento, ni tampoco -en el plano práctico- a consideraciones de tipo social, sino que arranca de la propia ontología, ya que para Sartre la pluralidad de las conciencias es insuperable. Y ello se explica por el modo mismo en que aparece el prójimo, a partir del cual la relación con él está necesariamente determinada por un conflicto esencial. En efecto: el prójimo se me aparece como sujeto cuando se me revela mi propio ser como objeto alcanzado por su mirada; pero si yo me revuelvo y trato de mirar su mirada, ésta se desvanece, puesto que en rigor no puedo mirar la mirada del otro, sino que sólo miro sus ojos, con lo cual yo le objetivo a mi vez recuperándome como sujeto que se impone sobre él. Es decir, yo y el prójimo no podemos ser ambos al mismo

\footnotetext{
${ }^{19}$ Sartre llama "circuito de la ipseidad" a la relación entre el Para-sí y el posible que él es, y con el que nunca coincide. Esa relación define a la persona. Y denomina "mundo" a la totalidad del ser en tanto que atravesada por el circuito de la ipseidad. Por lo tanto, el mundo me aparece en la relación con mi propia posibilidad. Y, por eso, escribe: "si hay un mundo es por la realidad humana". Vid. op. cit., pp. 135 y 334. Además, ya hemos leído antes que el mundo es un trastorno que sobreviene al En-sí por la nihilización operada por la conciencia. Vid. supra nota 6.

${ }^{20}$ Op. cit., pp. 297-8. La expresión entre corchetes es mía.
} 
tiempo sujetos el uno para el otro: si yo me afirmo como sujeto, le convierto a él en objeto; pero si descubro su subjetividad es sólo a través de mi vivencia de ser objeto para él. Por eso, no puedo conocer al otro como sujeto, ni él puede conocerme a mí como tal, ya que -como ya vimos antes-conocer es objetivar. De ahí que Sartre se refiera a esa relación con el prójimo, que no es una relación de conocimiento, denominándola "separación ontológica entre las conciencias" ${ }^{21}$.

Pero eso quiere decir que, en el sentido propio de la expresión, no hay intersubjetividad posible para el Sartre de El ser y la nada, puesto que no hay reconciliación posible entre las conciencias que permita una relación entre ellas como sujetos. $\mathrm{O}$, dicho en otros términos, no hay unidad posible en mí entre lo que soy como ser-para-sí y lo que soy en cuanto ser-para-otro. Ése es el sentido de la famosa sentencia de Huis clos: el infierno son los otros. En el capítulo titulado "Las relaciones concretas con el prójimo", a propósito -por ejemplo- del amor, del odio o del deseo, encontramos una amplia ilustración de esta posición: no hay intersubjetividad posible, si entendemos por ésta no la mera relación con el otro, sino la relación de reconocimiento entre los sujetos. Por eso, Sartre polemiza en este punto con la noción hegeliana del espíritu, que incluye el conflicto pero también el momento de reconciliación posible entre las conciencias, porque con esa idea Hegel no se coloca en la perspectiva de una de ellas, sino en la de la totalidad que las envuelve y supera sus diferencias. Para Sartre, no hay totalidad sintética posible (como el espíritu de Hegel) que pueda integrar a la pluralidad de las conciencias, porque no es producida ni por el otro, ni por mí, ni por intermediario alguno. Se trataría más bien de una multiplicidad dada en una colección, o -como él dice- de una "totalidad quebrada" o "destotalizada", pues aunque entre las conciencias hay una implicación y algo así como un proyecto de síntesis, ésta se quiebra en tanto no hay nada que funde su relación sino sólo una doble negación sin resultado positivo: yo niego en mí al otro y él me niega a mí en sí.

\section{Observación final acerca del concepto de intersubjetividad}

La posición de Hegel debe entenderse sobre todo como un rechazo de la filosofía del cogito, la cual prima la relación unívoca que va de mí -como ego cogito- al otro, sin superar nunca del todo la insularidad de las conciencias ni el subjetivismo asociado a su posición fundamental. En su lugar, Hegel se sitúa desde el principio en la relación recíproca: sólo puedo saber de mí como autoconciencia -capaz, por lo tanto, de objetivarme desde el principio- si soy otro en relación conmigo mismo, es decir, si me veo como otro, o a través del otro que, en realidad, siempre ha formado parte de mí, aunque esta verdad se muestre como resultado. La relación con el otro, por lo tanto, está ya conte-

${ }^{21}$ Op. cit., p. 271. 
nida en la unidad de la autoconciencia. Ésa es la explicación de lo que en términos especulativos denomina Hegel su "duplicación": el concepto mismo de la autoconciencia, en su verdad, comporta la relación intersubjetiva, aunque ésta se muestre inicialmente como una relación de dominio. Esa reciprocidad en que se encuentran las autoconciencias se puede entender, siguiendo a Marx, como la relación entre individuos en una realidad objetiva que les precede y que ellos contribuyen a redefinir intersubjetivamente; o bien, al modo hegeliano, interpretando de manera idealista que esa relación está sostenida por el espíritu, que no sólo se revela en la relación intersubjetiva, sino también en la propia realidad objetiva. En cualquier caso, esa reciprocidad originaria se funda en la comprensión del hombre como sujeto-objeto. Es decir, lo que hace Hegel es rechazar el carácter absoluto de la alteridad, pero no por la vía de reducirla a la unidad original e indiferenciada de un yo monádico, sino afirmando el significado dialéctico de esa reciprocidad. Pues bien, esa interpretación es abandonada por la filosofía del cogito, tanto por la de Husserl como -según nos parece- también por la de Sartre.

Husserl ya había reconocido que el mundo tal y como se revela a la conciencia es intermonádico, pues sus estratos de significación, su riqueza y unidad no pueden entenderse sino sobre la base de que ha sido constituido por el prójimo y es así un mundo común y compartido. Y, en ese sentido, admitía que mi ego psico-físico no goza de ninguna prioridad sobre el ego psico-físico del prójimo, el cual además es necesario para constituirme como yo mundano. Pero su idea de un ego trascendental rompe con aquella reciprocidad y termina por fijar en él el origen último de todo sentido: ese ego se anticipa al mundo en cuanto condición trascendental del mismo y de todo yo mundano. Por eso, su teoría de la intersubjetividad es inferior a la de Hegel. Por su parte, Sartre critica el planteamiento de Husserl y pretende volver a la idea hegeliana de la reciprocidad entre las conciencias. Pues, para él, en efecto, el prójimo me define internamente en mi ser afectando a mi relación con el mundo y al sentido que presto a las cosas. Sin embargo, nos parece que Sartre, en primer lugar, no sostiene hasta el final el significado de la reciprocidad originaria en la relación con el otro, porque sigue, al igual que Husserl, atenazado por la filosofía del cogito, a partir de la cual el Para-sí es primariamente ante-sí, antes de ser paraotro $^{22}$; y, en segundo lugar -y de manera paradójica, una vez establecido lo anterior-, no supera el significado absoluto de la alteridad, puesto que el prójimo, aunque aparezca con posterioridad a la definición inmediata del Para-sí, una vez ha surgido se me impone como ajeno, irreductible e inconciliable conmigo. Por eso, a partir del planteamiento sartreano, la intersubjetividad no puede pensarse como una conciencia intersubjetiva, sino sólo -si acaso- como la vinculación a un mismo mundo por parte de las conciencias, mundo cuyo espesor contribuyen a conformar entre todas ellas dándose la espalda las unas a las otras.

\footnotetext{
${ }^{22}$ Entre las denominadas por Sartre "estructuras inmediatas del Para-sî" no se encuentra el ser-para-otro, que es lo que el prójimo me hace ser.
} 
En cualquier caso, nos parece que el problemático concepto de la intersubjetividad no debe entenderse ni como anterior ni como independiente de la socialidad, sino como un momento de ésta, la cual tiene además un componente objetivo irreductible. Porque la intersubjetividad en la que se hace descansar la autoconciencia no es todavía por sí sola la realidad social, sino la relación entre los sujetos sin más. Para llegar a constituir la vida social es preciso que esa relación adquiera la forma endurecida que corresponde a la realidad objetiva de lo social, en los modos que la caracterizan, como son, por ejemplo, los ritos, las instituciones, las normas, las costumbres, etc., en las que aquellas relaciones intersubjetivas ya siempre han fraguado. La comprensión dialéctica de la unidad sujeto-objeto quiere decir en este caso que las relaciones intersubjetivas en sí mismas siempre envuelven también una realidad objetiva con aliento propio, $y$, a la inversa, que en la objetividad social hay siempre un componente de subjetividad sin el cual aquélla es incomprensible en cuanto constructo humano. Por lo tanto, no hay una relación directa o no mediada entre los sujetos, de manera que la intersubjetividad, considerada al margen de la totalidad de la vida social objetiva de la que forma parte y a la que está subordinada, es una abstracción. No existe en abstracto una relación pura entre los sujetos, fuera de la totalidad social en que se hallan. Y, por esa razón, el reconocimiento intersubjetivo entre los individuos depende de la forma objetiva de la sociedad.

Hegel muestra esa mediación de sujeto y objeto, pero su idealismo filosófico remite la unidad de ambos al espíritu, lo cual le permite presentar las relaciones intersubjetivas como si gozaran de una cierta antelación con respecto a la objetividad del mundo social y se pudieran entender con independencia de éste. Sólo más tarde, con el descubrimiento del espíritu, se hará patente para el lector de la Fenomenología la unidad de aquellos dos momentos, y, con ella, el carácter social objetivo de la relación interhumana. Pues el espíritu traspasa a los individuos y existe también como la relación objetiva entre ellos.

Por su parte, la filosofía del cogito adolece de un subjetivismo de base que le impide captar aquella unidad y, por ello, trata de comprender la objetividad social a partir de la intersubjetividad como su condición trascendental. Eso conduce a Husserl a dificultades insolubles, y, en el caso de Sartre se revela además como una tarea imposible, ya que El ser y la nada excluye la posibilidad misma de una conciencia intersubjetiva, al menos en el sentido que se refiere al reconocimiento de una conciencia por otra. A partir de ahí, la realidad social finalmente sólo se experimenta como ese fenómeno complejo que revela a la conciencia individual su pertenencia a un mundo compartido, necesariamente enajenante y en gran medida opaco, cuya unidad radica en el conflicto insuperable con los otros. La posterior evolución de Sartre, después de la guerra, y en gran medida empujado por su experiencia política, hacia una posición más abierta a la posibilidad de un reconocimiento intersubjetivo, debe entenderse al mismo tiempo no sólo como un acercamiento al marxismo, sino también como su esfuerzo teórico por abandonar su compromiso con la fenomenología. 


\title{
Hacia el Diálogo entre Filosofía y Ciencias Sociales: Dos Posibilidades de Constitución de la Subjetividad Hermenéutica
}

\author{
Diego Fernando Barragán Giraldo
}

Universidad de La Salle

La hermenéutica no es una reflexión
sobre las ciencias del espiritu, sino una
explicitación de la base ontológica sobre
la cual estas ciencias pueden erigirse.
(Ricoeur. Del texto a la acción. p. 84)

\section{Resumen}

Apoyándose en la hermenéutica filosófica, el texto siguiente busca abrir horizontes de sentido alrededor del diálogo entre Ciencias Sociales y Filosofía, desde lo denominado en este trabajo como subjetividad hermenéutica. En la primera parte, se hace una aproximación a la conceptualización heideggeriana de Dasein, como antítesis del sujeto moderno. Luego, con base en la memoria y la utopía, como también en el comprender-se y la narración, se presenta un aporte teórico para la comprensión de la constitución de subjetividad hermenéutica. Finalmente, en un tercer momento, se invita al necesario diálogo entre Filosofía y Ciencias Sociales.

\section{Sujeto, Subjetividad y Dasein El sujeto como problema}

Ya no se puede hablar propiamente de Sujeto. La subjetividad y sus horizontes de sentido parecen llenar cada vez más los discursos en todos los ámbitos sociales; en estos términos, la renuncia a una concepción estática de Sujeto es la herramienta fundamental de la comprensión de las dinámicas socioculturales; a esta condición no debe renunciar la filosofía. Hoy no se puede entender el mundo solamente desde las racionalizaciones modernas, especialmente en lo que concierne al modo como la modernidad erigió una única alternativa de interpretación y comprensión de la vida de los individuos: el Sujeto. Éste, enmarcado por las tensiones cartesianas y con los aportes de la ciencia, determinó para occidente el rumbo de su historia, impulsando comprensiones que daban como única alternativa de interpretación la visión hegemónica del ser humano, el cual debía entenderse desde lo que la ciencia o la racionalidad 
presentaban como teorías o conocimientos probados: lo no comprobable no es verdadero. Esta idealización no permitió sondear los aspectos concretos y particulares de las relaciones humanas; un Sujeto de esta índole no solucionó las utopías sociales, por ello: “(...) también hay que reencontrar al Sujeto personal en el Sujeto histórico, e incluso religioso, que están en el centro de las visiones de la sociedad y el mundo" 1 .

Hablar hoy del Sujeto en ese único sentido moderno, resulta sospechoso. Nuestras sociedades han reconfigurado su percepción de lo humano proponiendo desde lo teórico conceptos como: constitución de subjetividad, subjetivación, subjetivismo, entre otros tantos, que en resumidas cuentas dan razón del agotamiento de las propuestas racionales instauradas por la modernidad. Desde este horizonte, la constitución de subjetividad se convierte entonces en una alternativa de comprensión de lo humano: lo humano se constituye, se comprende. Una explicación del Sujeto, del individuo, del hombre, pierde sentido; a lo que se puede acceder es a las comprensiones de la constitución de la identidad, de la historia individual y colectiva, de la subjetividad política, en fin, de un ser humano dinámico que se inserta en un sistema interconectado de relaciones y que puede autodeterminar su propia constitución histórica en el ámbito privado y público.

$\mathrm{Al}$ momento de hacer un balance de lo que determina nuestros horizontes de sentido, tal vez una concepción de la subjetividad, como constitución, resulta ser una de las vertientes más fuertes que irrumpe en múltiples postulados teóricos. En la actualidad, el reconocimiento de las minorías, de los derechos individuales y las movilizaciones identitarias colectivas, son la evidencia más clara de las transformaciones sociales. Por ello, intentar acceder a las interpretaciones y comprensiones de las lógicas que determinan la manera como se constituye la subjetividad, es tarea de no poca monta en el universo de la investigación social y en la filosófica, o como lo manifiesta Nietzsche: "mirad al hombre; entonces sabréis lo que esperar del mundo"2.

\section{Del sujeto moderno al Dasein}

Las propuestas de Nietzsche frente al rechazo de toda razón única o de un sistema de creencias unitario, implica considerar lo humano como esa posibilidad de libertad que pretende constituirse autónomamente, al punto que las fuerzas desechadas por la racionalidad cobran y renuevan su importancia: “ ¡Cielo alto y puro! Esta es para mi tu pureza: que no existe la eterna arańa ni la tela de araña de la razón (...) ¡que seas un lugar de danza para los divinos

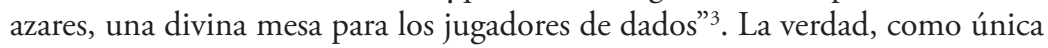

1 Touraine, Alain. ¿Podremos vivir juntos? Iguales y diferentes. Traducción de Horacio Pons. México: Fondo de Cultura Económica, 2003, p. 80.

2 Nietzsche, Friedrich. El libro del filósofo. Versión española de Ambrosio Berasain. Presentación de los textos por Fernando Savater. Madrid: Taurus, 2000, p. 62.

3 Nietzsche, Friedrich. Así habló Zarathrusta. Traducción de Juan Carlos García Borrón. Barcelona: Planeta-Agostini, 1992, p. 105. 
posibilidad, es cuestionada en la obra Nietzscheana, al punto que ya todo se hace fábula, es decir, depende del horizonte interpretativo con el que se realice acercamiento alguno; para ello el hombre debe reconfigurar sus creencias: “ ${ }_{i} Y$ rompamos todo aquello que podamos romper a nuestras verdades! ¡Hay aún muchas cosas por edificar!”’

Heidegger por su parte, como buen conocedor de Nietzsche, presenta una línea de reflexión que invita a profundizar aún más sobre la ruptura con la modernidad y en general, con la historia del pensamiento occidental. En primera instancia (recobrando su herencia fenomenológica), tiene gran confianza en las posibilidades del intelecto humano, no pensado este como algo acabado, sino como en dinamismo constante: "por otra parte cada uno de nosotros puede a su modo y dentro de sus límites, seguir los caminos de la reflexión ¿por qué? Porque el hombre es un ser pensante, esto es meditante"5; este rasgo hace que se evidencie de entrada, una ruptura con los sistemas anteriores donde todo le está dado al individuo, incluso la posibilidad de autodeterminar su propias posibilidades de pensamiento. Por otra parte, en términos metodológicos, este autor muestra su desconfianza en la ciencia moderna y sus métodos de aproximación a la realidad. Ya el joven Heidegger propone construir un aparato conceptual acorde con la época, por el que intenta develar los rasgos dogmáticos en la concepción misma de lo científico e incluso de la filosofía ${ }^{6}$.

Desde esta perspectiva, la obra de Heidegger está atravesada por una nueva posición frente a la construcción que la racionalidad occidental; la comprensión que ha hecho de la metafísica y ontología, afectó de manera definitiva también, las concepciones de ciencia y Sujeto, cuestionando (de manera muy cercana a la fenomenología de Husserl), la relación dicotómica entre lo subjetivo y lo objetivo ${ }^{7}$. Así por ejemplo, ya al inicio de El ser y el tiempo, en el primer parágrafo, Heidegger afirma que la comprensión del ser se ha convertido en un dogma; hace pensar que la pregunta por el sentido del ser sea superflua ${ }^{8}$; a partir de allí se podrá pensar en el ente de manera distinta al punto que este autor legará al pensamiento contemporáneo una nueva com-

\footnotetext{
${ }^{4}$ Ibid., p. 137.

${ }^{5}$ Heidegger, Martin. Serenidad. Traducción de Yves Zimmermann. Barcelona: Oidos, 1979, p. 28-29.

${ }^{6}$ Gadamer Hans-Georg. El giro Hermenéutico. Traducción de Arturo Parada. Madrid: Cátedra, 2001, p. 31.

${ }^{7}$ Heidegger, Martin. La idea de la filosofía y el problema de la concepción del mundo. Traducción y notas aclaratorias de Jesús Adrián Escudero. Barcelona: Herder, 2005, p. 124-128. Esta obra, que recupera el curso dictado por Heidegger como profesor no numerario de la Universidad de Friburgo, entre el 25 de enero y el 16 de abril de 1919, llamada también Semestre de emergencia por motivos de guerra o semestre de posguerra, permite vislumbrar y recuperar las línea del pensamiento del autor en relación con el método en la filosofía y la manera como la ciencia ya no se puede concebir desde la tensión entre lo objetivo y lo subjetivo, especialmente en el capítulo tercero; allí también se aprecia una clara distancia frente a la fenomenología de su maestro Husserl, y una opción fundamental por la hermenéutica filosófica.

${ }^{8}$ En la actualidad existen dos traducciones en español de Ser y tiempo de Heidegger: la de José Gaos, que data en su primera edición de 1951, y la más reciente de Jorge Eduardo Rivera, que a continuación se referencia: Heidegger, Martin. El Ser y El Tiempo. Traducción de José Gaos. Bogotá: F.C.E., 1995. / Heidegger, Martin. Ser y Tiempo. Traducción de Jorge Eduardo Rivera. Madrid: Trotta, 2003. En este trabajo se utilizarán indistintamente las dos traducciones buscando, dado el caso, las citas que aporten mayor claridad para la comprensión de los asuntos aquí tratados. Por ello siempre haremos referencia al parágrafo utilizado (el cual es común a los dos traductores), luego se enunciará la obra Ser y Tiempo y se colocará el traductor que corresponda.
} 
prensión de lo humano bajo el nombre de Dasein (ser ahi), a pesar que según el mismo Gadamer, recordando las palabras de Heidegger, en Ser y tiempo, no se pretendió una antropología filosófica, aun cuando existen descubrimientos antropológicos importantes y más bien de lo que se trataba era de un camino nuevo hacia la metafísica? ${ }^{9}$. El Dasein (ser ahi) no es al estilo de toda la tradición anterior aquel que se comprende desde la mismidad de su yo, no es más el Sujeto que a la manera moderna se pretende portador de conocimiento verdadero y estable: “Quizá el hombre moderno, 'el hombre más moderno', sea un 'sujeto', y quizá esto tenga sus fundamentos propios” ${ }^{10}$, no obstante, esto no garantiza que la totalidad de lo humano se tenga que entender desde estos parámetros o que siempre nos hubiésemos entendido como Sujetos o que de hecho tengamos que seguir haciéndolo" ${ }^{11}$. Este giro conceptual confronta la historia de la ontología occidental, especialmente en lo que tiene que ver con la concepción totalizante del Sujeto propuesto por Kant o por Descartes; tal orientación se ve claramente cuando afirma Heidegger:

Al adoptar la posición ontológica cartesiana, Kant incurre en una omisión esencial: la omisión de una ontología del Dasein. Esta omisión es decisiva, precisamente en la línea más propia del pensamiento de Descartes. Con el cogito sum, Descartes pretende proporcionar a la filosofía un fundamento nuevo y seguro. Pero lo que en este comienzo "radical" Descartes deja indeterminado es el modo de ser de la res cogitans, más precisamente, el sentido del ser del "sum". La elaboración de los fundamentos ontológicos implícitos del cogito sum constituye la segunda estación del camino que remonta destructivamente la historia de la ontología. (...) Descartes no podía menos que omitir la pregunta por el ser, sino también por qué llegó a la opinión de que con el absoluto "estar cierto" del cogito quedaba dispensado de la pregunta por el sentido del ser de este ente ${ }^{12}$.

En oposición a este dogma histórico, Heidegger presentará una manera diferente de pensar lo humano, a través del Dasein (ser ahi), que se sitúa e interpreta propiamente históricamente en función de su historicidad ${ }^{13}$ : “(...) la vida es histórica; ninguna fragmentación en elementos esenciales, sino conexión e interrelación ${ }^{14}$. Concebir lo humano como historicidad significa que el Dasein (ser ahí) simplemente no conoce el mundo, ni se piensa él mismo para poder fundar o transformar su realidad objetiva, por el contrario: "al 'ser ahî' es esen-

\footnotetext{
${ }^{9}$ Gadamer Hans-Georg. El giro Hermenéutico. Op. cit., p. 33.

${ }^{10}$ Heidegger, Martin. Conceptos fundamentales. Traducción, introducción y notas de Manuel E. Vásquez García. Barcelona: Altaza, 1994, p. 118.

${ }^{11}$ En la obra magna de Heidegger: Ser y tiempo, que data de 1926, el autor presenta la estructuras fundamentales, que como existenciarios determinan el horizonte de sentido del Dasein (ser ahí): este es un interpretante que acontece históricamente y que busca a su propia autocomprensión. No obstante, y siguiendo la evolución de su pensamiento, ya en el curso de verano de 1941, se exploran y ratifican otras posibilidades de comprensión de lo humano, que luego serán relacionados en Ser y Tiempo. Cf. Ibíd., No obstante, al no ser este un trabajo de profundidad sobre Heidegger, con la venia de los eruditos en el tema, estos aspectos son sintetizados en la presente indagación.

12 §. Ser y Tiempo. Traducción de Jorge Eduardo Rivera, p. 48.

13 §3. Ser y Tiempo. Traducción de Jorge Eduardo Rivera, p. 33

${ }^{14}$ Heidegger, Martin. La idea de la filosofía y el problema de la concepción del mundo. Op.cit., p. 142.

${ }^{15} \S 4$. Ser y Tiempo. Traducción de José Gaos, p. 23.
} 
cialmente inherente esto: ser en el mundo ${ }^{15 "}$ : Este giro implica presentar a la filosofía occidental, al Dasein (ser ahi) como un arrojado, en el mundo, para el cual en su entorno su identidad cobra sentido; éste se abre más allá del pensar en su mismidad (al estilo moderno), y se ocupa del mundo, ocupándose también de sí: "el Dasein no es tan sólo un ente que se presenta entre otros entes. Lo que lo caracteriza ónticamente es que a este ente le va en su ser este mismo ser. La constitución de ser del Dasein implica que el Dasein tiene en su ser una relación de ser con su ser" ${ }^{\prime 16}$.

En el fondo, lo que hace Heidegger, distanciándose de la tradición greco-cristiana y moderna ${ }^{17}$, es sondear el fundamento (grund) de lo humano; el Sujeto moderno ya no tiene aquí cabida. Buscar tal fundamento no significa ir desprevenidamente a la causa última; en la filosofía de Heidegger se entiende esta búsqueda como el "dar acogida de sí, el reunir en sí, reunión que garantiza lo abierto, aquello en donde todo ente es" ${ }^{\text {"18. }}$. Lo humano se asume desde la comprensión del Dasein (ser ahí) y del mundo, que en oposición a las tradiciones que preceden estas propuestas, el mundo "está presente en la vida y para ella, pero no en el sentido de algo que es simplemente mentado y observado ${ }^{19}$ ". De manera análoga la vida fáctica, constitutiva del Dasein (ser ahí), necesariamente se las arregla consigo misma y así la preocupación por el mundo se da en el mismo momento que se sale a su encuentro ${ }^{20}$; la vida fáctica no es un examinar el mundo, sino el ahí de ser.

En este estado de cosas, el Dasein (ser ahí) no es ya un Sujeto, y en consecuencia "no debe deducirse el ser del "ser ahî" de una idea del hombre"21; él es agente que comprende, comprendiéndose, está envuelto en la mundanidad del mundo, que como fenómeno ${ }^{22}$ (lo patente) histórico resignifica sus horizontes de sentido. Aquí aparece la distancia fundamental con las concepciones cercanas al Sujeto: Dasein (ser ahi) es fundamentalmente historicidad, "el

\footnotetext{
16 § 4. Ser y Tiempo. Traducción de Jorge Eduardo Rivera, p. 35.

${ }^{17}$ El problema de la vida fáctica tal como lo presenta Heidegger, es una temática olvidada por la tradición occidental. El ser fáctico, es primariamente el Dasein (ser ahí), que como fáctico, más allá de circunscribirse o situarse en el mundo, está cargado de posibilidades de realización como arrojado en este; es decir mundea. Para profundizar en estos aspectos se sugiere revisar las propuestas de Heidegger que en 1922 presentó, anunciando lo que ya en Ser y Tiempo, se presentará con mayor vehemencia, en el denominado informe Natorp. Cf. Heidegger, Martin. Interpretaciones fenomenológicas sobre Aristóteles. Indicación de la situación hermenéutica (informe Natorp). Edición y traducción de Jesús Adrián Escudero. Madrid: Trotta, 2002, p. 52 ss.

${ }^{18}$ Heidegger, Martin. Conceptos fundamentales. Op. cit., p. 129.

${ }^{19}$ Heidegger, Martin. Interpretaciones fenomenológicas sobre Aristóteles. Indicación de la situación hermenéutica (informe Natorp). Op. cit., p. 30.

${ }^{20}$ Cf. Ibíd., p. 69.

21 § 39. Ser y Tiempo. Traducción de José Gaos, p. 201.

${ }^{22}$ En el parágrafo 7 de Ser y Tiempo, Heidegger, al hacer la presentación de lo que él comprende por fenomenología, presenta una etimología bastante interesente alrededor del concepto fenómeno. Allí afirma que el término fenómeno $\phi \alpha \iota v o ́ \mu \varepsilon v o v$, está emparentado primariamente con el verbo $\phi \alpha \iota v \varepsilon \sigma \theta \alpha \iota$ que significa mostrarse; en consecuencia fenómeno se puede entender como: lo que se muestra, lo automostrante, lo patente. Pero por otro lado $\phi \alpha \iota v \varepsilon \sigma \theta \alpha$ es la voz media de $\phi \alpha i ́ v \omega$ : sacar a la luz del día, poner en claridad y a su vez esta palabra pertenece a la raíz $\phi \alpha-$, lo mismo que $\phi \omega \varsigma$ : luz, claridad. Con estos análisis Heidegger propone que la expresión fenómeno es lo-que-se-muestra-en-sí mismo o también como lo patente.
} 
Dasein 'es' su pasado en la forma propia de su ser, ser que, dicho elementalmente, 'acontece' siempre desde su futuro" ${ }^{23}$. Por ello, el ser humano puede ser investigado desde sus múltiples esferas vitales permitiendo, tal como lo manifiesta Heidegger, el que exista gran oferta de ciencias que aportan a un mejor conocimiento del hombre ${ }^{24}$ y que sin embargo desde allí no se busque el fundamento de éste.

El Dasein (ser ahi) es ante todo encontrase (Befindlichkeit) ${ }^{25}$, en la medida que éste es vida fáctica como "apertura de estar-en-el mudo en su totalidad"26; a la vez es comprender, no solamente en términos intelectivos ${ }^{27}$, como "poderser" ${ }^{28}$; esto implica que todo comprender (Verstehen) comporta interpretación: "el comprender lleva consigo la posibilidad de la interpretación, es decir, de la apropiación de lo comprendido" 29 y esto sólo es posible por medio del lenguaje o el habla (Rede): "hablar es articular 'significativamente' la comprensibilidad del 'ser en el mundo'" 30 . Estar-en-el- mundo es fundamentalmente compren$\mathrm{der}^{31}$, y es conciencia de finitud. El Dasein (ser ahi) es un interpretante comprensivo, que en virtud de los existenciarios ${ }^{32}$ que le son propios está situado en el mundo; en estos aspectos fundamentalmente se evidencia el distanciamiento con el Sujeto moderno, la persona o la universalización conceptual de hombre. Esto significa que el Dasein (ser ahi) vive, actúa, se ocupa del mundo, cuidando de sí, él es posibilidad, posibilidades, que a la vez se apropia de sus posibilidades ${ }^{33}$; todo esto se hace mediante su propia comprensión (como existenciario de modo de apertura), allí él es proyecto, es poder ser y que sin embargo es sólo en la medida que se entiende en relación con el otro ${ }^{34}$, quien también “(...) tiene, él mismo, el modo de ser del Dasein (ser ahi). En el estar con otros y vuelto hacia otros hay, según esto, una relación de ser de Dasein (ser ahi) a Dasein (ser ahi)" 35 , de este modo en el Dasein (ser ahi), que se sabe interpretativo todo el tiempo, se patentiza la desmodernización del Sujeto.

\footnotetext{
${ }^{23}$ § 6. Ser y Tiempo. Traducción de Jorge Eduardo Rivera, p. 44.

${ }^{24}$ Cf. Ibíd., p. 132.

25 \$29. Ser y Tiempo. Traducción de José Gaos, p. 151 ss. Jorge Eduardo Rivera asume este existenciario como disposición afectiva; en esta comprensión se muestra que el ser humano no conoce simplemente las cosas, sino que por su propia disposición afectiva, que va más allá de lo psicológico, se encuentra. Cf. Ser y Tiempo. Traducción de Jorge Eduardo Rivera, p.158 ss.

${ }^{26} \S 29$. Ser y Tiempo. Traducción de Jorge Eduardo Rivera, p. 161.

27 § 31. Ser y Tiempo. Traducción de José Gaos, p. 160 ss.

28 \$31. Ser y Tiempo. Traducción de Jorge Eduardo Rivera, p.167.

${ }^{29} \S 34$. Ibíd., p. 183.

30 § 34. Ser y Tiempo. Traducción de José Gaos, p. 180. No obstante en la traducción de Rivera esta misma cita se enuncia como: "El discurso es la articulación 'significante' de la comprensibilidad del estar-en-elmundo". Traducción de Jorge Eduardo Rivera, p. 185.

${ }^{31}$ Cf. § 34. Ser y Tiempo. Traducción de José Gaos, p. 179 ss.

${ }^{32}$ El existenciario en la filosofía heideggeriana, implica la analítica de la existenciaridad, que no es simplemente el análisis de la existencia. La traducción de Gaos introduce la palabra: existenciario. Esta tiene que ver con la posibilidad que el Dasein (ser ahí) asume en relación de su condición de arrojado o como comprender existencial, en el lenguaje de Jorge Rivera. Cf. § 4. Ser y Tiempo. Traducción de Jorge Eduardo Rivera, p. 36. y en la Traducción de José Gaos, p. 22.

${ }^{33}$ Villoria, Cesáreo. "Hermenéutica y reconstrucción de la razón”. Filosofía, política, religión. Más allá del pensamiento débil. Oviedo: Nobel, 1996, p. 177 ss.

${ }^{34}$ Cf. § 26. Ibíd., p. 133 ss.

35 § 26. Ser y Tiempo. Traducción de Jorge Eduardo Rivera, p. 149.
} 


\section{Comprensión de la Constitución de Subjetividad Hermenéutica}

Si se acepta lo que nos presenta Heidegger en relación con las particularidades del Dasein (ser ahi), pero especialmente cuando afirma que "a menudo nos contentamos con los fundamentos más cercanos" ${ }^{\text {"36 }} \mathrm{y}$ que esto nos hace olvidar que el intelecto del ser humano necesita explorar, al ritmo del contexto histórico en donde se enmarca, nuevas maneras de comprenderse que posibiliten su quehacer reflexivo, ético, político, epistemológico, etc., y si además se considera también que la búsqueda del ser humano siempre apunta a sondear lo fundamental de su existencia ya que "(...) el representar humano, busca fundamentos en todo lo que le rodea e importa" ${ }^{\text {" }}$. Por ello, sin temor alguno en este estudio se proponen, en búsqueda de una posible caracterización de la Subjetividad, dos posibilidades de comprensión (que no son las únicas, pero que se privilegian en este trabajo), que se pueden presentar desde la hermenéutica filosófica. Estas propuestas teóricas, que las expresamos como pares fundamentales, son: memoria y utopía, comprender-se y narración. Los desarrollos teóricos que se presentan permiten un acercamiento a lo que aquí se puede nombrar, como aporte al corpus conceptual de la filosofía, como Subjetividad Hermenéutica.

\section{Memoria y utopía}

La posibilidad de pensar temporalmente es una de las características más particulares de los seres humanos: el sentido de tiempo nos distingue ${ }^{38}$. Nosotros traemos a la memoria los acontecimientos del pasado, y en relación con lo que anhelamos y deseamos en el futuro, reinterpretamos el presente; somos fundamentalmente entes temporales e históricos ${ }^{39}$. Esta posibilidad temporal permite trazarnos proyectos, es el motor de la identidad individual y colectiva: "El Dasein 'es' su pasado en la forma propia de $s u$ ser, ser que, dicho elementalmente, 'acontece' siempre desde su futuro" ${ }^{\prime \prime 0}$. Es en estos términos que Heidegger presenta al Dasein en cuanto ser situado, es decir localizado, no sólo en términos espaciales sino también, fundamentalmente, en relación con lo temporal; situarse significa, desde esta perspectiva, estar (o ser) conciente de las posibilidades que se abren para interpretar y comprender la existencia. A esta disposición de posibilidades es a lo que Heidegger llama: estado de abierto ${ }^{41}$ : "

\footnotetext{
${ }^{36}$ Heidegger, Martin. La proposición del fundamento. Traducción de Félix Duque y Jorge Pérez. Barcelona: Oidos, 1991, p. 25.

${ }^{37}$ Ibíd., p. 25.

${ }^{38}$ Gadamer, Hans-Georg. El giro hermenéutico. Op. cit., p. 33.

${ }^{39}$ Cf. § 6. Ser y Tiempo. En las dos traducciones citadas.

${ }^{40} \S 6$. Ser y Tiempo. Traducción de Jorge Eduardo Rivera, p. 44.

${ }^{41}$ Se prefiere la utilización que hace Rivera de este concepto como estado de abierto, en virtud de la claridad conceptual de esta investigación. No obstante, la traducción que hace José Gaos en término de estado de yecto, resulta también válida ya que hablar de yecto implica una fuerza que lanza hacia alguna dirección, pero sin la determinación de un objetivo, el cual de alguna forma es necesario al momento de pasar de un estado de yecto a un pro-yecto concreto.
} 
el ser humano 'no tiene' únicamente lengua, logos, razón, sino que se encuentra situado en zona abierta, expuesto permanentemente al poder preguntar y al tener que preguntar, por encima de cualquier respuesta que pueda obtener. Esto es lo que significa existir, estar-ahí" ${ }^{42}$. El estado de abierto implica que el Dasein (ser ahi) no está determinado históricamente por su pasado, sino que por el contrario en su posibilidad de apertura ontológica se pro-yecta, con el único fin de poder interpretar y comprender su determinación histórica actual: el presente. En esta dialéctica, la Memoria se convierte en un elemento vital para la comprensión el Dasein (ser ahí), como también la manera como éste asume sus propios proyectos y los colectivos.

Ahora bien, ¿`cómo pensar estas consideraciones en relación con la constitución de Subjetividad?; a continuación se presentarán algunos elementos de reflexión. En primera instancia, se debe asumir que para que se constituya Subjetividad, en la línea que se ha venido trabajando, el Dasein necesariamente necesita traer a su presente su pasado como ente individual y como ente miembro de una colectividad. Este proceso, que no es el simple recuerdo de lo acontecido, se denomina Memoria (que implica hacer presente la historia para reconfigurar la propia historicidad). No se refiere, en el caso de esta investigación, solamente a una historia individual de corte psicológico, sino también a aquella que narrada por la cultura de manera oficial o no, constituye el horizonte de sentido desde donde el individuo concibe su propia constitución de Subjetividad. Hacer Memoria significa aquí interpretar y comprender el pasado colectivo e individual para reconfigurar el presente, en tensión de futuro.

Por otra parte, la Subjetividad se constituye, al mismo tiempo, en la medida que se traza un pro-yecto: "En cuanto fáctico, el proyectarse compresor del Dasein ya está siempre en medio de un mundo descubierto" ${ }^{43}$. Esta condición de posibilidad, que parte del presente y considera el pasado, permite que el Sujeto alce la mirada, se fije metas, se trace caminos propios, sin que por ello estén determinadas sus actuaciones. Proyectarse en el sentido hermenéutico, tiene que ver con los horizontes de sentido que se despliegan en un estado de abierto; allí él es posibilidad pura, la cual, sin embargo, está enmarcada por las márgenes históricas que la cultura y la sociedad le presentan a los individuos y a las colectividades.

Asociada a esta categoría aparece la noción de utopía ${ }^{44}$, la cual más allá de proyectos individuales, pero apoyándose en estos, involucra la colectividad.

\footnotetext{
42 Ibid., p. 36.

43 § 41. Ser y Tiempo. Traducción de Jorge Eduardo Rivera, p. 216.

${ }^{44}$ Lejos de una lectura moralizante, Ricœur muestra cómo al lado de la utopía la noción de ideología no comporta, en sí misma, un aspecto negativo; ésta hace que en la cohesión social de los grupos se desarrollen proyectos conjuntos. Por otro lado, de manera indisoluble la utopía permite transformar lo ideológico: "si la ideología preserva y conserva la realidad, la utopía la pone esencialmente en cuestión”. La tensión entre utopía e ideología, según este autor, permite el equilibrio entre lo establecido y lo deseable. Ricœur, Paul. Del texto a la acción. Ensayos de hermenéutica II. Traducción de Pablo Corona. Buenos Aires: F. C. E., 2006, p. 357.
} 
Lo utópico se eleva desde la motivación grupal, que como proyecto de futuro dinamiza los anhelos de los individuos, que a esta colectividad pertenecen, para sońar una transformación de la realidad social instaurada. Por otra parte, debe mencionarse, que todo grupo conforma su unidad e identidad, se constituye como colectivo en la medida que posee una imagen estable y perdurable de sí mismo, en cuanto posibilidad de ser y realizarse a futuro; tal identidad se hace posible por medio de la utopía ${ }^{45}$. La utopía tiene por función “(...) proyectar la imaginación fuera de lo real en otro lugar que es también ningún lugar.(...)" 46 , con miras a transformar la realidad social actual: "la utopía es un ejercicio de la imaginación para pensar en otro modo de ser de lo social.(...) entonces, no hay que sorprenderse de que las utopías no hayan dejado de producir proyectos opuestos entre sí, puesto que lo que tienen en común es socavar desde dentro el orden social en todas sus formas" ${ }^{37}$. Desde esta perspectiva, el individuo —éste que está abierto a las posibilidades y que no es el Sujeto moderno - configura su Subjetividad a partir de sus proyectos y de su identificación con los ideales utópicos que la sociedad le presenta como alternativa de transformación socio-cultural. La utopía es narrada por individuos y grupos, posibilitando la comprensión de unos y otros: "en todas las edades requiere, más que reciclarse profesionalmente, darse el tiempo y el espacio necesarios para recuperar el control de su existencia, reflexionar sobre su experiencia pasada, preparar las decisiones venideras" ${ }^{48}$.

\section{Comprender-se y narración}

Desde una mirada hermenéutica comprender significa esencialmente comprender-se. Tal auto-comprensión, es particularmente un evento situacional en el que el ser humano, más allá de hacer conciencia metafísica, psicológica, sociológica o antropológica, se las arregla con su condición de "ser ahî"; es decir, se enfrenta al ahi de su ser en cuanto ente histórico que acontece. Comprender-se implica, por demás, situarse de cara a los otros y a lo sociocultural.

Ahora bien, comprender-se, que es equivalente a la auto-comprensión, se hace privilegiadamente por medio del lenguaje, éste se convierten en el punto axial

\footnotetext{
${ }^{45}$ Ibid., p. 355.

${ }^{46}$ Ibid., p. 357.

${ }^{47}$ Ibíd., p. 357. En otra perspectiva, Zemelman ve en lo utópico la forma liberadora de los colectivos sociales, siempre y cuando esta no sea impuesta, sino que nazca de las necesidades y deseos de los involucrados: “(...) cuando la utopía que se levanta como posible no es la del actor, deviene en una meta externa al movimiento constitutivo de la Subjetividad, no pudiendo, por lo tato, cumplir ninguna función en la maduración de esa misma Subjetividad social. La utopía se transforma en un mecanismo que permite trascender soslayando la situación dada, en vez de ser un mecanismo de reconocimiento de la potencialidad que se contiene en esa situación": Zemelman, Hugo. "Sujetos y subjetividad en la construcción metodológica". Subjetividad: umbrales del pensamiento social. Barcelona: Ánthropos, 1997, p. 23.

${ }^{48}$ Touraine, Alain. Op. cit., p. 282.

${ }^{49}$ Cf. Heidegger, Martin. Hölderlin y la esencia de la poesía. Traducción de Juan David García Bacca. Santa fe de Bogotá: Ántropos, 1989, p. 17-64.
} 
de la comprensión y de la interpretación: el ser ahí es esencialmente lenguaje ${ }^{49}$. El lenguaje permite situarnos en el mundo, es por medio de esta disposición existenciaria que reconocemos a los otros y los otros nos reconocen, ya sea en términos individuales o proyectos culturales que asumen colectividades enteras. Ahora bien, el lenguaje y su consecuente dialéctica de comunicación e interiorización se asume, en este punto del discurso, como narración. En síntesis, Comprender-se o auto-comprender-se, se hace narrándose, en esta condición fundamental el ser humano se sitúa en el mundo; se narra como ser ahí históricamente situado: "en todo nuestro pensar y conocer, estamos ya desde siempre sostenidos por la interpretación lingüística del mundo, cuya asimilación se llama crecimiento, crianza. En este sentido el lenguaje es la verdadera huella de nuestra finitud. Siempre nos sobrepasa"50.

En esta investigación, y trasladando la reflexión desde el campo de la filosofía al del mundo social, se considera la narración sólo en la medida que permite al narrador comprender-se; desde esta perspectiva, se tiene entonces que la Subjetividad siempre es necesariamente narrada; en consecuencia, a la constitución de Subjetividad se puede acceder desde las narraciones de la Subjetividad. En las narraciones está primariamente la expresión del cómo el actor constituye su propia Subjetividad, situándose en el mundo, donde los otros juegan un papel de no poca importancia, acrecentando proyectos colectivos: "el relato pertenece a una cadena de palabras, por la cual se constituye una comunidad de cultura y mediante la cual esta comunidad se interpreta a sí misma por vía narrativa ${ }^{51}$ ”. Así, el papel que juega la narración está íntimamente relacionado con que se busca convencer por medio de argumentos a quien escucha de la veracidad de lo narrado, quien está frente a la narración, debe ser persuadido. En este sentido, al referirse a la argumentación es que Aristóteles afirma: los seres humanos se persuaden cuando por vía del discurso se les muestra la verdad, o al menos lo que se asemeja a lo verdadero ${ }^{52}$; en estos términos, persuadir al otro implica convencerlo para que transforme sus actuaciones, por medio de argumentos: "El objetivo de toda argumentación es provocar o acrecentar la adhesión a las tesis presentadas para su asentimiento: una argumentación eficaz es la que consigue aumentar esta intensidad de adhesión de manera que desencadene en los oyentes la acción prevista (acción positiva o abstención) o, al menos, que cree, en ellos, una predisposición, que se manifestará en el momento oportuno" 53 .

De este modo la Subjetividad se constituye mediante el relato; en esa posibilidad es que el individuo hace memoria y se proyecta, es decir, tiene la posibilidad de comprender-se; esto es lo que Ricœur — refiriéndose a lo escrito y que

\footnotetext{
${ }^{50}$ Gadamer, Hans-Georg. Verdad y método II. Traducción de Manuel Olasagasti. Salamanca: Sígueme, 1998, p. 149.

${ }^{51}$ Ricœur, Paul. Op. cit., p. 155.

52 Aristóteles. Retórica. Introducción, traducción y notas por Quintín Racionero. Madrid: Gredos, 1999, p. 177.

53 Perelman, Ch. y Olbrechts-Tyteca, L. Tratado de la argumentación. La nueva retórica. Traducción de Sevilla Muñoz J. Trad. Madrid: Gredos, 1989, p. 91.
} 
bien puede aplicarse a la constitución de Subjetividad en términos narrativos - presenta como apertura a horizontes de sentido: "lo que se ha de comprender en un relato no es en primer lugar al que habla detrás del texto, sino aquello de lo que se habla, la cosa del texto, a saber, el tipo de mundo que la obra despliega de alguna manera delante del texto" ${ }^{54}$.

\section{Del Diálogo entre Filosofía y Ciencias Sociales}

Es evidente que hoy la filosofía no puede pensarse aislada de las discusiones científicas o de las que provienen de otro tipo de saberes; necesariamente debe dialogar insistentemente y no cerrarse a la posibilidad de aprender constantemente. Una actitud contraria, que por cierto ha imperado muchas veces, deviene en dogmatismos y en la instauración de horizontes de sentido que no son permeables al cambio. La actividad filosófica, por naturaleza, está abierta al diálogo. Cada vez más las Ciencias Sociales estudian rigurosamente sus fundamentos filosóficos, especialmente en términos de lo epistemológico, como también en relación con las posibilidades de lo humano; sin embargo, pareciera que, salvo muy pocos casos, la filosofía no presenta hoy argumentos que permitan establecer bases teóricas sólidas para un diálogo con los resultados investigativos que provienen de otros saberes, en lo que se refiere a una antropología filosófica que no esté anclada a la modernidad. No se trata de establecer una metafísica del ser humano, al estilo de las racionalizaciones antiguas, medievales o modernas; a lo que se invita es a reflexionar sobre si una fundamentación de tal envergadura resulta metodológicamente válida para ir más allá de lo epistemológico y poder llegar al necesario diálogo con las Ciencias Sociales y así resignificar la manera de hacer investigación filosófica, sobre todo en lo que se ha denominado Subjetividad Hermenéutica.

En ese orden de ideas, es fundamental que desde la Hermenéutica filosófica se puedan abrir horizontes de sentido en lo relacionado con la interpretación y la comprensión de la Subjetividad, para así permitir reconfigurar los horizontes de comprensión en relación con lo humano en las Ciencias Sociales. No obstante, y en coherencia con la hermenéutica filosófica, que postula el diálogo como experiencia fundante de lo humano, la filosofía debe considerar seriamente los resultados de las investigaciones extrafilosóficas. Es desde esta perspectiva que el Dasein, tan extraño para la ciencia, debe servir de horizonte teórico de investigación. Por ello, al decir que existe una Subjetividad Hermenéutica y que ésta puede ser abordada de múltiples formas (aun cuando en este trabajo se ha privilegiado la memoria y la utopía, como también el comprender-se y el narrarse), lo que se pone de manifiesto es la necesidad de ahondar en lo que para la filosofía y para la hermenéutica significa evidenciar las nuevas subjetividades que irrumpen en el mundo real y que desde ya hace algún tiempo están siendo investigadas en las Ciencias Sociales. En esto consiste, fundamentalmente, repensar la filosofía hoy.

${ }^{54}$ Ricœur, Paul. Op. cit., p. 155. 


\title{
Fatiga y Acogida de Sí. Introducción al Problema de la Responsabilidad en E. Levinas
}

\author{
Enoc Muñoz \\ Universidad Andrés Bello
}

\begin{abstract}
Resumen
Este artículo se propone dejar señalado el encuentro temprano de Levinas con el problema de la responsabilidad. Para ello, establece un diálogo con el Heidegger de Ser y Tiempo (II), y retoma el análisis leviansiano de la fatiga como situación de subjetivación (III). Si el problema de la responsabilidad en Levinas se plantea como el lugar en el que se encuentran en juego, fundamentalmente, la cuestión de la significación de lo humano y de la filosofía misma, antes de esbozar estos dos puntos, será necesario recordar brevemente la formulación que el joven Levinas presenta de su proyecto filosófico (I).
\end{abstract}

Tempranamente Levinas sitúa el motivo platónico del Bien trascendiendo el Ser o la Esencia (tò àgasòn ... èpékeina tês oùsías) como una señal de orientación de su búsqueda ${ }^{1}$. Indicando de entrada que De l'existence à l'existant se inscribe en una búsqueda más amplia que toma por guía esta "fórmula platónica”, anticipa inmediatamente el golpe de fuerza movilizado con ella: esta frase "significa que el movimiento que conduce a un existente hacia el Bien no es una trascendencia por medio de la cual el existente se eleva a una existencia superior, sino una salida del ser y de las categorías que le describen: una ex-cedencia". Si en cierto sentido en esta acogida de la fórmula platónica se enuncia y anuncia la intriga del nudo y del desanudamiento de la subjetividad sobre la que insistirá Levinas a lo largo de todo su trayecto filosófico, esta insistencia devendrá precisamente tal insistencia porque ella no se apoya en un lugar ya establecido o asegurado por la tradición. En esta insistencia, aquella fórmula repercutirá más bien como un lugar en tensión que todavía busca su equilibrio, y como el lugar de una inmensa encrucijada en el que incluso si ella sobrevive como índice de orientación, se tratará inevitablemente de una búsqueda de orientación en el pasar o paso allí evocado.

Inmediatamente también se menciona, en el prólogo aquí citado, lo que constituye probablemente el nudo férreo de aquella intriga, y la más potente ame-

${ }^{1}$ Cfr. Levinas, Emmanuel. De l'existence à l'existant. 1947. Paris: Vrin, 1992, p. 9. En adelante: DEE. 
naza para ese pasar hacia el bien como lo otro que el ser: estima entonces Levinas que, para abordar ese movimiento de trascendencia que excede a la ontología y que no promete un estado superior o más auténtico de existencia, se requiere de un paso previo. Y es que esa ex-cedencia y lo que con ella se promete "hacen pie en el ser". Será, pues, la posición del existente en el ser, y con ello la subjetivación del existente a partir de su "relación" con el ser, el hilo temático más fuerte y explícito de este estudio, así como también en gran medida del conjunto de los escritos tempranos de Levinas. Tema que será desplegado a través de múltiples análisis que se quieren y conciben como "ontológicos"2.

Levinas hará pronto explícito que, en lo que concierne a la noción de "ontología" y a "la relación que el hombre mantiene con el ser", las reflexiones que allí arrancan se inspiran en gran medida en Heidegger ${ }^{3}$. Este empalme con las posiciones ontológico-existenciales de Ser y Tiempo traerá consigo, empero, algunas torsiones significativas, que darán impulso a la conducción de otro camino de pensamiento. $Y$ este es probablemente uno de los avisos a leer en aquella referencia al motivo platónico del èpékeina tês oùsías ${ }^{4}$. Ahora bien, y aunque no es un debate con Heidegger lo que nos interesa aquí establecer, cabe advertir que dichas torsiones ya se dejan percibir en el terreno desplegado por los análisis de la posición del existente en el ser. Y principalmente en la apropiación que éstos acusan de la temática de la diferencia ontológica, y en la significación que ésta puede tener para la localización de la responsabilidad. Para comenzar a entrever en qué sentido estos análisis nos remiten a nuestra cuestión directriz, a saber, al encuentro temprano de Levinas con la intriga de la responsabilidad, conviene citar la primera de las conferencias de Le temps et l'autre, contemporáneas a De l'existence à l'existant.

\begin{abstract}
Volvamos una vez más a Heidegger. Ustedes conocen su distinción - a la que ya he recurrido - entre Sein y Seiendes, ser y ente, pero que por razones de eufonía prefiero traducir por exister y existant, sin pretender por ello otorgar a estos términos un sentido específicamente existencialista. Heidegger distingue los sujetos y los objetos - los seres que son, los existentes - de su obra misma de ser. Los unos se traducen por substantivos o participios substantivados, lo otro por un verbo [...].
\end{abstract}

\footnotetext{
${ }^{2}$ Cfr. Ibid., pp. 18-19. Más explícitamente, las conferencias de 1946 / 1947 Le temps et l'autre. 1948. Paris: Quadrige / Puf, 1998, pp. 17-18.

${ }^{3}$ El reconocimiento de esta inspiración, el que va acompañado de una evaluación que instala a la obra de Heidegger como una suerte de "estado de la cuestión" de la búsqueda a emprender, no va sin embargo sin tensión. En una especie de homenaje y, al mismo tiempo, de distanciamiento, Levinas deja ya la marca de un conflicto siempre presente en su obra: el de pensar con y contra Heidegger: "Si al comienzo nuestras reflexiones se inspiran en gran medida - para la noción de ontología y de la relación que el hombre mantiene con el ser - en la filosofía de Martin Heidegger, ellas están accionadas por una necesidad profunda de abandonar el clima de esta filosofía y por la convicción de que no se podría salir hacia una filosofía pre-heideggeriana" (DEE, p. 19).

${ }^{4}$ Cfr. Taminiaux, Jacques. "La première réplique à l'ontologie fondamentale". Cahier de l'Herne. Emmanuel Levinas. Paris: L’Herne / Le Livre de Poche, 1991, pp. 278-292.
} 
Esta distinción heideggeriana es para mí la cosa más profunda de Sein und Zeit. Pero en Heidegger, se trata de una distinción, y no de una separación. El existir es siempre captado en el existente y, para el existente humano, el término heideggeriano de Jemeinigkeit expresa precisamente el hecho de que el existir es siempre poseído por alguien. No creo que Heidegger pueda admitir un existir sin existente. Le parecería un absurdo. Sin embargo, él ha forjado la noción de Geworfenheit [...], que se traduce habitualmente por abandono o desamparo. De manera que, así, se insiste sobre una consecuencia de la Geworfenheit. Es preciso traducir Geworfenheit por el 'hecho-de-ser-arrojado-a'...la existencia. Como si el existente no apareciera más que en una existencia que le precede, como si la existencia fuera independiente del existente y que el existente que ahí se encuentra arrojado no pudiera jamás devenir dueño de la existencia. Es por ello precisamente que hay desamparo y abandono. Con ello, pues, deviene clara la idea de un existir que se hace sin nosotros, sin sujeto, de un existir sin existente ${ }^{5}$.

Antes de examinar en qué sentido la noción heideggeriana de Geworfenheit podría conducirnos a la intriga de la responsabilidad, insistamos en el punto más explícito de estos pasajes, aquel de la problemática de la diferencia ontológica. Todavía a nivel de enunciados introductorios, pero ya decisivos, Levinas comienza refiriéndose también, en De l'existence à l'existant, a la dificultad que se presenta al pensamiento cuando se propone elaborar un discurso sobre el acontecimiento del ser o existir en tanto que irreductible a lo que es (ente, existente, cosa, objeto, sujeto). O, en términos gramaticales ${ }^{6}$, una suerte de "vértigo" asaltaría al pensamiento al "volverse hacia el vacío del verbo existir". El pensamiento procede inevitablemente a partir de nominaciones entitativas, de ahí que llevado a este "vacío" recurra insensiblemente a un sustantivo o participio sustantivado; o tienda a identificar "ser" con una causa o ente excelente. Y es que, en efecto, tal acontecimiento vuelve inapropiada, por ejemplo, la tentativa de comprenderle mediante el recurso a una explicación causal. Tentativa que pertenece a una mirada que, recurriendo a alguna cosa o archi-cosa (Ursache) para de este modo iluminar el acontecimiento, ya se ha instalado afuera de éste, ya se ha privado de la posibilidad de restituir el movimiento que introduce y por el que se introduce, y que le caracteriza en cuanto tal. Antes de comprenderle a partir de realidades ya constituidas, de los entes que se mueven o que se encadenan como causas y efectos de movimientos, restituir un acontecimiento significa atender a su "movencia". Si hay actividad y pasividad en el acontecimiento, estas deben ser abordadas como instancias en proceso antes que atarlas a una entidad - receptora o donante - supuestamente ya dada o ya constituida.

\footnotetext{
${ }^{5}$ Le temps et l'autre. Op. cit., pp. 24-25. También, "Intervention dans Petite histoire de l'existentialisme de Jean Wahl". 1947. E. Levinas. Les Imprévus de l'histoire. Paris: Fata Morgana / Le Livre de Poche, 2000, pp. 98 y 99. Además, el estudio introductorio de J. Rolland a De l'evasion, escrito de 1935 que suele ser considerado como el lugar del primer planteamiento original del pensamiento de Levinas (Cf. "Sortir de l'être par une nouvelle voie". En: E. Levinas. De l'evasion. Montpellier: Fata Morgana, 1982, pp. 9-64).

${ }^{6}$ Cfr. DEE, p. 15.

${ }^{7}$ Cfr. Romano, Claude, L'événement et le monde. Paris: PUF, coll. Épiméthée, 1998, pp. 6-7.
} 
Pero, ¿el ser no es siempre el ser de un ente? Esta frase parece poseer la fuerza de un evidencia tal, que sanciona (arrêt) cualquier intento que se propusiera mostrar $e l$ ser - y el recurso a este último artículo no deja de seńalar hacia dicha dificultad - que se propusiera mostrar, decía, el ser sin ente o en su anonimato verbal. La "adherencia" del existente al ser, realizándose en el a-nudamiento del ya siempre siendo del ente, parece constituirse en un instante "indescomponi-

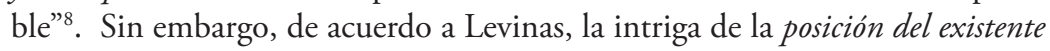
en el ser, o del comenzar a ser del existente, es esa ocasión diferenciante. Levinas va a explorar diversas instancias reconductoras en las que la "adherencia" del existente al ser se esboza en "su separación". Paradójicamente, al menos a la luz de una primera lectura, estas situaciones reconductoras parecen comprometerse con un pensamiento de la relación del ser y el ente donde el existente sólo podría asistir allí a la escena de su propia disolución en el anonimato del ser, en la noche del "il y a" del ser?: el hay más acá de lo que hay. De hecho, Levinas se adelanta a advertir que en estas exploraciones de la "relación primera" que ata al existente al ser, la operatividad misma de la palabra "relación" se encontrará en peligro. Ésta debe desde ya ser puesta bajo el cuidado de las comillas, pues su uso no es "propio" en este contexto ${ }^{10}$. Una relación supone términos o substantivos coordinados e independientes entre sí. A contraria, el movimiento introducido por tales situaciones reconductoras ya siempre ha perturbado tal posibilidad. Perturbación que viene a afectar también las posibilidades del gesto tematizante en general, y fenomenológico en particular: haciendo retroceder en su acontecimiento mismo las cosas o entes, lo que hay en general, interrumpiendo "el juego perpetuo de nuestras relaciones con el mundo", dicho movimiento problematiza y hasta disloca las chances abiertas para el pensamiento por la reducción fenomenológica concebida a partir de Husserl, pues tales situaciones no se comportan a modo de un hecho que la conciencia intenciona y hace ver como uno de sus estados. Se trata aquí de un movimiento que, antes de cristalizarse en un acto de presentación o en conformidad con el a priori correlacional fenomenológico, en su avanzar abisma también a la conciencia, pone fuera de juego la esencia intencional de ésta.

Pero la eficacia de tales instancias reconductoras no consiste solamente en la introducción de un movimiento que se sustraería al juego de lo intencionante y lo intencionado; su eficacia tiene también un efecto de traba para el proyecto onto-lógico encaminado por Heidegger en Ser y Tiempo, donde se hace depender la posibilidad de pensar la diferencia ontológica de la analítica del Dasein; ente, este último, "comprensor del ser". Si el "ser" se pone en escena a partir de su anonimato, rehusándose así a toda calificación o especificación, a encauzarse en tanto que tal o cual, la chance misma de la tematización de la cuestión del ser en términos de sentido, o del ser como cuestión, parece encontrarse entonces ofuscada. Más todavía, este énfasis en el anonimato del ser

\footnotetext{
${ }^{8}$ Cfr. DEE, p. 16 .

${ }^{9}$ Cfr. Ibid., pp. 20-21 y, especialmente, 93-105.

${ }^{10}$ Cfr. Ibid., p. 26.
} 
contraviene la posibilidad de la "comprensión del ser" como posibilidad susceptible de ser puesta en obra por un ente ${ }^{11}$.

Sería errado, sin embargo, interpretar estas situaciones reconductoras como un momento meramente negativo. Más aún, si los análisis allí emprendidos se privan de la oportunidad de presentarles como si estas implicaran un paso por la nada que, una vez sorteado, portaría en él mismo la significación de un desenlace que desembocaría en algo distinto que su acontecimiento mismo. La eficacia reveladora de tales situaciones obliga a desistir de la tentativa de presentarle bajo el modelo del cumplimiento de un movimiento dialéctico, pues aquello que precisamente se encuentra allí obstruido es la posibilidad de un instante siguiente o la ocasión de un relevo.

Y es hacia esta escena sin resolución, sin salida, característica de la relación primera con el ser, hacia lo que nos encamina el análisis de la fatiga que nos interesará retomar. Si la "adherencia" del existente al ser ya siempre ha tenido lugar, lo que procura dicho análisis es sorprender esta adherencia en estado naciente. En otros términos, este análisis nos permitirá asistir, en el sentido de un ir y de un auxiliar metodológicamente, al acontecimiento de la posición de la existente en el ser, a "la aparición de la existencia como une charge à [por, que hay que] assumer [nos. subrayamos]" 12 . Es decir, según la indicación de esta preposición de destinación: $\grave{a}$ - la que es preciso traducir tanto por el vocablo "por" como por el vocablo "que hay que", para así dejar señaladas las suertes de retardo y de obligatoriedad implicados en la situación en cuestión, y que nos remiten al rasgo ontológico-existencial del Dasein heideggeriano: al nudo factum de "que es y tiene que ser (Dass es ist und zu sein hat)"13 - el análisis de la fatiga arrojará también algunos indicios respecto a la subjetivación del existente como responsabilidad. Y este será el hilo temático que nos interesará seguir aquí. En esta dirección, resultará significativo resaltar la noción Geworfenheit. Junto con abrir la vía para un pensamiento del hay del ser, ella mienta, en Heidegger, el rasgo ontológico-existencial de la Factizität der Überantwortung, y que traducimos con José Gaos como "la facticidad de la entrega a la responsabilidad"14.

Una cierta idea de responsabilidad, en tanto que rasgo existencial del Dasein, es mencionada por Heidegger desde las líneas preliminares de la Primera Sección de Ser y Tiempo:

\footnotetext{
${ }^{11}$ Cfr. Calin, Rodolphe. "L'anonymat de l'ego et la phénoménologie emphatique chez Levinas". Rue Descartes $\mathrm{n}^{\circ} 35$ (2002), pp. 47-61.

12 DEE, p. 19.

${ }^{13}$ Cfr. Heidegger, Martin, Ser y Tiempo (Sein und Zeit, 1927). Traducción de J. Rivera. Santiago de Chile: Editorial Universitaria, 1997, pp. 159; y en la traducción de J. Gaos, El ser y el tiempo. México: FCE, 1988 (quinta reimpresión de la segunda edición), p. 152.

${ }^{14} \mathrm{Ibid}$
} 
El ente cuyo análisis constituye nuestra tarea lo somos cada vez nosotros mismos. El ser de este ente es cada vez mio (je meines). En el ser de este ente se las ha este mismo con su ser. Como ente de este ser, él está entregado a [remitido a la responsabilidad de: ist es (...) überantworten] su propio ser. Es el ser mismo lo que le va cada vez a este ente ${ }^{15}$.

En el contexto de una exposición programática de la analítica existencial, estas líneas destacan inmediatamente algunos de los rasgos estructurales del ente del que se ocupará dicha analítica, de ese ente ontológicamente ejemplar "que somos cada vez nosotros mismos": el existente humano en tanto que Dasein, en tanto que esencialmente concernido en la "pregunta por el ser". Concernimiento que, como modo de ser de este ente, es subrayado en este capítulo especialmente mediante las expresiones “je meines" y "Jemeinigkeit”. Expresiones que tienen, por una parte, una connotación temporal: el vocablo ' je indica aquí que el ser de este ente se realiza cada vez en la ocurrencia siempre singular, en la instancia o situación de un instante; y, por otra parte, una connotación que intenciona hacia la significación personal de dicho concernimiento, hacia una relación en la que el Dasein se encuentra tocado personalmente o en la unicidad de su miidad (je meines). Tal concernimiento implica que éste ha de asumir en primera persona su esencial "tener-que-ser" $(Z u \text {-sein })^{16}$. Asumir exigido en el que tiene que habérselas con su ser en la puesta en juego de su ipseidad misma. Puesta en juego o en cuestión en la que, según la penúltima frase citada, este ente se encuentra "remitido a la responsabilidad de su propio ser", al peso ob-ligante del ser en su ser.

La traducción de "ist es [...] überantwortet" por "está entregado a" tiende a encubrir las partes de responsabilidad (Verantwortung) y de respuesta (Antwort) implicadas en el sentido de esta expresión ${ }^{17}$. El uso pasivo del verbo überantworten permite pensar que "algo" le es dado en carga al Dasein, una suerte de transmisión de responsabilidad que le sería constitutiva. Es decir, ese "algo" no le es exterior, sino una suerte de asignación en cuyo factum transparece su propio ser, y del que tiene que responder. Remitido a la responsabilidad de su propio ser, el Dasein se encuentra afectado por un primer reparto: debe, ya siempre, responder de y ante su propio ser en tanto que responsabilidad. "Ya siempre" que significa que el Dasein se constituye cada vez, insustituiblemente, en toda Jemeinigkeit, como respuesta debida. La Überantwortung designa pues, en su vínculo con el esencial "tener-que-ser" o "destinación” (Bestimmung) ${ }^{18}$, el ya recibir-se el Dasein a sí-mismo, y en tanto que sí-mismo, como una carga por asumir irrecusablemente. Con la puesta en relieve de este vínculo no solo se

\footnotetext{
${ }^{15}$ Ibid., p. 67 (trad. de J. Rivera), pp. 53-54 (trad. de J. Gaos).

${ }^{16}$ Cfr. Ibid., p. 67 (trad. de J. Rivera).

${ }^{17} \mathrm{Cfr}$. Vanni, Michel. L'impatience des réponses. L'éthique d'Emmanuel Levinas au risque de son inscription pratique. Paris: CNRS ÉDITIONS, 2004, p. 214, n. 74.

${ }^{18}$ Cfr. M. Heidegger, Ser y tiempo. Op. cit., p. 67, apostilla d.

${ }^{19}$ Cfr. Ibid., pp. 158-159.
} 
insiste "en el carácter de carga del Dasein" ${ }^{19}$, sino también en la temporalidad de esta intriga ontológico-existencial. Esto es: el "ya siempre" o "cada vez" de esa respuesta debida describe también el trabajo de una pasividad en la responsabilidad propia al Dasein: el hecho de que para este ente todo comienzo es en verdad un re-comienzo. Pasividad o retardo que queda netamente señalada en el momento en que Heidegger se refiere al carácter ontológico-existencial de la disposición afectiva (Befindlichkeit), la que consiste fundamentalmente en abrir al Dasein en su "condición de arrojado" (Geworfenheit).

La disposición afectiva, ¿en qué sentido esta noción ontológico-existencial expresa la pasividad constitutiva del Dasein? Esta noción traduce un fenómeno que nos es familiar: "el estado de ánimo, el temple anímico (die Stimmung, das Gestimmtsein)"20. Más exactamente, ella pone de relieve el factum de que "el Dasein ya está siempre (je schon immer) anímicamente templado". Con muchas precauciones, y como un momento de este análisis, se puede decir que en este "encontrar-se" (sich befinden) - en el doble sentido de sentirse y situarse - dispuesto afectivamente, el Dasein se pone de manifiesto en tanto que auto-afección, en tanto que confrontado ya siempre a él mismo: "su ser en cuanto ahí" se revela al Dasein como una "carga", como "lo que hay que cargar (das Zu-tragende)" 21 . Incluso si el Dasein, por lo regular, esquiva "el ser que ha sido abierto en el estado de ánimo", desde el punto de vista ontológicoexistencial, en ese esquivar, que es también un estado de ánimo, "se desvela el Dasein en su estar entregado a la responsabilidad del ahí" 22 . Es para indicar ontológicamente este carácter de ser del Dasein, la Fakticität der Überantwortung, que Heidegger introduce aquí el término Geworfenheit: la "condición de arrojado de este ente en su ahí".

Si es lícito hablar, a propósito de este análisis de la disposición afectiva, de una puesta al descubierto del Dasein en tanto que auto-afección, es preciso advertir de inmediato que, en cuanto tal, no se trata aquí de una auto-percepción o, en términos más generales, de un acto reflexivo de presentación. La percepción, interna o externa, es una posibilidad que ya supone lo abierto por la disposición afectiva. A contraria, "el estado de ánimo no abre mirando hacia la condición de arrojado" ${ }^{23}$. Más todavía, este rasgo ontológico-existencial indica que, previo (vor) a toda actitud tematizante y voluntaria, "y más allá (über.. hinaus) del alcance de su capacidad de abertura", el Dasein, pasivamente, "ya está siempre puesto ante sí mismo", confrontado a él mismo como carga recibida y por retomar: apertura pasiva del nudo factum de "que es y tiene que ser”, retardo o precedencia misma de la transmisión de responsabilidad en su condición de arrojado.

\footnotetext{
${ }^{20}$ Ibid., p. 158.

${ }^{21}$ Cfr. Ibid., p. 159 y apostilla a.

22 "En el temple de ánimo, el Dasein ya está siempre afectivamente abierto como aquel ente al que la existencia (Dasein) le ha sido confiada (überantwortet) en su ser, un ser que él tiene que ser existiendo. Abierto no quiere decir conocido como tal" (Ibid.).

${ }^{23}$ Ibid., p. 160.
} 
Si Levinas hereda el encadenamiento ontológico-existencial establecido mediante las nociones de disposición afectiva, condición de arrojado y entrega a la responsabilidad, también es cierto, de acuerdo al texto de Le temps et l'autre citado arriba, que Levinas detiene el curso del análisis de Heidegger. Esta detención, sin embargo, no es una mera contención. Ella traerá consigo otras vías de ex-centramiento por donde el pensamiento tendrá que aventurarse. Más explícitamente, y en el marco del hilo temática que hemos establecido: Levinas no solo deja pasar de largo, en este contexto, las otras dos determinaciones esenciales de la disposición afectiva: la apertura del ser-en-el-mundo en su totalidad y el aperiente estar consignado al mundo desde el cual puede comparecer lo que nos concierne ${ }^{24}$, sino que junto con ello, en una tentativa en la que la vía de la pasividad abierta por la noción heideggeriana de Geworfenheit es intensificada, Levinas encamina un conjunto de análisis que tendrán como efecto el dejar entrever un desfase irreductible en el lazo de co-originariedad de la disposición afectiva y el comprender (Verstehen) destacado en Ser y Tiempo $0^{25}$. De entre esos análisis, retomamos a continuación aquel de la fatiga. Análisis en el que aquella intrusión de pasividad se pone de manifiesto, precisamente, en tanto que indisociable de lo que hemos llamado el encuentro temprano de Levinas con la intriga de la responsabilidad.

Este análisis presenta la fatiga como una disposición afectiva cuya dramática nos permitiría asistir a la "relación primera" que ata al existente al ser. Dejando entrever la obligatoriedad y el retardo como rasgos constitutivos de tal "relación", este análisis nos encamina hacia la acogida de la existencia o factum del existir en el existente ${ }^{26} ; \mathrm{y}$, de este modo, a la intriga de la subjetivación. Que la fatiga sea abordada en conformidad a la dramática de su acontecimiento, esto significa, por lo pronto, que se evita situarla en un sistema de referencias donde ella pudiera aparecer como efecto de una vicisitud exterior u ónticamente identificable; así como también, que se evita reducirla a la constatación de un estado psicológico o de un movimiento reflexivo ${ }^{27}$. Ciertamente, la

\footnotetext{
${ }^{24}$ Cfr. Ibid., pp. 161-162.

${ }^{25}$ Ibid., pp. 166 y ss. Dicho muy esquemáticamente: si en Heidegger la facticidad (ya-ser-en: Geworfenheit-Befindlichkeit) se articula con el pre-ser-se de la existencia como comprensión-proyecto (VerstehenEntwurf), el movimiento que Levinas lleva a cabo introduce una ruptura entre estos dos momentos que la "analítica" había puesto al descubierto como co-originarios. "Se podría decir - escribe Rolland comentando De l'evasión - que la reflexión de Levinas va a retrasarse en la Geworfenheit de manera de descubrir y de describir una situación donde la existencia no encuentra ya en ella una propensión que va más allá de la situación impuesta, una situación en la que el ser-arrojado paraliza de alguna manera toda posibilidad de proyectarse" (Cfr. "Sortir de l'être par une nouvelle voie". En: E. Levinas. De l'evasion. Op. cit., p. 22). ${ }^{26}$ Cfr. DEE, p. 16.

27 "La fatiga y la pereza, en tanto que contenidos, no revelan lo que ellas realizan, o, para el caso, aquello de lo que ellas finalmente son un impotente no-recibir. Toda su realidad está hecha de ese rechazo. Percibidos como contenidos es situarlos primeramente como 'realidad psíquica' en la trama de la conciencia, y otorgarles a título secundario - como atributo de su substancia psíquica - una intención de rechazo, un pensamiento de rechazo. Es interpretar como rechazo teórico el acontecimiento de rechazo que ellas son en su producción misma, el retroceso ante la existencia que constituye su existencia misma" (DEE, p. 30-31). Si bien con consecuencias no idénticas, cfr., M. Heidegger. Ser y tiempo. Op. cit., pp. 160-161.
} 
reflexión puede asirle como "contenido de conciencia", pero entonces la fuerza de su arribar es disimulada, y con ello la significación ontológico-existencial de su "rechazo imposible". En términos más generales: abordar el instante de fatiga significa aquí, tanto ontológica como metodológicamente, atenerse al movimiento intransitivo de su "impotente no-recibir".

Estas indicaciones, por esquemáticas que sean, ya arrojan algunas luces preliminares para la comprensión del uso cada vez más complejo que tendrá el concepto de "acogida" en Levinas. En efecto, la acogida de la existencia como una "carga por o que hay que asumir", no solo no es abordada mediante los instrumentos de una explicación causal, lo que supondría contar ya con entes pre-existentes, ni, por otro lado, a modo del funcionamiento de un receptáculo presto a ser intervenido por una forma intencional, lo que supondría conducir el análisis de la sensibilidad de acuerdo a la prerrogativas de una conciencia cognitiva o, más en general, tematizante; sino que además, y paradójicamente, esta acogida es descrita en su implicar esencialmente un movimiento de rechazo, un "no-recibir" que, realizándose en cuanto tal, fracasa. Es precisamente en este rechazo impotente que se manifiesta el peso ob-ligante del factum del existir en el existente, y lo que exige al análisis el reconocimiento de un desdoblamiento de la existencia en "ser y haber"; y, con ello, el reconocimiento de un desfase al interior del instante de la acogida. Dicho de otro modo: la implicación de este "impotente no-recibir" en la acogida de la existencia pone en relieve la adherencia del existente al ser in statu nascendi, la articulación o a-nudamiento del instante del comienzo en su dialéctica interna.

Es al finalizar el análisis de la pereza como rechazo o evasión imposible de la existencia que el análisis de la fatiga es introducido: si el rechazo impotente de la fatiga a la existencia se produce en un "cuerpo a cuerpo", aquello a lo que se rehúsa la pereza es a este "cuerpo a cuerpo". Sin embargo, esta suerte de negación de "segundo grado" no atestigua menos del factum del existir en su obligatoriedad. Y es que la pereza "es fatiga del porvenir. El comienzo no la solicita como una ocasión de renacer, como un instante fresco y alegre, como un momento nuevo; ella ya ha realizado previamente una suerte de presente de fatiga. Y anuncia que quizás a un sujeto solo, el porvenir, un instante virgen, es imposible"28.

El embotamiento que caracteriza al instante de fatiga se manifiesta como una imposibilidad de seguir, "desfase constante y creciente del ser en relación con aquello a lo que permanece atado" 29 . Como una mano que soltando poco a poco aquello que le agota y agobia, permanece al mismo tiempo prendada a ese peso. La fatiga, pues, no es simplemente un deslastre, un relajamiento o aflojamiento, sino que abre una tensión en la instancia misma del movimiento del esfuerzo, y que condiciona aquella otra tensión que se establece entre el esfuerzo y la meta de su operación. Si es cierto que no hay fatiga más que en

\footnotetext{
${ }^{28}$ DEE, 39-40.

${ }^{29}$ DEE, p. 43.
} 
el esfuerzo, la tensión que ella abre no consiste simplemente en dejar entrever una cierta coacción y servidumbre que, a modo de un obstáculo, sería exterior al esfuerzo, en la medida en que la meta por alcanzar ya orienta teleológicamente nuestras elecciones y posibilidades ejecutadas libremente. La tensión que abre la fatiga en el esfuerzo ya no mira hacia la meta o instante siguiente, sino que "despunta" en el permanecer ligado, el esfuerzo, a la operación que ejecuta, en su estar encorvado sobre la tarea. A diferencia de la palabra mágica que se desliga de lo operado por su operación, y a pesar de toda su libertad, en el esfuerzo se acusa la tensión de un desfase que afecta a la inicialidad de todo acto o actividad:

El esfuerzo se impulsa desde la fatiga y recae sobre ella. Lo que se llama la tensión del esfuerzo está hecho de esta dualidad de impulso y de fatiga. [...] En el adelantarse a sí mismo y al presente, en el éxtasis del impulso que quema el presente anticipándose, la fatiga marca un retardo en relación a sí y al presente. El momento por el cual el impulso está más allá está condicionado por el hecho de que está más acá. Lo que se llama el dinamismo del impulso está hecho de esos dos momentos a la vez, y no de la anticipación del porvenir como pretenden los análisis clásicos, que descuidan el fenómeno de la fatiga. El esfuerzo es un esfuerzo de presente en un retraso en relación con el presente ${ }^{30}$.

Si el esfuerzo supone la fatiga, si se realiza "a pesar" de la fatiga, él debe "triunfar", en su instante mismo, sobre esa dialéctica interna que le divide cada vez. En este sentido, seguir paso a paso la obra que se lleva a cabo es asumir el instante que desgarra y reanuda el hilo del tiempo; es encontrarse tomado en una "duración" que - a contraria de la duración musical analizada por Husserl, donde cada presente aparece para desaparecer y dar curso al instante siguiente, y a contraria también de la duración del impulso que ya se encarama al porvenir - "está hecha enteramente de detenciones" (arrêts). Si el esfuerzo se lleva a cabo en esta situación de retraso respecto al instante que va a asumir, en su llevarse a cabo a la vez ya "en lucha con el instante en tanto que presente inevitable en el que se encuentra comprometido sin vuelta. En medio del espeso fluir anónimo de la existencia, hay detención y posición”31.

¿En qué sentido esta obligatoriedad y este retardo como marcas del instante de fatiga nos remiten a la intriga de la subjetivación? Dejando pendiente algunos puntos de este complejo y rico análisis del instante de fatiga, avanzo un resumen para encaminarme hacia esta pregunta. Si la fatiga juega un rol análogo a la descripción heideggeriana de la Befindlichkeit, ello nos permite a su vez asistir a una suerte de desplazamiento respecto a la "afección" del Dasein en tanto "serarrojado”. Esto es, si con ella se pone de manifiesto el carácter de carga de la existencia como fatiga originaria, al mismo tiempo ella pone de manifiesto el "estar

\footnotetext{
${ }^{30}$ DEE, pp. 44-45.

${ }^{31}$ DEE, p. 48.
} 
clavado al ser" como de lo que hay que evadirse; sin que esta evasión pueda ser reducida a un movimiento óntico o a una suerte de recubrimiento ontológico. Pero si en este rechazo impotente la fatiga manifiesta la obligatoriedad del hecho de ser como una presencia ineluctable, su movimiento intransitivo, es decir su impotente no-recibir que es sin objeto o sin trascendencia intencional, aporta un desfase o retardo que hace lugar precisamente el presente del que se carga el esfuerzo $^{32}$. Ahora bien, si la fatiga como presente en retardo en relación con él mismo deja trasparecer la acogida de la existencia en el existente, en esta acogida repercute ya el encerramiento o movimiento intransitivo de la fatiga en el encadenamiento del yo (moi) a sí (soi $)^{33}$. Dicho de otro modo, en el despuntar de la fatiga, la mano no puede deshacerse del peso que le agota y le agobia, allí mismo "la mano se encuentra como abandonada a ella misma":

\begin{abstract}
Abandono sui generis. No la soledad de un ser dejado de lado por el mundo, cuya marcha ya no sigue, sino, si se puede decirlo así, de un ser que desarticulado de sí - en una luxación del yo (moi) en relación consigo (soi) -, no se reúne en el instante en el que sin embargo está inscrito por siempre ${ }^{34}$.
\end{abstract}

El no-recibir impotente de la fatiga, su movimiento de aflojamiento intransitivo, pone de manifiesto en su instante mismo la inscripción del existente en el ser, pues, en última instancia, "fatigarse, es fatigarse de ser". El carácter de carga de la existencia se atestigua entonces en el instante de fatiga como una remisión a sí, como un encadenamiento del yo a sí que, sin embargo, sufre un descalce a modo de una "luxación". Luxación que remarca un retardo o desfase en la relación del yo consigo mismo, pero al mismo tiempo el encadenamiento u la obligatoriedad ineluctable del yo con respecto a sí mismo. El instante de fatiga es el presente "en el que el yo retorna fatalmente a sî"; el venir a sí a partir de un "pasmo" que sin embargo no desata el a-nudamiento por el que el yo se carga de sí o se asume a sí como carga.

El movimiento intransitivo de la fatiga, el encontrarse situado en y por la fatiga, hace lugar a un presente que, antes de estar en relación con un instante que le precede o le sigue, se lleva a cabo en una relación con él mismo. Con ello, pone

\footnotetext{
32 "Obrar es asumir un presente. Esto no viene a repetir que el presente es lo actual, sino que el presente es, en el rumor anónimo de la existencia, la aparición de un sujeto que está en lucha con esta existencia, que está en relación con ella, que la asume. El acto es esta asunción. De ahí que el acto sea sometimiento y servidumbre; pero, por otra parte, la primera manifestación o la constitución misma del existente, de un alguien que es. Pues el retardo de la fatiga en el presente nutre una distancia donde se articula una relación: el presente está constituido por el cargarse del presente" (Ibid., pp. 48-49).

${ }^{33}$ Como ya señalaba Levinas en De l'evasion: "La existencia es un absoluto que se afirma sin referirse a nada más que a ella misma. Es la identidad. Pero en esta referencia a sí-mismo el hombre distingue una especie de dualidad. Su identidad consigo mismo pierde el carácter de una forma lógica o tautológica; ella reviste [...] una forma dramática. En la identidad del yo, la identidad del ser revela su naturaleza de encadenamiento pues ella aparece bajo la forma de sufrimiento e invita a la evasión. También la evasión es la necesidad de salir de sí-mismo, es decir, de quebrar el encadenamiento más radical, el más irremisible, el hecho de que el yo es sí-mismo" (De l'evasion. Op. cit., p. 73).

${ }^{34}$ DEE, p. 50.
} 
de manifiesto que "cada instante es un comienzo, un nacimiento" 35 , por lo cual el existente adviene cada vez a sí en una lucha con el instante. El presente representa la posibilidad misma del acontecimiento de la subjetivación, la inicialidad del comienzo por la cual existente adviene a sí. Pero esta inicialidad no es simplemente el lugar de nacimiento donde comienza el despliegue del existente en posesión de sí. Allí donde puede constituirse la inicialidad de la iniciativa o de la libertad del comienzo, el presente no libera al existente o sujeto de sí mismo: "En tanto que referencia a sí en un presente, el sujeto idéntico está ciertamente libre con respecto del pasado y del porvenir, pero permanece tributario de él mismo. La libertad del presente no es ligera como la gracia, sino una pesadez y una responsabilidad. Ella se articula en un encadenamiento positivo a sí: el yo es irremisiblemente sî”36.

Antes de ser el punto de partida de toda acogida intencional o comprensora, el instante de fatiga en su intransitividad se auto-afecta, y en esta auto-afección el sujeto se recibe pasivamente a sí. El surgimiento del existente en tanto subjetivación, es así la afirmación de un irremisible anudamiento a sí y a la existencia, atadura resentida como una carga. Y es precisamente en esta intriga que aparece la subjetivación como ya siempre responsabilidad, donde la inicialidad del comienzo, que haría lugar a una "concepción" de la libertad, ya ha virado, como anacrónicamente, en responsabilidad. Anacrónicamente, pues si la carga de esta responsabilidad no supone una historia de lo hecho o dicho por el existente, paradójicamente en el presente por el cual éste comienza, ya se encontraría afectado de una senectud absoluta e inmemorial, es decir no retencional: "El presente es comienzo puro. Pero en su contacto de iniciación, una instantánea madurez le envejece... él se pesa" ${ }^{37}$. Envejecimiento o pesadez que es la dramática misma del instante de la fatiga como instante del comenzar a ser, y por lo cual el yo no es un puro poder comenzar, sino que, en un al mismo tiempo no sincronizable, un a partir de sí en la acogida pasiva de sí, en el retardo y la obligatoriedad de la responsabilidad de sí y de la existencia.

Ahora bien, si este análisis de la fatiga es ya un desmantelamiento del ideal ontológico del sujeto autónomo, el pensamiento de lo otro y de la responsabilidad para con el otro no sólo proseguirá la necesaria puesta en cuestión del sujeto libre o autónomo, sino que también tendrá que abrir un espacio distinto de la responsabilidad, o pensar la apertura de la responsabilidad de otro modo. En efecto, si en este análisis la responsabilidad, tal como el pasado inmemorial o anacrónico del instante del comienzo que no supone ninguna historia, se constituye antes de todo acto o decisión, es decir no es la consecuencia de un acto libre, este análisis termina, también de un modo paradojal, presentando la responsabilidad como destino: "El retorno del presente a él-mismo es la afirmación del yo ya clavado a sí, ya doblado por un sí-mismo (soi). Lo trágico no viene de una lucha entre libertad y destino, sino del viraje de la libertad en destino, de la responsabilidad"38.

\footnotetext{
${ }^{35}$ Ibid., p. 130.

${ }^{36}$ Ibid., p. 150.

${ }^{37}$ Ibid., p. 135.

${ }^{38}$ Ibid., pp. 135-136.
} 


\title{
Perdón y Ágape: Dos Manifestaciones del Reconocimiento Mutuo *
}

\author{
Manuel Alejandro Prada Londońo \\ Universidad Pedagógica Nacional
}

Al colega y amigo, Patricio Mena Malet

Las notas que presento a continuación señalan algunas relaciones que pueden establecerse entre el ágape-cuya tematización se halla en dos obras del filósofo francés Paul Ricœur: Caminos del reconocimiento ${ }^{1}$ - y el perdón difícil -título del epílogo de La memoria, la historia, el olvido ${ }^{2}$ - como dos manifestaciones del plus del reconocimiento en términos de mutualidad ${ }^{3}$.

La primera y más general relación apunta a ver en ambas manifestaciones una vía para pensar la disimetría originaria entre el sí mismo y su otro, que no puede ser 'resuelta' ni desde el horizonte de una fenomenología que pone como punto de partida de la intersubjetividad al yo, ni desde aquel, también de estirpe fenomenológica, que sitúa el punto fontanal de la intersubjetividad en un otro casi inaccesible del que sólo cabe ser su rehén.

Para el filósofo francés ambas posturas impiden comprender cómo es posible que yo, siendo tal, sea capaz de ser y estar solícito ante el otro -otro que, como yo, puede reclamar para sí ser el polo constitutivo-; y, al tiempo, no caiga en el heroísmo solipsista de un sujeto incapaz de abrirme a la alteridad en su carácter constituyente, transformador, de mí mismo, de mi ipseidad frágil, móvil, insegura.

Ricœur no pretende diluir la disimetría, no la elude, no escamotea las dificultades que ella ofrece para pensar en qué sentido y cómo es posible "vivir juntos"; empero, tampoco la ensalza desde una postura pesimista ( $¡$ Fin de la intersubjetividad: la disimetría es un sino trágico!), ni desde un espepticismo desesperanzador ( $\mathrm{i} F i n$ de la intersubjetividad!: no existe un solo camino en el que el otro deje de ser un extraño).

\footnotetext{
* Este texto hace parte de la investigación "La traducción como problema hermenéutico: aproximación éticopolítica y pedagógica", dirigida por el Prof. Dr. Francisco Sierra, de la Pontificia Universidad Javeriana.

${ }^{1}$ Ricœur, Paul. Caminos del reconocimiento. Madrid: Trotta, 2005.

${ }^{2}$ Ricœur, Paul. La memoria, la historia, el olvido. Madrid: Trotta, 2003.

${ }^{3}$ Por la extensión máxima prevista para las comunicaciones, me abstengo de presentar tales asuntos a partir de una contextualización exhaustiva de su lugar en el argumento de cada una de estas obras (el ágape como 'salida radical' al reto de Hobbes o como índice de un estado de paz en el que se otearía el reconocimiento mutuo en su condición más prístina; el perdón como horizonte común de la memoria, la historia y el olvido).
} 
La confesión de la disimetría amenazada de olvido viene a recordar, en primer lugar, el carácter irremplazable de los miembros del intercambio; uno no es el otro; se intercambian dones, pero no lugares. Segundo beneficio de esta confesión: protege la mutualidad contra las trampas de la unión fusional, ya sean en el amor, en la amistad o en la fraternidad a escala comunitaria o cosmopolita; se preserva una justa distancia en el corazón de la mutualidad, justa distancia que integra el respeto en la intimidad ${ }^{4}$.

\section{El dar}

Teniendo a la vista la asunción de la disimetría en los términos señalados en la cita anterior, podemos mostrar que ágape y perdón están cifrados en la crítica a las relaciones intersubjetivas que simulan la distancia y el extrańamiento en una reciprocidad calculada: "te doy, me das". Una reciprocidad así está marcada por la intensidad de un egoísmo de los seres humanos incapaces de darse en un marco que no sea el de un trueque que hace manifiesto, en últimas, cuál de las partes es más poderosa tanto para dar algo más grande que lo que puede el otro, como para prescindir de lo que otro quiera o pueda dar; y, a contraluz, cuál es tan débil que requiere que otro le 'regale' algo o que tiene que aguantar el gesto altanero que acompańa el rechazo.

El ágape se pone en una altura diferente. La altura de la reciprocidad de los dones es la que compite por quién tiene un hombro más alto desde donde mirar o por quién posee un lugar más privilegiado, incluso para prescindir de aquello que le resulta innecesario o prescindible. La altura del ágape, en cambio, es una altura que se comprende en la horizontalidad, que tiene cabida cuando el yo deja de autoafirmarse en la contemplación autista de sus poderes y se desplaza a la consideración por su sí mismo capaz de generosidad, "que no se mide ni se calcula"'s.

Por otro lado, la altura de la primera mirada exige explicaciones, sea porque no basta el gesto de lo dado como muestra de superioridad y se requiere una explicación que confirme que se ha dado porque se quería y se tenía el poder para ello, con la seguridad adicional de no perder nada de sí, de no desestabilizarse, de no comprometerse, de no abandonar la altura de la mirada privilegiada (te doy esto porque puedo y sé que lo necesitas; más aún, sé que necesitas de mí. Pero, recuerda: yo no necesito de ti).

En cambio, la mirada de la horizontalidad, aun cuando adquiere la forma de una iniciativa, de un dar algo a alguien, incluso como respuesta a una necesidad confesada por o percibida del otro, no necesita el sello de su seguridad,

\footnotetext{
${ }^{4}$ Ricœur, Paul. Caminos del reconocimiento. Ed. Cit., p. 266.

${ }^{5}$ Ibíd., p. 229.
} 
expresada en explicaciones. Además, el que da mirando desde esta otra altura se da y, en el darse, se pierde, se desestabiliza, se abandona en la incertidumbre, que no es un motor de búsqueda de la vuelta multiplicada a sí de su acción (doy como sembrando para que, de pronto, la vida me compense): "El amor permanece sin réplica frente a las preguntas porque la justificación le es extraña al mismo tiempo que la atención a sí. Más enigmáticamente aún, el ágape se sitúa en la permanencia, en lo que persiste, ya que su presente ignora la ańoranza y la espera"'.

Con el perdón se pone en juego un dar que puede ser considerado desde las dos 'alturas' arriba planteadas. Un primer modo de perdón es el que caracteriza a un tipo de juez, que pretende ser neutral, imparcial y, sobre todo, conocedor de las tablas exactas en las que se registran las equivalencias entre las faltas y los castigos. Este perdón se sitúa en la altura de quien tiene el poder para juzgar porque conoce la ley (acaso la ha hecho) y sabe calcular incluso aquello que se puede dejar en el olvido.

"La altura del perdón" -tal como la denomina el francés en su obra de 2003no implica que "se debe asignar esta altura demasiado de prisa a alguien que sería su sujeto absoluto"'. Siguiendo a Derrida, Ricœur muestra que el perdón es extraordinario, en tanto deja por fuera el protagonismo de un sujeto que se convierte en marco, en límite o en condición de posibilidad de que el perdón sea efectivo ${ }^{8}$; asimismo, porque intenta escaparse a los cálculos en términos de "cuánto (me) fallaron, cuánto puedo (calcular) perdonar".

Siempre que le ponen condiciones al perdón, un castigo proporcionado, calculable, corresponde a quienquiera o a lo que sea que se perdone. (...) El perdón incondicional, el acto de perdonar lo imperdonable, no se puede reconciliar con el derecho y la política, porque no permite la negociación pragmática ni el intercambio equitativo ${ }^{9}$.

\section{El recibir}

Otra dimensión de la 'altura' del ágape y del perdón es el recibir. Éste no supone la disimetría en términos del poderoso que da y el subordinado que recibe, aun cuando se sabe que es posible ocupar alguna vez estos lugares, pasar de uno a otro, estar obligados a ocupar el primero o el segundo. Empero,

\footnotetext{
${ }^{6}$ Ídem.

${ }^{7}$ Ricœur, Paul. La memoria, la historia, el olvido. Ed. Cit., p. 606.

${ }^{8}$ Por supuesto, alguien es quien perdona, requiere una iniciativa, exige un compromiso para que sea posible. Sin embargo, el amor y el perdón se resisten a mostrarse desde la autoafirmación y prefieren situarse en el plano de las iniciativas que emergen del diálogo en el que, primero, se ha escuchado la conminación del otro.

${ }^{9}$ Borradori, Giovanna. La filosofía en una época de terror. Diálogos con Jürgen Habermas y Jacques Derrida. Bogotá: Taurus, 2003, p. 206.
} 
desde la altura que se abre en términos de horizontalidad, el recibir es también sinónimo de generosidad, de aceptación de lo que viene del otro hacia mí, de hospitalidad.

Por supuesto, así como hay maneras de dar (que Ricœur expone en Caminos siguiendo a M. Mauss o a L. Strauss) que están alejadas de la égida de la mutualidad, hay maneras de recibir que constriñen a una deuda permanente, inmovilizadora; que están centradas en el cálculo de lo que pierdo o lo que gano al recibir, de lo que estaría obligado a devolver -más y mejor, para mostrar un poder que sobrepase el que el otro ha hecho manifiesto-.

En cambio, el recibir que se pone en la altura del ágape es "respuesta a una llamada nacida de la generosidad del don inicial" ${ }^{10}$. Así, recibir no obliga en términos de un fardo pesado que hay que llevar, sino que compromete auténticamente con el otro en términos de gratitud:

Recibir se convierte, entonces, en la categoría base, en cuanto que la manera como el don es aceptado decide el modo como el donatario se siente obligado a devolver. (...) La gratitud aligera el peso de la obligación de devolver y orienta a ésta hacia una generosidad igual a la que suscitó el don inicial. (...) Bajo el régimen de la gratitud, los valores de los presentes son inconmensurables en términos de costes mercantiles. Ahí reside la marca de lo sin precio en el intercambio de dones. En cuanto al tiempo conveniente para devolver, se puede decir igualmente que no tiene medida exacta: ésa es la señal del ágape, indiferente al retorno, en el intercambio de los dones ${ }^{11}$.

¿Existe algo similar en las relaciones que abre el perdón? Perdonar tiene que ver con una iniciativa, es otra manera de dar, como hemos esbozado atrás; ¿acaso el perdón no se recibe? En la altura que propone un juez imparcial, o en las políticas del perdón vinculadas a los cálculos entre faltas y castigos, lo que se recibe es una rebaja de penas, una amnistía o la indiferencia ${ }^{12}$. Quizás uno de los desafíos que propone la filosofía ricœuriana apunta a una recepción del amor que no espera nada y que, no obstante, compromete como gratitud. Así, recibir el perdón es sentirse reconocido, aun cuando la falta, el error, la acción que supera los límites de lo tolerable no sean excusables; justamente allí, en lo imperdonable, radica el carácter extraordinario de la gratitud: aun a pesar de

\footnotetext{
${ }^{10}$ Ricœur, Paul. Caminos del Reconocimiento. Ed. Cit., p. 248.

${ }^{11}$ Ibíd., p. 249.

${ }^{12}$ Recordemos las palabras de Ricœur: “(...) el ágape se declara, se proclama; la justicia argumenta. En el tribunal, esta argumentación permanece al servicio de la disputa a la que se oponen los estados de paz. La distancia entre disputa jurídica y estados de paz alcanza, en cierto sentido, su culmen cuando la decisión de justicia pone fin al proceso y a su combate argumental; el fallo cae como una palabra que separa, colocando de un lado al demandante declarado víctima y del otro a su adversario declarado culpable; el juez viene, pues, a nuestra memoria como portador, no sólo de la balanza, sino también de la espada. La disputa está resuelta; pero sólo es sustraída a la venganza sin acercarla al estado de paz" (Caminos del Reconocimiento. Ed. Cit., 231).
} 
mis acciones, aun a pesar de lo que hice, sigo siendo reconocido como persona, más aún, se me es restituido el carácter de tal.

Bajo el signo del perdón, el culpable sería tenido por culpable de otra cosa distinta de sus delitos y de sus faltas. Sería devuelto a su capacidad de obrar; y su acción, a la de continuar. Es esta capacidad la que se proclamaría en los pequeños actos de consideración en lo que reconocimos el incógnito del perdón representado en la esfera pública. Finalmente, es de esta capacidad restaurada de la que se apoderaría la promesa que proyecta la acción hacia el provenir. La fórmula de la palabra liberadora, abandonada a la desnudez de su enunciación, sería: vales más que tus actos ${ }^{13}$.

Estas consideraciones generan una perplejidad muchas veces insoportable. ¿No se corre el riesgo de justificar las atrocidades, de ceder a la impunidad, de dar la espalda a las víctimas de los crímenes, las desapariciones, las deprivaciones más atroces, y exigirles una 'altura' imposible? Ricœur es consciente de ello. Quizás lo que se abre aquí como problema filosófico y político es el establecimiento de los límites (borrosos) entre amor y justicia. Por un lado, la exigencia ética del amor a los enemigos, la radicalidad del amor y del perdón que supera todo cálculo, el horizonte de un perdón incondicionado como figura de un plus de mutualidad; por otro, la urgencia histórica y política de la justicia, de la reparación, de la verdad.

Por ello, cuando Ricœur se refiere a las "políticas del perdón”, es claro en situar una dimensión social y jurídica que no puede esquivarse, so pena de convertirse en cómplice de la injusticia a la que podemos someternos los seres humanos: "La justicia debe llegar hasta el final. La gracia no debe sustituir a la justicia. Perdonar sería ratificar la impunidad; sería una gran injusticia cometida a expensas de la ley y, más aún, de las víctimas" (2003: 614) ${ }^{14}$.

No obstante, se pide que la justicia sea cada vez más justa, "es decir, más universal y más singular, más cuidadora de las condiciones concretas de la igualdad ante la ley y más atenta a la identidad narrativa de los acusados. La consideración de las personas conlleva todo eso". Y de nuevo, viene la perplejidad de la exigencia: "Que el horror de crímenes inmensos impida extender esta consideración a sus autores, ésa sigue siendo la señal de nuestra incapacidad para amar absolutamente" ${ }^{15}$.

\footnotetext{
${ }^{13}$ Ricœur, Paul. La memoria, la historia, el olvido. Ed. Cit., p. 643.

${ }^{14}$ Ibíd., p. 614.

De todas maneras, strictu sensu, no puede haber políticas del perdón, si éste se asume en la radicalidad de su altura: sólo se puede perdonar lo imperdonable (Cf. Ibíd., p. 636).

${ }^{15}$ Ibíd., p. 616.
} 


\section{El devolver}

El ágape y el perdón implican la gratitud, pero también el compromiso del retorno. Una gratitud paralizada deja intacta la distancia entre el que da y el que recibe, se acomoda a la fácil situación de la dependencia indiferente. Un perdón que no genera compromiso es un perdón vacío de sentido.

La generosidad del don suscita, no una restitución, que, en el sentido propio, anularía el primer don, sino algo como la respuesta a un ofrecimiento. En última instancia, se debe considerar el primer don como el modelo del segundo don, y pensar, si se puede hablar así, el segundo don como una especie de segundo primer don ${ }^{16}$.

Recibir en gratitud y devolver son correlativos, no porque sea imposible salir del círculo mercantil en el que los tres verbos no se comprenden sin especificar su complemento directo y sin medir con exactitud qué se requiere para que $l o$ que circula, el don, sea igual, en términos de precio; justamente, el tipo de gratitud al que elude el filósofo francés tiene la capacidad de romper con el círculo vicioso del don con un precio intercambiable, en tanto se fija en la relación, en el 'entre' que se abre generosamente entre los hombres, y no en el 'qué' dado o recibido: "Bajo el régimen de la gratitud, los valores de los presentes son inconmensurables en términos de costes mercantiles. Ahí reside la marca de lo sin precio en el intercambio de dones" ${ }^{17}$.

En el perdón hay algo similar. Ciertamente, se puede perdonar esperando recibir: "Si yo digo: 'lo perdono con la condición de que, al pedir perdón, usted haya cambiado y no vuelva a ser el mismo', ¿estoy perdonando? ¿Qué perdono? ¿Y a quién?" ${ }^{18}$. Pero la altura del perdón está en otro registro: el del amor. Poner al perdón en la dinámica de la retribución nos enfrenta con una característica singular del perdón mismo: con el mandato radical de amar a los enemigos. "Parece que este mandato imposible es el único a la altura del perdón. El enemigo no ha pedido perdón: hay que amarlo tal cual es" ${ }^{19}$. Y, al mismo tiempo, aun cuando el otro no ha pedido perdón, del amor -que es la clave en la partitura del reconocimiento mutuo- "se espera precisamente que convierta al enemigo en amigo" 20 .

¿Qué tipo de sujeto se pone en juego en el ágape y el perdón, en sus dinámicas de dar y recibir? Al final de Sí mismo como otro, Ricœur deja planteada la reflexión:

\footnotetext{
${ }^{16}$ Ricœur, Paul. Caminos del reconocimiento. Ed. Cit., p. 248.

${ }^{17}$ Ibíd., p. 249.

${ }^{18}$ Jankélévitch, Vladimir. L’Imprescriptible. París: Seuil, 1986. Citado en: Borradori, Giovanna. Op. cit., 204.

${ }^{19}$ Ricœur, Paul. La memoria, la historia, el olvido. Ed. Cit., p. 625.

${ }^{20}$ Ibíd., p. 626.
} 
"El reconocimiento es una estructura del sí que se refleja en el movimiento que lleva la estima de sí hacia la solicitud, y a esta hacia la justicia. El reconocimiento introduce la díada y la pluralidad en la constitución misma del si’”21.

El sujeto que se pone en juego en el ágape ha perdido la coraza del autofundamento. Nada más desgarrador que dar de sí mismo -no dar cosas, objetos, tiempos sobrantes, espacios en los que, de todas maneras, yo tengo el control, en los que la hospitalidad es milimétricamente controlada-, o acoger en la intimidad al otro que se me da sin que yo lo espere, sin que tenerlo pre-visto. Y, más aún, nada hay que genere un cambio de piel que la iniciativa del perdón incondicionado.

Tanto el ágape como el perdón, como vías del reconocimiento, sitúan el carácter pasivo y activo de la subjetividad: pasivo, en tanto hay una aceptación, un dejarse afectar por el don del otro, por el acto mismo de dar del otro, o por el perdón que restituye mi persona; activo, ya que no se abandona el camino de la iniciativa, puesto en una antropología del hombre capaz, en la que dar y recibir son 'acciones' que traslucen 'capacidades'. Pasivo, si atendemos al participio del verbo a partir del cual expresamos la afección que nos transforma en el recibir y, más aún en la gratitud: soy reconocido, me es dado, quedo agradecido; pero activo, al tiempo, porque tomo entre mis manos la voz, el gesto, el signo generoso del otro y lo acojo, y me comprometo a devolver por pura gratitud, no por el inicio de una competencia de dones o poderes.

Insistamos: la disimetría no se rompe, se mantiene la tensión que genera el carácter irreductible de la ipseidad y la alteridad. Pero esta tensión es el campo en el que se libran las luchas por el reconocimiento y la búsqueda de estados de paz. Es la disimetría la que permite pensar los contornos del espacio público en los que tiene lugar el dar, el recibir y el devolver: "La facultad de perdón y la de promesa descansan en experiencias que nadie puede realizar en la soledad y que se fundan totalmente en la presencia del otro. Si el origen de estas dos facultades es inherente a la pluralidad, su esfera de ejercicio es eminentemente política"22.

\footnotetext{
${ }^{21}$ Ricœur, Paul. Sí mismo como otro. México: Siglo XXI, 1996, p. 327.

${ }^{22}$ Ricœur, Paul. La memoria, la historia, el olvido. Ed. Cit., p. 633.
} 


\title{
Dynamique d'une Rébellion : La Notion Sartrienne de "Groupe» et la Rébellion de Lope de Aguirre en 1559
}

\author{
Hernán Neira \\ Universidad de Santiago
}

Dans la Critique de la Raison dialectique, Sartre crée des concepts qui permettent d'analyser certains aspects du pouvoir politique et de l'évolution qui mène vers la destruction d'un État et vers la création d'un autre. Ces concepts sont : le collectif, la série, le groupe, le serment, la terreur, l'organisation et le souverain (parmi d'autres), que Sartre développe au cours de son analyse de la dialectique de l'action révolutionnaire. Pour cela, il s'appuie sur l'histoire de la révolution française. Or, on peut se demander quelle est la portée de ces notions. C'est une question qui a deux aspects. Le premier est épistémologique et ne concerne que les études historiques. Le deuxième, c'est un aspect philosophique : si les concepts nommés ci-dessus se limitent au cas de la Révolution française, on serait en face à des concepts historiques et non pas en face à des catégories philosophiques. Dans ce cas, la Critique de la Raison dialectique serait un éclaircissement d'un cas politique français, et non pas un concernant la rationalité de l'histoire en tant que praxis de l'être humain, ni une praxis des révolutionnaires français. La philosophie sartrienne cherche des traits qui, tout en s'ancrant dans des faits individuels, soient en rapport avec une rationalité, non d'un phénomène historique, mais avec la rationalité du mouvement historique. Dans cette histoire de longue portée, des notions telles que groupe en fusion, collectif, serment et d'autres semblables ne doivent pas être uniquement événementielles, mais catégorielles. Afin d'étudier ce sujet, nous analysons la révolte de Lope de Aguirre dans le fleuve Amazonas, en 1559. Notre travail n'est pas une exégèse de la Critique de la Raison dialectique, mais une tentative d'évaluation épistémologique de certains aspects de celle-ci.

\section{Chronique et révolte de Lope de Aguirre}

Nous examinons un cas historique du XVIe siècle, tel qu'il est rapporté par la chronique intitulée Jornada de Omagua y Dorado, crónica de Lope de Aguirre ${ }^{1}$ (dorénavant Jornada). La Jornada est une chronique, genre littéraire très codifié dans le monde hispano-américain du XVIe. Siècle. Cette chronique est, en plus, le moyen juridique par lequel deux soldats cherchent à s'innocenter

\footnotetext{
${ }^{1}$ V. Francisco, et A. Pedrarias. Jornada de Omagua y Dorado; Crónica de Lope de Aguirre. Madrid: Miraguano Ediciones, collection Los Malos Tiempos, 1986.
} 
devant l'Audiencia de Santo Domingo, le tribunal chargé de faire justice à la rébellion conduite par Lope de Aguirre. La Jornada décrit une expédition partie du Pérou l'année 1559 dans le but de découvrir et conquérir l'Eldorado, une terre que les espagnols croyaient regorger d'or et qui devait être située dans les alentours du fleuve Amazonas. L'expédition, accordée entre le Vice-roi et Pedro d'Ursúa, qui la dirige avec le titre de "gouverneur », part du Pérou en 1559. L'expédition compte environ 250 espagnols, quelque 300 indiens et quelques esclaves noirs. Quelques mois après, il se produit une rébellion, planifiée par un soldat de 50 ans, Lope de Aguirre. Celui-ci et les révoltés tuent le gouverneur et désignent un nouveau chef : le jeune chevalier Fernando de Guzmán, qui devient général. Pourtant, Lope de Aguirre est le véritable maitre dans l'ombre. Quelque mois plus tard il fait promouvoir Guzmán au rang de Prince, pour le faire tuer en Mai 1560, deux mois après le couronnement. Dès lors, Lope devient le leader absolu de l'expédition. En Décembre 1559, après trois mois de navigation sur le fleuve Amazonas ils s'arrêtent pour célébrer Noël, puis, le Nouvel An (à l'époque, l'Amazonas était appelé Marañón, d'où le nom " marańones » appliqué aux expéditionnaires). Or, il y a dans le campement plusieurs mécontents. Les conditions sont dures et les soldats commencent à se rendre compte que l'Eldorado n'est qu'une chimère. De plus, le gouverneur voyage avec sa maîtresse et les expéditionnaires pensent que lui, en tant que représentant du roi, ne s'occupe pas suffisamment d'eux. Entre Noël et le 31 Décembre 1559 quelques soldats, dont Lope de Aguirre, se réunissent secrètement, décident de tuer le gouverneur, de prendre le pouvoir, et de nommer général le jeune chevalier Fernando de Guzmán. Ils exécutent leur plan la nuit du 31 Décembre, s'heurtant uniquement à une faible garde d'Ursúa. Quand le reste des soldats se réveille, il est déjà trop tard et ils n'entendent que les voix des rebelles en déclarant qu'ils ont agit au nom du roi, car le gouverneur était trop faible pour bien conduire l'expédition.

\section{Initiative politique et amorce du groupe en fusion : première assemblée}

Quelques heures après l'assassinat du gouverneur, le premier Janvier 1560, une assemblée a lieu. A la fin de l'assemblée, les criminels et les soldats signent une déclaration selon laquelle ils ont agit au nom du roi. Ils ajoutent qu'ils ont décidé de continuer la tâche que le Vice-roi avait négociée avec le gouverneur Ursúa, c'est-à-dire la quête de l'Eldorado. Lope s'y oppose, prend la parole et essaie de convaincre les soldats. En 1561 il aurait dit que:

... qué locura y necedad era aquella de todos que, habiendo muerto un Gobernador del rey, y que llevaba sus poderes y representaba su persona, pensaban por aquella vía quitarse de culpa? que todos 
habían sido traidores, y que, dado el caso que hallesen la tierra, y que fuese mejor que el Pirú, que el primer bachiller que allá viniese les cortaría las cabezas a todos : que no pensasen tal, sino que todos vendiesen sus vidas antes que se las quitasen..${ }^{2}$.

Dans son discours, Lope introduit parmi ses compagnons deux notions: celle du danger commun et celle de leur capacité politique. Ils sont en danger; or, il peuvent aussi échapper à ce danger. Comment? En prenant une initiative politique. Au lieu de se faire condamner, il vaux mieux se battre contre les troupes du roi. Lope essaie de faire voir aux soldats qu'ils sont tous en danger et qu'à cause de cela, ils ont intérêt à transformer leur manière d'agir. Il leur montre qu'ils ne peuvent continuer dans la situation où ils se trouvent, car avoir tué le gouverneur est déjà un crime puni par la mort. En revanche, parmi les soldats, il y a des partisans du gouverneur qui ont des doutes concernant la légalité des événements. Ils ont encore l'espoir de se présenter isolément devant les tribunaux et de s'innocenter de la mort du gouverneur, soit en accusant le groupe des criminels, soit en déclarant que le tuer a été nécessaire à cause de l'abandon que celui-ci avait fait de ses devoirs. La praxis des soldats apeurés est sérielle ; il s'agit de plusieurs praxis similaires, sans accord entre elles; ce n'est pas une praxis commune, comme celle des assassins.

Pourtant, Lope échoue et il ne parvient pas à les convaincre de rompre l'accord avec le Vice-roi, c'est-à-dire de rompre avec la Couronne. L'assemblée continue et les chefs rebelles octroient le titre de général au chevalier Fernando de Guzmán. Ils le font au nom du roi; ce n'était pas une procédure courante, mais c'était la procédure normale lorsqu'il fallait remplacer un chef et qu'on n'était pas à même de consulter les autorités. On voit ici la co-existence de deux manières de vivre les événements: la sérialité des soldats cohabite avec l'action du groupe des assassins, action fluide, violente et dirigée vers un seul but qui les constitue en tant que groupe. Regardons ce qui dit Sartre au sujet de la constitution du groupe. Il décrit un moment où, pendant la Révolution française, une partie de la foule se sent en danger d'être attaquée. Dans cette situation:

On sait que jusqu'ici l'objectivité d'un acte apparaissait aux Autres ou se reflétait pour moi dans l'objet produit. Dans le groupe en fusion, le tiers est mon objectivité intériorisée. Je ne la saisis pas en lui comme Autre mais comme mienne. Or, la raison de cette nouvelle structure [...] réside justement dans les caractères fondamentaux de la médiation. Car le médiateur n'est pas un objet: c'est une praxis. [...] Et la réalité c'est que je tente d'intégrer ma praxis à la praxis commune, (c'est-à-dire au projet de contre-attaquer, par exemple). Cette praxis est immédiatement donnée comme le sens compréhensible du regroupement ... ${ }^{3}$

\footnotetext{
${ }^{2}$ V. Francisco, et A. Pedrarias. Jornada de Omagua y Dorado; Crónica de Lope de Aguirre. Madrid: Miraguano Ediciones, collection Los Malos Tiempos, 1986, p. 44. Dorénavant Jornada.

${ }^{3}$ J.-P. Sartre. Critique de la Raison dialectique. Paris : Gallimard, 1960, p. 406. Dorénavant CRD.
} 
Or, c'est justement ce que Lope n'obtient pas, car les soldats voient en lui quelqu'un d'extérieur, un médiateur-objet et non pas une praxis commune comme médiation immédiatement donnée et partagée par tous. Le groupe d'assassins d'Ursúa, en revanche, se voit d'autant plus menacé qu'il ne parvient pas à convaincre les soldats ou qu'il ne parvient à les convaincre qu'à moitié. Le moteur de la transformation d'un collectif en groupe est, pour Sartre, " le danger " $(C R D, 384)$. Mais, on le sait, la tentative de Lope échoue et «l'échec de sa tentative renvoie l'individu à sa solitude et s'explique par sa relation négative aux tiers" (CRD 414). L'intelligibilité de deux moments historiques sera toujours singulière et s'il y a des concepts philosophiques qui permettent de comprendre les deux ce ne sera que dans la mesure où, tout en montrant leurs points communs, ils n'étouffent pas les différences.

Pendant les deux mois qui suivent (Janvier et Février 1560) la chronique ne décrit rien digne d'être mentionné. Pourtant, en Mars 1560 Lope propose à Guzmán de se faire élire général par une sorte de plébiscite, car lors de la mort d'Ursúa il a été désigné général par les assassins, sans aucune participation des soldats. Alors, Guzmán lui-même convoque une nouvelle assemblée et démissione devant les soldats afin que ceux-ci se sentent libres de choisir leur nouveau chef. Quelques instants après, les plus fidèles de ses officiers (qui ont aussi démissionné), déclarent aux soldats qu’ils veulent élire Guzmán général. Il est immédiatement confirmé dans ses fonctions. Réinstallé au pouvoir, il propose un serment en disant aux soldats :

que cada uno dijese su parecer, y sin ningún temor ; que el que quisiese seguir la guerra del Pirú, en que él y sus compañeros estaban determinados, había de firmar y jurar de la seguir, y obedecer a su General y capitanes en lo que se les mandase [...] Todos los del campo, y algunos, a más no poder, por temor que tenían que no los matasen, firmaron y juraron la guerra del Pirú [...] Otro día [los oficiales ....], acabada la misa, el dicho clérigo les tomó a todos estos Oficiales juramento muy solemne sobre un ara consagrada y un libro de los Evangelios, en que pusieron sus manos y juraron que unos a otros se ayudarían y favorescerían y serían unánimes [...] a pena que el que esto no hiciese y lo quebrantase, no pudiese ser absuelto sin ir a Roma. (Jornada, 49)

Il est presque certain que certains soldats on dû faire la transition de l'intériorité (apeurés par la justice royale) vers l'extériorité de la praxis des révoltés, en justifiant leur attitude et surtout en se justifiant par sa praxis, comme Sartre caractérise le groupe en fusion ( $C R D$ 407). Ils ne peuvent faire face à ce danger que par la transformation de leurs praxis isolées en une praxis commune. Or, c'est une situation labile. Lope reste toujours un peu extérieur aux soldats, car les soldats installent le général Guzmán en tant que médiateur, de sorte que 
la transition de l'intérieur vers l'extérieur au moyen de la praxis n'a pas dû être totalement spontanée et, par conséquent, n'a pas dû se réaliser comme le demanderait une définition stricte de "groupe en fusion ». Élire un général c'est une praxis commune, mais limitée dans ses buts et dans sa durée. Ils n'accèdent pas, pour l'instant, à une praxis qui se ré totalise de manière continue et il se peut qu'au moins certains des soldats aient élu le général, soit par peur de Lope, soit afin de ne pas avoir à choisir leur propre praxis dans le futur et placer la responsabilité de leur destin dans un chef extérieur. Le groupe d'assassins, en revanche, comme on le verra plus loin, éprouve le besoin de se ressaisir et de se confirmer à mesure qu'ils font face à un danger de plus en plus grand.

Cette labilité veut aussi dire que le mouvement qui transforme le collectif des marañones n'est ni linéaire ni ne va dans le sens d'une progression. On a déjà vu que l'existence en tant que collectif vécu par les soldats cohabite pendant les trois premiers mois de 1560 avec l'existence en tant que groupe vécue par les assassins. Ainsi que l'écrit Sartre, il n'y pas de séquence linéaire ni de transfert direct entre le collectif et le groupe. La rationalité de l'histoire révolutionnaire de 1789 décrite par Sartre, ne le mène pas à proposer une rationalité hégélienne : le collectif et le groupe peuvent être réversibles et l'on ne peut pas fixer le moment initial afin de dire lequel a précédé l'autre (CRD 384). Dans le campement les deux formes d'existence ont lieu, mais aussi, parfois, au sein de chacun des deux sous groupements qui cohabitent dans l'expédition.

Lope double le danger d'une justice royale, lointaine, par la menace immédiate constituée par lui-même et sa capacité d'imposer ses propres avis et décisions au nouveau général, car en plus d'être devenu maese de campo, il a fait exécuter quatre soldats loyaux à Ursúa après la mort de celui-ci. C'est pourquoi le reste des soldats n'ose pas défier Lope et ils ne parviennent ni ne parviendront jamais à devenir, vis-à-vis de lui, un groupe un fusion dans le sens strict du terme sartrien. Pour la compréhension des événement de l'Amazonas, il est important de ne pas s'en tenir à un sens rigide des notions de collectif et de groupe. Le groupe de la Révolution française ne peut être identifié avec le groupe des marañones, mais on peut mieux comprendre la rationalité de la praxis des hommes de 1789 au moyen de la compréhension de la praxis de ceux de 1550, ce qui demande de la flexibilité et même un élargissement de certains notions de la Critique de la Raison dialectique. Lors des événements de l'Amazonas, le groupe en fusion et le collectif se mêlent et, parfois, peuvent subsister synchroniquement dans le même ensemble de personnes. Les mêmes soldats qui peuvent acquérir certains traits de groupe lors de l'élection de Guzmán, deviennent collectif par rapport à Lope. Celui-ci leur a donné, en même temps, le courage et la peur ; Lope vole la praxis commune qu'il a contribué à créer au moyen d'une procédée efficace qui les séduit et qui en même temps les terrifié. Le danger de la couronne, présenté et amplifié par le discours 
de Lope aux soldats, fait que ceux-ci voient leur situation comme une impossibilité à vivre tant qu'ils ne modifient pas leur vie. Lope excite la peur extérieur et, grâce à cela, est le moteur de la transformation du mode de vie des soldats, sinon en groupe en fusion dans le sens strict du terme, au moins en groupe de rebelles. Ils sont donc prêts, grâce à Lope, à promouvoir Guzmán au poste de général, élu. Ainsi, les soldats commencent à devenir responsables d'une initiative qui, au début, ne concernait qu'un petit groupe d'assassins.

\section{Le Serment et la fraternité : deuxième assemblée}

Examinons, maintenant, d'autres aspects de la deuxième assemblée. On a vu qu’après se faire élire général, Guzmán propose un serment. Les soldats doivent " firmar y jurar " (signer et jurer) qu'ils continueront la conquête du Pérou et qu'ils lui obéiront, mais, on sait que quelques uns d'entre eux ont juré uniquement par peur de se faire tuer. De leur côté, on a aussi vu qu'un jour après les officiers renouvellent leur serment, d'une manière solennelle et, à la différence des soldats, ils jurent, aussi, "que unos a otros se ayudarian y favorescerían y serían unánimes ". Le mot "jurar " (jurer) d'alors a la même signification qu'aujourd'hui en espagnol et en français. Sartre précise le sens philosophique de ce mot, mais ce sens s'appui sur le sens courant du terme. Pour Sartre, le serment provient d'une crainte concernant une dispersion future :

... cette tension dans la survivance manifeste pour chaque tiers le double danger qui menace le groupe : se résumer dans une synthèse passive du champ pratico-inerte [...] se dissoudre dans un nouveau rassemblement sériel. La tension, vécue par le tiers, est précisément la prise de conscience, dans la mesure même où elle découvre le groupe en danger et où elle se dépasse : en se découvrant, vers une fin nouvelle, c'est-à-dire vers la conservation du groupe comme unité pratique et libre contre ce double danger [...] Le groupe devient en chacun l'objectif commun : il faut sauver sa permanence. (CRD 437)

Lorsque la liberté se fait praxis commune pour fonder la permanence du groupe en produisant par elle-même et dans la réciprocité mediée sa propre inertie, ce nouveau statut s'appelle le serment [...] Le serment est réciprocité mediée. (CRD 439)

La conduite de serment consiste donc à présenter librement dans l'avenir la dispersion du groupe comme impossibilité inerte (comme négation permanente de certaines possibilités) [...] Or, ce qu'il faut noter c'est que dans le milieu du même, le tiers craint la dissolution dispersive autant dans l'autre tiers qu'en lui-même... (CRD 440) 
Dans le cas qui nous occupe, les officiers prêtent un serment réciproque quelques jours après la deuxième assemblée et ils jurent de s'aider les uns aux autres. Or, comme nous avons lu dans la citation de Sartre, ni l'engagement des soldats ni le serment des officiers n'est à vraiment parler le fondement d'une société. On verra le véritable fondement de la société des marañones quelques paragraphes plus loin. Le serment vise à " à présenter librement dans l'avenir la dispersion du groupe comme impossibilité inerte ", car il s'agit, aussi bien dans la deuxième l'assemblée de soldats que dans la confirmation du serment fait par les officier de : 1) écarter ceux qui risquent de se séparer du groupe en leur donnant la possibilité (irréalisable) de ne pas prêter serment, et : 2) une fois que ceux-ci sont écartés (théoriquement), les soldats qui restent "ont signé et ont juré la guerre du Pérou "; et 3) les officiers resserrent les liens entre eux et ils ne promettent pas uniquement de continuer la guerre ensemble, mais "qu'il s'aideraient et se favoriseraient les uns les autres et qu'ils seraient unanimes ». La fraternité à peine amorcée par l'engagement des soldats vis-à-vis de Guzmán, acquiert toute son ampleur chez les officiers qui deviennent fraternité. La fraternité, telle qu'elle est définie par Sartre :

... c'est le droit de tous à travers chacun sur chacun [...] elle est la violence même en tant que celle-ci s'affirme comme lien d'immanence à travers les réciprocités positives. Par là nous devons entendre que la puissance pratique du lien de fraternité n'est pas autre chose (dans l'immanence) que la libre transformation par chacun, pour soi et pour l'autre tiers, du groupe-en-fusion en groupe de contrainte [...] Le traître n'est pas retranché du groupe [...] il demeure membre du groupe en tant que celui-ci — menacé par la trahison— se reconstitue en anéantissant le coupable c'est-à-dire en déchargeant sur lui toute sa violence. (CRD 454).

Autrement dit, uniquement le Pape, le pouvoir le plus grand et légitime qui existe à l'époque, le seul qu'ils respectent ou fassent semblant de respecter encore, pourrait absoudre un officier d'une faute contre la fraternité qui vient de naître. Que'est-ce que cela peut vouloir dire, sinon que la faute est impossible à pardonner et que, pourtant, elle doit être châtiée avec la rigueur maximale ? Cette rigueur est une contrainte qui oblige chacun des officiers à un certain comportement et qui ne lui permet pas de fuir, même lorsque, plusieurs mois après, affaiblis, ils seront face à une armée royale qui offrira "merced» (merci) à ceux qui abandonnent Lope. Ils savent qu'une situation semblable peut se produire ; cela a été le cas lors d'autres révoltes, comme celle de Pizarro, révolte dans laquelle ils est possible que quelques-uns des marañones aient participé avant de s'engager dans l'expédition d’Ursúa.

Du point de vu de la concordance de temps -point de vu très important dès lors que pratiquement la seule information sur Lope vient d'une chronique- 
, la premier partie du serment (jusqu’à " unánimes ») est conjuguée avec la structure dijo que + condicional (il a dit que + conditionnel) ce qui ne soulève aucun doute sur les rapports temporels et qu'on utilise dans le discours libre indirect. Le discours rapporté par la chronique parle d'une action qui a eu lieu dans un temps qui se situe entre le moment du rapport écrit (1561) et celui du serment (mars 1560).

La deuxième partie du serment est conjuguée au subjonctif (hiciese, quebrantase), car c'est le temps exigé en espagnol lorsqu'on exprime une menace, châtiment ou une crainte dans le futur. Les deux structures confirment que le groupe jure afin de se protéger contre les dangers futurs, dans ce cas intérieurs (risque de trahison). La constitution du groupe est elle-même une protection contre l'extérieur, mais cette protection ne pourrait durer que dans la mesure où la structure interne du groupe se protégerait, parallèlement, contre les risques de fissures intérieures. Cela confirme le fait que le serment des officiers porte sur l'avenir plus que sur leur complicité passée lors de l'assassinat d'Ursúa. Ils se solidarisent avec leur crime passé, solidarité qui empêche de se rendre à la justice royal afin d'obtenir merci.

\section{Fondation d'une nouvelle société : troisième assemblée}

Quelques jours après le serment des officiers (toujours en Mars 1560), Lope convoque une troisième assemblée, devant la hutte du général Guzmán, apparemment sans l'voir avoir prévenu. Il offre aux soldats de renoncer à leur engagement de faire la guerre. Quand ils confirment leur désir de continuer dans les rangs, il propose d'élever Guzmán au rang de Prince. Il aurait dit :

«... si alguno de vuestras mercedes, de los que el otro día firmaron, se han arrepentido, díganlo sin temor alguno " [ $Y$ tras esto dijo] " que para que la guerra llevase mejor fundamento y más autoridad, convenía que hiciesen y tuviesen por su Príncipe a D. Fernando de Guzmán desde entonces, para le coronar por Rey en llegando al Pirú, y que para hacer esto era menester que se desnaturasen de los reinos de España, y negasen el vasallaje que debían al rey D. Felipe [...] y que elegía y tenía por Príncipe y rey natural a D. Fernando de Guzmán [...] y que todos hiciesen lo mismo». Jornada, 50.

C'est lors de cette troisième assemblée qu'a lieu la fondation d'un contrat social, car c'est un véritable pacte de soumission au Prince, tel que l'exige par le droit traditionnel espagnol et qui est, aussi, la base de la notion féodal de liberté et d'obligation politique. La promotion de Guzmán au poste de général, tout en étant une rébellion, n'était pas la fondation politique d'une nouvel 
état, de même que ne l'était pas non plus le serment de ceux qui participent à la révolte. Le contrat social n'est ni un serment ni une rébellion, quoique la plupart des fois il la demande. C'est pourquoi Sartre a raison de séparer le serment de la fondation de la société, comme on a récemment vu, malgré le fait que, dans la Critique de la Raison dialectique, cette différence n'est guère expliquée. Sartre perçoit la différence, mais la Révolution Française ne se prête peut-être pas à l'éclaircir avec la richesse et subtilité de la rébellion des marañones.

Lors de la troisième assemblée, Guzmán prend le titre de Principe de Tierra Firme y Peru y Gobernador de Chile (Prince de Terre Ferme et du Pérou et Gouverneur du Chili). Ainsi, les soldats deviennent—ils déloyaux au roi Felipe II, crime de lèse__majesté puni par la mort, mort à laquelle ils ne peuvent échapper que par la transformation de leur manière de vivre et, surtout, de leur manière de vivre l'action, c'est-à-dire, par l'acquisition d'une praxis commune. Apparemment, avec la dénaturalisation, Lope a obtenu ce qu'il cherchait : les soldats rompent la sérialité qu'impliquait l'espoir de rester sans praxis commune et de se faire pardonner par les autorités. Cette description est cohérente avec le fait que dans la Critique de la Raison dialectique Sartre définit le groupe par le rapport à un danger extérieur. Jusqu’à la transformation du général Guzmán en Prince don Fernando de Guzmán, les soldats restaient dans une situation où coexistaient certains traits de sérialité et certains traits du groupe. Avec la soumission au Prince Guzmán, ils transforment la peur de comparution passive et isolée de chacun devant la justice $\mathrm{du}$ roi en une opposition commune contre celui-ci. Du point de vue philosophique, nous sommes devant une situation souvent décrite par des auteurs classiques (passage d'une sorte d'état naturel, sans chef, à la soumission à un pouvoir élu, bien qu'absolu). Mais, peut-on parler de la naissance du groupe chez les soldats?

Comme lors de l'élection du général Guzmán, la situation reste ambigüe. Lélévation de Guzmán au rang de Prince marque le succès de Lope dans ses efforts pour resserrer les liens de tous avec une seule praxis partagée : s'emparer du Pérou. Mais, en même temps, Lope reste extérieur à eux. Il leur donne un Prince, mais ce ne sont pas eux-mêmes qui se le donnent et même Guzmán participe à moitié forcé à son couronnement. Le chroniqueur, qui pourtant ne se montre pas condescend envers Guzmán, déclare que Lope aurait agit « ... según dijeron algunos, sin comunicarlo con él, ni él ser sabidor de ello... " Jornada, 50.

Don Fernando de Guzmán n'est qu'un Prince de pacotille, pacotille encore plus accentuée à cause de du fait qu'il se fait entourer d'ostentation. De plus, il ne survit pas longtemps : le 22 Mai 1560 il est tué par Lope de Aguirre et ses partisans les plus proches, qui voient en lui un obstacle pour s'emparer du Pérou. 
Leur plan consiste à arriver à l'Océan Atlantique, naviguer vers le Venezuela, pénétrer dans les terres et continuer à pied vers le sud, par les vallées des Andes jusqu'au Pérou, à travers la Colombie. À partir de la mort du Prince Guzmán, Lope devient détenteur incontesté du pouvoir. Or, Lope doit s'assurer que personne ne déserte ni n'affaiblisse ses forces. Dans ces conditions, Lope et ceux qui le suivent considèrent que tout et tous doivent se consacrer à une seule tâche. Le "droit de tous à travers chacun sur chacun " suppose une certaine égalité. Or, c'est justement qu'à partir du moment où Lope prend le pouvoir directement que les hiérarchies créées par la couronne espagnole, puis par le roi Guzmán, sont complètement abolies. La fraternité des marañones n’est pas seulement un droit de tous à travers chacun, mais c'est aussi l'établissement d'une égalité totale et radicale, une sorte de démocratie à outrance, mais sans le contrôle du droit et sans l'unité spontanée du collectif au moment où il évolue vers sa transformation vers un groupe en fusion. Or, puisque ce droit sur chacun est un droit sans limite, est en même temps l'élimination du droit. Le droit illimité devient nul et rejoint l'arbitrair pur. Dans la mesure où tout un chacun est soumis au droit total de tous, chacun est aussi dépouillé des tous les droits. C'est tout-à-fait naturel que la terreur soit la conséquence de la fraternité dans une condition de risque accru, où le risque rend convenable de s'écarter de la «fusion " et de reprendre un action individuelle. Par ailleurs, dès l'assassinat d'Ursúa, il se produit une oscillation du risque, qui dépend de l'accélération et du ralentissement des rythmes de la révolte, laquelle est, à son tour, très influencée par les décisions imprévisibles de Lope.

D'après la chronique, après la mort de leur Prince, les hommes se consacrent effectivement aux tâches proposées par Lope et personne n'essaie de s'y opposer. L'amorce de fusion qui s'est produite lors de l'élection du général Guzmán, se dissout après la mort de celui-ci. Pour Lope et pour quelques officiers les soldats deviennent une sorte d'outil au moyen de la terreur. Celle-ci est aussi exercée contre les officiers qui ont participé au doublement du serment. Ceuxci, de groupe en fusion lors de la planification de l'assassinat, se transforment en fraternité, mais c'est une fraternité qui permet l'existence d'un membre qui lui est toujours étranger : Lope. Soldats et officiers entrent dans une situation où tous sont un instrument pour faire aboutir leur visée commune et où les sacrifices personnels ne comptent pas. Face à cette tâche, ils sont tous égaux : matière et objectivité pures. L'existence de chacun d'entre eux ne compte que dans la mesure où ils sont disponibles pour la tâche que le tempérament toujours changeant de celui-ci leur assigne. La praxis de conquête justifie, remplit et surtout anéantit leur existence. 


\section{Lope prends le pouvoir : la terreur sans médiation politique}

À partir de la disparition du Prince Guzmán Lope impose l'obligation de poursuivre tous le même but, sous menace d'une violence qui ne vient plus de l'extérieur. Il n'y plus de place pour des délibérations ou pour des assemblées, même si celles-ci sont des parodies des véritables délibérations. C'est la terreur. Celui qui refuserait d'y participer, serait suspect. Sartre écrit :

L'invention de la Terreur comme contre-violence engendrée par le groupe lui-même et appliquée par les individus communs sur chaque agent particulier (en tant qu'il comporte en lui-même un danger de sérialité) est donc l'utilisation de la force commune, jusque-là engagée contre l'adversaire, pour le remaniement du groupe lui-même. Et toutes les conduites intérieures des individus communs (fraternité, amour, amitié aussi bien que colère et lynchage) tirent leur terrible puissance de la Terreur même. CRD 455.

... elle [la terreur] se manifeste aux individus sur la soumission totale de la matière (désagrégée ou traversée de rayons ou directement modifiée, sans travail, par la simple volonté souveraine) mais comme hétérogénéité, c'est-à-dire comme indépassable négation de leurs possibilités. En ce sens, son pouvoir a pour structure fondamentale ces possibilités niées en chacun, comme inertie de chaque liberté. CRD 457.

La nouvelle société fondée avec le couronnement de Guzmán est dissoute par les exigences terrifiantes de la fraternité, qui, dans le campement, prend la forme de délation et d'arbitraire totale de Lope vis-à-vis des soldats. Il tue ceux qu'il pense être trop « tièdes " pour la guerre, mais aussi « ...a un Enriquez de Orellana, que era Capitán de la munición, porque estaba mal con él, y porque decian que se habia emborrachado el día que entraron a la isla [de Margarita] ..." Jornada, 80.

C'est que la terreur s'enchaîne avec ce que Sartre appelle le souverain. L'organisation surgit du serment et implique une division et partage de tâches qui, dans le cas qui nous occupe, reste au deuxième plan sous l'égalité à outrance qu'établit Lope après la mort de Guzmán. Or, avec la prise de pouvoir de la part de Lope, surgit la figure du tiers régulateur et du souverain dans le campement. Le tierce régulateur conserve un rapport de :

... immanence-transcendance au groupe dont il fait partie [...] or, la structure de l'acte régulateur est complexe : c'est, en un sens, une affirmation limitée de souveraineté. Par souveraineté, en effet, j'entends le pouvoir pratique absolu de l'organisme dialectique, 
c'est-à-dire sa pure et simple praxis comme synthèse en cours de toute multiplicité donnée dans son champ pratique [...] Je l'appelle souveraineté parce qu'il n'est rien d'autre que la liberté même en tant que projet dépassant et unifiant les circonstances matérielles [...] Or, l'acte régulateur est, à première vue, quelque chose de semblable à l'exercice d'une souveraineté absolue et totale [...] Mais si l'exercice de la souveraineté était plénier, il faudrait que le souverain fût extérieur au groupe et qu'il le totalisât comme totalité-objet dans son champ pratique. CRD 563-564.

Après la mort de Guzmán surgit, plus qu'une institution impersonnelle, une autorité personnelle et infinie: Lope. Il incarne la fidélité à la conquête du Pérou et au défi contre Philipe II ; il est l'engagement de tous et le serment des officiers. Mais, en même temps, il dégrade le grupe, il le fige et le transcende du hors. Lope, est l'homme par rapport auquel « toute proposition est " divisionniste " " CRD 582. L'unité du groupe, même dans sa partie à peine amorcée, vient maintenant de l'extérieur, d'un extérieur absolu qui décide quand et comment quelqu'un se dévie du but. Or, l'institution qui se crée lors des premiers moments de la révolte des marañones partage des traits d'intériorité (le serment des officiers et l'engagement des soldats lors de la deuxième assemblée) et d'extériorité (la peur et les désertions augmentent au fur et à mesure que les troupes royales s'approchent). "L'unité de l'institution -écrit Sartrec'est l'unité de l'altérité en tant qu'elle s'est introduite dans le groupe et que le groupe l'utilise pour remplacer son unité absente. Mais son rapport à chacun est d'intériorité quoiqu'elle puisse se définir comme la praxis en extériorité : elle détermine, en effet, chacun en inertie et en obligation pratique " $C R D$ 584. Chez les marañones, l'institution acquiert un caractère labile dans laquelle extériorité et intériorité cohabitent aussi bien chez les soldats que chez les officiers. Quelques soldats ont, parfois, du pouvoir sur les autres (délations), quelques officiers font arrêter ou tuent d'autres officiers et, parfois, Lope agit contre certains soldats ou certains officiers en créant une extériorité que luimême avait niée en participant au serment des officiers.

Cette unité extérieure donne lieu à une nouvelle transformation du groupe. L'institution du général, puis du Prince Guzmán évolue vers l'autoritarisme à outrance incarnée par Lope. Cela se produit par étapes. On constate l'amorce de l'autorité extérieure et souveraine de Lope dès la deuxième assemblée, quand il propose de faire élire Guzmán général ; et on constate la manifestation éclatante de cette autorité lorsqu'il fait promouvoir Guzmán Prince ; et, finalement, Lope devient autorité souveraine avec la mort de Guzmán (Mai 1522). Or, qu'est-ce que l'autorité ? D'après Sartre,

A partir du moment où un tiers régulateur (ou un sous-groupe de tiers régulateur) est titulaire assermenté de la régulation comme 
fonction organisée et lorsque ce même tiers reçoit et concentre la violence interne du groupe comme pouvoir d'imposer sa régulation, la quasi-souveraineté tournante de chacun s'immobilise et devient l'autorité comme relation spécifique d'un seul à tous [...] L'autorité ne se manifeste dans son développement qu'au niveau des institutions : il faut des institutions, c'est-à-dire une renaissance de la sérialité et de l'impuissance, pour consacrer le Pouvoir [...] en d'autres termes, l'autorité repose nécessairement sur l'inertie et la sérialité, en tant qu'elle est Pouvoir constitué...CRD 587.

C'est l'inertie des soldats, incapables de s'opposer à Lope, qui permet à celui-ci avoir de l'autorité. Lope devient l'individu non dépassable dont parle Sartre plus loin (CRD 591) et il est certain qu'il s'empare de l'autorité totale. Pourtant, dans le cas français, qui sert de base à Sartre, la souveraineté et l'autorité sont liées à des institutions. Lors de la Révolution française, le pouvoir révolutionnaire est institutionnalisé ; celui-ci précède et succède à Robespierre, qui concentre un pouvoir déjà existent. La fin de la terreur coïncide avec la fin de Robespierre, mais la terreur est plus une manière d'agir dans la désespération qu'une institution nécessaire au long terme. Par ailleurs, Robespierre meurt sans perdre confiance en la révolution dans laquelle il a participé, ce qui n'est pas le cas de Lope. Celui-ci ne parle ni au nom d'une république, ni au nom d'une assemblée législative ni au nom d'une patrie ou de la vertu. Trois jours avant sa mort, sachant qu'il serait vaincu, Lope dit : "Si yo tengo que morir desbaratado en esta Gobernación de Venezuela, ni creo en la fe de Dios, ni en la secta de Mahoma, ni Lutero, ni gentilidad, y tengo que no hay más que nacer y morir " Jornada, 147. Il exerce la terreur, mais celle-ci n'est pas une inflexion d'un pouvoir révolutionnaire préexistent, car Lope a toujours été dans le cœur du pouvoir des autres grâce à la terreur ; c'est celle-là, probablement, une des sources de sa puissance. Ce qui change c'est que lorsqu'il fait tuer le Prince Guzmán, le lien entre lui et les soldats et entre lui et les officiers cesse d'être medié par une pseudo-institution politique. Cela rend Lope encore plus puissant, car il n'y a pas de médiation ni d'intermédiaire ni d'institution qui puisse modérer l'emprise de sa volonté sur ses actes. La dernière amorce de médiation/institution politique, ridicule, certes, qui existait chez les marañones, a été celle du Prince Guzmán. Après Guzmán, Lope gouverne sans médiation et avec autorité totale.

Nous considérons que la progression : groupe en fusion-serment-terreur ne se prolonge pas, chez les marañones, vers l'institution ni vers le souverain décrit par Sartre. Lope n'est pas ce souverain-ci, ni non plus celui décrit dans la philosophie plus traditionnelle de Jean Bodin. Lope ne parvient pas à devenir souverain, car il ne crée aucune république. L'exercice d'une certaine souveraineté par Lope est plénière dans l'Amazonas, mais c'est son arbitraire qui le situe hors du groupe et empêche d'identifier cette souveraineté avec la sartrienne. 
Lope devient le tiers régulateur, non plus pour régler les conflits à l'intérieur du groupe, mais pour mesurer, de manière absolue, la fidélité à l'entreprise de conquête du Pérou. Mais ce projet de conquête (qui est une conjuration contre le pouvoir espagnol établi à Lima), cesse d'être partagé à partir de la mort de Guzmán et devient un projet privé. C'est la conquête de Lope, la conquête qu'il impose, par la terreur, à un groupe devenu objet d'une volonté transcendante et qui, pour cela même, perd les traits, uniquement quelques traits, de groupe en fusion qu'il avait auparavant. Quand, finalement, en Octobre 1561, les marañones sont en face des troupes royales, la plupart des soldats accepte l'offre de pardon que celles-ci proposent et Lope reste accompagné uniquement par une dizaine d'hommes et par sa fille, qu'il tue de sa propre main. Quelques minutes après, il reçoit deux coups d'arquebuse de la part d'un de ses propres soldats, le 22 Octobre 1651.

\section{Catégories historiques ou philosophiques?}

Revenons à notre question initiale : les principales catégories utilisées par Sartre dans La Critique de la Raison dialectique et, en particulier, celle de " groupe en fusion ", sont-elles des concepts uniquement utilisables pour une description historique individuelle, même s'il s'agit d'une description rationnalisée ou, en revanche, s'agit-il de catégories philosophiques, qui servent, non à comprendre une histoire, mais, sinon l'Histoire, au moins, quelques aspects de l'Histoire?

Notre analyse montre que certains catégories sartriennes de la Critique de la Raison dialectique permettent d'éclaircir des événements historiques situés dans un domaine géographique et dans une époque différente de celle de la Révolution française, à condition qu'on n'essaie pas une " application " de celles-ci, mais plutôt un éclaircissement réciproque. C'est l'histoire qui doit éclaircir la portée de ces notions et ce sont ces notions qui doivent éclaircir l'histoire. Dans le cas des marañones, la labilité du pouvoir et aussi des rapports d'intériorite et d'extériorité empêchent qu'on puisse identifier, par exemple, le groupe en fusion avec n'importe lequel des groupements qui se sont formés dans les moments préalables ou postérieurs aux assemblées. Le groupe des marañones réalise un amorce de fusion, mais ne fait que l'amorcer, car il éprouve toujours une extériorité, une forme de se faire voler la praxis à cause de la peur, identifiée avec la justice royale ou le pouvoir grandissant de Lope et même, souvent, avec les deux. Uniquement à la fin de l'expédition, lorsque les soldats font le constat de la proximité des troupes royales et que celles-ci ont accueilli et pardonné les déserteurs, la majorité des soldats se libère de la peur et abandonne Lope qui, finalement, reçoit deux coups d'arquebuse tirés par l'un d'entre eux. Or, la libération de la peur n'explique pas, seule, 
leur désertion. L'autre cause de la désertion est que, finalement, ils se rendent compte qu'ils n'ont plus aucune possibilité de s'emparer du Pérou, raison pour laquelle ils avait convenu d'amorcer une sorte de praxis commune et de fusion lorsqu'ils s'engagent avec Guzmán. Par ailleurs, Il y a, lors de l'expédition, une ambigüité constante dans laquelle, aujourd'hui, on ne peut séparer, d'un côté, la part qui est due aux faits " tels qu'ils ont eu lieu "; et, de l'autre, les faits tel qu'ils sont racontés par les auteurs de la chronique, qui cherchent, eux, à s'innocenter des faits dans lesquels ils ont été partie prenante. La Jornada est une chronique à caractère judiciaire présentée par les soldats Francisco Vázquez et Pedrarias de Almesto devant les autorités lors de l'enquête sur le soulèvement de Lope qui a eu lieu après la mort de celui-ci.

Les catégories du groupe en fusion, serment, organisation, terreur, institution, autorité et souveraineté ont, donc, une portée qu'on peut appeler philosophique, à condition qu'elles soient placées dans un contexte philosophique et historique qui va au delà de la Révolution française. Certes, on pourrait nous demander de définir le concept de " philosophie » et on pourrait nous critiquer, aujourd'hui, d'accorder une universalité quelconque à la philosophie. On est conscient que la philosophie est ancrée et qu'elle a des forts liens territoriaux, mais ce sont justement ces liens ceux qui nous permettent de les considérer comme catégories philosophiques car elles permettent de comprendre la praxis humaine dans des situations très différentes sans pour autant les dissoudre dans l'uniformité. L'ancragre territorial et culturel de la philosophie explique que Sartre ait élaboré la Critique en s'appuyant sur la Révolution française. En le faisant, il s'insère dans une tradition de philosophie qui n'est pas uniquement française et qui remonte à des notions, comme celle de serment, de groupe ou de souveraineté, plus anciennes et à beaucoup d'égards communes avec le droit traditionnel espagnol. Lorsque les soldats élisent Guzmán général ou quand ils le promeuvent au rang de prince, aussi bien que lorsque les narrateurs font le compte rendu des événement dans la chronique, ils racontent une histoire rationnelle, telle qu'elle pouvait être comprise et admise par leurs contemporains. Dans le campement les soldats imitent une rationalité politique, dégradée mais cohérente avec une vision et un récit ajustés au droit traditionnel espagnol qui, à son tour, a des aspects communs avec le droit et la philosophie politique française du XVIe siècle. C'est Lope qui, à la fin, rompt la rationalité de la souveraineté traditionnelle et se sépare aussi bien du récit de la souveraineté féodale que des sources de celle-ci, qui demandent une "conjuration " (conjuración), mais pas uniquement, car le récit de la souveraineté demande, de plus, un pacte de soumission, sans lequel la conjuration devient illégale, comme c'est le cas de la conjuration des marañones. La conjuration est un serment. Le serment politique est une notion du droit et de la philosophie politique traditionnels, une notion non inventée par Sartre, mais renouvelée dans la Critique de la Raison dialectique en la situant, non au cœur de la féodalité, mais au cœur de la version française de la modernité politique. La coïncidence, 
donc, et la capacité que certaines notions clés de cet ouvrage — notamment la notion de groupe, de serment et de terreur- ont d'éclaircir les événement révolutionnaires de la Jornada tiennent à l'ancrage de la philosophie de Sartre dans une tradition plus élargie que l'histoire et le territoire français et qui remonte, au moins, au XVIe siècle. Sartre réactualise et "modernise " ces notions et les place au centre des luttes françaises pour la démocratie.

En revanche, il est naturel qu'on ne puisse pas utiliser ni " appliquer " d'une manière massive et/ou rigide les concepts sartriens aux événements de l'Amazonas. Le faire serait devenir des "schématisateurs ", phénomème que Sartre lui-même reproche aux auteurs marxistes qui transforment une méthode en dogmatisme (CRD 47).

C'est important de ne pas chercher à voir dans les événements de l'Amazonas la "réalisation " anticipée des notions sartriennes de la Critique de la Raison dialectique. Ni les soldats qui complotent contre Ursúa entre Noël et le Nouvel An 1559, ni ceux qui participent dans les assemblées de Janvier ou Mars 1560, ni les officiers que jurent de s'aider, ne constituent ni ne s'identifient avec une " essence " du groupe ni avec aucune autre essence, comme si le groupe en fusion pouvait exister sans aucune réalisation historique. La notion de groupe en fusion est une notion développée pour comprendre la praxis et, la praxis, reste toujours ancrée. Dès lors, l'analyse de la révolte de Lope et des marañones contribue à développer une notion comme celle de groupe en fusion plus qu'à faire l'exégèse d'une essence, chose, par ailleurs, qui supposerait n'avoir pas compris les aspects essentiels de la philosophie de Sartre. Si ces notions peuvent se développer aussi bien lors de l'interprétation de la féodalité décadente dans l'Amérique espagnole que lors de l'interprétation de la modernité française nous considérons qu'elles permettent de faire de la philosophie de Sartre une philosophie vivante. 


\title{
Olvido, Memoria y Esperanza \\ en Jean-Louis Chrétien
}

\author{
Rodrigo Figueroa Weitzman \\ Universidad Andrés Bello
}

\begin{abstract}
Resumen
Este artículo es un extracto sintético y adecuado, con breves ilaciones mías, del pensamiento de Jean-Louis Chrétien sobre el olvido, la memoria y la esperanza, expuestos con tanta finura y belleza en su libro L'inoubliable et l'inesperé y traducido al español por Javier Teira y Roberto Ranz. En este ensayo la reflexión filosófico-teológica del autor francés se muestra rigurosa, erudita y con una prosa impecable. Es un texto hermoso que me alegro de haber leído y de dar a conocer en este espacio.
\end{abstract}

\section{Lo inmemorial y la reminiscencia}

¿Hay un olvido primero?”, es la pregunta inicial que se formula Jean-Louis Chrétien en este escrito. ¿Puede haber un olvido radical que no presuponga la memoria, o que no la interrumpa o suspenda? Para este pensador francés el olvido está fundamentalmente subordinado a la memoria. Es obvio que la mera posibilidad de un olvido inicial parece contradictoria o absurda. Por cierto, ¿cómo podría borrarse aquello que no ha sido previamente inscrito o grabado? "Comenzar por el olvido conduce a comenzar por la pérdida, y ¿cómo se puede perder aquello que no se ha tenido previamente, aquello que en primera instancia no ha sido? Si la pérdida es privación, presupone aquello de lo que priva. Si es que hay un olvido primero, lo que éste hace surgir es un inmemorial absoluto: no un pasado que, habiendo sido presente, por tanto, ya abierto y destinado a la memoria, haya llegado a ser inaccesible en ella o para ella, sino un pasado inicialmente pasado y originalmente perdido, un pasado con antelación y esencialmente hurtado a toda memoria futura ${ }^{1}$.

Para que haya olvido verdadero no basta olvidar, pues olvidar recordando que se ha olvidado no es más que un modo de recuerdo que nos permite volver a encontrar aquello que fue olvidado. El verdadero olvido es olvido del olvido, es decir, cuando lo oculto se oculta a sí mismo. Esta potencia del olvido "no consiste en una forma más alta de olvido que sucede a otra exponencialmente, pues el olvido que no se olvida constituye, al contrario, una primera memoria,

\footnotetext{
${ }^{1}$ Chrétien, Jean-Louis. Lo inolvidable y lo inesperado. Salamanca: Ediciones Sígueme, 2002, pp. 13-14.
} 
una primera abertura para superar el olvido. Sucede igual que con la ignorancia socrática: la ignorancia que se ignora a sí misma no es una ignorancia excepcional, es la ignorancia misma, mientras que el saber de nuestra ignorancia es el primer saber y el acceso a todo saber"2.

\section{La reserva del olvido}

Según Chrétien, cada día vivimos la experiencia de un recuerdo que se nos sustrae y que estamos impedidos tanto de reencontrarlo como de disponer de él. A esta experiencia la llamamos olvido. Surge, entonces, una interrogación: ¿es esta sustracción una pérdida? El hecho de que un recuerdo no esté disponible, ¿̇manifiesta que éste puede haber sido destruido y perdido?, lo cual haría del olvido algo opuesto a la memoria, “ ¡o bien significa solamente que dicho recuerdo, en el presente fuera de nuestro alcance, resulta hurtado, reservado, en cuyo caso el olvido no sería más que otro nombre para la memoria, su tesoro latente, uno de sus modos esenciales?"3.

El olvido parece una de las más íntimas experiencias de la pérdida. "Eso que en mí mismo se pierde, se borra y desaparece, de haber tal cosa, se pierde mucho más profundamente que cualquier ser del mundo... Lo que pierde mi memoria no tiene ni puede tener presencia sino por mi rememoración” ${ }^{4}$. Sólo por el recuerdo el olvido deja de ser olvido, la pérdida debida a esta omisión deja atrás su extravío y recupera su presencia, aunque casi siempre expuesta a perderse nuevamente, a ser atrapada por este lazo y bajo el riesgo de que la cuerda de su desaparición nos aprisione otra vez.

Chrétien señala que si el olvido es equivalente a la pérdida, ésta nos arranca a nosotros mismos y nos mutila en nuestra intimidad, pues perder alguna cosa en sí misma es también perder algo de sí. "Esta pérdida de sí a pesar de sí se distingue de todo sacrificio y de toda renuncia, salvo que haya un sacrificio que se sacrifique a sí mismo, una renuncia que renuncie a sí misma. Pues la pérdida por el olvido de un aspecto de mi pasado se da en primer lugar como una impotencia, como pérdida del poder de recordarlo y de hacerlo presente" 5 . No se puede ignorar que el olvido de lo que hemos vivido acrecienta inevitablemente la sensación de una identidad frágil, una identidad que queda sometida al escarnio de su propio desvarío y que deambula en los territorios de esos secretos pasadizos no evocados.

El pensador francés se pregunta si ¿podrá ser destruido lo que entró en los amplios palacios de la memoria, o sólo desaparecer provisionalmente, devenir inaccesible de hecho mientras uno continúa buscándolo? ¿Puede quedar per-

\footnotetext{
${ }^{2}$ Ibídem, p. 14.

${ }^{3}$ Ibídem, p. 55.

${ }^{4}$ Ibídem, pp. 55-56.

${ }^{5}$ Ibídem, p. 56.
} 
dido para siempre aquello que se me sustrae? ¿O acaso sólo se ha retirado? Si es así, el olvido no es otra cosa que la reserva de la memoria, la bodega de la que ésta extrae sin cesar.

La mayor parte de nuestro pasado no se presenta inmediatamente a nuestra memoria, sino que para poder recordarlo se requiere de un esfuerzo. “¿Qué se puede decir sino que ese pasado ha de ser sacado del olvido? La misma experiencia del olvido es precisamente la prueba de que nada se pierde verdaderamente, a no ser como un objeto extraviado que se vuelve a encontrar, incluso en el instante en el que menos se esperaba"6.

Chrétien alude a Paul Valéry, quien distingue la pérdida de la sustracción: “ 'El olvido es la insensibilidad creciente del aparato de puesta en marcha de la memoria. Yo me inclino a creer que el recuerdo es indestructible en potencia. Pero el acto resulta raro. La Memoria no se pierde. El Recuerdo es indeleble. Lo que se pierde es el camino del recuerdo. ¿Podría alguna vez un recuerdo ser radicalmente abolido, es decir, podría alguna vez una circunstancia reanimarlo?'. Desde el momento en que se niega la pérdida, surge necesariamente la cuestión de si la sustracción puede ser definitiva, en cuyo caso valdría para nosotros como pérdida. Según estas concepciones, nada de lo que se me sustrae se pierde. La apariencia de la pérdida no equivale a la pérdida, puede valer incluso como lo contrario de la pérdida. Pues el recuerdo indeleble cuyo acceso no encontramos, el recuerdo olvidado mientras es recuerdo, ¿acaso no sería un recuerdo intacto, el más prometedor, el más rico en porvenir?"”.

En esta medida, sostiene Chrétien, es posible una poética del olvido, poética que se entiende percibiendo que el olvido, en vez de deshacer, hace; lejos de destruir y descomponer, produce y crea. Al negar un olvido radical, Valéry da lugar al elogio del olvido. Este elogio no ve en el olvido la negación o la privación de la memoria, sino su fundamento y su condición.

Nada se ha perdido puede significar que todo nuestro pasado está preservado y conservado en nosotros, no importa la manera en que se mantenga para nuestra presencia consciente. Podría ocurrir que los recuerdos tuviesen un porvenir que no sería sólo el de regresar. Una pequeña percepción podría enseguida, en cuanto preservada en nosotros, liberar y explicar su sentido y alcance, y la memoria podría ser a veces, como dijo Paul Valéry, un poder de la primera vez: "La memoria es utilizada con mucha frecuencia para percibir por primera vez ciertos acontecimientos tan breves que para ellos la percepción directa ha sido casi nula o inutilizable”. Podríamos volver a ver más de lo que hemos visto. Esta exaltación de la memoria sería el acto en el que recuperaríamos en un presente único la totalidad de nuestro ser pasado, sería el vistazo por el cual todo lo que nos ha acontecido quedaría expuesto a nuestro conocimiento.

\footnotetext{
${ }^{6}$ Ibídem, p. 58.

${ }^{7}$ Ibídem, pp. 59-60.
} 
La profundización de Chrétien en torno a esta idea es todavía mayor. "En una segunda acepción, nada se ha perdido puede querer decir también que de nuestro pasado todo se conserva en tanto que se salva para siempre lo que de dicho pasado es verdaderamente nuestro. En esta perspectiva, la memoria como poder de asimilación, integración, apropiación, es una con el olvido como poder de rechazo, desvanecimiento, expulsión. Si todo lo esencial se ha preservado, y si sólo se preserva lo esencial, ciertamente hay pérdida, a diferencia de la concepción precedente, pero esta pérdida no nos priva de nada. Perder lo que hay que perder es la condición esencial para guardar lo que hay que guardar, lo que, en consecuencia, equivale a no haber perdido nada verdaderamente, sino a haber ganado todo" ${ }^{\text {. }}$

Al darse una conservación total e íntegra de nuestro pasado (primera concepción), es preciso que éste sea en nosotros sin estarnos inmediatamente presente, o sea necesita retirarse y alejarse de nuestra conciencia actual. En condiciones habituales de conciencia no puedo acordarme en un mismo presente de todo lo que me ha sucedido. La presencia integral del pasado es idéntica a su latencia, está preservado al ser reservado, memoria y olvido coinciden, si entendemos por olvido la retirada fuera de la conciencia actual.

En la segunda concepción, que admite la necesidad de la pérdida, Chrétien piensa que la integridad del pasado está excluida de la memoria. Todo guardar equivaldría a no tener ni retener nada, y una memoria total, en lugar de garantizar la integridad del sentido de nuestra vida, desembocaría en el sinsentido y en el caos. La desaparición y el desvanecimiento de ciertos aspectos del pasado hacen que pueda aparecer el recuerdo como tal. Sin olvido no podría acordarme de nada. Y la imposibilidad de olvidar convertiría la vida en un verdadero infierno. Sin duda, si recordáramos absolutamente todo (como Funes, el prodigioso memorioso de Borges) viviríamos agobiados por una memoria incapaz de eliminar cualquier vivencia, diálogo, pena, o cualquier otra experiencia, por mínima y trivial que fuese. Seríamos un bastión de recuerdos sucesivos e imperdibles que posiblemente nos tendrían extenuados por no poder ser depositados en el imprescindible anaquel del olvido.

Chrétien dice que el olvido late como el corazón de la memoria: sea como latencia del recuerdo (toda nuestra vida se traza, se inscribe y no se borra nada que haya sido depositado en los archivos de la memoria, que son también los archivos del olvido); sea como reserva del pasado (escribir supone que se borra aquello que no se debe escribir, tachar lo que no merece ser recordado); sea como expulsión de un pasado inasimilable o insignificante. Si el olvido pertenece necesariamente a mi memoria, sea como la reserva de aquello que constituye su tesoro, sea como la eliminación de aquello que no tiene nada que retener, se trata de un acto cuyo origen soy yo. Pronunciar el nombre del olvido es tenerlo presente en la memoria. ¿Cómo se puede saber del olvido en

${ }^{8}$ Ibídem, pp. 61-62. 
sí mismo?, ¿cómo está presente en la memoria si estando presente no puedo recordarle?

Otro francés, Bergson, ha afirmado la imposibilidad de la pérdida. En las profundidades de la conciencia se encuentran los recuerdos en estado de "fantasmas invisibles", olvidados, pero latentes: "creo que nuestra vida pasada está ahí, conservada hasta en sus menores detalles, y que no olvidamos nada, y que todo lo que hemos percibido, pensado, querido desde el primer despertar de nuestra conciencia, persiste indefinidamente" .

Esta concepción, a juicio de Chrétien, plantea interrogantes. La inalterable memoria pura exige un añadido, carece del presente y de la presencia en ese pasado al que en su orden no le falta nada. La transformación de los recuerdos en sustancias autónomas es una construcción sin fundamento fenomenológico. Sólo hay memoria pura independientemente del cuerpo, sólo en lo incorporal puede haber conservación integral, y, sin embargo, lo incorporal exige encarnarse. ¿Cómo los recuerdos pueden ser el pasado en su inalterable plenitud? Esta es la primera aporía: cuando todo se ha conservado, sin defecto, a pesar de ello algo falta.

De la fundación de lo inolvidable en el olvido surge una segunda aporía. El "primer despertar de nuestra conciencia" es para Bergson el comienzo de lo inolvidable, puesto que a partir de él todo aquello que vivimos se conserva indefinidamente y sin pérdida alguna. Lo inolvidable pertenece a la esencia de todo recuerdo. ¿Pero qué sucede con ese primer despertar? ¿Es que hay un primer presente sin pasado, y un primer recuerdo como conservación de una primera percepción? Cualquiera de nosotros fue antes de poder decir yo, y todos vivimos bastantes meses antes de nacer. Venimos a la conciencia y al mundo cargados con un pasado que está radicalmente olvidado, poblados de acontecimientos de los que no tenemos la menor noción a pesar de haber sido parte en ellos.

La tercera aporía alude a la posibilidad de la presencia total de nuestro pasado. Bergson compara toda "nuestra vida interior" con "una frase única comenzada desde el primer despertar de la conciencia, frase sembrada de comas, pero en ninguna parte cortada por puntos". La pregunta que surge es si resulta posible "abrazar el sentido de la frase". Todo tiende hacia una rememoración total que sería acto de presencia total de mí a mí mismo, en la unidad de un sentido abrazado de una vez. "Esta rememoración total que me daría a mí mismo por entero y me permitiría captarme plenamente a mí mismo, memoria de sentido absolutamente hecho presente y presencia perfectamente actualizada de la memoria, sería en verdad el olvido perfecto. Olvido perfecto en cuanto aboliría totalmente el pasado como tal y la relación con él”"10.

\footnotetext{
${ }^{9}$ Ibídem, p. 64.

${ }^{10}$ Ibídem, p. 67.
} 
¿Acaso puede no ser alterada la percepción de sí por sí mismo? ¿Me acordaría yo de mí sin el otro?" Cuando San Agustín medita sobre el juicio final, lo hace evocando una rememoración total que tiende a la instantaneidad de una intuición. Ese pasado totalmente reunido soy yo mismo, ya no es pasado, ni mi pasado como algo distinto de mí. San Agustín lo señala de esta forma: "Es preciso entender aquí la virtud divina, que traerá a la recordación de cada cual todas sus obras, buenas o malas, y las hará ver rapidísimamente de un vistazo mental. Dios es el único que puede permitirnos leer el libro de la intimidad de nuestra vida ${ }^{11}$.

Esta intimidad, si bien es de uno, no es exclusivamente de uno. Pertenece también a quienes conocen nuestra historia y son parte de ella. Nuestra biografía ha sido hecha por otros, necesariamente, pues hasta la soledad es en relación con un alguien, en este caso ausente. No somos sin esos otros que nos puedan decir algo de nosotros mismos, sobre todo en relación con ese pasado que cuando ocurrió no aconteció como un hecho consciente o no quedó suficientemente instalado en el grueso libro de la memoria. Aquellos cuya vida se topa con la nuestra, necesariamente aluden al recorrido hecho por el yo y ayudan a definirlo, a dibujarle una identidad. "Mi pasado no es nunca sólo mío, ya que me lo pueden recordar los otros. Aceptar el olvido es también aceptar que yo no soy el único que se acuerda de mí, ni sólo yo el lugar en el que puedo captarme a mí mismo. Aceptar el olvido es también remitirme al prójimo a causa de mi memoria olvidadiza, creer su palabra acerca de lo que yo no puedo ver ni volver a ver. Sólo por la palabra de los otros puedo saber el lugar y la fecha de mi nacimiento. El olvido como pérdida, ¿acaso no hace surgir una relación con la palabra del otro? La rememoración total se hace olvido perfecto, la exaltación de la memoria la hace desaparecer como relación con el pasado, pero, inversamente, el olvido mismo es por excelencia la reserva de la memoria"12.

¿Qué sería de nosotros si no pudiésemos olvidar? Chrétien señala que "la imposibilidad de olvidar es la imposibilidad de adquirir: no una ganancia, sino una pérdida, la pérdida de la novedad y del presente. Para aprender, lo inmemorial tendría que sustituir a lo inolvidable, convertir lo inmemorial en aquello que aprendemos. Son muchos los pensamientos que constituyen la esencia de la memoria: la verdadera memoria consistiría en haber establecido de tal modo en sí, en haber hecho suyo un poder que se comportaría como si no hubiera tenido comienzo y se hubiera poseído siempre. Cuando Valéry dice "caminar es acordarse" está seńalando que "el que camina se acuerda de que sabe caminar - pero este recuerdo no es consciente-; no se regresa a la época en que se aprendió a caminar, sino que se camina como si siempre se hubiera sabido". Aquí acordarse es saber como si se hubiera sabido siempre, el recuerdo es perfecto. La posesión borra la adquisición, el saber olvida el aprendizaje. El

\footnotetext{
${ }^{11}$ Ibídem, pp. 68-69.

${ }^{12}$ Ibídem, pp. 69-70.
} 
hábito crea un saber que nos parece infuso. Esta identificación de la memoria y de lo inmemorial, en consecuencia, la hace reposar sobre el olvido"13.

Tras lo anterior, Chrétien añade lo siguiente. "Qué importa que se haya olvidado verdadera y totalmente aquello en virtud de lo cual no se sabía hablar, nadar y caminar, si ésta es la condición para saber siempre hablar, nadar y caminar. El para siempre de la memoria no tiene lugar sin la pérdida de su prehistoria. Como dice Stefan Zweig: “Todo lo que uno olvida de su propia vida, había sido condenado al olvido desde hace mucho tiempo por un secreto instinto. Sólo lo que se quiere conservar para nosotros mismos tiene algún derecho de ser conservado para el prójimo”. Lo que el olvido pierde, por tanto, purifica y eleva la memoria. La memoria inalterable, una con nuestro ser, tiene el poder de ejercer el arte de olvidar. Es como la "fuerza plástica" que, para modelar y dar forma, elimina.

Urge, entonces, dejar que haya olvido. "Olvidar es dejar que lo que se pierde y debe perderse se encamine hacia su pérdida para conquistar la indestructible plenitud de nuestra propia presencia. Para Louis Lavalle, por ejemplo, el pasado 'no es en absoluto un presente perdido. El pasado es un presente adquirido y que no nos abandonará jamás. Así, frente a lo dado, la memoria desempeña una triple función: interiorizarlo, por cuanto se nos presenta en primer lugar como viniendo de fuera; espiritualizarlo, por cuanto afecta siempre a una forma material; inmortalizarlo, por cuanto pertenece al devenir y no deja de perecer. La memoria es el lugar en que nos liberamos del tiempo, y luego lo reabsorbe en la eternidad"'14.

Si la memoria tiende hacia una resurrección o hacia una parusía ¿qué significa el olvido del olvido?, ¿de qué es olvido? La apuesta de este olvido del olvido, de esta negación de la pérdida en su posibilidad misma es la negación de la muerte. Al recoger lo que sucede en lo inalterable, el menor recuerdo en esos pensamientos es prueba de inmortalidad. Este horizonte indefinido de pasado que la memoria nunca puede recuperar y hacer presente por completo, conduce a fin de cuentas a la captación de su propia eternidad. "Yo soy ahora, y a este ahora pertenece un horizonte de pasado que puede ser desplegado hasta el infinito. Y esto mismo significa: yo fui eternamente'. A este pasado sin fin, le corresponde un porvenir sin fin" ${ }^{15}$.

Volverse mediante el recuerdo hacia el pasado como tal no es repetirlo ni hacerlo regresar, sino alcanzarlo incluso en su lejanía. El miedo a olvidar no es el miedo a perder lo que poseemos y guardamos, sino el miedo a perder lo que ya se ha perdido. Para sufrir la pérdida es menester estar en lo que se ha perdido, tender hacia su desaparición y alejamiento, donde se manifiesta en lo que tiene de único e insustituible.

\footnotetext{
${ }^{13}$ Ibídem, pp. 72-73.

${ }^{14}$ Ibídem, p. 79.

${ }^{15}$ Ibídem, p. 82.
} 
Para Kierkegaard es la existencia ética la que se acuerda de sí. Esto es así porque vive según la decisión, o sea, según la promesa. Sólo una promesa puede enlazar el haz de los recuerdos y aceptar de este modo que muchos de ellos se hayan perdidos. Y reúne los recuerdos en la medida en que guarda la memoria de su futuro, en la medida en que recuerda lo que ha prometido y el poder al que lo ha prometido. El acceso a lo inolvidable pasa por la pérdida y por el olvido. El instante en el que uno decide por sí mismo, en el que uno se une para siempre no es un nacimiento sino en la medida en que es también una muerte. Casi cualquier comienzo involucra el término de lo anterior.

A nuestros recuerdos el olvido los atraviesa y los habita como la marca en ellos de aquello que se hurta, de aquello por lo que entregan y dan su aliento. Responder de sí es responder en relación con lo que yo pueda ver y saber, y el lugar en el que yo puedo responder de ello es aquel en el que mi promesa se confía y se da, en otra parte, en lo otro. Kierkegaard escribe a propósito del perdón que hace surgir una vida nueva: "El pasado no es olvidado pura y simplemente, es olvidado en el perdón. Cada vez que te acuerdas del perdón el pasado se olvida, pero cuando te olvidas del perdón, entonces el pasado ya no se olvida, y el perdón se pierde". Kierkegaard mostrará "la oposición entre el "espíritu melancólico", que no quiere que se olvide nada y al hacerlo olvida el perdón, y el "espíritu ligero", que quiere que se olvide todo, incluido el perdón" ${ }^{16}$. El otro olvido del que habla Kierkegaard es la luz alcanzada por el perdón cuando lo hacemos nuestro, es decir, cuando lo recibimos. Él es el sí a este don recibido. Acordarse del perdón es acordarse, en el momento presente, de aquel que lo da. La memoria de Dios es la fuente de toda promesa que nosotros podemos hacer.

\section{Lo inolvidable}

¿Qué es lo que no puede ser olvidado? ¿Cómo pensar aquello que se sustraerá por siempre al olvido que sustrae? Lo inolvidable es lo propio de aquello que no se deja olvidar y que, de suyo, alumbra con una claridad que nada puede apagar o encubrir.

¿En qué sentido el pasado puede ser inolvidable? ¿Cómo algo pasado podría sustraerse por principio al olvido, sino en la medida en que jamás pudiese devenir sólo del pasado, en la medida en que no pasase y no estuviese superado? La palabra griega alastos, que significa inolvidable, se aplica de forma casi exclusiva al padecimiento, al duelo. "Inolvidable" es un sufrimiento a propósito del cual no tenemos poder alguno de rehuir, cuando nuestra capacidad de olvidar es impotente y no puede dejar de recordarlo. Lo inolvidable es presencia de la ausencia, permanencia punzante de lo insoportable. El sufrimiento

\footnotetext{
${ }^{16}$ Ibídem, p. 93.
} 
inolvidable acontece en el presente, no atañe de ningún modo a la memoria. Inolvidable es este cara a cara para el que no existe amparo alguno. Por lo mismo, el primer don de la memoria es el del olvido, el olvido de los males, el olvido de los padecimientos.

Lo inolvidable no es adecuado a nuestra memoria, sino que la excede, y al excederla, la destina. ¿Cómo pensar que lo inolvidable sea lo excesivo? Aquello que supera mis posibilidades de visión y de aprehensión, ¿̇no es por ello mismo lo que se me escapa, lo que olvido? La presencia inolvidable de Dios en la memoria puede ser pensada en su singularidad gracias a las palabras de San Agustín: "Porque tú estabas dentro de mí, más interior que lo más íntimo mío y más elevado que lo más sumo mío". Lejos de ser un objeto central para nuestra memoria, Dios sólo nos es presente al abarcarnos y excedernos por todas partes. Lo inolvidable no es aquello que aprehendemos a perpetuidad y que no puede hurtarse a la memoria, sino aquello que no cesa de aprehendernos y a lo que no podemos hurtarnos.

Si la memoria de Dios debe ser cristiana, no puede sustraerse a la muerte y resurrección. La existencia según la fe resulta indisociable de la memoria y el olvido, en cuanto que es esperanza. El olvido mismo es un don: pertenece a la fidelidad de la respuesta. El haber sido conquistado por Dios precede y desborda toda conquista: a esta anterioridad respondemos con el olvido. Este olvido no se reduce aquí al olvido del hombre viejo que fuimos; forma parte del movimiento hacia aquel que renueva todas las cosas y no cesa de hacerlas nuevas. Hasta lo nuevo que él ha hecho en mí debe ser olvidado, pues no soy yo el lugar donde debo contemplarlo. Con aquello que en mí se ha hecho nuevo, debo seguir corriendo ("revísteme del hombre nuevo" dice San Pablo) ${ }^{17}$.

Las palabras de Chrétien son imposibles de reemplazar. Su reflexión debe decirse tal cual él lo hace.

San Pablo renuncia a volver hacia sí y conquistarse a sí mismo: abraza por un olvido, por una pérdida, por un sacrificio, la fidelidad al haber sido conquistado por Dios. La fe es esencialmente rememoración de las promesas de Dios. Constituye, pues, el lugar donde la rememoración se transfigura en esperanza al pasar por el fuego del olvido, ese fuego que quema y consume en nosotros toda memoria propia. Esta última resultaría obstáculo para dicha transfiguración. Quien quiera salvar su vida la perderá, y la memoria forma parte de esta vida que queremos salvar a cualquier precio. Para esperar al rememorar y rememorar al esperar, cosa que hace la fe, es menester ofrecer y perder algo de la memoria propia. Cuando recordamos un

${ }^{17}$ Ibídem, pp. 110-111. 
acontecimiento de la historia santa, como la Navidad, esta memoria espera, pues llama y aguarda que Cristo nazca en nuestro corazón. Pero sólo él puede nacer en un corazón tan pobre y vacío como un pesebre; y por eso esta memoria también quiere el olvido, el olvido de sí como ofrenda ${ }^{18}$.

Hay una lucha entre dos memorias, la de Dios y la del hombre. La primera es siempre esperanzadora; la segunda, en cambio, está envuelta por un aire de tristeza, quizás debido a que el ser humano, cuando recuerda, nunca lo hace sin la sombra de sus culpas y de sus nostalgias. "A la memoria de Dios como lugar de esperanza se opone la memoria de nuestra vida como lugar de pesadumbre. Lo inolvidable está siempre por hacer y por guardar: no es la perennidad de un recuerdo grabado una vez para siempre en nuestra memoria. Sólo respira por su futuro siempre nuevo, y caracteriza una vida arrojada y proyectada, más allá de sus propias posibilidades, hacia lo que Dios le ha prometido. Sin embargo, olvidamos sin cesar aquello que habíamos dicho no poder olvidar jamás. En cambio, Dios no nos olvidará. Ahora bien, en un sentido eminente Dios olvida, pero olvida las ofensas del que se arrepiente. Si Dios no olvida al hombre es porque es el Dios fiel de la promesa. No somos inolvidables para y por nosotros mismos, mas somos inolvidables por Dios, pues su fidelidad es inquebrantable. La fidelidad humana por excelencia anuncia la fidelidad divina. Las manos de Dios portan eternamente lo inolvidable. Lo que por y para Dios resulta inolvidable tiene su origen en lo inesperado"19.

\section{Lo repentino y lo inesperado}

Los cálculos humanos son generalmente insuficientes y casi siempre se ven modificados: "La demasía del acontecimiento con relación a nuestras previsiones pone de manifiesto la finitud y falibilidad de la conciencia humana. Pero también puede ser comprendida positivamente como la marca de su origen más que humano. A menudo, el carácter radicalmente imprevisto de lo que ocurre aparece como la rúbrica misma del poder divino puesto por obra. Toda acción divina desconcierta: desbarata nuestras previsiones y cálculos. Lo imprevisto no tiene un sentido meramente negativo cuando se revelan en ello un poder y un designio diferentes de los nuestros. En el acontecimiento que nos coge desprevenidos y nos desengaña de toda ilusión de dominio, lo divino no es únicamente aquello que se sustrae a nuestra comprensión, sino aquello que se nos acerca, se apodera y obra sobre nosotros sustrayéndosenos. De este pensamiento de lo imprevisto procede el antiguo tema de la ambigüedad de los oráculos. Ni siquiera cuando los dioses proclaman lo que van a hacer aguardamos lo que se va a producir, pues interpretamos sus palabras en el horizonte de nuestras propias previsiones y deseos. Incluso cuando los dioses atienden

\footnotetext{
${ }^{18}$ Ibídem, pp. 112-113.

${ }^{19}$ Ibídem, pp. 116-118.
} 
nuestras plegarias y nos dan lo que pedimos, pueden hacerlo de tal suerte que aquello que obtengamos sea en realidad muy diferente y produzca consecuencias muy distintas de las que habíamos imaginado. Ver un deseo cumplido puede ser tan terrible como verlo frustrado" ${ }^{20}$. Lo tantas veces anhelado, si se alcanza, puede volverse una carga muy pesada e, incluso, podría el sujeto arrepentirse de haberla deseado.

Chrétien afirma que "el hecho de que lo aparentemente imposible a juicio del hombre tenga lugar por iniciativa de los dioses, manifiesta que toda situación, incluso la mejor calculada, puede invertirse, pero ello no significa que podamos o debamos esperar lo imposible, pues tanto nuestra guarda como nuestra espera están siempre determinadas por nuestros pensamientos tan humanos. Lo inesperado no es sólo aquello que no se puede, sino también aquello que no se debe esperar, so pena de caer en el extravío y la puerilidad" 21 .

Sin embargo, se puede ser contrario a esta opinión común. Heráclito dice: "si no esperas lo inesperado, no lo encontrarás". Desde el momento en que cobra sentido la posibilidad de esperar lo inesperado, se convierte en aquello que define la más alta espera. La espera se disocia de todo cálculo. Es el acceso de lo sin acceso. Por esto mismo, nos desvía de otras vías ya abiertas y de aquello a lo que pueden conducir.

Lo inesperado quiere que dejemos de disiparnos en mil esperas de toda clase. Esperar lo inesperado es casi un acto desesperado o que participa de una situación desesperada, que es la actitud ordinaria, en la que sólo se espera lo posible y en la que se espera mucho de ello, situación que se revela aciaga y funesta. Sigue muchas vías, pero que no conducen allí donde se cree. Nada como las falsas esperanzas para arraigar con más fuerza la desesperanza, pues lleva ya consigo el duelo por la esperanza de la que se carece.

¿Cómo entender esta espera de lo inesperado y este acceso a lo inaccesible? Es posible ver en lo inesperado la verdad y la sabiduría (consideradas en principio como algo oculto para nosotros). No es que lo inesperado parezca sin acceso, sino que lo es. Y esta es la razón por la que no encontramos lo inesperado más que al esperar y al esperarlo. La esperanza va al encuentro de lo que la excede por naturaleza. Lo inesperado es aquello que sobrepasa todas nuestras anticipaciones. Cuando surge, tiene necesariamente el carácter de lo repentino y discontinuo. Sorprende por el hecho de no haber sido previsto, prevenido, contenido por anticipado en nuestro pensamiento. Golpea como un rayo, de repente. Hay como un hallazgo, porque la anticipación de lo inanticipable es la del encuentro, que nos expone a la alteridad. El obstáculo principal para encontrar lo inesperado está en nuestra ausencia de espera, en nuestro recogernos ansiosos a las preocupaciones habituales, donde sólo buscamos lo que por anticipado sabemos que podemos encontrar sin cambio alguno de nuestra parte.

\footnotetext{
${ }^{20}$ Ibídem, pp. 119-120.

${ }^{21}$ Ibídem, pp. 123-124.
} 
La espera de lo inesperado es la espera de Abraham, pues "creyó contra toda esperanza". La esperanza bíblica tiene por objeto aquello que no puede esperarse más que de Dios, aquello que resulta imposible para toda fuerza humana, aquello que de y por nosotros mismos no podríamos ni deberíamos esperar. Esta espera, que es la de la fe, produce en quien espera un doble movimiento, aparentemente opuestos entre sí. Son los movimientos de la postración y de la exaltación. Ambos constituyen el espacio en el que se recibe lo inesperado: uno y otro revelan que esto no es ni puede ser obra nuestra, reconocen y confiesan su carácter excesivo. Por lo mismo, la verdadera esperanza siempre exige humildad. Abraham, el padre en la fe, es también el padre en la esperanza. Él se acuerda de la promesa y permanece fiel a lo inolvidable yendo al encuentro de lo inesperado. En su caso, el nacimiento de su hijo Isaac es una manifestación patente de lo inesperado. Isaac es el hijo de la promesa, la indiscutible presencia de la sorpresa divina.

La palabra divina, que aparece de improviso, aporta una alegría imprevista y que supera toda esperanza. Ella, que es también la acción de Dios, se da en el instante, sin preparativos ni prehistoria; irrumpe abriendo una novedad que no pasa y que no cesa de renovarnos. "Encontrar sin buscar es dejarse a sí mismo encontrar sin haber tenido la iniciativa. Y dejarse encontrar no tiene tregua cuando es Dios quien nos encuentra"22.

Saber esperar consiste en saber que no se puede alcanzar por sí mismo lo que se espera y, por ende, implica aprender a recibir. La correlación entre lo repentino, lo inolvidable y lo inesperado caracteriza a todo pensamiento de la promesa. Está en el corazón de toda teología bíblica. Chrétien sostiene que lo único que nos podemos dar es una promesa, es decir, un futuro. Con la promesa la persona se hace a sí misma, se otorga la transformación. La promesa es la única forma de recibir más de lo que podemos recibir, al abrir todo el futuro para el recibir. Es un dejar la puerta sin cerrar a que lo inesperado la golpee, la empuje y la abra. La revelación de Dios, Cristo el verbo encarnado, es la visita de lo inesperado. La revelación no suprime el misterio, sino que lo revela como tal. Se vuelve hacia nosotros sin dejar de ser el misterio de Dios. Cristo manifiesta la intimidad de la vida divina, lo que no obsta para que esta vida siga siendo un misterio que nos sobrecoge y nos sobrepasa. El inesperado relampagueo de la encarnación de Cristo lleva consigo todo el espesor del tiempo. Lo inesperado que se ha cumplido, Cristo como promesa de Dios, funda absolutamente el futuro. El fiel existe a partir de lo inesperado, y sólo lo inesperado da la esperanza y la funda.

Nuestra esperanza no podría ser tan segura, hasta el punto de que el don por ella esperado excediese toda esperanza humana, si ese don no se le hubiese hecho ya y si la promesa que recibimos no se hubiese mantenido ya. "La ocasión en la que Dios da su promesa es ya la ocasión en la que la cumple; la

\footnotetext{
${ }^{22}$ Ibídem, p. 134.
} 
ocasión en la que la cumple es todavía la ocasión en la que la da...En la medida en que espera, la fe es arrojada y lanzada a los extremos del tiempo por las promesas de Dios que ella se encarga de no olvidar. La promesa de Dios reúne lo inmemorial, lo inolvidable y lo inesperado. Inmemorial es la génesis, pues no éramos cuando Dios fundó la tierra, y el origen es siempre ya para nosotros un pasado, olvidado sin retorno. Lo inmemorial se convierte en inolvidable por la palabra de Dios, pues la historia sagrada, de la que siempre debemos hacer memoria, comienza por la creación misma. Esta rememoración de lo imposible es anticipación, esta memoria es esperanza. Recordar el origen pertenece a la esperanza tensionada hacia el fin. Pero esta esperanza en Dios no anticipa en el vacío, pues es al acordarse de lo inesperado dado en la gracia a nuestros padres y a nosotros mismos, al acordarse de lo que excede el corazón y la visión del hombre, como ella espera todavía y siempre. Reuniendo recuerdo y esperanza, el Deuteronomio relata la tierra prometida" 23 .

${ }^{23}$ Ibídem, pp. 124-125. 
V. EL PROBLEMA DEL MÉTODO 


\title{
Atisbos en Torno a un Problema Fundamental de la Fenomenología: El Concepto de Intencionalidad en Husserl y Heidegger con Respecto a los Presupuestos del Idealismo Cartesiano
}

\author{
Sandra Baquedano \\ Universidad de Chile
}

\begin{abstract}
Resumen
El siguiente trabajo tematiza un problema fundamental de la fenomenología: El concepto de intencionalidad en Husserl y Heidegger con respecto a los presupuestos del idealismo cartesiano. Ambos filósofos coinciden en que las implicancias del dualismo cartesiano resultan ser deshumanizantes. Lo que propone en una primera instancia Heidegger es dejar de lado dicho dualismo y mirar a nuestro mundo y a nosotros mismos directamente, frescamente, es decir, sin los presupuestos metafísicos tal como lo proponía la fenomenología. Mediante el concepto de intencionalidad con respecto a los presupuestos del idealismo cartesiano, sondearemos las diferencias y similitudes presentes en las filosofías de Heidegger y Husserl para superar la problemática de la intencionalidad generada a partir del enfoque cartesiano que la sustenta.
\end{abstract}

El curso que toma la filosofía occidental a partir de Descartes conduce al pensar reflexivo a convertirse en una filosofía de la conciencia. El cogito -el "yo pienso"se convierte en inicio fundamental tanto del mundo como del filosofar. Precisamente desde él surge el intento de aprehender el mundo real. La fenomenología de Husserl puede ser considerada también como una filosofía de la conciencia. Sin embargo, este concepto ha tenido una modificación profunda en la medida que la conciencia para Husserl es siempre conciencia intencional. La intencionalidad es la estructura misma de la conciencia. Se presenta como algo esencial a ella en la medida que es fundamental que la conciencia se dirija a un contenido que le es ajeno. La vida de la conciencia es precisamente aquel dirigirse hacia el mundo o simplemente constituirlo. "La palabra 'intencionalidad' significa la particularidad fundamental y general de la conciencia de ser conciencia de alguna cosa, de llevar, en sí misma, en su calidad de cogito, su propio cogitatum"1. Con esto queda en evidencia que la conciencia no es un vacuum, sino una relación a un objeto. De ahí su estructura bipolar consistente en ser la correlación entre una cogitatio y un cogitatum. Este hecho explica que Husserl transforme el cogito cartesiano en ego cogito cogitatum.

${ }^{1}$ Husserl, Edmund. Meditaciones Cartesianas. Ciudad de México: Fondo de Cultura Económica, 1986, II §14. 
Husserl comparte con Descartes la idea de encontrar una unidad y fundamento que posibilite superar la dispersión del conocimiento para de este modo encontrar la estabilidad propia de la verdad. Sin embargo, mientras que para Husserl en la duda metódica se trata de suspender el juicio, y las cosas se tornan fenómenos que simplemente aparecen, para Descartes, en cambio, la posibilidad de negar la existencia de las cosas lo lleva a anular el mundo exterior o lo que se da a la conciencia. Es por eso que la duda husserliana no considera el mundo como algo inexistente, sino que sigue dándose pero de manera distinta que en la existencia, en cuanto éste se transforma o pasa a ser considerado como fenómeno.

Por lo tanto, el pensar, incluso cuando es duda, está referido a un mundo. La conciencia es siempre conciencia de algo, de ahí la intencionalidad de la conciencia. Es decir, al acto de conciencia intencional le corresponde siempre un objeto intencional, así a un acto intencional de percepción le corresponde un objeto percibido o a uno de imaginación le corresponde un objeto imaginado, etc. Por eso debe entenderse por objeto intencional, todo aquello que puede ser correlato de un acto intencional de la conciencia o todo aquello que puede llegar a ser sujeto de un juicio lógico, como puede ser, por ejemplo, lo que veo, lo que imagino, etc. De esta manera el objeto no es necesariamente una cosa, una realidad espacio temporal existente. Las cosas son sólo un tipo de objetos entre otros. Ahora bien, la conciencia se manifiesta mediante la síntesis que une estos distintos modos de aparición del objeto y también los distintos modos de conciencia del objeto.

Es verdad que las ciencias se ocupan de los más variados fenómenos de estudios, pero lo cierto es que lo propio de la fenomenología es ocuparse de todo tipo de fenómenos. Sin embargo, debe modificar o reducir éstos, de tal manera que sólo como fenómenos reducidos entren a formar parte de la esfera fenomenológica. Cabe señalar que para Husserl, fenómeno quiere decir lo que aparece o se manifiesta en sí mismo a la conciencia. El fenómeno es manifestación, es decir, contiene su esencia, pero necesita ser purificado mediante la epoché para acceder a dichas esencias y situarlas en el ámbito de la conciencia pura o trascendental.

Es así como Husserl introduce en la formación del método la epoché, para conseguir la llamada reducción fenomenológica. Una de las características más esclarecedoras es la limitación de la universalidad de esta epoché, debido a que se podría entender que por el hecho de ser tan amplia puede modificar todo juicio o poner entre paréntesis toda objetividad que puede ser sujeto de juicios. Si esto ocurriera no quedarían juicios no modificados, no habría entonces manejo de ciencia alguna y, en cambio, lo que a Husserl precisamente le interesa, es descubrir un nuevo dominio científico mediante este método. Con 
sus palabras, esta limitación de la cual nos habla es un simple "poner entre paréntesis la tesis general inherente a la esencia de la actitud natural”.

La epoché implicaría entonces un cambio radical de la tesis natural. Consideremos que en la tesis natural la conciencia está situada frente al mundo, en tanto realidad que existe siempre o que se encuentra siempre ahí. Al cambiarse esta tesis se produce la suspensión, poner fuera de juego, desconectar ciertos conocimientos, ciertos aspectos del fenómeno para definir así una determinada perspectiva y un determinado objeto, es colocación entre paréntesis no sólo acerca de la doctrina acerca de la realidad y de la acción sobre la realidad, sino ante todo de la propia realidad. Enfatizamos el hecho de que éstas no quedan eliminadas, sino alteradas por la suspensión. La epoché respecto del mundo que llega a ser consciente, desconecta del campo fenomenológico el mundo que para el sujeto en cuestión pura y simplemente existe, pero en su lugar se manifiesta el mundo consciente, ya sea valorado, pensado, recordado, etc. Como tal, el mundo entre paréntesis, o lo que es lo mismo, en un lugar del mundo, en un lugar de algo mundano, singular, puro y simple, se presenta el respectivo sentido de conciencia en sus diferentes modos ya sea mediante los sentidos de la percepción, el sentido del recuerdo, etc.

A diferencia de Descartes, el mundo natural no queda negado ni se duda de su existencia. Así nos damos cuenta, que la epoché no es comparable ni a la duda cartesiana ni a la suspensión escéptica del juicio, ni a la negación de la realidad, ni a la sujeción del sujeto volente bajo los dominios del noumeno volente, ni a la abstención de explicaciones propugnadas en nombre de una actitud libre de teorías y supuestos metafísicos hechas por el positivismo, etc.

Al practicar la epoché fenomenológica, "se cierra completamente todo juicio sobre existencias en el espacio y el tiempo". Así se desconectan todas las ciencias referidas a este mundo natural (sin tomar en cuenta el valor que yo tengo de ellas) no haciendo uso de sus afirmaciones válidas. Sólo así es posible, según Husserl, constituir la conciencia pura o trascendental como residuo fenomenológico. De esta manera, tras haberse efectuado la reducción fenomenológica, permanece únicamente la conciencia pura con sus vivencias y contenidos respectivos.

El ego cogito ya no es este yo existente que yo soy, en su materialidad, en su mundo, en sus circunstancias e inmerso en su vida cotidiana. Es sólo una pura conciencia ante la que se presentan puros fenómenos. Todo aquello que resta del mundo real pasa a ser considerado un puro fenómeno, en el sentido de un puro aparecer ante la conciencia.

Con este hecho queda en evidencia ante todo no sólo su distanciamiento con respecto a Descartes, sino que se patentiza la naturaleza de su crítica contra 
los presupuestos del idealismo cartesiano. Para Descartes, la conciencia identificada con el alma sigue siendo una res cogitans, situada entre las cosas del mundo: Cogito, ergo sum; mientras que para Husserl, en cambio, pasa a ser cogito cogitatum. Bajo la lectura husserliana, filosofar exige abandonar el ámbito donde se sitúa la "actitud natural" para situar al pensador en otro ámbito, el de la conciencia pura. Si bien no es propósito de este trabajo hacer un estudio diferenciado entre la reducción filosófica, la eidética y la transcendental, no debemos olvidar que en esta última no se desecha lo conseguido mediante la reducción eidética, es decir, las esencias; simplemente las sitúa en el ámbito de la conciencia pura.

El dualismo cartesiano entre el mundo físico y el espiritual genera en la historia de la filosofía moderna una tensión entre objetivismo y subjetivismo. Husserl intenta superar dicha tensión haciendo ceder al objetivismo a favor del subjetivismo transcendental. Esto le devolvería, según Husserl, a la humanidad la autenticidad de su propia existencia. Sin embargo, debemos tener presente que en el ámbito trascendental se ha puesto entre paréntesis la existencia del mundo y del sujeto, no quedando otra cosa más que la conciencia pura y su estructura intencional, es decir, restando únicamente el flujo de las vivencias con su doble polo cogitatio cogitatum. Mediante estas distinciones vemos cómo se intenta superar el abismo existente entre sujeto y objeto presente en las teorías clásicas del conocimiento que datan no sólo desde Descartes, aunque nos valgamos de él como referente para entender cómo la intencionalidad de la conciencia en Husserl termina siendo el punto de fusión entre lo uno y lo otro. El mundo es el mundo pensado y éste pasa a ser el único que tiene sentido. Es decir, el objeto existe en función de la conciencia, y es ella a su vez quien realiza la constitución del sentido de los fenómenos y del mundo fenoménico.

Husserl y Heidegger coinciden en que los presupuestos del dualismo cartesiano resultan ser deshumanizantes. Lo que propone Heidegger es dejar de lado el dualismo cartesiano y mirar a nuestro mundo y a nosotros mismos directamente, frescamente, es decir, sin presupuestos metafísicos tal como lo proponía la fenomenología.

Heidegger cuestiona el enfoque cognitivista propuesto por Descartes que origina la bifurcación propia de senderos filosóficos cuyos dualismos impiden luego encontrar una convergencia existencial. Descartes formulaba su postulado con la distinción de sujetos pensantes (res cogitans) que contempla objetos (res extensas), los cuales se definían como sustancias que estaban presentes frente al sujeto y que eran consideradas directamente inteligibles por él. La relación fundamental entre sujeto y objeto es la de conocimiento de elementos presentes. Ahora bien, Heidegger objeta radicalmente este enfoque, para él lo primario no son ni sujetos, ni objetos; ni presencia, ni conocimiento. 
A través de la estructura ser-en-el-mundo, Heidegger intenta destacar los distintos elementos constitutivos que conciernen al existente de un modo esencial. Ser-en, no expresa algo meramente espacial, ya que es un existencial y como tal exclusivo del ser humano. Y nuestro conocimiento entendido en relación sujeto objeto implica ya el ser-en el-mundo del que es una forma derivada.

Heidegger distingue dos reinos del ser: ser-a-la-mano (el mundo circundante de las cosas materiales) y ser-ahí (el mundo del ser-con, el mundo de los otros existentes).

Ahora bien, de la inmanencia o trascendencia respectivas del ente cognoscente o conocido, pareciera que el conocimiento se fundamentara partiendo del sujeto. Los entes que no tienen la forma del ser-ahí, se caracterizan sólo por su relación al sujeto, por su condición de seres-a-la-mano y seres-ante-los-ojos; los demás existentes están determinados sólo por su ser-con.

Heidegger alude a esa relación que no es en lo esencial de índole cognitiva entre sujetos y objetos presentes, sino una relación de disponibilidad, de encontrarse con los objetos a-la-mano. Una relación con el mundo que no es de conocimiento sino de uso. La disponibilidad implica que nos relacionemos con las cosas en cuanto las usamos o tenemos disponibilidad de hacer uso de ellas. Este tipo de relación, de trato, nos remite a un tipo de preocupación que manipula las cosas y las utiliza. Estas cosas en su calidad de instrumentos o utensilios las reconocemos como potencialidades, en la medida que nos remiten a un determinado trabajo que debemos emprender. De esta manera, ellas son vistas como metas del obrar, como fines del curarse-de y del procurar-por. En cuanto útiles, las cosas del mundo externo no tienen ser para sí, sino que son solamente "algo para"; son sólo reales en cuanto están referidas al ser-ahí.

Nos encontramos con las cosas como cosas dotadas de valor. De ahí su reflexión sobre el problema de la técnica y la tecnología. Mientras ellas estén a-la-mano, no nos percatamos necesariamente de su presencia y nos concentramos en aquello que estamos resolviendo a través de su uso. El significado le está conferido por la inserción en el tipo de actividad en la que hacemos uso de ellas. Teniendo en cuenta que todas estas cosas emergen en nuestra conciencia al producirse un quiebre.

La relación sujeto objeto es derivativa, representa una alternativa particular dentro del conjunto de las formas posibles de ser-en-el-mundo. La relación primaria de ser-en-el-mundo no es la matriz ontológica sujeto-objeto.

Sin embargo, nuestro diario ser en el mundo no consiste propiamente en un conocer sino en un "andar por" el mundo en las múltiples formas de la ocupación. Esta forma de ser del útil es, como ya expuse, un "ser para" que 
implica una referencia de algo a algo, que Heidegger llama manejabilidad. El ser utilitario de las cosas tiene un carácter de referencia. Heidegger define esa estructura ontológica de lo manejable (referencia, ser para) como un conformarse con algo en algo. Aquello que implica un conjunto de relaciones con su respectiva estructura es lo que Heidegger denomina significatividad.

Ahora bien, esto no nos debe llevar al equívoco de pensar en un reduccionismo del mundo con sus cosas y entes intramundanos a puras relaciones abstractas, es decir, a puro pensar. Este sistema de relaciones es lo que posibilita posteriormente el conocimiento pragmático, en que los entes aparecen como manejables, y el conocimiento teorético, que los presenta como sustancias; ambos planos de interpretación son posibles sólo sobre el fondo de esta mundaneidad del mundo fundada a su vez en el Dasein.

Hemos dejado de manifiesto, que aquello que Heidegger contrasta con esta noción del mundo es precisamente la visión cartesiana del mundo que prevalece hasta hoy, a saber: el mundo como res extensa. Heidegger distingue la espacialidad del instrumento, de lo meramente presente, del ser-en-el-mundo y del ser humano Dasein. Las cosas manejables están siempre en una determinada cercanía impuesta por el conocimiento pragmático. El útil no tiene un lugar cualquiera en el espacio geométrico, sino un sitio determinado por la dirección a que apunta el "para" a que pertenece. La espacialidad del ser humano es distinta; no es ni un estar en el espacio cósmico, como el ser simplemente presente, ni un estar en un sitio, como el ser a mano; su espacialidad le proviene de su ser-en-el-mundo.

A raíz de ello Heidegger detecta el equívoco en la manera de comprender la intencionalidad. Dicha falencia estaría mucho más arraigada en los prejuicios implícitos que en los explícitos. Precisamente aquellos prejuicios que se presentan en forma de teorías filosóficas profundas, serían superficiales ante aquellos que surgen de la aprehensión e interpretación natural y sin cuestionamiento alguno de las cosas. Estos últimos son precisamente aquellos que proceden de la comprensión cotidiana del Dasein, la cual se sostendría en los supuestos no cuestionados del idealismo cartesiano. ${ }^{2}$

$\mathrm{Al}$ respecto nos dice: "En sentido estricto, designamos este comportamiento respecto-de como el intendere o la intentio. Todo comportamiento respectode y todo estar dirigido-a tiene su específico qué respecto del que se comporta y su qué hacia el que está dirigido. Designamos como intentum este qué hacia el que está dirigido. Designamos como intentum este qué, que pertenece a la intentio, respecto del cual es el comportamiento, el qué al que está dirigido. La intencionalidad abarca ambos momentos, la intentio y el intentum, en su hasta ahora oscura unidad. Ambos momentos son diferentes en cada comportamiento" 3 .

\footnotetext{
${ }^{2}$ Heidegger, Martin. Los problemas fundamentales de la fenomenología. Madrid: Editorial Trotta, 2000, p. 88.

${ }^{3}$ Op. cit., p. 87.
} 
Para Heidegger la diferencia de la intentio o del intentum constituye la diferencia de los modos de comportarse, los que difieren en referencia a su intencionalidad propia de cada caso.

Según mi opinión, la tergiversación fundamental que atisba Heidegger consiste en que esta relación subsiste en tanto que relación, sólo cuando ambos miembros de la relación subsisten y la relación se da únicamente mientras los propios miembros de la relación subsistan. Razón por la cual Heidegger afirma: "esta caracterización de la intencionalidad como una relación subsistente entre dos entes subsistentes, un sujeto psíquico y un objeto físico, deja escapar, desde el principio, tanto la esencia como el modo de ser de la intencionalidad" 4 .

En relación a ello, Heidegger sin embargo repara contra esta tergiversación que ésta se caracteriza por la errónea objetivación de la intencionalidad. En otras palabras: que dicha intencionalidad no es una relación subsistente entre dos entes subsistentes, sujeto y objeto, sino una estructura, que constituye el carácter de relación del comportarse del Dasein como tal.

Para Heidegger la relación intencional con el objeto no implica el mero sostener el sujeto sólo con y mediante la subsistencia del objeto, sino que el sujeto en sí mismo, implica el ser o el estar estructurado intencionalmente 5 . Debido a ello es que pertenezca a la esencia de los comportamientos la intencionalidad, por lo que hablar en la filosofía heideggeriana de comportamiento intencional resultaría efectivamente ser un pleonasmo ${ }^{6}$.

Llegados hasta aquí, nos es posible comprender que en oposición a la errónea subjetivación de la intencionalidad, y diferenciándose de la terminología husserliana, la filosofía heideggeriana nos señala que la estructura intencional de los comportamientos no es algo que sea inmanente a lo que se llama sujeto, y esté necesitada ante todo de trascendencia, sino que la constitución ontológica de los comportamientos, que ahora son propios del Dasein, ponen a éste en la situación existencial donde se da ontológicamente la posibilidad de toda trascendencia.

\footnotetext{
${ }^{4}$ Op. cit., p. 89.

${ }^{5}$ Ibíd.

${ }^{6}$ Op. cit., p. 90.
} 


\title{
Fenomenología Negativa. El Sentido Metódico de la Negatividad en Heidegger
}

\author{
Francisco de Lara López \\ Universidad Industrial de Santander
}

\begin{abstract}
Resumen
El presente trabajo pretende evidenciar el carácter eminentemente negativo de la propuesta filosófica del joven Heidegger a partir de una interpretación de su concepto de Dasein como la pura y simple concreción fenoménica. Desde aquí se esclarecerá, entonces, la función metódica negativa de la destrucción y de los conceptos filosóficos entendidos como indicaciones formales.
\end{abstract}

\section{Introducción}

La crítica a la positividad -y, por ello, en última instancia, a la postura que hace de ésta la noción directriz a la hora de entender el ser: el positivismo- supone una constante en el pensamiento dialéctico de los últimos siglos. Desde la crítica del joven Hegel a la positividad del cristianismo hasta la de Horkheimer y

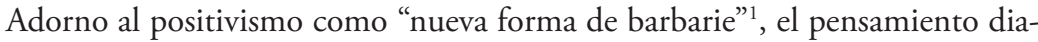
léctico ha desconfiado de lo que se presenta como dado sin más, considerando necesario introducir en ello una distancia o un extrańamiento y haciendo uso a tal efecto de la 'negación determinada'. No obstante, la negación y, en concreto, la negación determinada no es exclusiva del pensamiento dialéctico. Por el contrario, resulta a mi entender el elemento fundamental de una de las filosofías que, quizá precisamente por esta coincidencia, más críticamente se expresaron en contra de la dialéctica durante el pasado siglo. Me refiero a la filosofía de Martin Heidegger, quien, desdeńando hasta cierto punto o, cuanto menos, reinterpretando completamente la pretensión de Husserl según la cual la fenomenología es el auténtico positivismo, concibió la fenomenología como una filosofía esencialmente negativa. El propósito del presente escrito es, por ello, mostrar el carácter eminentemente negativo o destructivo de la propuesta filosófica de Heidegger.

A mi modo de ver, el tema que nos ocupa es algo así como una constante en el pensamiento de Heidegger, ya que la filosofía nunca consiste para él en una disciplina que se caracterice por el objeto que investiga, sino que ella se dirige

\footnotetext{
${ }^{1}$ Horkheimer, Max y Adorno, Theodor W.: Dialektik der Aufklärung. Philosophische Fragmente. Frankfurt a. M.: Fischer, $2001^{13}$, p. 1. Hay traducción castellana: Dialéctica de la Ilustración. Fragmentos filosóficos. Trad. de J. J. Sánchez. Madrid: Trotta, 2006, p. 51
} 
justamente a lo que no es en tanto que objeto -ya se entienda esto como el Dasein humano, ya como el ser de este Dasein, ya como el ser en general. Sin embargo, por contener aclaraciones más concretas y explícitas en este sentido, nos centraremos aquí en sus primeros cursos de Friburgo. La filosofía que se abre camino y se propone en estos cursos podría recibir, si de eso se tratara, los más diversos títulos. Yo mismo la denominé en otra ocasión, en la que también era necesario presentarla bajo un título, Fenomenología de la posibilidad ${ }^{2}$ esto es, del Dasein. Sin embargo, el escogido para esta ponencia, Fenomenología negativa, me parece ahora incluso más adecuado, por mostrar tanto el carácter no-positivo del Dasein como el del modo de dar cuenta de él. Al hablar aquí de una fenomenología negativa, por tanto, no pretendo tan sólo, y en este contexto ni siquiera propiamente, apuntar a un paralelismo entre la transformación adorniana de la dialéctica de Hegel en una dialéctica negativa y la transformación heideggeriana de la fenomenología de Husserl en una fenomenología hermenéutica. Lo que pretendo en primera instancia es señalar el sentido fundamental del método fenomenológico tal y como Heidegger lo concibe en estos años. 'Fenomenología negativa' está aquí como título para una filosofía en la que, primero, absolutamente todos los elementos tienen una función metódica particular, a saber, la de evitar que la investigación caiga en la positividad y en la objetividad. Una filosofía donde, además, esa función, digamos, defensiva tiene que permitir salvaguardar el carácter propio de aquello a lo que se apunta, de lo que se pretende tematizar. Como es sabido, a esto lo llama Heidegger de diversos modos en los años de los que nos ocupamos. Primero se refiere a ello como vivir preteórico o vivir en y para sí, poco después lo denomina sí-mismo (Selbst) y finalmente opta por llamarlo Dasein. Una fenomenología negativa, por tanto, será aquella que considere que al Dasein sólo se puede apuntar negativamente. Y que aquello que recibe este nombre, Dasein, no es nada positivo, no es un objeto particular.

A fin de desarrollar el tema propuesto será necesario, entonces, seguir esta idea, intentar ver claro en ella. Lo que nos preguntaremos en primera instancia será, por tanto, a qué se refiere propiamente Heidegger con el término 'Dasein' o, en otras palabras, de qué hace tema propiamente la filosofía entendida como fenomenología hermenéutica. A continuación, y desde aquí, será posible dilucidar el sentido metódico de todos los elementos de dicha fenomenología como elementos esencialmente negativos. En concreto, mencionaré la destrucción y la indicación formal como exponentes fundamentales de dicho método.

\section{Dasein como fenómeno}

Decíamos, por tanto que la fenomenología, según la entiende el joven Heidegger, se ocupa del Dasein. Así lo encontramos afirmado en múltiples pasajes

\footnotetext{
${ }^{2}$ V. De Lara, F.: Phänomenologie der Möglichkeit. Grunzüge der Philosophie Heideggers 1919-1923. Freiburg/München: Karl Alber, 2008.
} 
de los primeros cursos de Friburgo. Por citar sólo uno, recordemos aquel del Informe Natorp en el que se afirma que "el objeto temático de la investigación filosófica es el Dasein humano en cuanto interrogado acerca de su carácter de ser"3. Ahora bien, ¿qué se entiende aquí por Dasein? La primera respuesta nos viene dada por la aclaración que el propio Heidegger hace en el pasaje recién citado. Al hablar del Dasein humano, lo que se nos sugiere es que aquí se trata, de algún modo, de aquello a que la tradición designó como hombre. Así pues, siguiendo esta indicación, parece que la filosofía consistiría en una particular forma de antropología. Siendo su objeto temático el hombre y consistiendo ella en un estudio de dicho campo de objetos, la filosofía resultaría finalmente antropología. El propio Heidegger así parece afirmarlo en algunas ocasiones, como en el mismo Informe Natorp, cuando habla de una "antropología radical fenomenológica" ${ }^{4}$.

Sin embargo, es preciso prevenirse contra una interpretación de este tipo, si es que la filosofía, como Heidegger pretende, debe ser un modo de conocimiento originario y, por ende, fundamentalmente diverso al que es propio de las ciencias positivas. Podríamos pensar, evitando esta primera identificación entre fenomenología y antropología -que, por cierto, el propio Husserl recriminó a Heidegger-, que se trata de una antropología particular: a saber, de una que no transforma aquello de lo que se ocupa en un objeto, es decir, en algo dado y con unas características, también dadas, que es preciso descubrir y constatar. Por supuesto, acordaremos en que cuando Heidegger considera la posibilidad de denominar antropología al quehacer filosófico, lo hace siempre en este sentido. No en vano el parágrafo 10 de Ser y Tiempo diferencia entre la tarea que en dicha obra se emprende y las investigaciones propias de la antropología, la biología y la psicología. Sin embargo, se hace preciso poner en claro lo que cambia de raíz en la reinterpretación heideggeriana de la idea de hombre como Dasein. A tal efecto, no será preciso comentar en detalle los pasajes en los que Heidegger se distancia del concepto tradicional de hombre y muestra sus dos fuentes principales: la idea griega de animal dotado de lenguaje y la idea cristiana de persona. Bastará con volver a explicitar el 'preconcepto' (Vorgriff) que ambas fuentes comparten de algún modo, a saber, una consideración objetivista del hombre. En ambos casos, dice Heidegger, el hombre es visto de manera sustantiva, como un ente particular con una dotación concreta que lo diferencia de otros entes y, así, lo define por contraste con ellos. Ser ente, por lo tanto, significa aquí, en general, ser real, estar dado ahí siempre del mismo

\footnotetext{
${ }^{3}$ V. Phänomenologiche Interpretationen zu Aristoteles (Anzeige der hermeneutischen Situation) (en: GA 62). Frankfurt a. M.: Klostermann, 2005, p. 348: "Der Gegenstand der philosophischen Forschung ist das menschliche Dasein als von ihr befragt auf seinen Seinscharakter".

${ }^{4}$ Loc. cit., p. 371.

${ }^{5}$ V. Ontologie. Hermeneutik der Faktizität (GA 63). Frankfurt a. M.: Klostermann, 19952 , p. 21: "En ambas determinaciones conceptuales se trata de la fijación de los fragmentos que equipan una cosa dada de antemano, a la cual, entonces, y sobre la base de dicha fijación, se le asigna ulteriormente un determinado modo de ser o bien se lo deja indiferentemente en el ser real" (In beiden Begriffsbestimmungen handelt es sich um die Fixierung der Ausstattungsstücke eines vorgegebenen Dinges, dem dann aufgrund derselben nachträglich eine bestimmte Seinsweise zugesprochen wird bzw. das indifferent in einem Realsein belassen wird).
} 
modo, esto es, con unas determinadas características. El hombre, en cuanto un particular tipo de ente, se distinguiría del resto simplemente a ese nivel, como poseyendo alguna característica exclusivamente suya. La ciencia del hombre consistiría, por ende, en constatar lo más exactamente posible esa su dotación objetiva y, concretamente, la que lo distingue de otros entes. Lejos de esto, al afirmar que la filosofía se ocupa del Dasein, Heidegger estaría apuntando a una comprensión verbal, no sustantiva, del fenómeno del vivir humano. Ser hombre consistiría para él en un particular ejercicio (Vollzug). Lo mentado con el concepto de hombre no está dado, sino que es ejecutándose, teniendo que ser. Por ende, el ser, cuando se le atribuye al Dasein, no puede significar algo así como realitas, objetividad, carácter de objeto, sustancia. El Dasein no se caracteriza por poseer unas características particulares y distintivas. Por ello, resulta filosóficamente inadecuado estudiarlo de este modo, es decir, a la manera de una antropología en este sentido. Si algo caracteriza al Dasein, es justamente el no tener características. O, dicho en las célebres palabras de Ser y Tiempo, si alguna 'esencia' tiene el Dasein, no es otra que la existencia, el tener que ser en cada caso y de forma concreta ${ }^{6}$.

Todo esto es más o menos conocido, sin lugar a dudas. No obstante, me parece que no por ello deberíamos darlo ya por efectivamente comprendido. En efecto, lo más habitual es pensar que lo dicho hace un momento al respecto del Dasein -a saber su carácter, digamos, verbal, ejecutivo, y su no poseer una esencia en sentido sustantivo- son, finalmente, las características del Dasein, lo definitorio de este particular tipo de ente. Pero ya se ve que, de entenderlo así, estamos volviendo a considerar las características distintivas como lo definitorio. Definir seguiría siendo apuntar la dotación común y la dotación peculiar, el género próximo y la diferencia específica de un tipo ente cuyo modo de ser consiste en la sustancialidad. No parece difícil caer en la cuenta de este error y, sin embargo, así se explica a menudo lo que sea el Dasein. Definir qué sea algo parece obligar a este tipo de operación objetivante, a poner como base una comprensión del ser como realidad. Al preguntar qué es algo se abre el camino para que se responda ofreciendo una mostración de los qués, las cualidades, exclusivas del ente en cuestión. Pero entonces se pone ya lo ente como conjunto de qués dados y constatables, esto es, como objeto en el sentido indicado ${ }^{7}$. Además, resulta que el propio Heidegger parece apoyar en ocasiones esta explicación, como cuando afirma que el Dasein se diferencia de la piedra o la mesa o el animal porque él tiene que ser, porque en su ser le va este mismo ser, porque es proyecto, porque es formador de mundo, etc. Esto, según parece, sería lo particular del Dasein, lo definitorio. Una filosofía que se ocupa del Dasein será, por tanto, una disciplina que se define y distingue de las demás porque hace tema de un particular ente y no de otros. De este modo, el Dasein se definirá por lo que lo convierte en peculiar. Y la filosofía, como discurso sobre el Dasein, se definirá por ocuparse de él. Con su corrección del

\footnotetext{
${ }^{6}$ V. Sein und Zeit (GA 2). Tübingen: Niemeyer, $2001^{18}$, p. 42.

${ }^{7}$ Sobre la definición heideggeriana de "objeto", puede consultarse Phänomenologie des religiösen Lebens (GA 60). Frankfurt a. M.: Klostermann, 1995, p. 35.
} 
modo tradicional de entender al Dasein, Heidegger habría dado lugar a una antropología verdadera, es decir, capaz de descubrir las verdaderas características del ente estudiado como ente sin características sustantivas.

El riesgo de entender así el proyecto heideggeriano no es menor. Quizá esta malcomprensión sea especialmente tenaz y esté ligada al problema fundamental que Heidegger quiso pensar tanto bajo el título de Dasein como bajo otros títulos: a saber, qué signifique ser y por qué se entiende siempre de nuevo el ser como sustancia u objeto. Por ello, y al hilo del Heidegger en el que nos estamos aquí basando, debemos preguntarnos, ¿es una antropología en alguno de los dos sentidos antes indicados lo que Heidegger pretende y hace? ¿Es del modo antes expuesto como debemos entender al Dasein, como un ente distinto de otros? Esta última cuestión no apunta aquí a determinar si se trata de un ente especial, marcado, con una peculiar dotación característica; ni siquiera si se trata de un ente señalado por el hecho de tener una comprensión ontológica o por lo que sea. Esto último, en efecto, parece darse por sentado. Por lo menos en apariencia, al afirmar esto se habría dejado atrás ya la visión objetivista del Dasein. Sin embargo, parece seguirse entendiendo que el Dasein es un ente entre otros, por más que dotado de una manera especial que es, justamente, lo que impide o hace inadecuada dicha visión objetivista. La cuestión que planteamos, por tanto, se refiere más bien a si debe entenderse al Dasein como un ente, si es a esto a lo que apunta el término Dasein, si no se lo está volviendo a sustantivar de algún modo al pensarlo como uno entre otros, por más que diferente a los otros. En otras palabras, la pregunta es si en todo esto no se sigue viendo al Dasein como un posible contenido mundano entre otros, caracterizado precisamente porque sus contenidos son distintos a otros.

\section{Fenomenología del Dasein}

El joven Heidegger hace una diferenciación que podría resultarnos de ayuda para dar respuesta a estas cuestiones. Desde un principio, distingue entre 'mundo del sí-mismo' (Selbswelt), por una parte, y 'sí-mismo' (Selbst) o 'Dasein', por otra. Estas dos referencias distintas al sí-mismo o al Dasein parecen apuntar a lo que estamos buscando. Si la diferenciación debe tener algún sentido, el Dasein no puede identificarse simplemente con el mencionado mundo del sí-mismo, esto es, con el modo en que el Dasein comparece en cada caso fácticamente bajo la forma de un yo-mismo. Heidegger introduce el concepto de mundo del sí-mismo -junto con el de 'mundo compartido' o 'comundo' (Mitwelt) y el de 'mundo circundante' (Umwelt)- a fin de categorizar de alguna manera el contenido (Gehalt) de eso a lo que se llama experiencia fáctica del vivir (faktische Lebenserfahrung). El concepto de 'mundo del sí-mismo', por tanto, apunta al contenido de dicha experiencia. Pero entonces está claro que 
el de 'sí-mismo' o 'Dasein' apuntan a otra cosa, ya veremos a qué. En todo caso, la distinción recién mencionada indica que no se puede identificar al Dasein con un contenido particular de la experiencia fáctica del vivir.

En general, dicha categorización de la experiencia fáctica del vivir es entendida por Heidegger como una explicitación (Explikation), esto es, como despliegue o diferenciación de lo que originariamente no está diferenciado ni separado. Este es el motivo por el que dicha explicitación sea denominada también análisis (sin ir más lejos, en Ser y Tiempo). Originariamente -es decir, de manera concreta, preteórica, fáctica- lo que es el caso no está separado en distintos tipos de contenidos como los que se diferencian al hablar, por una parte, de mundo del sí-mismo, por otra, de mundo compartido y, por otra, de mundo circundante. Heidegger acentúa que al destacar y poner de relevancia una dirección de sentido con el fin de interpretarla explícitamente no se la está abstrayendo ${ }^{8}$ y, además, que esa dirección "debe ser comprendida siempre en la totalidad del fenómeno y como dirección de un sentido pleno" ${ }^{\text {. A su }}$ vez, estos 'contenidos' tampoco están separados de otros aspectos que, desde luego, el análisis puede perfectamente diferenciar en el experienciar concreto. Así, es posible distinguir no solamente entre contenidos, sino también entre el contenido y el modo en que se lo experiencia o bien entre éste y la forma de ejecución concreta de esa experiencia, etc. Sin embargo, es importante insistir en que originariamente, en el experienciar concreto, no se dan estas distinciones, sino que se trata de distinciones llevadas a cabo en aras de explicitar lo que es el caso originariamente.

A eso que es el caso originariamente es a lo que la fenomenología denomina fenómeno y, por tanto, a lo que ella debe atenerse bajo cualquier circunstancia. La tarea de la fenomenología consistirá en llamar la atención sobre eso originario, en apuntar a ello y explicitarlo, sin transformar su carácter propio. Fenómeno, por tanto, será aquello que es el caso originariamente, la concreción fáctica. Y fenomenología será una particular explicitación de esto, a saber, aquella explicitación que, incluso y justamente en las diferenciaciones que realiza, apunta siempre a lo concreto y originario y no lo oculta en objetivación o construcción alguna. Mi tesis es que a esta concreción, que es el asunto de la filosofía como fenomenología, es a lo que Heidegger apunta con el nombre de Dasein ${ }^{10}$. Este es el motivo por el que insiste en que el Dasein no es un ente más o una región de lo ente, sino, dice Heidegger, una "objetualidad específicamente arregional" ${ }^{11}$. Sin embargo, el Dasein sólo puede ser arregional si con ese concepto no se mienta más que la concreción experiencial, lo que es el caso,

\footnotetext{
${ }^{8}$ V. GA 60 , p. 88.

${ }^{9}$ Phänomenologische Interpretationen zu Aristoteles. Einführung in die phänomenologische Forschung (GA 61). Frankfurt a. M., Klostermann: 19942, p. 89: "Hier wie im folgenden, d. h. bei jeder aus einer Sinnrichtung [...] ausdrücklich interpretierten Abhebung, muß diese immer im Phänomenganzen und als Richtung eines vollen Sinnes verstanden werden. Kategorie ist interpretierend auf das volle Leben". V. también loc. cit., p. 94-95.

${ }^{10}$ V. por ejemplo, Phänomenologische Interpretationen ausgewählten Abhandlungen des Aristoteles zur Ontologie und Logik (en: GA 62). Frankfurt a. M., Klostermann, 2005, pp. 47-49.

${ }^{11}$ Loc. cit., p. 48.
} 
lo concreto, y no un tipo de ente, por señalado que éste resulte. A mi entender, esto es lo que significa para Heidegger que la fenomenología se ocupe del Dasein y, dicho sea de paso, es también el motivo, de que, finalmente, Heidegger deba rechazar una designación equívoca como la de antropología para lo que él pretende.

Pero, volviendo sobre lo que hemos dicho, tenemos que Heidegger entiende la fenomenología como explicitación del fenómeno, esto es, de lo concreto, del experienciar originario o fáctico. Dicha explicitación del fenómeno, de su "intencionalidad plena" 12 , como Heidegger también lo expresa, se hace distinguiendo, por así decir, aspectos en dicho experienciar concreto. A este ejercicio de distinción de una experiencia concreta lo denomina Heidegger precisamente "tomar en el fenómeno" o también "llevar al fenómeno"13. Así pues, toda experiencia, entendida como la unidad del experienciar y lo experienciado -del acto y el contenido, por expresarlo así- puede 'ser tomada en el fenómeno', es decir, se puede preguntar:

1o por el 'qué originario que es experienciado en él (contenido),

2o por el 'cómo' originario en el que es experienciado (referencia),

3o por el 'cómo' originario en el que el sentido de referencia es ejecutado (eje(ución $)^{14}$.

Sin embargo, Heidegger hace notar de inmediato que no se trata de tres cosas distintas o de cualidades que se den separadamente en la experiencia concreta, originariamente. En efecto, continúa diciendo, "estas tres direcciones de sentido (sentido de contenido, de referencia y de ejecución) no se encuentran simplemente una al lado de la otra. 'Fenómeno' es totalidad de sentido según estas tres direcciones" ${ }^{15}$. Lo que aquí se menciona como 'totalidad de sentido' (Sinnganzheit) ${ }^{16}$, en otros contextos se lo denomina "sentido pleno"17 o, como hemos visto, intencionalidad plena (volle Intentionalität), significando en todo caso que se trata de algo que originariamente se da de manera unitaria o, dicho más exactamente, que ese tipo de distinciones no se dan como tales en el experienciar fáctico.

\footnotetext{
12 GA 62, p. 365.

${ }^{13}$ GA 63 , p. 76.

${ }^{14}$ GA 60, p. 63: "Jede Erfahrung als Erfahren wie als Erfahrenes kann »ins Phänomen genommen werden «, d. h. es kann gefragt werden:

1. nach dem ursprünglichen »Was«, das in ihm erfahren wird (Gehalt),

2. nach dem ursprünglichen »Wie«, in dem es erfahren wird (Bezug),

3. nach dem ursprünglichen »Wie«, in dem der Bezugssinn vollzogen wird (Vollzug)". V. trad. cast., p. 88.

${ }^{15}$ Loc. cit.: "Diese drei Sinnesrichtungen (Gehalts, Bezugs, Vollzugssinn) stehen aber nicht einfach nebeneinander. »Phänomen« ist Sinnganzheit nach diesen drei Richtungen”.

${ }^{16}$ GA 60, p. 63.

${ }^{17}$ GA 61, p. 53: "Sentido pleno = fenómeno" $($ Voller Sinn = Phänomen $)$.
} 
La explicitación del fenómeno, de la concreción originaria de la cual pueden distinguirse los aspectos indicados, y en cuya distinción consiste la interpretación de dicho fenómeno, se hace necesariamente por este camino analítico. Al preguntarse por el qué originario, por el contenido de la experiencia concreta, Heidegger apunta a él mediante la categoría de mundo. Con ello, como con todas las categorías fenomenológicas que Heidegger acuña en su análisis, se pretende acentuar el carácter no-teórico ni objetivo de lo que es el caso originariamente. Mundo quiere decir justamente eso, que nada está dado como objeto y ni siquiera como dado. Lo mismo vale para la categoría fundamental de la referencia (Bezug), del modo en que, por así decir, se está en trato con un contenido. Heidegger la llama cuidar o bien ocuparse (Sorgen) justamente para acentuar eso mismo. Pero es preciso tener en cuenta, una vez más, que originariamente no se da algo así como una referencia a un contenido. Al contrario, como Heidegger indica a menudo, lo que se da originariamente, si acaso, sería el contenido. Pero ni siquiera es exacto decir esto. No es que se den contenidos aislados, lo que se quiere decir es que la atención suele estar fijada en los contenidos entendidos como significatividades y, en concreto, como un complejo, un entramado de dichos contenidos, siendo a esto a lo que el joven Heidegger denomina una situación. No hay algo así como papeles que estoy leyendo, un auditorio, personas y, por otra parte, yo que leo, mi disposición particular, etc. Originariamente eso no está distinguido en modo alguno.

\section{Destrucción e indicación formal como elementos metódicos ${ }^{18}$}

Ahora bien, hemos dicho que en la situación concreta de experiencia lo que de algún modo domina son los contenidos. Originariamente, el vivir sólo diferencia entre las diferentes situaciones que va experienciando y éstas, a su vez, las diferencia por los contenidos de cada una. El vivir fáctico presenta, según Heidegger, una particular indiferencia con respecto a los modos en que experiencia ${ }^{19}$. A esta fijación en los contenidos la denomina Heidegger 'ruinancia' (Ruinanz). Las distinciones que la fenomenología, a diferencia del vivir fáctico, lleva a cabo tienen por fin poner coto a la mencionada tendencia ruinante. Según Heidegger, la tendencia a objetivar que hemos constatado en las ciencias -pero no sólo en ellas, sino en todo modo de definir y, en última instancia, de pensar qué signifique ser- arraiga directamente en esa inclinación del vivir fáctico a los contenidos. Fijémonos que al definir buscábamos justamente los contenidos distintivos y considerábamos todo ente como un conjunto de tales contenidos. Al propio Dasein lo veíamos en un principio como un contenido más. De este modo, se harían precisas todo tipo de medidas metódicas para llevar a cabo el propósito fenomenológico de explicitar lo concreto, el Dasein, sin objetivarlo de algún modo. Las distinciones fenomenológicas tendrían por

\footnotetext{
${ }^{18}$ Dadas las limitaciones de espacio a que este trabajo está sometido, me permito remitir aquí a mi ya citado libro, y en concreto a los capítulos 3 y 5 , para una exposición detallada de la destrucción y la indicación formal, respectivamente.

${ }^{19}$ V. GA 60, p. 12.
} 
ende una función defensiva contra la mencionada ruinancia. En ellas se pone en obra una destrucción, en palabras de Heidegger, de la interpretación tendencialmente objetivista que el vivir hace de sí mismo. Esto es así no sólo porque cada una de las categorías de este análisis apuntaba contra dicha interpretación, como ya hemos visto, sino porque mediante ella se pone el acento en una unidad experiencial que no está definida ni en primera instancia ni principalmente por los contenidos. Todas las categorías, incluida la de mundo o incluso las diferenciaciones dentro de ésta, tienen la función de apuntar de nuevo a la totalidad concreta, a la situación.

Esta particular función defensiva es la que domina en todos los conceptos y expresiones filosóficas. Mediante ellas se apunta en cada caso a la concreción situacional. Por eso las denomina Heidegger indicaciones formales, esto es, no designadoras de un contenido específico. Estos conceptos, en su formalidad, pretenden evitar que lo explicitado se entienda como contenido y, finalmente, como objeto para una mirada teórica. Pero, además, funcionan como una indicación a lo concreto, por lo que su función no acaba aquí, sino que debe extenderse a las mismas distinciones que se han realizado en la explicitación fenomenológica. Su carácter formal-indicativo debe servir para que las distinciones realizadas no se tomen, una vez más, por la cosa misma o, mejor, por aspectos dados de hecho en un objeto dado también de hecho. En la indicación formal se pone de relevancia la necesidad de, por así decir, una autoregulación y autolimitación de la filosofía. Para apuntar al Dasein, al vivir fáctico, es preciso que éste no sea puesto como un objeto, sino que este concepto siga siendo él mismo una indicación para lo que no es contenido ni es objeto, para la concreción originaria de la que hace tema la fenomenología. 


\title{
Ampliación de la Razón y la Ciencia
}

\author{
Jorge Peña Vial \\ Universidad de los Andes
}

\begin{abstract}
Quisiera comenzar con un breve texto que compendia y orienta todo lo que quisiera plantear en este ensayo. Perfectamente pudiera pertenecer a Horkheimer, Adorno, Husserl o Heidegger, quienes han elaborado, a su modo, una concepción eminentemente crítica del proceso de instrumentalización de la razón en el que ha desembocado el pensamiento de la Modernidad tardía. Esta es la cita: "Este concepto moderno de la razón se basa, por decirlo brevemente, en una síntesis entre platonismo (cartesianismo) y empirismo, una síntesis corroborada por el éxito de la técnica. (...) Esto implica dos orientaciones fundamentales decisivas para nuestra cuestión. Sólo el tipo de certeza que se deriva de la sinergia entre matemática y método empírico puede considerarse científica. Todo lo que pretende ser ciencia ha de atenerse a este criterio. (...) Pero de este modo nos encontramos ante una reducción del ámbito de la ciencia y de la razón que es preciso poner en discusión”. Si bien este diagnóstico pudo haber pertenecido a cualquiera de los autores anteriormente citados, pertenece al famoso discurso de Benedicto XVI en Ratisbona, célebre por otros motivos.
\end{abstract}

El desafío es ampliar tanto el ámbito de la ciencia como de la razón para que permitan abordar las cuestiones cruciales que atañen al hombre de modo objetivo, sin relegarlas a opciones privado-subjetivas carentes de alcance universal. Para ello, es preciso tener en cuenta cómo se ha forjado esta visión reduccionista y estrecha de la ciencia que sistemáticamente ha prescindido de la sensibilidad y del sujeto. Me propongo primero analizar, de modo breve, el proceso histórico que condujo al ideal de la ciencia moderna y su radicalización por parte del círculo de Viena. Después, el aporte de Husserl que nos saca de la cárcel del positivismo. Acudiré a un ejemplo del fenomenólogo Michel Henry para ilustrar qué se entiende por saber de la ciencia, saber de la conciencia y saber de la vida. En la última parte de esta ponencia se plantea la paradoja de que precisamente, en momentos en que el proceso de racionalidad tecno-científica alcanza dimensiones globales y universales, es cuando irrumpe la irracionalidad bajo las formas de relativismo y nihilismo. Siguiendo sugerencias de Alejandro Vigo, se considera que son los criterios de necesidad, certeza y evidencia, proclamados como ideal de verdadero conocimiento, los que, como efecto perverso por sus desmesuradas exigencias, han alimentado el escepticismo; precisamente en su intento de superarlo y suprimirlo. No ha sido casual que muchas corrientes contemporáneas hayan procurado superar 
el monismo metodológico de la filosofía y la ciencia moderna para acercarse a un pluralismo metodológico que haga justicia a las diversas dimensiones de la realidad y a una mayor apertura de la razón.

A los objetos de los sentidos, captados de la realidad, Aristóteles los denominó sensibles propios, sensibles comunes y los sensibles per accidens. Sensibles propios son el objeto de los cinco sentidos (vista, oído, olfato, gusto, tacto), a saber, el riquísimo mundo de los colores, sonidos, texturas, olores y sabores: las cualidades sensibles. Son sensibles comunes las características cuantitativas de la realidad (movimiento, reposo, número, figura y magnitud). Se llamó sensibles per accidens a los que propiamente no son sensibles (sustancia, causa, esencia, fin), pero que se pueden inferir a partir de lo sensible: son los conceptos metafísicos. Por ejemplo, Sócrates no es ningún color ni tamańo, pero posee en sí (substancia) dichas características sensibles.

En el siglo XVII, se producirá un cambio de denominación y tanto los empiristas ingleses (Berkeley, Locke, Hume) como los racionalistas continentales (Descartes, Malebranche, Leibniz) llamarán cualidades primarias a los sensibles comunes y cualidades secundarias a los sensibles propios. Este cambio de terminología es asimismo un cambio en su valoración: revela la prioridad que se concede a lo cuantitativo sobre lo cualitativo en la nueva física, tal como había sido iniciada por Galileo. Propiamente es objetivo el saber que estudia los aspectos cuantitativos de las cosas, el estudio de las cualidades primarias o sensibles comunes; los sensibles propios o cualidades secundarias son modos subjetivos de percibir lo objetivo (el color no es más que una determinada longitud de onda). La novedad de la física moderna respecto a la aristotélica consiste en que se trata de una física matematizada, o sea, un estudio de la naturaleza en base a factores: movimiento, reposo, número, figura y magnitud, es decir, son las cualidades primarias las únicas que nos proporcionan un conocimiento verdaderamente objetivo, cientifico, mientras que las cualidades secundarias son no científicas y subjetivas. La radicalización positivista de la nueva física llevó a considerar que la física era la única ciencia objetiva; la psicología se ocupaba de cuestiones subjetivas y la metafísica, al no ocuparse de hechos ni objetivos ni subjetivos no se ocupaba de nada real y, por tanto, no constituía ninguna ciencia. En esta tesitura, la metafísica entra en crisis y acoge como tema propio la subjetividad, relegando lo objetivo a la ciencia positiva.

Será la fenomenología del siglo XX la que objetará esta tesis empirista y racionalista y reivindicará la objetividad tanto del saber psicológico como metafísico.

Pero veamos brevemente la génesis de este estrechamiento del dominio de la razón y la ciencia, para luego abordar el rescate de la fenomenología de la cárcel positivista. 
"El universo está escrito en el lenguaje de las matemáticas y sus caracteres son triángulos, círculos y otras figuras geométricas, sin las cuales es humanamente imposible entender una sola de sus palabras. Sin ese lenguaje, navegamos en un oscuro laberinto" (Galileo). Más importante que el llamado "caso Galileo" o presunto conflicto entre saber y religión, es la reforma del entendimiento que propone con su nuevo concepto de ciencia y su nueva aprehensión del mundo. Es la victoria definitiva de la ciencia como acción sobre la ciencia como contemplación, de la razón como experimentación sobre la razón como experiencia. También Platón elogiaba a las matemáticas. Mas, para él, sólo había ciencia de lo eterno y de lo necesario. Lo empírico, corruptible y contingente, se mostraba rebelde a la matematización. La ciencia galileana deja de tener intereses comunes con lo eterno: lo empírico se convierte en su objeto. Es el Todo que se debe leer como un libro de matemáticas. Propiamente el libro de la naturaleza deja de ser un libro. La metáfora del libro se empleaba para expresar que el sentido de las realidades naturales consistía en remitir a su complemento espiritual, que la tierra clamaba la gloria de los cielos, que el mundo sensible no existía más que en la débil medida en que reflejaba algo del esplendor divino, en la medida en que era símbolo de éste. Estas consideraciones, a partir de ahora, son propiedad de los poetas: ni huellas, ni símbolo, ni analogía: leyes. Desencantada de este modo, la naturaleza queda abierta a la experimentación y a la instrumentalización ${ }^{2}$.

La física de Aristóteles reposaba sobre nuestra percepción diaria de un mundo lleno de colores y sonidos. Eso lo hacía decir que en la naturaleza no había formas geométricas. Éstas eran demasiado perfectas para aquélla. Con Galileo, la física de la experiencia deja el sitio a una física deductiva y abstracta. "El paso de Aristóteles a Galileo no es el paso del dogmatismo teórico a la evidencia empírica, sino el de la evidencia empírica del sentido común a la autoridad de la evidencia matemática" ${ }^{3}$. Lo real y lo verdadero ya no se revelan, se demuestran. No proceden del mundo, sino del hombre y de su aptitud para reducir todo lo que él no es al esquema matemático que lleva en sí mismo. A partir de ahora la importancia de un saber ya no reposa sobre la sublimidad de su objeto, sino sobre su método. "El método pasa al centro luminoso del saber” (Ernst Cassirer). Y no hay método o certeza más que allí donde el objeto puede ser tratado en función de principios matemáticos. "Pasar por la forma de la demostración matemática -añade Cassirer- es la condición sine qua non de toda ciencia verdadera"4. Galileo abre la época de la mathesis universales. Se

\footnotetext{
${ }^{1}$ Galileo. El ensayador. Trad. al cast.: Buenos Aires: Ed. Aguilar, 1981.

${ }^{2}$ Este asunto ha sido abordado por diversos autores y desde distintas perspectivas. Cfr: Fabro C. L'uomo e il rischio di Dio. Roma: Edictrice Studium, 1967; Horkheimer, Max-Adorno, Theodor. Dialéctica de la Ilustración. Trad. de Juan José Sánchez. Madrid: Trotta, 1994; Finkielkraut, Alain. Nosotros, los modernos. Trad. de Miguel Montes. Madrid: Encuentro, 2006; Horkheimer, Max. Crítica de la razón instrumental. Buenos Aires: Sudamericana, 1969; Arana, Juan. El caos del conocimiento. Pamplona: Eunsa, 2004; Morin, Edgar. El Método 6, Ética. Trad. al cast. de Ana Sánchez. Madrid: Cátedra, 2006, pp. 77-87.

${ }^{3}$ Geymonat, Ludovic. Galileo Galilei. Trad. al cast.: Barcelona: Península, 1970; cfr.: Koyré, Alexandre. Estudios de historia del pensamiento científico. Madrid: Siglo XXI, 1990.

${ }^{4}$ Cassirer, Ernst. Individuo y cosmos en la filosofía del renacimiento. Trad. al cast.: Buenos Aires: Emecé, 1951.
} 
empieza a universalizar una expresión que no tiene sentido para los humanistas: " $y$ todo lo demás es literatura". Desde que reina el método sobre el saber, y lo real se identifica con lo calculable, es lícito y hasta natural emplear la palabra "poesía" en el sentido de inepcia, de elucubraciones o de algo absurdo.

Descartes empezó por transformar el estado de duda, en que le habían sumido los libros y los viajes, en ejercicio de duda, y resolvió no aceptar ningún término medio entre la certeza y la ilusión o el error. Ese fue su primer precepto: "no admitir como verdadera cosa alguna, como no supiese con evidencia que lo es" y "no comprender en mis juicios nada más que lo que se presenta tan clara y distintamente a mi espíritu, que no hubiese ninguna ocasión de ponerlo en duda”. De Descartes hemos recibido que la seguridad en esta vida no puede proceder más que del método, y el método mismo de la mathesis: las ideas absolutamente claras y distintas, compuestas con orden y medida, son conceptos matemáticos.

En 1929, aparece en Viena un libro delgado y de poca apariencia titulado $L a$ concepción cientifica del mundo ${ }^{5}$. El texto se presenta sin autor, aunque el prefacio está firmado por el matemático Hans Haan y los lógicos Rudolf Carnap y Otto von Neurath. Y el título ya da una idea de por dónde van los tiros: no hay otra aprehensión objetiva del mundo más que la concepción científica. El mundo no es más que lo que la ciencia dice de él, los enunciados científicos, con su simbolismo purificado de las escorias de las lenguas históricas, describen lo real; los enunciados metafísicos y teológicos expresan, como los enunciados poéticos, una emoción, algo legítimo y necesario, pero no debemos confundir los órdenes. Como escribía Carnap en un artículo publicado años después de lo que muy pronto se llamó el Manifiesto del Círculo de Viena, los metafísicos se embriagan con grandes palabras como "Incondicional", "Infinito", "ser del ente", "Espíritu Absoluto", "Esencia”, "ser-en-sí y para-sî", "Emanación”, "Manifestación", etc.: se imaginan que hablan de lo verdadero y lo falso. Sin embargo se extravían, se cuentan historias, se hacen ilusiones; de hecho, no dicen nada. "Pero entonces, ¿qué le queda a la filosofía -preguntaba Carnap, si todas las proposiciones que afirman algo son de naturaleza empírica y pertenecen, por tanto, a la ciencia fáctica?” Su respuesta es simple y tajante: "Lo que le queda no son proposiciones, no es una teoría ni un sistema, sino exclusivamente un método, esto es, el del análisis lógico". La filosofía no tiene nada que ańadir al conocimiento, su tarea consiste en clarificarlo poniendo de manifiesto la significación real de los enunciados. De otra manera, pulularán los pseudo problemas y se discutirá de cuestiones que no tienen sentido. El círculo de Viena apela a la disciplina argumentativa contra la poesía conceptual.

El mismo año que Rudolf Carnap debe huir de Europa, Edmundo Husserl pronuncia en Viena y en Praga (1935) unas conferencias sobre la "Crisis de la humanidad europea" (base de su última obra La crisis de la ciencia europea).

\footnotetext{
${ }^{5}$ Cfr.: Frank, V. El círculo de Viena. Madrid: Taurus, 1977.

${ }^{6}$ Incluido en La crisis de las ciencias europeas y la fenomenología trascendental. Barcelona: Ed. Crítica, 1991.
} 
En aquella época todo el mundo estaba inquieto y era corriente, e incluso trivial, hablar de crisis. Lo que era absolutamente novedoso era ir a buscar el origen de la crisis en el acontecimiento inaugural de los tiempos modernos que había hecho posible la concepción científica del mundo. Husserl se remonta a Galileo y muestra que la revolución galileana, cuya herencia reivindica el círculo de Viena, no se reduce a la victoria de la ciencia sobre la ignorancia. Consuma "la sustitución en virtud de la cual se toma el mundo matemático de las idealidades por el único mundo real”. Galileo es a la vez un gran descubridor y un gran encubridor: "Descubre la naturaleza matemática, la idea metódica, abre la vía a la infinidad de descubridores y descubrimientos en física". Al mismo tiempo encubre, vela "el mundo que se da realmente en la intuición, realmente experimentado y experimentable, en el que toda nuestra vida se desarrolla prácticamente". Surge la disyunción entre "el mundo de la ciencia" y el "mundo de la vida".

No se puede silenciar el extraordinario vuelco operado por la fenomenología de Husserl a esta ideología cientificista y positivista de nuestra época. Las determinaciones geométricas, a las que la ciencia galileana intenta reducir el ser de las cosas, son idealidades. Éstas están lejos de dar cuenta del mundo sensible, subjetivo y relativo en el cual se desarrolla nuestra actividad cotidiana: el mundo de la vida.

Por otra parte, en cuanto idealidades, las determinaciones geométricas y matemáticas de las que hacen uso las ciencias de la naturaleza suponen la operación subjetiva que las produce y sin la cual no existirían: no hay en la naturaleza ni número ni cálculo, ni suma ni resta, ni recta ni curva: son significaciones ideales que encuentran su origen absoluto en la conciencia que las crea.

La ilusión de Galileo -como de todos los que, tras su estela, consideran la ciencia como saber absoluto- fue haber considerado el mundo matemático y geométrico, destinado a suministrar un conocimiento unívoco del mundo real, como el mundo real mismo; este mundo que sólo podemos intuir y experimentar en los modos concretos de nuestra vida subjetiva. (Como si la única manera de conocer una casa fuera viendo sus planos y se despreciara el saber de los rincones, buhardillas, muebles, arcones; es decir, la riqueza de las cualidades sensibles con sus olores, sabores y colores).

Husserl, cuyo proyecto filosófico inicial fue hacer de la filosofía una ciencia estricta (así se llama su primera obra) da testimonio de su fracaso en su último libro, La crisis de la ciencia europea, al denunciar este alejamiento del mundo de la ciencia del mundo de la vida. Pero ¿qué entiende por "mundo de la vida"? Para ilustrarlo tomo un ejemplo de otro gran fenomenólogo, Michael Henry . Consideremos un estudiante de biología ocupado en leer una obra sobre el código genético. Su lectura está referida a los procesos complejos de concep-

${ }^{7}$ Cfr.: Henry, Michel. De la barbarie. Trad. al cast. de Tomás Domingo Moratalla. Madrid: Ed. Caparrós, 1996. 
tualización y de teorización contenidos en el libro. Para eso debe primero saber leer, debe ejecutar un saber de la conciencia que consiste en la percepción de las palabras. Pero además, mientras lee, y para que su lectura sea posible, pasa las páginas del libro con sus manos, mueve los ojos con la intención de recorrer con la mirada y fijarse en las líneas del texto. Cuando está fatigado por su esfuerzo, se levantará, dejará la biblioteca y cogerá una escalera para dirigirse a la cafetería, donde descansará, comerá y beberá. El saber contenido en el manual de biología, y que el estudiante ha asimilado en el curso de su lectura, es el saber científico. La lectura misma es otro tipo de saber que presupone el anterior, es el saber de la conciencia. El saber que ha hecho posible el movimiento de las manos y el de los ojos, el acto de levantarse, de bajar las escaleras, de beber y comer; el mismo descanso, es el saber de la vida. Saber de la ciencia, saber de la conciencia, saber de la vida.

Si preguntamos cuál de estos tres saberes es fundamental, es forzoso rechazar de entrada el conjunto de los prejuicios de nuestro tiempo, a saber, la creencia de que no solamente el saber científico es el más importante, sino que en realidad es el único saber verdadero; que saber quiere decir ciencia, es decir, este tipo de saber matemático introducido en la época de Galileo; que todo lo que ha precedido a esta llegada de la ciencia rigurosa en Occidente no ha sido más que un montón de conocimientos inorgánicos, presentimientos confusos, por no decir prejuicios e ilusiones.

Como observa Henry: "no es el saber científico el que le permite adquirir el saber cientifico contenido en el libro; no es gracias a él por lo que mueve sus manos o sus ojos, o concentra su espíritu" ${ }^{8}$. El saber-mover-las-manos, el saber-volver-los-ojos, el saber de la vida, no es objetivo en sentido alguno, no tiene objeto porque no comporta relación con el objeto, porque su esencia no es esta relación. El saber científico no es más que una modalidad del saber de la conciencia, es decir, de la relación con el objeto. Pero ésta misma sólo es posible sobre el fondo de la vida en ella.

Michael Henry sostiene que la abstracción de la ciencia es doble. En primer lugar, es la abstracción la que define el mundo científico en cuanto tal. Ello en la medida en que pone fuera de juego, en el ser de la naturaleza, a las cualidades sensibles y a los predicados afectivos que le pertenecen a priori, para retener de él tan sólo las formas susceptibles de prestarse a una determinación ideal. El no tomar en consideración los caracteres subjetivos de todo mundo posible es indispensable desde el punto de vista metodológico. Pero al desarrollar de modo indefinido este saber ideal, se prescinde de las propiedades sensibles y afectivas del mundo, y ello implica apartar la vida misma, es decir, lo que constituye la humanidad del hombre. Se encuentra aquí la segunda abstracción de la que procede la ciencia en el sentido que damos hoy a este término: la abstracción de la vida, es decir, de lo único que importa. En este sentido es

${ }^{8}$ Ibidem, p. 27. 
posible concebir un hiperdesarrollo del saber científico que vaya a la par con una atrofia de la cultura, con su regresión en muchos dominios, puesto que la cultura es cultura de la vida y es esencialmente práctico. Son las necesidades superiores del sujeto las que dan lugar a las formas elaboradas de cultura que son el arte, la filosofía, la ética y la teología.

El filósofo tiene el deber de intervenir cuando el dominio de la ciencia es comprendido como el único dominio verdaderamente existente y el ámbito en el que arraiga la vida y su cultura es arrojado al no-ser o a la mera apariencia de la ilusión. No es el saber científico el que se cuestiona, sino la ideología que se le une y según la cual es el único saber posible, el que está llamado a eliminar a los demás. Es la convicción universalmente extendida según la cual saber quiere decir ciencia.

La sensibilidad sólo es eliminada del mundo científico, y es por ello que este mundo es abstracto. El arte, una de las formas fundamentales de toda cultura, es una actividad de la sensibilidad, la realización de sus poderes: "Sólo por la sensibilidad se puede alcanzar lo verdadero en el arte” (Kandinsky). La ciencia moderna define su campo propio y se define a sí misma por la exclusión de esta misma sensibilidad, por la eliminación de las cualidades sensibles. No cabe mayor heterogeneidad entre ciencia y arte.

Como bien ha demostrado Heidegger -su influjo es patente en la última obra de Husserl- la ciencia que se cree sola en el mundo y que se comporta como tal se convierte en técnica. No es extraño que la noción de progreso parece designar de modo exclusivo al progreso técnico. La idea de un progreso estético, intelectual, espiritual o moral, con sede en la vida de la persona y consistente en el desarrollo y crecimiento de sus potencialidades, de su cultura, pareciera que ya no tiene vigencia, porque la ontología implícita de nuestro tiempo declara que no hay más realidad que la objetiva y científicamente cognoscible.

Suponiendo que, en el desarrollo monstruoso de la técnica moderna, apareciera un procedimiento nuevo -la fisión del átomo, una manipulación genética- que planteara un problema de conciencia al científico, dicho problema sería desechado como anacrónico, porque en la única realidad que existe para la ciencia no hay problemas ni conciencia. Y si, por un acaso, un científico se dejara retener por sus escrúpulos, otros cien se levantarían para tomar su relevo. Pues como atestigua Henry, "todo lo que puede ser hecho por la ciencia, debe ser hecho por ella y para ella, al no haber nada distinto a ella y a la realidad que ella conoce, a saber, la realidad objetiva, cuya autorrealización es la técnica"'.

Benedicto XVI, al sostener que se debe ampliar tanto la noción de ciencia como de razón, no se dirige contra un rasgo decisivo de la cultura moderna,

\footnotetext{
${ }^{9}$ Henry, M. Op. cit., p. 75.
} 
la cultura científica, sino contra la ideología cientificista cuya pretensión es la eliminación querida y prescrita por ella de todos los demás modelos espirituales. El precio a pagar es muy alto: la ocultación por parte del hombre de su ser propio.

Ahora bien, resulta altamente sorprendente que en momentos en que el proceso de racionalización tecno-científica alcanza dimensiones globales y se extiende en intensidad y amplitud jamás vistas hasta ahora, es cuando, paradójicamente, irrumpe por todas partes el irracionalismo en sus formas más radicales. Si algo caracteriza nuestra atmósfera cultural es la del "relativismo" y el "nihilismo". El relativismo está presente en las actuales discusiones en torno a la interculturalidad, el pluralismo y la democracia ${ }^{10}$; mientras que el nihilismo, caracterización sumaria de nuestra época, parece indicar, tal como Volpi lo ha señalado, un intinerarium mentis in nibilum ${ }^{11}$, consumación del proceso autodestructivo de la razón. Lo que cabe preguntar es si este creciente proceso de racionalización tecno-científico y el nuevo auge del irracionalismo bajo la figura del relativismo y el nihilismo, son dos fenómenos paralelos e independientes o son dos caras de un mismo fenómeno unitario. Según connotados pensadores de la postguerra (Adorno, Horkheimer, Husserl y Heidegger), el desarrollo, consolidación y finalmente la hipertrofia de una determinada concepción de la ciencia y de la racionalidad, con su desmesurada pretensión de encarnar la racionalidad y la ciencia sin más, serían los causantes a la larga, y tras un tortuoso proceso histórico, del nuevo auge del irracionalismo. Su reduccionista interpretación de la ciencia y la misma concepción de una racionalidad instrumentalista y calculadora no serían del todo inocentes de lo que paradójicamente quieren combatir, el irracionalismo. Ello es así porque proponer como paradigma de toda racionalidad y ciencia una determinada modalidad de la misma -la racionalidad puramente instrumental y calculadora que se despliega a sus anchas en una civilización tecno-científica y cuya garantía de validación y legitimidad es su notable eficacia utilitaria-, conduce a que todo otro saber y obrar que no se someta a esos parámetros metodológicos sea marginado por no satisfacer las exigencias de rigor, exactitud y certeza. Esta exaltación e hipertrofia de una determinada forma de racionalidad científica, y su pretensión de extrapolarla a otros modos de conducirse frente a la realidad, lleva a deslegitimar y corroer, en sus mismos cimientos, otras acreditadas formas de racionalidad que se han dado a lo largo de la historia. Como hemos visto, fue profético el diagnóstico de Husserl en los ańos 30, al considerar que la crisis que padece el ideal científico y cultural propio de la tradición del objetivismo naturalista de la Modernidad, se experimentaría bajo la forma de una pérdida de la significatividad vital de las ciencias y a una crisis del ideal de racionalidad universal. La hipertrofia de la razón matematizante que caracteriza a las ciencias objetivas iba a conducir, a través de un olvido creciente de sus propios fundamentos, a una crisis del sentido que amenaza al ideal de racionalidad que caracteriza a la cultura europea.

\footnotetext{
${ }^{10}$ Cfr: Hollis, M-Lukes, S (eds). Tarionality and Relativismo. Oxford University Press, 1990.

${ }^{11}$ Cfr: Volpi, Franco. El nihilismo. Madrid: Siruela, 2007.
} 
El intento presente en la modernidad, desde Descartes pasando por Kant hasta el mismo Husserl, que quiso hacer de la filosofía una ciencia estricta, fue la búsqueda de un fundamento indubitable de todo conocimiento. Nada se puede objetar a esta tentativa, y las nociones de certeza y evidencia son efectivamente criterios de verdadero conocimiento. El problema surge cuando estas nociones son elevadas a criterios últimos de toda verdad. Y ello no sólo porque no toda verdad es del toda cierta y evidente, sino sobre todo porque son muy pocas las verdades que pueden superar esas condiciones tan exigentes. La denodada búsqueda de esos estrictos criterios de rigurosidad, exactitud y certeza, alienta paradójicamente la amenaza de un escepticismo, que se nutre precisamente de esas radicales exigencias con los que se espera combatirlo y vencerlo. El fracaso de la filosofía posthegeliana en la búsqueda de un fundamento último e indubitable de la totalidad del conocimiento ha llevado a reconocer y poner de relieve el sutil lazo que une las exigencias de certeza y evidencia con el fenómeno del nihilismo. Asimismo, la actitud nihilista que impera en el auge del actual irracionalismo es también un efecto perverso de las excesivas demandas a las que se somete la razón. Ello debido a que nada se considerará verdadero, confiable y racionalmente justificado si no se estima como evidente, cierto e indubitable. Pero a las verdades a las que se accede siguiendo ese implacable método son muy pocas y nada relevantes. Son escasas las que se pueden considerar realmente fundadas si es que hay que atenerse a los criterios de necesidad, evidencia y certeza. También cabe plantearse si esta estrecha consideración de lo que se considera "la ciencia", indirectamente ha contribuido a dar un impulso al relativismo a la hora de interpretar la realidad social, cultural y política.

Todo esto lo ha visto con lucidez Alejandro Vigo cuando sostiene: "Tanto el nuevo auge del irracionalismo, bajo las figuras del relativismo y el nihilismo, como la reinterpretación reductiva de la racionalidad, como una racionalidad de corte puramente instrumentalista y calculadora, sólo pueden comprenderse en su motivación interna y en su verdadero alcance contra el trasfondo silente, pero no por ello menos efectiva pervivencia de las exigencias radicales de apodicticidad y certeza que caracterizan el ideal moderno del conocimiento"12. Mostraba asimismo que en el contexto del pensamiento griego de la época clásica, la noción de episteme, en su sentido más estrecho, que remite a un conocimiento necesario y apodíctico, nunca llegó a adquirir una centralidad tan excluyente como para servir de modelo de la racionalidad como tal. Sobre todo la filosofía aristotélica siempre destacó la existencia y legitimidad de otras formas específicas del conocimiento y de elaboración racional que no podían ser reducidas sin más a los patrones propios de la episteme. Aristóteles se niega a conceder que la filosofía práctica, es decir la ciencia que tiene por objeto el ámbito de comprensión moral abierto originariamente por la phronesis, la

\footnotetext{
12 Ponencia inédita de Alejandro Vigo "Entre certeza y nihilismo. La razón en busca de una nueva fortaleza" que presentará en el Congreso Cultura y Racionalidad. Líneas de diálogo y convergencia en la sociedad pluralista organizado por la Universidad de Navarra (19-20-21 de noviembre de 2007) en la mesa junto con Enrico Berti bajo el título "Necesidad de una racionalidad fuerte" (20 de noviembre).
} 
prudencia o sabiduría práctica, pueda ser concebida en términos semejantes a las matemáticas, y enfatiza, en cambio, que dicha ciencia posee un método propio y específico a la hora de abordar su propio objeto ${ }^{13}$. Se puede decir que un rasgo definitorio del pensamiento aristotélico es lo que se ha llamado (Vigo, Wieland) su pluralismo metódico, que contrasta nítidamente con la marcada tendencia al monismo metódico que caracteriza a la corriente principal del pensamiento filosófico de la Modernidad, cuyo ideal matemático del conocimiento adquirió un claro predominio y también fue, todo hay que decirlo, muy fecundo en frutos maduros y efectos benéficos. Para Aristóteles lo propio del hombre culto consiste en buscar, en cada caso, el tipo y el grado de exactitud que corresponde a la naturaleza del asunto tratado, con el fin de evitar las extrapolaciones metódicas ilegítimas. Tan absurdo sería exigir al matemático que argumente de modo persuasivo como pedir al orador que lleve a cabo demostraciones matemáticas ${ }^{14}$.

No ha sido casual que varias corrientes del pensamiento contemporáneo hayan adoptado la concepción aristotélica de la racionalidad, y particularmente la idea de la phronesis, como punto de partida para la recuperación de formas del conocimiento que el paradigma moderno había marginado. Bajo modalidades diversas cabe aludir aquí la hermenéutica de Gadamer y Ricoeur, la teoría de la racionalidad de MacIntyre y la teoría analítica de la acción y racionalidad práctica en la línea de Anscombe y Kenny.

No podemos dejar de considerar que el actual panorama científico y filosófico poco tiene que ver con el positivismo agresivo que predominó a fines del siglo XIX y primera mitad del siglo XX. El pensamiento contemporáneo ha realizado una significativa tarea de ampliación de la racionalidad y de la ciencia, en su esfuerzo por liberarla del estrechamiento producido por una interpretación puramente instrumental y calculadora de la razón. Baste considerar la actual reconstrucción hermenéutica de la racionalidad, en su lucha por ampliar el campo de la experiencia de sentido que está unido a la noción de comprensión. Esos intentos reincorporan tanto la dimensión narrativa de la racionalidad como el vínculo existente entre racionalidad e historicidad. También la filosofía contemporánea ha sometido a una crítica demoledora a la idea de una razón sin supuestos, pretendidamente libre de todo presupuesto que no sea ella misma.

Asimismo, la ciencia contemporánea, en su práctica efectiva, ya dejó atrás hace bastante tiempo la presunta absoluta "objetividad" del conocimiento científico. Tampoco se encuentra atada al viejo ideal monolítico de la ciencia como conocimiento apodíctico y necesario, que por sus mismas exigencias desmesuradas, ya no son viables. La epistemología contemporánea, entre ellas el principio de la falsabilidad de Popper, han contribuido a una mayor humildad metodoló-

\footnotetext{
${ }^{13}$ Cfr: Aristóteles, Ética a Nicómaco II, 1094b1-27.

${ }^{14}$ Cfr: Ética a Nicómaco II, 1094b22-27.
} 
gica y a dejar definitivamente atrás visiones superadas, por muy arraigadas que éstas pudieran estar en la génesis histórica e identidad de la ciencia moderna.

Los desarrollos más recientes, tanto en el campo filosófico como el de la epistemología de las ciencias, tienden a recuperar una visión más amplia y diferenciada de la racionalidad y de la ciencia, que hacen mayor justicia a las diversas dimensiones de la realidad. Si ello es así, ¿cómo se explica este rebrotar del irracionalismo en sus modalidades del nihilismo y relativismo, y la recurrente proclama de acta de defunción de la metafísica? Una posible respuesta a esta interrogante cultural la propone Alejandro Vigo, cuando considera que en la actualidad perviven elementos correspondientes a un estado de conciencia ya superados, que conservarían una suerte de operatividad residual, en virtud de la cual, por así decirlo, se sobreviven a sí mismos, durante un tiempo que puede ser incluso bastante largo. Es lo que acontece con las exigencias de necesidad, certeza y evidencia que son constitutivos del ideal moderno de conocimiento, y que durante mucho tiempo se han considerado merecedores exclusivos del nombre de verdadero conocimiento. Lo cito: "La representación de una razón autosustentada, completamente libre de presupuestos, orientada a partir de exigencias de certeza de carácter maximalista, que renuncia a la variedad de sus posibles formas de despliegue para refugiarse en una concepción unilateral del método, de la cual pretende derivar una representación puramente constructiva de su propia identidad, ha mostrado constituir, en definitiva, el ardid por el cual tiene lugar una fuga de la razón ante sí misma. La nueva fortaleza de la razón ha de buscarse, inversamente, por el camino de la recuperación de la totalidad de sus posibles formas de manifestación y despliegue, recuperación que, a su vez, sólo resulta posible, como tal, a partir de una clara conciencia de la especificidad de cada una de esas posibles formas de despliegue, así como también, en general, de los límites internos que están trazados de antemano a toda legítima aspiración de fundamentación y a toda genuina exigencia de autotransparencia que la propia razón pueda plantearse a sí misma”15. Si bien la cita es larga, y en su peculiar estilo germánico, es del todo aguda, lúcida y sintetiza la cuestión planteada.

Sólo una razón más consciente de su propia vulnerabilidad, y por ello más humilde, pero también capaz de recuperar la confianza en sí misma, puede tener la energía y magnanimidad suficiente para abrirse a dimensiones de trascendencia.

\footnotetext{
${ }^{15}$ Vigo, Alejandro. "Entre certeza y nihilismo. La razón en busca de una nueva fortaleza”. Art. cit. p. 19.
} 
VI. FENOMENOLOGÍA DE HEIDEGGER 


\title{
El Secreto Mejor Guardado: \\ La Historia bajo Reservas
}

\author{
Cristóbal Durán R.
}

Universidad Academia de Humanismo Cristiano

Para Manuela

Quisiera empezar a mostrar, con todo lo apresurado que pueda ser y por lo pronto intentando tomar todas las precauciones del caso, quisiera mostrar, pues, que hay una delgada pero ostensible línea que liga estrechamente el temprano proyecto de destrucción de la historia de la ontología, presente desde el umbral de Ser y tiempo, y especialmente sensible a la hora de reformular la noción de fenómeno-logía, pasando por la versión del método fenomenológico en Los problemas fundamentales de la fenomenología, hasta llegar a la caracterización más tardía de la epokhé, con el estatuto que ella adquirirá en el interior del plan de la historia del ser.

Con esto no espero decir nada nuevo, pues únicamente tiendo a relevar la línea que es posible seguir, y que ha sido advertida en varios lugares y para diversos propósitos, en el desarrollo específico de la fenomenología heideggeriana, tal y como ella se despliega transformándose desde, sobre todo, los años veinte hasta los años sesenta. Lo que primero me interesa aquí es cómo la cuestión de la época pareciera responder a una exigencia cuyos rastros pueden ser tempranos en el proyecto de Heidegger, y que ella no puede dejar indemne a la destrucción de la metafísica. Pero el problema de la época, y sobre todo de la epokhé (del ser mismo), no deja de comprometer al pensamiento heideggeriano de la historia, precisamente en el punto donde ella parece someterse a la más poderosa de sus fricciones. Que esto se sostiene en una relación con Hegel que sólo tardíamente se volverá más explícita en su cometido, es algo que aquí recién empezaré a avanzar.

Relanzar la pregunta por el ser concierne a una relación con la historia de la metafísica que sea capaz de repetir una pregunta, en una vuelta a solicitar que no sea la repetición de lo ya sido. Por ello, la relación con la ontología tiene que ser primero fenomenológica: "Por consiguiente, elaborar la pregunta por el ser significa hacer que un ente -el que pregunta- se vuelva transparente 
en su ser" ${ }^{1}$. Y para ello tendrá que tener lugar una nueva formalización de la reducción. Pero para poder llevar a cabo el bosquejo de dicha elaboración, es preciso que la pregunta por el ser ya se empiece a revelar en su fundamental historicidad. Ya que la comprensión del ser y aquel ente que puede plantear su interrogación se hace o se efectúa como marco pre-comprensivo de sus propias condiciones, la noción de reducción requiere de un paso crítico: para sustraer al ser de su mera determinación presente, para sustraerlo de su sentido determinado como ousía o parousía, es decir, cuando la historicidad se tenga que revelar $(\$ 66)$ como manera originaria de la estructura de temporalización de la temporalidad -pues el modo en que el ente que interroga se interroga es el extenderse- será necesario entonces una destrucción de la historia que permita alcanzar sus fuentes. Sólo así se podrá demostrar en qué sentido se puede hablar de una repetición [Wiederholung] de la pregunta ${ }^{2}$.

La destrucción quedará así, para siempre, atada a la posibilidad de una repetición o, quizá más precisamente, a la abertura de una repetición considerada como posibilidad. Pero antes de precisar el horizonte que aquí tendrá que apelar a la historia, la posibilidad es también ínsita a la determinación del fenómeno que se desarrolla en el marco metodológico de la analítica existenciaria del Dasein. Para empezar a abrir la determinación del ser del ente como parousía, Heidegger recurrirá a una reformulación del concepto de fenomenología, más allá de su comprensión husserliana, pero junto con ella. En lo que asemeja a un primer gesto de destrucción de un término fundamental, tratará de reconducir dicha palabra a otra parte que su uso escolar o, mejor, repitiendo lo que ella habrá podido llegar a ser, pero que efectivamente no ha sido ${ }^{3}$.

La historia de la consideración del fenómeno, del ente "fenómeno", ha sido su propio encubrimiento. Confundido entre la apariencia, la mera manifestación, o el brillo de lo que aparece, Heidegger resuelve que la mostración fenoménica ha tenido que ser siempre un supuesto incluso en la mostración sintomatológica como modelo que intenta señalar un campo ausente a partir de una presentación que se pretende indicándolo. La manifestación encubre el mostrarse. Pero al examinar la doble determinación que se reúne en la palabra fenómeno, tanto lo que se muestra como la apariencia de lo que se muestra, advierte una dependencia -histórica, si se quiere- que confiere a dicho doble

1 Heidegger, Martin. Ser y tiempo, § 2. Santiago: Editorial Universitaria, 1996, p. 30.

2 Ibid., $\$ 6$, p. 50 .

3 En lo que, recién advirtiéndose en la pronunciación de sus rasgos, podría empezar a mostrarse en conexión con cierta "hermenéutica de lo impensado", como la denomina Philippe Lacoue-Labarthe en otro contexto, pero también en referencia a Heidegger. Aquí empezamos a notar su filiación fenomenológica y, en lo que sigue, su dependencia de una destrucción de la cuestión misma del fenómeno y de lo que conlleva en otras determinaciones que remiten a la presentación y a su dificultad: la mostración, el aparecer, la manifestación, el síntoma. Habrá que tenerlo presente. De todos modos, y en cierto sentido de manera tangencial, la interrogante por dicha hermenéutica habrá sido una herencia de Hölderlin: finalmente una cierta relación con la tradición -en el caso hölderliniano, con los griegos- que simplemente intente decir lo que fue dicho (pero) como lo que no fue dicho; o, en suma, una mimetología que atormenta todo pensamiento de la referencia, incluso de una que esté por principio prohibida o que fuese originariamente soslayada (Cf. Lacoue-Labarthe, Ph. "La césure du spéculatif". L'imitation des modernes. Paris: Galilée, 1987, p. 53. Para el enunciado de una "hermenéutica de lo impensado", véase: Le sujet de la philosophie (Typographies, I). Paris : Aubier-Flammarion, 1979.) 
sentido, una coherencia interna estructural ${ }^{4}$. Sólo a partir de la destrucción de la palabra "fenómeno-logía", que busca afianzar el carácter de esta mostración, podremos empezar a reparar también en el doblamiento indisoluble que se hace necesario pensar así en la cuestión del fenómeno. El Decir que muestra, el logos apophantikos, va a ser la significación precisa que tendría que hacer notar que el mostrar -el mostrar en su decir, lo que se muestra en sí mismo, en cuanto tal- des-encubre el ser del ente en el enunciado. La fenomenología tendría que ser, así, el modelo de administración metodológica para reabrir -repetir- la pregunta por el ser del ente, reorientada ahora según el programa de la destrucción de la historia de la ontología.

Ahora bien, antes de ir al punto que aquí me interesa, quisiera detenerme sólo unos segundos sobre la llamada continuación de Ser y Tiempo, las lecciones de Marburgo del año 1927, publicada bajo el título Los problemas fundamentales de la fenomenología. Ahí, junto a la definición de la tarea fenomenológica en términos de la mostración del fundamento óntico de la ontología, se intenta abrir al problema de la aprehensión de las estructuras del ser que parecería anterior al ente y que, no obstante, tendría que no ser sometido a un esquema que piense en las determinaciones ónticas meros atributos de un ser considerado como hypokeimenon. Para ello tendrá que valerse de la reducción fenomenológica, entendida ahora como el pasaje que va desde la comprensión concreta de un ente hacia la comprensión del ser de ese ente, proyectada sobre el modo de su estar velado 5 . Esta proyección que se vuelve sobre las estructuras del ser, que literalmente empieza a abrir su posibilidad, es un segundo componente del método, que Heidegger denomina construcción. Pero además a este circuito del método le hace falta la destrucción, o lo que Heidegger aquí preferirá denominar Abbau, deconstrucción, implicando con ello la destrucción vigilada del ser del ente tal como ha sido recibida por tradición, construyendo lo que la ontología fundamental tiene que mostrar en destrucción en su superposición a la tradición. "La construcción de la filosofía -dice Heidegger- es necesariamente destrucción, es decir, una deconstrucción de lo transmitido llevada a cabo mediante un regreso a la tradición, que no significa una negación de ella ni un prejuicio que considere que la tradición no es nada, sino, por el contrario, una apropiación positiva de ella”'

Éste es, al parecer, la sistematización metodológica que tendría que dar a entender el fuerte enunciado, que pareciera definir todo el circuito metodológico de la ontología fundamental, "la ontología sólo es posible como fenomenología", y que obedece a intentar pensar imperativamente el ocultamiento o encubrimiento del ser del ente. La fenomenología es la posibilidad de la ontología, en tanto los fenómenos por los que tendría que pasar o conducir la interrogación ontológica no están dados ni inmediata ni regularmente; están encubiertos.

\footnotetext{
${ }^{4}$ Ibid., § 7, A, p. 52.

${ }^{5}$ Heidegger, M. Los problemas fundamentales de la fenomenología, § 5. Madrid: Trotta, 2000, p. 47.

${ }^{6}$ Ibid., § 5, p. 48-49.

${ }^{7}$ Ser y Tiempo. Op. Cit., § 7, C, p. 58.
} 
La mostración que tendría que encaminar a la ontología tal como Heidegger la va a empezar a pensar sería una mostración que tendrá que retener su encubrimiento. Pero para ello va a ser la misma fenomenología en su sentido husserliano, la comprensión heideggeriana de la fenomenología de Husserl, si acaso es una, la que no podrá ser entendida sólo a partir de un campo que circunscriba a sus entes, llamados "fenómenos" de una manera particular, sino que la clave de la fenomenología va a ser la de comprenderla no como la efectividad de una disciplina filosófica, sino que va a consistir, únicamente, "en aprehenderla como posibilidad". Quizá allí se decante toda la destrucción de la noción misma de "fenómeno": quizá la fenomenología es una posibilidad en la medida en que el fenómeno no podrá en principio estar dado.

Me interesa, entonces, en este punto tratar de delinear esta urgencia por pensar la posibilidad [Möglichkeit]; tanto la posibilidad que tendrá que abrir fenomenológicamente el nuevo sentido de la ontología, como la posibilidad que tendrá que ser la fenomenología para poder suspender su determinación óntica y, a través de ello, que en esta comprensión de la fenomenología como posibilidad algo haya quedado sin cerrar completamente a la historia misma del ser. La relación heideggeriana con la tradición se empieza a labrar en dicha posibilidad y ella trasunta precisamente lo que se denomina deconstrucción: La deconstrucción de lo transmitido como apropiación positiva de la tradición. La deconstrucción, que relanza bajo otros visos el tópico de la destrucción de la historia, posee un arraigo que no es puramente metodológico, sino por entero nocional y casi sistemático para el problema de la historicidad del Dasein en Ser y Tiempo. A fin de cuentas, la pregunta por el ser ha caído en el olvido en tanto aquel ente que esencialmente interroga no ha sido pensado por la tradición como acontecer que se proyecta sobre sus poder-ser, una tradición que ha obliterado de diversos modos la finitud que circunscribe la posibilidad más propia del Dasein, y que orienta existencialmente su relación con la tradición. La Entschlossenheit, la resolución, es aquello que envía existencialmente la abertura del Dasein a sí, reuniendo en dicha abertura -en su estar abierto- la relación con una herencia que se envía en cada posibilidad, o mejor, que se envía en cuanto posibilidad. Cito un breve pasaje del $\$ 74$ de Ser y Tiempo:

La resolución, en la que el Dasein retorna a sí mismo, abre las posibilidades fácticas del existir propio a partir del legado que ese existir asume en cuanto arrojado?

En lo que aquí es una entrega que el Dasein hace de sí mismo a sí mismo, y que traza la versión existencial del Destino [Schicksal], en cuanto posibilidad

\footnotetext{
${ }^{8}$ Ibíd., § 7, C, p. 61.

${ }^{9}$ Ibíd., p. 399.
} 
heredada y elegida, cifra también la repetición como modo en el cual la resolución se entrega a sí misma y se envía destinalmente ${ }^{10}$. Por ello, finalmente, el destino [Geschick] va a tener que ser considerado como historicidad propia y, según la definición de Heidegger de esta última, bajo la comprensión de la historia como "el "retorno" de lo posible"11. Trato muy rápidamente de articular varios pasos de mi argumento, tratando de enriquecer el motivo de la repetición. Justo cuando es decretada la finitud del Dasein como horizonte de su extenderse, no como término ni resto pendiente, es decir, no como efectividad, sino como posibilidad más propia, la repetición, en cuanto medida de relación con la tradición, tiene que ser pensada como re-petitio, como solicitación de lo posible que ha de permanecer siempre como posible. Es aquí donde, creo, la historicidad del Dasein tiene que volverse sobre la cuestión más amplia de la historia y que, en estos textos de fines de los años veinte, es la historia en deconstrucción que intenta, a partir de la repetición de un posible re-lanzar cualquier efectividad de la historia, cualquier conteo de la historia de lo ya-sido. Pero no hay que perder de vista que dicha repetición viene de un envío, enviada por tradición o como tradición, razón por la cual la historia de la ontología como historia del ser del ente tendrá que ir cediendo paso a una historia que se retira en la misma tradición, sin desacreditarla. El retorno a la tradición, deconstructivamente, no es un retorno a lo ya sido, sino una apropiación positiva que reposa en el carácter propio del Dasein, es decir, en la repetición propia de una posibilidad de existencia. Por eso, y lo sabemos, hacia el final de Ser y Tiempo se hace alusión a un pueblo, el reconocimiento de la historia se empieza decantando atado a su posibilidad de ser un pueblo. La asunción de la finitud, que desemboca en la simplicidad de su destino, de un destino común que es el de un pueblo, que se delinea en la resolución es la "repetición de una posibilidad de existencia recibida por tradición"12. Cito el que a mi parecer es el pasaje más comprometedor de Ser y Tiempo en este sentido:

La repetición propia de una posibilidad de existencia que ya ha sido -que el Dasein escoja su héroe- se funda existencialmente en la resolución precursora; porque en ella se hace por primera vez la opción que libera para el seguimiento combatiente y para la fidelidad a lo repetible ${ }^{13}$.

Desde luego sería casi imposible empezar a comprender dicho breve y apretado pasaje sin todo el argumento que lo hace posible. Me limito meramente a reconstruir -tendenciosamente, por cierto- lo que retendrá mi interés en lo que sigue. Si la resolución podría ser en cierto sentido el envío que el Dasein hace de sí y que hace posible su retorno a sí, y si este envío, Schicksal, es a fin

\footnotetext{
${ }^{10}$ Me permito remitir, al pasar, a un apartado precedente a este punto, desarrollado gruesamente en mi trabajo "La decisión silente. Voz y decisión en Heidegger". Anuario de Postgrado. № 6 (2005), Facultad de Filosofía y Humanidades, Universidad de Chile.

${ }^{11}$ Ibid., § 76, p. 407.

${ }^{12}$ Ibíd., § 74, p. 401.

${ }^{13}$ Ibíd.
} 
de cuentas destino, Geschick, todo el lanzamiento de la historicidad del Dasein reposa, por así decir, sobre la repetibilidad de una posibilidad, pero que ha sido sólo en cuanto posibilidad. El Dasein es destino porque se compromete en la fidelidad al "retorno" de lo posible, y porque esa es su historicidad propia. Esta fidelidad no es entonces la del miramiento limitado a lo ya sido, sino a lo que "ya ha sido" en cuanto posibilidad de existencia: o, dicho otra vez sintéticamente, una historicidad que queda definida en la fidelidad a la solicitación de lo posible que permanece reservado en cuanto posible. La posibilidad es engarzada más adelante con un retorno, según el cual lo que denominamos fidelidad es la estabilidad existentiva peculiar del Dasein. De este modo, la posibilidad encerrada en la repetición mantiene bajo resguardo lo inicial de lo que mucho más tarde Heidegger dirá que "no pasa nunca, no es nunca algo pasado"14.

Así, de la relectura del fenómeno "ente", que lo reduce para empezar a abrir el problema del ser, y gracias a una abertura incesante que tendría que pensar el envío superpuesto de sus presentaciones, conservando su abertura como posibilidad, el problema de la repetición es el problema de una atadura con la tradición que no se puede enviar por entero en su disponibilidad ${ }^{15}$.

\section{III}

Repetición, destrucción, tradición. Todo un pensamiento específico de la fidelidad está aquí en juego. Fidelidad a lo repetible, al retorno de lo posible. Un pensamiento de la herencia que tendrá que ser medido con la herencia del pensamiento, con el pensamiento como tradición heredada. Pero con esto, tendríamos que empezar a advertir que, en los términos que aquí hemos empleado, la repetición de lo posible en cuanto deconstrucción de lo transmitido es la modalidad de relación con la tradición, es decir, en este punto, algo así como el pensamiento heideggeriano de la herencia. Sobre cómo heredar, cómo recibir una herencia, y que ella se haga ostensible en una pregunta enviada en su sustracción, es algo que podremos pensar sólo más tardíamente en Heidegger. Ya que es la misma pregunta la que no puede quedar rendida en la respuesta que se pretenda clausurante; interrogación que es justamente la abertura a una tradición que nunca ha sido, sino que queda suspendida. Como en este breve pasaje del Epílogo a Was ist Metaphysik?, del año 1943: "La respuesta esencial saca su fuerza de la constancia del preguntar. La respuesta esencial es sólo el comienzo de una responsabilidad [Verantwortung], en la cual despierta el preguntar de modo más originario. Por eso, la auténtica pregunta tampoco es superada [nicht aufgehoben] por la respuesta hallada"16. El que la

\footnotetext{
${ }^{14}$ Heidegger, M. Nietzsche II. Barcelona: Destino, 2000, p. 397.

${ }^{15}$ Por lo demás, este tópico tendría que ser medido, siempre, cada vez, con la relación con la tradición y con la Rückfrage, pero sobre todo con la cuestión del modelo para una transmisión del origen en la fenomenología de la historia. Remito, por la íntima conexión que habrá que sopesar todavía, entre la historia heideggeriana y la husserliana, a mi trabajo "Una confianza infinita en la abertura. El mitema husserliano de la historia”. Patricio Mena e Iván Trujillo (comps.). La crisis interminable de la razón. Libros del entrevero / Universidad Alberto Hurtado, 2008.
} 
respuesta no logre nunca colmar su pregunta es que ella sólo es el comienzo de una responsabilidad ante la constancia o la insistencia del interrogar ${ }^{17}$. Pero también, que no logre nunca colmar su pregunta es que ésta última no puede ser superada, relevada, contenida, aufgehoben. Porque la tradición de dicha pregunta no podrá ser repetida a partir de una pura contención.

Pese al uso común de la palabra Aufhebung, no requeriría mucho esfuerzo mostrar que en el pasaje recién citado ella compromete a Hegel, o mejor aún, al esfuerzo de resguardo de la auténtica pregunta o incluso del asunto, del Sache des Denkens, frente a la consumación hegeliana del pensamiento. La contraposición -auseinandersetzung- con Hegel llega a ostentar desde muy temprano un cierto estatuto estratégico para la consignación de cierto horizonte epocal. Esto no sólo lo podemos advertir de manera evidente en una serie de textos de los ańos 1940 y 1950, sino también llegar a rastrearlo en las primeras discusiones concernientes a replantear la cuestión de la historicidad en el marco de la ontología fundamental. Pero, también, notar que ostenta dicho estatuto es empezar a advertir además que la urgencia de su enfrentamiento con Hegel es para Heidegger una señal de un punto aparentemente intransitable que plantea aquél. Entonces, de algo que ambos habrían de reconocer como una exigencia.

Hace ya unas décadas, el recientemente fallecido filósofo francés Philippe Lacoue-Labarthe dejaba señalada, al pasar, la siguiente inquietud, que parecía concentrar o sintetizar, en cierto sentido, algo referido a los alcances de dicha exigencia: "el cierre o la clausura heideggeriana, [es] en su género [...] incluso más temible que la hegeliana" ${ }^{18}$. El pasaje desde donde se desprende esta pequeña frase, enorme o arriesgándose incluso a ser desproporcionada en sus consecuencias, remite también al estatuto de Nietzsche dentro de la destrucción de la ontología y deja patente la situación de deslinde a la que nos enfrentaríamos también en la contraposición de Heidegger con el pensador de la Umdrehung des Platonismus. Pero sin todavía detenernos sobre esto, habría que volver sobre el enunciado mencionado, por lo que pareciera emparejar o nivelar, bajo un mismo género, aquello que no sólo mostraría las similitudes y diferencias entre la clausura heideggeriana y la hegeliana, sino que sobre todo supondría que hay algo en el género de la clausura heideggeriana que al compararla con la hegeliana la hace incluso más temible [encore plus redoutable]. Es esto mismo lo que llevará a Lacoue-Labarthe en otro texto, "L'oblitération", escrito a partir de la lectura del Nietzsche de Heidegger, a señalar que, al distinguir el pensamiento en Heidegger del pensamiento en Hegel, y considerando que precisamente lo que está en juego en su relación es el asunto del pensar, Sache des Denkens, "lo que constituye la dificultad del pensamiento -y por con-

\footnotetext{
${ }^{16}$ Heidegger, M. “Epílogo a « ¿Qué es metafísica? »”. Hitos. Madrid: Alianza, 2000, p. 252.

${ }^{17}$ Como se señala enfáticamente y de manera casi inequívoca en el siguiente pasaje de la Introducción a la metafísica, de 1935, a la metafísica se le oculta el ser como tal, "que permanece olvidado de manera tan decisiva que el olvido del ser cae, él mismo, en olvido: es decir, se olvida el desconocido pero constante impulso del preguntar metafísico.” Heidegger, M. Introducción a la metafísica. Barcelona: Gedisa, 1993, p. 27.

${ }^{18}$ Lacoue-Labarthe, Ph. "Nietzsche apocryphe". Le sujet de la philosophie (Typographies, I). Paris: AubierFlammarion, 1979, p. 79.
} 
siguiente la dificultad del acceso a Heidegger-, no es otra cosa que la dificultad del exceso (fuera) de Hegel (es decir, también, según la ley del retorno y de la apropiación, [la dificultad] del retroceso en Hegel)"19.

Al leer conjuntamente ambos pasajes, todavía desprendidos de la explicación acuciosa y detallada que requieren sus contextos, podríamos empezar a entrever los trazos de lo que tendríamos que llamar una exigencia. Lo formulo a la manera de una tesis: si la dificultad con Heidegger no es en este punto, más que la dificultad -imposible- del exceso en el interior de la clausura hegeliana del pensamiento, entonces la clausura heideggeriana será más temible por tanto que intentará responder a lo imposible de dicha tarea. Quizá, y eso es parte de nuestra hipótesis, intentando redoblar o sobrepujar los medios de dicho cometido.

Heidegger reconoce en todos los lugares en donde precisa hablar de Hegel, un mismo rasgo: en la medida en que la filosofía es el despliegue del espíritu hacia un saber absoluto y que por ello la historia es la historia de la filosofía, Hegel es el primero en reconocer que el filosofar se mueve en su historia y que, así, el movimiento de dicha historia es la filosofía misma ${ }^{20}$. "Hegel es el único pensador de occidente que hizo la experiencia pensante de la historia del pensamiento" ${ }^{21}$. Por eso en el caso de Hegel la filosofía es llevada a su cúspide, pues la misma palabra fundamental hegeliana, la dia-léctica, es la recolección y reunión de un pensamiento que se piensa a sí mismo en cuanto sujeto que auto-produce su subjetividad. La exigencia que mencionábamos a propósito de la rivalidad histórica con Hegel, no puede ser otra que la de discernir una historia oculta, como lo señala en la Introducción a la Metafísica, donde la pregunta por el ser -que es, como sabemos, la pregunta por la diferencia ontológica- pueda llegar a advertirse, recogiéndola, en cada pensamiento. A fin de cuentas, la medida del diálogo con la historia es la tarea que conduce desde un impensado en todo pensar, hasta el bosquejo de lo por-pensar. Cito:

...se trata de penetrar en la fuerza del pensar anterior. Sólo que nosotros no buscamos la fuerza en lo ya pensado, sino en un impensado del que lo pensado recibe su espacio esencial. Pero lo ya pensado sólo es la preparación de lo todavía impensado, que en su sobreabundancia, retorna siempre de nuevo. La medida de lo impensado no conduce a integrar lo pensado con anterioridad dentro de un desarrollo y una sistematización todavía más altos y que lo superan, sino que exige la puesta en libertad del pensar transmitido para que pueda entrar en su ser anterior todavía conservado ${ }^{22}$.

Este pasaje, tomado de Identidad y Diferencia, de 1957, recoge el intento de diferenciación explícita respecto al diálogo de Hegel con la tradición. Y no

\footnotetext{
${ }^{19}$ Lacoue-Labarthe, Ph. "L'oblitération". Le sujet de la philosophie. Op. Cit., p. 126-127.

${ }^{20}$ Cf., entre otros, "Hegel y los griegos". Hitos. Op. cit., p. 346.

${ }^{21}$ Heidegger, M. "Der Spruch des Anaximander" (1946). Holzwege. Frankfurt am Main: Vittorio Klostermann, 1980, p. 298.

${ }^{22}$ Heidegger, M. "La constitución onto-teo-lógica de la metafísica". Identidad y Diferencia. Barcelona: Anthropos, 1988, p. 111 (Subrayado mío).
} 
me detendré en él todo lo que debería. Tan sólo me interesa la iniciativa de ampliación rescendente -tomando la expresión de Schelling- frente a lo "ya pensado". Es lo impensado que, sobreabundante, retorna siempre de nuevo. La historia va a ser entonces una historia del pasar por alto ${ }^{23}$, que no obstante conserva destinalmente el envío de una fuente que es "lo no preguntado por nadie a lo largo de toda esa historia del pensar." (ID, 113) ${ }^{24}$. Si de lo que se trata aquí es de una apropiación no-dialéctica de la tradición, y por ende, tal como se sigue de las citas, de una programación de lo aún no ocurrido, que no por falta de atención nuestra, como se señala en las últimas líneas de la conferencia Hegel y los griegos, es incapaz de concertarse en una historia de lo ya sido, sino porque tendría que sostenerse sustrayéndose, insoslayable. ¿Pero cómo puede repetirse lo así insoslayable, sin una apropiación que termine siendo dialéctica? En varias ocasiones, Heidegger nos señala que lo impensado, ese "todavía no", digno de ser pensado, es retenido fuera de la representación metafísica ${ }^{25}$. Nos aguarda, así, en una proximidad que se retira, porque nunca está disponible; evitando la fijación, dejando al ser y no haciéndolo presente. La historia del ser, a la manera de un palimpsesto, reitera que el ser mismo ocasiona el dejar fuera ${ }^{26}$, que "el ser mismo esencia como este retener en sí" $^{27}$.

Si el precipitado de la deconstrucción tendrá que poder llamarse aquí impensado, si la reducción-construcción de lo ya pensado a una verdad esencial es posible, para ello tendrá que ser dado re-lanzar la suspensión, pues no se puede contaminar con la presencia. Sin la fijación del envío que sostiene lo impensado a través de la metafísica ininterrogado, no queda más que pueda dejar marcado su figura en retirada. Este es el sentido del verbo epekein. Pero también la contención. Por eso es posible, que quizá el envío sea epocal, es decir reservado y en sustracción, para que se anuncie recubriéndose. Hay que volver atrás para enlazar pasajes de Tiempo y Ser, o de La Sentencia de Anaximandro.

\footnotetext{
${ }^{23} \mathrm{Y}$ así, por ende, lo que acontece, es decir, la historia del ser es el ser mismo como "historia del permanecer fuera" (Heidegger, M. Nietzsche II, Op. cit., p. 315), en el que el permanecer fuera del desocultamiento del ser es en cuanto tal como un advenimiento del ser mismo.

${ }^{24}$ Como nos dice Heidegger, el destino [Geschick] también puede ser -y así ha sido- "ir en contra del ser mismo", un ir en contra que sólo se explica por el predominio de este olvido, que de alguna manera tiene que estar para que marche el "sistema" de lo descrito por Heidegger. (Cf. Nietzsche II. Op. cit., p. 298).

${ }^{25}$ Hago constar esto a partir del siguiente pasaje de "Envoi" de Jacques Derrida: “Así, el mundo del platonismo habría hecho el envío para el reino de la representación, habría destinado a éste, lo habría destinado sin estar sometido a su vez a él. Habría sido, en el límite de este envío, como el origen de la filosofía. Ya y todavía no. Pero ese ya-todavía-no debería ser el ya-todavía-no dialéctico que organiza toda la teleología de la historia hegeliana y en particular el momento de la representación (Vorstellung) que es ya lo que no es todavía, su propio desbordamiento. El Geschick, el Schicken y la Geschichte de los que habla Heidegger no son envíos del tipo representativo. La historialidad que constituyen no es un proceso representativo o representable, y para pensar esto es necesaria una historia del ser, del envío del ser que no esté ya regulada o centrada en la representación. Así pues, queda aquí por pensar una historia que no sea ya de tipo hegeliano o dialéctico en general. Pues la crítica hegeliana o neohegeliana de la representación (Vorstellung) parece que ha sido siempre un relevo (Aufhebung) de la representación que mantiene a ésta en el centro del devenir, como la forma misma, la estructura formal más general del relevo de un momento a otro, y esto además en la forma presente del-ya-todavía-no." (Derrida, J. Psyché. Inventions de l'autre. Paris: Galilée, 1987, p. 124)

${ }^{26}$ Heidegger, M. Nietzsche II. Op. Cit., p. 308.

${ }^{27}$ Idem, p. 310.
} 
La cuestión del fenómeno en tanto implicación esencial de lo que el ente es en sí mismo y lo que no es en sí mismo, implicación que al estar esbozada sobre la temporalización no es un dualismo, no sólo no-ocultamiento (Un-verborgenheit) sino des-ocultación (Ent-borgenheit), nos hace pensar en cómo la reserva puede ser no-representable, cómo se reserva una posibilidad que pueda retenerse sin poder apuntar su efectuación. Una abertura siempre posible porque ya cerrada en su envío, ya consignada en el límite de su abertura. Esa podría ser la metafísica, pero a través de la epocalidad de la historia del ser, de un encadenamiento destinal de envíos. Pero para ello la historia del ser tendría que ser, en algunos puntos, claramente distinguible o discernible de la filosofía, de la historia de la metafísica, o del despliegue espiritual de la conciencia hacia el saber absoluto. No confundirse con una anamnesis filosófica ni con el despliegue del Absoluto. Para ello el envío más inicial pudo nunca tener lugar, porque se entregó reservado, lo que quiere decir que llegando, puede no llegar, puede no encontrar el destinatario capaz de recibirlo, de escucharlo. Guarda el secreto, reservándolo, reservándoselo, antes de que pueda ocurrir, de que pueda efectuarse. Pero entonces que la historia reserve su fuente es o podrá ser también decir que reservando su fuente como secreto ocurre en cuanto secreto y que impide que pueda no ocurrir; en la fuente de la metafísica, el secreto mejor guardado. 


\title{
El Problema Antropológico en la Filosofía Heideggeriana
}

\author{
Enrique V. Muñoz Pérez \\ Universidad Católica del Maule
}

Para Marisela

\begin{abstract}
Resumen
La presente comunicación pretende mostrar que, a pesar de la interpretación habitual del pensamiento heideggeriano, el problema antropológico es desarrollado por Heidegger de manera detallada en el entorno de Ser y Tiempo. Como modelo, he elegido la "lección magistral" (Vorlesung) del año 1929/30 denominada Los conceptos fundamentales de la metafisica. Mundo, finitud, soledad (Die Grundbegriffe der Metaphysik. Welt-EndlichkeitEinsamkeit).
\end{abstract}

\section{Introducción}

Algunas lecturas del pensamiento de Heidegger tienden a obviar apresuradamente la relación entre el programa de Ser y Tiempo y la antropología filosófica. Tal parece que basta con interpretar correctamente el parágrafo $\$ 10$ de la obra principal de Heidegger para dar la discusión por terminada. En otras palabras, dado que Heidegger sostuvo allí que la analítica del Dasein tiene que ser diferenciada de ciertas disciplinas particulares - entre otras, de la biología y de la psicología ${ }^{1}$-, el desarrollo del problema antropológico a partir de la filosofía heideggeriana sería un esfuerzo inútil e innecesario.

La intención de la presente comunicación es discutir esta interpretación del pensamiento heideggeriano. En otras palabras, pretendo sostener que el problema antropológico es desarrollado por Heidegger de manera detallada en el entorno de Ser y Tiempo. Como modelo, he elegido la "lección magistral" (Vorlesung) del año 1929/30 denominada Los conceptos fundamentales de la metafísica. Mundo, finitud, soledad (Die Grundbegriffe der Metaphysik. WeltEndlichkeit-Einsamkeit) ${ }^{2}$. Esta lección, considerada por uno de los biógrafos de

\footnotetext{
${ }^{1}$ Será necesario mostrar que los cuestionamientos e investigaciones hechos hasta ahora apuntando hacia el Dasein, sin perjuicio de su productividad en los respectivos campos de averiguación, yerran el verdadero problema, el problema filosófico, y que, por ende, mientras persistan en este error no pueden pretender siquiera estar capacitados para llevar a cabo aquello a que en el fondo aspiran. La fijación de los límites de la analítica existencial frente a la antropología, la psicología y la biología, se refiere solamente a la pregunta ontológica fundamental". M. Heidegger. Ser y Tiempo. Traducción, prólogo y notas J. E. Rivera. Santiago de Chile: Editorial Universitaria, 1997, p. 70 ss. El subrayado es mío. En adelante será citado como $S T$.

${ }^{2}$ M. Heidegger. Die Grundbegriffe der Metaphysik. Welt-Endlichkeit-Einsamkeit, GA Bd. 29/30, editado por F.-W. von Herrmann, Frankfurt a.M.: Editorial Vittorio Klostermann, 1992.
} 
Heidegger, me refiero a Rüdiger Safranski, como una de las obras principales de Heidegger, si bien poco conocida ${ }^{3}$, constituye un gozne privilegiado entre Ser y Tiempo y los Aportes a la filosofía (Beiträge zur Philosophie).

Más precisamente, quiero demostrar que la caracterización del "ser humano como formador de mundo" (Der Mensch als weltbildend) es una respuesta, a modo heideggeriano, al problema antropológico central, es decir, a la pregunta: ¿qué es el hombre?

En consecuencia, la presente comunicación se dividirá en: (1) El lugar de la antropología filosófica al interior de ST, (2) El problema antropológico en la lección magistral Los conceptos fundamentales de la metafísica y (3) Algunas consideraciones finales.

\section{El Lugar de la Antropología Filosófica al Interior de Ser y Tiempo}

Desde su publicación en el año 1927, ST de Martin Heidegger es un texto que ha sido interpretado desde las más diversas perspectivas. La obra fundamental de Heidegger ha sido entendida, cuando menos, como una ruptura con la tradición metafísica occidental, como una heterodoxa manera de interpretar la fenomenología de Husserl, como uno de los impulsos decisivos del pensamiento postmoderno o como una original, pero a la vez, compleja manera de comprender la condición humana. Es decir, para algunos intérpretes, ST se enmarcaría en el ámbito de la denominada "antropología filosófica". Sobre esta manera de comprender $S T$ se pronunció el propio Heidegger explícitamente en desacuerdo ${ }^{4}$. Sin embargo, tal parece que este "provechoso malentendido" 5 ha seguido permaneciendo.

No pretendo insistir en una interpretación antropológica de la mencionada obra de Heidegger, sino que busco esclarecer el rol que ocupa la antropología filosófica en $S T$ y bosquejar sus proyecciones en el entorno de esa obra. Por ello, comenzaré caracterizándola como ambigua y relevante.

La noción de "antropología" en $S T$ es, sin duda alguna, ambigua. Heidegger, por ejemplo, utiliza expresiones como "antropología”, "antropología filosófica", "antropología tradicional” e incluso "a priori de una antropología existencial". Con los primeros usos, es decir, "antropología” o "antropología tradicional”, busca Heidegger deslindar, por un lado, metodológicamente la analítica existencial y, por otro lado, mostrar la insuficiencia ontológica de

\footnotetext{
${ }^{3}$ R. Safranski. Ein Meister aus Deutschland. Heidegger und seine Zeit. Frankfurt a.M.: Editorial Fischer, 2001, p. 217.

${ }^{4}$ La pregunta por la interpretación antropológica de $S T$ fue planteada, entre otros, por Richard Wisser en el diálogo con Martin Heidegger a propósito de su 80 cumpleaños. Cf. R. Wisser, Martin Heidegger im Gespräch, ZDF, p. 69.

${ }^{5}$ G. Figal. "Martin Heidegger", en Großes Werklexikon der Philosophie, editado por Franco Volpi, Stuttgart: Editorial Alfred Kröner, 1999, p. 660.
} 
caracterizaciones del hombre como "animal racional", "imagen y semejanza de Dios" o "sujeto". Sin embargo, la expresión "antropología existencial" reviste para mí una especial relevancia temática.

Recordaré, entonces, el pasaje correspondiente de $S T$.

Lo expuesto hasta aquí necesitaría ser completado en muchos sentidos si se quisiera obtener una elaboración exhaustiva del a priori existencial de la antropología filosófica. Pero ésa no es la finalidad de la presente investigación. Su propósito está en la línea de una ontología fundamental. (Heidegger, p. 156. La cursiva es mía.)

La pregunta que se impone es la siguiente: ¿por qué Heidegger deja un espacio abierto para una "antropología existencial" en ST? La respuesta inmediata sería sostener que una posible "antropología existencial” llevaría a cabo algunas investigaciones específicas, que no interesa o no sería necesario desarrollar en el marco de una ontología fundamental ${ }^{6}$. Siendo esta interpretación correcta, me parece insuficiente. Lo anterior, porque se restringe únicamente al marco dado por la obra fundamental de Heidegger, sin apreciar los alcances de una expresión como la de "antropología existencial".

Por el momento, me parece plausible afirmar que sobre bases filosóficamente suficientes, en terminología heideggeriana, a partir de la ontología fundamental, es posible identificar en el pensamiento de Heidegger el bosquejo de una "antropología filosófica”, en términos generales. Ella desarrollaría un rol complementario en relación al análisis del Dasein. Dichos análisis han sentado las bases de una descripción de la vida o de la existencia humana; ellos suministran, también, algo que debería quedar en un segundo plano, según lo entiende el propio Heidegger en $S T^{7}$, es decir: los rasgos fundamentales de una antropología filosófica, que no se ocupa del hombre como desde fuera, como si fuera un ser vivo al que nosotros pudiéramos "fijar" en su esencia, sino que hace comprensible el ser del hombre a partir del Dasein ${ }^{8}$. En otras palabras, si existiera algo así como una antropología de características heideggerianas, ella debiera fundamentarse en el ser del hombre, cuya base se encuentra en las estructuras del Dasein.

Con todo, esta no es la única pista que uno puede identificar en $S T$. Heidegger comenta, por cierto marginalmente, el estatus de la "pregunta por el hombre" en su pensamiento. Cito a Heidegger:

\footnotetext{
${ }^{6}$ Esta es, por ejemplo, la interpretación de von Herrmann. Cf. F.-W. von Herrmann. Hermeneutische Phänomenologie des Daseins. Frankfurt a.M.: Editorial Vittorio Klostermann, 1987.

7 "La analítica del Dasein así concebida está orientada por entero hacia la tarea de la elaboración de la pregunta por el ser, que le sirve de guía. Con esto se determinan también sus límites. Ella no puede pretender entregarnos una ontología completa del Dasein, como la que sin duda debiera elaborarse si se quisiera algo así como una antropología 'filosófica' apoyada sobre bases filosóficamente suficientes. En la perspectiva de una posible antropología o de su fundamentación ontológica, la siguiente interpretación proporciona tan sólo algunos 'fragmentos"”. M. Heidegger, Ser y Tiempo, p. 41.

${ }^{8}$ En este punto de mi comunicación sigo la interpretación de Figal. Cf. G. Figal, "El pensar como tomar un aliento", en Sileno. Variaciones sobre arte y pensamiento, editado por Félix Duque. Madrid: 2001, Volumen 11, p. 57.
} 
En la Introducción ya se hizo ver que la analítica existencial del Dasein contribuye a promover una tarea cuya urgencia es apenas menor que la de la pregunta misma por el ser: poner al descubierto aquel a priori que tiene que ser visible si la pregunta "qué es el hombre" ha de poder ser filosóficamente dilucidada. (Heidegger, pág.70. La cursiva es mía)

Responder la pregunta por el hombre es una tarea no menor y pendiente para Heidegger. Tendremos que esperar algunos años para conocer su respuesta. Específicamente hasta el semestre de invierno de 1929/30 donde se llevará a cabo la lección magistral Los conceptos fundamentales de la metafísica.

\section{El problema antropológico en la lección magistral Los conceptos fundamentales de la metafísica}

La mencionada lección está dividida en dos partes: en la primera, Heidegger describe fenomenológicamente un "estado de ánimo fundamental” (eine Grundstimmung) conocido como "el aburrimiento" (die Langeweile). En la segunda, nos presenta una nueva concepción del mundo, dentro de la cual emerge el problema antropológico.

Respecto de la primera parte de la lección magistral, hay que decir que el tema del "aburrimiento" se enmarca en una discusión más amplia, esto es, la crítica de Heidegger al análisis del hombre de su época. Ella se reduce a ser no más que una crítica cultural, sin percatarse que el ser del hombre ha devenido en "aburrimiento" en esta situación. Por eso, Heidegger insiste en distintos textos del entorno de ST en la "liberación del Dasein en el hombre" (die Befreiung des Dasein im Menschen). Finalmente, cabe decir que el "aburrimiento" es caracterizado por Heidegger como una relación con el tiempo o como un "sentimiento del tiempo" (Zeitgefühl) ${ }^{10}$, el que es comprendido en tres niveles: "el llegar a estar aburrido de algo" (das Gelangweiltwerden von etwas), "el aburrirse junto a algo" (das Sichlangweilen bei etwas) y "esto es aburrido" (es ist langweilig).

Como decía con anterioridad, la segunda parte de la lección magistral es particularmente fascinante. En primer lugar, Heidegger desarrolla una nueva aproximación a la noción de mundo, en comparación con $S T$ y con De la esencia del fundamento (1929). Él deja a un lado el análisis del "estar-en-elmundo" y también el estudio histórico de la noción de "mundo". Su intento, en Los conceptos fundamentales de la metafísica, toma la forma de una comparación entre la piedra, el animal y el hombre. Heidegger al respecto enuncia las siguientes tesis: "la piedra es carente de mundo" (der Stein ist weltlos), "el animal es pobre de mundo" (das Tier ist weltarm) y "el hombre es formador

\footnotetext{
${ }^{9}$ Cf. GA 29/30, p. 115.

10 "Langeweile - was immer ihr letztes Wesen sein mag - zeigt fast handgreiflich, und besonders in unserem deutschen Wort, ein Verhältnis zur Zeit, eine Art, wie wir zur Zeit stehen, ein Zeitgefühl”. GA 29/30, p. 120.
} 
de mundo" (der Mensch ist weltbildend). Con todo, antes de comentar estas tesis, es interesante mostrar cómo Heidegger rehabilita también la pregunta por el hombre en esta lección magistral: la pregunta por el hombre puede ser entendida como "la pregunta por la formación del mundo" (die Frage nach der Weltbildung). Esto es, aquella tarea pendiente de $S T$ es ahora cumplida. Cito a Heidegger:

Esta esencia general del hombre como tal, sólo llega a ser esencial, cuando el individuo se comprende en su Dasein. La pregunta, qué es el hombre, correctamente formulada, entrega al hombre explícitamente a su Dasein. Esta entrega al Dasein es el índice de la finitud interna.

Es necesario hacer referencia precisamente a esto: porque esta problemática hoy día está sometida a la corriente mal interpretación del entendimiento vulgar. (...) La pregunta por la formación del mundo es la pregunta por el hombre que nosotros mismos somos, es decir, la pregunta por nosotros mismos, o sea, concretamente, por lo que está pasando con nosotros. (...) Sin embargo nosotros no hemos dicho nada, en la primera parte de la lección de la esencia del hombre y todavía menos de lo que nosotros llamamos formación de mundo y mundo. (GA 29/30, p. 408. La traducción es mía).

Parafraseando a Heidegger, hasta el momento se ha dicho poco acerca del problema antropológico y de cómo éste se relaciona con el mundo. Para ello es necesario volver a las tesis antes mencionadas. Heidegger inicia su análisis con la comparación entre la primera y la segunda tesis, es decir, "la piedra carece de mundo" y "el animal es pobre de mundo". La diferencia entre el animal y la piedra se encuentra, a juicio de Heidegger, en una desigual aproximación al mundo. La piedra ni siquiera puede relacionarse con el mundo, cuestión que al animal le es permitido.

Por otro lado, una primera diferencia entre el hombre y el animal se encuentra en que el animal se comporta o se conduce de manera distinta que el hombre. Heidegger reserva el verbo alemán 'benehmen' para referirse al animal y el verbo 'verhalten' para referirse al hombre; en un español coloquial traduciríamos ambos verbos alemanes como 'comportarse'. Sin embargo, la diferencia decisiva entre el hombre y el animal está en la "capacidad de remitirse" o "en el remitirse" (die Versetzbarkeit y das Sichversetzen). Por eso puede sostener Heidegger que la expresión "Dasein im Menschen” signifique, en esta ocasión, "el poder remitirse a otros seres humanos" (das Sichversetzenkönnen in anderen Menschen). El fundamento de esta posibilidad se encuentra en una característica del Dasein: "el existir con" (das Mitexistieren): 
Dado que el ser humano existe, está ya remitido como tal a otros seres humanos, incluso cuando fácticamente no hay ningún ser humano cerca de él. Da-sein del ser humano, Dasein en el ser humano significa en consecuencia - no exclusivamente, pero entre otros significados - el estar remitido a otro ser humano. El poder remitirse a otros seres humanos, entendido como acompañarlos, con el Dasein en ellos, acontece ya siempre sobre la base del Dasein en el ser humano - como Dasein. Es decir Dasein significa coestar con los otros, concretamente, en el modo del Dasein, esto es, existir con. La pregunta podemos los seres humanos remitirnos a otro ser humano, es sin sentido, porque no es una verdadera pregunta. Ella es sin sentido, es más absurda, porque es esencialmente superficial. (GA 29/30, p. 301. La traducción es mía.)

No obstante lo anterior, el punto decisivo a mi juicio se encuentra en la asociación que hace Heidegger al final de la lección Los conceptos fundamentales de la metafísica entre la "formación de mundo" (die Weltbildung) y el "ser humano como historia” (der Mensch als Geschichte). Previamente clarifica Heidegger que la estructura básica o fundamental (die Grundstruktur) de la "formación del mundo" es el "proyecto" (der Entwurf) ${ }^{11}$. En ese marco, comenta Heidegger, que el "hombre es un tránsito" (der Mensch ist ein Übergang):

El ser humano es aquel no-poder-permanecer y sin embargo no poder salir de su lugar (...) Arrojado de esta manera en el arrojo es el ser humano un tránsito, tránsito como esencia fundamental del acontecimiento. El ser humano es historia, o mejor, la historia es el ser humano. (GA 29/30, p. 531. La traducción es mía.) ${ }^{12}$

Ante la pregunta por el hombre, Heidegger responde que éste es un modo de ser histórico, el que es representado como un tránsito en la dirección del Dasein. Por eso el hombre debe transformarse o debe cambiar o debe alcanzar el nivel del Dasein, que naturalmente no significa lo mismo que en $S T$. El Dasein es ahora un modo de ser advenidero, el Dasein es aquello que podemos ser, a partir del hombre que nosotros somos.

De este modo, el "ser humano" (der Mensch) se constituye en el pensamiento ontológico de Heidegger en un elemento relevante de su reflexión, que está en camino del "giro" (die Kehre). Él es percibido como una figura histórica, como una especie de "coagulado" o de "concentrado" de todo lo que ha se dicho respecto de la noción de ser humano, como una especie de tradición constituida, lo que pasa a ser parte del Dasein.

\footnotetext{
11 "Entwurf ist Weltentwurf. Welt waltet in und für ein Waltenlassen vom Charakter des Entwerfens". (GA 29/30, p. 527). Trad.: "Proyecto es proyecto de mundo. El mundo "tiene el poder" o "rige" en y para un "dejar regir" [propio] del carácter del proyectarse".

12 "Der Mensch ist jenes Nicht-bleiben-können und doch nicht von der Stelle Können. [...] So geworfen im Wurf ist der Mensch ein Übergang, Übergang als Grundwesen des Geschehens. Der Mensch ist Geschichte, oder besser, die Geschichte ist der Mensch". (GA 29/30, p. 531).
} 
De esta manera, me parece, que puede sustentarse razonablemente una relación entre el pensamiento ontológico de Heidegger y la pregunta por el hombre en la lección Los conceptos fundamentales de la metafísica.

\section{Algunas consideraciones finales}

El problema antropológico en el pensamiento heideggeriano puede ser constatado en sus tres dimensiones, esto es, el concepto "hombre" o "ser humano" (Mensch), la "pregunta por el hombre" y la "antropología filosófica". En este último caso, los desarrollos de Heidegger son menores; el tema es tratado en extenso en una conferencia inédita de Heidegger titulada Philosophische Anthropologie und Metaphysik des Daseins (1930), donde sostiene que una eventual "antropología filosófica" debe fundarse en la "comprensión del ser" (das Seinsverständis).

Por su parte, Heidegger no continúa en los textos que conforman el entorno de los Aportes a la filosofía el desarrollo de la pregunta por el hombre como "pregunta por la formación del mundo" (die Frage nach der Weltbildung).

Me parece, sin duda, que la reflexión más productiva de las tres es el tema del "hombre" o "ser humano" (der Mensch). Uno puede identificar una transformación en el pensamiento de Heidegger que va desde su rehuida en $S T$ hasta su reformulación en los Aportes a la filosofía, pasando por su rehabilitación en Los conceptos fundamentales de la metafísica. En otras palabras, uno puede encontrar en el pensamiento de Heidegger caracterizaciones tan variadas del hombre como "objeto" (Gegenstand), como "formador de mundo" (weltbildend), como guardián del ser (Wächter des Seyns), como animalidad (Animalitas) o como mortal (sterblich), que reflejan su distanciamiento de comprensiones del hombre propias de la antropología teológica, de la biología, de la psicología o de la técnica moderna.

Sin embargo, la filosofía heideggeriana no se queda en una mera crítica del problema antropológico; puesto que es posible reconocer claramente una concepción del hombre en el pensamiento de Heidegger. Ella, no obstante su desarrollo, modificación o transformación, puede ser caracterizada como: filosófica, liberadora, modeladora del mundo y finita.

1) La concepción del hombre en Heidegger es filosófica, porque independiente de los adjetivos con que uno califique ciertos períodos del pensamiento de Heidegger - esto es, "trascendental", "metafísico", "tardío" - uno puede reconocer una constante: la defensa de la tarea del filosofar. En ese marco, sale a luz la concepción del hombre de Heidegger que se aleja tanto de la intromisión 
de las ciencias como de los análisis filosóficos insuficientes. En otras palabras, dado que el hombre es un ente extraordinario, debe ser tematizado a partir de una nueva perspectiva filosófica.

2) La concepción del hombre en Heidegger es liberadora, no porque ella persiga una liberación política o religiosa, sino que porque ella quiere sacar a la luz la estructura ontológica de la existencia humana. Ello implica que el hombre actual debe transformarse y dirigir su mirada al Dasein que lleva dentro. Este es su desafío.

3) La concepción del hombre en Heidegger es propia de una esencia formadora del mundo. El hombre para Heidegger desarrolla un rol decisivo en la construcción del mundo. El hombre, sobre la base que le da el Dasein, modela o forma activamente su entorno; y es responsable de ello.

4) La concepción del hombre en Heidegger es finita, porque ella es, por así decirlo, consciente de los límites de la existencia humana. El hombre es un ente que, a diferencia de las plantas o los animales, tiene el privilegio de existir y no sólo de vivir; además, sabe que esa existencia está limitada por la muerte.

De este modo, espero haber presentado el problema antropológico en el pensamiento de Heidegger, meta de la presente comunicación. 


\title{
Juicio Retóricamente Motivado y Aperturidad: Heidegger Lector de la Retórica Aristotélica*
}

\author{
Roberto Rubio \\ Universidad Alberto Hurtado
}

\begin{abstract}
Resumen
El presente trabajo se centra en la recepción heideggeriana de la doctrina aristotélica sobre la formación del juicio retóricamente motivado. Se intenta mostrar que Heidegger encuentra en la teoría de los medios técnicos de persuasión el hilo conductor que le permite diseñar la tríada de disposición afectiva, dianoia práctica y logos práctico en tanto estructura formal de la aperturidad.
\end{abstract}

La publicación de la lección del semestre de verano de 1924 "Conceptos fundamentales de la filosofía aristotélica”, en el año 2002, ha arrojado nueva luz sobre la recepción heideggeriana de la Retórica de Aristóteles. El texto ratifica aspectos destacados por Heidegger en otros escritos, en particular su interés por el análisis aristotélico de las pasiones y su valoración de la Retórica como Hermenéutica de la cotidianidad.

Por otra parte, en la lección se manifiesta una apropiación de la Retórica que va más allá de los estudios del Dasein cotidiano. A continuación se intentará mostrar que la Retórica constituye un aporte para la elaboración de la estructura fundamental de la aperturidad.

\section{La Retórica y la doctrina de la aperturidad}

Sostiene Heidegger:

El hablar unos con otros es el hilo conductor para mostrar el fenómeno fundamental del estar al descubierto del Dasein mismo como ser-en-un-mundo. Tomamos como hilo conductor concreto la Retórica, en tanto ella no es otra cosa que la interpretación del Dasein respecto de la posibilidad fundamental del hablar unos con otros ${ }^{1}$.

A la base de este planteo se encuentra el siguiente razonamiento: la vida en

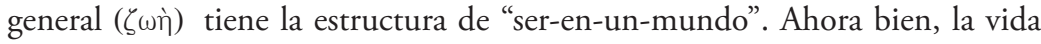

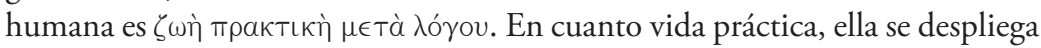

* Proyecto Fondecyt 11060023 


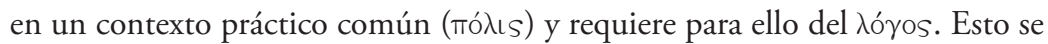
muestra concretamente en el fenómeno del hablar con otros sobre cuestiones prácticas: mediante el hablar con los otros se vuelve accesible el conjunto de los posibles caminos para la obtención del bien común. El mundo público, esto es, el complejo de cuestiones de la vida común, no es posible sin el discurso. La Retórica, en tanto se dedica al campo de la praxis y analiza el discurso público, ofrece entonces el hilo conductor para la investigación de la relación constitutiva entre el mundo y la conducción vital, y con ello, para el esclarecimiento de la aperturidad.

Lo que Heidegger tiene ante los ojos es el proceso en el que el mundo prefigura la deliberación práctica y ésta a su vez repercute sobre la configuración de mundo. Según esto, por un lado el mundo práctico, en tanto nexo de opiniones y valoraciones establecidas, predetermina la deliberación en cada situación. Y por otro lado la deliberación, motivada por la discusión y el discurso públicos, produce una determinada toma de posición integrable en el nexo de las opiniones reconocidas.

El énfasis sobre este fenómeno marca la interpretación de la definición de la Retórica en Ret. I $2^{2}$ :

Determinación de la retórica: ver aquello que está a favor de una

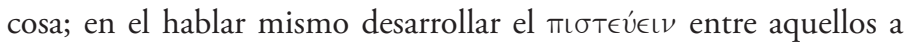
quienes uno habla, y en cada caso acerca de un asunto que está en debate: desarrollar una $\delta o ́ \xi a^{3}$.

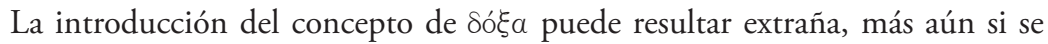
considera que Aristóteles explicita el fin de la retórica como el desarrollo de un

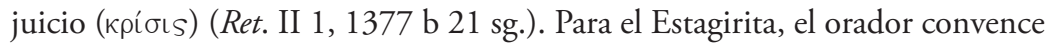
a su auditorio en tanto lo lleva a juzgar de determinado modo. Ahora bien,

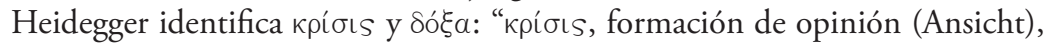

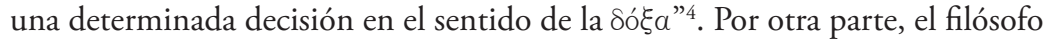
alemán concede que se trata de la opinión "en sentido estrecho" ${ }^{5}$, pues la $\delta$ ó $\xi a$ puede referirse tanto a lo contingente - característico del ámbito práctico cuanto a lo necesario.

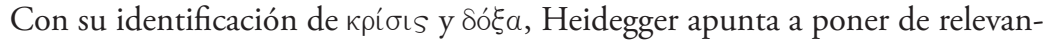
cia el proceso antes mencionado: El juicio del oyente, retóricamente motivado,

\footnotetext{
${ }^{1}$ Heidegger, Martin. Grundbegriffe der aristotelischen Philosophie. Francfort del Meno: Klostermann, 2002, editado por M. Michalski, p. 139. Este fragmento del texto en alemán y los que se citarán posteriormente han sido traducidos por el autor del presente artículo.

${ }^{2}$ Para las citas de la Retórica de Aristóteles se considera aquí la edición de las obras completas de Aristóteles realizada por Bekker y corregida por Olof Gigon: Aristoteles (1831-1870): Aristotelis opera. Berlin: Akademie, 1960-1963.

${ }^{3}$ Heidegger, Martin. Grundbegriffe der aristotelischen Philosophie. Francfort del Meno: Klostermann, 2002, editado por M. Michalski, p. 118.

${ }^{4}$ Ib., p. 163.

${ }^{5}$ Ib., p. 149.
} 
está predeterminado por las opiniones predominantes o $\epsilon^{\prime \prime} \nu \delta \circ \xi \alpha$. Ahora bien, el juicio mismo es $\delta o ́ \xi \alpha$, esto es, una toma de posición que introduce una nueva opinión en el contexto de los ê $ૈ \delta \circ \xi \xi$. "Sobre ello se tienen determinadas intuiciones, hay determinadas $\delta o ́ \xi \alpha$, a partir de las cuales habla el orador de

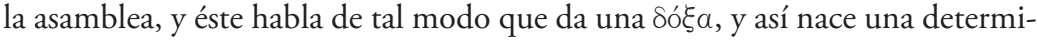
nada $\delta o ́ \xi a$ entre los otros"'.

La afirmación, según la cual la Retórica ofrece el hilo conductor para mostrar la estructura del estar al descubierto, puede explicitarse entonces del siguiente modo: La investigación acerca de la relación recíproca entre la formación del

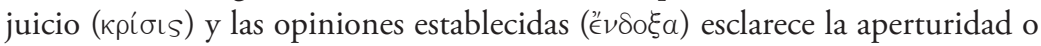
el "estar al descubierto" cotidiano.

En este punto se impone una doble tarea: en primer lugar, se debe exponer el concepto de aperturidad utilizado en la lección de 1924. En segundo lugar, hay que precisar de qué manera la interpretación sobre la formación del juicio retóricamente motivado da lugar a una presentación sistemática de la estructura de la aperturidad.

\subsection{El concepto de aperturidad en la lección sobre la Retórica}

Para Heidegger, lo que es se manifiesta de algún modo, y se manifiesta siempre en un ámbito de comprensibilidad ya vigente. La experiencia del ente a partir de dicho fondo de sentido es una interpretación. Ahora bien, el hacer accesible al espacio de comprensibilidad - necesario para la interpretación - es caracterizado como un "abrir" ("erschließen"). En correspondencia con ello, el ámbito de sentido tiene el carácter de la "aperturidad" ("Erschlossenheit").

Ahora bien, la doctrina de la aperturidad no concierne exclusivamente al "mundo", tomado como un momento aislado. Por el contrario, ella pretende dar cuenta de la unidad de la estructura mayor "ser en el mundo". En la terminología de Heidegger, la "aperturidad" (o bien el "estar al descubierto", como aparece en la lección sobre Retórica) corresponde al "ser en", es decir, a la perspectiva unitaria que engloba al sí mismo y al mundo. "Queremos sacar a la luz en última instancia el fenómeno del ser-en [...] El Ser-en-el-mundo es el carácter fundamental del Dasein respecto a su estar al descubierto."7 El "seren" no indica un tercer momento entre el vivir humano y el mundo de la vida. Significa más bien la relación recíproca en la que ambos se forman: por un lado el vivir mantiene abierto al mundo vital; por otro lado, el mundo prefigura los modos de vivir en él.

Para indicar estos dos momentos correlativos, Heidegger utiliza las expresiones

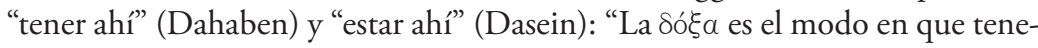

\footnotetext{
${ }^{6}$ Ib., p. 130.

${ }^{7}$ Ib., p. 139.
} 
mos ahí a la vida en su cotidianidad”; “ $\Delta$ ó $\xi a$ es el modo en que el mundo del ser unos con otros está ahí” . A la base de esta conceptualidad se encuentra el uso ontológico de la voz "ahí". Heidegger la utiliza para nombrar el espacio de sentido en el cual todo lo que es viene a manifestación. En última instancia, el "ahî" es la dimensión de sentido del ser del ente: todo ente, en tanto es, es "ahí", y esto significa: se muestra con sentido, aparece desde un horizonte de sentido. "Tener ahí" al mundo y a la vida significa entonces hacer accesible un ámbito estructurado de sentido que contenga las determinaciones de ser del viviente y de los entes con los que trata. Y correlativamente el modo en que tales determinaciones prefiguran la experiencia es el modo en que el mundo vital "está ahî"10.

\subsection{La interpretación heideggeriana de la formación del juicio retóricamente motivado}

Debido a la brevedad requerida para esta presentación, el presente trabajo se concentrará en uno de los momentos de la estructura general de la aperturidad, a saber: el "tener ahî".

Heidegger elabora su doctrina del "tener ahí", en gran medida, mediante la interpretación de la doctrina aristotélica sobre los medios técnicos de persuasión para la formación del juicio.

La lectura heideggeriana se asienta sobre ciertas decisiones previas. En primer lugar, cabe mencionar la marcada orientación hacia el discurso deliberativo ${ }^{11}$. Ella va de la mano con una peculiar interpretación de la situación retórica. Heidegger pone el acento, no en el discurso hacia los destinatarios, sino más bien en la situación del hablar unos con otros en el sentido de la deliberación conjunta en la asamblea. "El sobre-qué de la Retórica es el hablar-unos-conotros-deliberativamente [...]"12. En este sentido, la diferencia entre el orador y el oyente se relativiza, pues "cada uno es [...] tanto oyente como hablante." ${ }^{13}$ Tal concepción dialógica de la situación retórica le permite concentrar las determinaciones aristotélicas en una figura unitaria, esto es, el oyente-hablante que forma un juicio.

\footnotetext{
${ }^{8} \mathrm{Ib} ., \mathrm{p} .138$.

${ }^{9}$ Ídem.

${ }^{10}$ Esta terminología no está exenta de ambigüedades. El término "Dasein" no indica solamente un momento de la estructura "ser-en", sino que es utilizado ante todo para caracterizar dicha estructura en su conjunto. En este sentido, Heidegger habla de "Dasein humano".

${ }^{11}$ El primado de la oratoria deliberativa encuentra apoyo en diversos pasajes de la Retórica. La cuestión ocupa un lugar destacado en la discusión actual entre los intérpretes de Aristóteles. Véase, por ejemplo, Rapp, Christof. Aristoteles. Rhetorik. Darmstadt: WBG. 2002, 2 semitomo, pp. 172 sg; Rese, Frederike. Praxis und Logos bei Aristoteles. Handlung, Vernunft und Rede in Nikomachischer Ethik, Rhetorik und Politik. Tubinga: Mohr Siebeck, 2003, pp. 287-290.

${ }^{12}$ Heidegger, Martin. Grundbegriffe der aristotelischen Philosophie. Francfort del Meno: Klostermann, 2002, editado por M. Michalski, p. 136.

${ }^{13}$ Ib., p. 263.
} 


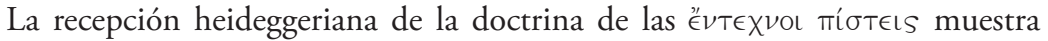
dos caras. Por un lado, Heidegger realiza una interpretación en estilo convencional. Ésta vale como exposición inicial del tema para los asistentes a la lección. Por otro lado, él desarrolla su peculiar interpretación, orientada a la estructura del "tener ahí". Para ello no se concentra en la influencia persuasiva del discurso respecto al juicio, sino en las condiciones estructurales de éste. El resultado es el planteo de la triple articulación del "tener ahî" en disposición

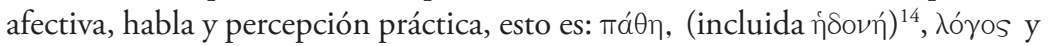
voũs práctico. " $\Lambda$ óos en el voũs. Noũs en cuanto "cómo" del ser-en, determi-

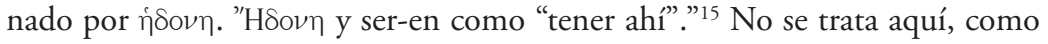

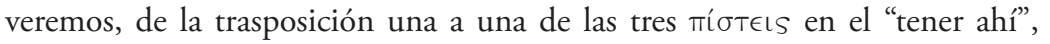
sino más bien de una reinterpretación que toma en cuenta además la teoría aristotélica del voũs.

\subsection{1. Пá日os}

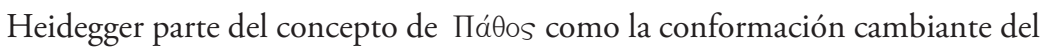
ser humano. No se trata de una pasividad estática, sino de la inquietud propia de la vida humana, que determina a ésta como el estar en tránsito de una conformación a otra. En concreto, se trata de los afectos como aquella movilidad del hombre, por la cual éste sale del dominio de sí.

Desde esta perspectiva se pone de relieve la cuestión ética de la relación hacia las pasiones. La relación del virtuoso hacia los afectos, es decir, la templanza, es interpretada como el estado de dominio. El acento está puesto en la conexión estructural entre el "estado de dominio" y el Пá $\theta$ os como la movilidad del "caer fuera de dominio" 16 .

Estas reflexiones abren el camino para la interpretación ontológica de la observación aristotélica, según la cual el modo en que se toma una decisión y se efectúa un juicio práctico está codeterminado por una disposición afectiva. Sobre el fondo de la reconducción del juicio práctico hacia la estructura del "tener ahí", la influencia de los afectos sobre el juzgar es interpretada en el sentido de que la disposición afectiva es un momento estructural del "tener ahí".

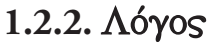

En sus análisis sobre la Retórica, Heidegger dirige la atención hacia el logos

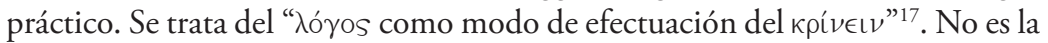
estructura lógica de los argumentos retóricos lo que ocupa el centro de interés,

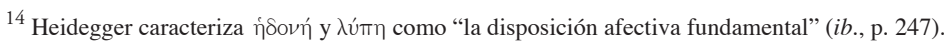

${ }^{15} \mathrm{Ib}$. , p. 365.

${ }^{16} \mathrm{Ib}$., pp. $184 \mathrm{sg}$.

${ }^{17}$ Ib., p. 248.
} 
sino la función del lenguaje como articulación de la vida práctica cotidiana. Los estudios aristotélicos sobre la argumentación retórica ofrecen un punto de apropiación en la medida en que refieren al proceso circular de la formación del juicio. "Para esta tarea, partir del e[ndoxon y alcanzar un $\epsilon^{\prime} \nu \delta o \xi o v$, están las

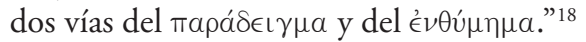

Heidegger traduce $\lambda \dot{\gamma}\} \in \nu$ por "hablar" (Sprechen). Éste comprende tanto al $\lambda o \gamma i \zeta \in \sigma \theta a$, esto es, el cálculo de las opciones de acción posibles, cuanto a la expresión de esas posibilidades, por ej. en el debate. Para Heidegger se trata de un mismo

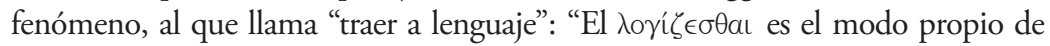

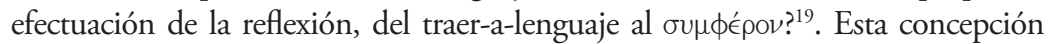
amplia de "hablar" tiene en su base la caracterización del lenguaje como articulación de sentido, en la doble acepción de organización y expresión ${ }^{20}$.

La doctrina sobre el logos aquí expuesta va de la mano con la comprensión heideggeriana de la praxis como interpretación que "deja ser" lo interpretado. Según dicha comprensión, el proceso de deliberación y resolución, en el cual se destaca el практóv a partir del horizonte de fines, consiste en una interpretación, mediante la cual el ente práctico aparece como tal desde un fondo de sentido. Que el "hablar" haga expreso al практóv, no significa que nombre algo que ya estaba ahí: "hablar" es interpretar, dejar que algo se muestre, poniéndolo en relación con su contexto de sentido. Así, la deliberación deja aparecer algo como provechoso o perjudicial.

\subsubsection{Noṽs y ठlávola}

La recepción heideggeriana del voũs no está orientada hacia la Retórica, sino hacia los libros primero y tercero del De Anima.

La caracterización aristotélica del voũs como luz o medio de visibilidad guía la presentación del fenómeno de la aperturidad como tal: "[...] así, todo enteahi en tanto ente requiere una iluminación fundamental para estar ahi. El ente mismo como ente-ahí debe tener la posibilidad del estar abierto. Esta posibilidad no es otra cosa que el voũs" 21 .

Por otro lado, Heidegger elabora un concepto más acotado de voũs, que indica un momento del "tener ahî". Se trata, ya no de la "claridad" en general, sino del "percibir" (Vernehmen) o captación inmediata, propia del vivir humano. Para estudiarlo, se dirige a los análisis aristotélicos sobre el voũs práctico.

La interpretación del voṽs y la dıávota prácticos aparece ya en el así llamado

\footnotetext{
${ }^{18}$ Ib., p. 130.

${ }^{19} \mathrm{Ib} ., \mathrm{p} .59$.

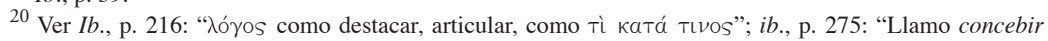
previo a la comprensibilidad dominante, que incluye al pronunciar como articulación".

${ }^{21} \mathrm{Ib}$., pp. $201 \mathrm{sg}$.
} 
"Informe Natorp". La argumentación principal de Heidegger en este punto es la siguiente: Toda interpretación consiste en dejar que algo se muestre "como" algo. Esta estructura caracteriza la vida práctico-operativa: allí, el ente nos adviene siempre "como" algo: una cosa como útil para algo, una acción posible como beneficiosa o perjudicial en relación a la jerarquía de fines. Ahora bien, debido a que la vida práctica es interpretación, también al voũs práctico le corresponde la estructura "como". En este caso se puede hablar de dıávota práctica. "El практıкòs voṽs, el percibir (Vernehmen) al modo del trato que

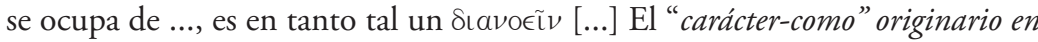

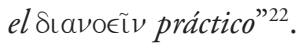

Con esto, Heidegger no niega que haya momentos de captación inmediata en la efectuación del saber práctico, tales como la aprehensión noética del fin y del практо́v. Su intención es más bien indicar que, en tanto el saber práctico consiste en coordinar el fin dado con los medios apropiados y guiar hacia la acción correspondiente, los momentos de captación inmediata están integrados en una estructura de mediación. Tal mediación corresponde al entendi-

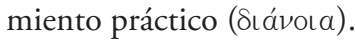

\subsubsection{La unidad del "tener ahí"}

Para explicar su tesis sobre el carácter "dianoético" del voũs humano, Heidegger

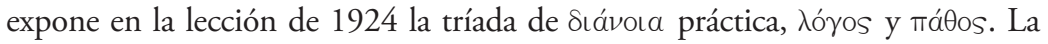
exposición considera el pasaje de De An. G 7, 431 a 8-12. Allí Aristóteles afirma la semejanza entre la percepción sensible, la mera enunciación y la intelección

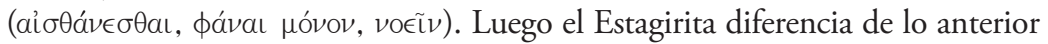
la percepción de lo placentero y doloroso. La idea es la siguiente: mientras la percepción sensible es simple, como la mera enunciación y la intelección, la percepción de lo placentero y doloroso tiene la estructura del perseguir o huir, ligada a la búsqueda de lo bueno y la repulsión de lo malo.

En su interpretación del pasaje, Heidegger enfatiza la doble movilidad - atracción y repulsión - de la vida práctica, en la que toma parte también la afectividad. Su intención es mostrar que la estructura del voũs humano está determinada de tal modo por esa movilidad vital, que la intelección práctica no es posible sino como un proceso sujeto a la estructura "como", es decir, una interpretación en la que algo aparece como provechoso o nocivo.

Particularmente interesante es el hecho de que Heidegger transfiera al ámbito de

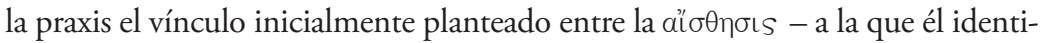
fica aquí con la afectividad -, el tóyos y el voũs. El resultado es un modelo que

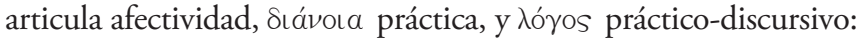

\footnotetext{
22 Heidegger, Martin. Phänomenologische Interpretationen ausgewählter Abhandlungen des Aristoteles zur Ontologie und Logik. Francfort del Meno: 2005, editado por G. Neumann, p. 409. El fragmento ha sido traducido por el autor del presente artículo.
} 
El voũs, en tanto posibilidad de orientación del Dasein así determinado, es un $\delta\llcorner\alpha$. Todo "dirigirse a..." como $\delta i ́ \omega \xi \iota s$ es dirigirse a algo como algo. El mundo, en tanto viene al encuentro primariamente para la disposición afectiva del alegrarse o deprimirse, está ahí como provechoso o perjudicial, en tanto el ai $\sigma \theta a ́ v \in \sigma \theta a \iota$ es caracterizado como "percibir" en la disposición afectiva. (...) El percibir como modo de la disposición afectiva es percibir algo como algo, el dirigir la palabra no es un simple nombrar, sino un dirigir la palabra a algo como algo $(. . .)^{23}$.

El pasaje destaca a la praxis humana como un proceso interpretativo unitario en el que toman parte la afectividad, la reflexión práctica y la articulación del logos. De este modo se anticipa la tríada de disposición afectiva, comprensión y discurso, presentada en Ser y Tiempo ${ }^{24}$.

\section{Conclusión}

A partir de los desarrollos anteriormente expuestos resulta claro que la Retórica no contribuye solamente a la doctrina acerca de la aperturidad cotidiana. Siguiendo el hilo conductor de la formación del juicio en la situación retórica, Heidegger presenta un modelo explicativo formal respecto al Dasein en gene-

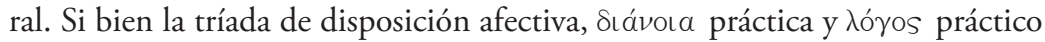

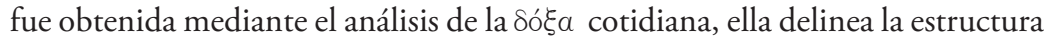
formal universal de la aperturidad.

Por cierto, la Retórica no constituye el único apoyo textual para la elaboración de esa estructura. También la Ética a Nicómaco y De Anima son de central relevancia. Sin embargo, con su tratamiento sistemático de la situación discursiva y de la formación del juicio, la Retórica ofrece un hilo conductor para el despliegue de un modelo unitario de Dasein.

No podemos pasar por alto la violencia de la interpretación heideggeriana. Ésta considera la formación del juicio motivada retóricamente desde el horizonte de la ontologización de la praxis. Quien juzga es visto como un obrante, cuya decisión está prefigurada por el mundo cotidiano. La situación retórica, que abarca al orador, los oyentes y al argumento, resulta ahora interpretada como la situación del práctico "ser en el mundo con otros". Si consideramos que la praxis es para Heidegger autointerpretación, entonces podemos hablar aquí de la transferencia de la situación retórica en la situación hermenéutica o situación de interpretación.

\footnotetext{
${ }^{23}$ Heidegger, Martin. Grundbegriffe der aristotelischen Philosophie. Francfort del Meno: Klostermann, 2002, editado por M. Michalski, p. 280.

${ }^{24}$ Heidegger, Martin. Sein und Zeit. Tubinga: Niemeyer, 1993, pp. 134-166; Heidegger, Martin. Ser y Tiempo. Santiago de Chile: Editorial Universitaria, 1997, traducido por J. E. Rivera, pp. 158-188.
} 


\title{
La Onto-teo-logía y su Superación
}

\author{
Cristóbal Holzapfel \\ Universidad de Chile
}

\begin{abstract}
Resumen
La filosofía, en particular desde Aristóteles en adelante, se constituyó en "filosofía teológica" (al decir de Weischedel) o en "ontoteología" (al decir de Heidegger). Es sobre todo Heidegger el que se propone la superación de ésta. Independientemente de cómo plantea esta superación el pensador de la Selva Negra, problematizamos aquí esta superación. Que a partir de la pregunta por el ser nos tengamos que preguntar a la vez por la posibilidad de Dios, no parece superable, pero sí en cuanto a entender a Dios de acuerdo a la doctrina de una religión en particular.
\end{abstract}

\section{El "dios de los filósofos"}

Martin Heidegger y Wilhelm Weischedel reconocen que la filosofía se constituyó desde antiguo como "ontoteología" (Heidegger) o "filosofía teológica" (Weischedel $)^{1}$. Al respecto podríamos decir que las palabras 'ser' y 'Dios' son de tal alcance que apuntan a lo más universal y esencial que pudiera concebirse, y en razón de que el territorio que abarcan es el mismo, ontología y teología tienen que unirse en algo uno. Esta unión puede ser en distintos tiempos, como efectivamente ha sido, un matrimonio feliz, como en otros, mal avenido. Cada palabra supone una demanda de significado que, como en la "ética del discurso", suele ser de carácter performático o deontológico. Por ejemplo, las palabras 'agradecer', 'ofender', 'respetar' y 'acordar' suponen no sólo algunos significados, sino ciertas acciones que se esperan. Sobre esta base podemos sostener que el alcance y la correspondiente demanda de significado de las palabras 'ser' y 'Dios' (nada más que en tanto palabras) es tal que nada queda fuera de sus dominios, y por lo tanto, dado que esos dominios son omniabarcantes, tienen necesariamente que cubrirse una con otra. La filosofía resulta ser entonces filosofía teológica u ontoteología (habiendo pues, como se llama el escrito de Heidegger, una "estructura ontoteológica de la metafísica") ${ }^{2}$. Para Weischedel, según desarrolla esto en su obra mayor Der Gott der Philosophen (El dios de los filósofos), la filosofía teológica habría tenido (como un ser vivo) - al modo de un arco - un movimiento de auge que va desde Aristóteles

\footnotetext{
${ }^{1}$ Cfr. Weischedel. Wilhelm. Der Gott der Philosophen. Gundlegung einer philosophischen Theologie im Zeitalter des Nihilismus (El dios de los filósofos. Fundamentación de una filosofía teológica en la era del nihilismo), vol. 1 y 2. Darmstadt: Wissenschaftliche Buchgesellschaft, 1983. En adelante GdPh.

${ }^{2}$ Cfr. Heidegger. Martin. Die onto-theo-logische Verfasszing der Metaphysík (La estructura onto-teo-lógica de la metafísica). En: Identität uind Differenz. Pfullingen: Günther Neske, 1957. En adelante, 'DoV'.
} 
hasta Hegel, y un movimiento de decadencia, que se inicia con el positivismo decimonónico (a la cabeza Feuerbach) y que se prolonga hasta la actualidad.

En el inicio de la filosofía teológica, con Aristóteles, es patente que la pregunta por el ser conduce a la pregunta por lo que es causa, y ello a la necesidad de una primera causa - Dios. Con él habría nacido propiamente el llamado "dios de los filósofos" (lo que le da el título a la obra de Weischedel), y éste se desplegará, de la mano de la filosofía, teológica hasta su culminación en Hegel (en el espíritu o razón universal).

Refirámonos ahora a la decadencia de la filosofía teológica, que se inicia con Ludwig Feuerbach, y con el ateísmo que sostiene. Según relata el propio Weischedel en Die philosophische Hintertreppe (La escalera trasera de la filosofía, libro aparecido en edición castellana bajo el título La filosofía tras bambalinas) - Feuerbach proclamó su ateísmo en la Universidad de Heidelberg, a raíz de lo cual fue expulsado y no volvió más a pisar el suelo de una universidad alemana ${ }^{3}$. La obra capital de Feuerbach - La esencia del cristianismo - es posterior a esta expulsión de la universidad. En ella fundamenta sólidamente el ateísmo. Mas, corresponde atender a lo singular que es éste. Desde ya llama la atención el título de la obra: la esencia del cristianismo, y que bajo ese título se sostenga una postura atea. La explicación de ello está precisamente en qué consiste este ateísmo. Digámoslo de una vez en la formulación más extrema de Feuerbach: la esencia del hombre es Dios. En otras palabras Dios no representa sino las máximas aspiraciones del hombre: un máximo poder: la omnipotencia; un máximo saber: la omnisciencia; una capacidad de determinar él mismo el curso de la historia: la Providencia; una máxima capacidad de amar: un Dios que es amor; una capacidad de perdonarlo todo: la gracia. Dios no es algo distinto en definitiva que el deseo humano, y consiguientemente a lo que procede Feuerbach es a reducir todo elemento teológico a elementos antropológicos. El filósofo de la llamada "izquierda hegeliana" propone que Dios = Hombre:

"El ser absoluto, el Dios del hombre, es su propia esencia"

Desde esta perspectiva, podemos entender que, aunque con Feuerbach se inicia la decadencia de la filosofía teológica, no obstante ésta pervive, aunque apagándose; Dios y lo divino quedan cada vez más en la retaguardia. Y de modo similar cabe referirse a lo que involucra la sentencia de Nietzsche, “¡Dios ha muerto!".

Wilhelm Weischedel sostiene a propósito de la filosofía teológica lo siguiente:

La exigencia de llegar a proposiciones sobre Dios acompaña a toda la

\footnotetext{
${ }^{3}$ Weischedel, Wilhelm. Die philosophische Hintertreppe. München: dtv, 2003. / Ed. Cast.: Los filósofos entre bambalinas. México: FCE, 1972.

${ }^{4}$ Feuerbach, Ludwig. De la esencia del cristianismo. Trad. de Franz Huber. Buenos Aires: Claridad, 1941, p. 19.
} 
historia de la filosofía; es más, ello constituye en extensos períodos su impulso esencial; y esto es tanto así que no se va descaminado, cuando se observan los esfuerzos de la filosofía teológica como el acontecer fundamental de la historia de la filosofía. (GdPh, vol. 1, p. 38)

Weischedel trae una colección de citas que avalan la tesis de que la filosofía ha sido principalmente filosofía teológica. En estas citas dispersas a lo largo de su obra se trata de que Dios es la verdad primera y última (Descartes); "Sólo es Dios, y fuera de él, nada" - Fichte - (GdPh, v. 1, p. 231); la filosofía es "ciencia de lo divino", "Contemplación de Dios", "servicio a Dios / Gottesdienstl" - Schelling - (GdPh, v. 1, p. 254); "Así es Dios uno y único objeto de la filosofía; ocuparse de él, reconocer todo en él, retrotraer todo a él, así como derivar todo lo particular de él” y "justificarlo todo, en tanto que emana de él, se mantiene en un nexo con él, vive de su iluminación y en ello tiene su alma" - Hegel-(GdPh, v. 1, p. 287).

\section{El “dios de los filósofos” y Kant}

Significativamente el dios de los filósofos se ha expresado en el intento de la razón de remontarse hasta él mismo, y valiéndose ella tan sólo de sí misma, sin apoyo en la fe. Es lo que advertimos en las demostraciones de la existencia de Dios. Salvo las demostraciones de Aristóteles, como ellas se presentan en un marco que ya es no solamente el de la filosofía teológica, sino más precisamente de la filosofía teológica cristiana, en definitiva se apunta en ellas al Dios cristiano. Ejemplares en este sentido son las palabras de Descartes, que Walter Schulz recuerda en El dios de la metafisica moderna, y justo en un Capítulo sobre el dios de los filósofos en la metafísica moderna, relativas a que en las Meditaciones Metafísicas él (Descartes) ofrece un camino seguro a Dios para el que vacila en la fe 5 .

Y así como hay pruebas o demostraciones, como es el caso de Anselmo o Descartes, también la posibilidad de vías, como es el caso de Tomás. El Aquinate ya ha leído a Dionisio Areopagita, el padre de la teología negativa, y está consciente de que cualquier supuesta prueba o demostración de la existencia de Dios constituiría un sacrilegio. De todos modos hay en esto algo de carácter puramente formal, desde el momento que las 5 vías tomasianas en lo concreto tienen igual el carácter indiscutible de demostraciones. Aún así, podemos decir que al menos el gesto de detectar el problema mencionado en cualesquiera demostración de la existencia divina e intentar entonces desbrozar vías para alcanzar a Dios, no deja de ser significativo. Ahora bien, si examinamos estas vías, ellas se pueden leer con independencia del supuesto de que su autor está pensando en el Dios cristiano. En otras palabras, en ellas está netamente en

\footnotetext{
${ }^{5}$ Cfr. Schulz, Walter. Der Gott der neuzeitlichen Metaphysik. Pfullingen: Neske, 1982, Cap.: "Der "Gott der Philosophen" in der neuzeitlichen Metaphysik" ("El "dios de los filósofos" en la metafísica moderna". /Ed. Cast.: Schulz, El dios de la metafísica moderna. Trad. de Fidelfo Linares. México: FCE, 1961.
} 
juego el dios de los filósofos, y suponen un tal grado de abstracción que se parte o se llega a la sola idea de Dios. Resulta así acertado el análisis de Kant en cuanto a considerar que en estas "demostraciones" lo que se lleva a cabo es un tránsito de la esencia (la definición, la mera idea que tengo de algo) al supuesto de su existencia real. Y Kant critica este tránsito justamente en su conocida "crítica al argumento ontológico". Este último nombre se debe a que, bajo la mirada de Kant, la prueba ontológica sería la más sólida, y es en ella donde se cumple este solo arrancar de la esencia (pensada), de la sola idea de Dios, para concluir en el supuesto de su existencia real. A su vez, para el filósofo de Königsberg las pruebas llamadas 'cosmológica' y 'físico-teológica' (o teleológica) son nada más que pruebas ontológicas disfrazadas: ${ }^{6}$

Toda la fuerza demostrativa contenida en el llamado argumento cosmológico no consiste, pues, en otra cosa que en el argumento ontológico, construido con meros conceptos; la supuesta experiencia es superflua; tal vez puede conducirnos al concepto de necesidad absoluta, pero no demostrar tal necesidad en una cosa determinada. (CRP, A 607)

Y respecto de la prueba físico-teológica o teleológica (la más cercana a la "razón ordinaria”), ella hace alusión a cómo la maravilla del orden del universo nos lleva a la conclusión de un Dios ordenador y omnisciente:

\section{/.../sostengo que la prueba físico-teológica nunca puede demostrar por sí sola la existencia de un ser supremo, sino que siempre se ve obligada a dejar que sea el argumento ontológico (al que el físico- teológico sirve de simple introducción) el que supla la insuficiencia del primero. (CRP, A 625)}

Aplicando la aseveración kantiana de que el tránsito de esencia a existencia es ilegítimo, esto quiere decir que por mucho que se le muestre al pensamiento que, por ejemplo, siendo Dios lo más grande que podemos pensar (Anselmo), tendría que existir no sólo en mi mente, sino también fuera de ella - en ello haríamos justamente el mencionado tránsito fuera de toda legitimidad. Y esta ilegitimidad Kant la refiere no sólo a Dios, sino también al ser. El ser, sostiene Kant, "/.../no es un predicado real/.../"(CRP, A 598), agregando que al decir que "/.../Dios es", o "Hay un Dios", no ańado nada nuevo al concepto de Dios" (CRP, A 599). Aquí aparece también el conocido ejemplo de los táleros, que reza así: "Cien táleros reales no poseen en absoluto mayor contenido que cien táleros posibles" (CRP, A 599). Desarrollando la misma idea, y para hacerla aun más gráfica, añade él que si cien táleros reales no fueran iguales a cien posibles, nos haríamos más ricos, agregando unos ceros en nuestra cuenta (ejemplo que aquí parafraseo). (Cfr. CRP, A 599)

\footnotetext{
${ }^{6}$ Cfr. Kant. Crítica de la razón pura. Trad. de Pedro Ribas. Madrid: Alfaguara, 1978, A591-B619. En adelante CRP.
} 
Así pues, aunque se le presenta al pensamiento algo como necesario, no por eso existe. $Y$ en efecto, podríamos agregar que en la matemática se trata de relaciones necesarias, y no por ello se justifica pretender que aquellas relaciones se realicen en algún lugar, se hagan realidad física y concreta, aunque en muchos casos ello, en efecto, ocurre. Incluso cuando en las demostraciones se estipula "la necesidad de un ente necesario", ya que Dios sería perfecto, y la perfección exige como aspecto consustancial la existencia, esa necesidad no demanda realidad, o si se quiere, realización alguna. Kant advierte la relevancia del problema que aquí se presenta y por eso sostiene que ante la presencia de lo forzosamente necesario, se le abre un abismo a la razón:

La incondicionada necesidad que nos hace falta de modo tan indispensable como último apoyo de todas las cosas constituye el verdadero abismo para la razón. (CRP, A 613)

Y al tenor de esta misma inquietud, provocativamente pone en boca del propio Dios la siguiente duda respecto de sí mismo:

Existo de eternidad en eternidad; nada hay fuera de mí, excepto lo que es algo por voluntad mía, pero ¿de dónde soy? (CRP, A 613)

Sin duda gran parte de la fuerza de determinación que ha tenido el pensamiento se debe a su nexo, su trabazón, su maridaje con la necesidad. Ya en los inicios mismos de la filosofía, concretamente en los fragmentos de Anaximandro - se hace presente el mencionado maridaje. Ello atañe a la expresión 'grh', que podemos traducir como "es necesario". En el caso particular de Anaximandro, en lo que atañe a su segundo fragmento, se trata de que es necesario que todo lo que llega a ser deje de ser, y que ello se cumple de acuerdo al orden de Cronos, el tiempo; en otras palabras, puede transcurrir mucho tiempo, y hasta eones, y habrá de cumplirse que lo que llegó a ser, habrá de dejar de ser. $\mathrm{Y}$ agreguemos que si los fragmentos de Anaximandro constituyen el legado más antiguo, y que, gracias a la filosofía, el hombre hizo el tránsito del mito al logos, ese tránsito se ha debido primordialmente a que al logos - a la razón y al pensamiento - se los entendió en su íntimo nexo con la necesidad. En otras palabras, si el pensamiento no expresa lo necesario, entonces se cae en la arbitrariedad y el subjetivismo.

Posteriormente, en el Poema del ser, Parménides ha tratado de esto, en tanto una cuestión crucial: el pensamiento está íntimamente ligado a la necesidad. En el mencionado Poema se presenta no sólo el término ' $\gamma \rho \eta$ ' 'es necesario', sino también ' $а \nu \alpha \nu \kappa \epsilon$ ', 'necesidad'. Es más, estando ya Parménides claramente situado en el nuevo terreno del logos, le da una expresión mítica a la necesidad en su alusión a Moira, que simboliza el destino. A su vez, el filósofo de Elea pone estos pensamientos en boca de la diosa 'Dike', la diosa de lo recto, que 
es tanto de la justicia como de la verdad. Lo notable de ello es que la diosa de la verdad no puede decir sino la verdad. Ello concierne ante todo a que "lo que es, es" y "lo que no es, no es". Aunque pueda decirse que esto es, por definición, de Perogrullo, a través de lo cual se formula además el principio de identidad, trae consigo consecuencias de proporciones, dado que si es así, el ser no puede haber comenzado a ser, ni tampoco podría dejar de ser, ya que en ambos casos, o bien "sería el no ser" antes de ese supuesto comienzo absoluto, o "sería el no-ser" después de ese supuesto fin absoluto. Todo ello se conecta además con este otro principio sostenido por Parménides:

"Lo mismo es pensar y ser".

En otras palabras, lo que se le muestra como necesario al pensamiento tiene que estar en correspondencia con el ser. Y si de acuerdo a lo anterior sucede que el ser no puede ser sino eterno, ésta podría ser una respuesta más válida que el supuesto de una finitud espacio-temporal del universo de la astrofísica contemporánea.

\section{La prueba de la 'contingentia mundi'}

Indiscutiblemente, con base en Aristóteles, la tercera vía de Tomás de Aquino para mostrar la necesidad de la existencia de Dios, es de lo más grande en lo que a posibles "demostraciones" de la existencia divina se refiere. En la tercera vía se parte de la aseveración de que los entes están caracterizados de acuerdo a la posibilidad, como que es posible que sean o no sean (y habría que agregar, que sean esto o lo otro). Pensemos que nosotros mismos alguna vez no fuimos y luego no seremos, y lo mismo cabría decir de nuestro planeta, de la vía láctea, y a fin de cuentas, del cosmos íntegro:

Ahora bien, es imposible que todas las cosas que son de este modo existan siempre, porque lo que puede no existir, en algún momento no existe. Por tanto, si todas las cosas pueden no existir, en algún momento nada ha existido. Pero si esto fuese verdad, tampoco ahora nada existiría, pues lo que no existe no empieza a existir sino por algo que existe: si nada fuese existente, sería imposible que algo comenzara a existir, y de este modo nada existiría, lo cual es manifiestamente falso;

de lo que infiere Tomás:

Por consiguiente, no todas las cosas tienen sólo la posibilidad de existir, sino que es preciso que algo exista necesariamente, concluyendo: 
Pues bien, todo lo que es necesario, o tiene causa de su necesidad en otro, o no tiene causa de su necesidad. No es posible que se proceda al infinito./... /Por consiguiente, es preciso que haya algo que sea necesario por sí mismo,/.../ a lo cual todos llaman Dios ${ }^{7}$.

Kant expone a su modo la prueba por la contingencia - contingentia mundi - (así también es conocida la tercera vía) diciendo simplemente que:

Si algo existe, tiene que existir también un ser absolutamente necesario. Ahora bien, existo al menos yo. Por consiguiente, existe un ser absolutamente necesario. (CRP, A 604)

Podemos reforzar la tercera vía con otros conceptos, no obstante valerse claramente nada más que de sí misma. Estos conceptos son los de 'contingencia' y 'condicionamiento'. Si todo lo que conocemos es condicionado, diríamos actualmente hasta los hoyos negros y cúmulos de galaxias, así también lo es el big-bang, y ello nos muestra a todas luces que el propio cosmos en su integridad no es autosuficiente, ya que sigue siendo condicionad. De ello se sigue que lo condicionado exige lo incondicionado, relativamente a su justificación, a una razón suficiente para ser. Podemos reconocer que el pensamiento y la ciencia, con todos sus avances hasta nuestros días, sigue encontrándose ante la misma disyuntiva: siempre podemos ir nada más que de lo condicionado a condiciones que lo suscitan, pero que siguen siendo ellas mismas condicionadas, sin que haya forma de salir de esto.

Es cierto que respecto de explicaciones parciales en la historia de la ciencia se ha recurrido a Dios, al supuesto éter o al flogisto con el fin de llenar el vacío tanto en lo macrocósmico como en lo microcósmico. En lo que atañe al flogisto en 1702 el químico Georg Ernst Stahl introdujo el concepto de los "cuerpos singulares", que más tarde se llamaría "elementos químicos". Ya en 1642 habían planteado Joachim Jungius y en 1661 Robert Boyle que todos los cuerpos estarían hechos de pequeñas partículas, que constituían los distintos materiales de la naturaleza. Algunos de estos materiales no se podrían seguir subdividiendo. El pensamiento fundamental de los elementos químicos no tuvo, sin embargo, consecuencia práctica alguna para la química. Georg Ernst Stahl deduce la existencia de estas sustancias elementales a partir de reacciones químicas. Él indaga sobre el parentesco ("afinidad”) de distintas sustancias (especialmente de ácidos y metales) entre sí y lo expone en una tabla. Junto con ello, reconoce él los "cuerpos singulares", cuya interrelación estaría posibilitada por un material hipotético de fuego común a todos: el flogisto ${ }^{8}$.

Mas, cabe aducir que en todo ello se trata de hipótesis redundantes, lo que nos

\footnotetext{
${ }^{7}$ Cfr. De Aquino, Tomás. Suma Teologica. Edición bilingüe, trad. de Raimundo Suárez. Madrid: BAC, 1964, quaest. 2, I parte, pass. En adelante ST. / Cfr. también De Aquino, Tomás. Antologia. Dirigida por el Instituto de Filosofía de la Universidad Católica de Valparaíso. Santiago: Gabriela Mistral, 1975, p. 44-45.

${ }^{8}$ Información extraída de Chronik der Deutschen (Crónica de los alemanes). Dortmund: Chronik, 1983.
} 
lleva a recordar el planteamiento de Newton: hypothesis non fingo. El pasaje se encuentra en el General Scholium de la segunda edición de Philosophia naturalis. Principia Mathematica, donde dice:

I have not as yet been able to discover the reason for these properties of gravity from phenomena, and I do not feign hypotheses. (No he sido capaz de descubrir la razón de estas propiedades de los fenómenos, y no finjo hipótesis) ${ }^{9}$.

El problema sin resolver para Newton es la actio in distans - cómo sucede que los astros atraen a otros a través de la distancia. Relacionado con ello se introducirá la hipótesis del éter, a lo que Newton se resiste.

Pero, una situación de otra naturaleza es cuando se trata de la totalidad, de una plenitud fuera de la cual no hay nada. Entonces efectivamente se muestra la insuficiencia de esa plenitud del cosmos que sigue siendo condicionada y no autosuficiente. Aquí entramos en un plano en el cual las hipótesis dejan de ser redundantes, ya que de por sí se trata no sólo de un enigma, sino del mayor de todos los enigmas: que haya ser, que algo sea, que sea el universo, que sea esa pléyade inconmensurable de cientos de miles de millones de galaxias, que seamos nosotros, que estemos conscientes, que hayamos nacido, que estemos aquí, que tengamos que morir. Aquí, por supuesto, toda teoría científica se queda corta y las concepciones filosóficas levantan vuelo. Tengamos en claro que se trata en esto más que nada de traer a nuestra conciencia ese enigma universal insondable, ése, el más arcano de todos los secretos, ése que es la llave maestra de todo, y a fin de cuentas de un supuesto sentido del hombre en la tierra. Mas, es patente que llegamos a este mundo con este secreto y con él nos vamos. Resulta perfectamente comprensible que quedemos siempre en un estado de azoramiento y estupefacción, y esta experiencia la tenemos toda vez que contemplamos el cielo nocturno, mas ¿qué forzosidad hay en que tenga necesariamente que haber una respuesta? De todos modos - cómo no - es cierto que nuestra razón en principio sabe de antemano que todo lo que encuentra a su paso tiene una explicación, una razón siquiera suficiente para ser como es. Esto es lo que establece el principio de razón suficiente de Leibniz. La razón entonces, llevada de este impulso, acaba por preguntar con Leibniz mismo: ¿por qué es el ser que no más bien la nada?

Pues bien, podríamos decir que con nuestro responder de esto, lo otro y lo de más allá, hasta aquí no más llegamos, y entonces lo único que parece justificarse es el silencio. Es cierto que la religión, a diferencia de la filosofía, nos entrega respuestas, mas ello es pasando al ámbito de la fe, y junto con ello, saliendo del ámbito del pensamiento, en sentido estricto.

\footnotetext{
${ }^{9}$ http://en.wikipedia.org/wiki/Hypotheses_non_fingo.
} 


\section{¿La fe como confianza o como creencia?}

¿Hay el camino de la fe a Dios? Se ha supuesto que sí lo hay y ello tiene una tradición milenaria. Mas, ¿qué es la fe? Si en griego el equivalente al término 'fe' es pistis, éste significa 'confianza'. El término latino 'fides' del cual más directamente proviene nuestra palabra 'fe', significa principalmente 'creencia', aunque también incluye 'confianza'. Pienso que es probablemente una experiencia más radical vivir la fe como confianza que como creencia. Ésta última fácilmente se puede extraviar y ser conducida a creer muchas cosas y así caer en la superstición. Podemos hacer de Dios un ídolo, al cual lo figuramos en cierto modo como más nos acomoda. Distinta es la fe como confianza, la cual no pretende representarse a un dios determinado con tales y cuales características, atributos, propiedades, sino más bien como algo profundo, insondable, como por lo demás y de modo análogo sucede con las personas en quienes depositamos nuestra confianza. Y aunque es cierto que posteriormente esas personas pueden defraudarte y ciertamente tú también puedes defraudar a quienes confían en ti, con la vivencia de la fe como confianza también podemos sentirnos en muchas ocasiones defraudados. Ello habla de lo viva que puede ser nuestra fe. Probablemente lo que sucede con la fe como confianza, dado que está referida nada menos que a Dios, es que tiene más posibilidades de persistir, pervivir, permanecer inquebrantable a lo largo del tiempo y de la vida entera.

Por otra parte, la fe como confianza tiene como aliada la intuición, mas ésta es una alianza muy particular, ya que ante todo cuenta cierta notable autonomía de la confianza; y justo, en razón de ello, no necesita de alianza alguna. Pero a ratos esta confianza llama a quien puede ser en distintos momentos su aliada: la intuición. Cuando en la confianza vacilamos y estamos desorientados y perdidos, en esa situación suele hacer acto de presencia la intuición para decirnos o sólo susurrarnos en el oído que hay Dios. Y ello naturalmente le da nuevas alas a la confianza.

Con todo, esta confianza de la cual hablamos puede estar nada más que referida al camino de nuestra existencia individual, al mundo o a cierta supuesta armonía cósmica, de acuerdo a la cual siempre las cosas se ordenan, se reparan, y lo que se había apartado, descarrilado, vuelve a estar en su lugar. Pero, aparentemente en la confianza profunda y radical de que estamos hablando, requerimos de algo más, y por eso que es comprensible que la depositemos únicamente en lo divino, y en nada más, y aunque esto divino sea tal vez lo que simplemente podríamos llamar "algo", una suerte de "no se qué", al fin y al cabo, simplemente un enigma.

¿Es el camino a Dios únicamente el de la fe? ¿Qué pasa, por ejemplo, con el sentir? ¿No hay esas vivencias de sentir la presencia de lo divino? Por supuesto que sí, pero tal vez no necesariamente sobre la base de la fe y sus prerrogati- 
vas, sino más bien sobre la base de la razón, ese sentir suscita desconfianza. A ese sentir se le ve propenso a la figuración, la ideación. Mas, en ello la razón tradicional ha sido autoritaria, ya que ante todo el sentir nos permite entrar mucho más en contacto con el otro ser humano que la razón. Y ese contacto, no necesariamente físico, sino ante todo afectivo y anímico, sería no sólo con las personas cercanas, sino con cualquier otro humano, y además no solamente humano, sino con animales, plantas, con el paisaje y al fin y al cabo con el entorno, y hasta con las estrellas. En la historia de la filosofía ha sido en particular Max Scheler quien de modo decidido llamó la atención sobre el sentir y la emocionalidad. No es la razón la que puede llegar a lo que él concibe como persona, que tiene particularmente que ver con una intimidad, un fuero interno, sino la emocionalidad. El otro me emociona y ello recién me permite contactarme propiamente con él (o ella). Esto tiene que ver a su vez con la empatía.

¡Cuánto de esto echamos hoy de menos en el mundo actual! Un mundo en buena medida numérico, de estadísticas, encuestas, "ratting", y demás, en el que frecuentemente sucede que algunos señores se sientan para planificar en abstracto y sobre la base de ciertos esquemas, con variables matemáticas, proyecciones tendenciales, y otros, cuestiones que habrán de incidir en la población, y sin que se haya escuchado ni atendido propiamente a las necesidades de nadie en particular.

Volvamos a nuestra pregunta inicial: si acaso a Dios nos podemos acercar también a través del sentir. Podría decirse que sí, pero tan sólo en la medida en que sea la fe lo que precede y orienta, una fe vivenciada más como confianza que como creencia en algo determinado. Esta fe como confianza vive a su vez de sentir la presencia de lo divino. Es más, si no hay la buena y enriquecedora compañía del sentir, probablemente ésa es una fe seca y vacía.

Y la razón, ¿no es otro camino legítimo a Dios? Por cierto, aunque este camino se ha prestado para el abuso. Éste se encuentra en las demostraciones de la existencia divina. Se echa de menos en ello la prudente distancia que habría que tener sobre esas demostraciones, por muy lúcidas y aparentemente conclusivas que sean. En otras palabras, el abuso (lo que a la vez puede recibir el nombre de sacrilegio o blasfemia, incluso) ha estado más que nada en no advertir que probablemente lo único que se está demostrando es la necesidad de un concepto, una idea, ya sea de lo absoluto, de lo incondicionado, de lo necesario, y aun de lo que no puede no ser, pero ello tan sólo teniendo una validez intrínseca a la razón y al pensamiento. 


\section{Pues bien: ¿̨Transitamos o no de esencia a existencia?}

Pese a la fuerza conclusiva que tiene la crítica kantiana al argumento ontológico y sus consecuencias, todos los filósofos que emprendieron demostraciones de la existencia divina, entre ellos particularmente Tomás de Aquino, pueden resguardarse de ella. Tomás sostiene que en el único caso en que se cumple un tránsito necesario de esencia a existencia (o ser) es en Dios. Con relación a ningún otro ente se cumple esto, ya que, por ejemplo, de la consideración de que habría una esencia que es "ser racional", no se sigue que haya efectivamente seres humanos (vale decir, animales racionales), como de la esencia de que habría la posibilidad de seres compuestos de una parte de caballo y otra de hombre, no se sigue que haya centauros. Pero, en cuanto a dios, tratándose de una esencia que es perfección, y la perfección demanda ser, sí se justifica el tránsito de esencia a existencia:

El ser es la actualidad de toda forma o naturaleza: La bondad o la humanidad no significan nada en acto, sino en la medida en que se significa que son. Es necesario, por tanto, que el mismo ser se compare a la esencia que es distinta de él, como el acto a la potencia. - Ahora bien, como en Dios nada es potencial, se sigue que en Él la esencia no es distinta de su ser. Por consiguiente, su esencia es su ser. (ST, 1, q. 3, a. 4., A, p. 46)

En ello trasunta la concepción de Dios como ens realissimum, el ente más real de todos. Todo otro ente es posible, contingente o condicionado, mientras que en el caso de Dios, su esencia es su existencia.

Si Kant planteó a su vez la posible demostración de la existencia de Dios en forma de antinomia, vale decir, por medio de un tipo de argumento, respecto del cual se formula tanto una tesis, en que se demuestra que Dios existe, y una antítesis, en que se demuestra lo contrario, podríamos - atendiendo a lo que decíamos anteriormente - formular una posible quinta antinomia. En la tesis de ésta planteamos la necesidad exclusiva en el caso de Dios, de transitar de esencia a existencia, por ejemplo haciendo ver como todo lo que conocemos del cosmos es condicionado y dependiente, y ello no se sostiene por sí mismo, ergo tiene que haber algo incondicionado y absoluto, llamado Dios; y en la antítesis planteamos que este tránsito de esencia a existencia no es legítimo.

Y así, a fin de cuentas, la razón queda oscilando entre Aristóteles, Anselmo, Tomás, Descartes, y todos quienes formularon distintas demostraciones de la existencia de Dios, y Kant que las critica a todas en bloque. Ésta es la situación de oscilación que la razón tendría que asumir como tal. 


\section{Heidegger y el "dios de los filósofos"}

Martin Heidegger se propone superar lo que él llama "onto-teo-logía". En La estructura ontoteológica de la metafísica dice el pensador de Friburgo:

El carácter onto-teo-lógico de la metafísica ha llegado a ser cuestionable / fragwürdig/ para el pensar. (DoV, p. 51)

Pero, ¿¿de qué dios se trata aquí? El texto nos da la predecible respuesta: se trata en primer lugar del dios causa sui. A través de esta expresión se alude especialmente al así llamado "dios de los filósofos", el cual, como ya veíamos, tiene su base en Aristóteles. Si Dios, por definición, tendría que ser primera causa de todo (ya que si fuera causa quinta, dice Aristóteles, por ejemplo, la cuarta sería más divina, y lo mismo, si fuera causa segunda, la primera sería más divina, entonces esta primera causa, ya no puede ser efecto de una causa anterior, sino ser causa de sí misma, vale decir, causa sui (aunque esta expresión no es de Aristóteles, sino muy posterior). Del "dios causa sui” dice Heidegger:

A este dios no le puede orar el hombre ni ofrecer sacrificios. Ante la Causa sui no puede el hombre caer de rodillas ni hacer música o bailar. (DoV, pág. 70)

Este "dios" estaría, por lo tanto, muerto. Heidegger plantea además aquí que éste sería no sólo el dios de los filósofos, sino el dios teológico-bíblico, sin duda considerando en ello lo que ha hecho la teología racional con el supuesto Dios.

Por otra parte, dado que precisamente el dios causa sui de uno u otro modo permite su demostración, así como veíamos en relación a la demostración aristotélica, Heidegger (y habría que agregar, sin reconocerlo) hace eco del planteamiento radical de la teología negativa, que sostiene simplemente que un dios demostrado, o un dios que se deja demostrar no es dios. Leemos en el Nietzsche de Heidegger que:

/... / un dios que tiene que hacerse demostrar su existencia, tiene que ser al final un dios muy a-divino /no- divino, ungöttlich/, y la demostración de su existencia conduce a lo más a una blasfemia ${ }^{10}$.

Esto explica el alcance del pasaje de La estructura ontoteológica /... / donde Heidegger expresamente opta por callar sobre dios y junto con ello, por el desenvolvimiento de un "pensar sin-dios":

El que ha experimentado desde madura proveniencia a la Teología, tanto aquella de la fe cristiana, como aquella de la filosofía, prefiere, en el ámbito del pensar, callar hoy sobre Dios. (DoV, p. 51)

${ }^{10}$ Heidegger. Nietzsche. vol. 1. Pfullingen: Neske, 1961, p. 366, trad. mía. En adelante N. 
Así como Ser y Tiempo ya está bajo la égida del desarrollo de una filosofía del más acá, en oposición a la transfilosofía o filosofía del más allá de la tradición, también en ello y en el conjunto de la obra heideggeriana es nítidamente reconocible el pensar sin-Dios. Probablemente atendiendo a varios de estos aspectos del pensamiento heideggeriano - fundamentalmente el pensar sin-Dios - Sartre en el escrito de 1945 El existencialismo es un humanismo pretendió hacer causa común con Heidegger en relación a su postura atea. Veamos a continuación cómo concibe él su ateísmo en sus rasgos más sobresalientes:

Y cuando se habla de desamparo, expresión cara a Heidegger, queremos decir solamente que Dios no existe, y que de esto hay que sacar las últimas consecuencias. El existencialismo se opone decididamente a cierto tipo de moral laica que quisiera suprimir a Dios con el menor gasto posible. Cuando hacia 1880 algunos profesores franceses trataron de constituir una moral laica, dijeron más o menos esto: Dios es una hipótesis inútil y costosa, nosotros la suprimimos; pero es necesario, sin embargo, para que haya una moral, una sociedad, un mundo vigilado, que ciertos valores se tomen en serio y se consideren como existentes a priori; es necesario que sea obligatorio a priori que sea uno honrado, que no mienta, que no pegue a su mujer, que tenga hijos, etc., etc.... Haremos, por lo tanto, un pequeńo trabajo que permitirá demostrar que estos valores existen, a pesar de todo, inscritos en un cielo inteligible, aunque, por otra parte, Dios no exista. Dicho en otra forma $-\mathrm{y}$ es, según creo yo, la tendencia de todo lo que se llama en Francia radicalismo-, nada se cambiará aunque Dios no exista; encontraremos las mismas normas de honradez, de progreso, de humanismo, y habremos hecho de Dios una hipótesis superada que morirá tranquilamente y por sí misma ${ }^{11}$.

Mas, Sartre, de modo similar a Dostoievsky, a través del personaje Raskolnikov, de Crimen y Castigo, plantea que el no creer en Dios, y al mismo tiempo en un bien absoluto que nos oriente, trae como consecuencia que "todo está permitido", y que únicamente a partir de esa libertad demasiado amplia del ser humano podemos darnos nosotros mismos un orden, aunque éste ya no tenga más un fundamento absoluto en el que apoyarse. Sartre:

El existencialista, por el contrario, piensa que es muy incómodo que Dios no exista, porque con él desaparece toda posibilidad de encontrar valores en un cielo inteligible; ya no se puede tener el bien a priori, porque no hay más conciencia infinita y perfecta para pensarlo; no está escrito en ninguna parte que el bien exista, que haya que ser honrado, que no haya que mentir; puesto que precisamente estamos en un plano donde solamente hay hombres. Dostoievsky escribe: "Si Dios no existiera, todo estaría permitido". Este es el

\footnotetext{
${ }^{11}$ http://www.geocities.com/Athens/Delphi/9247/Sartre.html. http://www.lainsignia.org/2001/febrero/cul_093.htm.
} 
punto de partida del existencialismo. En efecto, todo está permitido si Dios no existe y, en consecuencia, el hombre está abandonado, porque no encuentra ni en sí ni fuera de sí una posibilidad de aferrarse. No encuentra ante todo excusas. Si, en efecto, la existencia precede a la esencia, no se podrá jamás explicar la referencia a una naturaleza humana dada y fija; dicho de otro modo, no hay determinismo, el hombre es libre, el hombre es libertad. Si, por otra parte, Dios no existe, no encontramos frente a nosotros valores $\mathrm{u}$ órdenes que legitimen nuestra conducta. Así, no tenemos ni detrás ni delante de nosotros, en el dominio luminoso de los valores, justificaciones o excusas. Estamos solos, sin excusas. Es lo que expresaré diciendo que el hombre está condenado a ser libre. Condenado, porque no se ha creado a sí mismo, y sin embargo, por otro lado, libre, porque una vez arrojado al mundo es responsable de todo lo que hace.

El profesor de filosofía Ramón Alcoberro de la Universidad de Gerona, Cataluña, sostiene lo siguiente sobre los antecedentes del escrito de Sartre El existencialismo es un humanismo:

El existencialismo es un humanismo es en origen el resumen de una conferencia que Sartre pronunció el 29 de octubre de 1945 en el club Maintenant ["Ahora"], creado por Marc Beigbeder y Jacques Calmy, con el añadido de algunos momentos de la discusión que la siguió, en que se perfilan diversos temas. La conferencia marcó un hito en su momento, incluso como acontecimiento social. Hubo gente arremolinada a la entrada y en los días siguientes aparecieron reseñas en los principales periódicos de la época ${ }^{12}$.

En este texto Sartre describe a Heidegger como "existencialista ateo". Sin embargo, dos años más tarde, en 1947 en la Carta sobre el "bumanismo", que en parte es una respuesta al escrito de Sartre, Heidegger no admite aquella calificación de ateo. Leemos en la Carta de Heidegger, haciendo algunas aclaraciones respecto de su pensamiento y apartándose del tilde sartreano:

Por eso, con la determinación existencial de la esencia del hombre todavía no se ha decidido nada sobre la «existencia de dios» o su «no-ser», así como tampoco sobre la posibilidad o imposibilidad de los dioses. Por eso, no sólo resulta prematuro, sino incluso erróneo en su procedimiento, afirmar que la interpretación de la esencia del hombre a partir de la relación de dicha esencia con la verdad del ser es ateísmo. Esta clasificación arbitraria revela además una falta de atención en la lectura ${ }^{13}$.

\footnotetext{
${ }^{12}$ Alcoberro, Ramón. "El existencialismo es un humanismo". Notas para una lectura. http://www.alcoberro.info/pdf/sartre3.pdf.
} 
Y continúa luego Heidegger describiendo su pensamiento a través de sucesivos despejos que conducen al final a la pregunta por Dios:

Sólo a partir de la verdad del ser se puede pensar la esencia de lo sagrado. Sólo a partir de la esencia de lo sagrado se puede pensar la esencia de la divinidad. Sólo a la luz de la esencia de la divinidad puede ser pensado y dicho qué debe nombrar la palabra «dios».

En definitiva, la falta de preocupación por Dios se explica porque en nuestra época hemos perdido parejamente el vínculo con lo sagrado y la salvación:

¿O acaso no tenemos que empezar por comprender y escuchar cuidadosamente todas estas palabras para poder experimentar después como hombres, es decir, como seres exsistentes, una relación de dios con el hombre? ¿Y cómo va a poder preguntar el hombre de la actual historia mundial de modo serio y riguroso si el dios se acerca o se sustrae cuando él mismo omite adentrarse con su pensar en la única dimensión en que se puede preguntar esa pregunta? Pero ésta es la dimensión de lo sagrado, que permanece cerrada incluso como dimensión si el espacio abierto del ser no está aclarado y, en su claro, no está próximo al hombre. Tal vez lo característico de esta era mundial sea precisamente que se ha cerrado a la dimensión de lo salvo. Tal vez sea éste el único mal ${ }^{14}$.

Francois Fédier recuerda en el artículo "Heidegger et Dieu"15 (Heidegger y Dios) que el pensador le encargó a Bernhard Welte su propio Sermón Funerario (lo que habla de la singularidad del pensador de Friburgo). Posteriormente el Sermón, redactado por Welte, fue suscrito por Heidegger. Respecto de él corresponde destacar que se basa principalmente en el texto de Heidegger: $L a$ palabra de Nietzsche: “Dios ha muerto!”. Y así como Heidegger interpreta allí aquella sentencia en el sentido de que con ella Nietzsche habría estado gritando por Dios de profundis, así en este Sermón Welte supone que el pensador de Todtnauberg habría gritado de este modo. De acuerdo con ello, el Dios que ha muerto, declarado por Nietzsche alude a una estructura supransensible, dispensadora de sentido, que supone un quíntuple conjunto de fundamentoverdad-finalidad-valor-unidad. Todo ello se habría perdido, pero esto no significa que el supuesto Dios, que no necesariamente se deja representar por esas ideas "humanas demasiado humanas", realmente habría muerto.

Cabe hacer notar además lo problemática y cuestionable que resulta, nada más

\footnotetext{
${ }^{13}$ Heidegger. Brief über den «Humanismus» (Carta sobre el «humanismo»). En: Wegmarken (Marcas en el camino). Gesamtausgabe (Obras completas), vol. 9. Frankfurt am Main: Vittorio Klostermann, 1976, p. 351 (182) Cfr. trad. en: Carta sobre el «humanismo», trad. de Alberto Wagner de Reyna, en: Doctrina de la verdad según Platón /y/ Carta sobre el «humanismo», Santiago: Ediciones de la Universidad de Chile. s. a., p. 213-214.

${ }^{14} \mathrm{http}: / / \mathrm{www} \cdot$ heideggeriana.com.ar/.

${ }^{15}$ Cfr. Fédier, Francois. Heidegger el Dieu. En: Heidegger el la question de Dieu. Editado por Richard Kearney y ]oseph O’Leary. Paris: 1980
} 
que en términos lógicos, una afirmación que sostenga que "Dios ha muerto", porque por definición, si Dios es inmortal, no podría morir. A lo más se puede sostener que "Dios no existe", pero no que Dios murió. De todos modos, independientemente de la falta de fundamentación que hay en una afirmación así, el amigo de Heidegger, Bernhard Welte, finaliza el Sermón Funerario citando los pasajes finales del mismo texto, pero refiriéndolos a Heidegger, diciendo:

“¿Quizás ha gritado allí un pensador verdaderamente de profundis?" 16 .

Cabe preguntarse, en beneficio de la duda, si efectivamente hay en la obra de Nietzsche elementos suficientes como para asegurar que éste al sostener que Dios ha muerto, haya estado gritando por Dios de profundis, como se grita por él, por el "verdadero Dios" en los Salmos de la Biblia. Las razones que da Heidegger para ello y que resumíamos arriba no parecen suficientes. En cambio, habría razones suficientes para justificar la interpretación de Welte, dado que Heidegger mismo la suscribe. Y este grito, ahora de Heidegger, se reflejaría en varios aspectos, entre ellos: ir en busca de un Dios más divino (göttlicher Gott) y no quedarse en el Dios no-divino (ungötlich), el dios causa-sui, el dios concebido por los filósofos. Y lo mismo en lo que se refiere a los alcances que tiene el pensar sin-Dios o la afirmación de que la filosofía cristiana sería un "hierro de madera”. En todo ello se trata más bien de caminos a seguir por el pensamiento que nos permitan acercarnos al supuesto "verdadero Dios".

\section{¿Superación de la ontoteología?}

Pues bien ¿qué cabe decir respecto de la superación de la ontoteología?

Desde el momento que, como hemos visto, los términos 'ser' y 'Dios' cubren en buena medida un mismo territorio - el de lo más esencial y universal - la ontoteología no sería superable. La filosofía, al ser conducida hasta las últimas cuestiones, no puede dejar arbitrariamente a un lado la pregunta y la posibilidad de Dios. Y si de demostraciones se ha tratado en la tradición, ellas incluyen tanto inconvenientes como aportes, dado que nos llevan a algunos de los problemas filosóficos más severos y sugestivos, en particular lo que involucra el concepto de necesidad, en unión con el pensamiento, y del supuesto tránsito de esencia a existencia.

Sin embargo, por la contraparte, sí tiene justificación la posible superación y lo que Heidegger plantea como "pensar sin Dios", pero de un modo acotado, dado que esto tendría que referirse al Dios de alguna religión o creencia en particular, trátese de nuestro Dios cristiano, de Alá o Brahma.

\footnotetext{
${ }^{16}$ Welte, Bernhard. Suchen und Finden (Buscar y encontrar). En: Zum Gedenken an Martin Heidegger. Gedenkschrift der Stadt Messkírch fiir íhren Sohn llnd Ehrenbiirger (En memoria de Martin Heidegger. Escrito memorial de la ciudad de Messkirch para su hijo y ciudadano ilustre). Messkirch, 1977.
} 
Sólo así - pensamos - la filosofía se conserva en lo que es: de un lado abriéndose a la posibilidad de Dios, y del otro, evitando cualquier compromiso con la representación de un "dios" en particular. 


\title{
Sentido Práctico de la Existencia. Las Propuestas de Husserl y Heidegger
}

\author{
Hugo Herrera A.
}

Universidad de los Andes

\begin{abstract}
Resumen
En este artículo se pretende, por una parte, mostrar los intentos de Edmund Husserl y Martin Heidegger de acreditar el carácter originariamente práctico de la existencia, y por otra, exponer las contribuciones de ambos autores en lo que toca a la denuncia y detección de efectos negativos para el ser humano, de la reducción del sentido práctico de la existencia en propuestas de tipo cientificista.
\end{abstract}

\section{Filosofía y praxis}

La reflexión filosófica no parece capaz de suplir el saber práctico concreto. No luce posible establecer algo así como una continuidad sistemática entre los resultados de aquella reflexión y las decisiones que se adoptan en las diversas situaciones. Entre ambas mediaría un abismo. Si bien ese abismo clama por ser llenado de algún modo, para esta tarea se requeriría no ya de más filosofía, sino que de saber práctico concreto.

Lo dicho no importa sostener que toda participación de la filosofía en la praxis quede por principio vedada. Cabe pensar en maneras más modestas de participación que la de una justificación suficiente. A la filosofía le podría corresponder exponer los supuestos generales negativos de una praxis con sentido. Esta tarea le ha parecido exigible a algunos filósofos, especialmente cuando la praxis y su sentido han sido puestos en cuestión a partir de argumentos filosóficos. Por ejemplo, cuando animados por los desarrollos científicos de la modernidad, otros filósofos y científicos han llegado a sostener que la existencia resulta reconducible a pura facticidad. En tales circunstancias, no bastarían argumentos meramente prácticos ni de sentido común, tampoco simplemente aludir a la propia posición, por ejemplo, a una metafísica perenne en la que se tiene confianza, sino que se requeriría hacer filosofía, si lo que se quiere es la rehabilitación señalada de la praxis.

La intervención de la filosofía también se volvería para algunos exigible cuando lo que ha venido a llamarse inautenticidad se extiende socialmente. En este caso 
no se podría acudir ya a las opiniones dominantes, al sentido común, sino sólo a una reflexión emancipada de esas opiniones dominantes, vale decir, filosófica, capaz de enfrentarse críticamente a las condiciones de la inautenticidad.

En esta exposición pretendemos referirnos a ciertas contribuciones que, desde la filosofía, han hecho a la praxis dos autores altamente relevantes para el pensamiento fenomenológico y para la filosofía en general: Edmund Husserl y Martin Heidegger. Los dos pretenden, a su manera, acreditar un sentido en la existencia que explica la presencia de lo que llamamos praxis humana. Cada uno a su manera, decimos, pues se trata de propuestas que se diferencian en aspectos importantes, no obstante la motivación fundamental en la que coinciden.

Dividiremos la exposición en dos partes principales. La primera, dedicada a mostrar, de modo general, de qué manera Heidegger y Husserl intentan acreditar el sentido de la existencia como dimensión originaria. En ambos casos se distingue un acceso directo y originario al sentido, de una neutralización derivada. La segunda parte busca mostrar ciertos efectos relevantes que, para ambos autores, tiene la actitud neutralizante.

\section{Practicidad}

\section{Maneras de trato en Heidegger}

Martin Heidegger aparece habitualmente como quien, de entre estos dos autores, primero libera la practicidad misma de los intentos de reconducirla a datos objetivados. Ya antes de Ser y tiempo desarrolla la idea de que nuestro acceso originario a las cosas no es a unos objetos separados, meramente fácticos, sino que siempre a cosas-en-el-mundo, a cosas cargadas de sentido práctico. En esta parte queremos reconstruir en líneas muy generales, algunos de los planteamientos heideggerianos respecto a nuestras maneras de trato con los entes.

El ser humano se encuentra de alguna manera fuera de sí. No se halla encerrado completamente en él, sino que volcado hacia las cosas y las personas, en trato con ellas. El "Dasein es en sí mismo originariamente abierto-al-mundo, abierto para el mundo, que por su parte es abierto" ${ }^{1}$.

Este trato es originariamente práctico. "El ente es descubierto desde el paraqué de su servicialidad [Dienlichkeit]; es puesto ya en una interpretación [Deutung], es significado [be-deutet]. Y esto no debe ser entendido como si primero fuese dado un algo libre de significación, a lo cual le fuera agregada una significación, sino que lo que primero [...] es 'dado'” es lo originariamente práctico "en lo cual nosotros desde el inicio nos movemos", lo que "es-para" 2

\footnotetext{
${ }^{1}$ Heidegger, Martin. Logik. Die Frage nach der Wahrheit. En: Gesamtausgabe (en adelante GA) 21. Frankfurt a. M.: Klostermann, 1975 ss., § 12, p. 144.

${ }^{2}$ Ibídem.
} 
En la actitud práctica originaria no hay distancia radical con las cosas y las personas. Estamos con ellas, en ellas nos movemos desde el inicio y en ese estar con ellas forman de cierta manera parte de nosotros. El estar con ellas importa un abrirse que las incorpora en nuestra existencia. No se encuentran frente a nosotros, expuestas a nuestra mirada indagatoria, sino que nos acompańan y nos constituyen.

Pensemos por ejemplo en la relación de un carpintero en su taller con los materiales y las herramientas. Éstos no se le presentan originariamente como algo situado enfrente de él, guardando distancia neutral, sino que -mucho más- como algo con lo que el carpintero se encuentra en un trato práctico. Está con las cosas, no frente a ellas. Por ejemplo, cuando maneja una herramienta sobre la madera, esta maniobra lo introduce en el ser de la madera y de la herramienta; debe ajustarse, acomodarse a ellos. Así la herramienta y la madera se incorporan de cierto modo en la existencia misma del carpintero al realizar una obra. Él es con la herramienta y la madera, existe "a una con" ellas. Su relación con las cosas es afectiva, las siente cercanas, le ayudan a realizar una obra, las aprecia. De manera semejante, en el estar con otros seres humanos el otro no surge primariamente como un algo representado, puesto frente a mí, sino como alguien a quien recibo. Para tratar propiamente con él -esto es, para vincularme con él según el modo de ser que le corresponde- tengo que abrirme a él, hay aquí una cierta pasividad o receptividad. En la apertura al otro y en el trato abierto a él, éste pasa a formar también parte de mí. El trato con él me constituye como persona. Mis semejantes así recibidos no son sólo fuera de mí, sino de alguna manera también en mí. Estoy con ellos en grados de afecto que pueden alcanzar una gran intensidad, a tal punto que lleguen a faltarme cuando no están conmigo.

En esta actitud práctica originaria no hay ausencia de conocimiento. No es como si en el trato práctico se actuase sin más y en el conocimiento representativo se contemplase de manera inactiva ${ }^{3}$. Se trata, ante todo, de otro tipo de conocimiento, de un conocimiento que incorpora vivencial y teleológicamente y en lo incorporado se procura una visión ${ }^{4}$. Así, la acción del artesano supone una cierta visión prospectiva de lo que va a realizar y de lo que requiere para realizarlo, sólo que esa visión no es un conocimiento teórico que se represente separadamente las cosas. De modo semejante, el trato entre seres humanos supone una visión de la manera de realizarlo, una sabiduría que no implica la representación distanciante del otro, sino que lo incorpora en mi existencia. Padres e hijos no se tratan como entes ajenos y sin embargo saben como tratarse.

El ser humano, ubicado originariamente en este trato práctico con un mundo de sentido, puede también volverse reflexivamente sobre sí mismo y sobre las cosas y personas que están con él. Aquí "representa" a las personas y cosas, vale

${ }^{3}$ Cf. Heidegger, Martin. Sein und Zeit (en adelante SuZ). Tübingen: Max Niemeyer, 2001 (18a ed.), p. 69.

${ }^{4}$ Cf. GA 21, § 12, p. 144. 
decir, las pone enfrente, las saca de su existencia concreta, las desvincula, en mayor o menor grado, del trato práctico originario. No hay ya un estar con las cosas y las personas, sino que más bien un enfrentamiento a ellas. Así, me ubico por una parte yo como observador y por otra, frente a mí, separado de mí, lo representado, que es de algún modo expulsado, aislado de mí. De esta manera puedo entender, por ejemplo, a la herramienta no ya como algo con lo cual tengo familiaridad, cercanía, un cierto afecto, que me permite dar forma a la madera, sino como una cosa que me represento separadamente de mi existencia concreta. Así también puedo poner a los otros enfrente mío y representármelos 5 .

En esta capacidad de representación, de volver reflexivamente sobre las cosas y contemplarlas, radica el origen de la filosofía y de la ciencia, lo mismo que el de la negación de la dimensión de sentido por parte de la actitud a la que llamamos cientificista.

La capacidad de representación posibilita la toma de distancia respecto de lo que nos representamos. Esta toma de distancia importa un primer momento de "neutralización" del sentido de las cosas y personas. Pues quien reflexiona, quien representa, se desprende de alguna forma de la vivencia misma y su sentido originario al representársela, se sale, deja de jugar. Pensemos en una fiesta, por ejemplo. Sólo puedo estar en ella realmente en la medida en que me incorporo, comparto las bromas, participo en los bailes y en las conversaciones, etc. Si, en cambio, comienzo a observar lo que ahí está ocurriendo, desde ese mismo instante me he salido de alguna manera de la fiesta, la pongo frente a mí y dejo de estar en ella. Sin embargo, aunque me saca de la situación, la representación puede hacerse cargo de su sentido práctico, del sentido práctico, en este caso, de la fiesta. Es posible describir la fiesta aludiendo a la felicidad de los asistentes, a la tristeza de alguno de ellos, a la belleza de los adornos o de la música, etc. Más aún, una adecuada descripción de la fiesta no puede omitir estos elementos que la constituyen. En la medida en que la descripción se hace cargo del sentido de la fiesta no puede ser una descripción completamente neutral o distante, no pura objetividad. No todo distanciamiento reflexivo cancela el sentido de lo que se está mirando.

Sin embargo, en cuanto opera enunciativamente, esta descripción ha abierto ya la posibilidad a un mayor distanciamiento. Pues el enunciado tiene un modo de ser propio, es apto para independizarse de la vivencia originaria. Hay una "tendencia" en el enunciar, según la cual lo enunciado queda aislado de su contexto teleológico originario y pasa a ser entendido separadamente, como algo puesto enfrente, dotado de propiedades abstractas ${ }^{6}$. El ser humano puede ubicarse así en un "ser por relación al ente mentado en el enunciar"7, que es ajeno a aquella experiencia originaria. La referencia al sentido de la misma se debilita y puede llegar a perderse. En el enunciado independizado tenemos a

\footnotetext{
${ }^{5} \mathrm{Cf} . \mathrm{SuZ}, \S \S 32 \mathrm{~s}$.

${ }^{6}$ GA 21, p. 156. Lo dado originario es "nivelado hacia una cosa [Ding]"; ibídem, p. 158.
} 
un sujeto y sus propiedades. Si la vivencia misma está separada del enunciado, las propiedades pierden parcial o totalmente su sentido práctico originario. De este modo, en la predicación se lleva adelante una neutralización. Así, por ejemplo, Heidegger se refiere al enunciado: "las cosas flores tienen la propiedad o el estado del florecer". Agrega: "Nadie quiere estar diciendo algo así cuando dice: 'las flores florecen'. Aquello es mera construcción, tomada de un enunciado que en sí mismo tiene la tendencia hacia el mero determinar de un algo presente [Vorhandene]"8.

La capacidad de representación posibilita, de este modo, no sólo una manera de trato reflexivo que se distancia de la situación meramente para describirla, sino que otra que se distancia de ella para describirla prescindiendo del sentido práctico que la constituye. Es la manera de representar que está en la base de la ciencia natural moderna neutralizante.

No obstante, el "mundo" al que accedemos de la mano de la actitud objetivante, sería derivado respecto de aquél al que accedemos en la actitud práctica originaria $^{9}$. Esta actitud nos garantiza un acceso más directo a los fenómenos y, en esta medida, sería ontológicamente más informativa. En la actitud objetivante, en cambio, está supuesta una toma de distancia neutralizante respecto de lo originariamente accesible en el trato práctico. Recién luego de esa toma de distancia luce posible acceder a algo así como a un mundo de hechos objetivos.

\section{Husserl: mundo de la vida y mundo de la ciencia}

Hemos dicho que habitualmente se entiende que es Martin Heidegger el que libera la practicidad misma como ámbito originario no reconducible completamente a mera facticidad. Sin embargo, el aporte que Edmund Husserl hace en estos asuntos no debe ser menospreciado. Husserl no sólo descubre, también para Heidegger, el método y la intención fenomenológicos, la idea de la búsqueda de un acceso directo a las cosas, previa a un conocimiento representativo distanciante. También contribuye de dos maneras a justificar a la praxis como dimensión dotada de un estatus propio. Primero, en tanto acredita al llamado "mundo de la vida" (Lebenswelt) como originario respecto del mundo científico-natural. Segundo, en la medida que describe con detalle el modo en que la ciencia natural reduce el mundo originario y lo vuelve mundo científico-natural, así como los desplazamientos de sentido que esta conversión importa.

En ninguna de estas dos contribuciones se limita a parafrasear a Heidegger. Los conceptos básicos con los que Husserl opera no son simplemente secuelas de las reflexiones heideggerianas, un intento de aplicar su filosofía fenomeno-

\footnotetext{
${ }^{7}$ SuZ, p. 224.

${ }^{8}$ GA, p. 157 s.; sobre este punto, cf. Vigo, Alejandro. "Verdad, logos y praxis". En: García Marqués, Alejandro y García-Huidobro, Joaquín. Razón y praxis. Valparaíso: Edeval, 1994, pp. 154 ss.

${ }^{9}$ Cf. GA, p. 159.
} 
lógica a la nueva situación generada por Ser y Tiempo. Hay, por cierto, similitudes, pero también variaciones importantes. Y los conceptos husserlianos pueden pesquisarse en obras de Husserl anteriores a Ser y Tiempo.

La expresión "mundo de la vida", que desarrolla en plenitud en la Crisis de la ciencia europea y la fenomenología trascendenta $l^{10}$, es previa a $1920^{11}$. Es en los años 20 cuando se vuelve título de un problema fundamental para la fenomenología husserliana. También algunos de los temas que determinan este problema, se encuentran ya en obras anteriores. Así, por ejemplo, K.-H. Lembeck señala que "uno debe leer el trabajo tardío de Husserl sobre la 'Crisis de la ciencia europea' junto con el escrito programático temprano sobre la 'Filosofía como ciencia estricta", si se pretende entender el motivo cultural-terapéutico que está en la base de su reflexión ${ }^{12}$.

Es posible distinguir entre dos conceptos de mundo de la vida, que se presentan sucesivamente en el pensamiento de Husserl.

En un primer momento, el mundo de la vida es el mundo de la experiencia directamente accesible, preconceptual, antepredicativo. Se trata de un mundo a-histórico, en donde las construcciones culturales predicativas (teorías, artes, técnicas) no juegan todavía un papel ${ }^{13}$.

Más adelante, sin embargo, Husserl modificará este concepto, ampliándolo. Sería el mundo de la vida actualmente vivida, el cual incluye, junto a las vivencias antepredicativas, la vida teorizante. El mundo de la vida es "el mundo de la vida actual, en el cual la vida experimentante del mundo y teorizante del mundo están incluidas" ${ }^{14}$. Ambas formas de praxis quedarían incorporadas en el concepto.

Habría argumentos que explicarían esta ampliación. El mundo en el que concretamente vivimos no es un mundo de puras experiencias, sino que en él nos encontramos ya con teorías, técnicas y artes como hechos que forman parte de ese mundo vivido. "Pertenecen al acervo del mundo como mundo de experiencia pura" ${ }^{15}$. Se trata de construcciones culturales, con las que podemos entrar en un trato que no sea meramente representativo, sino incorporador, existencial, afectivo. Además, el fundamento de las ciencias del espíritu no

\footnotetext{
${ }^{10}$ El texto publicado por Husserl era originariamente una conferencia, que fue expuesta en mayo de 1935 en Viena. En noviembre del mismo año la expuso en dos conferencias dadas en la universidad alemana y dos en la universidad checa de Praga. El texto se publicó en la revista Philosophia, en Belgrado, el año 1936. Recién en 1954 apareció en Alemania, en el tomo VI de Husserliana. La Haya y otros, 1950 ss. (en adelante citado como $\mathrm{Hu}$, acompañada del número del volumen). Este tomo incorpora, además del texto publicado en 1936, una tercera parte, con observaciones acerca de la fenomenología y del concepto de Lebenswelt.

${ }^{11} \mathrm{Hu}$ IV (Ideen zu einer reinen Phänomenologie und phänomenologischen Philosophie, libro 2), p. 375.

${ }^{12}$ Lembeck, Karl-Heinz. Einführung in die phänomenologische Philosophie. Darmstadt: Wissenschaftliche Buchgesellschaft, 1994, p. 79.

${ }^{13}$ Hu IX, pp. 58 ss., 69.

${ }^{14}$ Esta frase es introducida por Husserl en sus lecciones más tarde; Hu IX, p. 56; cf. XIV, p. 396; VI, pp. 127 s.
} 
puede ser una experiencia muda sin conceptos, sino que sólo la participación vital en el mundo cultural vuelve posible el surgimiento de ese tipo de ciencias, cuyo desarrollo exige de sofisticadas articulaciones predicativas. Las teorías científicas, como construcciones intelectuales, desempeñarían una función propedéutica. En la medida en que nos familiarizamos con ellas y adquirimos los hábitos del oficio, podemos luego desarrollar nosotros mismos la actividad teórica. Porque Husserl centra su atención en el problema del alejamiento de la ciencia objetivante respecto de las preguntas humanas fundamentales (preguntas fundamentales y sin embargo representativamente formuladas). Precisamente la manera de rehabilitar el originario mundo de la vida es una "reflexión" de tipo filosófico, es decir, predicativamente articulada ${ }^{16}$.

Tanto la vida experimentante como la vida teorizante, serían así modos "legítimos" de praxis, pues en ambos se lograría vivenciar auténticamente sentido. En la vivencia "directamente" intuitiva, mediante la intuición misma. Pero la vida teorizante también provee de sentido, en la medida que las articulaciones predicativas permiten volver sobre las estructuras de la vida humana y descubrir, como ocurre, por ejemplo, precisamente en la reflexión filosófica sobre el mundo de la vida. Es posible un enunciar que se haga cargo del sentido de la existencia ${ }^{17}$. En la medida que descubre, la teoría misma sería una forma de praxis con sentido.

Así, Husserl parece ir más allá de Heidegger en su confianza en la capacidad enunciativa. Aunque esto puede ser sólo un asunto de énfasis. Para Heidegger, la fenomenología debe tener siempre en cuenta el riesgo de ocultamiento presente en el enunciar, si quiere ser descubridora. Pero puede ser descubridora ${ }^{18}$. Para Husserl, la capacidad enunciativa está en la base de la ciencia moderna alejada de la intuición. Sin embargo, ella también es rehabilitadora y descubridora del papel enajenante de la ciencia moderna. Además, en Husserl ella misma aparece con toda claridad y de modo manifiesto como una forma de praxis, tan originaria en lo que al acceso al sentido respecta, como la praxis no enunciativa ${ }^{19}$.

El mundo de la vida tiene el carácter de horizonte ${ }^{20}$. Los entes aparecen dentro de él no como objetos aislados que recién luego entran en relación con los

\footnotetext{
${ }^{15}$ Hu XIV, p. 397.

16 "El regreso correcto a la ingenuidad de la vida, en una reflexión que se eleve sobre sí misma, es el único camino para superar la ingenuidad filosófica radicada en la 'cientificidad' de la filosofía objetivista tradicional". Hu VI, $\$ 9$, l).

${ }^{17}$ El descubrir teórico constituye un aporte respecto del descubrir práctico originario, en la medida que contribuye con un mayor nivel de conciencia sobre la situación del ser humano, y permite acreditar filosóficamente el carácter originario de la praxis frente a la objetivación, lo mismo que mostrar vías de superación a la enajenación a que esta objetivación puede dar lugar.

${ }^{18}$ Cf. SuZ, p. 36.

${ }^{19}$ Husserl entiende que la tarea del filósofo no es exclusivamente teórica. El papel de los "auténticos filósofos", de los que viven en la verdad, es ser "funcionarios de la humanidad", responsables del "verdadero ser de la humanidad, que sólo puede verificarse como ser hacia un telos y sólo puede realizarse mediante filosofía”; Hu VI, $\$$ 7. También en este sentido debe entenderse la nostálgica evocación de Husserl al ideal de la filosofía moderna, que no sólo alcanzaría a orientar al filósofo, sino que, en general, a la humanidad moderna, con implicancias políticas y educativas; cf. Hu VI, $\$ 5$.
} 
otros y adquieren sentido. Originariamente se encuentran ya vinculados al mundo como tal y a los demás entes que se ubican en él, y originariamente están ya dotados de sentido. "Todo fin lo supone"21.

De esta manera, se puede superar, si no en todo en parte, la crítica que sostiene que el punto de partida de la fenomenología husserliana sería una relación teórica entre el sujeto y el objeto ${ }^{22}$. Tratándose del mundo de la vida, al menos, esta relación no es el modelo, sino que, en cambio, se reconoce el carácter "horizontal" de la existencia de los entes en él, lo que implica el reconocimiento del trato práctico como forma de acceso a los entes, y del carácter originario de las relaciones entre los entes y entre los entes y el mundo. Una "ontología” del mundo de la vida se tiene que hacer cargo de ese carácter propio, tal como el mismo Husserl lo entiende. Que para Husserl el mundo de la vida sea constituido trascendentalmente no altera necesariamente lo señalado. El mundo de la vida y sus estructuras típicas son, como plantea Lembeck, "un 'fenómeno' originario y no cuestionable posteriormente; el a priori del mundo de la vida se muestra como una 'capa' fundamental del a priori universal de la trascendentalidad [...] Así vista, la ontología del mundo de la vida provee uno de los 'hilos conductores' para el camino del preguntar trascendental, y concurre junto a otras vías que conducen en la misma dirección: junto a la vía cartesiana hacia el ego cogito y junto a la vía sobre la psicología intencional”23. Cabe así preguntar hacia la trascendencia por las condiciones del mundo de la vida como fenómeno último, no reconducible a las otras vías.

Nuestro acceso al mundo de la vida es directo, éste "se caracteriza por su real vivencialidad" 24 . Es el medio en el que concreta y realmente nos encontramos, la auténtica realidad en la que vivimos, que se encuentra dada ya a nosotros desde siempre, como suelo y horizonte existente sobre el que opera toda acción humana, teórica o extra-teórica ${ }^{25}$. No obstante que estamos inmersos en él, no lo volvemos necesariamente temático, sino sólo en la reflexión filosófica sobre él. Pero la tematización es, podríamos decir, excepcional. Habitualmente nos encontramos simplemente inmersos en él, viviendo concretamente y, en esa vida, haciendo teoría o actuando de maneras extra-teóricas.

En fin, cabe indicar que ese mundo de la vida es originario. Es "para nosotros siempre ya previamente dado, existente antes" ${ }^{26}$. Es previo a la praxis científica

\footnotetext{
${ }^{20} \mathrm{Hu}$ VI, p. 145. "El fenomenólogo sabe que lo mentado por la conciencia no es nunca un objeto aislado, sino que pertenece a un campo, medio o conjunto con el que mantiene una variedad de relaciones actualmente patentes o potencialmente desarrollables por experiencias sucesivas". Cordua, Carla. Verdad y sentido en "La Crisis" de Husserl. Santiago: Ril, 2004, p. 154.

${ }^{21} \mathrm{Hu}$ VI, p. 462; cf. p. 459.

${ }^{22}$ Esta crítica, que "autores recientes [...] se contentan con repetir", y que sin cuidado aplican a Husserl en general, valdría sólo para "los comienzos de la fenomenología" husserliana; Cordua, op. cit., p. 137.

${ }^{23}$ Lembeck, Einführung, p. 82; cf. Hu VI, pp. 176 s.

${ }^{24} \mathrm{Hu}$ VI, p. 130.

${ }^{25} \mathrm{Hu}$ VI, p. 145.
} 
y a la misma ciencia natural como producto de esa praxis. "Si dejamos de estar sumergidos en nuestro pensar científico, caeremos en la cuenta que nosotros los científicos somos sin embargo seres humanos y como partes del mundo de la vida, así se incorpora con nosotros toda la ciencia en el mundo de la vida -meramente 'subjetivo-relativo'"27.

Una idea fundamental del texto sobre la Crisis de la ciencia europea es que el "mundo objetivo de las ciencias" es el correlato de una idea-fin particular, la idea de un mundo existente en sí, descriptible adecuadamente mediante un conjunto de verdades predicativas ideales científicas. Ese fin responde, en definitiva, a un cierto afán de cálculo y predicción. El mundo de las ciencias, como correlato de un fin, se incorpora dentro del mundo de la vida, que abarca todos los fines. Veamos.

Kant muestra cómo el gran descubrimiento que posibilitó la aparición de este tipo de ciencia fue el experimento. En él lo dado en la experiencia es puesto en juego disciplinadamente con enunciados previamente formulados a modo de hipótesis. En estas hipótesis se enuncian hechos contrastables mediante sensopercepciones, los que son habitualmente formalizados de modo matemático. La naturaleza es forzada, de cierta manera, a aparecerse según los enunciados hipotéticos ${ }^{28}$, es "filtrada", hecha comparecer sólo en la medida en que se deja abarcar empírica y matemáticamente. Desde Galileo tiene lugar una formalización y "empirización" del mundo en el que concretamente vivimos. Este mundo no se ajusta necesariamente a las fórmulas matemáticas; tampoco se deja abarcar plenamente a partir de experimentos apoyados en la sensibilidad. Si bien puede ser comprendido según las fórmulas matemáticas, se escapa también a ellas. Con la matematización se pasa, así, por sobre el mundo concreto, se lo reduce o simplifica. Ese mundo no es reconducible completamente a fórmulas matemáticas ideales, siempre hay algo que en ellas queda fuera. Lo mismo puede decirse de los experimentos: si bien el mundo concreto responde en parte al método empírico, en parte relevante escapa a él.

Ya ciertos aspectos cualitativos del mundo, perceptibles sensiblemente, como los colores, los sonidos, los gustos, son reducidos por la ciencia moderna. El "mundo" de la ciencia es el mundo de los cuerpos, esto es, de las extensiones que podemos percibir por más de un sentido. Las cualidades sensibles específicas, en cambio, a saber, aquellas en las que sólo interviene un sentido, pasan a ser consideradas como "secundarias" 29 , como el producto de la acción de los cuerpos, de la acción de las cualidades "primarias". Sin embargo, esta reducción no podría llevarse a cabo plausiblemente. "Es una mala herencia de la tradición psicologista desde los tiempos de Locke” -nos dice Husserl al respecto-

\footnotetext{
${ }^{26} \mathrm{Hu}$ VI, p. 145.

${ }^{27} \mathrm{Hu}$ VI, p. 133.

${ }^{28}$ Cf. Kant, Immanuel. Kritik der reinen Vernunft. Hamburgo: Meiner, 1998, B XII ss.

${ }^{29}$ Locke, John. Ensayo sobre el entendimiento humano. Bogotá: Fondo de Cultura Económica, 1994, libro 2, cap. $8, \$ \$ 9$ ss., pp. 113 ss.
} 
"que permanentemente a las cualidades sensibles de los cuerpos vivenciables realmente en el mundo cotidiano e intuible -los colores, las cualidades táctiles, los aromas, el calor, la pesadez, etc., que son percibidos en los cuerpos mismos, justo como sus propiedades- les son puestas debajo los 'datos sensibles', 'datos de sensación', a los que se llama indistintamente cualidades sensibles, y que al menos en general no son distinguidos de ellas. Donde la diferencia es notada [...] se cuida de atribuirlas rápidamente a lo matemático-fisicalista" ${ }^{30}$. Pero el rojo, por ejemplo, o el dulzor, o una melodía, no parecen resultar directa y completamente reductibles a relaciones puramente corporales, por ejemplo, a vibraciones u ondas físicas. El rojo mismo es color y ese color es un contenido, que puede ser estudiado como color y como color es ya algo y no nada. Lo mismo se puede sostener del sabor dulce, de los sabores en general, un sonido, los sonidos en general, etc ${ }^{31}$.

Esta reconducción de las cualidades a los cuerpos persigue un fin determinado, a saber, lograr la idealización del mundo natural que procura la ciencia moderna. Se trata de matematizar la naturaleza. Las "plenitudes sensibles" o cualidades no se dejan matematizar directamente, por lo que se las entiende como correlato, expresión o epifenómeno de la acción de los cuerpos que subyacen a ellas ${ }^{32}$. El mundo natural (cuerpos y cualidades incluidos) es indexado matemáticamente. El paso decisivo en la idealización se da cuando se comienza a calcular con las fórmulas, de tal modo que resulta viable predecir con ellas el comportamiento del mundo natural indexado ${ }^{33}$. Este cálculo tiene, sin embargo, un valor predictivo incompleto, en la medida que el comportamiento del mundo natural admite variaciones. "Las cosas del mundo intuible que nos rodea se encuentran en general y en todas sus propiedades, en las variaciones de lo meramente típico; su identidad consigo mismas, su ser-iguala-sí-mismas, y su durar temporalmente en igualdad, son sólo aproximados, tal como su igualdad con otras" 34 .

El mundo de la ciencia moderna prescinde también de la practicidad originaria de la vida humana. El mundo de la vida, hemos visto, es, para Husserl,

\footnotetext{
${ }^{30} \mathrm{Hu}$ VI, $\$ 9$, b), nota al pie.

${ }^{31}$ Un cientista cognitivo podría replicarnos que no hay problema en conservar el modo habitual de referirse a lo que percibimos. Palabras como "rojo" tienen su ámbito de validez, pero otra cosa es que tales palabras tengan valor cognitivo. Si queremos conocer lo que significa "rojo", hay que empezar a hablar otro lenguaje. La ontología del color no se formula en primera persona, sino en tercera persona. Aquí cabría replicar, sin embargo, lo que Husserl dice a nuestro personaje, a saber, que descansa sobre la aceptación de premisas que son todo menos pacíficas: un mundo efectivamente existente, sobre el que cabría hablar de modo objetivo, en tercera persona. Ese mundo, sin embargo, resulta altamente problemático desde un punto de partida fenomenológico. Nuestro acceso originario no es a un mundo objetivo realmente existente, sino a vivencias de color, sabor, sentido, incorporadas en un contexto de remisiones teleológicas. Antes de "saltar" desde esas vivencias hacia un mundo objetivo, cabe todavía hacerse cargo de ellas en su carácter originario. Sólo así puede comprenderse propiamente de qué estamos hablando cuando decimos "mundo objetivo". Ese mundo objetivo, en cuanto arraigado en el mundo de la vida, es tan "subjetivo" como éste.

${ }^{32} \mathrm{Hu}$ VI, $\left.\left.₫ 9, \mathrm{~b}\right), \mathrm{c}\right)$.

${ }^{33}$ Cf. Hu VI, $\$ 9$, f).

${ }^{34} \mathrm{Hu}$ VI, $\$ 9$, a).
} 
práctico, en cuanto en él se contienen los fines por los que continuamente estamos orientando nuestras existencias. Esos fines son dejados de lado por la ciencia natural matematizada. Como tales "no pasan" por los criterios de cientificidad. No resulta posible para una ciencia de cuerpos acceder a algo como un sentido de la existencia. En el proceso de objetivación ese sentido queda de lado. "En nuestra necesidad vital -escuchamos- esta ciencia no tiene nada que decirnos. Ella se cierra por principio, justo a las preguntas [...] apremiantes: las preguntas por el sentido o sinsentido de la completa existencia humana". Incluso en las ciencias del espíritu, y en atención a un criterio de "estricta 'cientificidad", "todas las preguntas sobre la razón o sinrazón de la humanidad y sus construcciones culturales" son "cuidadosamente" desconectadas ${ }^{35}$.

El mundo concreto es, sin embargo, previo al mundo científico-natural. A éste se llegaría mediante la reducción o la separación de lo originariamente vivenciado. Si al mundo de la vida accedemos directamente, de modo aún no representativo u objetivante, al mundo científico natural accederíamos recién luego de una operación de representación distanciante y prescindente del sentido originario. El mundo científico-natural sería constituido a partir de una negación de ciertos aspectos del mundo concreto de la vida, mediante abstracción. De este modo, el acceso al mundo concreto de la vida luce ser más completo que el acceso al mundo científico natural, en cuanto se trata de un acceso directo, no mediado por representaciones distanciantes. Así, por ejemplo, cabe acceder a la vivencia del bosque en plenitud y abarcar aspectos del bosque que en la visión científico natural -que puede llegar a entenderlo como madera cuantificable- quedan fuera. El tiempo mundo-vital, que puede ser expectativa y recuerdo cargado de sentido, el espacio mundo-vital de las cosas dentro de un horizonte práctico, el medio cercano y "lo extranjero", etc. pasan a ser nivelados en un tiempo y un espacio matematizados, carentes de la vitalidad de lo concreto ${ }^{36}$.

La matematización y la empirización llevadas adelante por la ciencia moderna no son, a su vez, hechos puramente neutrales. Jürgen Habermas indica, en este sentido, que "las teorías científicas de tipo empírico abren la realidad bajo la guía del interés por la posible seguridad informativa" ${ }^{37}$. Vale decir, ese interés sería el que recién hace posible la actitud de la ciencia moderna, su manera de plantearse frente al mundo. Antes de pronunciarse sobre el mundo, el científico natural ya sabría, de alguna manera, lo que obtendrá de él: hechos neutralizados, calculables. La separación de lo originariamente dado y la obtención de algo así como hechos neutrales, supondría realizar una operación sobre eso originario. La operación puede ser llamada "artificial”, pues nos sacaría, de alguna manera, de nuestra experiencia originaria y separaría lo que en ella está unido. Así ocurriría cuando un científico natural separa lo que hay de sen-

\footnotetext{
${ }^{35} \mathrm{Hu}$ VI, $\$ 2$.

${ }^{36}$ Cf. Bernet/Kern/Marbach, Edmund Husserl, p. 208; Hu VI, p. 176.

${ }^{37}$ Habermas, Jürgen. "Conocimiento e interés". Ciencia y técnica como “ideología”. Madrid: Tecnos, 1992 (2a ed.), p. 170.
} 
tido en la experiencia cotidiana y la reduce a hecho material cuantificado. La operación misma de separación se encuentra, sin embargo -en cuanto acción humana, incorporada en el contexto originario de remisiones teleológicas, motivada cualitativamente, busca realizar un fin, por ejemplo: volver calculable un aspecto del mundo concreto originario.

\section{Enajenación}

\section{Husserl}

Para Husserl, la actitud objetivante de la moderna ciencia no es rechazable en principio. Plantea que la reducción es aceptable siempre que permanezca claro que se está llevando adelante una reducción. Los supuestos a partir de los cuales opera la reducción deben mantenerse accesibles, de tal modo que no se termine por tomar al producto de la aplicación de un método sobre el mundo concreto en el que nos encontramos originariamente, como el ser verdadero ${ }^{38}$.

La actitud objetivante permite incrementar las posibilidades de cálculo y previsión respecto de los fenómenos naturales, sin embargo, prescinde de caracteres relevantes del mundo de la vida, que no admiten ser "pasados" por la nueva ciencia ${ }^{39}$.

Husserl no se refiere detenidamente a las posibilidades de dominio de la naturaleza y del hombre, en cuanto natural, que generan el incremento de la calculabilidad y previsibilidad del mundo. Sí repara, en cambio, en otras consecuencias prácticas de la actitud objetivante en la que la ciencia se funda.

i) La actitud objetivante terminaría por reducir simplemente la complejidad del mundo de la vida. Las llamadas "plenitudes sensibles" o "cualidades secundarias" son reconducidas a las cualidades primarias, a meras relaciones corporales, a expresiones de datos corporales. Se llega a afirmar que "los fenómenos son sólo en los sujetos; en ellos son sólo consecuencia causal de los procesos que realmente tienen lugar en la verdadera naturaleza" material y matematizada $^{40}$, sin caer en la cuenta que las plenitudes sensibles son percibidas y como tales no lucen, en su cualidad misma, reducibles satisfactoriamente a relaciones que no contengan de modo alguno la cualidad respectiva.

\footnotetext{
${ }^{38}$ Cf. Hu VI, $\$ 9$, h). "El filósofo -indica en el mismo sentido Michel Henry- tiene el deber de intervenir sólo cuando el dominio de la ciencia es comprendido como el único dominio de ser verdaderamente existente y por ello resulta que el dominio en el que arraigan la vida y su cultura es arrojado en el no-ser o en la apariencia de la ilusión. No es [...] el saber científico lo que cuestionamos, sino la ideología que hoy en día se le une y según la cual él es el único saber posible, el que debe eliminar a los demás"; Henry, Michel. La barbarie. Madrid: Caparrós Editores, 1996, p. 39.

${ }^{39}$ Cf. Hu VI, $\$ 9$, h).

${ }^{40} \mathrm{Hu}$ VI, $\left.\$ 9, \mathrm{i}\right)$.
} 
La ciencia moderna no sería capaz de dar cuenta de la temporalidad, la espacialidad o la causalidad del mundo de la vida. Ellas no tienen la generalidad ni la neutralidad del tiempo, el espacio y la causalidad con las que trabaja la ciencia natural moderna ${ }^{41}$. Tampoco encuentran explicación en ella estructuras de ese mundo de la vida como "mundo cercano-extranjero" 42 .

En general, tanto el sentido del mundo de la vida, como todo cuanto tenga que ver con la subjetividad queda fuera en la actitud objetivante. Así, el ser humano y el mundo en el que concretamente existe, pasan a ser reducidos a una construcción. "Meras ciencias de hechos producen meros hombres de hechos" ${ }^{3}$.

ii) La actitud objetivante de la moderna ciencia deja sin orientación práctica al ser humano. "En nuestra necesidad vital -escuchamos- esta ciencia no tiene nada que decirnos" ${ }^{44}$, afirma Husserl, aludiendo probablemente a Max Weber. A comienzos de 1919 éste dio en Munich una conferencia titulada "De la vocación por la ciencia". En ella Weber rechaza los intentos de buscar en la ciencia algo así como un fundamento del sentido de la vida humana. La ciencia no provee de ese fundamento. "¿Cuál es [...] el sentido de la ciencia como vocación, luego que todas esas ilusiones: 'camino hacia el verdadero ser', 'camino hacia el verdadero arte', 'camino hacia la verdadera naturaleza', 'camino hacia el verdadero Dios' se han hundido? La respuesta más sencilla la dio Tolstoi, con las palabras: 'ella no tiene sentido, porque no da respuesta a la única pregunta que es importante para nosotros, a saber, qué debemos hacer, cómo debemos vivir'. El hecho que ella no entregue esa respuesta es absolutamente indudable" ${ }^{45}$. La ciencia puede mostrarnos la adecuación de los medios para lograr fines dados, que a su vez se fundan en decisiones valorativas. También puede mostrarnos las contradicciones entre un juicio de valor y otros. Sin embargo, no puede relevarnos al momento de tomar la decisión acerca de cómo debemos vivir. La ciencia sólo provee un conocimiento acerca de los medios. Los fines, en cambio, algo así como el sentido último de la existencia, escapan a ella, lo mismo que la subjetividad. Y sin embargo, la comprensión de ese sentido y de la subjetividad son decisivos para vivir una existencia con sentido. Husserl no reclama esta orientación a la ciencia natural, pero sí a la filosofía como disciplina última ${ }^{46}$.

iii) La ciencia positiva y la actitud objetivante tienden a alejarse de lo que podríamos llamar la trascendencia. El mundo científico-natural es un mundo encerrado en los límites del conocimiento sensible matematizado. Tanto el sentido de la existencia como una dimensión más allá de esos límites quedan, en principio, descartados. Husserl muestra, sin embargo, cómo esta constitu-

\footnotetext{
${ }^{41}$ Cf. Hu VI $\left.\$ 9, a\right)$.

${ }^{42} \mathrm{Hu}$ XV, anexos XI, XII, XIII, XLVIII.

${ }^{43} \mathrm{Hu}$ VI, $\$ 2$.

${ }^{44} \mathrm{Hu}$ VI, $\$ 2$.

${ }^{45}$ Weber, Max. Soziologie - Weltgeschichtliche Analysen - Politik. Stuttgart 1964, p. 322.

${ }^{46} \mathrm{Cf}$. Hu VI, $₫ 7$.
} 
ción que es el mundo científico-natural, queda remitida a condiciones trascendentes. La fenomenología de Husserl busca hacia la trascendencia las condiciones de la constitución de todos los fenómenos. Si se tiene en cuenta que, desde la fenomenología del mundo de la vida, este mundo se vuelve una de las estructuras irreductibles de la existencia fenomenológica, el preguntar trascendental debe hacerse cargo de sus condiciones de aparición. Aunque no hay un desarrollo sistemático ni de una determinación de las estructuras del mundo de la vida, ni de un preguntar hacia la trascendencia por sus condiciones, la dirección está marcada. De esas condiciones la nueva actitud objetivante no se hace cargo, y en este sentido las observaciones de Husserl dan pie para echar de menos esa ausencia.

\section{Heidegger}

Para Heidegger, la actitud objetivante y la ciencia y la técnica que esa actitud posibilita, también incrementan la calculabilidad y previsibilidad del mundo que tiene cabida dentro de sus límites, del mundo científico-natural. La naturaleza es representada como un "conjunto calculable de interacciones de fuerzas" $^{\text {” }}$, respecto del cual es posible una manipulación segura ${ }^{48}$.

Este incremento repercute en un correlativo avance del dominio técnico sobre la naturaleza. En la medida que el mundo se vuelve calculable y previsible, se torna también disponible para el hombre y sus aparatos técnicos. De paso, el propio ser humano, en cuanto parte de la naturaleza, se vuelve objeto de cálculo y dominio técnico. A diferencia de Husserl, Heidegger se detiene en las consecuencias para la vida de este dominio técnico. La naturaleza calculable y manipulable queda reducida a "existencias" (Bestand) y, con ello, el hombre se divide. Por un lado es "señor de la tierra", por otro, sin embargo, también "existencias" (Bestand) ${ }^{49}$. El cálculo y el dominio generan posibilidades de abuso, que luego de las guerras mundiales, la crisis ecológica y la amenaza nuclear, se han hecho generalmente conocidas. Pero este no sería el mayor peligro. "La amenaza al ser humano no proviene recién de las máquinas y aparatos de la técnica posiblemente mortales" ${ }^{\circ}$.

La amenaza también afecta al empresario y al obrero, al habitante de la gran ciudad y, en general, a todos los seres humanos en el mundo actual, y consiste en la imposibilidad de "volver hacia un desocultamiento más originario" que el de la técnica, "y así vivenciar el consejo [Zuspruch] de una verdad más inicial" 51 . Lo concreto es nivelado en abstracciones matemáticas sin sentido práctico y vital, que terminan por convertirse en existencias disponibles. $\mathrm{La}$

\footnotetext{
${ }^{47}$ Heidegger, Martin. "Die Frage nach der Technik”. Vorträge und Aufsätze. Stuttgart: Klett-Cotta, 2000 (9a ed.), p. 30 .

${ }^{48}$ Ibidem, p. 31.

${ }^{49}$ Ibidem, p. 30.

${ }^{50}$ Ibidem, p. 32.

${ }^{51}$ Ibidem, p. 32; cf. 29 s. y 31.
} 
técnica incrementa las posibilidades de manipular y nos rodeamos de objetos fabricados en los que no hay misterio, ni un sentido que nos aborde desde lo que podríamos llamar la profundidad de las cosas mismas ${ }^{52}$.

Así, por ejemplo, en la existencia tecnológica u objetivizada, el bosque originario es reducido a representaciones, puede ser objetivado como materia prima calculable y disponible, y reconducido a existencias. En esta operación el bosque mismo, aquél por el que puedo caminar, en el que puedo oler la humedad de la tierra y del follaje, sentir cantos de pájaros o verme abordado por el silencio, en el que veo formas y colores, ese bosque es olvidado y, con él, una cierta profundidad y un sentido de que nos provee. "Vivir en relación con [...] bosques-representaciones es fatigoso" - dice Rivera-, "porque no refresca nuestra alma, no la alimenta, no la llena de gozo ni de belleza [...] El ser humano se cansa de vivir entre meras representaciones. Necesita de la enjundia de lo vivo, de las cosas mismas" 53 . De la vida con las cosas mismas, con su plenitud originaria, de esa vida no nos cansamos porque es vida con sentido. En la vida de representaciones de la moderna ciencia y del dominio tecnológico, la profundidad y el sentido ceden paso a la superficialidad de un objeto que se encuentra manifiesto y disponible bajo todos sus aspectos, sin misterio, banal, lo mismo que a la prescindencia de ese sentido que las cosas nos brindan.

La actitud objetivante y sus derivaciones hace que se nos cierre el paso a la trascendencia.

El hombre no sólo está más allá de sí, con las cosas y con los otros. También se ubica más allá de ellos, puede trascenderlos. Se encuentra fuera de modo radical, fuera de sí mismo y de los entes. Puede abarcarse a sí mismo y a las demás cosas y personas como desde otra parte "como desde otro lugar". Este "estar fuera" no es posibilitado por un ente particular, pues los entes se hallan restringidos a la esfera óntica, siempre limitados, acotados. Cabe reconocer una cierta "dimensión" trascendente, que hace posible el afuera del hombre como ente respecto de la dimensión óntica. Esa dimensión constituiría el afuera radical en el que se ubica el hombre. Ella debe distinguirse de los entes, no es un ente. El ser es lo que le permite al hombre, que es un ente, abordar a los entes y abordarse a sí mismo como ente desde fuera.

El carácter trascendente del ser humano no implica que necesariamente se encuentre en actitud de apertura al ser. Que desde siempre nos ubiquemos más allá de los entes, nos permite tomar distancia de ellos para contemplarlos de modo abarcante y también para objetivarlos y someterlos al dominio tecnológico. Es justamente el estar en la dimensión abierta por el ser lo que posibilita esta toma de distancia objetivante. Al caer en la objetivación y en la existencia tecnológica nos cerramos paso a aquélla. El mundo termina por aparecerse

\footnotetext{
52 Cf. Schelsky, Helmut. Einsamkeit und Freiheit. Hamburgo 1963, p. 229.

53 Rivera, Jorge Eduardo. Itinerarium cordis. Ensayos filosóficos. Santiago: Brickle, 2006, pp. 296 s.
} 
como un mundo científico-natural en el que algo como el ser ya no cabe, ni teórica ni prácticamente (no obstante que lo supone).

La actitud objetivante también es capaz de hacer que los entes se nos acerquen, nos aborden como objetos expuestos, exteriorizados, calculables y disponibles. Los entes nos invaden en cierta manera, como aparatos tecnológicos o como objetos disponibles a partir de esos aparatos. Nos vemos "acosados" por ellos. El mundo tecnológico ofrece una infinidad de posibilidades de diversión, disposición y distracción. En la medida que los entes nos acosan, perdemos posibilidades de abrirnos al ser, de gozar del silencio y tiempo requeridos para realizar la apertura. La actitud objetivante se muestra como fuente de inautenticidad.

La pregunta por el ser no admite ser esquivada sin renunciar a una vida auténtica. Sin embargo, no puede ser abordada desde la actitud objetivante.

El modo de descubrir de la técnica nos cierra el paso a otros tipos de descubrimiento. Los entes neutralizados y vueltos en puras "existencias", nos cierran el paso al ser.

El ser se muestra como indisponible, infinito, supremo, misterioso, y llegamos a temerle. Una misma motivación se encontraría tanto en el temor al ser como en el afán de cálculo y disposición que mueve a la ciencia moderna. Pero la ciencia no nos permite controlar el ser, sino sólo los entes. Como dice Rivera: "El ser es lo incontrolable por excelencia. Es peligrosidad pura. Es puro misterio. Sobre el ser no podemos ejercer ningún control" ${ }^{4}$. Por eso, desde la actitud cientificista, no nos queda sino olvidarlo. Este olvido es evasión, pues importa "ser incapaz de agarrar lo que sin embargo nos concierne" $"$.

No obstante que llama la atención sobre el cierre a preguntas fundamentales para la existencia, dentro de las que se encuentra la pregunta por la trascendencia, el pensamiento de Husserl parece quedar atado a un cierto afán de disposición. Su idea de una filosofía como ciencia estricta, con paso continuo desde "comienzos absolutamente claros" ${ }^{56}$, y que determina su filosofar incluso en la $\mathrm{Crisis}^{57}$, no sería capaz de hacer justicia al ser en su infinitud. Una filosofía así luce demasiado estricta como para que el ser no se le escape. Más aún, un ser que, junto con descubrirse se oculta, no parece asible en una filosofía que se proyecta hacia un sujeto trascendental. En Heidegger, en cambio, la apertura a

\footnotetext{
${ }^{54}$ Ibidem, p. 286.

55 Ibidem, p. 287.

${ }^{56}$ Husserl, Edmund. Philosophie als strenge Wissenschaft. Frankfurt a. M.: Klostermann, 1965, p. 71.

${ }^{57}$ No obstante el reconocimiento de la crisis en la que habría caído la filosofía, Husserl aboga, precisamente, por retomar el camino hacia su ideal de una filosofía "universal que progresa en intuición consecuente y apodíctica y se norma a sí misma según un método apodíctico”; Hu VI, $\$ 6$.
} 
la trascendencia sería más decidida, especialmente en la medida que entiende al ser no como mero horizonte trascendental, sino que como dimensión autónoma e indisponible, a la que el ser humano puede abrirse y en la apertura vivenciar sentido ${ }^{58}$.

58 Cf. Heidegger, Martin. Brief über den Humanismus, en: GA 9, pp. 313, 316, 319, 323, 326, 329; Rosales, Alberto. Transzendenz und Differenz. Ein Beitrag zum Problem der ontologischen Differenz beim frühen Heidegger. La Haya: Martinus Nijhoff, 1970, pp. 312-315. 
VII. FENOMENOLOGÍA E HISTORIA 


\title{
Futuro e Historicidad en la Hermenéutica del Dasein
}

\author{
Carlos Di Silvestre \\ Universidad Nacional de Cuyo
}

\begin{abstract}
Resumen
En el siguiente texto se examina la interpretación de la historicidad en el contexto de la Analítica existencial del Dasein. A modo de introducción, se hace una breve referencia a la destrucción de la comprensión usual de la historia, orientada a partir de la noción de pasado. Posteriormente, se pro-cura aclarar los diversos sentidos y la función sistemática del concepto existencial de futuro en la interpretación positiva de la historicidad.
\end{abstract}

1. La interpretación existencial de la historicidad constituye un momento fundamental del modelo teórico que Heidegger desarrolló durante el período inicial de su producción bajo el título de ontología fundamental o analitica del Dasein. Desde un punto de vista arquitectónico, se podría incluso afirmar que la interpretación de la historicidad representa el punto culminante de la hermenéutica del Dasein expuesta en Ser y tiempo - no ciertamente del proyecto ontológico heideggeriano en su conjunto, dirigido siempre por la Seinsfrage. En efecto, si la determinación del Dasein como ser-en-el-mundo y cuidado es provisoria y brinda el suelo para una interpretación más originaria, donde se muestra el sentido del ser del Dasein como temporalidad [Zeitlichkeit], entonces la interpretación de la historicidad, en la medida en que es el resultado de una "elaboración más concreta de la temporalidad", constituye el concepto más desarrollado y extremo de la ontología del Dasein. La compleja textura conceptual del capítulo sobre la historicidad en $S Z$ lo atestigua suficientemente.

Pero la relevancia de la pregunta por el ser histórico se hace ostensible también cuando se considera la secuencia textual que condujo a $S Z$. Como se sabe, en 1923 se publica por primera vez la correspondencia filosófica entre Wilhelm Dilthey y Paul Yorck ${ }^{2}$. Heidegger quedó impresionado con la lectura de esta correspondencia, a tal punto que ella se convirtió en la motivación inmediata para la elaboración, a comienzos de 1924, de un tratado, titulado El concepto de tiempo, que fue publicado sólo en $2004^{3}$. En este texto Heidegger asume expresamente la tarea de "comprender la historicidad"

\footnotetext{
${ }^{1}$ Heidegger, Martin. Sein und Zeit. 17a ed. Tübingen: Max Niemeyer, 1993, p. 382. En adelante SZ.

${ }^{2}$ Briefwechsel zwischen Wilhelm Dilthey und dem Graf Paul Yorck v. Wartenburg 1877-1897. Halle (Saale): Max Niemeyer, 1923.

${ }^{3}$ Heidegger, Martin. Der Begriff der Zeit, GA 64. Frankfurt a. M.: Vittorio Klostermann, 2004. En adelante BZ.

${ }^{4}$ Briefwechsel, p. 185
} 
Dilthey en la correspondencia, como vía eminente para destacar la especificidad ontológica del Dasein, motivo rector que procede a su vez del programa heideggeriano de una ontología de la vida fáctica. En $B Z$ Heidegger sostiene que sus investigaciones acerca del tiempo pueden contribuir a aclarar radicalmente la concepción de la historicidad que se abría paso de un modo germinal en la filosofía de la vida. El texto es de gran importancia en el camino que conduce a $S Z$. Así, de acuerdo con su editor alemán, F.-W. von Herrmann, $B Z$ "puede ser caracterizado con perfecto derecho como la versión originaria [Urfassung] de Ser y tiempo" ". Y aquí nos encontramos con un dato ciertamente llamativo: la versión originaria de $S Z$ no se propone como meta fundamental plantear la pregunta por el sentido del ser en cuanto tal, sino la pregunta por el sentido del ser histórico del Dasein.

2. Desde un punto de vista metódico, la interpretación de la historicidad en el contexto de $S Z$ presenta dos momentos claramente distinguibles y mutuamente articulados. El primero consiste en la destrucción fenomenológica de la comprensión "vulgar" o usual de la historia. El segundo, de carácter positivo, consiste en lo que Heidegger llama construcción fenomenológica del ser histórico a partir de la estructura fenoménica de la temporalidad. Este segundo momento sólo puede ser comprendido y justificado sobre la base de los resultados del primero. Por ello, a continuación destacaremos brevemente dos resultados fundamentales de la destrucción de la "historia", que nos servirán de base para el tratamiento de nuestro tema acerca del sentido y la función sistemática de la noción de futuro en la interpretación positiva de la historicidad.

En primer lugar, la destrucción conduce a la siguiente tesis: "la determinación historicidad es previa a lo que se llama historia (el acontecimiento histórico)" 6 . Es decir, frente a la comprensión usual de la historia como una serie de acontecimientos (humanos) que se suceden en el tiempo y que pertenecen a la historia en la medida en que ingresan en el pasado, Heidegger muestra que el ser histórico del Dasein constituye lo primaria u originariamente histórico, de manera que el carácter histórico de los acontecimientos humanos e incluso de los entes intramundanos se funda en la historicidad del Dasein. Esta tesis ontológica, cuya fundamentación no podemos examinar aquí, implica que el carácter histórico de los acontecimientos y de los entes conservados no se debe exclusivamente a su pertenencia al pasado en el sentido usual del tiempo anterior, del ahora que ya no es, sino primariamente a su procedencia de un mundo sido, mundo que pertenece a la estructura de ser del Dasein. De este modo, se vuelve problemática la relación de la historia con el tiempo y también el concepto tradicional de tiempo que subyace en la noción de pasado histórico.

\footnotetext{
${ }^{5} B Z$, p. 133.

${ }^{6} S Z$, p. 19. La misma tesis en $S Z$, p. 382: "El Dasein siempre tiene fácticamente su "historia" y puede tenerla porque el ser de este ente se halla constituido por la historicidad".
} 
En segundo lugar, la destrucción conduce a un cuestionamiento de la inveterada orientación a partir del pasado que caracteriza a la comprensión usual de la historia. Si bien es cierto que esta orientación interpretativa es en cierto modo fenoménicamente legítima, Heidegger la considera como unilateral, pues también el futuro es relevante en la determinación de la historia, incluso ya en el plano de la comprensión inmediata, existentiva [existenziell]. En este sentido, sostiene: "si un pueblo ahistórico entra en la historia, con 'historia' no mentamos el pasado sino el futuro, que co-determina el pueblo que entra en la historia. Pero del mismo modo este pueblo puede ser expulsado de la historia;

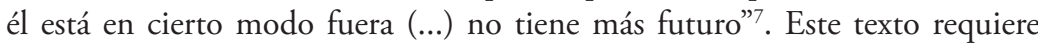
aclaraciones, ante todo la problemática expresión "pueblo ahistórico".

La interpretación heideggeriana está constantemente guiada por el supuesto de que el ser histórico "es lo que distingue el ser del hombre" ${ }^{\text {. La existencia }}$ humana es pues de suyo histórica. Por ello, todo pueblo, toda comunidad humana, es en sí misma histórica, está siempre ya en la historia. La expresión "pueblo ahistórico" no puede significar entonces que existan pueblos fácticamente carentes de historia, sino que se refiere a un modo determinado, defectivo, de ejercicio del ser histórico. En este sentido, Heidegger introduce en Logik la noción de no-historia: "En todo acontecer existe aquello que produce ruido, estrépito, hay ostentación, habladuría, maquinación (...) los sucesos diariamente constatables. Todo esto pertenece a la historia tan necesariamente como el valle a la montańa. Y esto no es historia en sentido propio, sino nohistoria [Ungeschichte]. Esto no-histórico tiene que ser nítidamente distinguido de lo ahistórico [Geschichtslose]. La vida de plantas y animales nunca puede ser no-histórica porque no conoce un acontecer como modo de ser"?.

$\mathrm{Si}$, como sugiere el texto citado, se reserva el término 'ahistórico' para caracterizar a todo ente no humano, entonces la expresión 'pueblo ahistórico' sólo puede significar que dicho pueblo es no-histórico. En efecto, en cuanto grupo humano, cuyo modo de ser consiste en un acontecer, un pueblo no puede ser ahistórico, pero puede ser no-histórico en el sentido de que está fuera de la "historia en sentido propio". Llegamos así a una distinción fundamental para nuestro tema: al ser histórico o acontecer [geschehen] en sentido lato, sea individual o colectivo, pertenecen las posibilidades de la historicidad propia y de la no-historia o historicidad impropia. En cuanto esencialmente histórico, el Dasein está siempre ya en una de estas posibilidades fundamentales del ser histórico, de manera que puede llegar a ser no-histórico o ingresar en la historia propia. Y así como la nohistoria puede ser encontrada inmediatamente en los acontecimientos mundanos, en los "sucesos diariamente constatables", la historicidad propia tiene lugar cuando el Dasein es capaz de determinar por sí mismo su propio futuro. Pero estas distinciones preliminares conducen a nuevas preguntas: ¿en qué consiste el

\footnotetext{
${ }^{7}$ Heidegger, Martin. Logik als die Frage nach dem Wesen der Sprache. Freiburger Vorlesung Sommersemester 1934, GA 38, Frankfurt a. M.: Vittorio Klostermann, 1998, p. 84. En adelante Logik.

${ }^{8}$ Logik, p. 81 .

${ }^{9}$ Logik, p. 85.
} 
acontecer del Dasein en cuanto fenómeno originario de la historia? ¿Qué distingue la historicidad propia de la impropia? ¿Qué significa 'futuro' en cuanto rasgo distintivo de la historicidad? ¿Por qué precisamente el futuro condiciona la posibilidad de la historicidad propia?

3. Con estas preguntas abandonamos el ámbito de la destrucción de la "historia” y llegamos al umbral de la construcción fenomenológica o proyecto existencial de la historicidad. Pues el sentido metódico de la destrucción implica que tales preguntas no pueden ser respondidas ya a partir de las "ideas" usuales acerca de la "historia" y del "tiempo", sino sólo a partir de las estructuras existenciales obtenidas en el análisis ontológico positivo del ser del Dasein y, particularmente, a partir de la temporalidad. Aquí no podemos examinar en detalle el proyecto existencial de la historicidad, sino sólo plantear una cuestión crítica que surge a propósito de una de sus tesis fundamentales, referida a la relación entre futuro e historicidad propia. La tesis afirma: "si el destino constituye la historicidad originaria del Dasein, el peso esencial de la historia no recae en el pasado ni en el presente en su "conexión" con el pasado, sino en el acontecer propio de la existencia, que brota del futuro del Dasein" ${ }^{10}$.

La tesis caracteriza la historicidad propia, a la que Heidegger denomina también destino [Schicksal]. Analicemos este concepto. El Dasein es histórico mientras existe, de manera que el ser histórico implica siempre un proyectarse en determinadas posibilidades de existencia. En cuanto fáctico o arrojado en un mundo, el Dasein encuentra estas posibilidades en su respectivo mundo circundante y compartido. En este sentido, todo mundo fáctico constituye un "legado [Erbe]"11, es decir, un espacio de significación que atesora un conjunto de posibilidades que han sido y que el Dasein puede descubrir y, eventualmente, hacer suyas, heredar. Lo intramundano en sentido amplio adquiere carácter histórico, llega a ser mundihistórico, precisamente porque conserva el testimonio de una posibilidad que ha sido. Las antigüedades y los acontecimientos pasados, de los que poseemos relatos o testimonios escritos, son mundihistóricos no simplemente porque pertenecen a un tiempo anterior, sino principalmente porque se ofrecen como huellas de posibilidades de existencia. Y el Dasein es histórico porque existe fácticamente, es decir, porque siempre está arrojado en un mundo a partir del cual descubre y recibe las posibilidades en las que de hecho proyecta su existencia. En el ejercicio de este existir fáctico tiene pues lugar el acontecer en cuanto fenómeno originario de la historia.

Por eso, lo que en principio distingue la historicidad propia de la impropia es el modo como el Dasein vuelve al legado de posibilidades mundanas de las que se nutre todo proyectarse fáctico. A este respecto, señala Heidegger: "La resolución (...) abre las respectivas posibilidades fácticas del existir propio a partir del legado, que ella en cuanto arrojada asume. El retorno resuelto a la condición de

\footnotetext{
${ }^{10} S Z$, p. 386.

11 SZ, p. 383.
} 
arrojado encierra en sí un transmitirse [Sichüberliefern] posibilidades recibidas, aunque no necesariamente como recibidas" ${ }^{12}$. Es decir, si bien todo Dasein toma las posibilidades en las que se proyecta a partir de su mundo circundante y compartido, sólo el Dasein resuelto asume esas posibilidades mundanas y no se limita simplemente a recibirlas. La recepción de posibilidades legadas en la resolución se distingue porque constituye una autotransmisión, esto es, porque el Dasein elige desde sí mismo las posibilidades que se transmite, que hereda a partir de su mundo. Por ello, la resolución o el estar decido [Entschlossenheit] es el modo propio de ser histórico. Sin duda el Dasein irresoluto también se proyecta en posibilidades recibidas a partir del mundo, de tal manera que en cierto modo se las transmite. Pero en este caso no se lleva a cabo una mediación expresa, esto es, una autotransmisión en el sentido de una elección explícita de las posibilidades. Antes bien, el Dasein históricamente impropio tiende a comportarse respecto de lo transmitido de modo tal que no ve en ello posibilidades, susceptibles de ser elegidas o rechazadas, sino que, inmerso en los "sucesos diariamente constatables", se atiene a los "datos", a los contenidos del presente, y acepta como algo "obvio" lo vigente en el respectivo mundo público compartido.

Pero la tesis que analizamos afirma que la historicidad propia, el destino, brota del futuro del Dasein. En relación con ello, cabe preguntarse cómo puede la historicidad, donde el Dasein está vuelto hacia lo sido, originarse en el futuro. Esta pregunta nos remite al contexto del proyecto existencial del ser histórico a partir de la temporalidad, donde el término 'futuro' no alude al tiempo posterior, a un ahora que todavía no es, sino que mienta una determinación de ser del Dasein. En efecto, como se sabe, Heidegger sostiene que el sentido del ser del Dasein consiste en una temporización cooriginaria de los éxtasis de futuro, haber sido y presentación. De acuerdo con ello, al sentido temporal del ser histórico pertenece no sólo un estar vuelto comprensor hacia lo sido, sino también la apertura extática del futuro y del presente.

En cuanto determinación existencial, 'futuro' significa que el Dasein es esencialmente venidero [zukünftig], esto es, que al proyectarse en posibilidades, el Dasein viene a sí mismo en el sentido de que se comprende a partir de ellas y de este modo llega a ser él mismo. Puesto que el Dasein resuelto recibe las posibilidades legadas que se transmite expresamente de tal manera que proyecta su existencia a partir de ellas, la historicidad propia no implica sólo una apertura extática propia de lo sido, sino también una apertura extática del futuro, que el Dasein determina expresamente desde sí mismo. Esto permite comprender porqué Heidegger ha insistido en Logik en el papel determinante que tiene el futuro en la constitución temporal de la historicidad propia, documentado ya en la comprensión usual de la historia. Desde esta perspectiva, un pueblo, una comunidad, es histórica en sentido propio no simplemente cuando en su seno se pueden constatar cambios, luchas, acontecimientos "relevantes",

12 Ibidem. 
personajes dominantes, etc., sino sólo cuando tal comunidad ha sido capaz de determinar desde si misma aquellas posibilidades en las que proyecta su existencia colectiva.

4. Pero la tesis acerca de la función determinante del futuro en la constitución temporal de la historicidad propia tiene aún otro sentido. En esta tesis Heidegger se refiere al futuro propio, que en $S Z$ es concebido no como un proyectarse en esta o aquella posibilidad mundana de existencia, sino en la posibilidad de la muerte, a partir de la cual el Dasein viene a sí mismo en la imposibilidad insuperable de la existencia, esto es, se comprende como no-poder-existir-más. Como se sabe, Heidegger denomina precursar [Vorlaufen] la muerte a esta peculiar proyección del Dasein. La tesis dice entonces que la auto-transmisión de una posibilidad legada, donde el Dasein abre extáticamente y asume lo sido de un modo propio, se origina en cierto modo a partir de una proyección comprensora de la muerte en cuanto fin de la existencia. Pero, ¿cómo puede el precursar la muerte ser el origen de la resolución en cuanto modo propio de ser histórico?

El futuro propio origina el ser histórico en el sentido de que "garantiza la totalidad y propiedad de la resolución" ${ }^{3}$. Al precursar la muerte, el Dasein accede a la totalidad de su existencia porque, liberándose de aquello que lo ocupa inmediatamente, proyecta su ser como un extenderse entre el nacimiento y la muerte. Y, por otro lado, el precursar garantiza la propiedad de la resolución porque permite que la elección de las posibilidades legadas sea menos fortuita, más certera y firme. La finitud, sostiene Heidegger, "lleva al Dasein a la simplicidad de su destino" 14 . Así entendido, el destino no es algo azaroso, con lo que cada cual se encuentra en el curso de su vida como producto del choque de las circunstancias, sino que, por el contrario, surge sólo como consecuencia de la elección expresa de determinadas posibilidades de existencia, elección que se afianza a la luz de la finitud asumida.

5. Es preciso reconocer que la tesis acerca del origen existencial de la historicidad propia en el precursar la muerte es altamente compleja y requiere aclaración y justificación. De hecho, ha sido ya blanco de objeciones críticas. Así, por ejemplo, Klaus Held, en un artículo titulado La experiencia generativa del tiempo, señala que "no es la muerte lo que garantiza la experiencia de la totalidad de la vida", sino que el ser humano abre su propia historicidad o generatividad "sólo por medio de una experiencia original de la inclusión de esta totalidad en la marcha de las generaciones", experiencia que no es sólo intelectual, sino que implica "la amorosa posibilitación natalicia de un nuevo poder-comenzar en la generación subsiguiente". Held formula su crítica mediante una oposición característica: "al pathos de la propiedad lo determina aquí no la muerte sino la vida"15. Esto es, mientras que en Heidegger la supe-

\footnotetext{
13 Ibidem.

${ }^{14} S Z$, p. 384.

${ }^{15}$ Held, Klaus. "Die generative Zeiterfahrung”. Edith Stein Jahrbuch, Band 2, Das Weibliche (1996), p. 277.
} 
ración de la sujeción a las ocupaciones cotidianas, el ingreso en la propiedad y la apertura de la totalidad de la existencia se alcanza mediante la asunción de la propia muerte, Held sostiene en cambio que se alcanza mediante la "amorosa posibilitación” de la vida, concretamente, mediante la asunción de la tarea del engendramiento y la educación de los hijos. "La propiedad surge aquí no del solitario tomar-sobre-sí la propia muerte, sino a partir del acto creador comunitario del amor conyugal, que de antemano libera un nuevo poder-comenzar" ${ }^{16}$. Así como para Heidegger, también para Held el auténtico ser histórico se alcanza mediante la asunción de una tarea que consiste fundamentalmente en la transmisión de posibilidades, pero en el caso de Held se trata de una transmisión de tipo peculiar: "sólo por medio de la transmisión [Weitergabe] natalicia de la vida se abre la existencia de un modo propio a la generatividad que posibilita la historia"17.

Más allá de la posible plausibilidad de la concepción de Held acerca de la experiencia generativa del tiempo, nos interesaba destacar su crítica a la posición heideggeriana, que puede ser considerada como índice de una tergiversación característica que consiste en reducir tácitamente el proyecto ontológico-existencial de la historicidad a proyecto óntico-existentivo, fáctico. En este sentido, la crítica de Held tiende a considerar la primacía del futuro propio en cuanto precursar en el contexto de la interpretación de la temporalidad y de la historicidad como "fijación de Heidegger a la muerte"18, es decir, como expresión de una determinada concepción de la "vida", de corte trágico o heroico. Esta tendencia interpretativa pasa entonces por alto el carácter metódico fundamental y la pretensión básica de la interpretación existencial heideggeriana, que se propone llegar a determinaciones de alcance ontológico-trascendental.

6. Nosotros quisiéramos proponer aquí brevemente una lectura de la tesis heideggeriana que permita aclarar y acaso ofrecer una justificación aceptable del "peso esencial" atribuido al futuro en el sentido del precursar la muerte en la constitución de la historicidad propia. Nuestra lectura destaca la noción de esquema horizontal como momento esencial de la estructura de la temporalidad, a fin de comprender desde una nueva perspectiva la función sistemática del futuro propio en el proyecto existencial de la historicidad propia a partir de la temporalidad.

El ser histórico en el sentido del extenderse entre el nacimiento y la muerte es un fenómeno existencial originario, es decir, un modo de ser previo y constante del Dasein, que puede asumir diversas formas de concreción fáctica. En cuanto tal, el extenderse está constantemente abierto y, por ello, es siempre fácticamente comprendido e interpretado de alguna manera. Heidegger señala que el Dasein comprende regularmente el extenderse como "trama de la vida"

\footnotetext{
${ }^{16}$ Ibidem, pp. 277-278.

17 Ibidem, p. 278.

18 Ibidem.
} 
o "trayecto de vida"19, es decir, como un transcurrir de la vida humana entre los sucesos ónticos del nacimiento y la muerte. Pero esta interpretación habitual, que construye el extenderse a partir de la suma de sucesos "subjetivos", pasa por alto, según Heidegger, el auténtico sentido ontológico del fenómeno, de carácter existencial. Frente a ella, sostiene: "el Dasein mismo se extiende, de tal modo que su propio ser queda constituido, desde un comienzo, como extensión. En el ser del Dasein se encuentra ya el "entre" del nacimiento y la muerte" ${ }^{\text {. }}$. Esto implica que ambos fenómenos no tienen sólo el sentido ontológico de dos sucesos orgánicos que ocurren en los extremos temporales de una vida humana, sino que el Dasein es "desde un comienzo", mientras existe, nacimiento, muerte y el "entre" ellos. En este sentido, Heidegger ha interpretado existencialmente la muerte como un ser respecto de la muerte [Sein zum Tode ${ }^{21}$. Y, al igual que la muerte, el nacimiento tiene que ser comprendido también como un modo de ser posible donde el Dasein está arrojado constantemente, mientras existe: "el Dasein fáctico existe nativamente [gebürtig]"22. Si el nacimiento y la muerte del Dasein no son sólo dos sucesos orgánicos que ocurren en dos "momentos" distintos del tiempo-ahora, entonces el "entre" ellos no puede ser concebido ontológico-temporalmente como un "espacio de tiempo" intermedio, como un segmento del tiempo-ahora. Antes bien, estos fenómenos tienen que ser pensados en el sentido ontológico característico del Dasein, esto es, a partir de la estructura del cuidado y de la temporalidad en tanto que fundamento de su unidad estructural.

Para caracterizar existencialmente el extenderse, Heidegger recurre a la noción de movilidad [Bewegtheit], que distingue expresamente del movimiento [Bewegung]. "La movilidad de la existencia no es el movimiento de un ente que está-ahí [vorhanden]. Se determina a partir del extenderse del Dasein"23. Esto implica que la movilidad de la existencia no se identifica con ninguna de las formas de movimiento del ente intramundano distinguidas por Aristóteles: cambio cualitativo, cuantitativo y local. Sin embargo, el concepto existencial de movilidad conserva la estructura formal fundamental inherente al movimiento en sentido categorial, la estructura œk tinoj $\mathrm{e} \neq \mathrm{j}$ ti, desde algo hacia algo, a la que Heidegger denomina distensión o extensión ${ }^{24}$. Es claro que, en el caso de la movilidad existencial, la distensión no tiene el sentido de un extenderse en las dimensiones del espacio ni del tiempo-ahora. Antes bien, Heidegger piensa la distensión existencial como un carácter de la temporalidad en cuanto extática ${ }^{25}$. En la concepción heideggeriana, el fenómeno de la temporalidad

\footnotetext{
19 SZ, p. 374 .

$20 S Z$, p. 374.

${ }^{21}$ Cf. $S Z \$ \$ 49-53$.

$22 S Z$, p. 374.

$23 \mathrm{SZ}$, p. 375.

${ }^{24}$ Heidegger, Martin. Die Grundprobleme der Phänomenologie. Marburger Vorlesung Sommersemester 1927, GA 24, 3a ed. Frankfurt a. M.: Vittorio Klostermann, 1997, p. 343: "En el "de algo a algo" se mienta un sentido totalmente formal del extenderse". En adelante GPh.

${ }^{25}$ Cf. GPh, p. 382: "En el carácter extático de la temporalidad se halla originariamente ya un extenderse que se inserta también en el tiempo expresado". SZ, p. 409: "La presentación que está a la espera y retiene no 'ex'-presa un 'mientras' tenso sino en la medida en que está abierta para sí misma como extensión extática de la temporalidad histórica, aunque no se conozca expresamente como tal”.
} 
tiene una estructura extático-horizontal, de manera que a cada éxtasis temporal corresponde un esquema horizontal, hacia el cual se extiende o distiende originariamente $^{26}$. El horizonte del futuro extático es la posibilidad en general, el horizonte del haber-sido es la condición de arrojado y el de la presentación es la estructura de la remisión o la presencia. El Dasein se extiende o distiende originariamente en la medida en que su ser se temporiza en el pluridimensional salir extático hacia el horizonte temporal respectivo. La movilidad del ser del Dasein tiene lugar entonces como temporización de los éxtasis, en la cual acontece, se gesta, el ser del ahí como un todo.

De acuerdo con ello, el nacimiento y la muerte, en tanto que términos de la movilidad del Dasein total, no son los "extremos" de su estructura de distensión: en sentido existencial, el Dasein total no se extiende en el tiempo-ahora desde el nacimiento hacia la muerte. Esta interpretación supone la comprensión de ambos fenómenos como sucesos ónticos que ocurren en el tiempo. Pero en cuanto pertenecientes al ser del Dasein, ambos son fenómenos existenciales, modos de ser posibles, y sólo en cuanto tales son los términos constitutivos de la estructura de distensión del Dasein total. En este caso son términos sólo en el sentido de aquello hacia lo cual se extienden los éxtasis temporales del haber-sido y del futuro. En este sentido, el nacimiento, en cuanto término u horizonte hacia el cual el Dasein está siempre ya distendido de diversos modos, tiene que ser comprendido existencialmente como el comienzo de la condición de arrojado, de la facticidad del Dasein. Mientras que la muerte en cuanto término significa existencialmente el fin insuperable del ser posible, de la existencia del Dasein. Entonces, en cuanto abierto extáticamente, el Dasein se extiende co-originaria y constantemente hacia el nacimiento y hacia la muerte en cuanto horizontes de su movilidad existencial total, aunque cotidianamente sólo de un modo impropio ${ }^{27}$. Por ello, la interpretación de la historicidad propia no es otra cosa que la tematización del modo propio, no encubridor, de la apertura de tales horizontes, que tiene lugar de un modo eminente en la apertura extática del futuro en cuanto adelantarse hacia el fin insuperable de la existencia. "La historia, en cuanto forma de ser del Dasein, hunde sus raíces tan esencialmente en el futuro que la muerte, como esa posibilidad antes descrita, rechaza a la existencia precursante hacia su fáctica condición de arrojada, otorgando así al haber-sido su peculiar primacía dentro de lo histórico" ${ }^{28}$.

La noción de horizonte temporal permite comprender también porqué el precursar la muerte "garantiza”, en un sentido ontológico-trascendental, la propiedad de la resolución. Los esquemas horizontales son concebidos por Heidegger como espacios abiertos de significación, cuya comprensión determina de ante-

\footnotetext{
${ }^{26}$ Para el examen del concepto de esquema horizontal de la temporalidad, véase $S Z \$ 69$ c, GPh $\$ \$ 20,21$ y Martin Heidegger. Metaphysische Anfangsgründe der Logik im Ausgang von Leibniz. Marburger Vorlesung Sommersemester 1928, GA 26, 2a ed. Frankfurt a. M.: Vittorio Klostermann, 1990, $\$ \$ 12,13$.

${ }^{27}$ Cf. SZ, p. 233: "La cotidianidad es precisamente el ser "entre" el nacimiento y la muerte" y $S Z$, p. 376: "Lo que bajo el término cotidianidad se presentaba para la mirada de la analítica existencial como el horizonte inmediato, se revela ahora como la historicidad impropia del Dasein”.

${ }^{28} S Z$, p. 386.
} 
mano el carácter de lo que puede ser abierto o descubierto a partir de ellos. Por ejemplo, a partir de la estructura de la remisión, del "para algo", previamente abierta como espacio de significación, es posible comprender un ente como un útil determinado, esto es, como algo que sirve para esto o aquello. En la existencia cotidiana el Dasein no fija su atención en estas estructuras de sentido: los horizontes permanecen constantemente atemáticos, a fin de que lo que puede ser abierto o descubierto fácticamente a partir de ellos pueda mostrarse temáticamente. Así, en el trato ocupado con los útiles la remisión es siempre comprendida pero nunca tematizada en cuanto tal. Del mismo modo, en el comprenderse existentivo, la posibilidad es proyectada, pero nunca conocida como posibilidad y, en el respectivo estado de ánimo, la facticidad es abierta, pero siempre embozada e incluso esquivada en cuanto tal.

Ahora bien, Heidegger describe determinadas experiencias en las que se produce un vuelco en la apertura extática de los horizontes en el sentido de que se vuelven temáticos y precisamente en la medida en que son experimentados como horizontes, es decir, en su carácter de término, de límite extremo, en su negatividad. Así, por ejemplo, el horizonte de la presentación, la remisión, se vuelve temático en la experiencia de la angustia, donde todo lo intramundano pierde su carácter significativo, se hunde en la insignificancia, de manera que el mundo mismo en cuanto complejo remisional se anuncia en su significatividad. Del mismo modo el horizonte del futuro, la posibilidad en cuanto tal, se comprende expresamente, se vuelve temática, en el futuro propio, es decir, mediante la experiencia de la muerte comprendida como la imposibilidad absoluta de la existencia. La angustia, la escucha de la voz de la conciencia, el precursar la muerte son concebidos entonces como fenómenos existenciales en los cuales el Dasein, mediante la experiencia negativa de su propio ser temporal, encuentra la posibilidad de una apropiación más originaria de su ser, es decir, la posibilidad del tránsito desde la existencia impropia a la propia. Visto desde esta perspectiva, el hecho de que Heidegger atribuya al precursar la muerte, al futuro propio, un "peso esencial", una significación ontológico-existencial destacada, no puede ser considerado simplemente como la expresión de una preferencia por una determinada concepción de la "vida". En consecuencia, en el marco del proyecto existencial de la historicidad a partir de la temporalidad, el futuro propio tiene el sentido hermenéutico de ofrecer una experiencia del límite temporal de la existencia arrojada y, por ello, es interpretado como el posible origen del tránsito desde la historicidad impropia a la propia, como una experiencia capaz de posibilitar una apropiación originaria del ser histórico del Dasein. "Cuanto más auténticamente se resuelva el Dasein, es decir, cuanto más inequívocamente se comprenda a sí mismo a partir de su más propia y eminente posibilidad en el adelantarse hacia la muerte, tanto más certero y menos fortuito será el hallazgo electivo de la posibilidad de su existencia" 29 .

\footnotetext{
${ }^{29} S Z$, p. 384.
} 
A diferencia de la concepción de Held acerca de la generatividad, la interpretación heideggeriana de la historicidad no propone como tarea la asunción de ningún proyecto mundano de existencia, sino que tiene un propósito y un alcance ontológico-trascendental: procura determinar las condiciones tempóreo-existenciales de posibilidad de la existencia histórica en cuanto tal. Sin embargo, desde la perspectiva de nuestro análisis, la concepción de Held puede ser considerada como complementaria de la interpretación ontológica de la historicidad. La asunción expresa de la tarea del engendramiento y la educación de los hijos constituye ciertamente un modo de ser histórico en forma propia, en la medida en que implica la autotransmisión explícita de una determinada posibilidad mundana legada. Pero esta tarea, que acaso puede permitir al Dasein acceder a una experiencia auténticamente generativa, tiene sólo el sentido de ser un proyecto de existencia entre otros. Y entonces es necesario reconocer que también este proyecto de existencia histórica puede suponer como condición de posibilidad de la constitución de su propiedad el momento de la apertura y la asunción expresa de la finitud temporal de la existencia fáctica. Es decir, como todo proyecto mundano de existencia que el Dasein está en condiciones de transmitirse, la paternidad o la maternidad, la amorosa posibilitación natalicia de un nuevo comienzo en la generación siguiente, tienen también la posibilidad de recibir la fuerza existencial de un destino a partir del futuro propio, esto es, a partir del horizonte de autocomprensión de la propia finitud expresamente abierto y asumido. 


\title{
La Constitución del tiempo y la Temporalidad de una Historia Colectiva Auténtica ${ }^{1}$
}

\author{
Víctor Farías \\ Universidad Andrés Bello
}

\begin{abstract}
Resumen
La diferenciación entre fenomenología y hermenéutica pasa por una radical diversidad en la comprensión de la historicidad en tanto que constitución del tiempo. La opción vitalista, voluntarista e irracionalista de Heidegger condujo necesariamente a su articulación en el proceso histórico conocido como nazi-fascismo y al inédito intento de entenderlo filosóficamente. La hermenéutica a su vez deviene dirección espiritual-política asumiendo con ello las formas más extremas del racismo y la eutanasia. Esta interpretación del fenómeno se fundamenta en una gran cantidad de documentos descubiertos en los últimos veinte años.
\end{abstract}

Fenomenología y Hermenéutica. El que estas dos palabras sean distintas, y en parte antagónicas, esconde toda una historia dramática. No sólo ciertamente la historia de la crítica relación entre sus representantes más relevantes, Husserl y Heidegger, sino también la del destino colectivo humano que ellos representan.

Para introducir a la reflexión quiero dar a conocer un documento recientemente descubierto en un archivo norteamericano. Es una carta de Martin Heidegger a la viuda de Max Scheler.

"Seminario de Filosofía I

De la Universidad de Friburgo i. Br.

Querida señora Scheler:

7 de marzo de 1933

Yo soy partidario del subtítulo "Sobre Ética y doctrina del conocimiento". Pese a que Max Scheler se encaminaba en la dirección de trabajo de la "Fenomenología", cuando lo hacía se trataba de la suya propia. Lo era ante todo en las perspectivas metafísicas que ya tenían vigencia en esa época. Como lo he escrito y expresado, yo

\footnotetext{
${ }^{1}$ Este artículo es un adelanto de la reedición de mi libro Heidegger y el nazismo (Muntaner, 2008) en el que incluyo la vasta documentación reunida desde la publicación de la primera edición (1987).
} 
ya no uso desde hace mucho los títulos "Fenomenología" o "fenomenológico", tanto más que Husserl, en su irresponsable conferencia berlinesa contra Scheler y contra mí, ha reivindicado ese título sólo para él. Puede quedarse con él. Nosotros queremos servir a la filosofía y no caer en esta inútil reyerta. "Teoría del conocimiento" recuerda demasiado al neo-kantianismo.

No me resuelvo a decidir al respecto ante todo porque mi participación en la preparación y edición del legado es demasiado reducida como para comprometerme a asumir un así llamado título. Lo que me importa es que ante todo y en primer lugar no es la repartición justa de merecimientos, sino de que le corresponda a usted como algo propio la gran tarea que ha asumido después de la muerte de Max Scheler como una parte de su vida solitaria. Es posible que esto no sea entendido por un editor, por más "decente" que sea.

Hitler dijo una vez: El terror sólo puede ser quebrado con el terror. Si usted realmente percibe el trabajo siniestro del comunismo en los últimos ańos, entonces usted no se asombrará del carácter de la embestida de nuestros días. Depende de nosotros apoyar la reconstrucción, limpiarla, esclarecerla y hacer fructíferas sus metas y jerarquías. El pensador "político" de la juventud, el que sirve a la Polis y quiere darle forma, es una nueva realidad y el inicio de una nueva grandeza interior de nuestro pueblo. Los viejos e incluso buenos conceptos de lo "espiritual" sirven muy poco en este sentido. Contemple usted la vida de un hombre joven en Horst Wessel. En ella usted va a poder percibir, cómo, en medio de la más devastada realidad, se mantienen firmes el corazón y el espíritu en tanto que ellos se quieren dar nuevamente una forma. Hace mucho tiempo que es necesario prestar oído al carácter interior y propio de nuestro destino alemán y actuar conforme a él, tanto más cuanto que hoy se dan importancia muchos "hombres de la coyuntura" que se suben al carro.

Espero que por fin le sea posible obtener un buen y merecido descanso.

Con un saludo cordial,

Martin Heidegger”.

La carta incluye dos momentos relevantes.

El primero destaca la agresividad con que Heidegger se distancia de Edmund 
Husserl y su fenomenología haciendo un frente común con Scheler para responder a la dura crítica que había formulado Husserl sobre el carácter liviano de sus filosofías: "Para entender mi fenomenología la gente suele buscar información confiable en las interpretaciones y críticas de Scheler, de Heidegger y otros ahorrándose con ello el muy arduo estudio de mis escritos"2.

El segundo momento pone de manifiesto la caracterización entusiasta que en marzo de 1933 hace Heidegger del carácter terrorista del nazi-fascismo y el perfil paradigmático con que reviste a Horst Wessel. La formulación de Adolf Hitler: "El terror solo puede ser quebrado con el terror" pone de manifiesto un extremismo agresivo. No se habla de "enfrentamiento", ni siquiera de "lucha" o de "combate", o "guerra", expresiones todas que incluyen un elemento no necesariamente bárbaro.

Heidegger y Hitler escogen el terror, es decir, aprueban la más extrema y animal forma de inhumanismo salvaje. En este sentido, la alusión a Horst Wessel como modelo existencial armoniza plenamente con la percepción heideggeriana del nazi-fascismo como populismo extremista fundado en el estudiantado revolucionarista. Como Albert Leo Schlageter, también Horst Wessel era "un joven alemán". Permaneció desde temprano a las SA y el NSDAP "combatiendo en las calles de Berlín contra comunistas y burgueses", como reza su curriculum partidario. Wessel, ya convertido en cabecilla de las hordas nazis, había abandonado en 1928 sus estudios de Derecho para unirse a las tropas de asalto SA. Devino un Führer muy prestigioso, particularmente violento y fue enviado por Goebbels para organizar en Viena los escuadrones callejeros. Encabezaba asaltos incendiarios a locales del movimiento obrero de izquierdas. Ya desde 1923 los enfrentamientos en Berlín y otras urbes eran extremadamente violentos, causando cientos de muertos por ambas partes. En ese contexto el joven Wessel conoció a una muchacha, Herna Jancke, que, según las informaciones más difundidas, era una prostituta "regenerada" por Wessel y con quien compartía una habitación en Berlín. La propietaria del inmueble, a fin de deshacerse de la incómoda pareja, solicitó la ayuda de las brigadas comunistas del sector. Estos aprovecharon la ocasión, provocaron un enfrentamiento en la habitación del joven nazi, ultimándolo a bala en febrero de 1930. El entierro del joven nazi con la presencia de Goebbels constituyó un acto de la mayor solemnidad. El órgano oficial Völkischer Beobachter del 24 de febrero escribió: "A medida que las SA iban entrando al Cementerio Nicolai se despojaron de sus cubiertos y abrigos para mostrar sus camisas pardas pese al terrible viento frío invernal.

Formaron columnas para el paso del cortejo fúnebre. El cementerio se llenó y llegó una columna con más de 10.000 militantes. Esta jornada en honor de Horst Wessel fue a la vez una marcha hacia un futuro cada vez más duro y

\footnotetext{
${ }^{2}$ Husserl, Edmund. Die Krisis der europäischen Wissenschaften und die transzendentale Phänomenologie. Eine Einleitung in die phänomenologische Philosophie. Haag: Husserliana, 1962, tomo IV, p. 439.
} 
fuerte para el movimiento. Durante mucho tiempo los hombres del batallón SA 5 velaron y vigilaron su tumba durante el día y la noche..." Esa tumba se convirtió en lugar de peregrinación para todo nazi que visitaba Berlín. Calles y plazas recibieron su nombre e incluso Adolf Hitler visitó la tumba con su camisa parda y bajo la nieve pronunció un discurso. Fue estilizado como "víctima inocente" y militante heroico y todos los Führer juraban en su nombre fidelidad al partido.

Durante el rectorado de Heidegger, comenzando por la ceremonia de su investidura como Rektor - Führer de la Universidad de Freiburg, se entonó el "Himno Horst Wessel" que se convirtió en una suerte de segundo himno nacional del Reich. Incluso uno de los más temidos batallones blindados de las SS recibió al nombre del así llamado "Mártir de las SA". Este era entonces el personaje respecto del cual Martin Heidegger le aconsejaba a la señora Scheler que "contemplara su vida porque en ella va usted a poder percibir cómo, en medio de la más devastada realidad, se mantienen firmes el corazón y el espíritu, si es que éstos quieren darse una forma...”. Porque es necesario desde hace mucho tiempo prestar oído al carácter interior del Destino Alemán y actuar conforme a él...”.

¿De qué y de quién estaba hablando así Heidegger aquí?

Para Alfred Rosenberg, el ideólogo nazi mayor, Horst Wessel era "una nueva víctima del Reich venidero, un hombre que ha sellado con su vida y su muerte la hermandad de sangre entre el estudiante y el trabajador. Uno que marchó en la vanguardia por el pan y la libertad para limpiar por fin las calles de Alemania..." Para entender lo que veía Heidegger en el nazismo, esta carta es más que relevante. Para entender esta carta en el contexto de un análisis de las diferencias entre la Fenomenología y la Hermenéutica es necesario dar una larga vuelta.

La polémica entre Husserl y Heidegger estaba fundada en momentos decisivos de sus filosofías: La una un idealismo trascendental, la otra un historicismo radical y voluntarista.

Para Husserl, problematizar algo, incluso el así llamado "Ser", equivalía siempre a reconstruir las condiciones de posibilidad de pensarlo (objetivarlo). "Ser" es siempre ser - constituido y acercarse a él es obtener su significación (Wesen - Schau).

En una de las tardes en que trabajé con él entre 1967-1971, llevaba yo bajo el brazo un ejemplar de Experiencia y Juicio. “¡No lea eso, me dijo con su acostumbrada y tosca llaneza, es puro Heidegger!” Como era precisamente eso lo que yo quería escuchar cuando llevé el libro, le pregunté de inmediato cómo 
caracterizaría él su diferencia esencial con Husserl. Heidegger solía con fruición relatar anécdotas. Anécdotas las más de las veces mordaces, pero precisas: "Un día cercano a la preparación de la publicación de Ser y Tiempo, Husserl me confesó: "Todo mi problema radica en que la constitución trascendental del tiempo se realiza en el tiempo". La respuesta aparentemente críptica era muy clara en realidad. La constitución trascendental del tiempo que debía terminar por dilucidar el tiempo como significación, era en sí misma un acto. Para Heidegger, era un acto, irreductible a no ser que fuera sometido a una hermenéutica que, como una forma de ser, lo explicase. Ese acto era el tiempo aunque fuese como "el horizonte trascendental de la pregunta por el ser". Se trataba sin embargo de una temporalidad especial. Ella se mostraba en la finitud y la finitud en la muerte. Le pregunté entonces si era eso lo que le importaba en la hermenéutica de la muerte, porque también la muerte ocurría en el tiempo "completando" el existente. Me dijo: «Sartre nunca supo bien alemán, y confundió las cosas. Eso de "pour-la-morte", no tiene nada que ver con nuestro "Sein zum Tode", "Ser 'de cara' a la muerte". A mí en realidad no me interesa la muerte para nada, a no ser como 'un podérselas con el morir' (Sterbenkoennen)». La muerte entonces no la ubicaba Heidegger en el horizonte de los significados, sino del sentido. La temporalidad sólo podía ser entendida como acto realizado en la historia, y ello semanas después me ayudó a entenderlo Heidegger nuevamente con otra anécdota que debía mostrar, sarcásticamente, las limitaciones que él veía en la fenomenología. «Husserl debía viajar a Inglaterra para dar las conferencias que él mismo resumiría para la Enciclopedia Británica. Lo acompañé en tren hasta la Badische Bahnhof desde la cual él debía continuar viaje. Durante el viaje le pregunté: "Professor, ¿`se acordó esta vez de incluir la historia en el texto?” Me miró entre asombrado y molesto y exclamó: “¡Carajo, de nuevo me olvidé de eso!”. La última anécdota al respecto que le escuché fue en torno a una pintura del maestro cubista George Braque. En uno de los libros homenajes al cumplir 65 años, Braque había incluido una litografía con una frase enigmática: "L'écho apelle l'écho ("El eco llama al eco"). Mi esposa quiso saber qué significaba la dedicatoria y la litografía y por encargo de ella se lo pregunté a Heidegger en otro de los jueves que acudía a su casa. De nuevo con su llaneza dura y precisa me espetó: “¡No tengo idea!”. Pero luego, casi al despedirnos, de pronto reconsideró el asunto: "Espere, quiero mostrarle algo". Subió por una escalera hasta sus libros y sacó uno pequeño con sentencias del pintor sobre el arte: "Me lo regaló Braque, ¡dedicado!, un gran hombre, no como el Picasso ése. Lea esta frase estupenda suya: "Las demostraciones cansan a la verdad"; ¡eso es la verdadera fenomenología!» Se iba así para mí componiendo un caleidoscopio apasionante. Volví más tarde a la anécdota sobre Husserl en el tren y quise averiguar mejor cómo entendía Heidegger lo que supuestamente Husserl ni siquiera llegaba a plantear: el vínculo entre temporalidad e historia. Fue en el contexto de un intento de interpretar los parágrafos 72-77 de Ser y Tiempo. Le dije que para mí el momento constituido más original de su filosofía era su interpretación del tiempo. Al 
reemplazar el tiempo entendido como temporalidad (Zeitlichkeit), él deviene la condición de posibilidad como un modo de ser temporal del Dasein selbst. La determinación "historicidad" es así anterior a lo que se llama historia.

"El interrogarse por el ser está en sí mismo determinado por la historicidad. La historicidad inauténtica, por otra parte, percibe la dimensión del destino sólo en los restos del pasado..." La cuestión sobre el ser, en cambio, como realización auténtica, debe, como un acto histórico, percibir la orden de entender la propia historia como una sucesión que viene del pasado al futuro como una dinámica que desde el origen pasa por el presente y se revierte a éste desde el futuro para constituirse así en tarea por asumir. Se produce así una identificación del tiempo y la temporalidad con la historia y la historicidad. Le hice notar esto a Heidegger y con ello la importancia de entender el Dasein de Ser y Tiempo ya no como el acaecer de un existente individual que, como una suerte de de Hamlet angustiado, incomunicado, determinado a la muerte, decidido por su poder ser y su poder morir solipsista, debía elegir entre ser auténtico o inauténtico para así asumir su temporalidad como finitud. Si esa fuese la situación, le dije yo a Heidegger, el principio fundamental "Herkunft ist Zukunft" (el origen es futuro, desde el futuro) contendría un sinsentido: la autenticidad del Dasein consistiría en una infantilización de la existencia porque el niño es el origen del individuo.

La autenticidad del tiempo histórico como recuperación del origen sólo es posible en realidad para un sujeto colectivo: el Pueblo. Así es como aparece en los parágrafos 72 y 77 al concretar el futuro como tarea en los héroes paradigmáticamente auténticos que el Pueblo recupera en la Lucha (Kampf). Constituido este todo en algo cualitativamente superior a la Sociedad (Gesellschaft), a saber, en la Comunidad del Pueblo (Volksgemeinschaft). Ella sólo puede ser conducida por los seres selectos, los únicos guías (Führer) capaces de asumir la verdad histórica (Dilthey, York von Wartenburg). Su tarea primordial es la destrucción de la opinión pública de los existentes por lo general vulgares, inauténticos. Por eso pienso, le dije, que su incursión en política estaba fundada y orientada por la corrupción de la historia tal como era analizada en Ser y Tiempo. "Exacto", me dijo, "No se ha entendido mi noción de historicidad y por eso siguen hablando de existencialismo. Sobre los acontecimientos de entonces estoy preparando algo con Der Spiegel. Podrá leerlo cuando me muera”.

Esta evolución se había iniciado, por cierto, como un pangermanismo radical. Ya en su primer texto como seminarista jesuita en 1910, su artículo-laudatio del monje agustino Abraham a Santa Clara, figura paradigmática del antisemitismo barroco alemán, Heidegger había asumido la mitománica afirmación de la lengua alemana como algo en sí superior al resto. 
Un tiempo más tarde, en 1918, en una carta a su mujer Elfride, recientemente publicada por su nieta Gertrud, Heidegger escribía: "La judaización de nuestra cultura y universidades es en todo caso algo espantoso y yo pienso que la raza alemana debería reunir aún toda su fuerza interior para levantarse. En todo caso, el capital...”3. En 1929, en una carta dirigida al Geheimrat Viktor Schwoerer, para recomendar a su alumno Eduard Baumgarten, Heidegger vuelve a advertir sobre la dramática judaización del espíritu alemán.

Su adhesión al nazismo, por lo demás anterior a la toma del poder del partido de Hitler en 1933, se caracteriza precisamente por ver en el nazi-fascismo el encuentro del ser alemán con su mismidad recuperada y como un acontecimiento que debe ocurrir ante todo en la Universidad y la Filosofía. Ambas son las instancias decisivas de la nueva historia, articuladas en la juventud revolucionaristas y agrupadas ante todo en las SA. Ellas eran el movimiento de Horst Wessel entendido como la reagrupación de las fuerzas espirituales alemanas. Su fanatismo llevó a Heidegger no sólo a enviar telegramas a Hitler exigiéndole mano más dura en la represión universitaria, sino también a exigir un populismo extremo en la universidad y la sociedad en general. Su nazismo lo denominó entonces Socialismo Alemán y llegó a articularlo filosóficamente en sus lecciones de 1934 y 1935, esto es, en una época en que según sus seguidores ya habría abandonado el nazismo. En 1987 logré recuperar las lecciones sobre Lógica en las que él articuló las nociones de Logos, Historia, Verdad, Trabajo como los pilares del Ser-alemán en el Socialismo Alemán. Recientemente Emmanuel Faye logró superar el muro construido por el hijo de Heidegger para impedir el acceso a los manuscritos conservados en el archivo de Marbach y descubrió los textos de la lección nazi más relevante de Heidegger: "Sobre la esencia y el concepto de Naturaleza, Historia y Estado", en el semestre de invierno 1933-34. Allí, entre muchísimos textos análogos, se puede leer: "El pueblo es el ser que es del modo y en la forma del Estado, el ser que es o puede ser el Estado (...) Ser un ser humano significa llevar en sí mismo la posibilidad y la necesidad de dar forma y llevar a su plenitud el propio ser en una comunidad y el ser de esa Comunidad (...) El carácter del ser es la determinación de la decisión de un pueblo por su Estado y en su Estado. De ahí la relevancia de la salud del pueblo como la salud racial. Estrechamente relacionada con esto está la palabra "Salud del Pueblo" en la cual se puede percibir también el lazo de la unidad de sangre y unidad de estirpe, de la raza (...) El uso más extenso es el de el Pueblo en armas". Lo fundamental del nuevo ser alemán es por tanto asumir y crear el "Estado del Führer". Heidegger lo explica, entonces: "El Estado del Führer tal como nosotros lo tenemos significa la plenitud del desarrollo histórico, la realización de pueblo en el Führer (...) No cualquiera puede ser Conductor-Führer porque en el origen de todo ser está el ser y no el saber. Todo Führer debe serlo según la determinada forma de su ser y simultáneamente en el vivaz despliegue de su ser propio, él entiende, piensa y pone en obra simultáneamente lo que es Estado y Pueblo. De este modo es que la

\footnotetext{
3 “Mein liebes Seelchen" Cartas de Martin Heidegger a su esposa Elfride 1915-1970, p. 51.
} 
forma, la Constitución del Estado, es la expresión esencial de lo que el Pueblo se pone como sentido para su ser. La Constitución no es un contrato social, un orden jurídico, una lógica política o cualquier otra cosa absoluta. Constitución y Derecho son la realización de nuestra decisión por el Estado, son los testimonios fácticos de lo que nosotros tenemos por tarea histórica y racial y que intentamos vivir (...) Entonces la existencia y la superioridad del Führer se hunden en el ser, en el alma del Pueblo y la ligan original y apasionadamente a su tarea. Si el pueblo percibe esta entrega, se dejará conducir en el combate, querrá y amará el combate. El pueblo desplegará sus fuerzas y perseverará, será fiel y llegará hasta la inmolación. En cada nuevo instante el Führer y el Pueblo se unirán más estrechamente para poner en obra el ser esencial del Estado, su ser, por tanto, creciendo uno junto al otro, el Führer y el pueblo opondrán su ser auténtico y su voluntad histórica a los poderes amenazadores de la Muerte y el Dominio, esto es a la corrupción y la decadencia de su ser auténtico... Hay que formar en el Tercer Reich un Estado nacional racial verdadero (...) Él se fundará en el principio sic gestamus principatus ut sciant rem esse populi non UNAM privatam" ${ }^{4}$.

Pese al colapso del nazi-fascismo en 1945, los vínculos de Heidegger con momentos constitutivos genéricos del nazismo volvieron a revelarse continuamente. Así por ejemplo en Brenen, en los años 50, afirmaba que "La fabricación de cadáveres en las cámaras de gas y la transformación de la agricultura en industria alimenticia son en esencia lo mismo". Durante una conversación con Rainer Marten, su alumno más calificado, se le oyó afirmar: "Todavía se pueden contar con los dedos de las manos los judíos que continúan enseñando filosofía en Alemania”. Ni Marcuse, ni Paul Celan ni nadie pudo nunca arrancarle una condenación explícita del Holocausto y ya en 1968 me confesaba con toda naturalidad que "las lenguas latinas carecen de fuerza espiritual para penetrar en las cosas. Sólo se puede pensar en alemán” La misma frase espiritual racista que iba a repetir en la entrevista póstuma. Allí Heidegger afirmó sin ambages la "verdad interior y grandeza del Nacional Socialismo del inicio" y "la imposibilidad que con la democracia se solucionen los problemas del hombre moderno".

Desde el punto de vista sistemático habían sucedido sin embargo algunas cosas. La convicción metodológica de que el Dasein (el ser ahí del ser) debía servir de horizonte trascendental para entender el así llamado ser incluía una cierta nomenclatura fenomenológica (horizonte trascendental es terminología husserliana). Ella va a ser reemplazada al menos programáticamente por una hermenéutica en que el ser mismo es lo que posibilita todo horizonte, incluso la hermenéutica misma como acto.

Aquí debe encontrarse el acta de nacimiento de la posmodernidad, la era de la destrucción del sujeto y su reemplazo por lo indeterminado. En dos anéc-

\footnotetext{
4 "Nosotros ejercemos nuestros poderes de modo que aquello que pertenece al pueblo no tiene NADA de privado".
} 
dotas Heidegger solía ilustrar el modo como había que hacer referencia al ser: "Es como la leyenda de los dos puercoespines que desafiaron a la liebre a una carrera. Uno de ellos apostó con la liebre a quién llegaba primero a un arbusto. Tras éste se había escondido el otro puercoespín que al llegar la liebre la recibió diciéndole “iyo ya estoy aquí!" La liebre, que no logró percibir la diferencia corrió y cada vez llegó tarde hasta agotarse o morir. El ser sólo puede ser percibido en su haberse ya escapado". La otra anécdota me la hizo hablando sobre los juicios sin sujeto tematizados por Franz Brentano. "Llueve", "truena", "nieva" y otros. Este era precisamente es caso del famoso "Es gibt Sein" que significa algo así como: "hay algo como el ser", pero también: "lo indeterminado da (gibt) el ser (Sein) en acusativo y esta es la versión valedera”.

El objetivo de la hermenéutica es así lo que la hermenéutica "explica”, pero a la vez es lo que explica a la hermenéutica. Lo indeterminado que sólo resulta determinable como indeterminable, no ofrece ninguna posibilidad para pensar productivamente. Mucho menos permite pensar éticamente y por ello deja sin defensa a quienes necesitan de la filosofía para construir y defender la vida. Heidegger terminó por transformarse en oráculo que emitía sentencias inverificables o derivaciones tautológicas: el ser "es", es en su mismidad, es en su verdad en tanto que develamiento de la mismidad, es sí mismo dejando verse como lo que se oculta mostrándose o mostrándose en su ocultarse. Todo ello no es otra cosa que una mistificación de la tautología. El entender y el argumentar son reemplazados por el decir del oráculo que sólo cabe escuchar. Leyendo con él uno de los fragmentos de Heráclito, me dijo una vez: "Yo no leo a Heráclito, yo lo escucho. Eso es la hermenéutica”.

El reemplazo del ser-en-el-mundo por el ser como lo indeterminado perceptible desde sí mismo va así a recibir un espacio mítico para mostrarse: el lenguaje, "la casa del ser", pero esa, la casa del ser administrada por el hombre devenido "pastor del ser" conserva una cualidad irrenunciable: el ser la lengua de los alemanes pensada y hablada por Heidegger y Hölderlin, el pensador y el poeta del pueblo metafísico de los pensadores y los poetas. El mundo recibe así, como destino, escucharlos como se escucha a quienes son per se, la auténtica instancia conductora histórico-ontológica. Esto es lo que supone la superación de la fenomenología que Heidegger postulaba con su comprensión de la hermenéutica. 
VIII. HERMENÉUTICA 


\title{
La Experiencia de Apropiación del Sentido de la Comprensión. \\ Hacia una Hermeneútica Histórico-Figurativa de Modernidad
}

\author{
Fernando J. Vergara Henríquez \\ Universidad Católica del Maule
}

\begin{abstract}
Resumen
El siguiente texto ensaya la modulación hermenéutica bajo la forma de la "figuratividad". Se han escogido personajes teóricos o conceptuales (Deleuze y Guattari) del ideario nietzscheano como antecedentes metafóricos del devenir histórico de la modernidad. Se pretende dar claves de una "hermenéutica figurativa" de la modernidad a partir del perspectivismo nietzscheano situado en la plataforma histórico-lingüística-dialógica de Gadamer.
\end{abstract}

Sostendremos que el propósito más propio de la hermenéutica consiste en ser una búsqueda de posibilidades fecundas de un sentido específicamente humano justamente allí donde aparecen "concordancias discordantes" en el tiempo y cuyo fin es establecer una "identidad narrativa" atendiendo a la presencia de un carácter preso en una antigua palabra sedimentada en el tiempo. Asumiendo tal propósito, partimos -y presentamos tal partida en una cuádruple vertiente de significado: como "juego" (interpretación), como "movida" (perspectiva), como "inicio" (expectativa) y como "división” (quiebre)- con la innovación semántica propuesta por la hermenéutica y sus significaciones inéditas, que tiene que ver más bien con una imaginación productiva desplegada a la función interpretativa. La función que se deriva de lo anterior, tiene que ver con que la hermenéutica permite captar una semejanza a pesar de no presentarse a primera vista: captación de un "parecido", semejanza o similitud donde la visión habitual no percibe ninguna conveniencia mutua. Por ello, "da noticia" sobre la realidad, una "nueva realidad" a partir de eslabones de sentido en unidad dinámica para un recambio de interpretaciones.

Para alcanzar lo anterior, hemos aventurado levantar bases de viabilidad y perspectiva de una plataforma interpretativa bajo el rótulo de "hermenéutica figurativa" que sirva de tablado que soporte: primero un armazón para bosquejar y montar un mecanismo de interpretación figurativa de la experiencia 
de modernidad a partir de eslabones metafóricos de posibilidad hermenéutica, y segundo un púlpito o tarima para que vociferen sus guiones ciertos personajes alineados de manera -aparentemente- dispar y así establezcan un orden determinado y un discurso significante que los sitúe en rincones privilegiados al interior de las tramas de poder y dominación de la historia. Estos personajes son los de "sacerdote asceta", el "pastor de la metafísica" y el "hombre frenético" provenientes del ideario histórico y simbólico nietzscheano, como voces metafóricas de una modernidad que se presenta como un estar móvil de modos en el tiempo: ese es el cuerpo de la modernidad; un no-estar inmóvil de estilos en el espacio: esa es la nervatura moderna; como un irrepetible del tiempo presente del progreso: ese es el sentido de la modernidad; y, una renovación de la infinitud del progreso: ese es el propósito de la modernidad.

Además y sin apoyarnos en literatura filosófica anterior sobre "hermenéutica figurativa" ni sobre la consideración de los personajes nietzscheanos en su "similaridad" como encarnaciones simbólicas en su eslabonamiento de sentido para la modernidad, la entenderemos como aquella experiencia de interpretación que revela las conexiones ocultas de los acontecimientos y de las simbolizaciones -de allí su correlación con la genealogía- con el fin de que aquella experiencia devenga experiencia hermenéutica de apropiación de(l) sentido de la comprensión, y tales figuras acaezcan en "figuras de interpretación/comprensión” hermenéutica - de allí su correlación con el simbolismo- moldeadas como símbolos encarnados y metáforas teatralizadas como claves o códigos comunes para que, al situarlos en ángulo de perspectiva interpretativa coherente en su desfile o modulación histórica, destaquen un "modo" de la modernidad entre todas las modernidades que se han levantado: la modernidad en su constante mutabilidad expresada ahora en "figuras de sentido" hermenéutico.

Lo que intentamos es señalar, apuntar (todo señalar denota un sentido) líneas de sucesión, vínculos de familiaridad: eslabones de una cadena de dis-cursos que alineados en perspectiva narran una perspectiva con la que se experimenta este mundo y no una imagen preconfeccionada de él, es el objeto-sujeto de comprensión, una suerte de "tejido hermenéutico" que urde este mundo y que acoge a un sujeto con una peculiar comprensión del devenir transformativo de la historia y a la vez, un pliego que ha fraguado este sujeto sobre un representativo modo de este mundo comprendido a partir de ciertos personajes o "figuras de significación" nietzscheanas alineadas -cómo el sacerdote asceta del sentido mezquino se convierte en pastor transfigurado por la cesantía de su misión y éste en el poseso por el frenesí de la búsqueda de Dios-.

Asumimos la acción de estas figuras situada más allá de la presencia significativa. Por ello, tanto su representación como alcance de sentido hay que buscarlos, rastrearlos, citamos a Peñalver, «tras la presencia inmediata de las significaciones (no en el más allá del aparecer sino del significar primero). Hay 
que buscarlo [el sentido de la acción y presencia de las figuras] tras el presente vivido (no en un más allá intemporal sino en la virtualidad de presente que se oculta en la memoria del pasado y en la espera de lo futuro). La 'presencia' diferida del sentido es la de una ausencia. El sentido se aparece en suma como el fondo no presente (no como el fundamento perdido) de las presencias significativas, y como el fondo virtual (no intemporal) constituido por la urdimbre temporal de pasado-futuro sobre la que se teje el proceso visible e intencionable que llamamos el presente (en proceso). [...] El sentido es así, en cierto modo, el fondo de toda presencia. No es lo que hace posible sino lo que hace comprensible para otro. No está fuera de lo que es, ni es propiamente su fundamento (¿qué sería ser fundamento de los que ya es?), pero ocupa una cierta ausencia, se disimula bajo la penumbra del segundo plano, se escapa bajo la secundariedad de lo implícito. [El] sentido es el fruto recolectado de esa dispersa variedad de las presencias de significación ${ }^{1}$.

Estas figuras simbo-hermenéuticas cambian, permutan, metamorfosean su identidad, pero mantienen su "similaridad" -que se revela ante la secundariedad de su representación- como espejos para un mismo rostro: su tiempo y la ambivalente relación respecto a la tradición histórica y su curso. La fábula de la "metamorfosis del espíritu y de la existencia humanos" enseńada por el Zaratustra nietzscheano expresa la capacidad de la modernidad y de sus personajes fundantes, de sobrevivir dentro de nosotros, incluso cuando creíamos superadas las contradicciones externalizadas por la modernidad: el sacerdote asceta es el reflejo del camello-tradición, el pastor de la metafísica deviene león-moral anquilosado por la historia y, finalmente, el niño-danzarín es el frenético-vocero del acontecimiento de la "muerte de Dios" y su perturbador mensaje renovador.

La apuesta es entonces por una "hermenéutica histórico-figurativa" con el objetivo de revelar la "figuratividad de(l) sentido" y se funda en la hermenéutica gadameriana en perspectiva histórico-interpretativa nietzscheana.

El "perspectivismo" supone una realidad compleja y vertiginosa -que acepta la diferencia y la contradicción- puesto que carece de unidad por su intrínseca multiplicidad expresada en pliegues para interpretar "intensamente" la realidad, incluso la misma interpretación. Con ello Nietzsche intenta introducir nuevamente el delirio creador de la vida en una multiplicidad de interpretaciones, con el fin de abrir las posibilidades de aproximación a la realidad no mediada por la razón, sino por la intensidad y desenfreno de una libertad creativa/interpretativa, y de una vida que encuentra en el "perspectivismo" su «condición fundamental» ${ }^{2}$ y condicionamiento mismo ${ }^{3}$ que rompe la unidad de lo invariable.

\footnotetext{
${ }^{1}$ Peñalver, Mariano. Las perplejidades de la comprensión. Madrid: Síntesis, 2005, pp. 279-280.

${ }^{2}$ Nietzsche, Friedrich. Más allá del bien y del mal. Preludio de una filosofía del futuro. Madrid: Alianza, 1993, p. 18

${ }^{3}$ Nietzsche, Friedrich. Humano demasiado Humano. Un libro para espiritus libres. Vol. II. Madrid, Akal, 1996 $\$ 6$, p. 39.
} 
Este hecho cumple la función de ser un prisma con el que las perspectivas cambian su colorido original: lo pierden por un lado y, por otro, se multiplica en profundidad y forma. El sacerdote o administrador del sentido de la moral cristiana se transforma en el buscador frenético secularizado y el hombre frenético es el sacerdote asceta conciente de la "muerte de Dios". El "pastor" es un estadio intermedio entre la nostalgia del pasado y la perspectiva que se abre en la visión enigmática de lo por-venir.

La propuesta de Gadamer por una "universalidad ontológica del lenguaje" radica en cuanto envuelve a la experiencia lingüística del apalabrar sobre el mundo como medio de exhibición manifestativa de(l) sentido en un diálogo entre singularidad de la tradición y totalidad de la historia. El lenguaje, seguimos Verdad y Método, es aquella "realidad intermedia" y «aparece [...] como la verdadera dimensión de la realidad $»^{4}$ que hace que exista el mundo y de que se manifieste para el hombre como totalidad ordenada de significaciones en interacción dialéctica. El lenguaje y la tradición histórica articulan la experiencia humana de comprensión presentada bajo la forma de diálogo entre intérprete y texto, entre tiempo e historia en una fusión horizóntica de sentido -mediación, integración- como red de inteligibilidad, haciendo posible una real y efectiva transformación en la vida del intérprete debido a la interpretación realizada bajo el signo de la "verdad". El lenguaje y su carácter especulativo opera como un "centro en el que se reúnen el yo y el mundo, o mejor, en el que ambos aparecen en su unidad originaria ${ }^{5}$ de manera omni-abarcante. La filosofía hermenéutica propuesta por Gadamer tiene un carácter general que analiza las condiciones de posibilidad de todo proceso de comprensión, es decir, del proceso de "comprender-algo-como-algo» ${ }^{6}$.

El preguntar por el "ser de la comprensión" o "en qué modo comprender es ser" estará bajo la forma lingüística -eje de la experiencia de apropiación de(l) sentido de la comprensión- de diálogo histórico: «el ser que puede ser entendido está lingüísticamente articulado, es lenguaje» ${ }^{7}$-que expresa la relación entre lingüisticidad y comprensibilidad del ser- y esa articulación, es el diálogo, y ese entender que nos tiene prendidos ${ }^{8}$, es la comprensión.

Lo que el hombre puede experimentar, se incluye en esta experiencia de apropiación comprensiva de mundo de forma abarcante sobre el fenómeno de la comprensión: un contenido de verdad que penetra y actúa en el ámbito de nuestra existencia. La comprensión no es un modo o aspecto meramente epistemológico, sino un constitutivo ontológico del ser del hombre, pues rebasa la radical finitud del comprender, toda fundamentación última como asimismo

\footnotetext{
${ }^{4}$ Gadamer, Hans-Georg. “Texto e interpretación (1984)”. Verdad y método II. Salamanca: Sígueme, 2004, p. 327. En adelante VM II.

${ }^{5}$ Gadamer, Hans-Georg. Verdad y método. Salamanca: Sígueme, 2005, p. 567. En adelante VM.

${ }^{6}$ Dutt, Carsten ed. En Conversación con Hans-Georg Gadamer. Hermenéutica-Estética-Filosofia Práctica. Madrid: Técnos, 1998, p. 33.

${ }^{7} V M$, p. 23.

${ }^{8}$ Gadamer, Hans-Georg. "Hermenéutica clásica y hermenéutica filosófica (1977)”, en VM II, p. 110.
} 
toda pretensión de irrefutabilidad absoluta, siendo el comprender pura posibilidad de ser como rasgo ontológico de un ser que es puro proyecto en lo "histórico". Además, toda comprensión es mediata, pues se encuentra en medio de conformaciones históricas, prejuicios, pre-opiniones, valoraciones que delinean toda comprensión que, a su vez, es la estructura previa de toda interpretación como despliegue de esta misma estructura comprensiva.

Se hace entonces «visible la estructura de la comprensión histórica en toda su fundamentación ontológica, sobre la base de la futuridad existencial del estar ahí humano» ${ }^{10}$. El comprender supone estar siempre pendiente del hacer de la historia y de la tradición que determinan al sujeto en el aquí y el ahora y que provoca la apertura hacia el diálogo que es la mecánica de la comprensión.

El comprender es un proceso de fusión de presuntos "horizontes para sí mismos" 12 : pasado y presente fundidos en "tradición horizóntica" o eslabonados en un "horizonte tradicional" en y desde la alteridad históricamente mediada. La fusión horizóntica posibilitada por el lenguaje, revela el acontecimiento significante de la "unidad del sentido" desde un diálogo histórico transmitido y establecido por la tradición: el diálogo es la epifanía lingüística como totalidad de significatividad de(l) sentido.

Recapitulemos y avancemos: el deslizamiento desde un origen cognoscitivo a un punto de llegada referido a los rasgos que fundan las conceptualizaciones y reconceptualizaciones de la realidad, es posibilitado por la figuratividad hermenéutica, en tanto que apertura de una visión alternativa dada por el sujeto cognocente; la coimplicación de los diversos elementos que hacen de la realidad una realidad interpretable a partir de una serie de factores que hacen posible la comprensión de la misma. Abordamos, entonces, el concepto de figuratividad como clave de apertura al sentido de la comprensión y articulación de significados a partir de la fusión entre "comprender" y "experiencia".

La retirada de la disputa por el estatuto epistemológico, estético y político que incorpora la Ilustración en sus puntos de partida: «la reivindicación de otras formas de experiencia que trascienden la legitimidad del método científico y las reivindicaciones veritativas de la ciencia, y la crítica de la ciencia moderna, que no está en condiciones de comprender la experiencia humana del mundo y de la vida.» ${ }^{13}$ Nietzsche es considerado por Vattimo como el precursor de la hermenéutica ontológica contemporánea, al afirmar que «la orientación filosófica que asume como tema central el fenómeno de la interpretación, considerando como rasgo esencial de la existencia humana y como base apropiada para la crítica y la "destrucción" de la metafísica tradicional». ${ }^{14}$

\footnotetext{
${ }^{9} V M I$, p. 327.

${ }^{10}$ VM I, p. 326.

${ }^{11}$ Vid. Gadamer, Hans-Georg. "La incapacidad para el diálogo (1971)”, en VM II, p. 203-210.

${ }^{12} V M I$, p. 376-377.

${ }^{13}$ De Santiago Guervós, Luis Enrique. “¿Nietzsche contra Gadamer?” En Acero, J. J., Nicolás, J. A., P. Tapias, J. A., Sáez, L. y Zúńiga, J. F. eds. El Legado de Gadamer. Granada: Universidad de Granada, 2004, p. 177.

${ }^{14}$ Vattimo, Gianni. Diálogo con Nietzsche. Ensayos 1961-2000. Barcelona: Paidós, 2002, p. 128.
} 
Tanto Gadamer como Nietzsche comparten la crítica a la historia específicamente en lo relacionado a los límites de la autoconciencia histórica de una cultura moderna que se alza incapaz de valorar lo propio de los fenómenos de la vida, ambos «evitan la ingenuidad positivista y objetivista que consistiría en negar por una parte la eficacia del prejuicio (Gadamer) o la determinación de la perspectiva individual, esperando poder hacer hablar a las cosas mismas sin ninguna especie de intrusión del sujeto ${ }^{15}$. Gadamer se mantiene en equilibrio entre la autodisolución del intérprete propuesta por el positivismo y el perspectivismo nietzscheano y su apertura a la infinitud de perspectivas:

Pero es en el concepto de "interpretación”, donde se encuentran coincidencias vinculantes entre los dos pensadores. Para Gadamer interpretar constituye la estructura fundamental del ser-en-el-mundo; para Nietzsche, significa la posición previa al descubrimiento del sentido, es decir, una proyección de sentido sobre las cosas, lo que Gadamer evita, pues representaría la apoteosis del subjetivismo. A pesar de las diferencias, la vinculación radica en aceptar que tanto la interpretación y comprensión son "acontecimientos", "padecimientos", es decir, un dejarse interpelar por la tradición, por el texto, por el otro. Así, «la comprensión e interpretación son propiamente un acontecer, un devenir, un proceso que no comienza con la "subjetividad"». ${ }^{16} \mathrm{Y}$ ese padecer implica un impulso, una determinación, un hacer y un que-hacer. Entonces, «el problema está en saber, si la interpretación es sólo una proyección de sentido o más bien sólo un descubrimiento, o ambas cosas a la vez»" ${ }^{17}$. Tanto para Gadamer como para Nietzsche, "interpretación” y "perspectiva” no suponen una radicalización sin sentido de la subjetividad, sino la designación del "horizonte interpretativo" de una forma de vida, que se autoproclama como centro de valoraciones que abarcan desde los efectos hasta las organizaciones culturales y sociales: el «individuo [...] es una configuración de perspectivas» ${ }^{18}$. Configuración en la que el sujeto es una construcción, un añadido, pues incluso la afirmación "todo es subjetivo", es resultado de una interpretación "pues, se ve envuelto en el juego de la interpretación [como] una "posición" de perspectiva de una voluntad de poder» ${ }^{19}$.

El conjunto de consideraciones precedentes, abren el espacio para observar, que las "figuras hermenéuticas" expresan una actividad de pensamientos compuestos, un "tejido" de líneas de perspectiva sobre un objeto, una actividad nominal a partir de proposiciones sobre la realidad. Es la móvil conexión, la innombrable trama en la que somos parte. En este sentido, la figuratividad posibilita la tensión entre un "es, pero no es", aun cuando lo desemejante para poder formar un "nuevo objeto", resalta su acción antes que su resultado, es decir, insiste en su capacidad de transferencia de sentido más que en su facul-

\footnotetext{
${ }^{15}$ Ibid., p. 178.

${ }^{16}$ Vattimo, Gianni (2002). O.c., p. 181.

${ }^{17} \mathrm{Id}$.

${ }^{18} \mathrm{Id}$.

${ }^{19}$ Vattimo, Gianni. Introducción a Nietzsche. Barcelona: Península, 1987, p. 117.
} 
tad de producción: entender la figuratividad como núcleo hermenéutico que permite diseńar mundos posibles, forzando connotativamente los límites de imágenes -figuras- dispares o anacrónicas.

La "hermenéutica figurativa", asume como una modalidad auténtica de comprensión las conexiones que no pueden circunscribirse al limitado núcleo de una "discursividad absoluta" no dispuesta a "ser sustituida por predicados reales" en el mismo plano del lenguaje. Podría decirse que se ha invertido la dirección de la mirada: ésta no se refiere ya ante todo a la constitución de lo conceptuable sino además a las conexiones hacia atrás con el mundo de la vida, en cuanto sostén motivacional constante de toda teoría.

La figuratividad convierte la imagen -la mera presencia- del sujeto en una entidad dinámica y cambiante, posibilitando el rebasamiento de la metáfora, para situarse en la "figuratividad transformadora" de la autorreferencialidad y de la subjetividad cerrada.

Las "figuras de significación" hermenéutica gozan de una "similaridad" estructural, y por ello, son refractarios de "similaridad" anacrónica, que revelan un proceso estructural transformativo de la modernidad que ha venido difiriendo su fundación, y las expresiones de este aplazamiento se encuentran en las figuras, que, a su vez, concuerdan con las teorías de modernidad -sociológicas, filosóficas, políticas- su voces teóricas y prácticas. Estas "figuras de significación" hermenéutica expresan una "similaridad" en el sentido de "asemejarse" y, por tanto, como una forma de "reconocimiento" que le vinculan desde los lazos heredados por la historia bajo la forma de memoria genealógica y genética. Asimismo, expresan una "similitud", es decir, una afinidad en una multiplicidad de puntos, de ejes y campos, de cruces e intersticios, consolidando ciertos enclaves de reconocimientos mutuos: el de la narratividad de la figuratividad en tanto encarnación simbólica y acervo hermenéutico de la interpretación sobre la modernidad.

Asumimos como punto de partida de nuestra apuesta la exploración de nuevas figuraciones, representaciones alternativas y localizaciones identitarias desplegadas en el devenir histórico de la modernidad. Las figuras representan posiciones situadas, es decir, puntos referenciales, orientadores, marcas inscritas y encarnadas, respondiendo a las exigencias histórico-genealógicas como asimismo a exigencias hermenéutico-interpretativas por presentar esquemas alternativos de representación y comprensión de una realidad que a veces cae seducida por inclinaciones interpretativas totalitarias.

Se ha inaugurado una perspectiva -y creemos que eso ya ha sido un logro-: la figuratividad de(l) sentido de la modernidad, es decir, no se ha hecho otra cosa que interpretar figurativamente a una modernidad que se diluye y se aplaza en 
sus transformaciones buscando fuentes de legitimación a pesar de su declive y depotencialización como proyecto socio-cultural-intelectual, como aspiración político-normativa y conquista expresivo-estética para un sujeto secularizado, individualizado y "des-identizado", que ha abandonado la contemplación, asumido la explicación y se ha perdido en la dominación.

La tragedia de la modernidad es la que nos ocupa con desazón, y tiene que ver con su vigente -y constante- "re-configuración" diferida desde una llamada encrucijada cultural hacia una encrucijada planetaria de reordenamiento global, que ha decantando en proceso transformativo del sujeto en sus escenas ascéticas, metafísicas y nihilistas como estrategias de un esquema sígnico e instituyente de la modernidad. Lo épico, heroico de la modernidad -correspondiente a la metafísica ascética- y autocomplaciente con su fundación y confiada de su futuro, experimenta de una manera similar a la situación social y cultural del sacerdote asceta en tanto que habitáculo del saber, administrador del sentido, narrador de las profecías de la fe como de su promesa, del hacer y del pensar. Articula su voluntad y poder en concordancia a las necesidades políticas y "extramorales" y a los grados de carencia de sentido o proximidad horrorosa al vacío. El pastor es el medio operativo o etapa transicional hacia la embriaguez de lo siempre nuevo del frenético; tal como el niño re-creador que todo lo juega, que todo lo apuesta en la novedad, el frenético es el observador de la multiplicidad de la interpretación de la historia en visiones que retornan en el moderno aplazamiento de su re-interpretación.

La modernidad desamparada, descuidada -correspondiente al desafío del pastor custodio de la metafísica agónica- e indulgente consigo misma, experimenta el cese de las funciones de resguardo pastoril de su rebaño y custodio del temor de la posibilidad del sinsentido. Articula su voluntad y poder en función de mantener a cualquier precio y riesgo las aspiraciones de(l) sentido moderno. La modernidad desventurada, desamparada -correspondiente al frenético desaliento de la metafísica nihilista- y alienada por la ignorancia de la ausencia, verbaliza la delirante conciencia de la fisura, de la lejanía, del extrańamiento por la retirada de Dios. Articula su desánimo y debilidad en función de la apariencia y de la memoria nostálgica de los tiempos pasados que no se pueden fusionar en virtud de principios operativos vaciados de su consistencia vinculante.

En fin, se trata de interpretar el acaecer -y los matices de su propia metamorfosis como proceso diferenciador ante lo indistinto de los tantos orígenes de la modernidad- de las energías revolucionarias de la modernidad ilustrada desde la autoafirmación racional hasta su condición agónica, desde el énfasis de la razón moderna hasta el agotamiento cultural de la Ilustración en manos de la tecnología. Tales procesos o modos, versiones, estilos y condiciones revelarán 
la instalación y acción de la detracción de la modernidad en su fase de crisis y resultan sintomáticos de una figuratividad hermenéutica de la historia.

Nosotros, lectores apóstatas de los relatos/promesas modernos y de las profecías/visiones postmodernas, in-creídos de sus ofertas ni seducidos por la perplejidad, buscamos la comprensión del "cuerpo" y "nervatura" modernas, su significado vacilante, y por ello planteamos la pregunta que hilvana sus voces, sus máscaras, sus figuras y símbolos anacrónicos en tiempos por su ocultamiento, pero sincrónicos y simultáneos como líneas indisolubles de una "figuratividad moderna" en sus representaciones, con la perspectiva/expectativa que nos farfulle su sentido y dirección; nos declare sus proporciones y promociones, limitaciones y aperturas; nos delate sus modelos y diseños, certezas y errores; nos confiese sus pendientes e inreacabadas intenciones.

Nosotros, insatisfechos y ansiosos, inspirados en los deustenses Andrés OrtizOsés, Patxi Lanceros y otros, hemos querido dar forma/figura a una «Hermenéutica concebida no como un Ismo sesgado sino como un Istmo mediador: lengua que une dos continentes, lenguaje que reúne dos contenidos, relación/relato de contrarios [y] opuestos. En este sentido la Hermenéutica se sitúa críticamente entre el protorrelato mítico y el metarrelato lógico a modo de Interrelato mitológico, y ello dice, antropomórfico o humano. Por ello la hermenéutica no ofrece la solución (absoluta) sino soluciones plurales y comunes: consolaciones como consolaciones basadas en una [...] complicidad unidiversal $»^{20}$.

\footnotetext{
${ }^{20}$ Ortiz-Osés, Andrés y Lanceros, Patxi dirs. Claves de hermenéutica. Para la filosofía, la cultura y la sociedad.
} Bilbao: Universidad de Deusto, 2005, p. 9. 


\title{
Lenguaje, Diversidad y Escucha en la Hermenéutica Filosófica de H-G Gadamer
}

\author{
Cecilia Monteagudo \\ Pontificia Universidad Católica del Perú
}

\begin{abstract}
Resumen
En el presente trabajo se abordará la articulación que tienen los temas del lenguaje, la diversidad y la escucha en la hermenéutica filosófica de H-G Gadamer. Se asumirá como referencia principal su obra Verdad y Método. Sin embargo, por tratarse de una obra que Gadamer siguió repensando en diálogo con la tradición y en debate con sus contemporáneos, tomaremos en cuenta también algunos ensayos de su obra tardía.
\end{abstract}

\section{1. 'Verdad y método' como punto de partida de la hermenéutica dialógica de H-G Gadamer ${ }^{1}$}

El tema del lenguaje, como bien lo dice Jean Grondin, es quizás la problemática más malinterpretada de la filosofía de Gadamer, cuando no criticada por muchos por tener una retórica difusa y ambigua en momentos medulares ${ }^{2}$. En nuestra exposición no soslayaremos dichos cuestionamientos, ni tampoco las críticas relativas al carácter heterogéneo de $V M$ que hicieron sospechar de una falta de unidad en el planteamiento hermenéutico de Gadamer. Por el contrario, esperamos mostrar que vista la producción intelectual de Gadamer en su conjunto, lo que se destaca es un dinamismo en su reflexión que le permite ahondar en el 'fenómeno de la comprensión' desde distintos ángulos, pero rescatando en todos los casos su carácter de apertura a lo diverso y las posibilidades de escucha que le son inherentes.

Ahora bien, en tanto el 'fenómeno de la comprensión'3 es también el 'fenómeno de nuestra vida en el lenguaje', no sorprende que Gadamer en uno de sus últimos escritos demande desde su hermenéutica filosófica 'aprender a pensar de forma ecuménica', como uno de los desafíos más decisivos que debe enfrentar la sociedad contemporánea para evitar su autodestrucción ${ }^{4}$. En este sentido, nuestra exposición también señalará los puntos de articulación entre su ontología del lenguaje y la filosofía práctica que se sigue de dichos planteamientos.

\footnotetext{
${ }^{1}$ Gadamer H-G. Verdad y método. Fundamentos de una hermenéutica filosófica. Salamanca: Ediciones Sígueme, 1977. Cada vez que mencionemos esta obra lo haremos con las siglas VM.

${ }^{2}$ Cf. Grondin, J. Introducción a la hermenéutica filosófica. Barcelona: Herder, 1999, pp. 170-171.

${ }^{3}$ Fenómeno que para Gadamer atańe a toda nuestra experiencia del mundo y praxis vital.

${ }^{4}$ Gadamer H.G. "Europa y la oikoumene” (1993). El giro hermenéutico. Madrid: Cátedra 1998, p. 223.
} 
Pero volviendo a $V M$, la obra que encarna el núcleo central del planteamiento hermenéutico de Gadamer, caben algunos breves comentarios. Como sabemos, se trata de una obra que en el marco de la lucha contra el objetivismo y metodologismo del paradigma científico moderno nos invita a pensar nuevamente el 'fenómeno de la comprensión', pero haciendo justicia a su historicidad y lingüisticidad esenciales. En esta perspectiva, si la lingüisticidad de toda experiencia hermenéutica ha estado presupuesta desde el inicio de la obra en mención, Gadamer se ocupa recién en la tercera parte de tematizar el sentido ontológico de dicha lingüisticidad y la estructura dialógica y universal que la caracteriza ${ }^{5}$.

Pese a lo dicho antes, el título 'El lenguaje como hilo conductor del giro ontológico de la hermenéutica', que precede a los tres últimos capítulos de la obra, podría llevarnos a pensar que lo que se opera en Gadamer es un cambio de rumbo y con ello las sospechas de una falta de unidad en VM reaparecen con gran verosimilitud. Sobre todo, si se toma en cuenta que la primera parte de la obra se propuso pensar el tema de la verdad desde la experiencia del arte y la segunda desde la experiencia de las ciencias del espíritu. Sin embargo, lo que tenemos es una radicalización del trabajo conceptual que Gadamer emprende en esta obra y que él mismo define en términos de 'un entender el universo de la comprensión mejor de lo que parece posible bajo el concepto de conocimiento de la ciencia moderna' ${ }^{3}$.

En esta misma perspectiva, un autor como Luis Garagalza sostiene que ya desde el tratamiento de la tradición en la segunda parte de VM se ha hecho evidente que ésta tiene la naturaleza del lenguaje y, por ello, "la fusión de horizontes" que acontece en toda comprensión es para Gadamer resultado de "un rendimiento del lenguaje". Es decir, en la tercera parte de la obra la hermenéutica de la tradición, sin quedar anulada, habría dejado paso a la hermenéutica del lenguaje. Así también, el lenguaje considerado como mediación de sentido intersubjetivo, interlingüístico y dialógico, sería resultado del proceso de radicalización de la reflexión hermenéutica donde la lingüisticidad se convierte en principio hermenéutico de la comprensión, al mismo tiempo que contiene al de la historicidad ${ }^{8}$.

Pues bien, respecto del amplio campo de problemas y temáticas que abre esta tercera parte de VM, nosotros nos concentraremos en la articulación que alcanzan los términos señalados en el título de nuestro trabajo y lo haremos a

\footnotetext{
${ }^{5}$ Respecto de las nociones gadamerianas de lenguaje y de lingüisticidad (Sprachlichkeit), éstas deben entenderse tanto en un sentido ontológico, por ejemplo cuando hablamos de 'nuestra vida en el lenguaje' o de 'la lingüisticidad de nuestra existencia en el mundo', como en un sentido estrecho cuando hablamos del lenguaje formado por palabras o de la lingüisticidad referida a las estructuras lingüísticas.

${ }^{6}$ Cf. $V M$, p. 26.

${ }^{7}$ Cf. Garagalza, L. La interpretación de los símbolos. Hermenéutica y lenguaje en la filosofía actual. Barcelona: Antrophos, 1990, p. 147.

${ }^{8}$ Cf. Garagalza, L. Introducción a la hermenéutica contemporánea. Cultura, simbolismo y sociedad. Barcelona: Antrophos, 2002, p. 37.
} 
partir de la presentación de la idea gadameriana del lenguaje como horizonte dialógico y medio de toda experiencia hermenéutica.

\title{
2. El lenguaje como 'medio' de toda experiencia hermenéutica y su carácter de apertura.
}

\begin{abstract}
“...el lenguaje es el medio universal en el que se realiza la comprensión misma. La forma de realización de la comprensión es la interpretación... Todo comprender es interpretar y toda interpretación se desarrolla en el medio del lenguaje que pretende dejar hablar al objeto y es al mismo tiempo el lenguaje propio de su intérprete"x.
\end{abstract}

La tematización de la experiencia hermenéutica llevada a cabo en las dos primeras partes de $V M$ se recoge ahora desde el giro lingüístico que opera la reflexión gadameriana, y en éste el reconocimiento del carácter simbólicamente mediado de nuestra relación con el mundo convierte al lenguaje en el auténtico medium de nuestro "ser en el mundo" y de toda experiencia hermenéutica.

Gadamer se inscribe pues de partida en una concepción ontológica del lenguaje, pero entendido fundamentalmente como habla y, por ello, como el horizonte y "el medio en el que se realiza el acuerdo entre los interlocutores y el consenso sobre las cosas" ${ }^{10}$. Lo que significa que tanto la experiencia hermenéutica como el lenguaje mismo son entendidos desde el modelo de la conversación.

La comprensión entonces es para Gadamer algo que ocurre siempre de forma lingüística, en el sentido de que comprender no es algo distinto del hablar de la cosa misma y ponerse de acuerdo sobre algo, lo que implica a su vez que el lenguaje es él mismo comprensión e interpretación.

Así también, desde el marco de una crítica a la visión apofántica y proposicional del lenguaje predominante en la tradición occidental, Gadamer emprende el desmontaje del enfoque subjetivista e instrumental del lenguaje propio del pensamiento metodológico. Pero esta labor de desmontaje no se da en $V M$ de manera inmediata, sino por efecto de una profundización gradual que también representa una forma de ganar una nueva relación con los conceptos y las problemáticas imbricadas en la temática del lenguaje.

Del campo vasto de estas reflexiones se destaca en primer lugar la idea ya mencionada, de que el lenguaje no es ni el objeto, ni el sujeto de la experiencia hermenéutica, sino más bien el lugar, el medium donde se conectan y conjugan el hombre y el mundo o, en otros términos, donde se da la apertura del ser humano a la verdad y al sentido de las cosas y de los otros. En este sentido, el

\footnotetext{
${ }^{9} V M$, p. 467.

${ }^{10} V M$, pp. 461-462.
} 
lenguaje no es un medium vacío en el que se encuentre lo uno o lo otro, sino la suma de todo lo que puede encontrarse con nosotros. Es decir, este vivir en el lenguaje, significa para Gadamer moverse en el lenguaje sobre algo y en el lenguaje encontrarse con alguien ${ }^{11}$.

En esta línea de interpretación que destaca el carácter intersubjetivo y dialógico del lenguaje, Gadamer hace suya la definición aristotélica del hombre como un ser dotado de lenguaje ${ }^{12}$ y sobre esa base desarrolla su tesis que el lenguaje sólo existe en la conversación. Es decir, aunque éste pueda ser codificable y encontrar una relativa fijación en el diccionario, la gramática y la literatura, su propia vitalidad y renovación dependen del intercambio dinámico de los interlocutores. Así también se explica por qué, desde la perspectiva hermenéutica, los 'lenguajes artificiales' no son propiamente lenguajes, en tanto no tienen de base una comunidad de vida, sino que se introducen y aplican meramente como instrumentos y presuponen siempre un entendimiento ejercido en vivo. En este sentido, el consenso que se alcanza sobre estos 'lenguajes artificiales' pertenece necesariamente a otro lenguaje. De este modo, de lo anterior se sigue, que no sólo la vida del lenguaje dependerá del diálogo que seamos capaces de promover en nuestra cultura contemporánea, sino que la capacidad misma de entrar en diálogo constituye la verdadera humanidad del hombre ${ }^{13}$.

Ahora bien, Gadamer no sólo encuentra los antecedentes de esta concepción dialógica del lenguaje en la concepción aristotélica del hombre como un ser vivo dotado de logos, sino que también nos remite al relato bíblico de la creación, como al relato de la Torre de Babel. En su concepto, en ambos relatos también se encuentran los gérmenes del carácter dialógico del lenguaje, así como su condición de medio universal en el que se realiza la comprensión misma.

Aceptar lo anterior implica, sin duda, para Gadamer cuestionar la clave negativa con la que se suele interpretar la confusión babélica entre las lenguas y asumir una interpretación de la diversidad como la nota que singulariza al lenguaje humano. Es decir, dicha diversidad daría cuenta de la condición del lenguaje como aquello que expresa toda la distancia que media entre un ser humano y otro y que, sin duda, nos expone a la confusión, pero al mismo tiempo a la posibilidad de su superación. Porque el lenguaje para Gadamer, como hemos visto, es fundamentalmente diálogo, capacidad de buscar la palabra que alcance al otro, capacidad de emigrar al lenguaje del otro ${ }^{14}$.

\footnotetext{
${ }^{11}$ Cf. Gadamer, H-G. "La herencia de Hegel” (1980). Antología. Salamanca: Ediciones Sígueme, 2001, pp. 316-317.

12 "La capacidad para el diálogo es un atributo natural del ser humano. Aristóteles definió al hombre como el ser dotado de lenguaje, y el lenguaje se da sólo en el diálogo", Gadamer, H-G., "La incapacidad para el diálogo". Verdad y método II. Salamanca: Ediciones Sígueme, 1992, p. 203, Cada vez que mencionemos esta obra lo haremos con las siglas VM II.

${ }^{13}$ Cf. Gadamer, H-G. "La incapacidad para el diálogo". VM II, pp. 203-210.

${ }^{14}$ Cf. Gadamer, H-G. "Destrucción y deconstrucción” (1986). VM II. Op. cit., p. 352.
} 
La riqueza metafórica del relato de la Torre de Babel será recurrentemente objeto de la obra tardía de Gadamer, que articula sus reflexiones sobre el carácter dialógico del lenguaje con temas de filosofía práctica. En esta perspectiva, la diversidad de familias lingüísticas y culturas que han adquirido voz propia en las últimas décadas del siglo XX, en su concepto, dan cuenta de las condiciones culturales de una "nueva Babel", cuya supervivencia precisamente dependerá de que seamos capaces de desplegar las posibilidades más creadoras del lenguaje. Es decir, comprender que si el lenguaje es finalmente para Gadamer "un estar de camino a lo común de unos con otros" (ein Unterwegs zum Miteinander), éste sólo llega a ser tal si porta tentativas de entendimiento, de apertura y escucha al otro ${ }^{15}$.

Lo anterior, sin embargo, no significa que Gadamer eluda las dificultades que se presentan para este "vivir en el diálogo". A pesar de ellas, él sostiene que debemos desligar el fenómeno del comprender de la preferencia por los trastornos de la comprensión, si no queremos perder de vista su lugar en el conjunto de nuestra realidad humana. En este sentido, él insiste una y otra vez en lo imprescindible de dicha tarea, y señala que cuando el entendimiento parece imposible porque se hablan lenguajes distintos, la tarea de la hermenéutica no ha terminado aún, sino que precisamente se plantea como la tarea de encontrar el lenguaje común. Pero este lenguaje común no debe entenderse como algo dado, sino como el lenguaje que juega entre los hablantes y que pueda dar lugar al inicio de un entendimiento ${ }^{16}$. Al respecto Gadamer precisa lo siguiente:

Si yo parto de esta idea, eso no significa (.....) que siempre sea posible, -tal es el orgullo de nuestra razón-, cuando surge un disenso, alcanzar el acuerdo mediante la conversación. No siempre lo conseguiremos, pero nuestra vida social descansa en el presupuesto de que la conversación, en su sentido más amplio, deshace el bloqueo producido por el aferramiento a las propias opiniones ${ }^{17}$.

De la cita precedente se sigue pues, que también desde la perspectiva de Gadamer, no intentamos únicamente el diálogo para entender mejor al otro, sino que nosotros mismos nos hallamos amenazados por la rigidez de nuestros conceptos cuando queremos decir algo y el otro ha de percibir lo que decimos. Pues cuando tratamos de entender a otro tenemos la experiencia hermenéutica de que tenemos que romper en nosotros una resistencia, si es que queremos escuchar al otro como otro que es. Esto, concluye Gadamer, "es realmente una radical nota básica de todo existir humano, y es algo que domina incluso lo que solemos llamar nuestra autocomprensión"18.

\footnotetext{
${ }^{15}$ Cf. Gadamer H-G. "La diversidad de las lenguas y la comprensión del mundo" (1990). Arte y verdad de la palabra. Barcelona: Paidós, 1998, pp. 111-130.

${ }^{16}$ Gadamer, H-G. "Autopresentación de H-G. Gadamer" (1977). VM II, p. 392.

${ }^{17}$ Gadamer, H-G. "Lenguaje y Comprensión” (1970). VM II, p. 185.

${ }^{18}$ Gadamer, H-G. "Hermenéutica y diferencia ontológica” (1989). Antología. Op. cit., p. 359.
} 
Por todo lo anterior, puede verse que, para Gadamer, el "vivir en un lenguaje" tampoco nos condena a una lengua concreta, como lo prueba el aprendizaje de idiomas extranjeros y el mismo ejemplo singular de la traducción. Por el contrario, considera que las posibilidades más propias del lenguaje radican precisamente en su carácter de apertura y en el hecho que todas las lenguas comparten la misma unidad de pensar y hablar. Esto quiere decir, que ellas pueden hacerse comprensibles entre sí mediante la traducción, aunque ésta sea siempre ya una interpretación en el medio del lenguaje.

Ahora bien, la traducción es sin duda para Gadamer un caso extremo de dificultad hermenéutica, pero tiene la virtud de hacernos conscientes de la lingüisticidad como el medio del posible acuerdo, aunque este tenga que ser producido artificiosamente a través de una mediación expresa. Es decir, como el interlocutor en un diálogo, el traductor debe hacer valer los derechos de su lengua materna enfrentándolos a lo dicho en la lengua del texto original, pero al final de lo que se trata, como en una auténtica conversación, es de alcanzar un lenguaje común que haga justicia a las dos lenguas. Esto, sin embargo, no significa que en la traducción pueda superarse la distancia que separa a las lenguas, pues al darse ésta en el medio del lenguaje, ella debe pensarse también como un proceso infinito de diálogo de las lenguas históricas, donde inevitablemente se conjugará la fidelidad al texto, la libertad y la parcialidad inherente a toda interpretación.

En esta perspectiva de mostrar el carácter de apertura que tiene nuestra 'vida en el lenguaje', Gadamer sostiene que la crítica es un producto de la virtualidad lingüística de nuestra razón, porque la lingüisticidad de nuestra existencia en el mundo se muestra como una apertura ilimitada a una formación continua y las lenguas naturales viviendo permanentemente en vías de transformación. De lo que se sigue también que las posibilidades finitas de la palabra están asignadas al sentido de su referencia como una orientación hacia el infinito, y por lo tanto el lenguaje vive también en una tensión irresuelta entre 'la palabra interior' (intención comunicativa) y 'la palabra exterior' ${ }^{19}$.

Así también, cuando Gadamer desarrolla en su obra tardía la problemática de los límites del lenguaje, ciertamente nos recuerda que toda experiencia de esos límites sigue participando de la universalidad del medium lingüístico, pues lo indecible es indecible únicamente a la luz de lo que hubiera de decirse, aunque no haya lenguaje capaz de hacerlo. Sin embargo, pese a lo dicho, también añade que en tanto el lenguaje es la "huella de nuestra finitud", éste posee una fuerza desocultadora y ocultadora a la vez, lo que significa que realmente no es posible concluir una conversación de forma definitiva.

De todo esto resulta entonces, que la desocultación como la ocultación serían momentos estructurales del ser y su representarse en el lenguaje y, por lo tanto,

\footnotetext{
${ }^{19}$ Gadamer hace suyas estas expresiones propias de la concepción agustiniana de la palabra, y que aluden a la concepción del lenguaje como un proceso en el que la intención comunicativa nunca se agota en su expresión externa.
} 
quizá este 'vivir en el medio del lenguaje' se caracterice más por ese insatisfecho deseo de la palabra pertinente, que por la compresibilidad del ser a la que también nos abre ${ }^{20}$. Pero por otro lado, el giro ontológico hacia el lenguaje que opera la reflexión hermenéutica no sólo nos ha mostrado que el ser ahí se encuentra en el lenguaje como en casa, sin que sólo en el lenguaje que hablamos unos con otros el ser está ahí ${ }^{21}$. De este modo, concluimos que en el contexto contemporáneo de la diversidad de las lenguas, el fenómeno de nuestra 'vida en el lenguaje' es en último término el fenómeno de la escucha al otro en el horizonte de una conversación a la que no podemos dar término.

${ }^{20}$ Cf. Gadamer, H-G. "Los límites del lenguaje" (1985). Arte y Verdad de la palabra. Op.cit., pp. 144-149.

${ }^{21}$ Cf. Gadamer, H-G. "Acerca de la verdad de la palabra” (1971/1993). Arte y Verdad de la palabra. Op. cit., p. 20. 


\title{
El Doble Sentido de la Experiencia Hermenéutica
}

\author{
Marcelino Arias Sandí \\ Universidad Veracruzana -Xalapa
}

\begin{abstract}
Resumen
Este texto presenta una lectura de la experiencia hermenéutica en la obra de H. G. Gadamer. En esta lectura se propone que la experiencia hermenéutica debe ser entendida en un doble sentido, no excluyente, esto es: en un sentido ontológico, en tanto se refiere al modo de ser del "ser-ahî"; y el otro, un sentido epistemológico, que corresponde al modo de investigar en la hermenéutica, entendido como hacer experiencia de la experiencia.
\end{abstract}

En este texto me propongo presentar una lectura de la experiencia hermenéutica en la que se destacan dos dimensiones, a saber, una dimensión ontológica y otra epistemológica, esta segunda en tanto se muestra como un modo específico de preguntar al mundo.

La experiencia hermenéutica atraviesa de lado a lado la obra de Gadamer. Este tema aparece desde el inicio de Verdad y método I, cuando se aborda la experiencia del arte. Pero no es sólo en esa parte inicial que se toca el punto, sino que lo reitera en su análisis de las ciencias del espíritu para finalizar en la sección del giro ontológico de la hermenéutica. Aun cuando es hasta el final de la segunda parte del libro que trata específicamente de "la esencia de la experiencia hermenéutica” y, posteriormente del lenguaje como medio de ésta, él mismo señala que la experiencia hermenéutica era lo que tenía presente desde el principio de su reflexión.

No se trata aquí de exponer todos los aspectos que constituyen la experiencia hermenéutica, sino sólo aquellos que permitan comprender su sentido ontológico y universal, a la vez que aquellos que la presentan como un modo de preguntar. Por esto es que se señala aquí su presencia a lo largo de la obra.

Uno de los aspectos centrales de la experiencia hermenéutica es ser un modo de la experiencia humana del mundo. Gadamer, cuando se refiere al lenguaje dice: "se trata del centro del lenguaje, desde el cual se desarrolla toda nuestra experiencia del mundo y en particular la experiencia hermenéutica"1. Cabe retener de lo anterior, el carácter particular de la experiencia hermenéutica respecto a la experiencia humana del mundo. Esto será a su vez la posibilidad de su universalidad. Si la experiencia hermenéutica es un modo particular de la

${ }^{1}$ Gadamer, Hans-Georg. Verdad y Método I. Salamanca: Ed. Sígueme, 1993, p. 584. 
experiencia del mundo, entonces se puede afirmar que comparte con ella sus rasgos fundamentales.

De estos rasgos cabe destacar que "La constitución lingüística de nuestra experiencia del mundo está en condiciones de abarcar las relaciones vitales más diversas"2. Así, también la experiencia hermenéutica está constituida lingüisticamente y reclama su derecho a abordar cualquier ámbito de la experiencia humana. Esto ha dado lugar a uno de los puntos centrales del debate con Habermas, a saber, los límites de la experiencia hermenéutica. Limitar la experiencia hermenéutica es algo que Gadamer no acepta, aun cuando sí deba dejarse claro su alcance y pretensiones.

La experiencia hermenéutica, al igual que la experiencia humana del mundo, no puede tratar como objeto aquello a lo que se aboca, esto considerando que "no existe ningún lugar fuera de la experiencia lingüística del mundo desde el cual éste pudiera convertirse en objeto"3.

También puede señalarse que la relación de la experiencia hermenéutica con la tradición no es objetivadora, ya que "la tradición no es un simple acontecer que pudiera conocerse y dominarse por la experiencia, sino que es lenguaje, esto es, habla por sí misma como lo hace un tú" ${ }^{4}$. En tanto la tradición habla como un tú, la experiencia hermenéutica no puede colocarse por fuera de la escucha de ese tú, es decir, por fuera de la conversación y, por lo tanto, no es un simple conocer la tradición, sino que es un verse afectado por ella, y afectarla, reconociendo la pertenencia a esa tradición.

A manera de paréntesis, pero con el propósito de ahondar en el sentido amplio de los conceptos gadamereanos, es pertinente comentar algunos rasgos de la tradición. Sobre todo considerando que la pertenencia a la tradición es un modo propio de ser del "ser ahî". Además, en la relación con la tradición se muestra también el doble sentido de la experiencia hermenéutica.

En primer lugar, cabe destacar que aun cuando se habla de la tradición, en realidad se trata de una diversidad de tradiciones, es decir, según cada caso que se revise se podrá reconocer alguna tradición específica. Gadamer se refiere a distintos tipos de tradiciones. El más reconocido sería la tradición cultural, pero ésta no se presenta como algo homogéneo sino que adquiere diversas formas, tales como religiosa, filosófica, artística, histórica, social, disciplinaria $\mathrm{e}$, incluso, la de tradiciones generadas a partir de individuos como son las de actor o director. Y aún al interior de estas grandes divisiones, Gadamer señala la existencia de una rica variedad de tradiciones.

\footnotetext{
${ }^{2}$ Ibid, p. 538.

${ }^{3}$ Ibid, p. 543.

${ }^{4}$ Ibíd, p. 434.
} 
Por ejemplo, en el campo religioso menciona tradiciones como la mitológica, la cristiana, la bíblica, y aún, la Reforma.

Para la tradición filosófica se refiere a un amplio catálogo de tradiciones, que incluye la metafísica, la inglesa, la humanista, la conceptual aristotélica, la escolástica, la metafísica moderna, la moralista y la hermenéutica, por mencionar las más identificables a lo largo de sus textos. Obviamente en el caso de las tradiciones hermenéuticas considera desde la antigua hasta la clásica, y sus desarrollos en las distintas disciplinas, filología, derecho, filosofía y teología.

En el campo del arte y las disciplinas, las referencias a las tradiciones se multiplican: estética, literatura, música, poética de los pueblos, clásica, romántica, clásico-romántica, de reflexión sobre lo trágico, filológica, histórica, míticohistórica, retórica y lingüística.

En el caso de tradiciones sociales menciona la político-social, la político-moral, de vida estatal, y de vida social. En una parte de sus respuestas a Habermas señala cómo "...el historiador, aun el de la ciencia "crítica”, está tan lejos de abandonar las tradiciones vigentes, como las de los Estados nacionales, que él como historiador nacional interviene en las mismas con su acción formadora y conformadora..."

Después de este inventario es que podemos concluir que al formular afirmaciones relativas a la "tradición como tal", "la totalidad de la tradición" o "la unidad de la tradición", no cabe caer en la tentación de pensar que Gadamer tiene una visión reduccionista o metafísica de la tradición o que está hablando de algo incomprensible e inaprehensible. Más bien, nos da entrada a pensar situadamente, desde una experiencia hermenéutica situada las afirmaciones que, en un sentido general, aparecen en los textos gadamereanos. Esto es, es conveniente tener presente que las referencias se dan en el acontecer de tradiciones específicas. Hasta aquí, la reflexión sobre la tradición como muestra del complejo entramado con que se construyen los conceptos gadamereanos, y que de un modo especial es propio de la experiencia hermenéutica. Además, recordemos que Gadamer afirma que:

La experiencia hermenéutica tiene que ver con la tradición. Es ésta la que tiene que acceder a la experiencia. Sin embargo, la tradición no es un simple acontecer que pudiera conocerse y dominarse por la experiencia, sino que es lenguaje, esto es, habla por sí misma como lo hace un tú ${ }^{6}$.

Para esto es importante señalar que las relaciones con la tradición tampoco son algo unidimensional. A lo largo de los textos de Gadamer se pueden identificar varios modos de relación con la tradición.

\footnotetext{
${ }^{5}$ Gadamer, Hans-Georg. Verdad y método II. Salamanca: Ed. Sígueme, 1992, p. 223.

${ }^{6}$ Gadamer, op. cit., p. 434.
} 
La experiencia hermenéutica es auténtica experiencia, y todo lo que acontece en ella es relación vital con la tradición, con el mundo y no sólo un conocimiento.

Si se reúnen los rasgos mencionados de la experiencia en una sola idea, ésta es el comprender. La experiencia hermenéutica es un modo del comprender, entendido como modo de ser del "ser ahî". Aquí cabe recuperar el modo en que Gadamer se refiere al comprender:

La analítica temporal del estar ahí humano en Heidegger ha mostrado en mi opinión de una manera convincente, que la comprensión no es uno de los modos de comportamiento del sujeto, sino el modo de ser del propio estar ahí. En este sentido es como hemos empleado aquí el concepto de "hermenéutica". Designa el carácter fundamentalmente móvil del estar ahí, que constituye su finitud y su especificidad y que por lo tanto abarca el conjunto de su experiencia del mundo. El que el movimiento de la comprensión sea abarcante y universal no es arbitrariedad ni inflación constructiva de un aspecto unilateral, sino que está en la naturaleza misma de la $\cos ^{7}$.

Al vincular de este modo el comprender, la experiencia y la hermenéutica es posible afirmar el carácter radicalmente ontológico de la experiencia hermenéutica. También se debe entender, en este mismo sentido, que la experiencia hermenéutica no es algo por lo que se puede optar o no, sino que es el modo de ser propio del "ser ahí".

La experiencia hermenéutica, que se realiza en el medio universal del lenguaje, es una experiencia del sentido transmitido y la comprensión de este sentido. Esta experiencia puede realizarse en cualquier ámbito de la experiencia humana y, por lo tanto, es universal.

A modo de ejemplo de las resistencias a la propuesta ontológica de la hermenéutica, cabe recordar que en textos donde Habermas trata de la hermenéutica, aún aquellos textos separados por varios años, insiste en "poner en cuestión la autocomprensión ontológica de la hermenéutica" y señalar que "se exageró la importancia de la hermenéutica para convertirla en un sustituto filosófico de la ontología heideggeriana", para reconocer que "los argumentos principales de la hermenéutica filosófica gozan hoy de amplia aceptación (aunque no como doctrina filosófica, sino como paradigma de investigación) dentro de las ciencias sociales" ${ }^{10}$. Habermas afirma que cuando distingue entre ciencias hermenéuticas y no hermenéuticas, solamente sostiene una distinción metodológica

\footnotetext{
${ }^{7}$ Ibíd, p. 12.

${ }^{8}$ Habermas, Jürgen. La lógica de las ciencias sociales. México: Ed. Rei. 1993, p. 300.

${ }^{9}$ Habermas, Jürgen. Conciencia moral y acción comunicativa. Barcelona: Ed. Península. 1996, p. 34.

${ }^{10}$ Ídem.
} 
entre las ciencias que requieren de la comprensión y las que no para el acceso a su ámbito de conocimiento. Rechaza una hermenéutica radical, con las fundamentaciones de Gadamer y Rorty, que prescinde tanto de la pretensión de objetividad como de la aspiración a un conocimiento explicativo ${ }^{11}$.

También afecta, y esto es mucho más ampuloso, a los conceptos de subjetividad y objetividad científica, a los cuales es más difícil renunciar o modificar en el sentido que abre Gadamer. Para muchos, la pérdida de un concepto fuerte de objetividad y, sutilmente, de su contraparte la subjetividad, acarrea la pérdida de las pretensiones de verdad y legitimidad del conocimiento. Por lo que aun simpatizando con la superación de la metafísica no aceptan extender esta superación a los citados conceptos. Uno de los caminos más socorridos para resistir esta segunda superación es precisamente negar el giro ontológico de la hermenéutica, en este sentido, los mejores ejemplos son los aportados por las objeciones y reconocimientos a la hermenéutica realizados por Habermas.

Con lo dicho hasta este momento queda planteada la dimensión ontológica y algunos de sus rasgos más significativos. Ahora bien, toca explorar la otra dimensión de la experiencia hermenéutica, la que se refiere a "hacer experiencia hermenéutica" desde la filosofía. Cabe revisar previamente algunos rasgos de la experiencia científica para tenerlos como puntos de contraste para resaltar los rasgos propios de la experiencia hermenéutica en el sentido señalado en las líneas previas.

Por lo que toca a la historicidad, Gadamer critica que la concepción científica de la experiencia ha desatendido la historicidad interna de la experiencia / MISMA, al respecto señala: "El objetivo de la ciencia es objetivar la experiencia hasta que quede libre de cualquier momento histórico. En el experimento natural-científico esto se logra a través de su organización metodológica" ${ }^{12}$. Desde luego, que la característica que esta orientación metodológica le otorga a la experiencia científica es, justamente, su repetibilidad o reproducibilidad. Toda experiencia regida por el método científico tiene como característica central que puede ser repetida por cualquiera, siempre y cuando tenga las competencias científicas necesarias para seguir el método. Esto no se encontrará en modo alguno en la experiencia hermenéutica, ni en su sentido vital, ni en el sentido de indagación hermenéutica.

Gadamer señala que la pretensión de realizar este tipo de experiencia alcanzó también a las ciencias del espíritu, y su método histórico y crítico. Desde luego que no es alcanzable, por más que traten de contar con control total sobre el procedimiento completo. Si se cumple con tal condición se puede formular la siguiente regla: una experiencia sólo es válida si se confirma al ser reproducida. Esto vitalmente es imposible de cumplir. Si la experiencia hermenéutica es vital además de ser un modo de preguntar teóricamente orientado, no

${ }^{11}$ Ibíd, p. 42.

${ }^{12}$ Gadamer, op. cit., p. 421. 
tiene manera de cumplir con el requisito metodológico de la ciencia natural, y debiera tenerse claro que no es su propósito hacerlo. La validez de la experiencia hermenéutica no pasa por esta vía.

Gadamer también revisa el modo en que Husserl trata a la experiencia. Aquí recuperamos principalmente lo relacionado con la experiencia científica. Al respecto dice:

En los últimos tiempos Edmund Husserl ha dedicado particular atención a esta cuestión, emprendiendo una y otra vez la tarea de ilustrar la parcialidad inherente a la idealización de la experiencia que subyace a las ciencias. Con esta intención Husserl ofrece una genealogía de la experiencia que, como experiencia del mundo vital, antecede a su idealización por las ciencias. Sin embargo, el propio Husserl me parece también dominado por la parcialidad de la crítica; Husserl sigue proyectando el mundo idealizado de la experiencia científica exacta sobre la experiencia original del mundo en cuanto hace de la percepción, como cosa externa y orientada a la mera corporalidad, el fundamento de toda experiencia ulterior ${ }^{13}$.

No se trata aquí de seguir puntualmente las diferencias o posibles debates entre las propuestas de Husserl y de Gadamer, sino más bien de resaltar en riesgo de subordinar toda la experiencia al modelo científico de la misma. En realidad se trata, más bien, de desmarcar la experiencia hermenéutica del modelo emanado de la ciencia. Tal desmarque no se da sólo en la dimensión ontológica de la experiencia sino también, y aquí importa, en la dimensión epistemológica, es decir, la vinculada al desarrollo de las "investigaciones" hermenéuticas. En realidad, al hablar de "investigación" se trata de cómo se hace experiencia hermenéutica en relación con un asunto específico.

Tenemos que recordar que la experiencia hermenéutica no es superada en el conocimiento científico. Es más, la "investigación” hermenéutica no pretende dejar de ser experiencia hermenéutica en su doble sentido. Los resultados de una indagación conducida por la lógica de la pregunta y la respuesta, que propone Gadamer, por más sofisticados, amplios o eruditos que puedan ser, no dejan de ser al mismo tiempo experiencia y no se transforman, por decirlo así, en un conocimiento que deja atrás a la experiencia. / LA DEJA ATRÁS.

Por otra parte, y resaltando la historicidad de la propia experiencia, se tiene que reconocer que aquello que ofrece una indagación hermenéutica como "saber", no es repetible, puesto que no podrá repetirse no sólo la experiencia, tampoco el horizonte del preguntar. Esta imposibilidad alcanza tanto al mismo hermeneuta que hubiese llevado a cabo una interpretación como a cualquier otro que

\footnotetext{
${ }^{13}$ Ibíd, p. 422.
} 
pretendiera repetirla. Al primero, porque su propia experiencia le impediría seguir igual a como había empezado. Igual que sabemos como entramos a una conversación pero no como terminaremos. Al segundo, se le podría recordar la imposibilidad de ponerse en los zapatos del otro, o de la importancia de reconocer la distancia en el tiempo, o la diferencia de horizontes.

Así pues, si la experiencia hermenéutica es un modo de ser, también es un modo de proceder. Gadamer señala algunas vías para realizar la experiencia hermenéutica, lo cual indicaría que no toda experiencia del mundo es hermenéutica. Esto parece una paradoja. No obstante, sólo lo parece, pues si se retoma la diferencia entre preontológico y ontológico, o bien, entre precomprensión y comprensión, se advierte la ruta de salida de tal paradoja. Para aclarar esta diferencia es útil la siguiente cita de Heidegger:

Si reservamos por ende, el título de ontología para el preguntar en forma explícitamente teorética por el sentido de los entes, hay que designar este "ser ontológico" del "ser ahî" como "preontológico". Pero esto no significa tan sólo ser ónticamente, sino ser en el modo de un comprender el ser ${ }^{14}$.

Así, la experiencia hermenéutica es a su vez experiencia humana del mundo, y también una estrategia de preguntar al mundo. De este modo se resalta el doble carácter de la experiencia hermenéutica.

El multicitado texto sobre los "Fundamentos para una teoría de la experiencia hermenéutica" 15 puede ser especialmente útil para resaltar la doble dimensión de la experiencia hermenéutica que aquí hemos señalado.

Como un apoyo a la propuesta de identificar una doble dimensión de la experiencia hermenéutica, se puede recurrir, por analogía, a la aclaración que hace Gadamer sobre la cierta ambigüedad del concepto de historia efectual. El texto dice: "Esta ambigüedad consiste en que con él [el concepto de historia efectual] se designa por una parte lo producido por el curso de la historia y a la conciencia determinada por ella, y por la otra a la conciencia de este mismo haberse producido y estar determinado" 16 .

Algo similar sucede con la experiencia hermenéutica. Cuando se revisa la parte mencionada, renglones arriba, sobre la teoría de la experiencia hermenéutica, se tiene la impresión de que está sucediendo simultáneamente un doble juego, paradójico, pero no contradictorio. Por un lado, se muestra como se constituye la experiencia hermenéutica, y por el otro, estamos participando del modo de hacer, desde la filosofía, experiencia hermenéutica.

\footnotetext{
${ }^{14}$ Heidegger, Martin. El ser y el tiempo. México: Ed. Fondo de Cultura Económica, 1980, p. 22.

${ }^{15}$ Este texto se encuentra en Verdad y método I.

${ }^{16}$ Gadamer, op. cit., p. 16.
} 
Es decir, reconocer el círculo hermenéutico, los prejuicios, la autoridad, la tradición, lo clásico, y claro, la primacía hermenéutica de la pregunta, nos llevan a pensar que hacer hermenéutica filosófica es hacer experiencia de la experiencia. 


\title{
Hermenéutica sin Verdad Hermenéutica. Comentarios Críticos acerca del Concepto de Verdad Hermenéutica de Gadamer
}

\author{
Matthias Günther \\ Universidad Austral de Chile
}

\begin{abstract}
Resumen
El concepto de verdad hermenéutica, tal como Gadamer lo introduce, es problemático. Después de exponer algunos problemas relacionados con la verdad hermenéutica, se argumentará que, a pesar de que el concepto de verdad hermenéutica parece ser sumamente central en la filosofía gadameriana, quizás se pueda renunciar a él sin que se pierdan los objetivos filosóficos esenciales de Gadamer.
\end{abstract}

Los filósofos, esto no es nada nuevo, corren el riesgo de ser marginados. Esto quizás siempre haya sido así porque la filosofía no es, como tal, muy directamente relevante para el funcionamiento de la sociedad, lo que posiblemente nunca haya sido un problema para los filósofos mismos, ya que, en su mayoría, tampoco aspiran al efecto público. Se trata tal vez de un problema personal para algunos filósofos, pero no es un problema para la filosofía en general.

Es más, la filosofía a veces también se encuentra marginada en el conjunto de las disciplinas académicas. No me refiero a la destinación de menos dinero a la filosofía que a varias otras disciplinas, ya que esto pertenece más bien a su posición social. La filosofía también parece marginada a veces en el sentido de que no se le atribuye gran capacidad de solucionar problemas científico-intelectuales. Y este destino lo comparte con las humanidades, o sea, generalmente con todas las disciplinas que tienen que ver menos con la explicación y el manejo de la naturaleza o con la solución de problemas formales sino más bien con la interpretación de acciones y enunciados humanos.

Hay algo como un déficit epistémico observado en las humanidades y en la filosofía que va más allá de una falta de atención social y que es una humillación, por lo menos para la filosofía que estaba acostumbrada más bien a una posición intelectualmente privilegiada e incluso autoritaria. La discrepancia entre, 
por una parte, la pretensión epistémico de la filosofía, y, por otra, el hecho de que el ambiente social general e incluso el ambiente académico le nieguen parcialmente peso epistémico, marca, indudablemente, la autoconciencia de la filosofía, y marca también actitudes personales de algunos filósofos.

Esta situación hace susceptibles a los filósofos a ofertas terapéuticas, sobre todo a ofertas que provienen de los mismos filósofos.

Gadamer fue un filósofo que ofreció tal terapia. El éxito de Gadamer en el mundo filosófico, e intelectual en general, se debe, sin duda, no sólo a la calidad y originalidad de sus tratados filosóficos, sino también al hecho de que su obra ha tenido un efecto terapéutico para los filósofos humillados en su pretensión tradicional de importancia y relevancia por lo menos epistémicocientífica.

Ahora bien, para el efecto de una terapia, no siempre es importante que sea sostenible lo que dice el terapeuta. Lo importante es que tenga el efecto que se desee. Pero, si es un filósofo quien es el terapeuta, entonces sí importa si trabaja con instrumentos filosóficamente sostenibles o no. En esta contribución quiero plantear la pregunta de si la terapia gadameriana es o no es filosóficamente sostenible. Específicamente me voy a dedicar al papel del concepto de verdad en ella.

\section{II}

El efecto terapéutico de la filosofía gadameriana se deriva del hecho de que Gadamer trata de salvar, por decirlo así, la dignidad epistémica a los filósofos y a los intelectuales en general. Las humanidades y la filosofía (que, para Gadamer, forma parte de las humanidades ${ }^{1}$ ) aspiran también al conocimiento, aunque en un sentido distinto que las ciencias naturales. Un sentido distinto, pero no inferior. Con esto, Gadamer sigue con una tradición que tuvo como uno de sus representantes más importantes a Dilthey y que siguió, después de éste, sobre todo en la tradición hermenéutica y también en la filosofía analítica.

Ahora bien, Gadamer no sólo se dedica a las diferencias epistemológicas entre las ciencias naturales y las humanidades. No sólo distingue entre diferentes tipos y metodologías de conocimiento relacionados con los diferentes objetos de conocimiento. Además, Gadamer distingue entre diferentes conceptos de

\footnotetext{
${ }^{1}$ La clasificación de la filosofía como una de las humanidades corresponde también al hecho de que, en general, en el mundo académico, se ubican los departamentos de filosofía en las facultades de humanidades. Sin embargo, si se definen las humanidades como las disciplinas que se dedican al estudio y a la interpretación de textos, enunciados, acciones, artefactos e instituciones humanos (siguiendo la definición de las "ciencias del espíritu" según Dilthey), entonces la filosofía difícilmente puede contar como una de las humanidades. El trabajo filosófico se desarrolla, generalmente, en forma del estudio de textos filosóficos, pero su objetivo no es, al fin y al cabo, la interpretación de estos textos, sino más bien la solución de problemas sistemáticos.
} 
verdad que se refieren a las ciencias naturales por un lado y a las ciencias interpretativas, a las ciencias del espíritu, por otro ${ }^{2}$. Existe, además de la verdad objetiva, la verdad hermenéutica.

Con esta jugada, Gadamer no sólo les asegura la participación en el negocio del conocimiento a los filósofos y a los investigadores en las ciencias interpretativas, sino que además les concede participar en la noble actividad de la búsqueda de la verdad. El efecto de la terapia aumenta si no sólo se concede a las ciencias interpretativas que se produce conocimiento en ellas, sino que si se les atribuye además que participan en la empresa intelectual de la búsqueda de la verdad que parece tener una dignidad especial. Negarles tal participación a los filósofos en particular, con toda su historia cargada de ambición y también de pretensiones, significa una humillación. Pero argumentar que su actividad sí consiste en algún tipo de seguimiento de la verdad, significa una oferta terapéutica para aquellos filósofos que se sienten amenazados por tal humillación.

Ahora bien, Gadamer es un filósofo. Una oferta terapéutica aceptable de él debe ser también filosóficamente sostenible. A continuación quiero plantear la pregunta de si Gadamer, introduciendo el concepto de verdad hermenéutica, realmente trabaja con un remedio que también filosóficamente es sostenible.

\section{III}

Analizar el concepto de verdad gadameriano no es una tarea fácil, ya que Gadamer no lo desarrolló de una claridad deseable. Jean Grondin, el autor de una monografía amplia sobre este concepto, lamenta que cualquier estudio acerca de la verdad hermenéutica en Gadamer dependa de una labor interpretativa minuciosa y también, hasta cierto grado, especulativa ${ }^{3}$.

De hecho, Gadamer no ha tratado de ubicar su concepción de la verdad dentro del debate contemporáneo acerca de este concepto. Por un lado, esto es sorprendente, ya que el concepto de verdad parece sumamente central en la hermenéutica gadameriana. Por otro lado, se refleja en esto su falta de relación con la filosofía analítica en la cual se desarrolló la mayor parte del debate filosófico contemporáneo sobre la verdad ${ }^{4}$.

\footnotetext{
${ }^{2}$ Prefiero el título "ciencias interpretativas", entendiendo las humanidades como las disciplinas que apuntan a interpretaciones de acciones racionales (humanas) y de los productos de estas acciones (textos, obras de arte, objetos culturales en un sentido muy amplio, instituciones y formas de organización). Interpretaciones son explicaciones que hacen uso, utilizando vocabulario de la tradición analítica, de propiedades intensionales, es decir, de propiedades con contenido semántico (significados lingüísticos, actitudes proposicionales).

${ }^{3}$ Cfr. Grondin, Jean. Hermeneutische Wahrheit? Zum Wahrheitsbegriff Hans-Georg Gadamers. 1982. Weinheim: Beltz Athenäum, 1994, p. 123.

${ }^{4}$ Aparte de Wahrheit und Methode (Gadamer, Hans-Georg. Wahrheit und Methode. 1960. Tübingen: Mohr (Siebeck), 1990), los textos gadamerianos más importantes acerca de la verdad son "Wahrheit in den Geisteswissenschaften" (Gadamer, Hans-Georg. "Wahrheit in den Geisteswissenschaften". 1953. Gesammelte Werke, Band 2. Tübingen: Mohr (Siebeck), 1986, 37-43) y "Was ist Wahrheit?" (Gadamer, Hans-Georg. "Was ist Wahrheit?". 1957. Gesammelte Werke, Band 2. Tübingen: Mohr (Siebeck), 1986, 44-56).
} 
En la tradición analítica se ha formado una sistematización de diferentes conceptos de verdad que puede servir como mapa en el debate tan ramificado sobre la verdad ${ }^{5}$. Orientándose por la terminología correspondiente, se podría decir que el concepto de verdad gadameriano es, primero, un concepto de verdad epistémico, y, segundo, un concepto de verdad pragmatista. Estas características distinguen su concepto de verdad hermenéutica del concepto de verdad objetivista, que pertenece, según Gadamer, a la investigación científica.

Llama la atención que las diferencias entre las concepciones de la verdad en las ciencias naturales y en las ciencias interpretativas corresponden directamente a las diferencias epistemológicas entre las diferentes disciplinas. En cuanto a éstas últimas, Gadamer sostiene que en las ciencias interpretativas no existe el ideal de la objetividad, mientras que sí existe en las ciencias naturales. Ahora bien, esta diferencia Gadamer la transfiere a los conceptos de verdad respectivos. La tesis de que la idea de la objetividad no existe en las ciencias interpretativas no lo motiva a sostener que la categoría de la verdad, por tanto, tampoco aparezca en ellas. Más bien, sostiene que les pertenece otro concepto de verdad, a saber, un concepto de verdad que corresponde a sus particularidades metodológicas.

¿En qué sentido el concepto de verdad gadameriano es epistémico y pragmatista?

Entender la verdad como epistémica significa entender la verdad y falsedad de, por ejemplo, las creencias de un sujeto como dependiendo de la posición epistémica que éste adopta frente a ellas.

El carácter epistémico del concepto de verdad gadameriano se muestra sobre todo en su tratamiento de los prejuicios. La "rehabilitación de los prejuicios" no sólo se refiere al hecho de que sea imposible hacer concientes todos los prejuicios y cuestionarlos. Es más, para Gadamer, los prejuicios como tales son portadores de verdad. Gadamer concede una valoración normativa positiva a los prejuicios, la cual se debe al hecho de que éstos determinen por buena parte el horizonte del entendimiento. El entendimiento que alcanza un intérprete, lo alcanza dentro del horizonte estructurado y delimitado por sus prejuicios. Ahora bien, esto no necesariamente significa que la verdad misma sea de alguna forma relativa al horizonte del sujeto epistémico. Pero Gadamer sí vincula la relatividad del entendimiento con la relatividad de la verdad. En el contexto de la relatividad de la interpretación, Gadamer enfatiza que "hay que destruir el fantasma de una verdad disuelta de la situación del sujeto" ${ }^{\text {" Es }}$ decir, no sólo el entendimiento depende del horizonte y de la perspectiva de un sujeto epistémico, sino también la verdad misma ${ }^{7}$.

\footnotetext{
${ }^{5}$ Cfr., por ejemplo, la sistematización de las diferentes teorías de la verdad en la Introducción en Lynch, Michael. The Nature of Truth. Classical and Contemporary Perspectives. Cambridge/London: MIT Press, 2001.

${ }^{6}$ Gadamer, Hans-Georg. "Wahrheit in den Geisteswissenschaften". 1953. Gesammelte Werke, Band 2. Tübingen: Mohr (Siebeck), 1986, p. 40 (traducción propia).

${ }^{7}$ Esta consecuencia es inevitable si se parte, primero, de la dependencia de cualquier interpretación respecto de las condiciones particulares del intérprete, y, segundo, de una concepción no trascendental de la verdad, es decir, de una concepción que entiende la verdad como accesible de cierta forma. Ambas suposiciones son, evidentemente, centrales en la hermenéutica gadameriana.
} 
Un concepto pragmatista de la verdad es un concepto que considera como definitorio para la verdad de una creencia algún rol práctico que tiene esta creencia para su portador. El pragmatismo de Gadamer (él mismo seguramente no hubiera aceptado este término para su concepción de la verdad ${ }^{8}$ ) se muestra en lo que se podría llamar la influencia hermenéutica existencial en Gadamer. El entender, para Gadamer, no es sólo un proceso teórico, determinado por la situación epistémica de un sujeto epistémico, sino que además es un proceso que se determina por los intereses y las preguntas del intérprete mismo. Gadamer habla del "prevalecer de la pregunta" y de una "relación vital con la tradición" que es esencial para el entender. ${ }^{9}$ Los textos y otros documentos no se entienden, o no se entienden exclusivamente, como respuestas a las preguntas del autor o como respuestas a preguntas posibles, sino que se entienden más bien como respuestas a preguntas reales del intérprete. El interpretar también es algún tipo de "aplicación”, como Gadamer lo suele formular.

\section{IV}

Si la concepción gadameriana de la verdad es a la vez epistémica y pragmatista, entonces está confrontada con los problemas típicos y conocidos de estas concepciones ${ }^{10}$.

Quiero mencionar sólo dos problemas que quizás sean poco controvertidos:

1) Ser verdadero es una propiedad estable, mientras que la justificación de una creencia no es estable. Lo que en algún momento está justificado, en otro momento quizás no esté justificado. Un concepto epistémico de la verdad, entonces, no respeta la estabilidad de esta. Lo mismo vale para las concepciones pragmatistas.

\footnotetext{
${ }^{8}$ Se encuentra una referencia parcialmente positiva y parcialmente negativa al pragmatismo en Gadamer, Hans-Georg, "Was ist Wahrheit?". 1957. Gesammelte Werke, Bd. 2. Tübingen: Mohr (Siebeck), 1986, p. 53. Gadamer destaca allí el mérito del pragmatismo norteamericano de haber vinculado el tema de la verdad con la situación de un sujeto. Sin embargo, agrega que su propio entendimiento de la verdad no es pragmatista, y que la verdad no se determina por los efectos prácticos que tiene la posesión de una creencia.

Lo último parece debilitar considerablemente mi interpretación del concepto de verdad gadameriano como un concepto epistémico y pragmatista. Sin embargo, primero, no sostengo que el concepto gadameriano sea un concepto puramente pragmatista sino un concepto que contiene rasgos pragmatistas, y, segundo, parto de un concepto de pragmatismo más amplio según el cual el papel práctico no necesariamente tiene que ver con un efecto en un contexto de acción. Un efecto práctico también puede ser la satisfacción de algún interés intelectual o existencial. La vinculación gadameriana de la verdad a los intereses y las necesidades prácticos, indudablemente, tiene que ver más con los intereses intelectuales y existenciales de un sujeto que con sus acciones exteriores.

${ }^{9}$ Ambas formulaciones se encuentran en Gadamer, Hans-Georg. Wahrheit und Methode. 1960. Tübingen: Mohr (Siebeck), 1990. La primera es el título del capítulo 3.c de la segunda parte, la segunda formulación en la página 366.

${ }^{10}$ Hay posiciones neo-pragmatistas que evitan los problemas que son mencionados a continuación. El más conocido es el neo-pragmatismo de Rorty. Pero el pragmatismo de Gadamer no corresponde a tal posición.
} 
2) Las concepciones epistémicas y pragmatistas de la verdad pertenecen a las concepciones sustanciales de este concepto. Es decir, tratan el concepto de verdad como si fuera un concepto descriptivo "normal". Pero cualquier concepción sustancial del concepto de verdad tiene el problema de explicar la notoria equivalencia de los enunciados afirmativos "p" y "es verdadero que p".

La verdad, en el sentido gadameriano de la verdad hermenéutica, no es estable ni respeta la equivalencia de los enunciados afirmativos "p" y "es verdadero que p".

Si la verdad de una creencia depende de la situación epistémica del sujeto y de las preguntas propias de él, entonces se trata de una dependencia realmente extrema de la verdad respecto de las condiciones específicas del sujeto. La verdad de una creencia, entendiéndola en un sentido objetivista, es estable justamente por su independencia respecto de las condiciones epistémicas y prácticas de los portadores de creencias.

Además, afirmar "es verdadero que p" no es simplemente lo mismo que afirmar "p" ya que la afirmación de que p no necesariamente se refiere a un portador de la creencia de que p mientras que la afirmación de que es verdadero que p sí se refiere a un posible portador de la creencia de que $\mathrm{p}$ (ya que el concepto de verdad respectivo es relativista).

Para Gadamer, éstos no parecen ser problemas, ya que su objetivo era justamente la búsqueda de un concepto de verdad que no tuviera las características que el concepto de verdad tiene "normalmente". Pero, entonces, Gadamer tiene que responder a la misma crítica que Tugendhat, por ejemplo, hizo frente a Heidegger: ¿Por qué tenemos que entender ese concepto de verdad gadameriano como un concepto de verdad? Si es tan diferente del concepto de verdad "normal", sea éste cual sea, ¿por qué se trata de un concepto de verdad y no, por ejemplo, de un concepto de creencia aceptada? ${ }^{11}$

\section{V}

Parece que Gadamer, de cierta forma, vacilaba en cuanto a la posición del concepto de verdad hermenéutica. A veces parece que Gadamer lo entiende como un concepto superior al concepto objetivista de la verdad y, por tanto, éste último como subordinado a aquél. Otras veces, en cambio, parece que considera ambos conceptos de verdad como cooriginarios. E incluso se encuentran enunciados de Gadamer que parecen sugerir que el concepto objetivista de verdad es, como tal, un concepto confuso que hay que evitar en absoluto (como en la conocida afirmación, ya citada, de que "hay que destruir el fantasma de una verdad disuelta de la situación del sujeto”). Sin embargo, estas

\footnotetext{
${ }^{11}$ Cfr. Tugendhat, Ernst. Der Wahrheitsbegriff bei Husserl und Heidegger. Berlin: de Gruyter, 1967, pp. 3-4.
} 
sugerencias no son predominantes de modo que parece que habría que atribuirle la idea de que la verdad en áreas diferentes tiene rasgos diferentes. Existe la verdad hermenéutica y la verdad objetivista.

Ahora bien, admitir tal diferencia no soluciona el problema. Más bien, lo resalta más aún porque se plantea la pregunta de qué es lo que vincula ambos conceptos de verdad. Si los conceptos de verdad son tan profundamente diferentes, en rasgos tan fundamentales como objetividad o relatividad, estabilidad o inestabilidad, etc., entonces surge la pregunta de por qué ambos conceptos son, sin embargo, conceptos de verdad, y no conceptos de cosas muy diferentes. $\mathrm{Si}$, en las ciencias interpretativas, realmente falta el ideal de una verdad definitiva y objetiva, que sí existe en las ciencias naturales, ¿por qué habría que hablar, al fin y al cabo, de la verdad de una interpretación? ¿No sería suficiente hablar de interpretaciones que son mejores o peores, más interesantes o menos interesantes, más fructíferas o menos fructíferas? ¿Cuál es el motivo por el que es necesario hablar de la verdad de una interpretación aparte de estas categorías epistémicas y pragmáticas? ${ }^{12}$ Si Gadamer sostiene la tesis de que no se puede hablar de interpretaciones objetivamente verdaderas o falsas, entonces se plantea la pregunta de si se puede hablar, después de todo y sin embargo, de la verdad y de la falsedad de interpretaciones. Gadamer se decide a favor de una aplicación del concepto de verdad en cuanto a las interpretaciones, pero, al fin y al cabo, se deja en el aire cómo es compatible la aplicación del concepto de verdad si éste tiene características tan distintas en relación a su aplicación en las ciencias naturales.

Entonces, se combinan los problemas típicos de una concepción epistémica o pragmatista con el problema adicional de que Gadamer admita dos conceptos de verdad cuyas diferencias hacen cuestionables en qué sentido ambos pueden ser, a la vez, conceptos de verdad.

\section{VI}

La referencia de Gadamer a un concepto de verdad hermenéutica, entonces, conlleva problemas sistemáticos considerables. Pero posiblemente, para los objetivos filosóficos fundamentales de Gadamer, el concepto de verdad hermenéutica sea menos importante de lo que parece. Incluso tal vez se puede hacer la audaz propuesta de reformular la teoría de la interpretación gadameriana sin hacer uso de este concepto tan problemático.

De hecho, es ésta la propuesta que quiero hacer. De todas maneras, evita los problemas mencionados, pues el concepto de verdad hermenéutica ya no aparece. Éste sería un motivo negativo para considerar esa propuesta. Pero aparte

\footnotetext{
${ }^{12}$ Este es, por supuesto, un problema de cualquier concepción epistémica de la verdad (si no operan con algún tipo de idealizaciones de las condiciones epistémicas, tal como lo hacen las teorías de coherencia ideal (por ejemplo Rescher) o de consenso final (por ejemplo Peirce)).
} 
de este motivo negativo, también hay motivos positivos a favor de ella. La manera como Gadamer caracteriza la "verdad hermenéutica" justamente destaca criterios importantes que determinan si se acepta o no una interpretación. La aceptación de una interpretación depende, por cierto, de los "prejuicios" de un intérprete y también depende de sus intereses y necesidades. Es decir, lo que Gadamer desarrolla como la dependencia de la verdad respecto de la situación epistémica y pragmática de un intérprete se deja reformular como la dependencia de la aceptación de una interpretación respecto de la situación epistémica y pragmática de un intérprete. De cierta forma, no se pierde absolutamente nada de su filosofía de la interpretación aceptando tal reformulación. La dimensión de la "aplicación" que domina el interpretar y que se expresa en la determinación del interpretar por la situación epistémica y pragmática del intérprete puede formularse de la misma manera, con la única diferencia de que ya no se habla de la verdad de una interpretación sino de la aceptación de una interpretación.

Me atrevo a decir que tal formulación incluso captaría mejor el sentido de la teoría de la interpretación de Gadamer. Al fin y al cabo, trata del proceso interpretativo tal como se presenta, por ejemplo, a un lector de textos filosóficos o también a un participante en una simple conversación cotidiana, y trata de las condiciones bajo las cuales alguien acepta una determinada interpretación. ¿No sería, entonces, casi consecuente atribuir a Gadamer un uso desviado, y desviante, de la palabra "verdad", diciendo que Gadamer usa "verdad de una interpretación” en el sentido de "aceptación de una interpretación”?

\section{VII}

Una creencia es la creencia de que una determinada proposición es verdadera. Aceptar una creencia es aceptar que una determinada proposición, o bien la creencia misma ${ }^{13}$, es verdadera. Si se fundamenta una creencia, entonces se fundamenta la verdad de la proposición correspondiente, o bien de la creencia misma. Suponiendo que una interpretación es un conjunto de creencias, si se habla de la fundamentación de una interpretación, entonces se habla de la fundamentación de la verdad de una cierta cantidad de creencias. Ahora bien, un tema de Gadamer es justamente cómo se eligen y cómo se fundamentan las interpretaciones. Su tema, por tanto, también es cómo se fundamenta la verdad de las interpretaciones ${ }^{14}$. Esta pregunta de cómo se fundamenta la verdad de las interpretaciones se puede comprender a su vez como la pregunta

\footnotetext{
${ }^{13}$ La verdad de la proposición que expresa el contenido de una creencia corresponde a la verdad de la creencia misma. La verdad de la proposición "Santiago es grande" corresponde a la verdad de la creencia de que Santiago es una ciudad grande.

${ }^{14}$ Supongo aquí que tiene sentido, después de todo, hablar de la verdad y de la falsedad de interpretaciones. Esto no es evidente en absoluto (como argumento a continuación), pues, si se sostiene, tal como lo hace Gadamer, que no hay interpretaciones objetivamente verdaderas, y si se sostiene además, en contra de Gadamer, que no tiene sentido hablar de una verdad no objetiva, entonces no tiene sentido hablar de la verdad de interpretaciones. Parto en este párrafo de la idea de que tiene sentido hablar de la verdad de interpretaciones para no alejarme demasiado de las presuposiciones filosóficas de Gadamer.
} 
de cuáles son los criterios de verdad de las interpretaciones y, al fin y al cabo, de cómo se define la verdad de una interpretación. Aceptando esta línea de ecuaciones, se llega a la siguiente conclusión: analizando cómo se fundamentan las interpretaciones, se analiza a la vez cómo se define la verdad de las interpretaciones.

Me parece que éste es, a grandes rasgos, el camino más probable por el que se llega a una posición como la de Gadamer, según la cual se identifica la manera de cómo se fundamentan las interpretaciones con la manera de cómo se define la verdad de las interpretaciones. Y si no se habla de interpretaciones sino de creencias en general, entonces se trata del camino más probable por el que se llega a las teorías que quieren determinar la naturaleza de la verdad a través de la pregunta de cómo se averigua el valor veritativo de las creencias en general. Es un camino que consiste básicamente en una serie de ecuaciones de las cuales algunas son evidentes y otras por lo menos plausibles a primera vista. Sin embargo, no todas son aceptables. Obviamente no hay problema, por ejemplo, en equiparar la pregunta de cómo se fundamenta una creencia con la pregunta de cómo se fundamenta la verdad de la misma creencia. Pero sí resulta sumamente problemático equiparar esta pregunta con la pregunta de cuáles son los criterios de verdad y, más claramente aún, con la pregunta de cómo se define la verdad de una creencia. La pregunta de cómo se fundamenta una creencia simplemente no corresponde a la pregunta de cómo se define la verdad de una creencia. La primera pregunta tiene que ver con criterios epistémicos, y la segunda tendría que ver, por lo menos desde el punto de vista objetivista, con la relación entre una determinada creencia y aquello que acaece en el mundo ${ }^{15}$.

Gadamer justamente no diferencia entre estas preguntas, lo que lo lleva a identificar la verdad misma con un conjunto de criterios que determinan la aceptación de una interpretación.

Ahora bien, ¿pero no es posible que justamente en el caso de las interpretaciones esta diferencia entre los criterios de la aceptación de una interpretación y las condiciones bajo las cuales una interpretación es verdadera desaparece porque la verdad de una interpretación no se determina por lo que acaece en el mundo objetivo? Pues, si la diferencia realmente desaparece, entonces, más bien, resulta cuestionable si, después de todo, tiene sentido hablar de la verdad de las interpretaciones aparte de su fundamentación y aceptación. Quizás el uso de la palabra "verdad" simplemente se vuelva superfluo, ya que no expresa un concepto realmente propio.

\footnotetext{
${ }^{15}$ En un texto clásico, Russell enfatizó que hay que distinguir estrictamente entre estas dos preguntas (cfr. Russell, Bertrand "Truth and Falsehood". The Problems of Philosphy. Oxford: Oxford University Press, 1912). Otros autores (por ejemplo Rescher, cfr. Rescher, Nicholas. "Truth as Ideal Coherente". Review of Metaphysics. 38 (1985), pp. 795-806), en cambio, argumentaron que debe haber una relación estrecha entre los criterios de la aplicación de un concepto y su definición. Ahora bien, esta última argumentación parece equiparar el concepto de verdad a un concepto descriptivo "normal", lo que resulta dudoso por diferentes razones, de modo que esta respuesta tiene una base frágil.
} 
Entonces, siguiendo la teoría de Gadamer de que la idea de la objetividad no juega ningún papel en el ámbito de la interpretación, se ofrece la propuesta de entender su teoría como una teoría acerca de cómo se fundamentan las interpretaciones, en vez de una teoría acerca de la verdad. Pues, si la idea de la objetividad no juega un papel en cuanto a las interpretaciones, si, por lo tanto, el concepto de verdad mismo, tal como se entiende en otros ámbitos, no tiene un rol claramente definido en ellas, y si, de todas maneras, hay que distinguir la pregunta de cómo se define la verdad de una interpretación de la pregunta de cómo se fundamenta una interpretación, entonces sólo esta última pregunta realmente tiene sentido. Y, como mencioné arriba, la teoría de la interpretación de Gadamer se puede entender como una teoría acerca de los criterios y condiciones de la aceptación de interpretaciones. Por supuesto, las formulaciones de Gadamer indican claramente que él apunta al tema de la verdad. Pero ¿qué impide atribuir a Gadamer un uso desviado de la palabra "verdad" refiriéndose no al concepto de verdad sino al concepto de aceptación de una interpretación? Si tal suposición soluciona los problemas mencionados, y si, además, no se pierden las intenciones filosóficas esenciales de Gadamer, entonces habría que considerarla.

Lo que sí podría perderse es una parte del efecto terapéutico mencionado arriba. Pero si este efecto se alcanza gracias a un medio que resulta como no sostenible filosóficamente, si se alcanza a través de un uso de la palabra "verdad", con todo su particular brillo, en un ámbito en el que el papel de este concepto es más bien opaco, entonces, como filósofos, deberíamos rehusar la aplicación de este medio. 
IX. ESTÉTICA 


\title{
El Concepto de Continuo Subjetivo Hacia una Estética Fenomenológica y una Hermenéutica de la Imaginación
}

\author{
Francisco de Undurraga \\ Universidad de Chile
}

\begin{abstract}
Resumen
Propongo aquí estrategias posibles para la constitución de una hermenéutica de la imaginación. Me valgo, para esto, de formulaciones provenientes de las Ciencias Cognitivas, la Fenomenología y la Hermenéutica, e inspecciono las fronteras de un aparato crítico a través del cual el desarreglo de funciones preestablecidas en el uso del lenguaje hace posible la producción de sentido. La imaginación se muestra, en el presente texto, a la vez como objeto de la encuesta y núcleo fenomenológico que nos permite volver sobre la referencia y las relaciones del mundo, que se juegan en el lenguaje, el gusto y el estilo.
\end{abstract}

En su texto "Cuatro pautas para el Futuro de las Ciencias Cognitivas", Francisco Varela nos dice: "del mismo modo que la percepción es imaginaria, la imaginación se basa en la percepción [...] en otras palabras, fenomenológicamente, nuestros espíritus no presentan una división clara entre la memoria, por un lado, y la afección o la visión, por el otro". ${ }^{1}$ Cito aquí a Varela para comenzar una ponencia que no concierne tanto a las Ciencias Cognitivas, en las que el autor trabajó, como a la Fenomenología y a la Hermenéutica, si bien uno de los objetivos de mi exposición en el día de hoy es precisamente resaltar los múltiples aspectos comunes, en lo que atañe a la investigación de estas tres disciplinas. Memoria, voluntad, afecciones e imaginación no son más que denominaciones/disecciones más o menos arbitrarias que afectan a una misma productividad. Este es mi punto de partida.

Retrocediendo un poco en el tiempo, y re-visitando los planteamientos de Aristóteles en el De Anima, constatamos que no habría algo así como una petición o un mandato presentado por el intelecto a la memoria, sino más bien una producción de éste (el intelecto) a través de imágenes que se manifiestan en la subjetividad en la forma de una lucha por la predominancia. En lo que concierne a la expresión "lucha por la predominancia", hago aquí la transposición con la idea de las Ciencias Cognitivas según la cual "un conjunto

\footnotetext{
${ }^{1}$ Francisco Varela. "Cuatro Pautas para el Futuro de las Ciencias Cognitivas". El Fenómeno de la vida. Santiago: Dolmen ediciones, 2000, p. 247.
} 
neuronal se hace finalmente más predominante y se transforma en el modo de conducta del siguiente momento cognitivo" 2 . Concebir en estos términos los intercambios entre memoria e intelecto constituye una forma de comprender el alcance contemporáneo de las doctrinas de Aristóteles y también las de Tomás de Aquino. Se trata, entonces, en un primer momento, de volver a la idea acuñada en el de De Anima (431a 14-18), según la cual el alma no piensa nunca sin el concurso de la imagen.

Consideremos una segunda fuente para abordar el texto de Aristóteles y el de Tomás de Aquino. No se trata ya de los aportes de las Ciencias Cognitivas a la elaboración de una teoría del continuo imaginario, sino del libro Machina Memorialis (2003), de la inglesa Mary Carruthers. Esta investigación se refiere a las prácticas de lo que la autora llama el "arte de la memoria" en los monasterios medievales. Su texto nos permite elaborar una aproximación a la distinción aristotélica del intelecto agente y del intelecto posible - la cual será retomada, como sabemos, por Tomás de Aquino - a partir de las prácticas de la memoria en los monasterios medievales.

La memoria, lo diré en otros términos, no constituye una facultad delimitada, nunca completamente delimitable en la oligarquía de su constitución imaginaria, sino más bien el proceso mismo de síntesis intra-subjetivas (utilizo este término para precisar que me referiré aquí a los intercambios al interior de la subjetividad, y no entre subjetividades distintas, o lo inter-subjetivo; no obstante el hecho que la elucidación de lo primero implica ciertamente a la vez una indagación en lo que concierne a las reciprocidades de una y otra esfera). La manifestación del continuo imaginario se presenta primero como una respuesta a su propia espontaneidad de acción, y luego por requerimientos específicos de la subjetividad, respecto a la cual el intelecto no constituye más que una de sus formas - tal vez la más secundaria y languidecida. Como la muerte o la justicia (pienso aquí en Kafka, en Patocka, en Blanchot y en Derrida), la imagen es lo que está siempre latente y adviene de manera no deliberada. Su relación con las afecciones es descrita por Patrick Vauday en términos de "la génesis subjetiva [...] que conduce tan decididamente a la producción material de las imágenes"3. La intuición, por su parte, se manifiesta en la forma de un dato descentrado, a partir de esa zona autónoma y auto-constituyente de la imaginación.

La función principal de la intuición, nos dice Bergson en El pensamiento y lo moviente (1938), es "la visión directa del espíritu por el espíritu”‘ La referencia de la subjetividad a sí misma, podemos agregar, es al mismo tiempo agente detonador y objeto de la apercepción. Precisemos un poco. Las consideraciones: 1- del estado de cosas del mundo; 2- del funcionamiento de los distintos momentos e

\footnotetext{
${ }^{2}$ Francisco Varela. "El Reencantamiento de lo concreto". Op. cit., p. 232.

${ }^{3}$ Patrick Vauday. La matière des images. Paris: L'Harmattan, 2001, p. 20.

${ }^{4}$ Bergson, Henri. La pensée et le mouvant. Paris: Presses Universitaires de France, 1998, p. 42.
} 
intercambios intra-subjetivos; y 3- de la información espontánea, voz o imagen, que surge a partir de la subjetividad pre-racional, son, al mismo tiempo, agente detonador y objeto de la apercepción. En el caso de la información espontánea, en particular, ésta nos habla de la existencia de un dominio anterior a la lógica, así como de la relación con el mundo que se genera en los orígenes del lenguaje, antes de la utilización que hacemos de éste y, al mismo tiempo - volveré sobre esto - en el proceso mismo de esta utilización (está el ejemplo, en este sentido, del reconocimiento por parte de los escépticos antiguos de este doble carácter del lenguaje y, por lo mismo, el uso crítico que los escépticos hacen de él).

Volviendo con Aquino, éste retoma la idea de Aristóteles, según la cual la imagen ejerce una acción permanente en el intelecto, y la explicita en los términos que siguen: "la experiencia nos muestra que incluso la gente que ya tiene conocimiento, habiendo adquirido las ideas de esta manera, no puede pensar en lo que conoce en ausencia de imágenes"5. La imagen se encuentra, de esta forma, todo el tiempo en interacción con el intelecto, tanto en el momento de la gestación de las ideas, como en el de la utilización de ellas en el ejercicio del pensamiento. La imagen constituye la posibilidad misma de la operación del pensamiento. Esto se hace evidente una vez que ya no contamos con la presencia del objeto frente a nosotros.

Sobre la base de lo planteado, y con el fin de reconocer en el pensamiento todas las dimensiones de lo que Deleuze llama la "modulación” de lo real comprendida en la identidad de la imagen y del objeto ${ }^{6}$ (idea de origen ciertamente Bergsoniano), podemos concebir la imaginación en la forma de un río. Los conceptos son, en esta analogía, las hojas transportadas en la superficie del agua, y la corriente en su conjunto constituye el pensamiento. Las imágenes, o lo que propongo llamar "percepciones-memorias", figuran aquí como las hojas que no se muestran totalmente en la superficie, sino que quedan más bien sumergidas en el flujo.

Lo que el concepto de "emergencia" desarrollado por Varela nos hace ver en este sentido es que, en los términos de la analogía que propongo, las hojas de la superficie y las hojas sumergidas desarrollan relaciones que, lejos de responder a una contigüidad, constituyen "redes distribuidas que generan un estado global para el medio" (los términos son de Varela) - lo que Marvin Minsky, con su analogía de la mente en tanto que sociedad de agentes, entiende por "conjunto heterogéneo de procesos no unificados" (La sociedad de la mente, 1986), y Wolf Singer llama "extensas asambleas de neuronas distribuidas cuya identidad de relación es una sincronía generada internamente por las descargas”"

\footnotetext{
5 Aquino, Tomás de. "Quaestio Disputata de Anima, 13" "Sententia Libri de Sensu et [De Memoria]". Textos Filosóficos de Tomás de Aquino. Trad. y notas de Giannina Burlando. Inédito. 449b 30-450a 25.

${ }^{6}$ Deleuze nos dice: "La imagen-movimiento es la modulación del objeto mismo [...] puesto que la modulación es la operación de lo Real, en tanto que constituye y no cesa de reconstituir la identidad de la imagen y del objeto.” Deleuze, Gilles. Cinéma 2 - L'Image-Temps. Paris: Les Editions de Minuit, 1985, pp. 41-42.

${ }^{7}$ Singer, Wolf. "Phenomenal Awareness and Consciousness from a Neurobiological Perspectiva". http:// www.mpih-frankfurt.mpg.de/global/Np/index.htm (Max-Planck-Institut für Hirnforschung), 05/01/2006.
} 
Si consideramos el arte de la memoria en los monasterios de la Edad Media -cuestión prolijamente documentada por Mary Carruthers en su libro-, podemos oponer la siguiente proposición a las nociones de Aquino sobre la imaginación y la memoria: no es el intelecto (agente) el que extrae de una suerte de depósito (la memoria o intelecto posible) aquello que es necesario para una finalidad determinada, sino que las imágenes se presentan de manera involuntaria -en la forma de un continuo que propongo llamar "voluntad primera"-, produciendo ese momento subjetivo que denominamos memoria. Lo anterior, se encuentra sin duda presente en el binomio de Aristóteles -retomado por Aquino- del "intelecto agente" y del "intelecto posible", el cual propongo abrir aquí a nuevas formulaciones, a partir de la consideración de los intercambios intra-subjetivos en la forma de un continuo.

La unidad y el orden del intelecto, según nos muestra Carruthers, no resultan, de acuerdo a las prácticas meditativas medievales -digamos, en consideración de una parte tan importante como descuidada del pensamiento medieval- de una separación de la percepción, así como lo piensa en la misma época Aquino. La unidad y el orden del intelecto responden, más bien, a una distribución a la vez ordenada y fundamentalmente asimiladora de todos los datos, tanto sensoriales como intelectuales. La división del intelecto y de la percepción, si es posible hablar en tales términos -digo esto último, tras ejercitarnos en la actividad que propongo aquí, que consiste en oponer lo planteado explícitamente por Aquino, a la cosmovisión materialista también presente en sus textos- tal separación, de ser efectiva, constituiría una ruptura extremadamente inoperante para la unidad del intelecto. Cabe hacer notar que el carácter operativo de la subjetividad es lo que concentra el interés tanto de Aquino como de Aristóteles, en los textos mencionados.

El concepto de "memoria", nos dice Carruthers, es mucho más amplio que lo que designamos con este vocablo hoy en día, "[...] éste reconoce el rol esencial que juegan la emoción, la imaginación y la meditación en la actividad de la memoria" ${ }^{8}$. Es así que, en el corazón de las prácticas meditativas medievales, no había una verdadera distinción entre la sensibilidad y la actividad del intelecto, sino que, por el contrario, las operaciones del intelecto se valían -como siempre lo han hecho- del concurso de las imágenes. Esto, a la manera, podemos decir, en que posteriormente la crítica kantiana brindará claridad y precisión a la razón y la pondrá a prueba de sus propios límites, no sin la intervención de la experiencia y del juicio, los cuales determinan tanto la aplicación como la aplicabilidad de los conceptos puros de la razón.

Del mismo modo en que no es necesariamente el intelecto el que actúa sobre los datos de la percepción, sino que estos datos organizan un producto determinado de dicha facultad, la unidad del intelecto no se funda en su carácter aislado en relación a la diversidad contenida en la percepción, sino que surge

\footnotetext{
${ }^{8}$ Carruthers, Mary. Machina memorialis, Méditation, rhétorique et fabrication des images au Moyen Age. Trad. de l'Anglais par Fabienne Durand-Bogaert. Paris: Editions Gallimard, 2002, p. 10.
} 
a partir de un proceso de lucha por la predominancia llevada a cabo por los agentes imaginarios. La unidad, por consiguiente, no es una entelequia que trasciende el dominio de la percepción, sino más bien un criterio que toca a la percepción considerada en actividad. En este sentido, no hay separación entre el intelecto y la percepción. La imaginación se sitúa permanentemente en la agencia recíproca de ambos. Ésta opera las particiones y las diferencias del encuentro. En la medida de este encuentro, la imaginación hace posible cada vez la manifestación del estado de cosas del mundo, ese mundo respecto al cual elaboramos permanentemente nuestras ideas. Éstas, según podemos constatar en todo momento, no están faltas de un gran componente imaginario, afectivo y sensitivo.

Volvamos al concepto de voluntad que propuse antes. Si podemos hablar de un momento de la voluntad en el conocimiento, es preciso hacer la distinción entre al menos dos maneras en las cuales concebir dicha operación. La primera, según mencioné, se relaciona con el continuo imaginario, el cual alcanza la hegemonía en el medio subjetivo, en la forma de una lucha por la predominancia. La segunda (o voluntad segunda), concierne un vínculo posterior a la gestación propiamente imaginaria, una relación que genera, sobre la base de sus propias disposiciones idiosincrásicas, los modos del imaginar. Esta segunda forma de la volición interfiere a menudo con la transparencia del juego imaginario, pero establece, por otra parte, un límite, produce el movimiento de coacción que fuerza al continuo imaginario a revocar elementos degradados en el curso de las variaciones. Este mecanismo tiene lugar en la forma de una depuración.

En lo que concierne la memoria, la unidad de apercepción desarrolla su síntesis sobre el conjunto de imágenes aportadas por los objetos percibidos, y no solamente sobre el objeto o imagen actual. Es así como el desfase y el juego de analogías se hace posible al interior de la subjetividad, instaurando para la referencia una intemporalidad relativa al acontecimiento. Los intercambios intra-subjetivos que sostienen el juego analógico generan un objeto propiamente "subjetivado", atemporal y libre de las limitaciones del presente, gracias a su inserción en las variaciones que lo enriquecen y que lo contrastan con los otros aspectos apercibidos. A través de este proceso, el objeto integra el mecanismo de depuración del cual hablaba. Más allá de relaciones puramente imaginarias, esta depuración constituye la operación misma del lenguaje y de la gestación de sentido. De esto hablaba hace un rato, al referirme al lenguaje no simplemente como momento posterior a nuestra relación con el mundo, sino como proceso en cuya utilización se juega el devenir del mundo (está sin duda el tema escéptico de la superación del lenguaje como estrategia para ver revitalizada la experiencia del mundo, pero esta problemática nos aparta del tema que nos convoca ahora). 
Si debemos designar una facultad -tal como lo hacemos arbitrariamente con las otras dimensiones subjetivas que llamamos intelecto, voluntad, percepción, memoria, etc.- que es la más apta para desarrollar el sentido, sin limitarlo en su clausura, ésta es la imaginación. No porque la imaginación produzca un mundo de ilusiones que nos distraen del "verdadero" mundo, sino porque ésta nos inserta en el proceso mismo de producción de ilusiones que nos presentan cada vez el mundo. La imaginación es, en este sentido, la facultad fenomenológica por excelencia, el órgano que me muestra a mí mismo observando mientras observo, sintiendo mientras siento, pensando, amando, gozando (para tomar el caso de los placeres en Sade) ${ }^{9}$ mientras me hago materia en tales reciprocidades. La imaginación es, en fin de cuentas, el instrumento del deseo y de la referencia a sí de la subjetividad, que hacen posible el acontecer del mundo y sus relaciones (entiendo aquí el deseo en el sentido de la Begierde hegeliana, más que en el del Wunsch freudiano) ${ }^{10}$.

Es a partir de la situación del sujeto en el mundo que éste puede operar el retorno a su propio ilogismo fundador $-\mathrm{y}$, no obstante, co-extensivo al logos. Tanto la posibilidad del conocimiento, como las limitaciones en la comunicación entre el objeto y el sujeto, no se encuentran fuera del sujeto, sino al interior de éste. Esta problemática es tal vez uno de los principales leitmotiv de la Fenomenología. Resulta oportuno destacar que esto había sido concebido en ciertos aspectos por los antiguos, con la utilización que hacen del logos. Es lo que nos propone Heráclito, por ejemplo, con su idea de la identidad de estructura entre el mundo interno, personal de la psyché, y el orden del universo, del logos en el cual se articula toda consideración, el logos que es, según la expresión de Diels, a la vez el discurso del propio Heráclito, la naturaleza del lenguaje, la estructura de la psyché y el principio universal de las $\operatorname{cosas}^{11}$. Gadamer, según sabemos, se sumará a esta tradición, con su idea del "pensar dentro del lenguaje", de la inserción del pensamiento en el lenguaje, el cual no es nunca meramente instrumental ${ }^{12}$.

Si hay una continuidad entre el lenguaje y el mundo, hay también un distanciamiento. Esto también caracteriza al logos. Es esa continuidad, y sobre todo el distanciamiento, los que propongo que consideremos en términos de una Estética Fenomenológica.

\footnotetext{
${ }^{9}$ Dolmancé nos dice en La Filosofía en el tocador: "La imaginación es el aguijón de los placeres; [...] ella arregla todo, es el móvil de todo; ¿no es acaso por ella que gozamos? ¿No es acaso de ella que vienen las voluptuosidades más agudas?" Sade. La Philosophie dans le boudoir. Paris: Editions Gallimard, 1976, p. 101.

${ }^{10}$ Elisabeth Roudinesco nos recuerda que "la Begierde es el deseo por el cual se expresa la relación a sí de la conciencia: se trata de reconocer al otro o la alteridad en tanto que la conciencia se reencuentra con ella misma". Lacan, nos dice Roudinesco, se inspira en las páginas manuscritas de Kojève, quien propone el paso de una filosofía del "yo pienso" (Descartes) a una filosofía del "yo deseo" (Begierde). Roudinesco, Elizabeth. « Le stade du miroir, concept et archive ». Lacan. Paris : Bayard, 2005, p. 47.

${ }^{11}$ Sigo en esto a Diels, citado en Kahn, Charles H. The art and thought of Heraclitus. Cambridge: Cambridge University Press, 1989, pp. 21-22.
} 
A continuación, me referiré brevemente al desfase del sujeto y el mundo, es decir, al desfase del sujeto consigo mismo, según al menos tres formas, que son variaciones de una misma problemática que afecta a la subjetividad en su conjunto:

1. La incapacidad del individuo de producir en él un intercambio permanente de los distintos momentos del continuo subjetivo, intercambio que hace de la empatía con su entorno una tensión perfecta, un desarreglo acabado entre las diversas capas de la interioridad y el mundo (reemplazo, por consiguiente, la noción de "equilibrio" baudelairiano en El vino y el Hachis, por la de desarreglo). La consecución de tal estado supone la supresión del lenguaje, o bien el abandono a los mecanismos analógicos de éste. La analogía abre el lenguaje a la serie de variaciones y la identidad es abiertamente asimilada en tanto que digresión indefinida. Esta actitud - la cual se hace posible a través de la poesía y de las prácticas artísticas - consiste en el abandono por parte de facultades activas como la voluntad (segunda), a la materia interior. Este gesto ya no concierne a las dificultades de un organismo que lucha por la predominancia, sino más bien el perfeccionamiento del tono y el estilo.

2. Sólo algunos de los aspectos del objeto se muestran a la subjetividad. La comunicación se desarrolla en la forma de latencia, hasta reencontrarse una vez más con el objeto, o su imagen, y acrecentar de este modo la imagen real - que es una forma material y subjetiva de éste. Este mecanismo llama a una concordancia (o correspondencia) cada vez más grande con la cosa. Sin embargo, ésta no cesará nunca de mostrarse de nuevas maneras. En la compenetración total del sujeto y el objeto queda siempre algo por venir, y podemos darle el nombre de ilusión, en el más puro sentido kantiano del término. El sujeto y el objeto son dos materialidades disímiles e irreductibles el uno al otro. Esta segunda variación del tema del desfase del sujeto y del mundo, dice menos relación con el hecho que los objetos tendrían una riqueza infinita y exterior al sujeto, que con la diferencia entre actividad y pasividad intra-subjetivas, cuyos intercambios producen esos objetos.

3. Existe una distancia entre el continuo subjetivo consciente -el cual hacemos actual, configurando el tiempo de la imagen- y el continuo que conserva los objetos en su materialidad imaginaria, y tanto más inexpresable, por cuanto escapa en uno o muchos puntos a la imposición volitiva (en segundo grado) que los lleva a manifestarse. En términos de una estética fenomenológica, esta distancia concierne a la relación problemática entre el lenguaje de las transacciones y el lenguaje puramente poético -límite que la poesía del siglo XX se encargó de explorar y de transgredir, elaborando de este modo sus nuevas poéticas (Pound con el verso libre y la traducción; Cardenal y Ginsberg con el activismo; Maquieira y el artificio, etc.). Hay sin duda grados en la relación del lenguaje de las transacciones y el lenguaje puramente poético, que van del purismo simbolista de Mallarmé al ilogismo contingente de Allen Ginsberg. 
$\mathrm{Al}$ alejarse de su disposición instrumental, el lenguaje alcanza la acción en un primer grado: aquel que concierne las particiones estéticas del mundo. El problema es que la historia instrumental del lenguaje, las prácticas no comunes y los usos a-críticos de éste imponen su peso sobre la totalidad del lenguaje, impregnándolo de motivaciones finalistas, o bien de la vieja trama de la interioridad -contenida también en la imagen, según la denuncia de Foucault ${ }^{13}$. En tanto que el lenguaje se aleja de su propia desocupación, éste se distancia al mismo tiempo de la más activa de las finalidades: no simplemente dar cuenta de ella, sino que ejercitarse en el arte de las agencias de la sensibilidad.

No es de ninguna manera imposible para el lenguaje romper con el automatismo operacional que le es transmitido - en cada ámbito de su utilización- a través de su historia, de sus prácticas no comunes y de sus usos a-críticos. Se trata aquí de trazar bien las coordenadas de su propio abandono, el cual figura en la base de su relación y de su no relación con el mundo. Para convertirse en agente de lo sensible, el lenguaje debe hacerse objeto y sujeto de una confrontación asidua con las instancias materiales y afectivas que lo constituyen -en otras palabras, con la experiencia de la gestación del sentido- del mismo modo que debe templar su proceder en el dominio de la imposición analítica (el genio y el regreso a la infancia, en Baudelaire). La analítica acerca el lenguaje a la materia respecto de la cual éste es un antiguo testigo. Frente a la continuidad generalizada de las apariencias que toman la forma de imágenes y a la ubicuidad de lo virtual en el mundo de hoy, el pensamiento ha debido encarar la imagen y hacerse cargo de su propia circulación afectiva. Tal actitud altera todo ciclo de recurrencia del lenguaje en un mismo trabajo de sensibilidad y de estilo. Es así como en el centro de la articulación afectiva de la subjetividad que restablece sus vínculos con el mundo, el gusto o sentimiento estético constituye la arquitectura desarreglada del acontecimiento.

Antes de tomar la forma del lenguaje, si acaso la toma, la intuición se manifiesta en inclinaciones afectivas que son goce de su propio estado. Estas inclinaciones nos comunican disposiciones posibles, arreglos deseables. Es hacia tales arreglos que se dirige la encuesta lacaniana de la conexión entre significantes (no de la conexión entre significantes y significados) ${ }^{14}$. Michel Henry nos señala en esta dirección: "[...] la afectividad es el fundamento universal de todos los fenómenos [...] La afectividad de los fenómenos reside en la auto-afección de la trascendencia que despliega el horizonte" ${ }^{15}$. Ya sea en los términos de la "paradoja de la inmanencia y de la trascendencia", que caracteriza la percepción según Merleau-Ponty ${ }^{16}$, en la formulación bergsoniana de la "visión directa del espíritu por el espíritu", en el "goce" lacaniano que se fija en el sín-

\footnotetext{
${ }^{12}$ Gadamer, Hans-Georg. "Hombre y lenguaje”. Verdad y Método II. Salamanca: Ediciones Sígueme, 1994, p. 147.

${ }_{13}^{13}$ Foucault, Michel. La pensée du dehors. Paris: Fata morgana, 1986, p. 21.

${ }^{14}$ Soler, Colette. "Les paradoxes du symptôme en psychanalyse. Lacan sans paradoxes." Lacan. Paris: Bayard, 2005, pp. 111-128.

${ }^{15}$ Henry, Michel. L'Essence de la Manifestation, v.II. Paris: Presses Universitaires de France, 1963, p. 608.

${ }^{16}$ Merleau-Ponty, Maurice. Le primat de la perception et ses conséquences philosophiques. Paris: Editions Verdier, 1996, p. 50.
} 
toma, pero que constituye primero el reencuentro del deseo del sujeto con su propio desear, o bien en "la auto-afección de la trascendencia que despliega el horizonte" de Michel Henry, la referencia a sí misma de la subjetividad como condición del acontecer del mundo y de la producción de sentido puede ser pensada en términos de un retorno permanente a los intercambios intra-subjetivos e imaginarios, como acto necesario para el pensamiento.

Es sobre el plano de las imágenes (o voluntad primera) que la habilidad del lenguaje se desarrolla, en la forma del largo y paciente ejercicio para alcanzar el estilo. La sensación interna, que surge de la confluencia y de la confrontación de las imágenes entre sí, es infinitamente más rica y más pobre que lo que el lenguaje alcanza a manifestar - tan rica y tan pobre como nuestra producción de mundo lo es. La sensación interna es más pobre, en el sentido que los conceptos del lenguaje nos presentan un mundo ya constituido de objetos, y más rica, en el sentido que los aspectos desconocidos del mundo acceden primero al continuo imaginario (ya sea a través del lenguaje, o no) y no son necesariamente retransmitidos al lenguaje -lo son rara vez, en una búsqueda estética del pensamiento que combate formas degradadas, poco críticas en el uso de éste. Es importante constatar aquí este aspecto intransitivo del lenguaje que ilumina el imaginario con las complejidades del mundo, pero cuyo uso para producir el mundo requiere de un esfuerzo que supone, entre otras cosas, la superación de lo utilitario -o su sublimación- así como la búsqueda consciente del imaginario. 


\title{
Para una Poética de la Invención entre Paul Ricoeur y Claude Romano
}

\author{
Patricio Mena Malet \\ Universidad Alberto Hurtado
}

\begin{abstract}
Resumen
El presente texto se sitúa entre la fenomenología hermenéutica del sí mismo de Paul Ricoeur y la fenomenología acontecial de Claude Romano. A partir de esta doble lectura, se busca esbozar una poética de la invención, de la experiencia como acontecimiento que aporta novedad al sí mismo o al adveniente, según la conceptualidad de Romano; esto a partir de un diálogo crítico con la fenomenología trascendental que, sin embargo, aporta los primeros antecedentes para una filosofía que busca inspeccionar lo posible.
\end{abstract}

Si hay un tema que convoca a las generaciones posteriores a Husserl y a Heidegger, y que ha tomado fuerza a partir de los estudios, por ejemplo, de Henry Maldiney, es la emergencia de lo nuevo, de la novedad, de lo imprevisible, en definitiva, del acontecimiento. Lásló Tengelyi en su libro L'éxpérience retrouvée. Essais philosophiques I, que también aborda esta temática tomando como hilo conductor la experiencia en cuanto Erfahrung antes que Erlebins, cita a Husserl, como testimonio de la antigüedad de esta cuestión en los márgenes del método fenomenológico. Un acontecimiento, dice Tengelyi para introducir la cita de Husserl, "puede 'emerger' sin anunciarse de antemano, es decir, sin

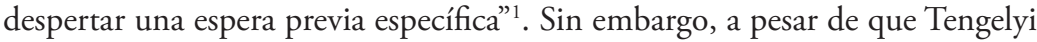
reconozca en el padre de la fenomenología el primer antecendente de la cuestión abierta del acontecimiento, de la imprevisibilidad, de la novedad o de la invención, filósofos como Claude Romano creen ver en la fenomenología trascendental una imposibilidad para describir el aparecer mismo del acontecimiento, en cuanto la conciencia del ego trascendental no puede constituir el fenómeno del acontecimiento si este, en verdad, es un evenire y advenire, en los sentidos más radicales posibles. La cuestión no es, entonces, la pregunta por el acontecimiento a secas, sino por su advenimiento, y por el modo en que su arribo altera al sujeto de tal modo que este ya no puede ser pensado como una sustancia, un hypokeimenon, un sustrato que cambia y, por lo mismo, se mantiene el mismo ante las transformaciones y mutaciones accidentales. Aquello que está en cuestión en la filosofía de Claude Romano es, por tanto, el adveniente o sujeto capaz de acontecimiento. Es preciso guardarse, sin embargo, de los múltiples malentendidos a los que podría conducirnos este modo de definir al sujeto que se enfrenta, no accidentalmente sino originariamente, a

\footnotetext{
${ }^{1}$ Husserl, Edmund. Die Bernauer Manuskripte über das Zeitbewusstsein 1917-1918. Husserliana, tomo XXXIII, bajo la dirección de R. Bernet y D. Lohmar, Dordrecht / Boston / London: Kluwer, 2001, p. 282, in Tingelyi, Lázló. L'éxpérience retrouvée. Essais philosophiques 1. Paris: L'Harmattan, 2006, p. 19.
} 
los acontecimientos. La capacidad no puede ser homologada, en este contexto, con una facultad que el sujeto despliega ante las cosas que le suceden: su sentido, que será interrogado acá, tiene relación, más bien, con la pasibilidad, esto es, con el aprender mediante la experiencia que trastoca y disloca el sentido completo de la existencia del sujeto orientado en el mundo. Precisamente, con el fin de reconocer algunos de los sentidos posibles del ser capaz de acontecimientos y, por tanto, de novedad, de advenir, de invención, es que la filosofía del "hombre capaz" de Paul Ricoeur parece un buen contrapunto a la fenomenología acontecial de Romano. Esto, en cuanto el mismo autor de Temps et récit puede ser catalogado como un pensador del acontecimiento. En efecto, podemos leer al menos cinco "momentos" en que toma posición al respecto: 1) en los desarrollos de una poética de la voluntad, con respecto al acontecimiento de la falta; 2) en diálogo con las teologías de la palabra, es cuestión acá del acontecimiento de palabra; 3) en los márgenes de su teoría narrativa desde donde libera las cuestiones del acontecimiento y sentido, de la "síntesis de lo heterogéneo" y la "puesta en intriga", etc.; 4) en los desarrollos de Soi-même comme un autre, con relación a la pregunta ¿quién actúa?; 5) con relación a la condición histórica del sí mismo, por ej. en La mémoire, l'histoire, l'oubli.

Reconociendo los diferendos que se dan en el examen de ambas filosofías hermenéuticas, se esbozará un hilo común que, sin embargo, debe mantener las diversas hebras en su justa distancia. No se busca comparar lo incomparable, sino abocarnos propiamente a pensar en ayuda de ambos filósofos franceses, en los márgenes de la fenomeno-logía hermenéutica, que se esfuerza en "decir los fenómenos" (legein ta phainomena). Por otro lado, si hay un hilo común, en relación a la fenomenología, que los liga, es su desconfianza por la versión idealista y trascendental de la ciencia de los fenómenos; ambos deciden distanciarse del ego trascendental, situándose ante la historia de la filosofía, y del cogito particularmente, de un modo singular, para dar paso a una fenomenología del sujeto trastocado, al ser mutados sus horizontes de sentido.

Tramar este diálogo entre Romano y Ricoeur, implica partir de la preponderancia de lo que Bernard Stevens llama "el aprendizaje de los signos" o, en palabras de Michael Foessel, "la vehemencia fenomenológica" 2 al hilo de la legibilidad del mundo, cuyo exceso es la invención o innovación de sí mismo. Centrarnos en esta clave de lectura de la obra de Ricoeur permitirá medir los diferendos con Romano, que vuelven aún más provechoso cualquier intento de articulación, a nivel de problemas, entre ambos pensadores.

La estructura del artículo será la siguiente. Primero, se intentará esbozar una presentación de la obra de Romano, considerando: 1) la caracterización que da el autor respecto del acontecimiento y del adveniente. 2) La relación entre acontecimiento y mundo, sopesada a partir de la cuestión del nacimiento.

\footnotetext{
${ }^{2}$ Foessel, Michael. "La legibilidad del mundo. La vehemencia fenomenológica de Paul Ricoeur". Patricio Mena M. (compilador). Fenomenología por decir. Homenaje a Paul Ricoeur. Santiago: Ed. Universidad Alberto Hurtado, 2006, pp. 247-265.
} 
El segundo momento consistirá en presentar algunas de las tesis de Ricoeur respecto de la vehemencia fenomenológica de la hermenéutica, y esto para reflexionar sobre el hombre capaz en cuanto capaz de indagación de lo posible o invención de sí mismo. Este es el momento en que es posible testimoniar el erigirse de un ipse capaz - de acontecimiento, de invención de sí mismo - que no termina nunca de constituirse desde la implicación en el mundo y el acontecimiento. La capacidad que es el ser humano es la prueba de su inacabamiento, pero también de su apertura a los posibles, mediante la inspección que promueven las variaciones imaginativas (Ricoeur) ${ }^{3}$ o la pasibilidad (o transpasibilidad en lenguaje de Maldiney) en tanto apertura a los acontecimientos (Romano).

\section{Prefiguración del acontecimiento y el adveniente en la herme- néutica acontecial de Claude Romano}

Aquello que hila la reflexión de Claude Romano, desde sus dos primeros libros, L'événement et le monde (1998), L'événement et le temps (1999), pasando por Ily $a$ (2003), y por un intento de lectura de la obra de Faulkner en clave fenomenológica, como es Le chant de la vie (2005), es la cuestión del acontecimiento como fenómeno por excelencia que se da para ser descrito.

Son cuatro los rasgos que definen el carácter acontecial del acontecimiento a juicio de Romano: 1) el acontecimiento es siempre susceptible de una asignación determinada, sobreviene a mí mismo y me constituye como aquel que puede advenir a sí a partir de lo que le adviene; 2) el acontecimiento aclara su propio contexto sin quedar reducido tampoco a este mismo, con él adviene un nuevo mundo; 3) así entonces se absuelve de toda causalidad antecedente y se anuncia como su propio origen $\left.{ }^{4} ; 4\right)$ el acontecimiento, finalmente, no se inscribe en el tiempo, sino que lo abre y temporaliza.

Lo que pone en cuestión Romano es la mostrancia misma del fenómeno de la sobrevenida, del arribar, del acontecer, lo que podría tal vez abrir el diálogo con la tesis que formula Jean-Luc Marion ${ }^{5}$ y que dice que "todo lo que se muestra primero se da", siendo entonces la donación del acontecimiento lo que está en cuestión. Pero el problema, a juicio de Romano, es "remontar del aconteci-

\footnotetext{
${ }^{3}$ Tres intérpretes de la obra de Ricoeur han puesto suficientemente el acento en el rol que juegan las variaciones imaginativas: Skúlason, Páll. Le cercle du sujet dans la philosophie de Paul Ricoeur. Paris: L'Harmattan, 2001. Abel, Oliver. Paul Ricoeur. La promesse et la règle. Paris: Michalon, "Le bien commun", 1996 ; "L’indépassable dissensus", in Abel, Olivier / Castelli-Gattinara, Enrico / Loriga, Sabina / Ullern-Weité, Isabelle (dir.). La juste mémoire. Lectures autour de Paul Ricoeur. Paris: Labor et Fides, 2006. Foessel, Michael. "Introduction. Paul Ricoeur ou les pissances de l'imaginaire". In Ricoeur, Paul. Anthologie. Paris: Seuil, 2007; "La legibilidad del mundo. La vehemencia fenomenológica de Paul Ricoeur". Op. cit.

${ }^{4} \mathrm{Al}$ respecto, Marion, Jean-Luc. "L'événement ou le phénomèn advenant". De surcroît. Paris: PUF, "Perspectives critiques", 2001, p. 37: "adviniendo [el acontecimiento], atestigua un origen imprevisible, surgiendo de causas a menudo desconocidas, incluso ausentes, al menos no asignables, que no se podrían por ende reproducir más, porque su constitución no tendría ningún sentido".

${ }^{5}$ Marion, Jean-Luc. "L'événement ou le phénomèn advenant". Art. cit.
} 
miento que aparece al aparecer mismo del acontecimiento" ${ }^{6}$, de modo tal, de cuestionar "el sentido fenomenológico de su sobrevenida" movimiento mismo del aparecer, su acontecialidad, lo que primeramente se da como "objeto" primero de la fenomenología, esto es: el acontecimiento o, aún mejor, la acontecialidad del acontecimiento. Sin embargo, he aquí también que se revela el modo propio de la aproximación fenomenológica de Romano. No es posible a juicio del autor una apropiación inmediata, directa e intuitiva del acontecimiento, cuestión suficiente para constatar el carácter hermenéutico de toda fenomenología, que en la descripción del fenómeno a partir de sí mismo busca "comprender todo lo que hay que comprender". Es preciso agregar la continuación de esta cita:

[...] la hermenéutica aporta un complemento esencial, que equivale más bien a una inflexión de método: no hay jamás fenómenos que se ofrezcan tal cuales a una descripción, ninguna inmediatez de una donación de la que se podría esperar toda claridad: todo acceso a los fenómenos es irremediablemente mediato. Conviene, renunciar al mito de un 'puro dado', solidario del de (cartesiano y husserliano) una ausencia total de presuposiciones cuya descripción podría prevalecer. La transparencia de un contacto originario con la experiencia, cuyo ministerio podría ser atribuido a la intuición, es aquí batido en brecha por la necesidad de un rodeo y un recorrido histórico al término de los cuales, solamente, el 'fenómeno' podrá dejarse aprehender y 'ver's.

El acontecimiento es siempre lo "ya arribado", desde el exceso de sentido, adviniendo de modo inesperado. Así, a juicio de Francoise Dastur:

Es, de este modo, siempre una sor-presa, algo que se capta de manera inatendida, de improviso, y según el exceso de un por-venir que viene a nosotros contra toda espera, toda tensión e intención? 9

Siendo, entonces, que el acontecimiento adviene como lo siempre "ya arribado" o "antes de toda cosa”, no queda sino apostar por una descripción aprés coup, retrospectivamente descrito en su sobrevenir. Así entonces, sólo puede ser descrito exigiendo mediaciones y desvíos, siendo que su aparecer rechaza de plano toda intuición directa para captarlo. Delia Popa, en un artículo sobre la obra de Romano aparecido en 2004, resume esta idea del siguiente modo:

No hay apropiación inmediata, intuitiva del acontecimiento, pues se presenta como lo que escapa a nuestras aveniencias existenciales

\footnotetext{
${ }^{6}$ Romano, Claude. Il y a, Paris: PUF, 2003, p. 17. Por lo demás, este es el paso que Romano intenta dar desde L'événement et le monde a Il y a.

${ }^{7}$ Idem.

${ }^{8}$ Romano, Claude. L'événement et le monde. Paris: PUF, 1998, p. 3.

9 Dastur, Françoise. "Phénoménologie de l'événement". La phénoménologie en questions. Paris: Vrin, 2004, p. 165 .
} 
y a nuestras comprensiones frontales, viniendo de los bastidores de la existencia, lateral u oblicuamente y haciendo siempre su entrada en la vida de la conciencia cuando es demasiado tarde para una intuición directa ${ }^{10}$.

Este retardo - pero también sustracción, por ej. "de toda búsqueda de fundamento ontológico como de toda tentativa de búsqueda causal"11 - respecto de la mostrancia del acontecimiento, da cuenta del acceso mediato al fenómeno aquí descrito [el acontecimiento], pero además, de la no transparencia "de un contacto originario con la experiencia"12. De este modo, el acontecimiento es lo inconstituido e inconstituible por la subjetividad trascendental. El "ego" no tiene la medida del advenir pues su medida es el acontecimiento que sorprende al sujeto en la impreparación de su recepción. Dicha inanticipación implica al menos dos cosas distintas: 1) El verdadero fenómeno capaz de dar cuenta de la fenomenalidad del aparecer, en sentido husserliano, es el acontecimiento. No hay ego trascendental capaz de constituirlo, sino que él mismo adviene a sí en la acogida de las múltiples metamorfosis que trae consigo el événement ${ }^{13}$. 2) Este último es a su vez acogido y, por otra parte, no recibido. No es, entonces, posible no acoger el acontecimiento en cuanto no hay sí mismo si no es en relación a lo que le pasa, siendo lo que le pasa un suceso que lo muta y transforma al tiempo que metamorfosea sus posibles mundanos, sus posibles de sentido. Así, el ipse adviene a sí mismo desde, lo que podemos llamar, una perpetua natalidad a partir de la cual no deja de recibirse en el acontecer de sí, esforzándose por retomarse en el arribo de los acontecimientos, por dar respuesta y ser, de esta forma, un sí responsivo de su propio acaecer, incluso, si el acontecimiento es siempre aquello que arriba sin que él mismo haya anticipado dicho advenimiento ${ }^{14}$. De este modo, no es posible recibir totalmente lo inesperado y aquello que excede todo gesto de hospitalidad, en cuanto el acontecimiento quiebra acontecialmente toda expectativa posible. $\mathrm{Al}$ respecto, Françoise Dastur argumenta del siguiente modo:

Contra toda espera, incluso cuando ha sido en parte esperado y anticipado, tal es en efecto 'la esencia' del acontecimiento, del que se podría decir sin paradoja que es un 'posible imposible'. Lo imposible que arriba, de manera terrorífica o maravillosa, tal es el acontecimiento en su contradicción íntima, él que viene siempre a nosotros por sorpresa

\footnotetext{
${ }^{10}$ Popa, Delia. "Advenir à soi-même à partir de ce qui excède. Claude Romano et l'aventure du sens". Studia Phenomenologica IV, 1-2 (2004), p. 192.

${ }^{11}$ Khabbaz, Lyne. "Claude Romano, philosophe de l'événement”. Iris. Annales de philosophie. Université Saint-Joseph, Beyrout, Vol. 28, 2007, p. 41.

12 Romano, Claude. L'événement et le temps. Paris: PUF, 1999, p. 3.

${ }^{13}$ Como bien lo expresa Longneaux, Jean-Michel. "L'égoité comme véritable événement", Iris. Annales de philosophie, Université Saint-Joseph, Beyrouth, Vol. 28, 2007, p 144 et ss., este es un punto conflictivo cuya resolución se vuelve problemática con la entrada de la ipseidad distinguida, esta, de la egoidad.

${ }^{14}$ Respecto de la problemática de la acogida y hospitalidad del acontecimiento, cf. Mena, Patricio, "Paul Ricoeur y Claude Romano. Hospedar el mundo y el acontecimiento". Iris. Annales de philosophie. Université Saint-Joseph, Beyrouth, Vol. 28, 2007, pp. 91-109.
} 
y del lado de lo que no se esperaba justamente. Es por tanto este exceso (excès), este exceso (surcroît), esta desmesura del acontecimiento que una fenomenología debería proponerse pensar y a este respecto la fenomenología de la eventualidad se encuentra en una posición muy semejante a la de la fenomenología de la mortalidad ${ }^{15}$.

Siendo que el acontecimiento es lo ya-arribado, sin contexto que no sea el suyo propio que trae por sí en el advenir mismo, este es siempre para alguien. No hay acontecimiento, en sentido acontecial, sino en cuanto alguien es capaz de acontecimientos, y con ello, de advenir a sí a partir del arribo mismo. El adveniente debe ser definido como sujeto capaz de acontecimientos, pero también es preciso afirmar que si hay algo que caracteriza y define acontecialmente al sujeto es que, primeramente no sea capaz ${ }^{16}$. Que el sujeto sea y no sea capaz, es un modo de afirmar que, acogiendo el acontecimiento, no lo recibe sino en el hacer experiencia de él. Es capaz de verse afectado, trastocado por él, hasta el punto, incluso, de no poder volverse responsable de aquello que le sucede (trauma) "o" de no ser capaz de dicha abertura al acontecimiento, tal como pasa con el sujeto psicótico según Maldiney ${ }^{17}$. En resumen, hay, entonces, cierta pasibilidad, ni totalmente activa ni totalmente pasiva, pero siempre con vocación al pathein, que testimonia la receptiva pero sobrepasada capacidad del sujeto para volverse a los acontecimientos y reconocerlos, en su total alteridad, como propios o rechazarlos y sumirse en el trauma de no ser capaz de responder por lo que le ha acontecido:

Que este acontecimiento se dirija a mí y me sobrevenga, que me advenga, en dativo, y que, literalmente, yo esté 'sujeto' allí, no significa de ningún modo que sea capaz de mantenerme a mí mismo ante eso que, así, me adviene. El carácter destinado, dirigido del acontecimiento que le toca como a ningún otro, no implica de ningún modo que el adveniente pueda apropiarse en propiedad este acontecimiento, aproximándose a él en primera persona, comprendiéndolo en cuanto tal. Es porque conviene distinguir aquí entre 'la egoidad', del adveniente, su posición de 'sujeto' indefectible de lo que le sucede, indisociable del carácter dirigido del acontecimiento y de su ipseidad, que implica la posibilidad de relacionarse en propiedad y en primera persona con este acontecimiento, y que hace manifiestamente falta en el caso del nacimiento. Ciertamente es $a$ mí a quien eso arriba, pero yo no puedo precisamente reconocerme como tal (como 'yo mismo') en este acontecimiento, ni compren-

\footnotetext{
${ }^{15}$ Dastur, Françoise. "Phénoménologie de l'événement". Art. cit., p. 167.

${ }^{16}$ Cf. Romano, Claude. "Acontecimiento y mundo". Presentación del autor. Tr. esp. de Patricio Mena y Enoc Muñoz. Persona y Sociedad. Volumen XXI, n 1/ Abril (2007), p. 114.

${ }^{17}$ Maldiney, Henry. Penser l'homme et la folie. Grenoble: J. Millon, 1991, p. 114 - citado por Dastur, art. cit., p. 172 -: "Lo que hace falta [en la psicosis], es la receptividad, que no es del orden del proyecto, sino de la acogida, de la abertura, y que no admite ningún a priori, que esperando sin esperarse a lo que sea, se mantiene abierto más allá de toda anticipación posible. Es lo que llamo transpasibilidad...”.
} 
derme a mí en mi ipseidad a partir de la totalidad de los posibles que configura $^{18}$.

Claramente, el acontecimiento, sustrayéndose a toda constitución que no sea sino una reconsideración a posteriori, figura, refigura y desfigura los posibles de modo inatendido. Es, tal vez, la irrupción desfigurante del acontecimiento lo que hace del sí mismo siempre una promesa que no termina jamás de advenir. ¿No hay una insistencia del ipse por recobrarse en el arribar(se) que es él mismo cada vez? Y al mismo tiempo, ¿cuán difícil puede ser pensar al adveniente que es el sí mismo ${ }^{19}$, si la total implicación da siempre nuevos horizontes de sentidos que proyectar, esperar, etc.? Si el ipse nace cada vez, pareciera que también algo se mantiene ante cada metamorfosis que permite la insistencia en el mundo. Pues el adveniente que no es capaz de asegurarse su propia mismidad, sin embargo se promete como respondiente ante lo que le pasa, como si después de cada original y novedosa metamorfosis del mundo y de sí, algo permaneciese intacto: la responsividad y el testimonio de su propio advenir. ¿No es la ipseidad en cuanto responsividad lo que signa la exposición radical del sí mismo a los acontecimientos? Y en este sentido, ser un sujeto capaz de acontecimientos es dar cuenta de la abertura radical a estos, abertura que implica la posibilitación de la desfiguración de la propia desfiguración ${ }^{20}$. ¿Qué hay que entender, entonces, por figuración / desfiguración? Al respecto, Carla Canullo aporta algunas luces:

¿Por qué el acontecimiento "da que pensar"? Tal vez justamente por el modo en que des-figura lo ir-reductible. Yo no entiendo el verbo desfigurar (y el substantivo que se extrae de allí, desfiguramiento) en el sentido de "abismar, alterar el rostro de alguien", sino que propongo leerlo siguiendo el doble valor del prefijo "de-" que indica no sólo una privación (despojar, descentralizar) sino también un engrandecimiento (tal como de-nominar [y de-nominación] significan "dar el nombre", designar, denotar). Desfiguramiento significa, en el contexto que es el nuestro, dar un rostro; no alterar, suprimir, abismar un rostro, sino dar un nuevo rostro, una figura que, en lengua francesa; indica el rostro, la faz, la cabeza tomada en su forma ${ }^{21}$.

Sin embargo, es preciso destacar que esta exposición de la ipseidad, que es propia del adveniente, implica también la ex-per-iencia o la pasibilidad en cuanto abertura a los acontecimientos. O dicho de otra forma, el fenómeno

\footnotetext{
${ }^{18}$ Romano, Claude. L'événement et le monde. Op. cit., p. 102.

${ }^{19}$ Totalmente implicado en los acontecimientos, entonces acogido en el arribar de los múltiples sentidos resultantes de la trastocación de aquellos que parecían ser los más propios.

${ }^{20}$ Popa, Delia. Art. cit., p. 196: "Si esta dimensión de la ipseidad analizada por Romano comparte con el sujeto levinasiano su exposición absoluta, desprovista de toda precaución a priori y su incapacidad para ocultarse a lo que le concierne, se opone más firmemente a la figura del sujeto cartesiano y husserliano, pretendiendo plantearse como previo a las experiencias que lo cambian".

${ }^{21}$ Canullo, Carla. "Naissance et origine". Transversalités. Revue de l'Institut Catholique de Paris, n 96 (2005), p. 2.
} 
en retardo no puede de este modo ser colmado por el ego y sin embargo le es imposible no hacer la prueba de él, que en este caso significa hacer su experiencia. No se trata de un tener experiencia (Erfahrung haben), sino de un hacer, esto es, de un pasar a través de (durchmachen), de un soportar (annehmen), incluso de un acoger. Es lo que nos recuerda Romano con el verso 177 del Agamenon de Esquilo: tô pathei mathos: "el conocimiento por la prueba" o "sufrir para comprender"22. Lyne Khabbaz, comentando la obra de Romano, se refiere del siguiente modo respecto de la experiencia:

La experiencia solo es a la medida del acontecimiento en su carácter experimentable. Es, en efecto, lo que nos pone en juego, eso porque un trastocamiento de nuestros posibles deviene posible, a la luz de mi propio devenir. Pues yo devengo, en la ex-per-iencia: si el PER de la palabra, en su riqueza etimológica y por tanto también significante, remite a la idea genérica del peligro, del estar en peligro, el EX viene a apoyar el sentido por la referencia a la excentricidad de la que también era cuestión ${ }^{23}$.

El sujeto o el adveniente está entonces expuesto al acontecimiento que nunca se repite, que no es posible de colmar pero que se dona en la experiencia que el adveniente hace de él, en la trastocación de sí y de los posibles del mundo que le conciernen. En este sentido, ex-per-iencia no debe ser pensada bajo el modelo de la reiteración, repetición ni de la prise, la aprehensión de las cosas a partir de la habitude. Más bien, hace referencia al peligro, la travesía y la aventura misma que es la experiencia. Exposición del sí mismo a la alteridad que lo trastoca adviniendo a sí. No se trata, entonces, de tener experiencia sino de hacer experiencia, en cuyo hacer, contemporáneamente, se aclara e ilumina de modo comprensivo el advenir como lo "ya-arribado" y como excedente de sentido. Que el adveniente haga experiencia de lo que le sucede significa que padece la prueba de lo que le acontece de modo singular. El ipse se pone a riesgo en el acaecer y sufre la prueba de su arribada cada vez como testimonio del proto-acontecimiento que es el nacimiento, a partir del cual el ipse se comprende como expuesto al acaecer originariamente aunque no originalmente, en la medida, esto último, en que no es él mismo la fuente de su propio origen. Naciente, el adveniente se ha desposeído de sí mismo en pos de la capacidad de apertura inmemorial a los acontecimientos. El nacimiento también es la prueba del imposible recobramiento "feliz" del ipse herido por el arribar de los eventos, mas señala también la responsividad misma que es el adveniente,

\footnotetext{
${ }^{22}$ Falque, Emmanuel. "Phénoménologie de l'éxpérience". Transversalités, n 96 (2005), p. 24 : "Lo que Henry Maldiney llama la 'dimensión patética de la existencia' en tanto que 'adviene en persona' y refiriéndola muy directamente al pathei mathos o al 'aprendizaje por la prueba' de Esquilo (Agamenon), se vuelve a encontrar aquí en Claude Romano como el lugar fuente de una nueva hermenéutica cuya prueba consiste menos en comprender que en comprenderse, en conocer de modo teórico que en conocerse 'co-naciente' [en francés, co-naissant, juego entre co-nocimiento y co-nacimiento] en lo que no es yo - el acontecimiento mismo".

${ }^{23}$ Khabbaz, Lyne. "Claude Romano. Philosophe de l'événement”. Art. cit., p. 67.
} 
siendo este capaz de dar respuesta, de apropiarse en definitiva, lo que le pasa sin que él mismo sea el origen de su acaecer. En palabras de Marion:

Mi nacimiento no se califica como fenómeno (el de un origen no originario), porque se mostraría, sino porque, en la falta misma de toda mostración directa, adviene como acontecimiento nunca presente, siempre pasado, pero jamás superado por tanto - de hecho siempre por venir. Mi nacimiento se fenomenaliza, pero a modo de acontecimiento puro, imprevisible, irrepetible, excediendo toda causa y haciendo posible lo imposible (a saber mi vida siempre nueva), sobrepasando toda espera, toda promesa y toda predicción. Este fenómeno, que se realiza en una perfecta reducción de lo que se muestra, atestigua, por tanto, de un modo excepcional y paradigmático, que su fenomenalidad se deriva directamente de lo que se $\mathrm{da}^{24}$.

Hacer experiencia, entonces, es ser un ipse pasiblemente vuelto y dispuesto al toque de los sucesos, sufriendo su posibilitación. La ex-per-iencia signa la posibilitación de la posibilidad del adveniente en cuanto disponibilidad a la transfiguración de los sentidos posibles destacados en la abertura a los acontecimientos. La ex-per-iencia es ya la aventura de sentido en la que el sujeto no deja de implicarse y, por lo mismo, se da como abertura a la alteridad originaria del fenómeno por excelencia: el acontecimiento. Mas, si implica un peligro es porque la mostrancia del acontecimiento no deja indemne sino que obra la transformación del sujeto que lo acoge. Tocar, transformar en su aperturidad al adveniente es ya darse a sí. El acontecimiento, su propia acogida, no solo aportando su propio contexto, su propia desfiguración y la apertura de su tiempo propio, en la capacidad del sujeto para recibir(se) en lo que le pasa. La experiencia, por tanto, requiere de una relacionalidad nueva con los sentidos desplegados por el mundo, los otros, etc. La respuesta del adveniente en el hacer experiencia es la asunción de la innovante novedad del mundo, a partir de la cual nunca deja de recibirse en su capacidad de apertura y de advenimiento, manteniéndose en la tarea de comprenderse en la prueba de la alteridad más alteridad que cualquier otra, parafraseando claramente a Lévinas.

\section{Paul Ricoeur y el hombre capaz de invención}

Si Claude Romano ponía el acento en la renuncia a un ego trascendental en pos de un adveniente que no termina nunca de advenir en el hacer experiencia de los acontecimientos, Paul Ricoeur hace lo suyo enriqueciendo, también, el concepto de experiencia al alero de la fenomeno-logía, como indagación de lo posible, dejándose instruir, privilegiadamente, por las variaciones imaginativas en cuanto dan un acceso siempre nuevo a los fenómenos, manteniendo la indi-

\footnotetext{
${ }^{24}$ Marion, Jean-Luc. Art. cit., pp. 50-51.
} 
rección noemática en cuanto tal. Sólo en tanto el noema queda indeterminado en la descripción fenomenológica, se puede afirmar que esta ha sido lo más completa posible sin completar en nada al objeto descrito (Natalie Depraz). La invención aparece entonces como el gesto a partir del cual Ricoeur hace de la ciencia de los fenómenos una fenomenología poética, si acaso cabe la expresión. A juicio de Ricoeur,

[...] el discurso poético lleva al lenguaje los aspectos, cualidades, valores de la realidad, que no tienen acceso al lenguaje directamente descriptivo y que no pueden ser dichos sino en favor del juego complejo de la enunciación metafórica y de la transgresión regulada de las significaciones usuales de nuestras palabras ${ }^{25}$.

He aquí que se puede afirmar que la fenomenología ricoeuriana hace de la imaginación el modo privilegiado de acceso a las cosas mismas en cuanto permite desvelar en ellas sentidos posibles que enriquecen los múltiples modos de su aparecer. Pero también testimonia la necesaria dialéctica entre proximidad y distancia que Ricoeur ve en la descripción de los fenómenos dados. En este sentido, se puede afirmar que imaginar es aproximarse en la distancia a los sentidos posibles de las cosas mismas. La distancia que opera la imaginación permite una mejor proximidad con el fenómeno. Precisamente, porque "el noema es la posibilidad de la decibilidad de la vivencia" ${ }^{26}$, este abre al conflicto por el cual el sentido se deja destejer para volver a tomar forma en la descripción. Son las variaciones imaginativas que manifiestan

la esencia, rompiendo el prestigio del hecho; imaginando otro hecho, otro régimen, otro reino, percibo lo posible y en lo posible lo esencial ${ }^{27}$.

De este modo, su recurso refiere también a la productividad que aporta el poner entre paréntesis el mundo pre-objetivo, dejando de lado su contingencia en pos de los posibles del mundo imaginado a modo de "provocación para actuar y pensar de otro modo" 28 .

Ricoeur reactiva la potencia del logos de la fenomenología, rehabilitando el sentido y la distancia para la aproximación a los fenómenos mismos, y abriendo la vía descriptiva a la indeterminación noemática: la inspección de lo posible se vuelve, entonces, una tarea propia del fenomenólogo. Decir lo apareciente con una visión inédita, ese podría ser uno de los lemas de la intención ricoeuriana.

\footnotetext{
${ }^{25}$ Ricoeur, Paul. Du texte à l'action. Paris: Seuil, 1985, p. 24.

${ }^{26}$ Gissel, Pierre. "Paul Ricoeur". Études Théologiques et religieuses. 1974, p. 32.

${ }^{27}$ Ricoeur, Paul. Philosophie de la volonté 2, Finitude et culpabilité 1, L'homme faillible. Paris: Aubier, 1960, p. 128.

${ }^{28}$ Foëssel, Michael. "Introduction. Paul Ricoeur ou les pissances de l'imaginaire”. Art. cit., p. 21.
} 
Considerado esto, no queda sino un sujeto expuesto a su propia potencia variativa, abierto a las posibilidades que se abre a partir de la inspección esbozada por el sujeto reflexivo, capaz de retomarse en el esfuerzo por ser y permanecer en la existencia histórica, temporal, finita y tramada desde su devenir. La capacidad de invención es, de este modo, la fuente primera del homo narrans, que narrando explora sus propios posibles de habitar el mundo. Ciertamente, la función de las variaciones imaginativas en Ricoeur está instruida a partir de la narración como capacidad inventiva a partir de la cual el sujeto se recobra, adviene a sí en la apertura posible de su propia trama. Con relación a Husserl, Natalie Depraz afirma:

Mi ego es sometido a variaciones que, en tanto que son esenciales, hacen de aquel un eídos. El acceso a un ego en general no siginifica la salida del ego hacia otro ego. Non fingo hypothesis, pudo haber dicho Husserl, - yo no tengo necesidad de la hipótesis del otro ego: la reducción eidética no lo requiere. También el otro está excluido no solo a título de existencia corporal, como sujeto trascendental, pero también en tanto que efectivamente posible. La variación imaginaria de mi ego es del orden de un posible FORMAL, en ningún momento OTRO ego posible, pues esta variación no es ni presentificación imaginativa, ni transferencia en imaginación en el otro, es este acto que produce el otro que puedo ser en el modo del quasi, del 'como si fuese otro', sin crear por tanto otro EFECTIVAMENTE posible $^{29}$. (Las mayúsculas son de la autora)

Lo que trae a colación esta cita sobre Husserl es la imposibilidad de intencionar la alteridad a partir de la posición imaginativa del ego. No es el otro que verdaderamente aparece o se presenta, sino la potencia del sujeto para navegar en torno a sí, en la apertura de posibles comprensivos. Se trata, entonces, de la alteridad de sí que es testimoniada en la atestación de las capacidades del sujeto. Lo que aportan las variaciones imaginativas, en el caso de Ricoeur, es una visión inédita, un "ver como" dispuesto por el lenguaje en tanto innovación. Es la imaginación creativa aquella que se devela aquí en comercio con el sentido. Su función, por tanto, es la de una esquematización sintética, a partir de la cual es posible innovar nuevas lecturas posibles del mundo y del actuar humano.

La invención es un índice de exceso que testimonia el lugar privilegiado del sentido en el mundo, previo a la posición y afirmación del existente humano. De una u otra forma, es la intervención más propia del sí mismo en cuanto se trata de su propio devenir comprensible a partir de la configuración y refiguración del mundo mediante la potencia de lo posible. El sujeto tramándose en los signos, las obras, los textos, las acciones, no deja de regularse a sí mismo en dicho esfuerzo mimético. Pues el inventar o el innovar toma cuerpo o figura

\footnotetext{
${ }^{29}$ Depraz, Natalie. Transcendance et incarnation. Le statut de l'intersubjectivité comme altérité à soi chez Husserl. Paris: Vrin, 1995, pp. 93-94.
} 
desde lo ya-ahí, a partir de cierta regularidad o inteligencia narrativa. El sí mismo que es invención y fuente de innovación es por ende sujeto histórico que dice de otro modo para explorar mejor aquello en lo que se trama. Al respecto, un texto de Ricoeur citado por Olivier Abel:

La verdadera mimesis de la acción hay que buscarla en las obras de arte menos preocupadas de reflejar su época. La imitación, en el sentido común del término, es aquí el enemigo por excelencia de la mimesis. Es precisamente cuando una obra de arte rompe con esta suerte de verosimilitud que ella despliega su verdadera función mimética [...] Si es verdad que una de las funciones de la ficción mezclada con la historia es liberar retrospectivamente algunas posibilidades no efectuadas del pasado histórico, es en favor de su carácter cuasi histórico que la ficción misma puede ejercer después su función liberadora. El cuasi-pasado de la ficción deviene así el detector de los posibles ocultos en el pasado efectivo ${ }^{30}$.

La potencia refigurativa del lenguaje permite inspeccionar los fenómenos a partir de la narrativización y la metaforización de la experiencia y recordar o hacer historia a través del recurso de la ficción, así como bosquejar la iniciativa de la acción humana. La acción, en cuanto iniciativa, opera tanto la metamorfosis del mundo como el devenir propio del sujeto. El sentido que despliega la acción, precisamente en cuanto legible, siempre direccionado hacia un otro, es intencionado por lo que se deja leer en términos de motivos de acción, y al interior de una red semántica propia del actuar humano. De este modo, estar expuesto a la posibilidad de la interpretación es comprenderse en tanto serafectable por la acción y por el despliegue de su sentido o falta de sentido. La innovación que toda acción humana puede traer consigo testimonia la pasibilidad del sujeto ante el curso del mundo.

Si ante la pregunta “¿qué soy?” es posible que desfilen una serie de cualidades propias del ser humano: homo sapiens, loquens, faber, pictor, ludens, etc., solo ante la pregunta “¿quién soy?” aparece la figura del sí mismo. En el esfuerzo por responder a la cuestión “¿quién soy?”, Ricoeur descubre al sujeto en su deseo de ser y esfuerzo por perseverar en su existencia, en la exigencia del recobramiento del sujeto capaz de plantearse a sí mismo, ya siendo un problema para sí. Pero, porque la atestación del acto de existir del sujeto no tiene un tiempo distinto a la invención misma de parte suya, es que quien busca responder a la pregunta “¿quién soy?” se esfuerza también en darse a si mismo de otro modo que sí, afirmándose en sus capacidades para devenir en el mundo. Así, la capacidad originaria del sujeto que se devela en su devenir, es la de la invención, sin la cual ni la pregunta “¿quién soy?” ni las exigencias de reconocimiento, serían posibles. El sí mismo se descubre en la herida de ser por la pérdida y desorientación que lo habitan, habitando él mismo el mundo. Pero,

\footnotetext{
${ }^{30}$ Ricoeur, Paul. Temps et récit 3. Paris: Seuil, 1983, p. 278. Citado por Abel, Olivier, "L'indépassable dissensus". Art. cit., pp. 22-23.
} 
si originaria es la pérdida y las heridas que ella deja, el extravío no es definitivo, pues cabe siempre la posibilidad de volver sobre sí, aunque nada asegura que dicho regreso dé crédito de que quien vuelve sea precisamente el mismo. La imposible asunción total de sí solo se es en la alteridad que implica al sujeto porque lo extravía y lo orienta a la vez, pero sin contar del mismo modo con el tiempo. Incluso, si la alteridad es solo la alteridad de sí.

\section{Conclusiones}

Finalmente, arribamos por vías distintas a lo que se podría llamar si no la destitución del ego trascendental, al menos su puesta en cuestión. Ambos filósofos, Claude Romano y Paul Ricoeur, apuestan por un sujeto que 1) abierto al arribo del acontecimiento, 2) en la exploración de los posibles de su propia ipseidad mediante la narrativización de la experiencia, por ej., no terminan nunca de constituirse a sí, privilegiando lo que Ricoeur llama el "inacabamiento" de su condición. No es sino a partir de dicha vía que el sí mismo o el adveniente se dan en la tarea de una perpetua responsividad ante lo que los implica (el acontecimiento o la alteridad de sí), arrebatándoles la medida de su propia constitución. Si el adveniente es la humanidad en su capacidad de apertura al acontecimiento, el sí mismo también es definido con relación a la capacidad de apertura a su propio e inconcluso recobramiento que exige del uso de las variaciones imaginativas, de la narratividad y de la escucha de las voces de la alteridad que aportan nuevos modos de comprensión del ipse que se busca a sí en su propia invención. Dos filosofías, una del acontecimiento antes de toda cosa, otra de la inspección de lo posible, se articulan a partir de un modo nuevo de interrogar la experiencia que nos dice que ser un ipse es, primeramente, hacer la experiencia del acontecimiento y del mundo, esto es, recobrar al sujeto en cuanto responsivo ante aquello que no termina nunca de constituirlo ni de implicarlo. Dos vías diversas que nos abren a una filosofía de la espera inatendida: pues ¿qué cabe esperar sino la espera misma: el arribo del acontecimiento o, como afirma Ricoeur, simplemente estar en la verdad? 


\title{
El Secreto de un Secreto que Puede (No) Ser que lo Sea. Del Anuncio Público del Secreto o de la Literatura
}

\author{
Iván Trujillo \\ Universidad Alberto Hurtado
}

\begin{abstract}
"Pues un posible que fuese solamente posible (no imposible), un posible seguramente y ciertamente posible, de antemano accesible, sería un mal posible, un posible sin porvenir, un posible ya dejado de lado, cabe decir, afianzado en la vida. Sería un programa o una causalidad, un desarrollo, un desplegarse sin acontecimiento". Politiques de l'amitié, p. 46.
\end{abstract}

"Todo está dejado al porvenir de un "puede (no) ser”. La littérature au secret, p. 10.

\section{Problema: El porvenir de un "puede (no) ser"}

Puede que una de las cosas que impida que el pensamiento derridiano no sea político sea la experiencia de lo im-posible, o sea de la aporía o la paradoja de lo posible imposible ${ }^{2}$. Pero esta es una cuestión no tan evidente. En principio podríamos hallarla en relación con un debate aparentemente muy circunscrito. Tal el caso de la interpretación derridiana del psicoanálisis lacaniano y teniendo como fondo su interpretación de Más allá del principio del placer de Freud. En este debate destaca el problema de la destinerrancia, es decir, aquel

\footnotetext{
${ }^{1}$ Nuestro problema atañe a cierta decisión de traducción en relación con la locución francesa "peut-être". Traducida ante todo por "quizá" en el caso de la traducción de Patricio Peñalver de Politiques de l'amitié, y ante todo por "puede ser (que)" en el caso de la traducción de Cristina de Peretti y Paco Vidarte de Donner le temp I. La fausse monnaie y de Donner la mort, hemos optado por mantenernos en el filo de esta última decisión. Hacemos esto no sin un añadido que quizá hace falta y que atañe menos a la traducción de Peretti y Vidarte que a cierta lógica de pensamiento que sobrepuja a ésta última a su decisión de traducción. Muy económicamente nos atrevemos a introducir en la traducción del "peut-être" derridiano la palabra no entre paréntesis: "puede (no) ser"; y esto con el objeto de mantenerla lo más cerca posible de (lo más cercado posible por) la problemática derridiana de lo "im-posible" y su sesgo gramatical. En esta parte intentamos justificar esta decisión de traducción.

${ }^{2}$ Como Derrida, no oponemos aquí paradoja a aporía. Lo que por supuesto no quiere decir que se esté diciendo lo mismo. Ver a este respecto los siguientes textos de Jacques Derrida: El siglo del perdón seguido de fe y saber. B.A.: Ediciones la flor, 2006, p. 24; Aporías. Barcelona: Paidós, 1998, p. 33.
} 
de la estructural posibilidad que la carta pueda siempre no llegar a destino ${ }^{3}$. Ahora bien, sin pretender otorgarle aquí un privilegio a estos pasajes dedicados a este poder no llegar (pouvoir-ne-pas-arriver) de la carta al interior del más extenso tratamiento que Derrida le ha brindado a la problemática de lo posible imposible, pretendemos no obstante hacer trabajar lo más posible la sintaxis de este poder no, en particular en la medida en que sea extensible a la cuestión de lo político. Encontramos en Derrida mismo, en un escrito relativamente reciente ${ }^{4}$, el auspicio de una extensión tal, pues saliéndole al paso a la interpretación de un posible giro ético y también político de su pensamiento, muestra que "en el intervalo" de La carte postale (1980), ya se ligaba un pensamiento de lo posible imposible, en su sesgo afectivo, pasional, en duelo, obsesionado y espectral, con la decisión imposible y con lo posible como poder. Dirá entonces enseguida: "No hay nada fortuito en que ese discurso sobre las condiciones de posibilidad, allí precisamente donde su pretensión está obsesionada con la imposibilidad de superar su propia realizatividad, pueda extenderse [esta cursiva es mía, I.T.] a todos los lugares en donde alguna fuerza realizativa adviene o hace advenir (el acontecimiento, la invención, el don, el perdón, la hospitalidad, la amistad, la promesa, la experiencia de la muerte: posibilidad de lo imposible, imposibilidad de lo posible, la experiencia en general, etc. Et caetera, pues el contagio carece de límites; arrastra finalmente todos los conceptos $y$, sin duda, por consiguiente, el concepto del concepto)" ${ }^{\text {. }}$. Bajo este auspicio, el motivo de la destinerrancia, de la sintaxis del poder no con la cual parece estar estrechamente ligada, y el sesgo de esta imposibilidad posible, parecen indicar una vía de acceso al pensamiento derridiano de lo político. Bosquejaremos aquí esta vía, pero introduciendo un punto de inflexión específicamente fenomenológico del asunto, o más exactamente, cuasi-fenomenológico.

Se trata de un aspecto fenomenológico o quizá cuasi-fenomenológico, en el sentido de cuasi-trascendental ${ }^{6}$. En la nota 28 del texto citado, podemos constatar que Derrida mismo hace ver el modo en que ha tratado la im-posibilidad

\footnotetext{
${ }^{3}$ Ver Jacques Derrida. La carte postale. De Socrate a Freud et au-dela. Paris: Aubier-Flammarion, 1980, p. 472, 517. Esp. La tarjeta postal. De Sócrates a Freud y más allá. México: Siglo XXI, 2001, p. 417, 459460. En el contexto de esta problemática, que no se circunscribe por supuesto al psicoanálisis en general y al psicoanálisis lacaniano en particular, están también los "Envois" de Derrida. Ver Ibíd., p. 133, 135. Esp. Ibíd., p. 122-124.

${ }^{4}$ Cfr. Jacques Derrida, "Como si fuese posible, 'Within such limits'...”, en Papel Máquina. La cinta de máquina de escribir y otras respuestas. Op. Cit., pp. 449-280.

${ }^{5}$ Ibíd., p. 269. Ahí mismo un poco después esto: "Intento únicamente llevar adelante con cierta coherencia un pensamiento comprometido desde hace tiempo con las mismas aporías. La cuestión de la ética, del derecho o de la política no surgió ahí de improviso, como a la vuelta de la esquina".

${ }^{6}$ En relación a la utilización del cuasi-trascendental en su pensamiento y tras calificar de "potente interpretación" lo que hizo con respecto a éste Rodolphe Gasché en su trabajo The Tain of the Mirror, Derrida and the Philosophy or Reflection (Harvard, 1986), Derrida va a señalar lo siguiente: "era ya una manera de salvar, al tiempo que la traicionaba, la herencia de la filosofía, a saber la petición de de la condición de posibilidad (del a priori, de lo originario o del fundamento, otras tantas formas diferentes de la misma exigencia radical y de toda 'cuestión' filosófica). Era asimismo comprometerse, sin disimularse uno mismo la dificultad, con la tarea de pensar todavía lo que quiere decir lo 'posible', como lo 'imposible', y de hacerlo en torno a la susodicha 'condición de posibilidad', a menudo demostrada como 'condición de imposibilidad'. Lo que así se dice de la condición de posibilidad vale, por analogía, para el 'fundamento', el 'origen', la 'raíz' de la 'radicalidad', etc.". Ibíd., p. 263.
} 
en la fenomenología husserliana. Como "imposibilidad de la intuición plena e inmediata", como "posibilidad esencial de la no-intuición", como "posibilidad de la crisis", crisis indisociable de la producción de la objetividad ideal, etc ${ }^{7}$. A nosotros nos parece que esta imposibilidad como "posibilidad esencial de la no intuición" es indisociable de lo que tempranamente Derrida va a llamar "trascendentalidad de la abertura", indicando con ello la imposibilidad de todo posible cierre estructural en el plano de cierto estructuralismo fenomenológico ${ }^{8}$. En este punto resulta decisiva la problemática cuasi-fenomenológica de la anarquía del noema, es decir, aquello que Derrida va a entender como su irregionalidad, su inclusión no real sino intencional, o el que no sea ni conciencia ni mundo. Y esto es decisivo porque será precisamente esto mismo, o la imposibilidad misma que hay en esto, la condición de toda experiencia, de toda objetividad y fenomenalidad. Ahora bien, si se toma en cuenta que esta anarquía es la que aparecerá años más tarde en el corazón de la espectralidad derridiana de lo político en su libro Spectres de Marx (1993), entonces no resulta descaminado observar en Derrida una vía cuasi-fenomenológica (cuasi-trascendental) a la cuestión de lo político. Problemático es, sin embargo, el hecho que una cuasi-fenomenología como im-posibilidad, habida cuenta que a Derrida la fenomenología se le aparece como "posibilidad esencial de la no intuición", obtura la presentabilidad de lo político como tal. La vía cuasi-fenomenológica a lo político es, de partida, una vía bloqueada. Y tan sólo por eso es posible.

De la anarquía del noema Derrida va a decir en Spectres de Marx que en ella "habría que buscar la posibilidad espectral de toda espectralidad", que dicha 'irrealidad' entraña una "independencia tanto [et] respecto del mundo tanto [et] respecto del tejido real de la subjetividad egológica", que es la posibilidad general del espectro y que es, por lo mismo, capaz de inscribir "la posibilidad del duelo y del otro en la fenomenalidad misma del fenómeno" 10 . Esta anarquía, "condición de toda experiencia, de toda objetividad, de toda fenomenalidad" volvería imposible el aparecer de lo político como tal, tema expresamente desarrollado bajo el título "Aparición de lo inaparente. El 'esca-

\footnotetext{
${ }^{7}$ Ibíd., p. 273. Con respecto a la evaluación de la crisis y de su alcance en la fenomenología husserliana ver, además, del más reciente texto dedicado a ello ("Téléologie et architectonique", en Vouyous. Paris: Galilée, 2003) y de los textos más tempranos (De la gramatologie. Paris: Minuit, 1967; Introducction a L' Origine de la géométrie de Edumnd Husserl. Paris: PUF, 1962; y la tesis de 1954 hace pocos años publicada: Le probleme de la genese dans la philosophie de Husserl. Paris: PUF, 1990), el interesante trabajo de Paola Marrati-Guénoun: La genèse et la trace. Derrida lecteur de Husserl et Heidegger (Kluwer Academic Publishers, 1998).

${ }^{8}$ Cfr. La escritura y la diferencia (1967). En la edición en español (Anthropos, 1989). Nos referimos aquí al texto sobre la fenomenología husserliana que lleva por título "Génesis y estructura”" y la fenomenología” (pp. 211-232). La problemática de una abertura de la estructura es tratada también a propósito de la antropología de Levi-Strauss a título de "estructuralidad de la estructura". Cfr. "La estructura, el signo y el juego en las ciencias humanas" (Ibíd., pp. 383-401).

${ }^{9}$ La traducción española dice: "independencia tanto $[e t]$ con respecto al mundo como $[e t]$ con respecto al tejido real de la subjetividad egológica" (cfr. Jacques Derrida, Espectros de Marx. Madrid: Trotta, 1995, p. 153). Nos parece totalmente correcta. Pero no destaca de manera suficientemente gráfica la iterabilidad ligante de dicha independencia, donde mundo y conciencia reales están indisociablemente ligados a una iterabilidad irreal, ideal o noemática, cuya generalidad vuelve problemática la aparición como tal de la diferencia entre lo real y lo irreal. Esta ligadura general, su dificultad, es la cuestión más álgida del presente escrito.

${ }^{10}$ Cfr. Jacques Derrida. Spectres de Marx. Paris: Galilée, 1993. Ver sobre todo nota 2 en la p. 215. En la edición en español ver especialmente nota 9, en la p. 153.
} 
moteo’ fenomenológico"11. Y se podría, sin duda, ir más allá en este punto, por ejemplo hasta la pensativa ligazón del acontecimiento y la máquina (de lo incalculable y lo calculable), o hasta la histórica producción del Presente Vivo, que vive alterándose y disimulándose cuasi-autoinmunitariamente ${ }^{12}$. Pero lo que nos importa aquí ${ }^{13}$ es que la anarquía del noema corrompe el punto de vista intencional que a la vez supone ${ }^{14}$. Antes de cualquier determinación de algo como tal, antes que tal o tal tipo de fenomenalidad, una fenomenalidad general (un 'fainezsai', dirá Derrida) "lleva la muerte, da muerte, trabaja (en) el duelo"15. Entonces, una posibilidad general o espectral hace que cada vez uno mismo sea otro, que allí donde no hay más que uno ya haya demasiados. $\mathrm{Y}$ es en el trasfondo de esta escena múltiple, de esta différance inaccesible e irreductible, que habría que comenzar a comprender qué puede significar que un punto medio (Mittelpunkt) ${ }^{16}$ es lo que haga posible que un tercero venga a asegurar dialécticamente la economía de un reparto entre uno y otro, haciendo que ese otro sea dos por y para (el) uno mismo ${ }^{17}$. Lo que está en juego en esta

${ }^{11}$ Cfr. ibíd. Cap 5: “Apparition de l'inapparent: 1' 'escamotage'phénoménologique, pp. 201-279. Esp., Espectros de Marx. Madrid: Trotta, 1995, Cap. 5: “Aparición de lo inaparente. El ‘escamoteo’ fenomenológico”, pp. 143-196.

${ }^{12}$ Mekhané y acontecimiento en Jacques Derrida (2002), Papel máquina. La cinta de máquina de escribir y otras respuestas. Madrid: Trotta, 2003, pp. 31ss. Una razón cuasi-autoinmunitaria en Jacques Derrida, Voyous. Paris: Galilée, 2003, p. 178. En esp. Canallas. Dos ensayos sobre la razón. Madrid: Trotta, 2005, p. 154. Más o menos directamente en otra parte hemos incursionado en ambos textos y sus problemáticas: "Historicidad y Mekhané. Consideraciones en torno al cuasi-trascendentalismo de Salvoj Zizek", en Rev. Actuel Marx Intervenciones $\mathrm{N}^{\circ} 3$, Santiago: ARCIS/Lom Ediciones, 2005, pp. 103-114. "Derrida y la razón autoinmunitaria" (a publicarse en un número de la Revista de la Academia, Universidad Academia Humanismo Cristiano).

${ }^{13}$ En otra parte he intentado bosquejar lo que podría llegar a ser cierta trayectoria fenomenológica de la cuestión derridiana del noema desde sus tempranos escritos hasta estos últimos. Los motivos de este bosquejo, en gran medida programáticos, se desplegaban a propósito de lo políticos. Y eso, a la espera de un texto como el que ahora desarrollamos. Ver "La ligadura. A propósito de artefactualidad e historia en Jacques Derrida". Ponencia presentada en el Coloquio Internacional de Filosofía, Universidad de Buenos Aires. Buenos Aires, 2006.

${ }^{14}$ Aunque sometido a un trabajo de de-limitación, más de una vez Derrida ha defendido el recurso a la fenomenología. Por ejemplo en este pasaje: "Porque nada puede desacreditar el derecho a la cuestión trascendental u ontológica. Ésta es la única fuerza que resiste al empirismo y al relativismo (...) nada resulta menos empirista o relativista que una cierta atención a la multiplicidad de los contextos y de las estrategias discursivas que éstos rigen, una cierta insistencia en el hecho de que un contextos siempre está abierto y no es saturable, así como el hacerse cargo de "quizá" y del "casi" en un pensamiento del acontecimiento, etc.". Jacques Derrida, Papel máquina. Op, cit., p. 273. Ver también Simon Critchley et alia, Desconstrucción y pragmatismo. Buenos Aires: Paidós, 1998, p. 59.

${ }^{15}$ Cfr. Jacques Derrida. Spectres de Marx. Op. cit., p. 215.

${ }^{16} \mathrm{Al}$ punto medio, al Mittelpunkt hegeliano, estamos en vías de consagrarle toda nuestra atención en un texto sobre Glas en preparación. Nos interesamos en efecto por aquello que Derrida dice allí del espíritu hegeliano: que es "unidad ligada a sí, enrollada cerca y alrededor de sî", que "está -solo-, que tiene su propia esencia, su propio centro y su propia unidad en sí mismo" y que esta proposición especulativa "enuncia la identidad dialéctica de la identidad y de la no-identidad" (Glas. Paris: Galilée, 1974, pp. 30-31). Nos interesamos, sobre todo, por el modo en que Derrida concibe esta ligazón dialéctica, no sin una cierta relación con el psicoanálisis: "El proceso de idealización - va a decir un poco más adelante-, la constitución de la idealidad como medio [milieu] del pensamiento, de lo universal, de lo infinito, es la represión del impulso [poussée, traducción de Trieb, y que Derrida distingue del deseo -desir- y de la pulsión -pulsion]. La Aufhebung es entonces también un contra-impulso, una contra-fuerza, una Hemmung, una inhibición, una especie de anti-erección" (p. 34).

${ }^{17}$ Cuestión de (la) mediación, a propósito de la cual Derrida va a decir por ejemplo lo siguiente: "la mediación: el retorno cerca de sí que vence la división y la pérdida. El relevo del dos en el tres, retorno a sí de la unidad" (Glas, op. cit., p. 36). Pero se podría ir más allá y no sin todavía una cierta relación con Hegel; a propósito de Carl Schmitt y de la posibilidad real, no ya dialéctica, de matar. En un texto en preparación nos preguntamos si lo que Derrida va a decir de cierta "hostilidad absoluta", podría acaso dar a pensar la posibilidad absoluta de la víctima (de su producción como culpabilidad absoluta) en términos de dicha posibilidad real. Algo de esto se encuentra en Spectres de Marx a propósito de la relación especular que Marx mantiene con Stirner. Cfr. Jacques Derrida, op cit., pp. 221 ss. Esp. op, cit., pp. 157 ss. 
posibilidad es la invención del otro, de otro que ya no es lo posible, tal y como lo va a indicar Derrida en otra parte ${ }^{18}$.

En efecto, desde que para Derrida "una invención debe anunciarse como invención de lo que no parecía posible" ${ }^{19}$, una invención del otro no es la invención de "lo posible". Luego, lo posible debe poder no suceder (llegar). Lo posible debe aparecer al mismo tiempo como lo imposible para que una invención del otro pueda anunciarse. Todo lo cual sucede si "la venida de la invención no puede volverse extrańa a la repetición y a la memoria” ${ }^{20}$. Repetición y memoria no son ya sólo lo que hace posible el despliegue de una dynamis de lo que se encontraba allí, sino aquello que envuelve a dicha dynamis excediéndola suplementariamente. En efecto, "hay una lógica de la suplementariedad" que "introduce hasta la estructura de la psyché una fabulosa complicación que hace más que lo que dice e inventa otra cosa que esa que da a certificar. El movimiento mismo de esta fabulosa repetición puede, según un cruce de oportunidad [chance] y necesidad, producir lo nuevo de un acontecimiento" ${ }^{21}$. Una invención del otro entonces no viene más que a través de la repetición heterológica de la economía de lo mismo ${ }^{22}$. Sólo esta repetición deja venir al otro.

"Quizá", habría que decir. O bien: "puede (no) ser", dado que lo que "puede ser", puede siempre no ser. Por ejemplo, porque hay más de un ejemplo, cuando se trata del concepto de lo político. Así en el caso de aquella posibilidad real de matar de la que dependería la comunidad política. De acuerdo a la interpretación derridiana del pensamiento de Carl Schmitt, esta posibilidad real ya no va a seguir el esquema aristotélico de la potencia y el acto, no alcanza su realización en "la actualización de un posible", sino en "la radicalización de una realidad posible o de una posibilidad real" 23 . Se trataría así de un pensamiento de la posibilidad real, en la que la excepción sería la regla de lo que llega (arrive, pero también: de lo que sucede), la ley del acontecimiento. Una excepcionalidad entonces fundaría la eventualidad del acontecimiento. Derrida dirá que "un acontecimiento como tal" será siempre excepcional. En adelante, dado que esta excepcionalidad lo será de la decisión, de la decisión que decide quién es el enemigo, la decisión será también la decisión de su contrario, del amigo. No hay decisión sin hostilidad absoluta ${ }^{24}$.

\footnotetext{
${ }^{18}$ Cfr. "Psyché. L'invention de l'autre", en Psyché. París: Galilée, 1987.

${ }^{19}$ Ibid., p. 50.

${ }^{20}$ Ibid., p. 61.

${ }^{21}$ Ibid., p. 58.

${ }^{22}$ Cfr. a este respecto el célebre trabajo de Rodolphe Gasché, Le tain du miroir. Derrida et la philosophie de la reflexión. Paris: Galilée, 1995.

${ }^{23}$ Cfr. Jacques Derrida, Politiques de la amitie, Galilée, París, 1994, p. 147. Edición en esp. Políticas de la amistad seguido de El oído de Heidegger. Madrid: Trotta, 1998, p. 146.

${ }^{24}$ Derrida dirá entonces que, desde que la excepción se liga a un quizá determinante, "es ella, y sólo ella, la que devela la esencia, el centro y el fondo de las cosas. Es aquello que puede no suceder [llegar; arriver], aquello que sucede [llega; arrive] tan sólo en la medida en que podría no suceder [llegar; arriver], es esa indecidible eventualidad como posibilidad real lo que constituye la decisión y lo que constituye la verdad". Y agrega más adelante: "El desvelamiento de las cosas, del corazón de las cosas, en el desgarro de la decisión, no se produce quizá en la acción de guerra que lleva la muerte, sino seguramente en la posibilidad desgarradora de un dar muerte [matar; mise a mort], en esa posibilidad como posibilidad real y presente [...] Como si bastase que un acontecimiento sea posible para que suceda [llegue; arrive], para que haya sucedido [llegado; arrivé] ya realmente en su quizá mismo, al cabo de la frase [de Nietzsche] que nombra su posibilidad... “¡Oh, enemigos, no hay ningún enemigo!”. Cfr. Jacques Derrida, Politiques de la amitié. Op. cit. Esp., op. cit., p. 151.
} 
Pero podríamos decir también que no hay quizá hostilidad sin hospitalidad. Podríamos entonces ir a buscar un tercero entre un yo y un tú, en el cara-acara, y ver surgir en el umbral de la ética -y este sería aquí un segundo ejemplouna hospitalidad cuya pervertibilidad vuelve a ésta inseparable de su contrario, la hostilidad. Porque el tercero no esperaría, un perjurio cuasi-trascendental u originario, pre-originario, que Derrida no deja de llamar "ontológico" sería capaz de soldar (souder) "la ética a todo aquello que la excede y la traiciona (la ontología, precisamente, la sincronía, la totalidad, el Estado, la política, etc.)"25. Todo lo cual incluso podría significar que se trata de "un mal irreprimible o una perversión radical, si no fuera, ante todo, porque la mala voluntad no puede estar ausente de ello y porque su posibilidad, el asedio al menos de su posibilidad [la hantise au moin de sa possibilité], esto es, cierta pervertibilidad [pervertibilité], no fuera asimismo la condición del Bien, de la Justicia, del Amor, de la Fe. Y de la perfectibilidad"26. Entonces, en el umbral de la ética es imposible "situar el umbral", imposible separar "la pervetibilidad de la perversión”. Una "'posibilidad' espectral”, va a decir Derrida, es la “imposibilidad de controlar, de decidir, de determinar un límite; la imposibilidad de situar para mantenerse en él, mediante criterios, normas, reglas, el umbral que separa la pervertibilidad de la perversión” ${ }^{27}$. Puesto que el umbral ético puede siempre no tener lugar, puesto que puede siempre faltar, esta imposibilidad de un umbral ético es en cierto modo necesaria, ella nunca falta, desde el umbral. Desde entonces, la perversión efectiva no es separable de la pervertibilidad, o para decirlo en términos de hostilidad absoluta, no es separable lo real de lo posible ${ }^{28}$. Una irreductible "hospitalidad con lo peor" es lo que hace falta para que la hospitalidad "tenga su oportunidad": "hace falta [il faut] que ese umbral

\footnotetext{
${ }^{25}$ Cfr. Adieu a Emmanuel Lévinas. París: Galilée, 1997, p. 69 (En esp. Adiós a Emmanuel Lévinas. Madrid: Trotta, 1998, p. 54). El motivo de la soldadura (soudure), que representa temáticamente el núcleo políticoartefactual de mi texto más arriba citado (ver nota 7), parece articular indecidiblemente el acontecimiento al aparato político en Spectres de Marx (1993). Habiendo dicho que Marx ha ligado el fantasma a la ontología y habiéndose preguntado cuál sea el lazo de este lazo ("le lien de ce lien"), preguntando entonces por lo que liga a "la ontología con el materialismo, el partido, el Estado y el devenir totalitario del Estado", Derrida dice un poco más adelante a propósito de esta soldadura: "Por soldadura podemos entender una adherencia artefactual pero sólida [adhérence artefactuelle mais solide] y cuyo acontecimiento mismo ha constituido toda la historia del mundo desde hace un siglo y medio, y por tanto, toda la historia de mi generación" (pp. 151-152; esp. pp. 106-107). El carácter indecidible de esta articulación, no obstante la confiscación ontológica de Marx, parece ser lo que lleva a Derrida a ir con Marx más allá de esta usura ontológica, hasta el Marx (del) por venir.

${ }^{26}$ Cfr. Adieu a Emmanuel Lévinas, op. cit., p. 69. Esp. op. cit., p. 54.

${ }^{27}$ Ibíd. Pensamos que la cuestión del umbral (seuil) preside el texto de Derrida sobre Lévinas. Y esto no solo porque se le hace mención 14 veces (como en ningún otro de sus textos, hasta donde sabemos), sino sobre todo porque en Derrida mismo el tópico de una no-presencia originaria no va a dejar de aparecer ligado aquí y allá a la expresión "desde el umbral" (En este sentido resulta interesante vincular, esto a sugerencia del profesor Carlos Contreras, la cuestión del umbral (seuil) a la cuestión del duelo (deuil)). En este sentido, bien se podría establecer un vínculo entre el motivo de la anarquía del noema, que aquí hemos tratado, con el motivo levinasiano del otro acogido en la anarquía. Ver a este respecto, Jacques Derrida, op. cit., p. 51. Esp. p.41.

${ }^{28}$ Lo que nos atrevemos a decir aquí tiene a la vista la prudencia con la que Derrida, a pie de página en este texto sobre Emmanuel Lévinas, da a entender que entre pensamientos tan antipódicos como son los de Lévinas y Schmitt es necesario proceder "con toda la reserva de paradojas e inversiones que pueda abrigar una oposición absoluta” (p. 161 / Esp. p. 119). Esta reserva, además, no se circunscribe a la presente relación. Al final de la nota se consigna la relación entre Heidegger y Rosenzweig bajo el respecto del "encabestramiento tenso e inestable de una herencia". Habría que seguir el hilo de esta cuestión a propósito de la relación entre Rosenzweig y Herman Cohen en una referencia a cierta psique judeo alemana en "Interpretations at war. Kant, el judío, el alemán” (Cfr. Acabados seguido de Kant, el judío, el alemán. Trotta, 2004), o a propósito de la relación entre Benjamin, Heidegger y Schmitt en "El nombre de pila de Benjamin" (Cfr. Fuerza de ley. El "fundamento místico de la autoridad". Tecnos, 2002).
} 
no se encuentre a disposición de un saber general o de una técnica regulada. Hace falta $[I l$ faut $]$ que exceda todo procedimiento reglamentado para abrirse a aquello mismo que corre siempre peligro de pervertirse (el Bien, la Justicia, el Amor, la Fe, -y la perfectibilidad, et). Hace falta [Il faut] todo esto, hace falta [il faut] esta posible hospitalidad con lo peor para que la buena hospitalidad tenga su oportunidad [la chance], la oportunidad de dejar venir al otro, el sí del otro no menos que el si al otro"29.

Con lo dicho, deberíamos estar prevenidos de una visión politizante, politológica o politista de lo político en Derrida ${ }^{30}$. Tanto en relación con el concepto de "posibilidad real" como en relación con el concepto de "pervertibilidad", no se trata de dar cuenta del concepto propiamente político de la decisión o del concepto propiamente político de la ética. Y esto porque tanto lo político como lo ético pueden (no) ser. Hemos intentado mostrar en otra parte ${ }^{31}$ que esto sucede, en el primer caso al menos, porque desde que la inadecuación de lo político a su concepto es esencial al concepto de lo político, lo político nunca abandona el concepto que no lo contiene. Habría, desde entonces, una disyunción política-del-concepto que nunca podría presentar ni la forma conceptual de lo político propiamente tal, ni la apariencia eidética de lo político como tal. En el segundo caso, sucede al menos porque desde que la pervertibilidad no es separable de la perversión, la prescripción ética de la política, qua mandato formal, nunca deja aparecer un contenido político determinado. Antes bien, dirá Derrida, que permanece "indeterminado, siempre por determinar, más allá del saber y de cualquier presentación, de todo concepto y de toda intuición posibles, singularmente, en la palabra y en la responsabilidad asumidas por cada cual, en cada situación, y a partir de un análisis cada vez único -único e infinito, único pero a priori expuesto a la substitución, única, y sin embargo, general, interminable, no obstante la urgencia de la decisión" ${ }^{32}$.

Hostilidad absoluta y hospitalidad con lo peor vuelven a lo político tan irreductible como indisponible a su concepto o a su eidos. Desde que hay más de uno, una posibilidad espectral no se presenta nunca. Pero lo que hace falta sin presentarse nunca, lo que permanece irreductiblemente anárquico, esta especie de lazo cuasi-trascendental que se deja señalar como posibilidad real de matar y como pervertibilidad, es a la vez irreconciliable e indisociable de su

\footnotetext{
${ }^{29}$ Ibíd. Decidimos traducir aquí "Il faut" por "hace falta" para acentuar su carácter a la vez defectivo, precipitado e inminente. Un hace falta (el) tiempo, aquí para controlar, para decidir, para determinar un límite, para situar el umbral que separa la perversión de la pervertibilidad, el hecho de la perversión, de su posibilidad real, es lo que conecta con la necesidad de detenerse ("es preciso detenerse"), con la necesidad de seleccionar ("es preciso seleccionar"). Y ambas necesidades fuera de una posible determinación especulativa o práctica de la razón. Cfr. a este respecto Jacques Derrida, Donner le temp, I. La fausse monnaie. París: Galilée, 1991. Esp. Dar (el) tiempo, I. La moneda falsa. Madrid: Trotta, 1995, p. 153s.

${ }^{30} \mathrm{He}$ intentado interrogar esta visión en el postmarxismo. Cfr. mi artículo "Abertura y revolución. Consideraciones en torno a la deconstrucción de Ernesto Laclau”. En Revista Actuel Marx Intervenciones, $\mathrm{N}^{\circ} 2$, Santiago: ARCIS/Lom, 2005. Asimismo he intentado proseguir esta discusión en torno al pensamiento de Slavoj Žižek, en mi artículo "Historicidad y Mekhané. Consideraciones en torno al cuasi-trascendentalismo de Slavoj Žižek", en Revista Actuel Marx Intervenciones, № 3. Santiago: ARCIS/Lom, 2006.

31 Todo lo que venimos diciendo aquí en torno a la lectura derridiana de Schmitt y de Lévinas, en un texto en preparación que lleva por título "Hostilidad absoluta y pervertibilidad".

${ }^{32}$ Cfr. Jacques Derrida, Adieu, op. cit., p. 199. Esp. op. cit., p. 146.
} 
presentabilidad, como lo incondicional respecto de lo condicional. Por ello, en cuanto a la paradoja del don, en Donner le temp Derrida va a decir: por un lado, que "como el acontecimiento, como acontecimiento, [el don] debe permanecer imprevisible, pero permaneciéndolo sin (res)guardarse. Debe dejar que lo estructure la aleatoriedad: debe parecer suertudo [paraître chanceux], en cualquier caso, debe ser vivido como tal, aprehendido como el correlato intencional de una percepción absolutamente sorprendida de encontrarse con lo que percibe, más allá de su horizonte de anticipación: lo cual parece ya fenomenológicamente imposible”; mientras que, por otro lado, va a decir "¿Qué sería un don mediante el cual yo daría sin querer dar y sin saber que doy, sin intención explícita de dar, ni siquiera a mi pesar? Es la paradoja en la que nos hemos adentrado desde el principio. No hay don sin intención de dar. El don no puede tener sino una significación intencional - en los dos sentidos de esta palabra que remite tanto a la intención como a la intencionalidad"33. Fenomenológicamente imposible pero no sin la fenomenología. Sin horizonte de anticipación, sin campo fenomenal o sin fenomenalidad, correlato intencional de una percepción siempre sorprendida de encontrarse con lo que percibe ${ }^{34}$, ¿se podrá seguir hablando de fenómeno? ¿Acaso un fenómeno que debe parecer suertudo (chanceux)? ¿Una moneda falsa que no se da como tal? ¿Se podrá hablar quizá a partir de aquí de una fenomenalidad meteórica?

Porque la posibilidad imposible de la que aquí se trata sólo puede (no) ser, puede ella suceder o llegar. Si fuera conceptual o fenomenalmente posible, entonces no tendría oportunidad (chance). Y sólo porque quizá no deja de parecer suertuda (chanceux) es que hace falta esta posibilidad. Todo lo cual podría hacer pensar que tal posibilidad imposible es del orden de la ficción. En efecto, dado que lo que no debe dejar de parecer suertudo es también lo que al mismo tiempo aparece como tal, ella como tal aparece como una ficción. Pero si la ficción es lo que es como tal cuando siempre puede (no) ser lo que es ${ }^{35}$, entonces la ficción puede siempre no aparecer como tal. He aquí el secreto sin profundidad de la ficción, "la superficialidad esencial de su fenomenalidad", lo "demasiado-evidente" que da a ver ${ }^{36}$. Habrá que ver enseguida porqué este secreto lo será de la ficción literaria, de la llamada "literatura". En lo inmediato digamos que se va a tratar de la ficción literaria como una posibilidad ya no regional sino general de la imposibilidad de aparecer como tal. En este sentido, el orden de la literatura no vendría a ser ya sólo un ejemplo de esta posibilidad, sino ante todo un ejemplo ejemplar o una ejemplaridad. Antes vimos que lo político y lo ético pueden (no) ser. Ahora comenzamos a ver que en una medida inconmensurable (e indeterminable) de lo que puede (no)

\footnotetext{
33 Ambas citas en Jacques Derrida, Donner le temp I. La fausse monnaie, Galilée, 1991, p. 156-157. Esp. Dar (el) tiempo I. La moneda falsa, Paidós, 1995, p. 121-122.

${ }^{34}$ A esta problemática de un correlato intencional de una percepción que descubre lo que inventa, se la podría ir a buscar en el primer trabajo de Derrida sobre Husserl, en su tesis del 54. Ver Jacques Derrida, Le probleme de la genese dans la philosphie de Husserl, op. cit.

${ }^{35}$ Así traducimos: "Elle n'est qu'en pouvant être, peut-être, ce qu'elle est.". Cfr. Jacques Derrida. Donner le temp I. La fausse monnaie, op. cit., p. 115. Esp. op. cit., p. 89.

${ }^{36}$ Ibíd., 194. Esp. Ibíd., p. 150.
} 
ser se anuncia la literatura. Por lo mismo es que también ahora comenzamos a ver que sólo en dicha medida inconmensurable (e indeterminable) es posible lo político y lo ético. La literatura abrirá otra posibilidad del espacio público, una secreta, singular, pero no ya privada. Por ello es que del anuncio de la literatura, del secreto sin profundidad de la literatura, podrá hacer parte (podrá "convertirse en una cosa literaria") "cualquier texto confiado al espacio público, relativamente legible e inteligible, pero cuyo contenido, cuyo sentido, firmante y destinatario no son realidades plenamente determinables, realidades a la vez no-ficticias o libres de toda ficción, realidades entregadas, como tales, por una intuición, a algún juicio determinante" ${ }^{37}$.

\title{
El secreto de un secreto que puede (no) ser que lo sea: la literatura
}

\author{
"Siempre se hereda de un secreto - que dice 'léeme, \\ ¿serás tú capaz de ello?’” \\ Spectres de Marx, p. 40
}

\section{a) Leer, el secreto del otro}

En una pequeña comunicación Michel Lisse ha puesto de relieve "el secreto ejemplar de la literatura" ${ }^{38}$. De manera absolutamente justa ha enhebrado tres textos derridianos que tratan de este secreto en el siguiente orden: Passions (Galilée, 1993), Donner (le) temp (Galilée, 1991) y Donner la mort (Galilée, 1999). Ha hecho esto no sin utilizar al primero como hilo conductor. Además, nos ha facilitado el pasaje de Spectres de Marx que aquí emplazamos como epígrafe. Partiremos con este pasaje.

Se trata de un pasaje del primer capítulo ("Inyunciones de Marx"), al comienzo de su largo comentario de "Los tres discursos de Marx" de Maurice Blanchot, contenidos en su libro La amistad". Decimos "largo comentario" y, añadimos, entre corchetes, porque la edición española cierra el comentario apresuradamente: apertura y cierre en la página 30, cuando en verdad debía cerrarlo en la página 49. En la edición francesa el comentario se abre en la página 39 y se cierra en la página 66. Pues bien, al comienzo de este comentario Derrida refiere a la herencia de más de un discurso ("parole") de Marx y de la necesidad (il faut: hace falta, es preciso, hay que) de responder hoy "como de una inyun-

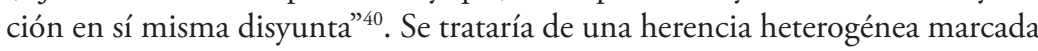
por una "diferencia sin oposición", "una cuasi-yuxtaposición sin dialéctica",

\footnotetext{
37 Jacques Derrida, "La littérature au secret", en Chantal Zabus (comp.), Le secret: motif et moteur de la littérature, Louvain, Louvain-La-Neuve, Collége Erasme, 1999, p. 10. Esp. Dar la muerte. Barcelona: Paidós, 2000, p. 123. (Agradezco a Cristóbal Durán el haberme facilitado el acceso a este texto en francés).

${ }^{38}$ Michel Lisse, "Le secret exemplaire de la littérature", en Chantal Zabus (comp.), Le secret: motif et moteur de la littérature, Louvain, Louvain-La-Neuve, Collége Erasme, 1999, pp. 425-436. Agradezco nuevamente a Cristóbal Durán el haberme dado acceso al presente escrito.

${ }^{39}$ Cfr. "Los tres lenguajes de Marx", en Maurice Blanchot, La amistad. Madrid: Trotta, 2007, pp. 94-96.

${ }^{40}$ Jacques Derrida, op. cit., p. 39. Esp. op. cit., p. 30.
} 
que señala desde lejos al plural de los espíritus de Marx que serán considerados más adelante en el libro. Tras lo cual Derrida afirma que una herencia "no se reúne jamás, no está nunca consigo misma”, por lo que su "unidad presunta" no consiste más que en "la inyunción de reafirmar eligiendo". No siendo la unidad de la herencia sino una pura presunción consistente en la inyunción de una elección reafirmante, la posibilidad misma de la herencia va a depender precisamente, necesariamente, de su elección. Y esto desde que la herencia no se presenta más que como un secreto inaccesible, cuya inyunción está transida de órdenes contradictorias. Un legado es legible, no se es afectado por él como por una "causa - natural o genética. Se hereda siempre de un secreto - que dice 'léeme, ¿serás tú capaz de ello?”’41. Repitámoslo: el legado no afecta al modo de "una causa - natural o genética", sino que al heredarse de un legado siempre "se hereda de un secreto - que dice léeme...". Leemos lo siguiente: así como por afección causal podemos entender causa natural o genética, podemos entender que "se hereda de un secreto" como se hereda del mandato de una lectura incierta o de un secreto no compartido que se comparte. Secreto i-legible dado a leer.

Este secreto i-legible no es ya lisa y llanamente lo in-visible. En Dar la muerte dirá Derrida lo siguiente a propósito del léxico griego de la críptica: "Se extiende más allá de lo visible. Y en la historia de esta semántica, lo críptico vino a ampliar el campo de lo secreto más allá de lo no-visible hacia todo aquello que resiste al des-encriptado: el secreto como ilegible o indescifrable más que como lo invisible" ${ }^{42}$. No ya lo in-visible visible sino lo in-visible absolutamente no visible: "todo cuanto no se refiere al dominio de la vista, lo sonoro, lo musical, lo vocal o lo fónico (y, por consiguiente, lo fonológico o lo discursivo en sentido estricto), mas también lo táctil y lo odorífero. Y el deseo como la curiosidad, como la experiencia del pudor y de la puesta al descubierto del secreto, el desvelamiento de la pudenda o el ver en secreto (videre in abscondito) - que conduce, dentro del secreto, más allá del secreto- juega constantemente, no puede más que jugar, entre estas dimensiones de lo invisible: lo invisible como visible oculto, lo invisible encriptado o lo no-visible como otro que lo visible" ${ }^{3}$. Y antes ha dicho: "lo absoluto de la invisibilidad sería más bien aquello que no tiene una estructura visible, la voz por ejemplo, lo que se dice o quiere decir, y el sonido..."44.

Entonces, el secreto i-legible no abandona la escena de la escritura. Se podría tirar este hilo e ir a recoger el motivo de la cripta en una infinidad de textos derridianos. Con el objeto de exorcizar un fantasma que nos rondó durante algún tiempo, digamos por lo menos que la deconstrucción del fonologocentrismo y del privilegio del habla plena solidario con éste, nunca dio lugar a un énfasis en lo exterior visible o al deseo de otorgarle un cierto privilegio, ni en la

\footnotetext{
${ }^{41}$ Ibíd., p. 40. Esp. Ibíd.

42 Jacques Derrida. Dar la muerte. Op. cit., p. 88. Fr. p. 86.

${ }^{43}$ Ibíd., p. 89.

${ }^{44}$ Ibid., p. 88.
} 
forma de una crítica al predominio metafísico del oído (por ejemplo en el caso de Hegel y de Heidegger), ni en la forma de una crítica al predominio fenomenológico-teorético husserliano basado en el privilegio de la intuición (por ejemplo en el caso de Lévinas), ni siquiera, y ya más recientemente, en la forma de una defensa muy desviada del mismo a propósito del modelo áptico y no ya óptico de la fenomenología husserliana (en discusión con Jean-Luc Nancy). Todo esto, claro está, no quiere decir tampoco lo contrario. Antes bien, esto quiere decir que la preocupación derridiana se ha mantenido concernida por la problemática de la huella y del texto allí donde ésta logra conmover el privilegio metafísico otorgado al presente. A propósito de La moneda falsa de Baudelaire, Derrida viene de formular varias preguntas, entre otras, "¿Quién da? Y ja quién? ¿Qué y a quién?”. Este texto, dirá Derrida, "para nosotros, es algo que está dado". Dice enseguida: "Está ahí, ante nosotros que leemos y empezamos, pues, por recibirlo. Si tiene la estructura de algo dado no es sólo porque estamos, en primer lugar, en una situación receptiva con respecto a él, sino porque nos ha sido dado. Desde el momento en que lo publica e incluso aunque no lo hubiese publicado, desde el momento en que lo escribe y lo constituye dedicándoselo a su 'querido amigo', el presunto firmante (...) lo deja constituirse en sistema de huellas, lo destina, lo da, no sólo a otro o a otros en general distintos de su 'querido amigo' Arsene Houssaye, sino que hace entrega de él [le livrait] -y eso es el dar- por encima de cualquier destinatario, donatario o legatario determinado" 45 . De manera que un texto nos ha sido dado sin que eso signifique que estábamos ahí para recibirlo, sin que eso signifique, además, que el donatario (aquí el presunto firmante) nos lo haya enviado a nosotros. Sólo dejándolo, entregándolo, en cierto modo abandonándolo, al otro en general, cual un sistema de huellas, cual testamento o incluso archivo, nos ha sido dado. Todo esto vuelve inseparable la problemática del don con la problemática del texto, único modo de tratar aquella consecuentemente: "no hay problemática del don sino a partir de una problemática consecuente de la huella y del texto. Jamás puede haberla a partir de una metafísica del presente, ni siquiera del signo, del significante, del significado o del valor. Ésta es una de las razones por las cuales partimos siempre de textos en la elaboración de esta problemática, de textos en el sentido corriente y tradicional de letras escritas, incluso de la literatura, o de textos en el sentido de huellas de différance, de acuerdo con un concepto que hemos elaborado en otro lugar. $\mathrm{Y}$ no podemos hacer otra cosa que partir de los textos, y de los textos en tanto que, de partida, parten (que se separan de sí mismos y de su origen, de nosotros)" ${ }^{36}$.

\section{b) Literatura y ejemplaridad}

Concernido por la problemática de la huella y del texto, de lo que en relación con ésta puede pensarse, consecuentemente, del don, del secreto y de la herencia, venimos de decir que, según Derrida, no podemos más que partir de textos

\footnotetext{
45 Jacques Derrida. Donner le temp. Op. cit., pp. 129-130. Esp., Op cit., pp. 100-101.

${ }^{46}$ Jacques Derrida. Donner le temp. Op. cit., p. 130. Esp., op cit., p. 101.
} 
que, de partida, parten, "separándose de sí mismos y de su origen, de nosotros". Todo lo cual parece, de partida, problemático para un concepto de literatura suficientemente determinado en virtud del cual podamos reconocerle un cierto privilegio, acaso estético, antiestético o de otro tipo, que sirva de hilo conductor para el tratamiento de las problemáticas ya mencionadas ${ }^{47}$. En Passions (1993) podemos hallar un texto que parece extenuarse en llevar la ejemplaridad literaria a los confines de una especie de democratismo incondicional.

Derrida da a entender en la última nota de este texto (nota 12) que la literatura puede comenzar fuera de lo que, acaso muy determinadamente, se entiende son sus límites. En una formulación que recuerda "La loi du genre" (Parages, 1986), Derrida sugiere en términos cuasi-noemáticos que "Alguna cosa de la literatura habrá comenzado cuando no habrá sido posible decidir si, al momento en que hablo de algo, hablo de algo (de la cosa misma, ella misma, por ella misma) o si doy un ejemplo, un ejemplo de alguna cosa o un ejemplo del hecho que puedo hablar de algo, de la posibilidad de hablar en general de alguna cosa en general, o incluso de escribir este discurso, etc." ${ }^{28}$. No que la literatura en cuanto tal haya comenzado, sino que si algo de la literatura habrá comenzado (en francés en futuro anterior), entonces ella habrá comenzado como tal. Lo que, por otra parte, nunca podrá ser una evidencia presente. Ahora bien, eso de la literatura está ligado aquí a la indecidibilidad entre decir algo determinado y la ejemplaridad. Y para hablar de ésta, otro ejemplo: "pongamos que diga 'yo". Enseguida se plantea la posibilidad de no poder objetar seriamente que al escribir un texto autobiográfico se esté escribiendo un texto sobre la autografía del cual el texto autobiográfico es un ejemplo. "Nadie podría seriamente contradecirme si afirmo (o subentiendo elípticamente, sin tematizarlo) que no escribo un texto 'autobiográfico' sino un texto sobre la autobiografía del que este texto es un ejemplo" ${ }^{4}$. Pero la ejemplaridad no se detiene allí, pues nadie "podrá seriamente contradecir si yo digo (o subentiendo, etc.) que no escribo sobre mí (moi), sino sobre "mí” ("moi”), sobre un yo (moi) cualquiera o sobre el yo en general, proponiendo de eso un ejemplo: no soy más que un ejemplo o soy ejemplar" ${ }^{50}$. La ejemplaridad incluso se precipita: "Lo que voy a decir de la palabra con respecto a alguna cosa no espera la palabra, quiero decir el enunciado discursivo y su transcripción escrita" ${ }^{51}$. Lo que es igualmente válido ya para toda "huella en general" (pre-verbal, deíctica u otra). Hay pues "disociación entre yo y 'yo', entre la referencia a mí y la referencia a (un) 'yo' en el ejemplo de mi yo"; disociación en la que permanece una diferencia "pragmática" con respecto a lo propiamente lingüístico o discursivo

\footnotetext{
${ }^{47}$ Una consideración antiestética de la literatura, o más exactamente de la teoría literaria, podríamos hallarla en los trabajos de Paul de Man. Ver al respecto mi trabajo de tesis: El arte bajo el signo de la hostilidad. La estética de Hegel después de la época del arte. Universidad de Chile, 2006. Ver también Hegel y la desilusión de la historia. En torno a Paul de Man y la tesis del fin del arte (de próxima publicación).

48 Jacques Derrida. Passions. París: Galilée, 1993, p. 89.

49 Ibid.

${ }^{50}$ Ibíd.

${ }^{51}$ Ibid., p. 90.
} 
y no tiene que estar marcada en las palabras (mots). La diferencia entre funciones no tiene que ser tematizada. A veces "ella debe no serlo - y es el secreto".

El secreto, ya se ha dicho, no tiene profundidad. La literatura puede jugar todo el tiempo, por otra parte gracias a una licencia no poética de lo poético, de la que hablaremos enseguida. "Ella es ejemplar solamente en aquello de lo que llega (arrive) en todas partes" 52 .

\section{c) Fenomenalidad meteórica: el porvenir de una frase}

Con lo dicho difícilmente podríamos resumir en una frase a la literatura. Todo indica que la literatura, aquella que identificamos como tal, puede todavía volverse literatura. Tal el secreto que la separa siempre de sí misma. Y si ella es sólo ejemplar en aquello de lo que llega en todas partes, entonces lo que llega en todas partes se vuelve literatura porque puede no llegar. Literatura es lo que siempre puede (no) ser. Por eso, esta frase: "perdón por no querer decir", puede llegar a convertirse en literatura. En verdad, hay mucho que decir sobre esta frase. Nos limitaremos aquí a proseguir la herencia lectora del secreto o el modo como ella, segregando la literatura, (a)filiando la singularidad absoluta, anuncia lo público.

Lo que nos interesa de esta frase entonces es "la ausencia de contexto plenamente determinante", la cual la predispone al secreto y a su devenir-literario. Si tomamos en cuenta la ejemplaridad de la que hemos venido hablando, podríamos pensar que debemos entender en relación con el espacio público una cierta indeterminabilidad de base en la que la literatura es ejemplar. Aquí como en Donner le temp, y a propósito de La moneda falsa, la ficción literaria, circunscrita, es metonímicamente más grande que el "en todas partes" del acontecimiento. Ahora bien, Derrida se va a preguntar en relación con dicha indeterminabilidad, qué relación puede haber entre la literatura y el sentido, entre la literatura y la indecidibilidad del secreto. “Todo está en manos del porvenir de un 'puede (no) ser" 53 . Desde entonces, porque podría detentar "más de un secreto", es que dicha frase podría volverse literaria. Y en la medida misma en que dicho secreto sea secreto, vale decir, en la medida misma en que dicho secreto sea uno que "puede ser, puede ser que podría no serlo" ${ }^{54}$.

¿Hay una fenomenalidad que arroje el sentido de esta frase? Esta frase se mantendría "en el aire". Y esto incluso en cualquier parte que se halle inscrita. "Y es de permanece en el aire que guarda su secreto, el secreto de un secreto que puede (no) ser uno y que, debido a ese hecho, anuncia la literatura" 55 . Secreto sin secreto entonces, de una frase que se mantiene en el aire; especie de meteorito que se mantiene allí según el tiempo de "una caída posible". Frase

\footnotetext{
52 Ibíd.

53 Jacques Derrida. "La littérature au secret". Op. cit., p. 10.

${ }^{54}$ Ibíd. Sigo aquí la traducción española, p. 124.

55 Ibíd., p. 11.
} 
"fenomenal": "Fenomenal, esta frase parece serlo, puesto que, en primer lugar, ella parece. Aparece, está claro, se trata incluso de la hipótesis o de la certeza de principio. Aquella se manifiesta, parece pero 'en el aire', venida no se sabe de dónde, de forma aparentemente contingente. Contingente meteorito en el momento de tocar un suelo (pues una contingencia también dice, de acuerdo con la etimología, el tocar, el tacto o el contacto). Al permanecer en el aire, ésta pertenece al aire, al estar-en-el-aire. Tiene su morada en la atmósfera que respiramos, queda suspendida en aire incluso cuando toca. Allí mismo donde toca. Por eso digo que es meteórica"s6.

Digamos, para terminar (todavía muy precipitadamente sin duda): se trataría aquí de una "virtud fenomenológica", "meteórica" del "fenómeno literario"57; una suspensión de aquello con lo cual la fenomenología suspende, a saber, la tesis del sentido. Todo lo que la suspensión de la referencia hacía aparecer en la fenomenología de Husserl como sentido, como reducción trascendental que, no obstante su radicalidad egológica, seguía brindando acceso a una región determinada qua reducción eidética, le había parecido al temprano Derrida como un camino que debía sortear la oclusión del sentido prometida por la abertura general del noema. Ahora que la fenomenología ha brindado todavía en su forma husserliana una muy precipitada tangencialidad al motivo de la presencia (cfr. Toucher, 2000), Derrida parece poder suspender nuevamente al noema, pero esta vez en el momento mismo en que es la inminencia de un encuentro imposible, secretamente compartido, entre el sin-sentido y la posibilidad del mundo.

\footnotetext{
${ }^{56}$ Ibíd., p. 12. Esp. p. 125. Ver el motivo del tocar, el acto y lo contingente, en Jacques Derrida, Toucher. París: Galilée, 2000.

${ }^{57}$ Ibíd., p. 32. Esp. p. 147.
} 


\title{
El Acceso a la Noción de Alegoría en la Poesía de Dante.
}

\author{
Joaquín Barceló \\ Universidad Andrés Bello
}

\begin{abstract}
Resumen
La Divina Comedia posee, según Dante, un sentido literal y un sentido alegórico, y este último sería una tipología teológica. Pero en tal caso su sentido literal debería considerarse verdadero, en circunstancias de que el de la Comedia parece obviamente ficticio. La dificultad se resuelve si se considera que el viaje de Dante al otro mundo es una figura cuyo figuratum es una experiencia de conversión religiosa vivida por su autor.
\end{abstract}

Para el lector de hoy, la lectura de la Divina Comedia suele ser un fatigoso encuentro con personajes desconocidos que ya no nos interpelan y con problemas que apenas figuran en las agendas de los grupos e instituciones actuales, es decir, con todo un lastre que termina por ahogar a los ojos del lector la fuerza creadora de la fantasía poética de Dante. Ello se debe, aunque tan sólo en parte, a que en nuestra época ya no manejamos las técnicas de lectura habituales en los tiempos en que fue escrito el poema. Y si bien esas técnicas, que el mismo Dante explicó para beneficio de sus lectores, son perfectamente conocidas por los estudiosos, que también las han aplicado con éxito a la exégesis de otras obras, ha habido serias dudas acerca de las condiciones de su aplicación en el caso de la Comedia, debido principalmente a la incertidumbre acerca de la autenticidad de un documento, a saber, de una carta en la que el poeta aparece dedicando la tercera parte de la obra, el Paradiso, a su protector Cangrande della Scala, señor de Verona; se trata, pues, de la ya célebre Epistola XIII, de discutida atribución al poeta.

En dicha epístola enfatiza Dante el carácter alegórico de la Divina Comedia, cosa que también se afirma explícita y claramente por lo menos en dos pasajes del poema. El primero se encuentra en un episodio altamente dramático del Inferno:

O voi ch'avete li intelletti sani, mirate la dottrina che s'asconde sotto 'l velame de li versi strani. (Inf., IX, 61.63)

("Vosotros, los que tenéis sanos los intelectos, atended a la doctrina que se esconde 
bajo el velo de estos extraños versos"). El otro lugar, no tan dramático pero no menos importante, se halla en el Purgatorio:

Aguzza qui, lettor, ben li occhi al vero,

ché 'l velo è ora ben tanto sottile,

certo che 'l trapassar dentro è leggero. (Purg., VIII, 19-21)

("Aguza bien la vista aqui, lector, para la verdad, porque el velo es ahora tan sutil que, ciertamente, es fácil traspasarlo").

Los términos velame y velo nos introducen inmediatamente en el terreno bien conocido de la alegoría literaria medieval. El velo (lat. integumentum) o envoltura (involucrum) es el relato fabuloso que encubre a alguna verdad oculta pero a la vez sugerida por él; tarea del lector es descorrer tal velo y dirigir la mirada de la inteligencia hacia la verdad escondida. Ésta es, en su esencia, la técnica de lectura de una obra alegórica.

Dejando aparte las prosopopeyas o personificaciones, que también fueron consideradas como formas alegóricas durante la Edad Media, Dante se refirió a la alegoría literaria stricto sensu en un pasaje de su Convivio, destinado a exponer los criterios para interpretar sus propias canciones reunidas en esa obra. Dice el pasaje en cuestión: "[...] los escritos pueden entenderse y se deben exponer a lo sumo en cuatro sentidos. El uno se llama literal, [y es aquél que no se extiende más allá de la letra de las palabras ficticias, como son las fábulas de los poetas. El otro se llama alegórico,] y éste es el que se esconde bajo la cubierta de tales fábulas, siendo una verdad oculta bajo bella mentira; como cuando dice Ovidio que Orfeo, con su cítara, amansaba a las fieras y hacía que los árboles y las piedras se movieran hacia él; lo que significa que el hombre sabio, con el instrumento de su voz, amansaría y humillaría a los corazones crueles, haciendo moverse según su voluntad a quienes no poseen vida de ciencia o de arte, porque quienes no tienen vida racional alguna son como piedras. [...] En verdad, los teólogos entienden este sentido de otro modo que los poetas, pero ya que mi intención es seguir aquí el modo de los poetas, tomo el sentido alegórico tal como es empleado por ellos. El tercer sentido se llama moral, y éste es aquél que los lectores deben andar acechando en los escritos para su provecho y el de sus discípulos [...] El cuarto sentido se llama anagógico, es decir, suprasentido; éste es cuando se expone espiritualmente un escrito, el cual, aun [siendo verdadero] en sentido literal, por las cosas significadas expresa las cosas de la vida eterna; como puede verse en aquel canto del profeta que dice que en la salida del pueblo de Israel de Egipto, Judea se hizo santa y libre. Si bien ello es manifiestamente verdadero según la letra, no menos verdadero es lo que se entiende espiritualmente, a saber, que al salir el alma del pecado, se hace santa y libre en su potestad. Al mostrar [todo] esto, hay que empezar siempre por el sentido literal, que es aquél en cuya sentencia están incluidos los demás 
y sin el cual sería imposible e irracional entender los otros, principalmente el alegórico" (Conv., II, i, 2-8).

En el pasaje citado llaman la atención varias cosas. En primer lugar, es notorio el hecho de que Dante utiliza en él, aunque no sin introducirle modificaciones, la doctrina de Sto. Tomás de Aquino concerniente al cuádruple sentido de la sagrada Escritura, tal como se halla expuesta en la Summa theologiae (I, q.1, a.10) o en las Quaestiones quodlibetales (VII, q.6, a.2 [15]). Las modificaciones introducidas por Dante son aquéllas necesarias para adaptar el esquema tomista a la interpretación de poesía profana, incluso de las creaciones poéticas paganas. Los cambios son: el primero, caracterizar al sentido literal (de los poetas) como una bella mentira, en circunstancias de que los teólogos defienden la verdad del sentido literal de la Escritura (con el matiz que se indicará luego); el segundo, sustituir la definición teológica de la alegoría (fundada en último término en Gal., 4:21-31, y entendida como tipología) por la noción tradicional de alegoría literaria, según la cual aliud dicitur, aliud intelligitur, una cosa es lo que se dice y otra lo que se entiende. Esta tradición es mucho más antigua que la interpretación tipológica propia de la alegoría tomista; procede de la antigüedad pagana, de los tiempos de la ilustración griega, cuando se intentó defender a Homero contra los intelectuales que habían perdido la fe en esos dioses y diosas antropomorfos, lujuriosos, adúlteros y embusteros. Originada, pues, en la antigua Hélade, esta tradición se mantuvo durante la Antigüedad tardía, toda la Edad Media y hasta bien entrado el Renacimiento. Dante no fue ajeno a ella, ni habría podido serlo, toda vez que gracias a ella pudo tener lugar la conservación de muchos textos literarios de la Antigüedad, que de otro modo habrían sucumbido ante los empeños de la primera evangelización cristiana, así como también pudo mantenerse la continuidad del estudio de dichos textos. La exégesis alegórica habrá atribuido tal vez a los clásicos antiguos doctrinas que ellos jamás sostuvieron ni sospecharon, pero gracias a ella dichos clásicos se salvaron para nosotros.

Si no se reconoce la autoría dantesca de la epístola a Cangrande, hasta este punto, y no más allá, llegaría lo que Dante ha dicho expressis verbis acerca de las alegorías contenidas en sus versos, incluida la Divina Comedia. Pero, en tal caso, nos hallaríamos en serias dificultades para entender esta última obra y para resolver o explicar ciertas presuntas contradicciones que aparecerían en ella y que afectan al sentido literal mismo, del que dicen Dante y toda la tradición que ha de ser el comienzo de la comprensión de la obra porque en su sentencia están incluidos los sentidos restantes. Mencionemos aquí la que es tal vez de mayor gravitación. Dante no ignoraba que, como se ha sostenido tradicionalmente en las Iglesias cristianas, no es lícito al hombre juzgar el fuero interno de sus semejantes, cuya conciencia íntima sólo puede ser juzgada por Dios, y que el juicio humano no coincide necesariamente con el divino ni 
siquiera cuando las acciones públicas de las personas dan testimonio de sus virtudes o de sus vicios. Así lo consignó en los versos:

Non creda donna Berta e ser Martino, per vedere un furare, altro offerere, vederli dentro al consiglio divino;

ché quel può surgere, e quel può cadere. (Par., XIII. 139-142)

("Que no crean don Fulano y doña Zutana, porque ven a uno robar y a otro hacer ofrendas, que los ven conforme al consejo divino; porque el uno puede levantarse y el otro, caer").

También los espíritus bienaventurados, que ven a Dios en el paraíso, advierten contra los juicios apresurados, porque ni siquiera ellos conocen los designios divinos respecto del destino ultramundano de los hombres (Par., XX, 133135). Sin embargo, y contrariamente, en apariencia, a toda esta cautela, Dante parece haber juzgado en la Comedia, por sí y ante sí, a un gran número de personajes históricos (y otros legendarios, que él, empero, consideraba históricos), enviando a unos al infierno y a otros a la salvación eterna. Podemos preguntarnos, entonces, ¿con qué derecho lo hace? Es claro que las simpatías o antipatías personales no confieren derecho alguno para juzgar a los demás. Tampoco lo confieren los juicios morales que un autor puede sustentar, en la medida en que éstos pueden estar contaminados de subjetividad y, por tanto, de arbitrariedad. Podrá tal vez argüirse que los personajes históricos presentados en la Comedia son parte del sentido literal de la obra, y que, por consiguiente, son mera ficción y "bella mentira", para usar las palabras del mismo Dante en el texto citado arriba. Si así fuera, la excusa sería peor que la falta, porque en tal caso los personajes enviados por el autor al infierno podrían haber sido calumniados por él si -cosa que Dante no podía saber- la misericordia divina los hubiera favorecido con un oportuno arrepentimiento.

Más aún. El sentido literal de la Comedia relata de modo inmediato la peripecia de su autor, el poeta Dante Alighieri de Florencia, quien se identifica a sí mismo en un punto culminante de la obra (Purg., XXX, 55); el poeta, de acuerdo con el relato, mediante una ayuda de origen celestial, logra escapar de una "selva oscura", la "selva errónea de esta vida" (Inf., I, 2; Conv., IV, xxiv, 12), y, durante un viaje en que recorre los reinos ultramundanos, hace la experiencia del mal en todas sus formas, la de la purificación espiritual y la del goce concedido a los espíritus bienaventurados, hasta que alcanza, finalmente, una determinada visión de la divinidad; es decir, el sentido literal nos muestra todo un itinerario espiritual que conduce desde el pecado (en cuanto ausencia de Dios) hasta la salvación. Pero si el sentido literal, que en sí mismo contiene y muestra todo esto abiertamente, no pasa de ser una bella mentira, según se dice en el pasaje citado del Convivio, ¿qué significado espiritual podemos atri- 
buir al poema? ¿No quedaría más bien en el nivel de un notable divertimento fabuloso, en cuanto tal intrascendente, incapaz de inspirar a nadie en el sentido que habría querido su autor, de "sacar a quienes viven esta vida de su estado de miseria y conducirlos al estado de felicidad?” (Epist. XIII [X], 39 [15]).

En buenas cuentas, entender la alegoría de la Comedia como la "alegoría de los poetas", que reduce el sentido literal a mera ficción, significa privar a la obra de todo significado espiritual.

¿Qué nuevas perspectivas se abren respecto de estos problemas si se admite la autenticidad de la epístola a Cangrande, como lo hacen hoy los más connotados dantistas, o, lo que sería equivalente, si se admite que el pensamiento del desconocido autor de la epístola coincide con el del poeta? Escuchemos ante todo lo que dicha carta dice sobre la alegoría: "[...] el sentido de esta obra [esto es, de la Comedia] no es simple, sino que puede decirse polisemos, esto es, de muchos sentidos; porque el primero es el que se tiene por la letra, otro el que se obtiene de las cosas significadas por la letra. El primero se llama literal y el segundo, alegórico o moral o anagógico. Este modo de proceder puede ser considerado, para su mejor comprensión, en los siguientes versos: 'Al salir Israel de Egipto, la casa de Jacob de un pueblo bárbaro, Judea se hizo su santificación e Israel su potestad'. Porque si atendemos a la sola letra, nos hablan de la salida de los hijos de Israel de Egipto en tiempos de Moisés; si a la alegoría, significan nuestra redención hecha por Cristo; si reparamos en el sentido moral, significan la conversión del alma desde la aflicción y miseria del pecado hasta el estado de gracia; si en el anagógico, significan la salida del alma santa desde la servidumbre de esta corrupción hacia la libertad de la vida eterna. Y aunque estos sentidos místicos sean llamados con diversos nombres, en general todos pueden ser considerados alegóricos por ser diferentes del literal o histórico. Pues alegoría viene del griego alleon, que en latín se dice 'otro' (alienum) o 'diverso' (diversum)". (Epist. XIII [X], 20-22 [7]).

Nuevamente nos encontramos, pues, con el cuádruple sentido de la Escritura según Sto. Tomás de Aquino, pero esta vez sin modificaciones que lo adapten para aplicarlo a la poesía profana. Lo establecido aquí por Dante o por el autor de la epístola es, en todo caso, asombroso: ¡la Divina Comedia ha de ser leída en la misma forma en que se lee la Biblia! La alegoría de la Comedia será, pues, la de los teólogos, a la que se alude en el pasaje del Convivio citado arriba. ¿En qué consiste esta última? La epístola la define mediante un ejemplo: la salida del pueblo de Israel de Egipto significa alegóricamente la redención de la humanidad operada por Cristo. Sto. Tomás la había definido diciendo: "En cuanto las cosas que son de la ley antigua significan las que son de la nueva ley, el sentido es alegórico", y "el sentido espiritual [...] puede fundarse en aquel modo de figuración en el cual el Antiguo Testamento es figura del Nuevo; y así, el sentido alegórico o típico es aquél según el cual las cosas que ocurrieron en 
el Antiguo Testamento se refieren a Cristo y a la Iglesia". (S. theol., I, q.1, a.10; Quaest. quodlib., VII, q.6, a.2 [15]). Es lo que la teología actual no llama ya sentido alegórico (acaso para evitar la confusión con la "alegoría de los poetas") sino "sentido típico". Según éste, un personaje o un hecho pertenecientes al Antiguo Testamento es "figura" o "tipo" de otro personaje o hecho relacionado con el Nuevo Testamento, que constituye el "antitipo" del anterior. La relación entre tipo y antitipo es que ambos son personajes o hechos reales, y el tipo, temporalmente anterior, anuncia velada o "alegóricamente" al antitipo, el cual, por su parte, consuma al tipo y le confiere pleno sentido.

Pero en la Comedia no parece relevante la distinción entre la antigua ley y la nueva ley para establecer su sentido alegórico. Efectivamente, no lo es, pero sí es decisiva la distinción entre esta vida y la del Más Allá. Podríamos pensar, entonces, al menos provisoriamente, que el sentido alegórico de la Comedia reside en que, en último término, las cosas de la vida en este mundo significan, insinúan o aluden, anticipándolas, a las de la vida en el otro mundo, que las cumple y consuma revelando el auténtico significado de ellas. Así, el pecado cometido en la tierra durante esta vida recibe en el infierno, después de la muerte, su verdadera significación como ausencia de lo divino y el consiguiente dolor; y la virtud ejercida aquí en este mundo se consuma y adquiere su pleno sentido en el goce de la visión de Dios. Con ello sería consistente el uso amplio que hace Dante de la técnica del contrapaso para describir el estado de las almas en el mundo eterno. El contrapaso es, en el fondo, una derivación más refinada de la ley del talión, y esta última, una consecuencia del principio teológico según el cual Dios respeta la libertad humana y no otorga premios ni castigos que no concuerden con los deseos y aspiraciones íntimos y fundamentales del ser humano que los recibe. Para que haya contrapaso es necesario que exista una cierta correspondencia (por analogía o por contraste) entre la falta y su castigo o su purificación; así, los indecisos que nunca tomaron partido por alguna causa, corren insensatamente en el otro mundo tras una bandera, aguijoneados por avispas y mosquitos (Inf. III); los negligentes que esperaron hasta el momento de su muerte para convertirse, deben esperar un tiempo igual al de su vida para ser admitidos en el purgatorio (Purg. IV); Bertrand de Born, de quien se decía que había provocado la separación y la enemistad entre Enrique II de Inglaterra y su hijo Enrique III, aparece llevando en la mano, a modo de linterna, su propia cabeza separada del tronco, y explica: "Así se muestra en mí el contrapaso” (Inf. XXVIII, 142); y así sucesivamente.

Con lo dicho hasta aquí podría tal vez darse por resuelto el problema del sentido alegórico de la Comedia. ¿Qué ocurre, sin embargo, con su sentido literal, que lo incluye y expresa, a la vez que lo oculta? En la concepción teológica, el sentido literal (de la Escritura) es verdadero. ¿Lo es también el sentido literal del poema de Dante? Al parecer, no. Podemos presumir confiadamente que Dante Alighieri, si bien era él mismo un ser humano real, jamás anduvo 
paseando por el infierno, el purgatorio y el paraíso si no lo hizo en alas de su propia fantasía. El viaje ultramundano de Dante no es, pues, verdadero en el sentido de físicamente real, sino ficticio. El sentido literal de la Comedia no satisfaría, pues, la condición impuesta por la alegoría teológica. Por otra parte, en la medida en que las otras figuras que comparecen en la obra son personajes históricos o tenidos por tales, es obvio que ellos tienen o tuvieron realidad física. Pero ellos son, a la vez, figuras cuyos antitipos están representados por sus destinos ultramundanos. Sólo que ni Dante ni nadie podía saber algo sobre el destino de aquellas almas en la otra vida. Si, por consiguiente, consideramos que los hechos de esos personajes reales constituyen el sentido literal de la Comedia y que la alegoría consiste en su relación con el destino ultramundano de sus almas, nos hallaríamos en la situación paradójica de que el sentido literal de la Comedia se mostraría como verdadero y su sentido alegórico sería ficticio, lo que se contradice tanto con la noción de alegoría de los poetas como con la de los teólogos! Habríamos caído, pues, a todas luces en un error fundamental.

En un intento de resolver de una vez por todas el problema, consideremos también la determinación de los sentidos literal y alegórico de la Comedia hecha por el mismo Dante o por quienquiera que haya sido el autor de la Epistola XIII atribuida al poeta. Éstas son sus palabras: "En vista de lo dicho, es manifiesto que el asunto en torno al cual giran los sentidos alternativos ha de ser doble. Por consiguiente, se debe considerar el tema de esta obra en lo que concierne a la letra, y luego considerarlo en lo que expresa alegóricamente. Es, pues, el tema de toda la obra, tomado sólo literalmente, el estado de las almas después de la muerte considerado como tal, pues de él y en torno a él se desenvuelve todo el argumento de ella. Si, en cambio, se la considera alegóricamente, su tema es el hombre en la medida en que, mereciendo o desmereciendo por la libertad de su arbitrio, está sometido a la justicia que premia y castiga”. (Epist. XIII [X], 23-25 [8]).

¿Es posible obtener un cuadro consistente de la noción de alegoría que sustentaba Dante a partir de este último texto?

En la determinación que la Epistola XIII hace de los sentidos literal y alegórico, es fácil observar que la diferencia entre ambos es doble. Por una parte, el sentido literal está referido a "las almas", en tanto que en sentido alegórico se habla de "el hombre". Las almas, en plural, son entidades individuales; el hombre, en singular, es un concepto genérico. Henos aquí frente al viejo problema de la multiplicidad y la unidad ontológicas, de lo particular y lo universal lógicos, y de sus mutuas relaciones. En segundo lugar, el sentido literal habla simplemente del "estado" de las almas en el otro mundo, mientras que el sentido alegórico explica dicho estado retrotrayéndolo a las nociones de la libertad humana y la justicia divina. El estado de las almas es algo concreto, fácilmente inferible del 
testimonio directo de los sentidos de la vista y del oído; la libertad y la justicia son conceptos altamente abstractos que el hombre sólo puede alcanzar tras una compleja elaboración intelectual. Retengamos entonces que el sentido literal está referido a lo individual, lo múltiple, lo concreto, en tanto que el sentido alegórico apunta hacia lo universal, lo unitario, lo abstracto.

Estas mismas relaciones fueron sugeridas por Dante, apoyándose en la teoría aristotélico-tomista del conocimiento, al tratar en la Comedia el problema de la comunicación y adquisición del saber. $\mathrm{Al}$ comienzo de su recorrido por el paraíso, se pregunta el peregrino Dante por qué las almas de los bienaventurados se le muestran en los diferentes cielos planetarios, tal como pudieron imaginarlo los autores paganos, en circunstancias de que la Iglesia le enseñaba a él, cristiano, que todos los espíritus bienaventurados se encuentran en el cielo empíreo, gozando de la visión de Dios. Beatriz, su guía, le explica que, efectivamente, todas ellas están en el empíreo, pero que se le muestran a Dante, que aún vive y percibe a través de sus sentidos corporales, en los diferentes cielos planetarios, que distan más o menos del empíreo, como una señal de la menor o mayor gloria que les ha deparado la justicia divina. Y añade:

Così parlar conviensi al vostro ingegno, però che solo da sensato apprende ciò che fa poscia d' intelletto degno. (Par., IV, 40-42)

("Asi corresponde hablarle a vuestro ingenio [i.e., al ingenio de los vivientes] porque sólo capta por los sentidos aquello que luego eleva a la dignidad de la intelección").

En efecto, según la tradición aristotélica, todos nuestros conocimientos tienen su origen en los sentidos, que sólo perciben lo individual aquí y ahora, y únicamente después de un complejo proceso de elaboración de los datos así obtenidos, proceso que recorre los estadios del "sentido común" (en la acepción técnica que da Aristóteles a este término), de la memoria y la "fantasía" (otro término técnico), del intelecto pasivo y del intelecto agente, se logra obtener, desde los datos particulares, principios y conceptos universales y abstractos. Hay, pues, una clara distinción entre el conocimiento sensible y el conocimiento intelectual, distinción que Sto. Tomás pone en los siguientes términos; "Los sentidos, que son facultades corporales, conocen lo singular, que está determinado por la materia; pero el intelecto, que es una facultad independiente de la materia, conoce lo universal, que ha sido abstraído de la materia y que contiene infinitas [cosas] singulares" (S. theol., $\mathrm{I}^{\mathrm{a}} \mathrm{II}^{\mathrm{ae}}, \mathrm{q}$.2, a.6). El conocimiento sensorial aprehende lo individual, concreto y múltiple, en tanto que el conocimiento intelectual concierne a lo universal abstracto y uno. De inmediato se observa la analogía: el sentido literal de un texto se corresponde con el conocimiento sensorial, porque ambos están referidos a lo individual concreto 
y múltiple; el sentido alegórico, en cambio, es análogo al conocimiento intelectual, pues ambos tienen como objeto lo universal abstracto y unitario.

Dante ha dado así una fundamentación filosófica a la práctica de escribir alegorías; es, para él, la forma que corresponde al proceso del conocimiento humano tal como lo describió Aristóteles. Si el texto escrito posee dos niveles, uno literal y otro alegórico, ello se debe a que el conocimiento se constituye también en dos niveles, uno sensorial y otro intelectual. Por ese motivo, en la poesía, el sentido literal está constituido por imágenes de cosas sensibles (héroes, guerras, pastores, ganados, amores), pero el sentido alegórico de esas imágenes sólo puede alcanzarse mediante una elaboración intelectual.

Los sentidos y el intelecto son en el hombre facultades separadas; por eso, el sentido literal y el sentido alegórico son también distintos. Pero el texto poético es único; en él están encerradas la letra y la alegoría, y ambas se expresan a través de las mismas palabras. ¿Cómo así? El hecho evoca otro pasaje del aquinate que dice: "Así como el hombre conoce todas las clases de cosas mediante diversas facultades cognoscitivas, a saber, las cosas universales e inmateriales mediante el intelecto, y las cosas singulares y corporales mediante los sentidos, así también el ángel conoce las unas y las otras a través de una sola facultad intelectiva" (S. theol., I, q.57, a.2).

Charles S. Singleton caracterizó la escritura de la Comedia por Dante como una imitación del modo de escribir de Dios, puesto que había introducido en ella alegorías de carácter tipológico como las que hay en la Biblia. Creo que no es necesario ir tan lejos; me basta con pensar que Dante quiso pensar su Comedia imitando el modo de conocer de los ángeles.

Pero aún no hemos terminado con el análisis del sentido literal, en el cual se apoyan todos los restantes, y es necesario profundizar más en su noción. Para este fin es de importancia decisiva un pasaje de la Summa de Sto. Tomás acerca de lo que él llamó sentido parabólico o metafórico. Dice así: "El sentido parabólico está contenido en el literal, porque las palabras significan algo en propiedad y algo figuradamente, y el sentido literal no consiste en la figura misma (ipsa figura) sino en lo figurado (figuratum). Cuando la Escritura menciona el brazo de Dios, su sentido literal no es que en Dios exista un miembro corporal de esa índole, sino lo que dicho miembro significa, a saber, la capacidad de actuar. Por lo que es manifiesto que en el sentido literal de la sagrada Escritura nunca puede haber falsedad". (S. theol., I, q.1, a.10 ad 3; el énfasis es nuestro). Así, pues, la primera tarea del lector deberá ser la de establecer cuáles son los figurata correspondientes a las figurae del sentido literal, para poder luego determinar la alegoría oculta en él. 
La Epistola XIII dice que el sentido literal de la Comedia es el estado de las almas después de la muerte (cosa que el poeta no podía conocer), pero omite agregar que dicho estado era contemplado por Dante (a pesar de que el poeta nunca estuvo en el otro mundo, al menos antes de haber terminado de escribir su obra) acompañado por Virgilio, luego por Beatriz y finalmente por San Bernardo de Claraval (cosa que nunca ocurrió realmente). ¿Significa esto que el sentido literal de la Comedia es ficticio de cabo a rabo? No necesariamente. Lo único que significa es que el sentido literal de la obra se expresa en estilo figurado, y que, de acuerdo con el texto de Sto. Tomás recién citado, no consiste en las figurae sino en el figuratum, lo que parece obvio. Figura es un término derivado del verbo fingo, que significa formar, hacer, construir, y, como tal, se emparenta con fictio, formación o ficción. Las figurae del sentido literal son, pues, creadas por el poeta. ¿Pero cuál es entonces el figuratum en que realmente consiste el sentido literal de la obra? Tiene que ser una experiencia real susceptible de ser expresada mediante las ficciones creadas por el poeta. ¿De qué experiencia, sin embargo, puede tratarse en el caso de la Comedia? Por fortuna, las grandes obras clásicas siempre responden a las preguntas pertinentes que se les hace, y la Comedia no es una excepción. Cerca del final de la obra, Dante, el personaje ficticio creado por el poeta Dante, pero que indudablemente lo representa, se llena de estupor al contemplar la cándida rosa que forman los espíritus bienaventurados en torno del Creador, y para expresarlo, lo hace en términos que el poeta no podría haberle prestado si ellos no correspondieran a una experiencia real:

io, che al divino da l'umano,

a l'etterno dal tempo era venuto,

e di Fiorenza in popol giusto e sano. (Par., XXXI, 37-39)

("yo, que habia venido a lo divino desde lo humano, a lo eterno desde el tiempo, desde Florencia a un pueblo sano y justo").

Es, claro está, una experiencia espiritual decisiva y transformadora, que sólo puede entenderse como una conversión religiosa. Ése es el figuratum, en eso consiste el sentido literal de la Comedia; y de esa experiencia vivida por el poeta Dante nadie podrá decir que es ficticia, porque si lo fuera, él no habría sido capaz de escribir esta obra.

Una vez establecido este punto, aclarado cuál es el auténtico sentido literal de la Comedia, la determinación de los restantes sentidos se facilita notablemente. Para lograrla, basta preguntarse: ¿qué puede significar este personaje, este acontecimiento o este símbolo en relación con el proceso de conversión religiosa experimentado por Dante el poeta, representado por la figura ficticia de Dante el peregrino, visitante del otro mundo? 
En resumen: En el relato de la Comedia tenemos un sentido literal figurado. Las figuras (ficticias) son Dante (el personaje que recorre los reinos ultramundanos), Virgilio, Beatriz, San Bernardo, todas las almas de condenados y bienaventurados que aparecen en el texto, los ángeles, diablos y monstruos que pueblan el mundo del Más Allá imaginado por el poeta, los paisajes, los episodios, los diálogos, circunstancias, etc. Lo figurado real es, en cambio, la experiencia espiritual vivida por el poeta Dante, que lo conduce desde una existencia sujeta a las solicitaciones y requerimientos de este mundo, con todos los condicionamientos que les son propios (una "selva oscura"), hasta una liberación hecha posible por el reconocimiento de los múltiples aspectos y matices del mal y la paulatina interiorización en las posibilidades del bien y de la salvación, que son apropiadas por el autor mediante la penitencia y la reflexión en el orden moral del universo.

Podrá objetarse, sin embargo: si todo ello es así, ¿hace falta todavía buscar un sentido alegórico en la Comedia? Después de haber cargado lo anteriormente dicho a la cuenta del sentido literal, parece no quedar gran cosa que constituya la alegoría de la Comedia. Pero la hay, y la hay en un doble sentido, porque ciertamente coexisten en el poema la "alegoría de los poetas" y la "alegoría de los teólogos". Cuando decimos, por ejemplo, que en el poema el león representa a la soberbia, la pantera a la lujuria, la loba a la codicia, el monstruo Gerión (rostro de hombre justo, cuerpo de serpiente) al fraude, reconocemos fácilmente alegorías poéticas. Menos evidente parece ser el uso de la alegoría teológica en la Comedia. La Epistola XIII dice claramente, sin embargo, que la alegoría del poema "es el hombre en la medida en que, mereciendo o desmereciendo por la libertad de su arbitrio, está sometido a la justicia que premia o castiga”. En la obra encontramos, en efecto, multitud de almas, cada una de las cuales representa un pecado, una inclinación pecaminosa o una virtud, que explican por qué sufren el castigo o el proceso de purificación que se les ha impuesto, o por qué gozan de la recompensa otorgada por la justicia divina. Ellas son, en su dolor, su esperanza o su beatitud, los antitipos cuyos tipos son las vidas que presuntamente vivieron en este mundo. Dicho antitipo le otorga al tipo un sentido trascendente, por cuanto revela su valor positivo o negativo en el juicio divino. Se trata, pues, de una alegoría en su acepción teológica. 


\title{
La Metáfora del Agua como Expresión Mágica y Misteriosa de la Unión entre el Cielo y la Tierra en "Ángeles De Compostela", de G. Diego
}

\author{
Ángel Rodríguez Gónzález \\ Universidad Andrés Bello
}

\section{Apertura de Horizontes Contextuales}

\begin{abstract}
1. Autor
Gerardo Diego (Santander, 1896 - Madrid, 1987) fue profesor, crítico literario, pianista destacado y poeta, uno de los más grandes poetas espańoles contemporáneos. Integrante de la Generación del 27 , destacó por su capacidad para otorgar modernidad a las formas más clásicas de la poesía lírica. El sentido vanguardista impregnó toda su vida y su obra. Su poesía lírica manifiesta inicialmente claras influencias neorrománticas, parnasianas, simbolistas, modernistas, cubistas y de Juan Ramón Jiménez. (Iniciales, Nocturnos de Chopin, Evasión, Romancero de la novia)
\end{abstract}

Con Imagen (1922) inicia la aventura vanguardista, que prosigue con obras totalmente creacionistas (Limbo, Manual de espumas, Versos humanos, Vía crucis, Fábula de Equis y Zeda, Poemas adrede).

Su plenitud poética se logra con Ángeles de Compostela (1940) y con Alondra de verdad (1941), escritas ambas entre 1926 y 1936). Sus últimas obras manifiestan mayor intención clásica y humana: La suerte o la muerte, Amor solo (1951), Odas morales (1966), Versos divinos (1970), La fundación del querer (1970), Carmen jubilar (1975), etc.

\section{Génesis textual}

Ángeles de Compostela es uno de los libros poéticos predilectos y más elaborados de Gerardo Diego. Esta obra, verdadera tarea arquitectónica a la cual dedicó varios años de trabajo, constituye una especie de anhelo casi místico, estructurado sobre tres pilares fundamentales:

2.1 - Ángeles de piedra, descubiertos espiritualmente el 1 de noviembre de 1929, en el Pórtico de la Gloria de la Catedral de Santiago de Compostela, cuando la ciudad se encontraba sumida en un ambiente medieval, debido a un 
apagón eléctrico que la había dejado en tinieblas. Aquella noche escribió un soneto que reflejaba la impresión que la ciudad y la visión de los ángeles le produjeron (“Ante las torres de Compostela"). En ese momento decidió, además, poner nombre propio a los cuatro ángeles apocalípticos del Pórtico: Maltiel (ángel de la resurrección), Urjan (inclinado y con los ojos cerrados), Razías (el del aire más juvenil) y Uriel (prototipo de gracia y donaire). Posteriormente, nacieron los poemas. Los cuatro ángeles de piedra corresponden a la expresión del pensamiento y sentimientos religiosos.

2.2- A los cuatro ángeles de piedra unió cuatro personajes relacionados con la tierra gallega, de distintas épocas: Macías, trovador de la corte de Enrique III, R.M. del Valle Inclán, Rosalía de Castro y Santiago Apóstol. A ellos se une Martín Codax, trovador medieval, que parece acompañar e identificarse con el poeta. Estos escritores reflejan, para Gerardo Diego, cuatro momentos del mundo del espíritu.

2. 3 - Gerardo Diego imaginó, además, cuatro ángeles de agua: ángel de niebla, ángel de ría, ángel de lluvia y ángel de rocío. Estos cuatro ángeles representan el espíritu de la tierra, especialmente de la tierra gallega.

Ángeles de Compostela es una de las obras más poéticas y estructuradas de la lírica espańola. Los temas gallegos se ensamblan perfectamente con una intención teológico-dogmática y mística de la existencia: la verdad de la muerte y el misterio de la resurrección a la nueva vida gloriosa. Toda la obra es un verdadero retablo barroco que representa un esquema ascensional y teológico desde lo más sombrío (Maltiel): "ángel de niebla” y "nube interior”, "edificado en niebla", "templo en ruina") a lo más excelso y luminoso (Uriel): "gloria de excelsitud", "techumbre abierta"); en definitiva, un viaje de la carne a la resurrección ("Huesos juntándose a los huesos"), de la tumba a la vida gloriosa.

\section{Textualidad: Reconocimiento-Explicación-Comprensión (Significante-Significación-Significado-Sentido)}

El poema "Ángel de rocío" es el que mejor encarna y sintetiza el carácter religioso y misterioso de toda la obra. Es la cima de la arquitectura teológica y barroca de toda la obra, es como la imagen de la creación, aurora jubilosa de la unión mística entre el cielo y la tierra.

El poema está dispuesto y organizado en cuatro momentos significativos, que corresponden a la tendencia general de toda la obra, estructurada con un claro propósito aritmético de carácter simbólico: una intencionalidad excelsa expresada con sentido vanguardista y creacionista en perfecto equilibrio con 
la más pura tradición poético-lírica, un afán de originalidad estética, de gran sutileza técnica en el manejo de la lengua y una búsqueda afanosa de imágenes y metáforas.

Los tres primeros momentos del poema, todos con un número de versos eneasílabos (verdad y perfección: triplicidad de lo triple), múltiplo de cuatro, corresponden a las tres etapas del gran misterio religioso-teológico:

-Génesis y formación del misterio: 16 versos eneasílabos

-Revelación del misterio: 12 versos eneasílabos.

-Instante del milagro: 24 versos eneasílabos.

En la última parte, conformada por diez versos (número de perfección religiosa y teológica), se produce la constatación del milagro esperado: La unión entre el cielo y la tierra: 10 versos eneasílabos.

\section{Génesis y formación del misterio (encarnación: noche)}

\section{Toda la noche caminando.}

Anduvo vacío y sin sangre por los montes todos los rumbos, todas las flores por los valles, por los prados todas las hierbas, todas las hojas por los árboles.

\section{Anduvo y anduvo y anduvo}

- Caricia de cola de ave -

Cada paso, un beso sin peso.

Cada beso, una estrella errante

rayando con fuego la lija

de un cielo desierto de ángeles.

Nadie le vio. $\mathrm{Ni}$ ¿̨cómo verle

si era transparencia de aire?

Nadie le oyó, nadie le supo,

misterio mudo, nadie, nadie.

El primero y último verso de esta parte del poema son profundamente significativos, pues en forma precisa y exacta resumen la esencia del misterio y lo incomprensible que resulta para los mortales: "Toda la noche caminando" - "misterio mudo, nadie, nadie". 
Las figuras y recursos estilísticos de la alegoría inicial revelan y actualizan las fuerzas e influencias que actuaron en la génesis del texto y posibilitan el acceso a las motivaciones profundas del sentido vanguardista y creacionista del poema.

- Toda la noche caminando: hipérbole popular, imagen onírica evidente que sirve para expresar el profundo misterio que se inicia. Se intensifica por el carácter inclusivo absoluto del adjetivo indefinido "toda”, por el notorio hipérbaton inicial y por la presencia del gerundio simple "caminando" (participio de presente), que otorga un claro dinamismo a la expresión. El corte oracional, punto al final del primer verso, tiende a resaltar aún más el carácter impresionista de la acción presente y persistente. La elipsis del sujeto ("ángel de rocío" y la metáfora animizadora ("caminando") revelan el paso del tiempo.

- La paradoja que surge al relacionar los dos primeros versos ("Toda la noche caminando" -"Anduvo vacío y sin sangre") intensifica la imagen onírica inicial, que se va incrementando gracias a las figuras (metábolas e isotopías) que aparecen en los versos siguientes y al tono general que se manifiesta por el carácter de los recursos (hiperbólico y obsesivo) enigmático.

• Metáforas enigmáticas: "anduvo”, "vacío”, "sin sangre”.

- Anáfora: versos $4^{\circ}$ y $6^{\circ}$ (“todas”).

- Epanáfora: versos $3^{\circ}$ y $5^{\circ}$ (“todos” - "todas").

• Elipsis verbal mantenida: “anduvo”.

- Metábasis: "anduvo" (forma verbal transitiva más sicológica) < recorrió > $<$ por > "todos los rumbos".

- Alternancia (inversión) de los complementos directos y de los complementos circunstanciales (ambigüedad semántica).

- Metonimia: "rumbos" en vez de caminos (connotación subjetiva y misteriosa).

- Similicadencia: recurrencia fónica del fonema indicador de plural (fenómeno impresionista que evoca y sugiere el sonido sibilante del viento frío de la noche).

- Gradación: clímax o cadena o enumeración descendiente muy clara: “montes”, "valles”, "prados”, “árboles”, "flores”, "hierbas”, "hojas”. 
- Alusión a la técnica del cuento maravilloso que continúa en los versos siguientes $\left(7^{\circ}\right.$ al $\left.12^{\circ}\right)$.

- Polisíndeton del verso $7^{\circ}$ que contrasta con el asíndeton de los versos anteriores.

- Se mantiene la elipsis verbal onírica y obsesiva.

- Epanalepsis del verso $7^{\circ}$ que origina un superlativo popular (cuento maravilloso).

- Metáfora doble: “caricia” (suavidad) y "cola de ave” (suavidad y armonía).

- Presencia de guiones: cambio en la dirección semántica (del movimiento a la sensación).

- Sustantivos de gran cercanía fónica: "paso", "beso","paso" (obliga a la reflexión).

- La esticomitia del verso $9^{\circ}$ destaca el carácter nominal e impresionista del mismo y rompe con la concatenación o anadiplosis que debía establecer con el verso siguiente. Con estos juegos fónicos se prepara al receptor para descubrir el sentido de las metáforas que siguen y que son el comienzo de la revelación del misterio. La relación se incrementa por efecto de las figuras o recursos siguientes.

- Aliteraciones: en los versos $9^{\circ}$ y $10^{\circ}$ (bilabial, sibilante, vocal abierta), con lo cual se mantiene la atmósfera obsesiva inicial de carácter onírico, acrecentada por el efecto de la anáfora presente ("cada paso"/ "cada beso").

- Las metáforas comienzan a intensificarse para evidenciar e intensificar la constatación del misterio y su pronto esclarecimiento:

- Metáfora in absentia de carácter sinecdóquico: “cada paso" (movimiento, cambio, transcurso).

- Metáfora in absentia atributiva: "un beso" (caricia, suavidad, lentitud).

- Metáfora in absentia determinativa: "sin peso" (levedad, delicadeza, ingravidez).

- Metáfora in absentia y apositiva: "cada beso, una estrella errante" (suavidad y lentitud que van dando origen a la luz). 
- Metáfora in absentia prosopopéyica: "errante" (luz que se va esparciendo y apareciendo por distintas partes).

- Metáfora in absentia múltiple (compuesta o visionaria): "rayando" (surcando, imagen de las luces que comienza a aparecer en el horizonte), "con fuego" (luz brillante y cálida), "la lija de un cielo" (firmamento gris y plomizo: sinestesia), "desierto de ángeles" (vacío de estrellas: metáfora doble).

- El verso $13^{\circ}$ comienza con un pronombre indefinido de carácter exclusivo total y negativo ("Nadie"), expresión del misterio desconocido por todos, pero a punto de esclarecerse y que contrasta con el carácter inclusivo total y afirmativo de la palabra que inicia el poema ("Toda la noche caminando"): antítesis enigmática. El fenómeno se personifica por el uso del complementario "le" (personal, alusivo al "ángel") en lugar del complementario "lo" (cosista, referido a "rocío").

- El anacoluto del verso $13^{\circ}$ ("Ni...") es la expresión de un estado emocional intenso del yo lírico (tácito hasta el momento en el poema), que interrumpe el pensamiento lógico iniciado para seguir otra asociación mental diferente y que se manifiesta, además, en el erotema que sigue, el cual sirve para expresar un enunciado afirmativo y enfático, evidencia de una realidad física misteriosa que ya se empieza a comprender (“¡cómo verle si era transparencia de aire?”).

- La primera parte del poema (Génesis y formación del misterio) se cierra con dos versos de sentido totalmente acabado y completo. El pronombre indefinido de carácter exclusivo, absoluto y negativo, reiterativo por efecto de la anáfora (versos $13^{\circ}$ y $15^{\circ}$ ), origina una epanáfora ("Nadie le oyó, nadie le supo") y una epanalepsis final ("nadie, nadie"). Estas reiteraciones acentúan el tono hiperbólico que se pretende otorgar a esta parte del poema: misterio, arcano, secreto que sólo se podrá conocer mediante imágenes reveladoras y visionarias.

- El misterio se hace más patente y sensible por efecto de la aliteración consonántica (bilabial, oclusiva nasal, alveolar: $n-m-b-p)$ y vocálica $(e-a$ - o), de la rima interior ("supo... mudo"), de la metáfora prosopopéyica ("misterio mudo": silencioso, desconocido) y de las metábasis del verso $15^{\circ}$ ("le" en vez de "lo": nadie le supo"). En el caso de la metábasis, se intensifica el carácter personificador que se pretende otorgar al fenómeno: "ángel de rocío" como mensaje y mensajero.

- Después de reconocer, constatar, explicar e interpretar los recursos lingüísticos de esta primera parte del poema, el sentido, que está más allá de la significación explícita o significado, se convierte en símbolo (signo nuevo) de una realidad poética transcendente y con dimensiones humanas, realidad claramente interpretable de la siguiente manera: 
Durante toda la noche y por toda la extensión de la tierra (montes, valles, rumbos, prados, árboles, hierbas, hojas), el "ángel de rocío" (misterio mudo de suavidad, mensaje y mensajero de la unión entre el cielo y la tierra) se fue misteriosamente conformando y transformando (de "transparencia de aire" en "ángel de rocío") y acercándose lentamente a la tierra ("cada paso un beso sin peso").

Este fenómeno climático, mítico y luminoso, espíritu del cielo y de la tierra, va surcando de suavidad y de luz ("caricia de cola de ave") la plomiza extensión de un firmamento sin estrellas ("rayando con fuego la lija/ de un cielo desierto de ángeles"). Silenciosamente, misteriosamente, lentamente se fue formando por todas partes. Y el agua, materia del rocío, se transformará, durante el amanecer, en luminosidad y transparencia.

\title{
2. Revelación del misterio: anunciación (amanecer)
}

\author{
17 - Era el ángel de cinco puntas \\ girando, sembrando sus ángeles. \\ Por una rendija de oriente \\ el alba desliza su túnica. \\ La yacente ya se incorpora, \\ Se desespereza, se desnuda. \\ Los gallos desclavan estrellas \\ y las golondrinas las buscan. \\ Corren los ángeles el ángelus \\ desde Ribadeo a Coruña, \\ y en el hálito augur del alba \\ se empaña el oro de la luna
}

El segundo momento del poema se inicia con una metáfora compuesta: "ángel” (mensaje-mensajero), "de cinco puntas", metáfora enigmática (enigma) de difícil interpretación, pues la correspondencia entre la imagen con sus notas y el término real con las suyas no se percibe con claridad y se resiste a una interpretación segura. Pareciera referirse a una imagen del ser supremo, a la perfección de lo divino, simbolizado en la estrella de cinco puntas, imagen de la manifestación central de la luz del centro místico (regeneración por la luz: estrellas = ángeles, Apocalipsis, VI, 13). Las dos metáforas del primer verso $\left(17^{\circ}\right)$, in absentia y complementaria, constituyen un segmento metafórico de carácter visionario, una especie de epifonema, pues parece resumir lo que se 
expresó en los versos precedentes, acentuado, además, por la presencia de la forma verbal al comienzo del verso, sin anacrucis. También es posible señalar una especie de epitroscasmo o braquilogía, pues se condensa textualmente un proceso activo que después se desarrollará, extensamente. En efecto, el verso $18^{\circ}$, con claro efecto alternativo fricativo velar, fricativo alveolar y oclusivo nasal alveolar ( $\mathrm{g}$-s-n) y con un encabalgamiento sirremático con el verso anterior, sugiere actividad continua ("girando": metáfora), proyección y permanencia ("sembrando sus ángeles”: metáfora, esparciendo sus mensajes).

El verso $19^{\circ}$ comienza con una inversión o hipérbaton (el sujeto, la forma verbal y el C.D. se posponen al C.C.) para destacar la forma y el lugar por donde comienza el amanecer, momento en el que se evidenciará el milagro y el misterio. Con el mismo verso se inicia, también, una alegoría, es decir, se van sucediendo una serie de metáforas relacionadas todas con el mismo tema - el amanecer -, metáforas cuyas imágenes están condicionadas significativamente por la metáfora central:

- Metáfora in absentia doble: "por una rendija" (el horizonte, lugar por donde se inicia el efecto luminoso del amanecer) "de oriente" (metáfora metonímica: lugar geográfico preciso del inicio del alba).

- Metáfora prosopopéyica cuádruple (continúa la alusión mítica): "el alba desliza su túnica”, alusión a la mítica Aurora o Eos, quien vestida de túnica amarilla y dedos rosados - colores del alba - llevaba un cántaro en los brazos como portadora del rocío, lágrimas que supuestamente derramaba por la muerte de sus hijos y por lo efímero y pasajero del día que comenzaba.

- Metáfora prosopopéyica cuádruple (continúa la alusión mítica): "La yacente" (Eos, imagen del amanecer) "ya se incorpora" (luz sonrosada que comienza a formarse haciendo desaparecer las tinieblas de la noche), "se despereza" (aumento de la luz), "se desnuda" (imagen de la plenitud luminosa del amanecer, color rosado del horizonte, simbolizado en el color de la piel de Eos, que arroja su túnica o manto de estrellas). El verso $21^{\circ}$ parece, incluso, presentar un caso de antanaclasis fónica (por efecto del seseo posible) que sugiere cierta lentitud en el proceso luminoso.

- La alegoría del despertar de la naturaleza, del amanecer, no sólo se logra con las tres metáforas verbales y activas ("incorpora”, "despereza", "desnuda”), sino que también por efecto de la misma gradación que presentan dichas formas verbales (clímax o cadena) y por la aliteración de tipo paronímica, semántica y reiterativa (“se...se...se").

- En el verso $23^{\circ}$ se inicia una metáfora compuesta o perífrasis metafórica del tipo animización-prosopopeya: "Los gallos desclavan las estrellas". 
Es una metáfora activa del amanecer, que no sólo se expresa en el sujeto, sino que se prolonga en el predicado y que clarifica lo expresado mediante la acción del sujeto. Esta metáfora activa recuerda, de manera muy evidente, una metáfora similar de Lorca ("Las piquetas de los gallos/cavan buscando la aurora":"Romance de la Pena Negra"), y ambas evocan la estructura y sentido de las greguerías de Gómez de la Serna. La metáfora activa continúa en el verso siguiente: "y las golondrinas las buscan". La imagen no puede ser más poética y exacta: las estrellas - metáfora de la noche - van desapareciendo en lo alto con la luz del amanecer. Las gotas del rocío (metáfora: estrellas de agua que comienzan a brillar en el firmamento) son recogidas por el vuelo rasante y rápido de las golondrinas (“y las golondrinas las buscan”), metáfora que, basada en la técnica del desdoblamiento o de los espejos, pretende expresar la paulatina aparición y llegada de las gotas del rocío hasta la superficie de la tierra.

- La alegoría metafórica iniciada en el verso $19^{\circ}$ se prolonga hasta los cuatro últimos de esta parte. El sentido alegórico se completa y es el último paso antes de la revelación final: el ángel de rocío, gestado durante toda la noche, se manifestará a los hombres (mortales) en el momento del amanecer:

- La metáfora in absentia y activa "corren" sirve para expresar la rapidez del cambio que se está operando en la naturaleza. Es como una cortina que se corre y todo lo aclara. Traspasan el mensaje.

- La metáfora siguiente, in absentia y doble ("los ángeles el ángelus") es sumamente interesante y compleja. Se basa en una derivación, es decir, en dos palabras que preceden de una misma raíz, léxicamente emparentadas, y con una evidente alusión religiosa. En efecto, el ángelus es la oración que recuerda el misterio de la Encarnación, la bajada de Dios a la tierra. El amanecer era, y es, el primero de los momentos en que esta oración se reza. El simbolismo religioso es notorio, el milagro está a punto de consumarse. El anuncio de la unión entre el cielo y la tierra, expresada en el rocío que desciende, es ya una realidad. El misterio se hace patente y se aclara por todas partes, desde oriente ("Ribadeo", extremo este de Galicia: metáfora topológica) a occidente ("Coruña", extremo occidental: metáfora topológica).

- En el "hálito" (metáfora: soplo suave y apacible del aire matinal) que anuncia el amanecer ("augur" del alba: metáfora íntimamente relacionada con los versos $23^{\circ}$ y $24^{\circ}$, cuyos términos hacen referencia al anuncio de algo medio por medio del canto y del vuelo de las aves), hasta el "oro de la luna" (metáfora que hace referencia al color amarillo que la luna adquiere al amanecer) para impregnarse de la condensación del agua de la noche - rocío - ("se empaña": metáfora). 
- La luminosidad del amanecer y la estrecha unión entre el cielo y la tierra, expresadas con imágenes visuales y activas, se complementa con una verdadera sinfonía vocálica y consonántica (aliteración: consonantes líquidas y vocales con cambios acentuales rítmicos en los tres sustantivos claves del momento ("hálito", "augur", "alba"), los tres en el mismo verso).

El enigma inicial ("ángel de cinco puntas") se ha aclarado totalmente. El amanecer, que está a punto de comenzar, evidencia el milagro y aclara el misterio. La aurora se transforma en luminosidad creciente que va de oriente a occidente e inunda de luz el firmamento y la tierra. Se anuncia, además, la cercana unión entre el cielo y la tierra, milagro que se expresará mediante la imagen del rocío.

\section{El instante del milagro: luminosidad excelsa y suprema}

$29^{\circ}$ - "Es el instante del milagro.

Despertad, dichosos mortales.

El cielo, el cielo aquí en la tierra.

Un cielo de cielos. Un ángel.

Un ángel pasó, un ángel queda

en gotas y gotas de ángeles.

Ángel de cristal y de lágrimas,

ángel de temblor y de cárcel,

ángel de niebla y lluvia y río,

ángel que se muda de ángel.

$39^{\circ}$ - Ángel de rocío y de número,

el siempre y nunca, el infinito.

¿Qué arcángel te enseñó la tabla

de multiplicarte por filo?

Flores y hierbas te comulgan,

esférico y puro y preciso.

¿Por dónde entraste, iris y fuego,

en tu inconsútil paraíso?

Mas, ¿no eres tú mismo el alcázar

y el príncipe dentro cautivo?

¿El encantador encantado,

eterno, cambiante y efímero,

ángel entero en cada lágrima,

ángel cabal, igual, distinto? 
- El verso $29^{\circ}$ constituye una afirmación rotunda, pero es todavía un enigma (metáfora enigmática), pues lo connotado se intuye, pero aún no se percibe con claridad. La interpretación del enigma (“instante del milagro") podrá realizarse después.

- El apóstrofe del verso $30^{\circ}$ es la clave para el esclarecimiento del enigma. El receptor de la manifestación y revelación recibe un llamado ("Despertad": metáfora onírica de tono bíblico) para establecer un verdadero lazo sicológico con el hablante lírico. El apóstrofe, que recuerda la excitación del Apocalipsis y el vehemente llamado del ángel el día de Nochebuena, se complementa con la sinécdoque final: "dichosos mortales" (seres humanos).

- El verso adquiere, pues, una connotación religiosa, como todo el poema: comunión entre el cielo y la tierra, asombro y maravilla por la revelación del misterio, dicha y felicidad ante la posibilidad del descubrimiento. La comunión entre el cielo y la tierra se explicita en el verso siguiente: "El cielo, el cielo aquí en la tierra". Dicho sentido se intensifica semánticamente por efecto de la epanalepsis o reduplicación inicial, que, por su carácter de hipérbole popular, parece dicha y compromete en forma simultánea al hablante lírico y al receptor del enunciado (los hombres, los "mortales"). Esta sensación se acrecienta por el sentido nominal del verso y por el carácter casi pleonástico del proadverbio (prosustantivo que llamaría Lenz "aquî", en este lugar donde yo estoy, donde nosotros estamos).

- El verso $31^{\circ}$ se inicia con una metáfora apositiva en la que se produce una absorción del significante por el propio significado, es decir, el objeto metafórico central ("cielo") se compara consigo mismo ("de cielos"). Este procedimiento otorga a la expresión claro sentido popular e hiperbólico, similar al del verso anterior. En la última parte vuelve a aparecer el enigma y la revelación del enigma ("Un ángel": mensaje y mensajero). Contribuye a ello, además, la peculiar puntuación y la tendencia nominal absoluta del verso, totalmente impresionista.

- En el verso $33^{\circ}$ se inicia una nueva alegoría sobre el sentido del milagro, sobre la unión que se ha producido entre el cielo y la tierra. Dicha alegoría comienza con una paradoja ("Un ángel pasó, un ángel queda”), que sirve para expresar el sentido pasajero y efímero del milagro, pero al mismo tiempo permanente y eterno, por su carácter mítico de repetición periódica. El sentido alegórico e impresionista del momento se intensifica en los cinco versos siguientes mediante una serie de procedimientos figurativos interesantes:

- Metáfora onírica e hiperbólica: "en gotas y gotas de ángeles”, imagen de la multiplicación del milagro, incrementado por el superlativo popular originado por la epanalepsis ("En gotas y gotas"). 
- Polisíndeton: “y...y...y...y...y”, que aisla y destaca cada una de las metáforas y otorga una sensación de ambigüedad semántica, de misterio y de solemnidad.

• Metáforas anafóricas: “Ángel” / "ángel” / “ángel” /"ángel” / "Ángel”, obsesivas y emotivas, anunciadoras de momentos transcendentes (plenitud) y que se concretan mediante las metáforas complementarias que siguen al proceso de la anáfora.

- Metáforas determinativas o complementarias in absentia (B de B), que son más complejas por referirse a un núcleo también metafórico ("ángel”): "de cristal”, "de lágrimas", “de temblor”, "de cárcel”, “de niebla”, "de lluvia”, "de río”, "de rocío", "de número". Son verdaderas metáforas cosificadoras, que siguen un proceso inverso a la prosopopeya al tratar de materializar lo abstracto y espiritual (sentido del mensaje y de la unión), creando imágenes impresionistas de gran ambigüedad poética. Las metáforas determinativas parecen aludir al brillo, a la forma, a la delicadeza, a la ubicación, a la materia y al sentido general. Como en el acto sublime de la creación, el cielo se está uniendo con la tierra. El rocío es el mensaje y el mensajero de esta unión y brilla como el cristal, tiene la forma de una lágrima (referencia mítica a las lágrimas de la aurora), tiembla y se estremece, se encierra en las plantas, se manifiesta en las diferentes formas del agua y se renueva permanentemente ("ángel que se muda de ángel”, "ángel ...de número"). Los versos y las metáforas están constituidos por series binarias ("cristal" - "lágrima”, "temblor" - "cárcel”), con evidente relación semántica, y por una serie terciaria ("niebla" - "lluvia" - "río"), casi sinonímicas, verdadero caso de metábole que desemboca en una metáfora reiterativa al estilo de Catulo ("Carmen V"). Es necesario destacar, además, la presencia del cuarto elemento de agua ("rocío"), con lo cual se completa la alusión a los cuatro ángeles de agua en la obra Ángeles de Compostela (clave de la obra entera): mensaje del agua.

- El carácter alegórico religioso de este momento continúa en los versos $39^{\circ}$ y siguientes y al sentido de multiplicación y persistencia del fenómeno se agrega una paradoja de origen bíblico ("el siempre y nunca, el infinito": alfa y omega), el que es, con sentido panteísta del fenómeno y con claro sentido religioso de la naturaleza.. El sentido multiplicador del fenómeno se intensifica por el erotema de los versos $41^{\circ}$ y $42^{\circ}$, por la metáfora prosopopéyica "te enseńó la tabla") y por la metáfora divinizadora y vivificadora (de "multiplicarte por filo"). En efecto, en los sistemas filogenéticos o filéticos, "multiplicarse por filo", consiste en la multiplicación y génesis a partir de uno mismo. Se alude claramente, por lo tanto, a la Eucaristía, donde Cristo se hace presente (se multiplica) en cada una de las hostias. 
- Lo insinuado en los versos anteriores, se evidencia y explicita en la metáfora prosopopéyica y de carácter religioso del verso $43^{\circ}$ : "Flores y hierbas te comulgan”. Es una clara alusión a la Eucaristía, misterio que recuerda la presencia de Dios en el mundo y en las almas. El ángel (el rocío) es como Dios o Cristo, multiplicado en el misterio. El rocío, como una imagen visible y externa, se expande y lo reciben todas las plantas. La sinonimia o metábole que sigue ("esférico y puro y preciso") hace referencia al mismo sacramento de la Eucaristía (hostia) y al sentido de perfección de la unión mística. El polisíndeton otorga la solemnidad casi religiosa al segmento y permite destacar cada uno de los elementos.

- La actitud apostrófica con que se iniciaba esta parte del poema se vuelve a manifestar en el erotema que comienza en el verso $45^{\circ}$ y que desemboca en dos nuevas metáforas cuyos matices significativos son variados e interesantes:

- La metáfora in absentia "iris" alude, probablemente, al carácter mensajero del rocío. Es, por lo tanto, una alusión a la mítica diosa Iris, símbolo de la unión del cielo con la tierra. Sin embargo, esta metáfora es, a su vez, un claro ejemplo de dilogía, pues se está usando con varios y simultáneos sentidos con el fin de intensificar el sentido de la expresión. En efecto, "iris" connotaría también color, lo que contrastaría con la siguiente metáfora in absentia y apositiva "fuego", símbolo del amor. La paradoja de las dos metáforas se suprime por efecto de la conjunción copulativa "y" para transformarse, una vez más, en una metáfora compuesta y compleja, de carácter religioso, alusiva a Cristo (mensajero del amor). Habría que agregar, además, que la metáfora "iris", en otro de sus sentidos (dilogía), también puede hacer referencia a la persona o acto que contribuye a apaciguar o terminar graves disturbios o trastornos. Es como la imagen de Cristo que trajo la paz y el amor a la tierra (mensajero de la paz y del amor). Este sentido religioso parece reafirmarse y completarse con el epíteto metafórico del siguiente ("inconsútil paraíso"), referido al cáliz de las plantas que reciben el rocío ("paraíso": metáfora que alude a las plantas receptoras) y a la túnica de Cristo, sin costuras ("inconsútil”), que cubría su cuerpo (dilogía).

- Los versos $47^{\circ}$ y $48^{\circ}$ inician una clara alusión eucarística a La vida es sueño auto sacramental de Calderón de la Barca, especialmente si se consideran las metáforas "alcázar" (casa-habitación, recinto fortificado del príncipe), "príncipe” (Cristo) y “cautivo” (ofrecido) y el carácter paradojal de las mismas.

- La elipsis que se produce en el verso $49^{\circ}$ (supresión del sintagma oracional "Mas ¿̨no eres tú...?”) sirve para destacar la metáfora "encantador encantado", verdadera antilogía y paronomasia (parecido etimológico), manifestación de una viva y grata impresión que se produce en el alma llena de gracia y belleza subyugante. 
- El juego de la antítesis, que ha sido una constante en el poema, continúa en el verso $50^{\circ}$ ("eterno...y efímero"), pero que disminuye su carácter por la inclusión, justo entre los dos términos antitéticos, del adjetivo "cambiante", lo cual, además, agrega una evidente connotación de movimiento incesante.

- Los dos últimos versos cierran el erotema iniciado anteriormente y nos entregan el sentido pleno y profundo del milagro. El rocío es el enviado, el intermediario entre el cielo y la tierra. Como Cristo, presente y multiplicado místicamente en cada hostia, es siempre completo, exacto y a la vez distinto en cada gota ("ángel cabal, igual, distinto"). El asíndeton del verso acentúa el carácter impresionista e individualizador de los adjetivos metafóricos.

- La metáfora in absentia "en cada lágrima” es doble en su sentido, pues nos remite a un significado mítico (el rocío como lágrima de la aurora) y a una metáfora del dolor humano por la transitoriedad de la vida. Sobre el particular, conviene recordar una greguería de Gómez de la Serna, de tanta influencia en el creacionismo de la Generación del 27, y que tan bien calza en este preciso momento: "Las gotas del rocío son unas lágrimas anticipadas por lo efímero que es el día que nace".

- El momento no sólo se cierra con el final del erotema ya señalado, sino que también concluye la alucinante aliteración fricativa velar (“j”), que se ha producido en toda esta parte, y el epímone temático ("ángel”). Para redondear todo, el último verso nos entrega una imagen acústica constituida por dos palabras que provocan rima interna, consonántica y alveolar ("cabal, igual”), y que contrasta con la última paradoja (“...distinto”).

El instante del milagro es totalmente apostrófico y enigmático. Sin embargo, tras la excitación inicial (mover, estimular, provocar, inspirar sentimientos, pasión o movimiento), el sentido alegórico comienza a descifrarse y a transformarse en luminosidad excelsa y suprema.

Lo paradojal y contradictorio del momento sólo sirve para expresar el carácter pasajero y efímero del milagro y su sentido, al mismo tiempo, de permanencia y de repetición mítica, maravillosa y sorprendente.

El rocío es la imagen que anuncia la unión mística entre el cielo y la tierra y que, como un nuevo Cristo, desciende con un mensaje celestial de aurora y de vida gloriosa y excelsa. 


\section{La unión entre el cielo y la tierra: Epifanía}

$51^{\circ} \quad$ "Y me acerco para mirarte
y sobre el césped me arrodillo
para verte sobre los cálices
celestialmente repetido.
El cielo ha bajado a la tierra
en la noche rasa de frío,
el cielo puro de los ángeles
temblando al verso sin abrigo,
el cielo ofrecido a los hombres,
el cielo, un ángel de rocío".

- Finalmente, la última parte del poema, diez versos, imagen de plenitud absoluta, es como la consecuencia lógica de la revelación del milagro y del misterio, la unión definitiva y perfecta entre el cielo y la tierra y el sentido de epifanía. Por primera vez aparece el "yo lírico", tácitamente presente en el carácter apostrófico y pragmático del momento anterior.

- La alegoría sobre la Eucaristía se prolonga en estos versos y el hablante lírico se hace presente y contempla el milagro en actitud religiosa, arrodillado, como ante el misterio eucarístico. La intensidad de la participación del hablante se prolonga, nuevamente, mediante varios procedimientos figurativos intensificadores:

- Isocolon o plurimembración paralelítica, que sirve para destacar los dos elementos lingüísticos que dan cuenta de la epifanía: "Y me acerco para mirarte /...para verte..."

- Polisíndeton anafórico, que intensifica la solemnidad del momento: "Y me acerco.../ y sobre el césped..."

- Dilogía: "sobre los cálices" (de las flores y de la Eucaristía)

- Aliteración consonántica linguointerdental sorda ("c") y vocálica ("e"), que acentúan el tono de solemnidad, misterio, regimiento, tranquilidad y paz: "acerco", "césped", "cálices", "celestialmente", "cielo", "ofrecido", "rocío".

- En los seis últimos versos desaparece el hablante lírico para dar paso nuevamente a la enunciación lírica $\left(57^{\circ}\right)$. La alusión al nacimiento de Cristo se hace más evidente. El rocío, lo mismo que el hijo de Dios, "ha bajado a la tierra (metáfora activa de la unión) en la noche rasa de frío" (metáfora doble: durante la fría noche, que, finalmente ha quedado libre y desembarazada de 
nubes y nieblas, luminosidad plena por efecto del milagro. La metáfora prosopopéyica (o animizadora) del antepenúltimo verso ("temblando al verse sin abrigo") confirma aún más la alusión al nacimiento de Cristo. Esta metáfora se intensifica por efecto de la anáfora de los dos últimos versos ("el cielo.../el cielo...”), referida a dicha metáfora.

- La metáfora "cielo" - "agua de rocío" se transforma en el poema en símbolo por su capacidad para evocar otra realidad, por su carácter motivado (motivaciones convencionales de génesis cultural y religiosa), por su reiteración y persistencia a lo largo del poema, por sus referencias extralingüísticas, por su capacidad para unir lo concreto y particular con lo abstracto y universal. Del plano sensorial (realidad física con efectos afectivos y emotivos) se ha pasado al plano de la expresión, cuyos signos se han convertido en símbolos vivenciales de carácter mítico y sagrado.

El poema, cuyas cuatro etapas recuerdan el nacimiento de Cristo (misterio preparado y anunciado, revelación y epifanía-adoración), expresa un mensaje en el agua: la unión del cielo y la tierra, encarnada y manifestada en las gotas de rocío que caen al amanecer. Mensaje divino y efímero, como todo mensaje ("instante del milagro"), pero eterno, pues se renueva periódicamente en una nueva, íntima y constante comunión entre el cielo y la tierra ("El cielo ha bajado a la tierra.../el cielo, un ángel de rocío").

La aurora es un anuncio de vida gloriosa, donde una "lluvia de pétalos" (rocío) cubrirá los huesos del llanto y del dolor (tierra sombría). El llamado hecho a los hombres ("Despertad dichosos mortales") es una invitación y una revivencia de la transfiguración del monte Tabor, pero una invitación a la gloria de la excelsitud, al triunfo final de la unión mística, que está más allá de lo simbolizado en el retablo barroco elaborado por el poeta, es el cielo ofrecido a los hombres que sólo ahora comienza. Es necesario cruzar la puerta (¡Ultreya! ¡adelante!) de la Gloria, Puerta Santa de los Perdones. 


\title{
O Que é Isto?
}

\author{
Gabriela Castro
}

Universidade dos Açores

\begin{abstract}
Resumo
A possibilidade da manipulação da natureza pelo homem e a vida humana produzida em laboratório coloca-nos uma questão onto-estética que passa pela alteração da noção de substância e suas implicaçóes ao nível estético. Face ao "constructo" o quesito impóe-se: "o que é Isto?"
\end{abstract}

Quando o Homem se espanta face ao objecto do seu deslumbramento e se pergunta "O que é Isto?", o que pretende encontrar é a essência, a identidade e a diferença, desse algo que de um modo determinante o interpela.

"Isto", sendo gramaticalmente classificado como pronome indefinido, contém matéria indeterminada do domínio gnoseológico capaz de nos projectar numa longa e interessante digressão onto-estética.

Numa tentativa de explicitar o nosso percurso reflexivo caminharemos pelos trilhos da arte e da estética passando pelos caminhos da técnica e da ciência, tendo por companheiras de jornada a hermenêutica e a fenomenologia.

\section{Arte e Natureza}

Desde a Antiguidade Clássica que a noção de arte se prende com a capacidade que o ser humano tem para criar, fazer aparecer algo, o mesmo é dizer, produzir. Ora a natureza também produz e os seus produtos não são classificados como obras de arte, mas sim, entendidos como produtos naturais.

$\mathrm{Na}$ esteira de Aristóteles entendemos essa diferença ao nível das causas. $\mathrm{Na}$ natureza não encontramos uma causalidade eficiente produtora mas, constitutiva, isto é, orgânico-metafísica; enquanto que na arte, entendida como techné ou como poiésis, a causalidade eficiente encontra-se no próprio homem, justificando o aparecimento do facto como um produto cultural. Também Kant, no séc. XVIII se preocupou com a distinção entre arte e natureza e fá-lo nos seguintes termos: a «arte distingue-se da natureza, [por uma causalidade diferente] como o "fazer" (facere) se distingue do "agir" ou "causar" em geral, e o produto ou consequência da arte se distingue, enquanto obra (opus), do 
produto da natureza enquanto efeito» ${ }^{1}$. Para Mikel Dufrenne este fazer da natureza será para nós um eterno enigma, na medida em que "da natureza só sabemos metaforicamente, porque não sabemos como ela faz o que para nós parece estar feito" ${ }^{2}$.

O estudo do criar humano, do produzir, do fazer aparecer a obra no mundo, foi colocado por Aristóteles no domínio da razão poética, possuindo o termo poiétiké mais do que um significado: no seu sentido mais geral, incluía as artes úteis e as belas-artes sendo as primeiras as que produziam para as necessidades $\mathrm{da}$ vida e as belas artes aquelas cujas produçóes visavam o prazer. O termo poiétiké incluía ainda a techné enquanto capacidade produtora mediante regras estruturadas para alcançar o resultado final. Por exemplo a "arte de navegar" ou a "arte da política" eram entendidas como resultado de uma techné e não como genialidade criadora do artista. Esta distinção, que a ocidentalidade herda de Aristóteles, irá influenciar toda a filosofia posterior nomeadamente, a título de exemplo, os dois ramos da mecânica cartesiana, arte e técnica, unidos pelo engenho porém distintos pelos respectivos produtos.

Ainda nos nossos dias, tentar definir arte é tarefa difícil e complexa no dizer de Mário Perniola ${ }^{3}$, na medida em que esta noçáo se encontra intimamente relacionada com a conjuntura sócio-cultural em que está inserida. Para este autor a fórmula explicitante do que é a arte conheceu três viragens culturais e económicas fundamentais: o renascimento, o romantismo e o pós-industrialismo, onde ainda hoje nos encontramos. "A ideia fundamental que está na base [da] primeira viragem cultural da arte, que levou mais de três séculos a realizarse, permanece indiscutível e válida, ainda hoje, na teoria da arte ocidental: o artista não pode ser ignorante. (...)" ". A aliança "entre arte e saber, ou mesmo entre arte e ciência, como se espera que aconteça com todo o domínio de produção" justificou a noção crítica de "indústria da cultura" como o "modo de produção industrial característico de uma dada racionalidade tecnológica" ${ }^{\prime}$ que, na nossa conjuntura, está intimamente relacionado com o cientista.

Com o avanço científico-tecnológico, que a segunda metade do séc. XX conheceu, o objecto científico deixou de ser o "dado" e passou a ser o "construído", isto é, o produzido ou o criado pela inter-relação existente entre o cientista e a sua investigação apoiada pela tecnologia. Esta posição que Bachelard assume na sua perspectiva científica abre, no domínio especulativo, um enorme campo justificativo do "Poema" em Heidegger, ou da afirmaçáo orteguiana de que "a física é poesia”.

\footnotetext{
${ }^{1}$ Kant. Crítica da faculdade do juízo. Int. de António Marques, trad. e notas de António Marques e Valério Rohden. Lisboa: Imprensa Nacional, Casa-da-Moeda, 1992, § 43.

${ }^{2}$ Mikel Dufrenne. "L'esthéthique de Paul Valéry". Sens et existence, en hommage a Paul Ricoeur. Paris : Éd. du Seuil, 1975, p. 39.

${ }^{3}$ Professor da Universidade Tor Vergata - Roma.

${ }^{4}$ Estética e Artes. Controvérsias para o séc. XXI, Colóquio Internacional, Maio 2003. Lisboa: Centro de Filosofia da Universidade de Lisboa, 2005.
} 
No dealbar do séc. XXI, com os avanços da ciência e da tecnologia aplicados à dimensão artística, aparece-nos uma arte onde a racionalidade científica está presente. Não é uma arte útil. Não é uma arte que visa apenas o prazer da fruição do objecto produzido, é mais do que tudo isto. O que ela pretende é intervir no momento genésico da produçáo natural originando uma nova arte que, de um modo muito peculiar se entrecruza com a técnica e com o saber científico.

Hoje, o artista faz aparecer uma obra, não num material tradicional como a pedra, a madeira, a tela, o papel, a película, ou a palavra mas, a matéria prima da sua produção é agora a própria natureza. Através da manipulação científica daquela o artista-cientista faz aparecer a dimensáo mais recente da arte onde a vida e a arte se enredam numa nova criaçáo produzindo o novíssimo campo artístico da Bio-Arte.

A Bio-Arte demonstra como as tecnologias biológicas podem ser utilizadas como meio para a criação artística, e o produto dessa união clama por uma nova ontologia capaz de despoletar uma nova dimensão estética, a Bio-Estética.

\section{Nova Noçáo de Substância}

Tendo em conta os pressupostos anteriores para onde nos poderão levar os estudos sobre o conteúdo semântico-filosófico da noçáo de arte se aplicada a campos tâo distintos dos tradicionais, como o forjar transgénicos ou a manipulação genética, por exemplo? A possibilidade da vida humana produzida em laboratório coloca-nos a questão sobre a dimensão ontológica do Homem: objecto natural ou objecto artístico? Produto natural ou produto cultural?

Esta questão sobre a constituiçãoo ontológica do homem como ser orgânicometafísico ou produto técnico-científico abre-nos à reflexão sobre a noção de Substância. Será que a noção de ousia aristotélica permanece a mesma, ou sofreu uma profunda alteração com os progressos científicos conhecidos no seio de um universo transcendental?

\section{Aquilo que o nosso olhar vê é afinal o quê?}

Retomemos Aristóteles na sua obra Péri Hermeneias, ou Da Interpretação e o termo hermenéia que, enquanto discurso significante engloba o discorro, "que interpreta a realidade na medida em que diz "algo de algo"; há hermenéia porque a enunciação é uma captação do real por meio de expressốes significantes”.

\footnotetext{
${ }^{5}$ Idem, p. 191.

${ }^{6}$ Idem.

${ }^{7}$ Aristoteles. Organon, I Catégories, II De l'interprétation. Trad. et notes par J. Tricot. Paris : J. Vrin, 1977, pp. 77-144.

${ }^{8}$ Paul Ricoeur. Le conflit des interprétations, essais d'herméneutique I. Paris : Ed. du Seuil, 1969, p. 8.
} 
Ora estas expressôes significantes dizem a unidade objectiva, alcançada pelo cruzamento do sentido com a verdade, que Aristóteles chamou ousia. No universo aristotélico chamar a Fernando, a Paulo ou a Jorge homens significa que todos eles possuem a mesma essência, razão que nos leva a afirmar que a ousia é, pela sua permanência, o fundamento da unidade, não só objectiva, como também de sentido, neste caso, do ente que é o homem. Em Aristóteles é, pois, a ordem imanente à ousia, o que possibilita a interpretação como captação de sentido e de verdade do ente enquanto ente. Estamos perante um discurso de cariz ontológico, onde o quarteto causal suporta a inteligibilidade do próprio ente.

Na nova ontologia, a arte, enquanto campo privilegiado para o aparecimento do ente deixa de ser criaçáo livre para a produção do prazer mas passa a alcançar o domínio onto-bio-estético onde o objecto criado clama por integração no ser e se projecta em novos cambiantes estéticos.

Com Marta Menezes, directora artística da Ectopia, o laboratório de experimentaçâo artística do Instituto Calouste Gulbenkian de Ciência, em Lisboa, a nova dimensão da arte exige novas significaçóes. Por exemplo a modificação do padrão das asas de borboletas vivas, bem como a utilização de diferentes técnicas biológicas incluindo a Ressonância Magnética Funcional do Cérebro para criar retratos onde a mente pode ser observada, aos fragmentos de ADN fluorescente para criar micro-esculturas no núcleo de células humanas, passando por esculturas feitas com proteínas com $\mathrm{ADN}$ ou com neurónios vivos, demonstram bem que as novas tecnologias aplicadas à genética justificam uma nova ideia de arte, a bio-arte e esta uma nova noção de substância, uma nova ontologia.

Quando o homem é capaz de intervir deste modo, não podemos deixar de pensar numa hipotética alteração da noção de substância. Questôes como: o que é o objecto natural? ou, o que é o objecto artístico?, perdem o seu substrato diferencial uma vez que os objectos se aglutinam numa nova versão nocional orgânico-metafísica-cultural.

Tomemos como exemplo um tomate transgénico. Possui a mesma aparência que um tomate natural, mas será um produto natural? $O$ transgénico não possui como causalidade eficiente a physis, a geração espontânea, mas sim o homem através de uma actividade técnico-científica sobre a natureza.

Aprofundemos um pouco mais a nossa reflexão e apliquemo-la à engenharia genética operada nos seres humanos. Aqui encontramos uma das maiores conquistas da ciência no seu cruzamento com a técnica: a clonagem.

Não sendo as ciências naturais a nossa formação académica, abramos um parêntesis científico no nosso estudo e recorramos ao Relatório no 48 do Conselho Nacional de Ética para as Ciências da Vida sobre a temática da clonagem. ${ }^{9}$ 


\section{Clonagem: Ciência e Techné}

O desenvolvimento da técnica de clonagem humana, quer como finalidade reprodutiva, para a obtenção de um indivíduo geneticamente idêntico à pessoa a clonar, quer para fins de investigação biomédica, continua a fomentar numerosas discussões em diferentes fóruns de reflexão.

Esta situação desenvolve-se de uma forma evidente desde que foi noticiado o nascimento da ovelha "Dolly" em 1997 (Ian Wilmut, et al., 1997). Desde então, várias espécies de mamíferos (ratos, porcos, bovinos, coelhos, caprinos, gatos, macacos, cães e cavalos) foram clonadas, embora com eficiências relativamente baixas (até 10\% para a maioria das espécies referidas) (Susan M. Rhind, et al., 2003). A principal finalidade do desenvolvimento desta tecnologia foi a reprodução fiel de genótipos elite idênticos ou obtidos por transgénese, alguns dos quais capazes de produzir proteínas humanas, obtidas por recombinação que terão actividade terapêutica compatível com os seres humanos (como seja a hormona de crescimento), de forma a garantir a obtenção eficiente de indivíduos idênticos expressando as características desejáveis e raras de uma forma homogénea e permanente, sendo esta a intenção originária do Instituto Roslin ao desenvolver a metodologia que deu origem à "Dolly". (...) Na metodologia que [lhe] deu origem, um núcleo de uma célula somática, cultivada in vitro e tratada para parar o seu ciclo celular num estado quiescente, é retirado da célula dadora e transferido para um ovócito previamente enucleado, sendo este produto, após recepção do núcleo, activado por uma corrente eléctrica e assim induzido a multiplicar-se e diferenciar-se. Este método é genericamente denominado de transferência nuclear somática, mas é popularmente designado por clonagem. ${ }^{10}$

Segundo Pedro Ferreira existem diferentes métodos de clonagem actualmente disponíveis, porém, iremos salientar apenas a) a clonagem por cisão, e b) a transferência nuclear somática, por nos parecerem as que de um modo mais claro facilitam a exposição da nossa argumentação.

\section{a) Clonagem por cisáo}

Em 1891 Hans Driesch demonstrou que isolando as duas células resultantes da primeira divisão de um zigoto de ouriço-do-mar se podiam obter dois animais adultos completos (Klaus Sander, 1992). Esta descoberta foi mais tarde confirmada por outros embriologistas em rãs e salamandras, provando que células isoladas do estado mais precoce do desenvolvimento embrionário não perdem as capacidades necessárias para se diferenciarem num animal independente (...). ${ }^{11}$

\footnotetext{
${ }^{9}$ Patrão Neves, M e Ferreira, Pedro. Relatório $n^{\circ} 48$ CNECV/06, Relatório sobre a Clonagem Humana. Lisboa: Presidência do Conselho de Ministros, Abril, 2006, in http://www.cnecv.gov.pt

${ }^{10}$ Idem.

${ }^{11}$ Idem.
} 


\section{b) A transferência nuclear somática em mamíferos para produçáo de clones}

"Os principais passos que permitem, actualmente, a produção de clones vivos de mamíferos, com recurso à transferência nuclear somática são:

1. Disponibilização de ovócitos de uma fêmea da espécie a clonar;

2. Remoção do DNA nuclear do ovócito de forma a produzir um ovócito enucleado (ooplasto);

3. Inserção do núcleo de uma célula adulta dadora num ooplasto, de forma a produzir uma estrutura celular híbrida (alternativamente é possível a fusão entre a célula adulta e o ooplasto);

4. Activação da estrutura celular híbrida através de estímulos eléctricos ou químicos para que este inicie a divisão celular;

5. Manutenção do desenvolvimento do embrião clonado até um estádio adequado à sua transferência para um útero devidamente preparado para o receber;

6. Nascimento de um animal geneticamente idêntico (excepto no que se refere ao DNA mitocondrial) ao animal que doou o núcleo da célula adulta.

Em teoria qualquer animal pode ser clonado, seja macho ou fêmea, recém nascido ou adulto e em qualquer quantidade. (...)"12.

Chamamos a atençáo para a nota que o autor tem o cuidado de salientar: "Ora o embrião singamético e o embrião clonado possuem conteúdos semânticos diferentes"13 e continua numa perspectiva deveras interessante para nós: "com base nesta perspectiva foi proposto que ao produto da transferência nuclear somática fosse atribuída a denominação de "clonoto" (Rudolf Jaenisch, 2004), mas também de "constructo" (Mário de Sousa, 2005) ou de "unidade de transferência nuclear" ("nt-unit").

Existe ainda a clonagem humana para fins de investigação biomédica e as aplicaçóes da clonagem de seres humanos para fins biomédicos, porém, centremos a nossa atenção num clone vivo de um mamífero específico, o homem. Aqui o nosso quesito inicial assume toda a sua carga questionante: $\mathrm{O}$ que é Isto?

${ }^{12}$ Idem. 


\section{Estética e Bio-Estética}

Percorramos os caminhos da reflexão assentes na nova ontologia de modo a captarmos a noção de Bio-Estética.

Sendo a Estética uma palavra que encontra no grego, em aisthesis, a sua origem etimológica, explicitante da sensibilidade ou acto de sentir, ela foi inicialmente entendida como a capacidade de captação dos objectos que nos rodeiam por intermédio dos nossos sentidos.

É apenas no século XVIII, na sequência de Wolf e de Leibniz, filósofos que integravam as correntes racionalista e realista e especificamente com Baumgarten, na sua obra denominada Aisthesis, publicada em dois volumes, um em 1750 e outro em 1758 que a Estética começa a constituir um domínio filosófico específico, porém, ainda entendido como o estudo da perfeição do conhecimento sensitivo. Nestes contextos a Estética pode ser entendida apenas como a "Ciência do Belo", ou a "Ciência dos Sentidos", ou mesmo como uma "Filosofia da Arte". No entanto, após Kant, ela vem conhecendo diferentes campos que a fenomenologia e a hermenêutica ajudam a desvelar. A Estética integra hoje, para além do seu conteúdo semântico histórico tradicional, uma vertente da afectividade que nos abre a uma auto-compreensão e conhecimento do "Si" não tanto como ipseidade mas como alteridade, seguindo as noçôes de Paul Ricoeur. ${ }^{14}$

Se olharmos a História da Estética vemos que ela foi ganhando a sua própria identidade e Etienne Souriau aponta com precisão a diferença radical entre a Filosofia da Arte e a Estética. Para este filósofo a Filosofia da Arte caracteriza-se por uma vasta meditação reflexiva que toma por objecto a amplitude da arte, das suas actividades, das suas leis, das suas obras, sendo um ramo especial da filosofia, a qual pode meditar à sua vontade sobre todas as coisas, porém, a Estética é um saber mais limitado e de natureza científica, que tem por objecto o estudo positivo do fazer estético; é a forma, cujo facto intervém incessantemente quer na arte, quer no estudo da natureza do "ponto de vista" do artista.

Arte e Estética são assim dois campos que, na investigação filosófica, se interligam e se completam numa relação de intimidade e de cumplicidade. Elas revelam um determinado espaço e um determinado tempo, bem como o sentido e a significação do mundo. Mundo que encontra as suas raízes e o seu eco na imaginação ou na razão, consoante o universo filosófico em que encontramos a origem da criatividade. Mundo do sentimento, da ficção e do sonho. Mundo que não é isolado, à parte, desintegrado, separado. Mundo que integra o artista e o espectador, o primeiro como momento facilitador da eclosão do indizível e do invisível no acto da criação, o segundo, como elemento capaz de captar

\footnotetext{
${ }^{13}$ Idem.

${ }^{14}$ Paul Ricoeur. Soi-même comme un autre. Paris : Ed. du Seuil, 1990. Traduzido para português com o título O si-mesmo como um outro. Campinas: Papirus Editora, 1991.
} 
e de apreender a revelação artística no momento identificativo ao do criar, o do re-criar. Re-criar é um processo assente na imaginação do esteta que integrando a obra na sua "experiência de vida" lhe dá um novo sentido e uma nova significação.

Na verdade é pela imaginação que criamos, é pela imaginação que recriamos e é pela imaginação que, no fundo, nos tornamos homens numa dupla natureza dimensional que mais nenhum ser vivo possui: a de sermos simultaneamente entes finitos e infinitos. Por um lado relacionamo-nos com os animais e por outro somos criaturas que trazem consigo a marca do seu criador: isto é o dom ou a capacidade que temos de como Deus podermos criar.

Isto dá-nos uma visão sobre o homem que nos eleva às raias da infinitude mesmo acorrentados à nossa realidade finita. Mas, como pode o homem operar mediaçóes entre duas dimensóes dicotómicas, finita e infinita, porém de uma presença táo real na sua existência?

A resposta a esta questão encontramo-la em Kant, na Crítica da Razão Pura quando afirma ser a imaginação essa "arte escondida nas profundezas da alma humana”, a dimensão capaz de mediatizar a sensibilidade finita, porque percepcionante, e o entendimento infinito porque determinante de sentido.

Na continuação desta inteligibilidade ensina-nos Ricoeur que o "corpo-próprio" é a nossa abertura ao mundo e a imaginação pela sua natureza mista a nossa característica humana de seres tensionais entre o finito e o infinito. Neste contexto a nossa abertura ao infinito mediatiza-se na e pela imaginação que, precisamente por isso perde as suas possíveis raízes finitas porque inundadas pela imensidade do ilimitado.

Retomemos a dimensão Estética propedêutica da Bio-Estética.

O homem é, para além de outras dimensóes constitutivas da sua identidade, imaginação e criatividade. Assumindo a imaginação e a criatividade como as duas dimensóes capazes de identificarem o homem no seu modo de ser, não nos podemos olvidar de que ele é também "Afectividade".

Ora, afectividade encontra a sua raiz etimológica em Afectos que é uma palavra que nos chega pelo latim, "Afectus" e que expressa a capacidade de receber. Afecto tem assim a ver com o modo como somos afectados por aquilo que nos rodeia, que nos toca. Isto é, tem a ver com a nossa reacção, emoção, com o nosso sentimento.

Platão, filósofo do séc. V-IV aC, chamava o coração Thumos, isto é, o modo como eu, pessoa, sou afectada por aquilo que vem ao meu encontro. 
O Thumos é a mediação entre a dimensão da afectividade vital ou desejo (bios) e a da afectividade espiritual (logos), síntese essa que no Simpósio, o filósofo denomina Eros ou seja, o Amor. O Thumos, o sentimento, é assim esta ambiguidade que o coração encerra, a meio caminho entre a finitude do corpo e a infinitude da razão.

A função universal do sentimento é a de realizar aquilo que estava à partida separado; ele liga-nos às coisas, aos entes, ao ser. Enquanto que todo o movimento de objectivação tende a opor-nos um mundo, o sentimento une a intencionalidade que nos projecta fora de nós à afecção pela qual nos sentimos existir. O sentir é porquanto o momento de entroncamento do conhecer e do ser numa reconstituição da nossa própria totalidade. Pelo sentimento o homem projecta-se para lá da sua própria natureza finita e lança-se na dimensão ilimitada dos possíveis.

É justamente nesta dimensão infinda dos possíveis que a Bio-Arte ganha o seu lugar na classificação das artes, arrastando consigo o seu correlato da BioEstética, na medida em que o objecto que produz provoca um sentimento cujo impacto ultrapassa o Belo e o Sublime e se perde no ilimitado do espanto e do questionamento traduzido na expressão: o que é Isto? 